\title{
CHARACTERISATION OF A NOVEL NITROGEN-FIXING, POLYHYDROXYALKANOATE-PRODUCING BACTERIUM, NOVOSPHINGOBIUM NITROGENIFIGENS Y88
}

By

Anne-Marie Smit

\begin{abstract}
A thesis
submitted to the Victoria University of Wellington in fulfilment of the requirements for the degree of Doctor of Philosophy in Cell and Molecular BioSciences
\end{abstract}

Victoria University of Wellington 2008 


\section{Abstract}

The novel sphingomonad Novosphingobium nitrogenifigens $\mathrm{Y}^{\mathrm{T}} 8^{\mathrm{T}}\left(\mathrm{Y}^{\mathrm{T}} 8^{\mathrm{T}}\right)$ is an obligate aerobe able to grow in nutrient-imbalanced environments where nitrogen is naturally limiting, but carbon is found in abundance. Due to its ability to fix atmospheric nitrogen and produce the bioplastic polyhydroxyalkanoate (PHA), $\mathrm{Y}^{\mathrm{T}} 8^{\mathrm{T}}$ is well-suited for growth in a nitrogenlimited but carbon-enriched environment. Because of these metabolic abilities, $\mathrm{Y}^{\mathrm{T}} \mathrm{T}$ is of interest as a model organism for PHA production unconstrained by nitrogen-limiting conditions. Growth profiles and PHA production profiles were determined for $\mathrm{Y}^{8} 8^{\mathrm{T}}$ under conditions of carbon enrichment, nitrogen sufficiency and depletion to investigate carbon and nitrogen utilisation as well as PHA production in this organism. Also, since the nitrogenase enzyme required for nitrogen fixation is oxygen labile, the effect of DO concentration and the relationship between aerobic metabolism and the nitrogen-fixing and PHA-producing abilities of $\mathrm{Y}^{8} 8^{\mathrm{T}}$ was investigated. This study demonstrated: that glucose is the preferred growth substrate for $\mathrm{Y}^{\mathrm{T}} 8^{\mathrm{T}}$; that no direct relationship exists between nitrogen fixation and PHB accumulation in Y88 that $\mathrm{Y}^{\mathrm{T}}$ can reliably produce in excess of $80 \%$ of its dry weight as polyhydroxybutyrate (PHB), a type of PHA, from glucose under nitrogenlimiting conditions. Proteomic signatures were determined for the various physiological responses of $\mathrm{Y}^{8} 8^{\mathrm{T}}$ to growth, nitrogen utilisation, PHB production and exposure to different levels of DO. More than 250 unique proteins, including the core nitrogen-fixation, PHB-synthetic and glycolytic proteins were identified. $\mathrm{Y}^{8} 8^{\mathrm{T}}$ apparently converts glucose to $\mathrm{PHB}$ via three interrelated glucose catabolic pathways and proteins likely involved in these pathways were identified. This study revealed that, regardless of growth conditions and despite decreased abundance of the $\mathrm{Y} 88^{\mathrm{T}}$ nitrogenase enzyme, growth and PHB synthesis were not inhibited at DOhigh concentrations. Proteomic characterisation of the $\mathrm{Y}^{\mathrm{T}}$ phasin, a PHA granule-associated protein, ii 
identified an amino-terminal, low complexity alanine and proline rich segment found only in other sphingomonads. The expression level of the $\mathrm{Y} 88^{\mathrm{T}}$ phasin correlated well with PHB yields, suggesting the use of this protein as a biomarker to optimise PHB yield in a production environment. $\mathrm{Y} 88^{\mathrm{T}}$ has the potential to be a useful production strain in pure culture, utilising its natural and robust propensity to metabolise glucose to preferentially produce PHB. Targets for biotechnological improvement and the potential for application of $\mathrm{Y}^{\mathrm{T}}$ to biofuel production are discussed. 


\section{Acknowledgements}

In Africa, we have a proverb: "Not everyone who chased the zebra caught it, but he who caught it chased it." In other words, many chase after their dreams but they do so only half-heartedly. Those who "caught the zebra," stayed focused and let nothing divert them from their path until they had achieved their goal.

My supervisor at Scion, Gareth Lloyd-Jones, reminded me of this proverb several months ago when I was finding it a somewhat daunting task to overcome the writer's block that precipitates the final leap of faith that allows one to overcome the mental anguish of completing a $\mathrm{PhD}$ write-up. At that time, it was becoming increasingly obvious that my first draft was anything but complete. Suffice it to say, a PhD is ALL it is made out to be! To sum it up in the understated words of Bill Jordan, my supervisor at VUW: "Writing a thesis is a terrible business." I can now confirm this with utter conviction. Therefore, it is only appropriate at this point to thank the many people who turned this "terrible business" into a somewhat "bearable business".

First and foremost I would like to thank my mentor, Tim Strabala, who did this all a long time before I did and whose pearls of wisdom, support and endless discussions on the biochemical aspects of my project constantly benefited me throughout my intrepid journey. Without his willingness to part with his prized copy of "Zubay" for endless periods of time, and his constant belief in my ability to conquer any self-doubt, I really do doubt that I would be anywhere near journey's end. I have to admit, being my partner-in-crime on the daily coffee-run, did wonders for my morale if not my bank balance! Also, without his wonderful foresight in obtaining a nearly completed $\mathrm{Y}^{\mathrm{T}} 8^{\mathrm{T}}$ genome sequence, my task would have been that much more difficult. 
Next I would like to thank both Gareth and Bill for their guidance and input into my project, each in their own field of expertise. I am most grateful for their valuable advice and encouragement, which was particularly useful in the writing-up stage. Their continued support is highly appreciated.

A special thanks to Nicki Reid who was instrumental in selecting $\mathrm{Y}^{\mathrm{T}} 8^{\mathrm{T}}$ as a potential organism of interest long before I arrived at Scion. Without her perseverance in the "old" days together with the work of Sarah Addison who isolated $\mathrm{Y}^{8} 8^{\mathrm{T}}$, there would have been no $\mathrm{Y} 88^{\mathrm{T}}$ project to begin with. Also, sharing an office and many lighthearted moments have been a welcome respite from some very "terrible" PhD “business"!

Furthermore, special thanks must go to the following people who each in their own way, contributed to some aspect of my project and to whom I am most grateful: Pisana Rawson for her technical expertise in 2-D DIGE and running some of the repeat gels at a time when her own workload was heavy; Lifeng Peng for her willingness to run many of my samples on the mass spec and making the time in her own busy schedule to do so; Danyl McLauchlan for enabling me to have access to the FTP server at Victoria University of Wellington (VUW) so that I could access my files remotely as well as converting files for me when required; Shaun Taylor, Daniel van de Pas and Sheree Anderson who each inherited the PHA analysis job at Scion at different times and who were always willing to carry out any PHA analysis when required; the ladies at Veritec, Kaye Eason and Carli van Zyl for some of the carbon and nitrogen analyses; Stefan Hill (Scion) and Michael Schmitz (Auckland University) for the ${ }^{13} \mathrm{C}-\mathrm{NMR}$ analysis; Armin Thumm for the GPC analysis; Sarah Addison for maintaining requisite lab supplies; Lucy Macdonald for helping me with the $\mathrm{Y} 88^{\mathrm{T}}$ Mascot database; Lucy and Vincent Liu for their great work on the $\mathrm{Y} 88^{\mathrm{T}}$ sequence annotations that expedited my protein discoveries carried out at Scion; Lloyd Donaldson for the $\mathrm{Y}^{\mathrm{T}} \mathrm{T}$ TEM photos and the team at 
John Morris Scientific who provided technical support for the Bioflo110 during installation and subsequent replacement of probes and control units.

Financial support for this project including travel to and from Scion and VUW as well as attendance at conferences, were provided by Scion and VUW. Many thanks especially to Trevor Stuthridge and Bill Jordan who were instrumental in making this possible.

Thank you to Dad and Mom for all your love, guidance and support always. I treasure you more than you could possibly know. You truly are the best parents anyone could wish for. Last but never least, thank you to Bronwyn, Tarryn and Travis, my amazing children, for their enduring love, support and encouragement. They were as committed to me completing my $\mathrm{PhD}$ as I was, and I consider myself the most fortunate mother in the world to have such wonderful children as they have been, and continue to be. Bron, Taz, Trav - you make me so proud and you make everything totally worthwhile. I know you will be happy to know that, finally, I think I may have caught my zebra. 


\section{Table of Contents}

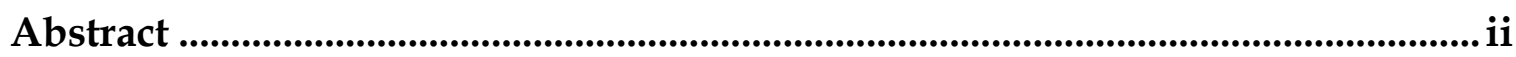

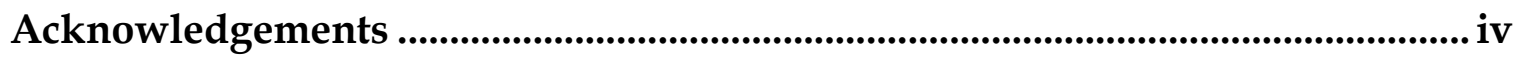

Table of Contents .............................................................................................................. vii

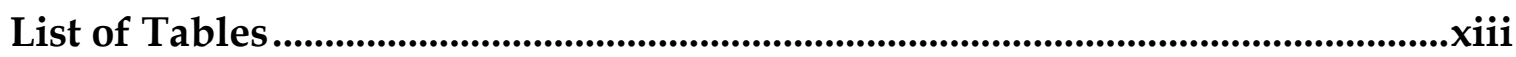

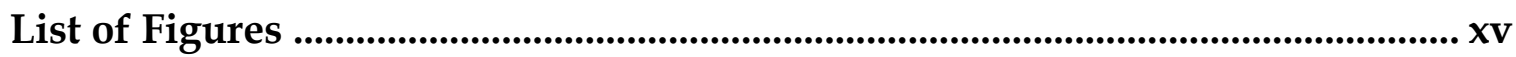

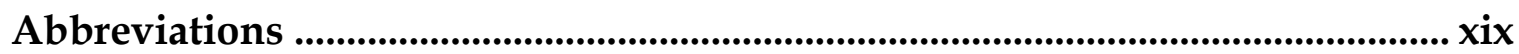

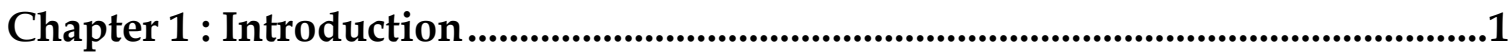

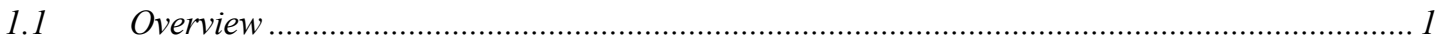

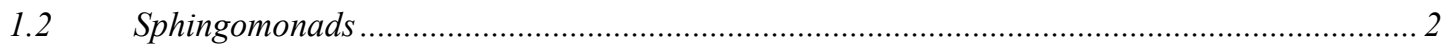

1.2.1 Novosphingobium nitrogenifigens $\mathrm{Y}^{\mathrm{T}} 8^{\mathrm{T}}$ sp. nov.: a newly characterised sphingomonad

as a model organism for low nitrogen waste stream remediation ................................................ 5

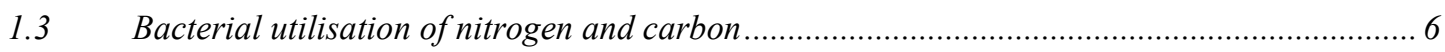

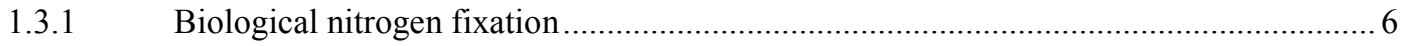

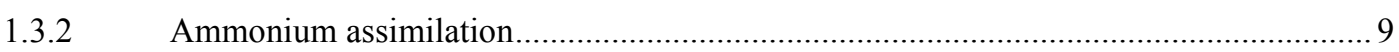

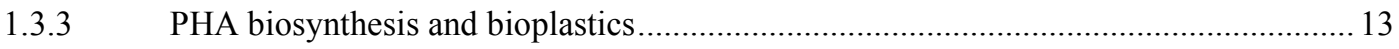

1.3.3.1 Overview and commercial application ..................................................................... 13

1.3.3.2 Bacterial PHA and the biosynthetic pathway .......................................................... 14

1.3.4 Carbon utilisation and partitioning .......................................................................... 20

1.3.4.1 Central metabolism and its relationship to PHA biosynthesis...................................20

1.3.4.2 Carbon flux and the regulation of PHA biosynthesis .............................................. 21

1.4 Proteomic approaches for protein expression profiling …........................................ 23

$1.5 \quad$ Aims

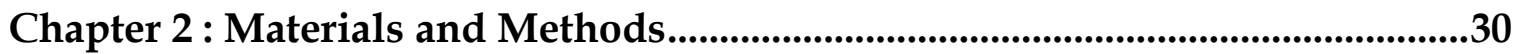

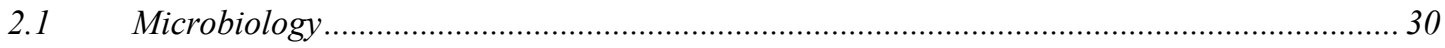

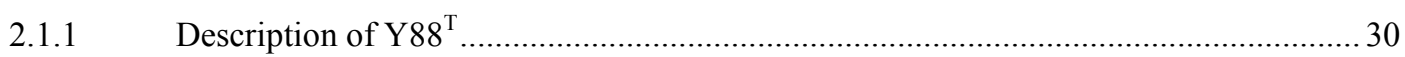

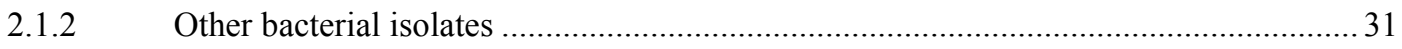


2.1.2.1 Azotobacter vinelandii ICMP4036, Pseudomonas putida mt2 and Sphingomonas sp.

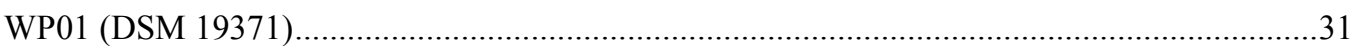

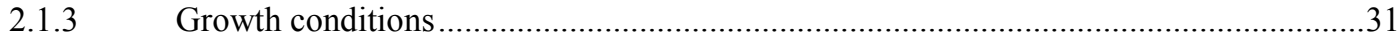

2.1.3.1 Cell stocks, plate inoculation and pre-culture inocula ............................................. 31

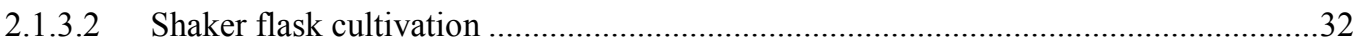

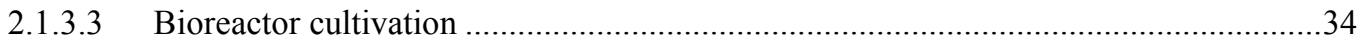

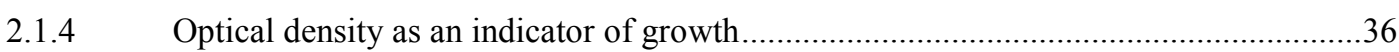

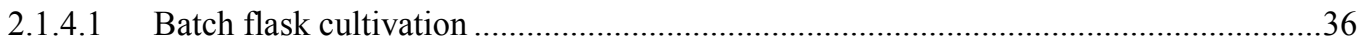

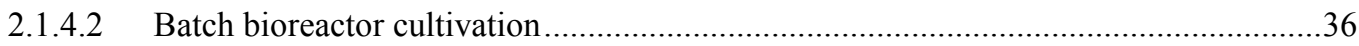

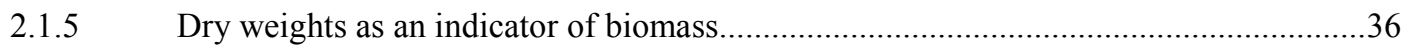

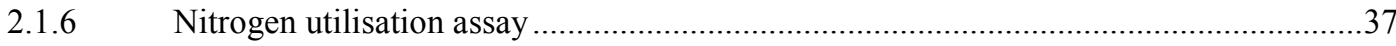

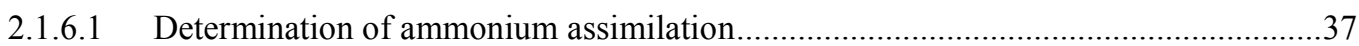

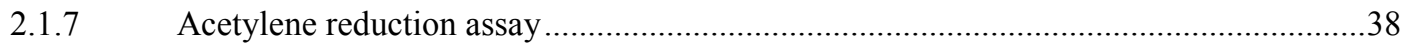

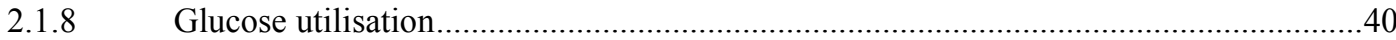

2.1.8.1 $\mathrm{Y} 88^{\mathrm{T}}$ growth on glucose and acetate.................................................................40

2.1.8.2 Comparative growth of $\mathrm{Y}^{\mathrm{T}} 8^{\mathrm{T}}$, A. vinelandii and $P$. putida $\mathrm{mt} 2$ on glucose under ammonium-free, ammonium-supplemented or ammonium-depleted conditions .....

2.1.8.3 Comparative growth of $\mathrm{Y}^{2} 8^{\mathrm{T}}$ and WP01 during PHA accumulation in the presence of

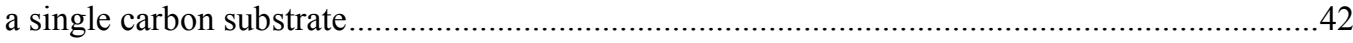

2.1.9 Total organic carbon as a measure of dissolved organic carbon ................................42

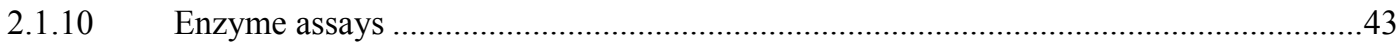

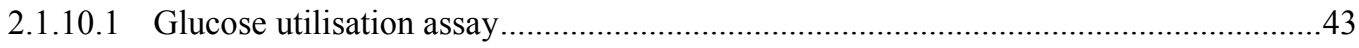

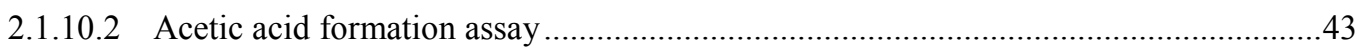

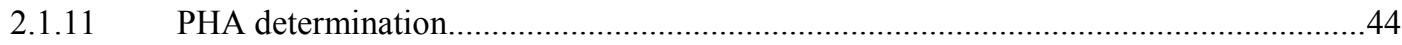

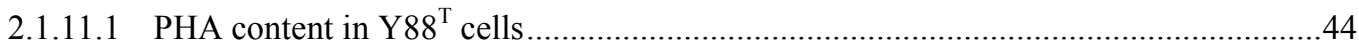

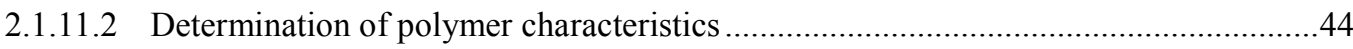

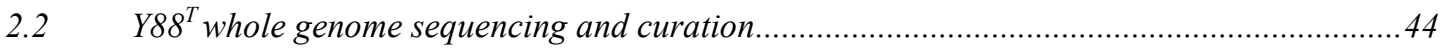

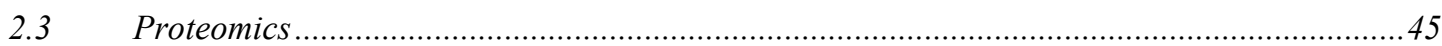

2.3.1 Generation of samples for 2-D DIGE and LC-MS/MS analysis ...............................45

2.3.1.1 2-D Gel Experimental Design 1 .........................................................................45

2.3.1.2 2-D Gel Experimental Design 2 2........................................................................49

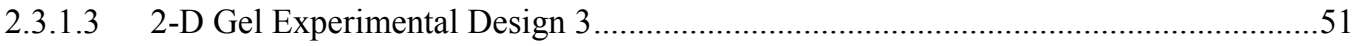

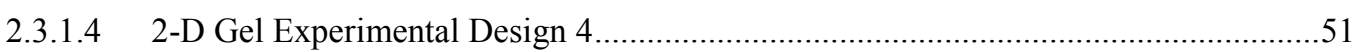

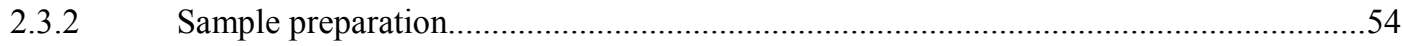

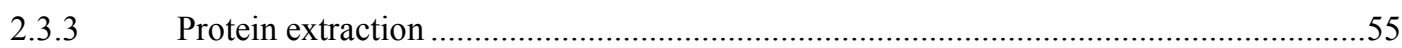

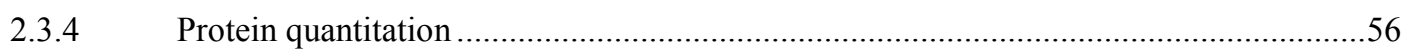

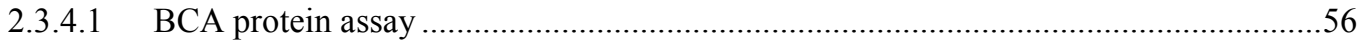

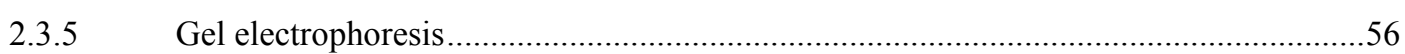

2.3.5.1 Assessment of protein by 1-D SDS-PAGE .............................................................56

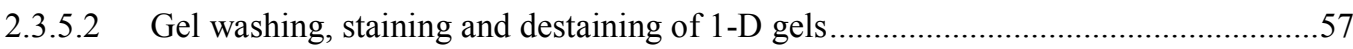




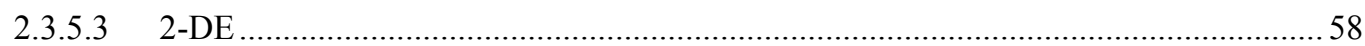

2.3.5.3.1 Preparative gel sample preparation ............................................................ 58

2.3.5.3.2 Sample rehydration and loading onto IPG strip ...........................................5 58

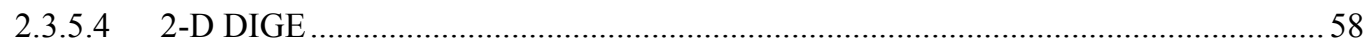

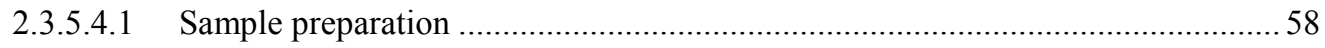

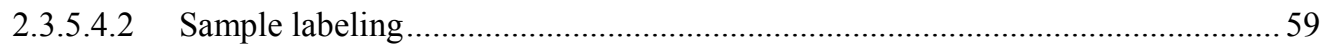

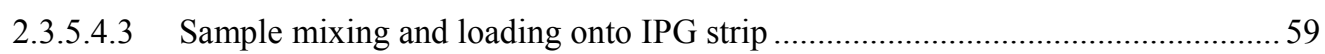

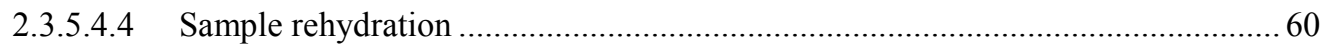

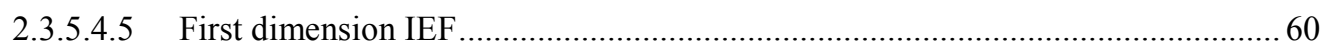

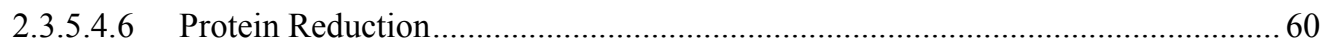

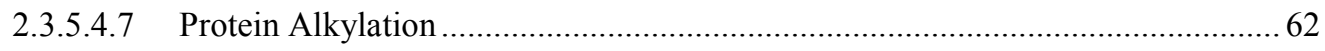

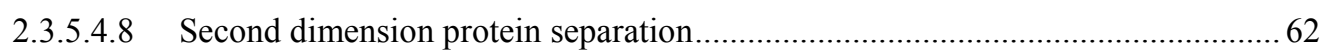

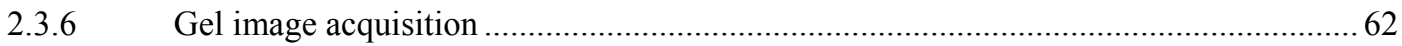

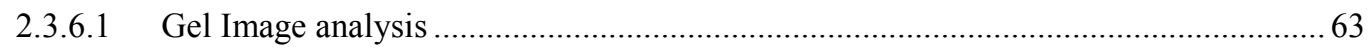

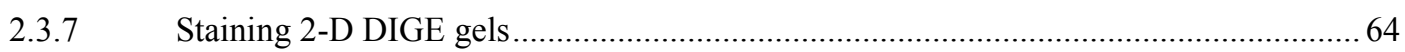

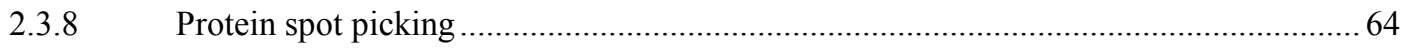

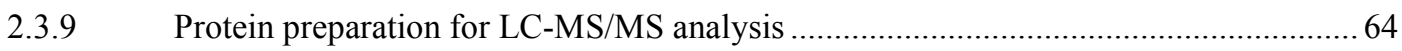

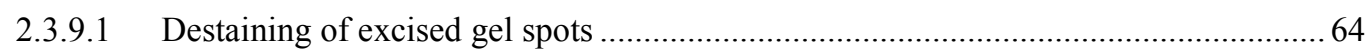

2.3.9.2 In-gel reduction and alkylation of protein prior to LC-MS/MS analysis .................. 65

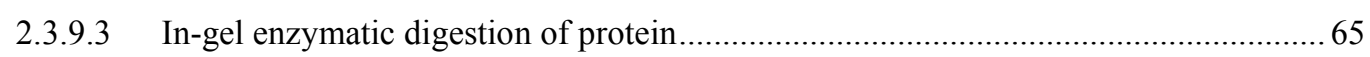

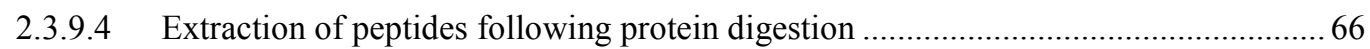

2.3.9.5 $\mathrm{C}_{18}$ membrane binding of peptides for reversed phase LC-MS/MS ....................... 66

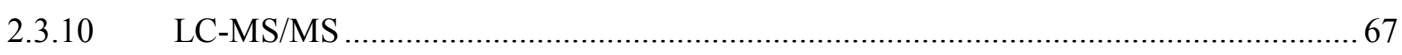

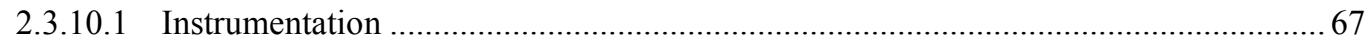

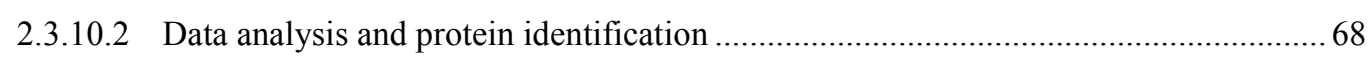

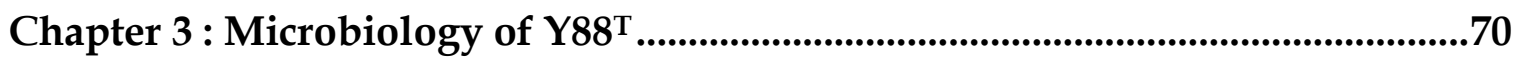

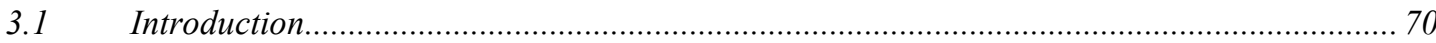

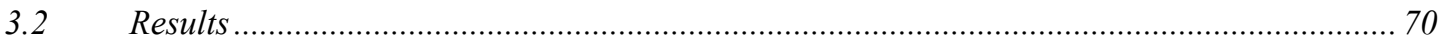

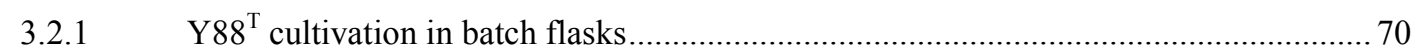

3.2.1.1 Growth in a glucose-enriched minimal nitrogen medium ..................................... 70

3.2.1.1.1 Modeling Y88 ${ }^{\mathrm{T}}$ growth to the Gompertz model ................................................. 70

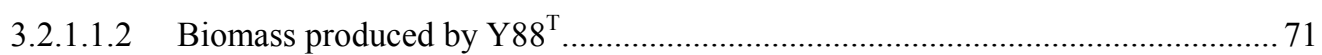

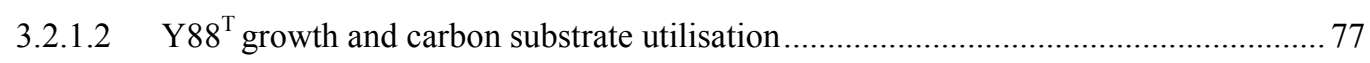

3.2.1.2.1 Single substrate utilisation: glucose vs. acetate.................................................. 77

3.2.1.2.2 Mixed substrate utilisation: glucose and acetate ............................................ 79

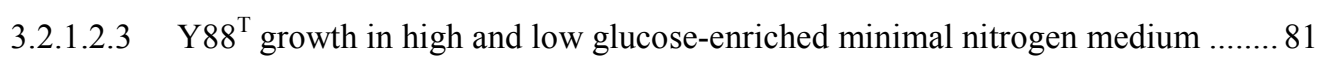

3.2.1.2.4 Composition of the PHB polymer produced by $\mathrm{Y}^{8} 8^{\mathrm{T}}$ from glucose ................... 84

3.2.2 Comparison between $\mathrm{Y}^{2} 8^{\mathrm{T}}$, A. vinelandii and P. putida $\mathrm{mt} 2$.................................. 86 
3.2.2.1 Growth and nitrogen fixation in $\mathrm{NH}_{4}{ }^{+}$-free and $\mathrm{NH}_{4}{ }^{+}$-supplemented glucose-enriched media 86

3.2.2.2 Growth, biomass and PHB production in $\mathrm{NH}_{4}{ }^{+}$-supplemented media.......................92

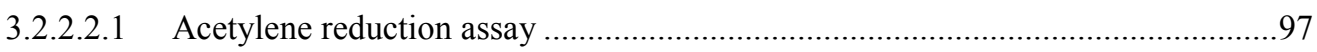

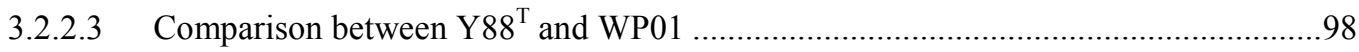

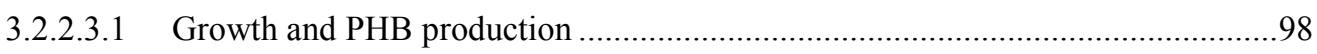

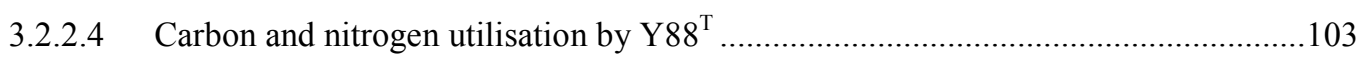

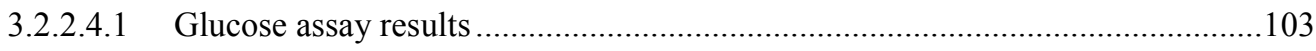

3.2.2.4.2 Total dissolved organic carbon (DOC) in spent medium ..................................103

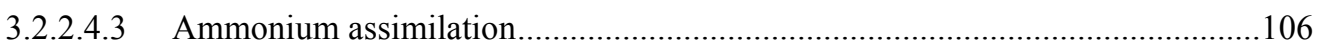

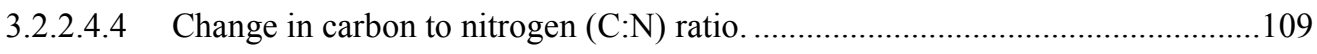

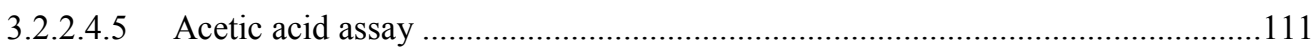

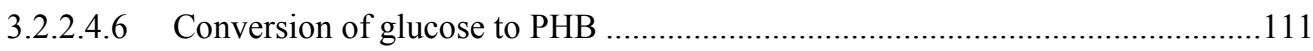

Chapter 4 : "Proteomic signatures" for the Fix"n/Fix off physiology of Y88T during PHA synthesis .......................................................................................................115

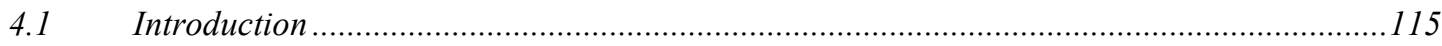

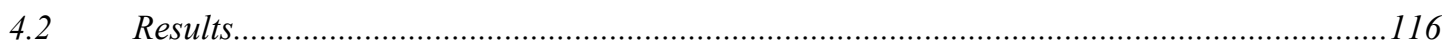

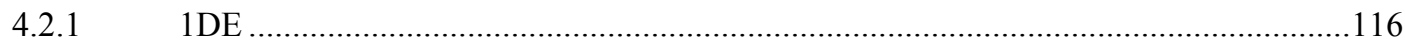

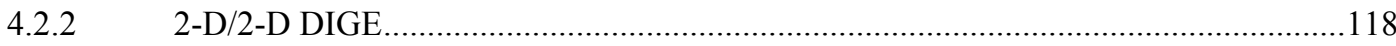

4.2.2.1 Differential protein abundance between the $\mathrm{Fix}^{\text {on }}$ and $\mathrm{Fix}^{\text {off }}$ physiologies of $\mathrm{Y}^{\mathrm{T}} 8^{\mathrm{T}}$

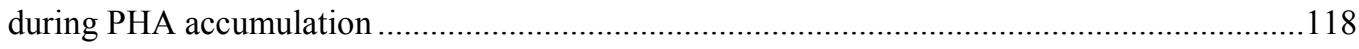

4.2.2.2 Differential protein abundance at different optical densities for the Fix ${ }^{\text {on }}$ and Fix ${ }^{\text {off }}$

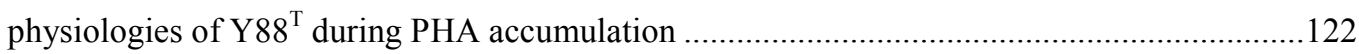

4.2.2.2.1 Nitrogen-fixing and associated proteins .................................................... 125

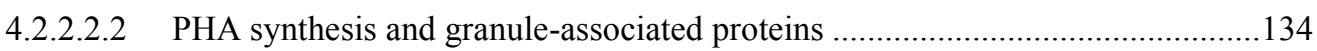

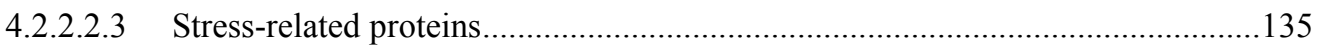

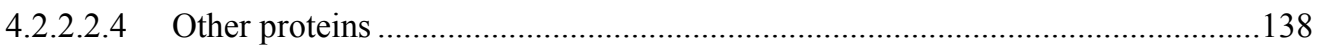

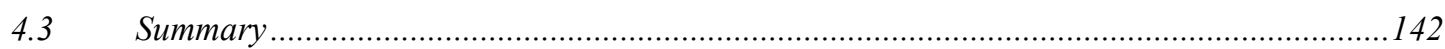

Chapter 5 : The paradox of $\mathrm{Y}^{\mathrm{T}}$ growth at high oxygen concentration .............144

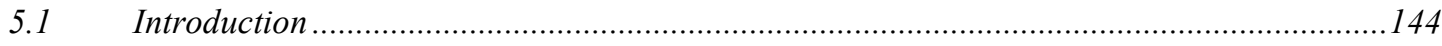

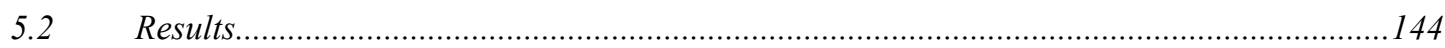

5.2.1 Cultivation of $\mathrm{Y}_{8} 8^{\mathrm{T}}$ in a bioreactor at $\mathrm{DO}^{\text {low }}$ or $\mathrm{DO}^{\text {high }}$ concentrations ......................144

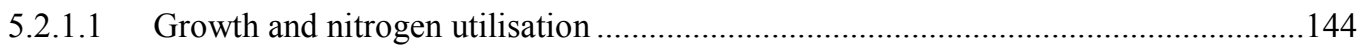

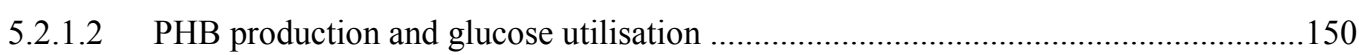

5.2.1.3 Comparison of protein profiles obtained for $\mathrm{DO}^{\text {low }}$ or $\mathrm{DO}^{\text {high }}$ conditions at high cell

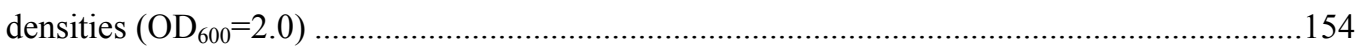

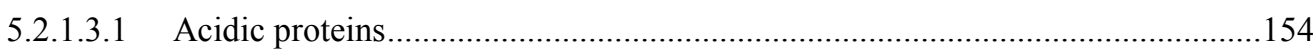


5.2.1.3.1.1 Nitrogen-fixing proteins ...................................................................................157

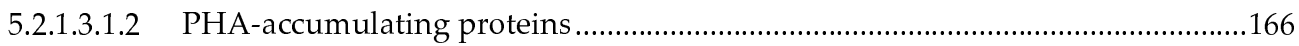

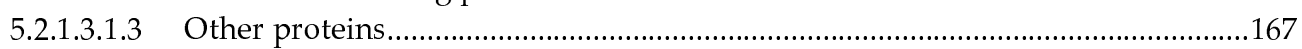

5.2.1.3.2 Basic proteins .......................................................................................... 173

5.2.1.3.2.1 Nitrogen fixation proteins.....................................................................................175

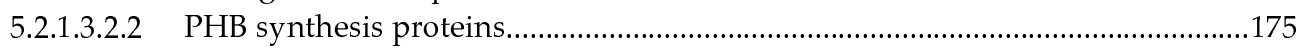

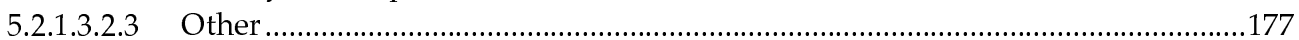

5.2.1.4 Comparison of protein profiles obtained for $\mathrm{DO}^{\text {low }}$ or $\mathrm{DO}^{\text {high }}$ conditions at high cell

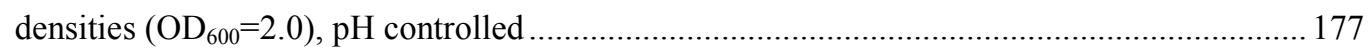

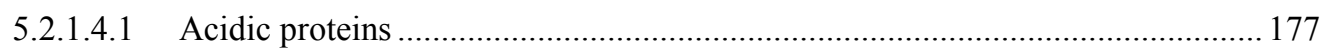

5.2.1.4.1.1 Linear gradient pH 4-7 range .................................................................................178

5.2.1.4.1.2 Nitrogen fixation proteins..............................................................................181

5.2.1.4.1.3 Nitrogen assimilation ......................................................................................186

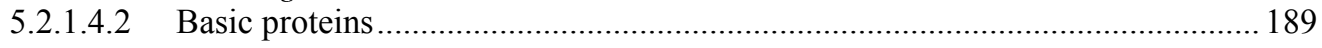

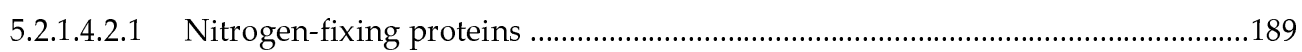

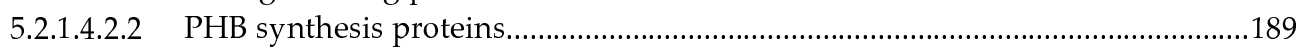

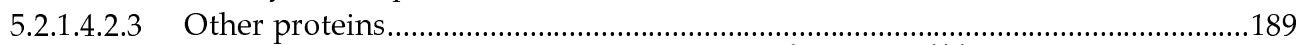

5.2.1.5 Comparison of protein profiles obtained for $\mathrm{DO}^{\text {low }}$ or $\mathrm{DO}^{\text {high }}$ conditions at low cell

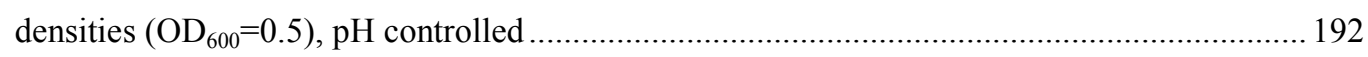

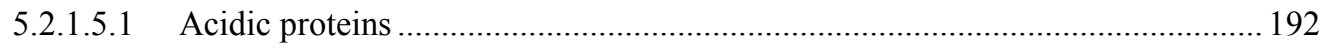

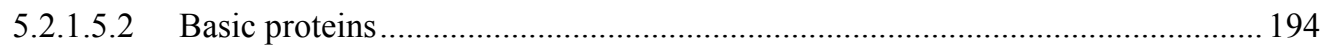

\section{Chapter 6 : Bioinformatic analysis of post-translational modifications and primary and secondary structure of selected $\mathrm{Y}^{2} 8^{\mathrm{T}}$ nitrogenase and PHB synthesis proteins.........................................................................................................200}

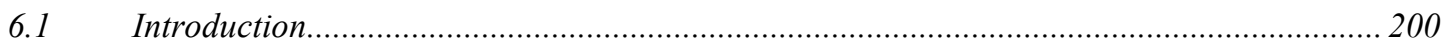

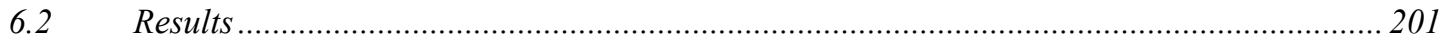

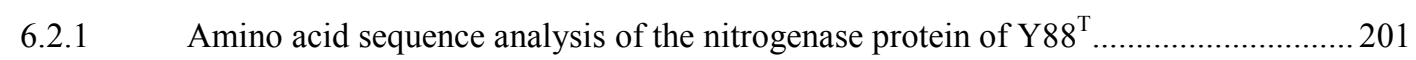

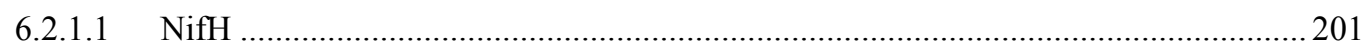

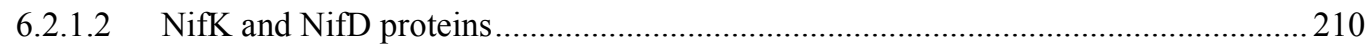

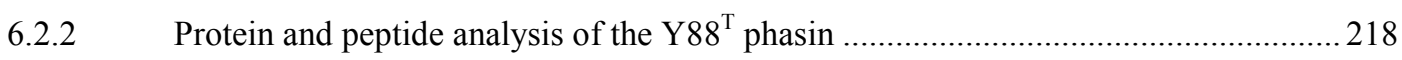

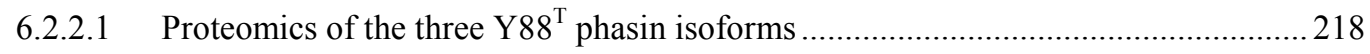

6.2.2.2 Phasin protein sequence alignments ............................................................ 222

Chapter 7 : Summary and Discussion ........................................................................231

7.1 Y88 $:$ Microbiology, Nitrogen Fixation and Carbon Utilisation ...................................... 231

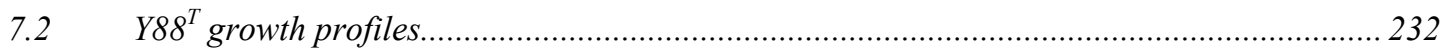

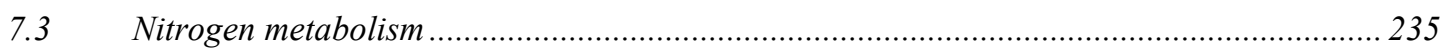

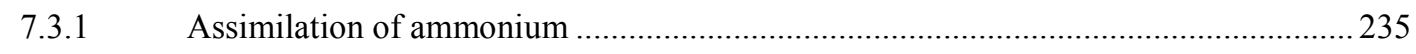

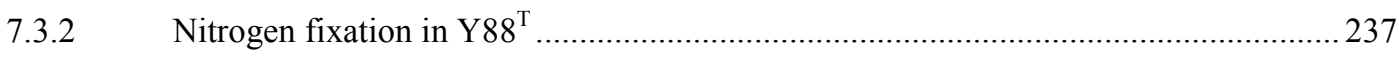




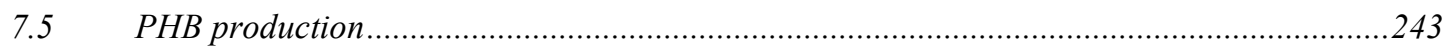

7.6 Amino acid and nucleic acid metabolism proteins .....................................................24

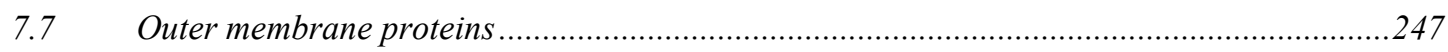

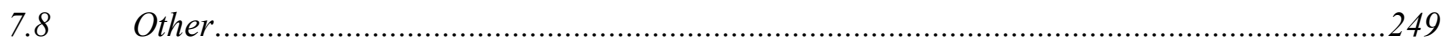

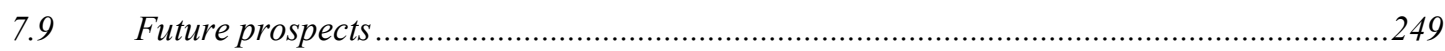

Chapter 8 Appendices ........................................................................................253

8.1 Appendix A Additional proteins (following six pages) not all discussed in chapters 4-7 identified by Mascot-based searches of LC-MS/MS data.

8.2 Figure A.1 A representative 2-D preparative gel showing additional proteins identified in the pH 4-7 linear range and 6-100 kDa range using LC-MS/MS and not all discussed in chapters 4-7...260

8.3 Appendix B Additional protein identifications not all discussed in Chapters 4-7.... 261

8.4 Figure B.1. A representative 2-D DIGE gel showing additional proteins identified in the $p H$ 6-11 linear range using LC-MS/MS and not all discussed in chapters 4-7. ...................................263

8.5 Appendix C Additional protein identifications not all discussedin Chapters 4-7................264

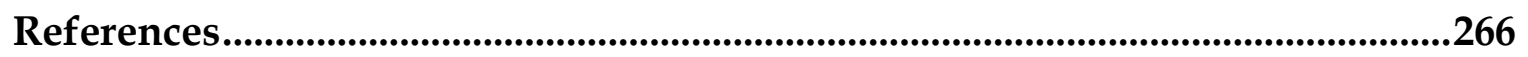




\section{List of Tables}

Table 2.1. Growth media and corresponding cell physiological state with regard to nitrogen fixation defined for $Y 88^{\mathrm{T}}$ growth conditions. 33

Table 2.2. Physiological state of $Y 88^{\mathrm{T}}$ cells defined for a specific set of growth conditions........... 47

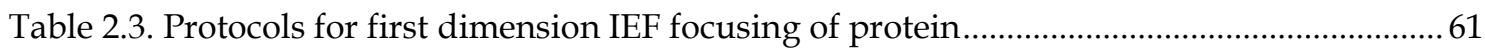

Table 3.1 Gompertz equations for $\mathrm{Y} 88^{\mathrm{T}}$ replicate growth curves .................................................... 73

Table 3.2 Dry biomass (cumulative over $72 \mathrm{hrs}$ ), actual change in dry biomass (for each time interval separately), rate of change in dry biomass produced (for each time interval separately) and yield of biomass by $\mathrm{Y}^{8} 8^{\mathrm{T}}$ in a glucose-enriched minimal nitrogen medium.

Table 3.3. Glucose consumed by $\mathrm{Y}^{88^{\mathrm{T}}}$ during $72 \mathrm{hr}$ growth in a glucose-enriched minimal nitrogen medium

Table $4.1 \mathrm{Y}^{8} 88^{\mathrm{T}}$ proteins showing altered abundance in for the Fix ${ }^{\text {off }}$ state $\left(\mathrm{OD}_{600}\right.$ of 0.5 and 1.0$)$ compared to the Fix on state $\left(\mathrm{OD}_{600}\right.$ of 2.0), identified using LC-MS/MS. 127

Table 4.2 LC-MS/MS peptide analysis of $\mathrm{Y}^{8} 8^{\mathrm{T}}$ proteins showing differential abundance for the Fix ${ }^{\text {off }}$ state $\left(\mathrm{OD}_{600}\right.$ of 0.5 and 1.0) compared to the Fix ${ }^{\text {on }}$ state $\left(\mathrm{OD}_{600}\right.$ of 2.0$)$....... 129

Table 5.1 Carbon and nitrogen content of $\mathrm{Y}^{\mathrm{T}} 8^{\mathrm{T}}$ cells grown in glucose-enriched, nitrogenlimiting medium

Table 5.2 Oxygen input to meet the demand of Y $88^{\mathrm{T}}$ cells and maintain set DO levels constant during $\mathrm{Y}^{8} 8^{\mathrm{T}}$ growth in a glucose-enriched, nitrogen-fixing medium in bioreactors 155

Table 5.3 2-D DIGE protein spot analysis ( $\mathrm{pH} \mathrm{4-7)} \mathrm{and} \mathrm{LC-MS/MS} \mathrm{analysis} \mathrm{of} \mathrm{protein} \mathrm{from} \mathrm{cells}$ grown at $\mathrm{DO}^{\text {low }}$ or $\mathrm{DO}$ high 159

Table 5.4 2-D DIGE protein spot analysis showing statistical values and LC-MS/MS identification of proteins with altered abundance at high OD600 (2.0), and $\mathrm{pH}$ not controlled at DOlow or 176

Table 5.5 2-D DIGE protein spot analysis ( $\mathrm{pH} 4-7$ ) and LC-MS/MS analysis of protein from cells grown at $\mathrm{DO}^{\text {low }}$ or $\mathrm{DO}^{\text {high }}$ at constant $\mathrm{pH}$ and high $\mathrm{OD}_{600}(2.0)$ 183

Table 5.6 2-D DIGE protein spot analysis ( $\mathrm{pH}$ 6-11) and LC-MS/MS analysis of protein from cells grown at $\mathrm{DO}^{\text {low }}$ or $\mathrm{DO}$ high at constant $\mathrm{pH}$ 191

Table 5.7 2-D DIGE spot analysis (pI 4-7) and LC-MS/MS of Y88 ${ }^{\mathrm{T}}$ protein from cells grown to a low $\mathrm{OD}_{600}$ under ammonium-depleted conditions at DOlow or DOhigh at constant pH 7...195

Table 5.8 2-D DIGE protein spot analysis (pI 6-11) and LC-MS/MS analysis of Y88 cells grown to a low $\mathrm{OD}_{600}$ under ammonium-depleted conditions at $\mathrm{DO}^{\text {low }}$ or $\mathrm{DO}^{\text {high }}$ at constant $\mathrm{pH} 7$ 197 
Table 6.1 Bacterial species names and the corresponding abbreviated names in the NifH

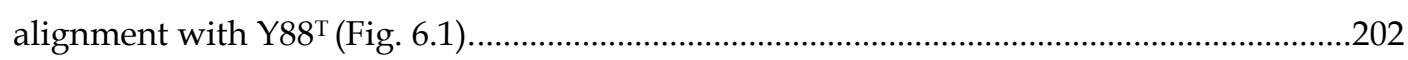

Table 6.2 Bacterial species names and the corresponding truncated names in the order of appearance in the list of phasin sequences in the alignment with $\mathrm{Y}^{8} 8^{\mathrm{T}}$ (Fig. 6.2)...............223

Table $7.1 \mathrm{Y}^{\mathrm{T}} 8^{\mathrm{T}}$ enzymes involved in protein and nucleic acid synthesis that showed unaltered states irrespective of the growth conditions. 


\section{List of Figures}

Figure 1.1 A schematic of the energy-demanding reaction catalysed by the nitrogenase complex.

Figure 1.2 Schematic representation of adenylylation/deadenylylation of GS in response to ammonium status. .12

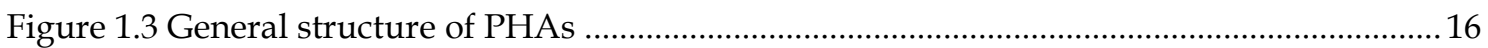

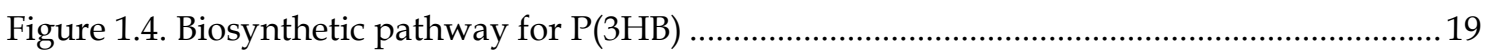

Figure 1.5 Schematic of NADH and NADPH production and utilisation via catabolic vs.

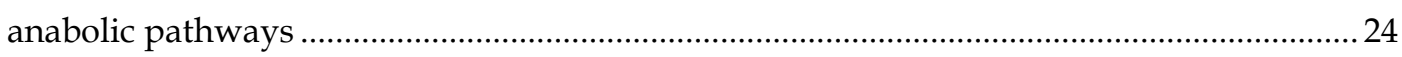

Figure 2.1. Schematic representation of workflow to investigate the microbiology of $\mathrm{Y}^{\mathrm{T}} \mathrm{P}^{\mathrm{T}}$ growth, nitrogen assimilation, carbon utilisation and PHA accumulation under different growth conditions 35

Figure 2.2. Schematic representation of workflow to investigate the proteome of $\mathrm{Y}^{8} 8^{\mathrm{T}}$ under

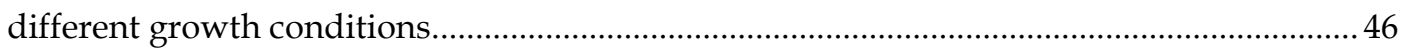

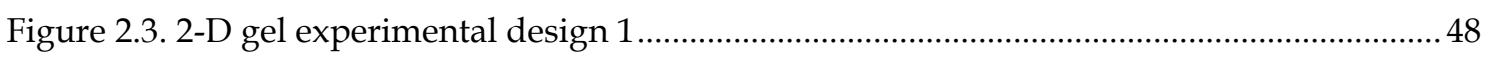

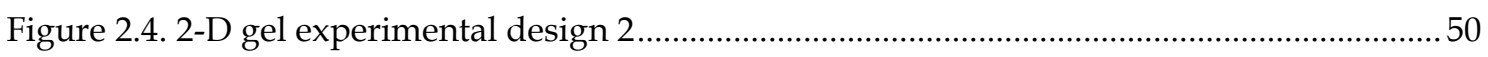

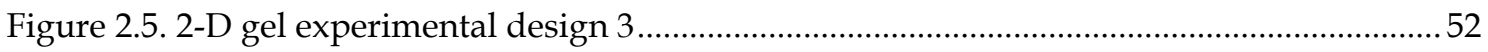

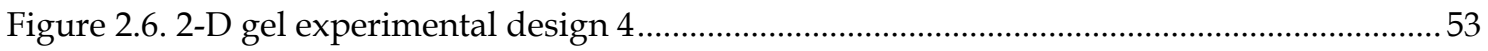

Figure $3.1{\mathrm{Y} 88^{\mathrm{T}}}^{\mathrm{g}}$ growth data fitted to the Gompertz model .............................................................. 72

Figure $3.2 \mathrm{OD}_{600}$ and dry biomass produced by $\mathrm{Y}^{8} 8^{\mathrm{T}}$ in a glucose-enriched minimal nitrogen

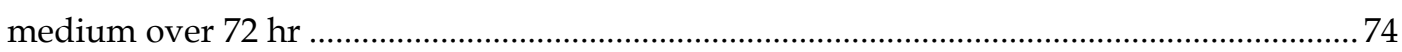

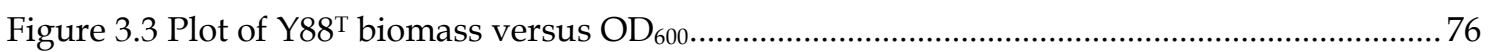

Figure 3.4. Total dry biomass and PHB mass produced by $\mathrm{Y}^{8} 8^{\mathrm{T}}$ after $24 \mathrm{hr}$ growth in a minimal nitrogen medium with various carbon substrates ................................................................... 78

Figure 3.5 Comparative growth of $Y 88^{\mathrm{T}}$ in high and low glucose minimal nitrogen media........ 82

Figure 3.6 PHB and dry biomass produced by $\mathrm{Y}^{8} 8^{\mathrm{T}}$ in high and low glucose minimal nitrogen

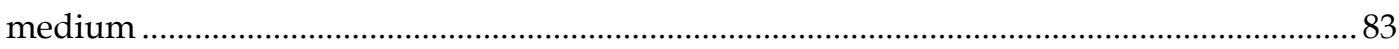

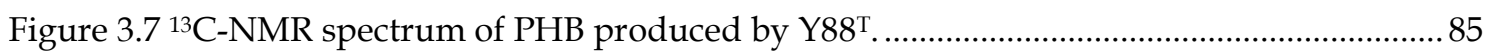

Figure 3.8 Transmission electron micrograph (TEM) of Y88 $8^{\mathrm{T}}$ cells containing PHB accumulated

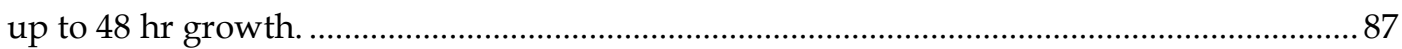

Figure $3.9 \mathrm{Y}^{\mathrm{T}} 8^{\mathrm{T}}$ growth in minimal nitrogen and nitrogen-free media........................................... 88

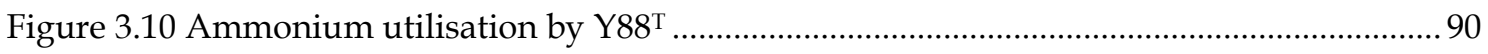

Figure 3.11 Comparative growth of $\mathrm{Y}^{8} 8^{\mathrm{T}}$, A. vinelandii, and P. putida $\mathrm{mt} 2$.................................. 91 
Figure 3.12 Comparative PHB mass and total dry biomass production by $\mathrm{Y}^{8} 8^{\mathrm{T}}$ and $A$. vinelandii .93

Figure 3.13 Comparative PHB production by $\mathrm{Y}^{8} 8^{\mathrm{T}}$ and $A$. vinelandii at 24,48 and $72 \mathrm{hr}$...... .94

Figure 3.14 Acetylene reduction assays of $\mathrm{Y}^{\mathrm{T}} 8^{\mathrm{T}}$ and A. vinelandii under various growth conditions .95

Figure 3.15 Growth of Y88 ${ }^{\mathrm{T}}$ and WP01 in a glucose-enriched, acetate-enriched and carbon-free medium 100

Figure 3.16 PHB and biomass produced by Y88 ${ }^{\mathrm{T}}$ and WP01 grown for $24 \mathrm{hr}$ in glucose-enriched nitrogen-fixing medium, acetate-enriched nitrogen-fixing medium, acetate-enriched $1 x$ BSM and acetate-enriched variant 1x BSM with no nitrogen source .101

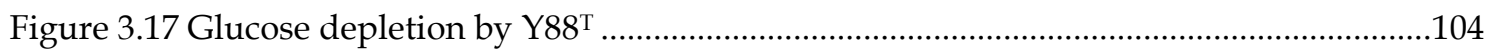

Figure 3.18 PHA production by $\mathrm{Y}^{\mathrm{T}} 8^{\mathrm{T}}$ during glucose depletion...............................................105

Figure 3.19 Total dissolved organic carbon (DOC) change during $\mathrm{Y}^{8} 8^{\mathrm{T}}$ growth.......................107

Figure 3.20 Change in C:N ratio during ammonium assimilation by $\mathrm{Y}^{8} 8^{\mathrm{T}} \ldots \ldots \ldots \ldots \ldots \ldots \ldots \ldots \ldots . . . . . . . . . . . . . . . .108$

Figure 3.21 Y $88^{\mathrm{T}}$ glucose depletion: change in C:N ratio and rate of glucose depletion..............110

Figure 3.22 Schematic representation of glucose conversion to PHB and ammonium assimilation by $\mathrm{Y} 88^{\mathrm{T}}$. 112

Figure 4.1 Coomassie-stained 1-DE gel showing comparison of $\mathrm{Y}^{8} 8^{\mathrm{T}}$ total protein extracts ......117

Figure 4.2.Total protein gel of $\mathrm{Y}^{8} 8^{\mathrm{T}}$ at various stages of culture growth . 119

Figure 4.3 Overlay image of $\mathrm{Y} 88^{\mathrm{T}}$ protein profiles generated from minimally labeled pooled Fix ${ }^{\text {on }}$ and Fix ${ }^{\text {off }}$ samples.

Figure 4.4 2-D DIGE profiles of $\mathrm{Y}^{\mathrm{T}} 8^{\mathrm{T}}$ cells for the Fix ${ }^{\text {off }}$ physiological state of the cells (A and B)

Figure 4.5. 2-D DIGE profiles of $\mathrm{Y}^{8} 8^{\mathrm{T}}$ cells for the Fix ${ }^{\text {off }}(\mathrm{A})$ and Fixon $(\mathrm{B})$ physiological state of the cells 124

Figure $5.1 \mathrm{OD}_{600}$, biomass production and nitrogenase assays of $\mathrm{Y}^{8} 8^{\mathrm{T}}$ grown at DOlow or DOhigh for $24 \mathrm{hrs}$ in a glucose-enriched, minimal nitrogen medium 146

Figure 5.2 Total nitrogen (Kjeldahl) determined in the spent medium after removal of Y88 ${ }^{\mathrm{T}}$ cells grown at $\mathrm{DO}^{\text {low }}$ or $\mathrm{DO}$ high 147

Figure 5.3 Change in total biomass nitrogen content with change in biomass during growth in nitrogen-depleted medium DOlow (maroon bars) and DOhigh (blue bars) during $24 \mathrm{hr}$ growth. Error bars represent standard deviations, $(n=2)$...............................................149

Figure 5.4 PHB produced by $\mathrm{Y}^{8} 8^{\mathrm{T}}$ at $\mathrm{DO}^{\text {low }}$ and DOhigh during changing $\mathrm{C}: \mathrm{N}$ ratios .................151

Figure 5.5 Glucose utilisation by $\mathrm{Y}^{8} 8^{\mathrm{T}}$ and change in $\mathrm{C}: \mathrm{N}$ ratio .... .152

Figure 5.6 Glucose consumption by $\mathrm{Y}^{2} 8^{\mathrm{T}}$ showing inefficiency of glucose utilisation at DOhigh 153 Figure 5.7 Overlay image of $\mathrm{Y}^{\mathrm{T}} 8^{\mathrm{T}}$ protein profiles generated from minimally labeled samples showing differential protein abundance under $\mathrm{DO}^{\text {low }}$ or $\mathrm{DO}^{\text {high, }}$ uncontrolled $\mathrm{pH}$ conditions in the linear gradient $\mathrm{pH}$ 4-7 range 156 xvi 
Figure 5.8 2-D DIGE images (pI 4-7) showing protein profiles of $\mathrm{Y}^{8} 8^{\mathrm{T}}$ cells grown to high $\mathrm{OD}_{600}$ (2.0) under ammonium-depleted conditions at $\mathrm{DO}^{\text {low }}$ or DOhigh concentrations, $\mathrm{pH}$ not controlled. 158

Figure 5.9 Magnification of the protein spots from 2-D DIGE pH 4-7 gels that showed altered abundance between $\mathrm{DO}^{\text {low }}$ and $\mathrm{DO}^{\text {high }}$ under constant $\mathrm{pH} 7$ conditions in the growth medium. 169

Figure 5.10 2-D DIGE images (pI 6-11) showing protein profiles of $\mathrm{Y}^{8} 8^{\mathrm{T}}$ cells grown to high $\mathrm{OD}_{600}(2.0)$ at DOlow or DOhigh concentrations, $\mathrm{pH}$ not controlled. 174

Figure 5.11 Overlay image of $\mathrm{Y}^{\mathrm{T}} 8^{\mathrm{T}}$ protein profiles generated from minimally labeled samples showing differential protein abundance under DOlow or DOhigh, constant $\mathrm{pH} 7$ conditions in the linear gradient $\mathrm{pH} 4-7$ range. 179

Figure 5.12. 2D DIGE images ( $\mathrm{pI} 4-7$ ) showing protein profiles of $\mathrm{Y} 88^{\mathrm{T}}$ cells grown to a high $\mathrm{OD}_{600}(2.0)$ under ammonium-depleted conditions at DOlow or DOhigh at constant $\mathrm{pH} . . . .180$ Figure 5.13 Magnification of the protein spots from 2-D DIGE pH 4-7 gels that showed altered abundance between $\mathrm{DO}^{\text {low }}$ and $\mathrm{DO}$ high under constant $\mathrm{pH} 7$ conditions in the growth medium. Arrows denote increased abundance for the protein under $\mathrm{DO}^{\text {low }}$ or DOhigh conditions. 182

Figure 5.14 2-D DIGE images for the linear gradient pI 6-11 range showing protein profiles of $\mathrm{Y}^{8} 8^{\mathrm{T}}$ cells grown to a high $\mathrm{OD}_{600}$ at $\mathrm{DO}^{\text {low }}$ or $\mathrm{DO}$ high at constant $\mathrm{pH} 7$. 190

Figure 5.15 2-D DIGE images ( $\mathrm{pI} 4-7$ ) showing protein profiles of $\mathrm{Y}^{\mathrm{T}} 8^{\mathrm{T}}$ cells grown to a low $\mathrm{OD}_{600}$ under ammonium-depleted conditions at $\mathrm{DO}^{\text {low }}$ or DO $\mathrm{DO}^{\text {high }}$ at constant $\mathrm{pH} 7$ 193

Figure 5.16 2-D DIGE images for the linear gradient pI 6-11 range showing protein profiles of Y88 ${ }^{\mathrm{T}}$ cells grown to a high $\mathrm{OD}_{600}$ under $\mathrm{DO}^{\text {low }}$ or $\mathrm{DO}^{\text {high }}$ conditions at constant $\mathrm{pH} 7 \ldots . . .196$ Figure 6.1 CLUSTALW (1.83) multiple sequence alignment of the $\mathrm{Y}^{\mathrm{T}} 8^{\mathrm{T}} \mathrm{NifH}$ protein sequence with $20 \mathrm{NifH}$ sequences from other bacteria (Table 6.1) 203

Figure 6.2 CLUSTALW (1.83) multiple sequence alignment of the $Y 88^{\mathrm{T}} \mathrm{NifD}$ and NifK protein sequences with the $A$. vinelandii NifD and NifK sequences 211

Figure 6.3 CLUSTALW (1.83) multiple sequence alignment of the $\mathrm{Y}^{8} 8^{\mathrm{T}}$ phasin protein with representative phasin sequences randomly selected from Genbank (Table 6.2) 219

Figure 6.4 Neighbour-joining bootstrap analysis of the $\mathrm{Y}^{8} 8^{\mathrm{T}}$ phasin with 44 phasins from Genbank. 226

Figure 6.5 Secondary structure predictions for the $\mathrm{Y} 88^{\mathrm{T}}$ and R. eutropha phasins. ...................... 227

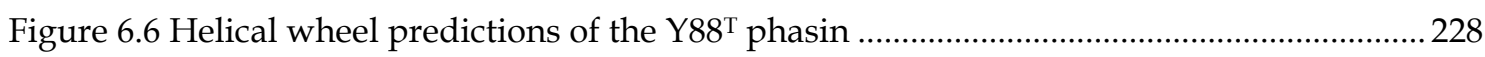

Figure 6.7 Helical wheel predictions of the R. eutropha phasin 229

Figure 7.1 Schematic of proposed carbon and reducing equivalent pathways relating to central metabolism, nitrogen fixation and PHB accumulation in $\mathrm{Y}^{8} 8^{\mathrm{T}}$ 241 
Figure 7.2 Schematic of proposed PHB pathway in Y88T including possible alternative routes to PHB production, based on proteomic identification of enzymes (red) involved in the relevant pathways. 


\section{Abbreviations}

2-DE two-dimensional electrophoresis

2-D DIGE two-dimensional difference in-gel electrophoresis

ACN acetonitrile

BVA Biological Variation Analysis

DO, dissolved oxygen

DOlow, DOhigh low dissolved oxygen, high dissolved oxygen

DTT dithiothreitol

ED Entner-Doudoroff pathway

EM Embden-Meyerhof pathway

Fix off non-nitrogen-fixing physiological state

Fix on nitrogen-fixing physiological state

GC gas chromatography

GDH glutamate dehydrogenase

GOGAT glutamine oxoglutarate aminotransferase

GS glutamine synthetase

IEF isoelectric focusing

LC-MS/MS liquid chromatography tandem mass spectrometry

MS mass spectrometry

MQ MilliQ

OPP oxidative pentose phosphate pathway

ORF open reading frame

PHA polyhydroxyalkanoate

PHB poly(3-hydroxybutyric) acid

SDS sodium dodecylsulfate

SDS-PAGE sodium dodecylsulfate-polyacrylamide gel electrophoresis

TCA tricarboxylic acid cycle

TFA trifluoroacetic acid 


\section{Chapter 1: Introduction}

\subsection{Overview}

Effluent from pulp and paper mills is a carbon-rich, nitrogen-poor material which must be remediated prior to its release into the environment. Currently, the remediation process requires the addition of nitrogen to allow naturally occurring bacteria to maximally metabolise and detoxify the effluent. Nitrogen supplementation adds significantly to the cost of the remediation process and presents environmental difficulties of its own, such as eutrophication of lakes that receive much more nitrogen than they require. Researchers at Scion (Rotorua, New Zealand), are exploring the application of bacteria capable of fixing atmospheric nitrogen via biochemical reduction to ammonium ion as a potential lower-cost alternative to nitrogen supplementation in the bioremediation process (Slade et al., 2004). Combining nitrogen fixation with other bacterial metabolic capabilities to convert the waste carbon into useful raw materials would be a highly desirable further enhancement to the process.

Global warming, increased energy demand and increased petroleum costs have been major drivers toward the search for sustainably produced, biologically based, biodegradable plastics as substitutes for petroleum-based plastics. To this end, many microbes have been identified that naturally accumulate carbon in the form of PHA, a class of storage polymers (metabolically equivalent to fats in animals) that has properties similar to conventional plastics, but is completely biodegradable. Despite such promise, attempts to commercially produce PHAs as substitutes for petroleum-derived polymers have been challenging and considerable effort has focused on producing greater amounts of PHA at reduced cost. Thus, there is a great potential in utilising industrial waste streams as low-cost sources for PHA production.

To study the possibility of further enhancement of the value proposition of pulp mill waste remediation from cost-neutrality to profitability, Scion has isolated 
and identified nitrogen-fixing bacteria that also naturally accumulate PHA from remediating pulp mill effluent. Through such bacteria, much of the remediable carbon could be converted to PHA, which could be harvested and used to make biodegradable consumer products. Both nitrogen fixation and PHA synthesis are energy-intensive and require significant amounts of reducing equivalents, thus competing for intracellular resources. The emphasis of this thesis has been on understanding the metabolic dynamics between nitrogen fixation and PHA accumulation to aid in identifying bacteria from pulp and paper wastewater that carry out these activities in an optimal manner. To conduct these studies, a model organism was required.

Y88 ${ }^{\mathrm{T}}$, a novel Gram-negative bacterium was isolated from a mixed culture bioreactor at Scion. DNA sequence analysis has shown this strain to possess the $n i f \mathrm{H}^{+}$gene required for nitrogen fixation, and the strain can produce a positive $\mathrm{C}_{2} \mathrm{H}_{2}$ reduction assay, both of which are indicative of an ability to fix nitrogen. Furthermore, this strain possesses the $p h a \mathrm{C}^{+}$gene required for PHA synthesis. The combined ability of $\mathrm{Y}^{\mathrm{T}}$ to fix nitrogen and synthesise PHA makes it particularly suitable as a model organism to develop novel and potentially less costly industrial applications. This study aims to elucidate underlying pathways of PHA synthesis and nitrogen fixation in $\mathrm{Y}^{8} 8^{\mathrm{T}}$, using microbiological and proteomic techniques to identify proteins and enzymes differentially altered under specific opposing growth conditions to clarify the relationship between nitrogen fixation and PHA accumulation in this species.

\subsection{Sphingomonads}

Sphingomonads are a group of organisms belonging to the $\alpha-4$ subclass of the proteobacteria (Kawahara et al., 1999; Yabuuchi et al., 2002). The nomenclature of the commonly used appellation, $\alpha$-proteobacteria, as proposed by Garrity et al., (2005) is Alphaproteobacteria and has subsequently been validated as such (Euzéby, 2006). An extensive body of literature describes the phylogenetic affiliation of sphingomonads to closely related genera based on 165 rDNA sequence analysis as well as structural and morphological distinctions 
(Takeuchi et al., 1994; Takeuchi et al., 2001; Yabuuchi et al., 2002; Pal et al., 2006; Yang et al., 2006). The type species Sphingomonas paucimobilis was previously considered to be a member of the genus Pseudomonas, reflecting some of the confusion that has prevailed in the classification of this group of Gram-negative bacteria. Sphingomonads have been shown to have similar properties to phylogenetically closely related taxa such as Zymomonas and Erythrobacter (Kosako et al., 2000), but on the other hand they have unique traits such the ability to utilise homospermidine as the major polyamine that separate them from other Gram-negative bacteria (Busse et al., 2005). Members of these genera contain some unusual structural features such as glycosphingolipids (Kawahara et al., 1999; Fujii et al., 2003; Gupta \& Mok, 2007) instead of the signature lipopolysaccharide profile characteristic of Gram-negative bacteria (Sriram et al., 2005) and possess ubiquinone 10 as their major respiratory quinone (Takeuchi et al., 2001). At present, sphingomonads are considered a homogeneous group of five phylogenetically distinct genera within the Alphaproteobacteria, viz., Sphingomonas sensu stricto, Sphingobium, Sphingosinicella, Sphingopyxis and Novosphingobium (Takeuchi et al., 2001). Historically, the genus Novosphingobium has been controversially classified in the genus Sphingomonas (Yabuuchi et al., 2002), but more recent phylogenetic and chemotaxonomic studies have confirmed that Novosphingobium is appropriately considered a separate genus (Takeuchi et al., 2001; Kampfer et al., 2002; Liu et al., 2005; Tiirola et al., 2005). The genus Novosphingobium comprises a diverse group of bacteria that now includes nineteen species with the most recent additions of $N$. naphthalenivorans (Suzuki \& Hiraishi, 2007), N. nitrogenifigens (Addison et al., 2007) and N. acidiphilum (Glaeser et al., 2009).

Sphingomonads display diverse ecological as well as physiological properties such as heteropolymer assimilation and biofilm formation (Koskinen et al., 2000; Barrios et al., 2006; Pal et al., 2006). They are further characterised as a group of bacteria known to possess a number of traits such as the ability to biodegrade artificial compounds (Nakagawa et al., 2002) and utilise 
contaminants as a growth and energy source (Kawai, 1999; Bastiaens et al., 2000). Their physiological properties enable them to exploit a variety of habitat types from water supplies (Koskinen et al., 2000; Kelley et al., 2004) to soil (Leys et al., 2004) and subsurface sediments (Fredrickson et al., 1995). They also occur in association with humans and plants as causative agents of disease (Yabuuchi et al., 1990; White et al., 1996; Kelley et al., 2004).

Their versatility and scavenging behaviour as well as their ability to accumulate carbon confers a distinct biological advantage to the sphingomonads that inhabit naturally carbon-enriched, but otherwise nutrient-limited environments such as activated sludge (Neef et al., 1999) as well as soil environments where they are commonly associated with the roots of plants (Takeuchi et al., 1995; Xie \& Yokota, 2006). Studies on their unique traits have focused on their unusual membrane structures and lipid compositions, as well as their abilities to induce corrosion, cause disease in humans (Kaplan, 2004) and plants, produce polymers and biodegrade refractory pollutants such as polycyclic aromatic hydrocarbons (Dilworth et al., 1993). Their biosynthetic and biodegradative capabilities have been widely exploited for a range of biotechnological applications from producing extracellular polymers to bioremediation of environmental contaminants. Although their extraordinary ability to biodegrade recalcitrant carbon sources in particular has led to several genome sequencing projects (Leys et al., 2004; Thiel et al., 2005; Zhou et al., 2006) with the completed genomes of Novosphingobium aromaticivorans, Sphingopyxis alaskensis (Kwon \& Kim, 2007) and Sphingomonas wittichii RW1 (JGI) as well as other genome sequencing projects such as Sphingomonas elodea (Hiran College), Sphingobium chungbukense DJ77 (Chungbuk National University, Korea) and Sphingomonas sp. SKA58 underway (Kwon \& Kim, 2007), more widespread investigations are needed to understand the reasons for their unusual biology and versatility. In particular, more comprehensive studies on diazotrophy and biopolymer synthesis are still lacking within this group. Members within the sphingomonads such as S. chilensis, S. adhaesiva, S. macrogoltabida, S. alaskensis 
and N. aromaticivorans are known to produce PHA. More recently, N. aromaticivorans was shown to possess the PHA granule-associated phasin gene (Xie \& Yokota, 2006). Sphingomonas azotifigens is the first known diazotrophic sphingomonad (Sprent \& Sprent, 1990). Diazotrophy and biopolymer synthesis may therefore be more common among members of this group than is currently known. Given the widespread occurrence of sphingomonads that biodegrade refractory organic compounds (White et al., 1996; Oshiman et al., 2007), nitrogen-deficient environments could be augmented with diazotrophic sphingomonads that have the ability to degrade the carbon in these environments and store it in the form of polymer. Thus the identification and characterisation of additional sphingomonads that meet these criteria is of immediate practical interest from both a bioremediation and a biotechnological perspective.

\subsubsection{Novosphingobium nitrogenifigens Y88T ${ }^{\mathrm{T}}$ sp. nov.: a newly characterised sphingomonad as a model organism for low nitrogen waste stream remediation}

The bacterial strain originally designated Y88 was isolated under nickelenriched growth conditions from a naturally nitrogen-limited but carbonenriched pulp and paper wastewater mixed culture bioreactor at Scion (Addison et al., 2007). Y88 is a diazotrophic, Gram-negative, rod-shaped, nonsporulating obligate aerobe that is capable of storing carbon in the form of a polymer, primarily PHB. Although Y88 shares distinct characteristics with other members of the sphingomonads, biochemical and chemotaxonomic data distinguish Y88 from other genera within this group and 16S rRNA sequence analysis confirms its phylogenetic affiliation to members of the genus Novosphingobium. Based on its genotypic (with a characteristic signature 21 base pair gap in the 16S rRNA sequence) and chemotaxonomic characteristics as well as its phenotypic traits, Y88 has recently been classified as the type strain of a new species, Novosphingobium nitrogenifigens $\mathrm{Y}^{2} 8^{\mathrm{T}}$ sp. nov. (Addison et al., 2007), hereafter referred to as $\mathrm{Y}^{2} 8^{\mathrm{T}}$. DNA sequence analysis has confirmed that $\mathrm{Y}^{\mathrm{T}} 8^{\mathrm{T}}$ contains the niff $\mathrm{H}^{+}$gene required for nitrogen fixation and reproducible nitrogen 
fixation was confirmed biochemically via $\mathrm{C}_{2} \mathrm{H}_{2}$ reduction assays. A more definitive measurement of biological nitrogen fixation by ${ }^{2} 8^{\mathrm{T}}$ was subsequently obtained using enriched ${ }^{15} \mathrm{~N}_{2}$ to trace the incorporation of nitrogen into $\mathrm{Y}^{\mathrm{T}} 8^{\mathrm{T}}$ cells grown under reduced nitrogen-limiting conditions (Addison et al., in preparation). Within the Novosphingobia, the combined ability to utilise dinitrogen as a nitrogen source and to produce PHA currently appears to be unique to $\mathrm{Y} 88^{\mathrm{T}}$ (Addison et al., 2007).

The combined abilities to fix nitrogen and accumulate carbon as a metabolic reserve made $\mathrm{Y}^{8} 8^{\mathrm{T}}$ ideal as a model sphingomonad for studying PHA accumulation in carbon-rich, nitrogen-poor growth conditions that necessitate nitrogen fixation. Therefore, this strain was chosen for detailed proteomic analysis to better understand the interrelationship between the metabolically competing activities of nitrogen fixation and PHA accumulation during growth in a carbon-rich environment. An improved understanding of the dynamic interplay between these two important metabolic capabilities has applicability for all similar sphingomonads, which will assist in optimising waste stream remediation as well as polymer production under controlled conditions in pure culture.

\subsection{Bacterial utilisation of nitrogen and carbon}

\subsubsection{Biological nitrogen fixation}

Biological nitrogen fixation is the reduction of atmospheric nitrogen to ammonia that is catalysed by the nitrogenase enzyme complex (Rees et al., 2005). Atmospheric nitrogen is available in the form of dinitrogen. The reduction of dinitrogen to ammonium ion is an ATP-dependent reaction involving the production of two moles of ammonia from one mole of molecular nitrogen at the expense of 16 moles of ATP, with a supply of electrons and protons. The process can be represented by the following equation:$$
\mathrm{N}_{2}+8 \mathrm{H}^{+}+8 \mathrm{e}^{-}+16 \mathrm{ATP} \rightarrow 2 \mathrm{NH}_{3}+\mathrm{H}_{2}+16 \mathrm{ADP}+16 \mathrm{P}_{\mathrm{i}}
$$ 
Dinitrogen, as it exists in the biosphere, is only useful to most organisms once it is either biologically or abiotically fixed into ammonia and becomes part of the nitrogen cycle. Biological nitrogen fixation is an intensively studied process (Burris \& Roberts, 1993; Mancinelli, 1996; Rees et al., 2005), with virtually every aspect of the nitrogen cycle biology (Rudolf \& Kroneck, 2005), the structure and role of nitrogenase enzymes (Burris, 1991; Zhang et al., 1995; Zhang, 1997; Fisher et al., 2006) and the genes encoding nitrogen-fixing proteins (Auman et al., 2001) described in detail. Also, nitrogen-fixing organisms involved in hostmicrobe interactions (Oke \& Long, 1999), root nodule metabolism (Zakhia et al., 2006), symbiotic relationships (Steenhoudt \& Vanderleyden, 2000) and bacterial endophytic associations (Sandhiya et al., 2005) have been characterised. Activities of the proteins involved in nitrogen fixation are also described, as are the conditions under which these enzymes and proteins are active (Davis et al., 1964; Dilworth et al., 1988; Joerger et al., 1991; Fisher et al., 2000; Fisher et al., 2006).

The enzyme nitrogenase is composed of two metalloproteins, the molybdenumiron (MoFe) protein as well as the iron (Fe) protein (Rees et al., 2005). The MoFe protein provides the active site for substrate reduction whereas the Fe protein couples ATP hydrolysis to electron transfer (Rees et al., 2005). Nitrogenase uses these electrons to reduce atmospheric nitrogen to ammonia (Fig. 1.1). Nitrogenase is highly oxygen-labile and bacteria that fix nitrogen are either obligate anaerobes or utilise mechanisms to protect nitrogenase from exposure to oxygen (Sabra et al., 2000). In Azotobacter vinelandii, a "switch-off" mechanism is postulated to counteract the effects of $\mathrm{O}_{2}$ stress on nitrogenase (Kuhla \& Oelze, 1988; Linkerhagner \& Oelze, 1995; Sabra et al., 2000). Nitrogenase "switch-off" has also been postulated for other bacteria such as Azospirillum brasilense, but ammonium ion rather than oxygen is considered to be the "switch-off" agent (Klugkist \& Haaker, 1984; Tsagou et al., 2003; Klassen et al., 2005). Conflicting reports have proposed that nitrogenase activity is inhibited 


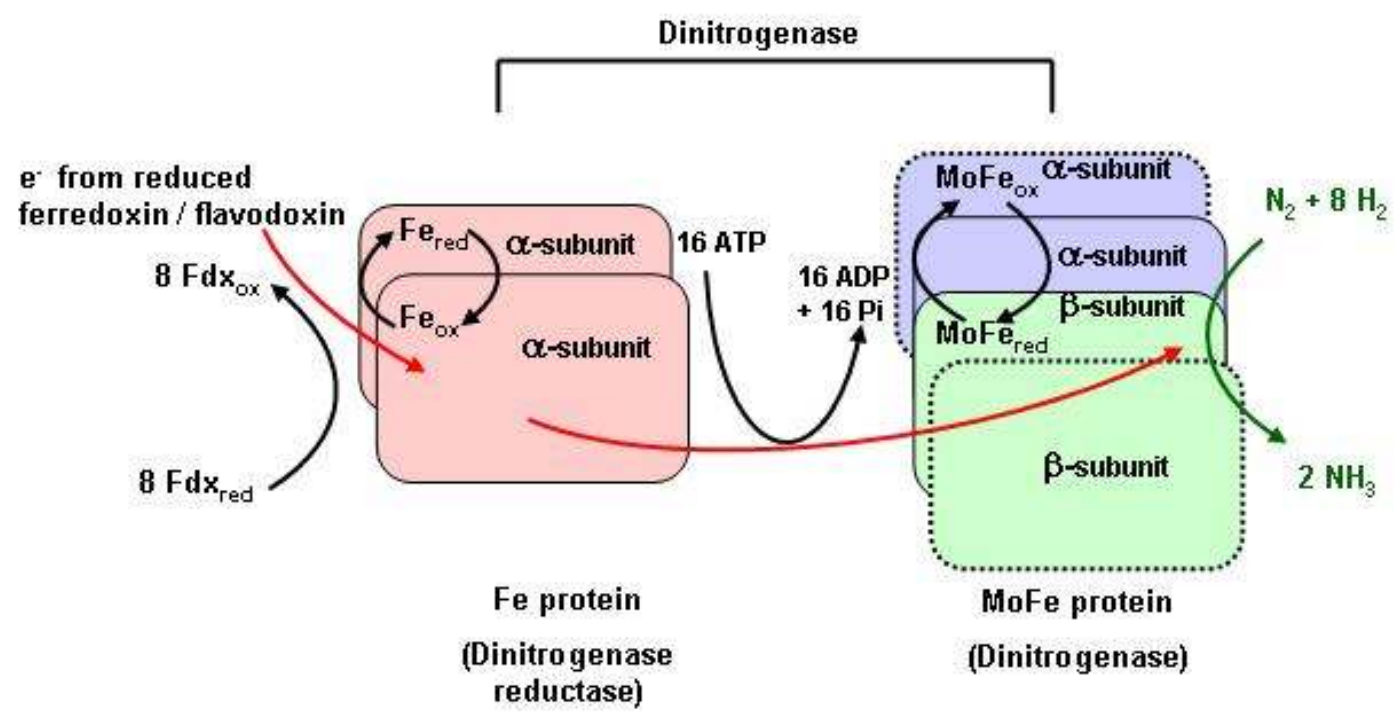

Figure 1.1 A schematic of the energy-demanding reaction catalysed by the nitrogenase complex. Repeated cycles of association and dissociation of dinitrogenase reductase (homodimeric component II $\alpha$-subunits, red oblongs) with dinitrogenase (heterotetrameric component I $\alpha$ - and $\beta$-subunits, mauve and green oblongs respectively) result in the transfer of $8 \mathrm{e}^{-}$from ferredoxin $(\mathrm{Fdx})$ (one per cycle) to the iron (Fe) cluster of $\mathrm{NifH}$, thereby reducing NifH. After the binding of 16 ATP to NifH (two per cycle) and the subsequent hydrolysis of ATP, dinitrogenase reductase transfers $\mathrm{e}^{-}$to the MoFe core of dinitrogenase. The reduction of one molecule of $\mathrm{N}_{2}$ to form two molecules of $\mathrm{NH}_{3}$ therefore requires the hydrolysis of 16 molecules of ATP and eight cycles of binding/dissociation of dinitrogenase reductase and dinitrogenase for electron (e-) transfer, with the concomitant formation of eight molecules of $\mathrm{H}_{2}$. 
by ammonium ion (Drozd et al., 1972; Laane et al., 1980; Eady, 1981; Gordon et al., 1981; Hartmann et al., 1986; Hartmann \& Burris, 1987) with Klugkist \& Haaker (1984) contextualising the differences observed in ammonium ion inhibition of nitrogenase and the reasons for this. Other aspects of nitrogenase activity have been considered (Fu \& Burris, 1989; Fu et al., 1989) with evidence for the use of the three oxygen sensitive nitrogenases, MoFe-nitrogenase, vanadium-iron ( $\mathrm{V}-\mathrm{Fe})$ nitrogenase and iron-iron (Fe-Fe) nitrogenase, containing different active-site central metals in A. vinelandii (Dilworth et al., 1988). The utilisation of any of these nitrogenases is reported to depend on, among other conditions, the specific metal ions present with MoFe preferentially used (Fisher et al., 2006). The V-Fe and Fe-Fe nitrogenases are apparently only utilised when molybdenum is not available. In addition to being able to reduce dinitrogen, all three nitrogenases are able to reduce $\mathrm{C}_{2} \mathrm{H}_{2}$ to $\mathrm{C}_{2} \mathrm{H}_{4}$ although with varying efficiency. Additionally, an oxygen-insensitive nitrogenase that is unable to reduce $\mathrm{C}_{2} \mathrm{H}_{2}$ to $\mathrm{C}_{2} \mathrm{H}_{4}$ is known to exist only in Streptomyces thermoautitrophicus (Ribbe et al., 1997). The possibility that other alternative nitrogenases exist is under investigation (Zhao et al., 2006)

\subsubsection{Ammonium assimilation}

Reduced nitrogen in natural ecosystems is often scarce and can be a growthlimiting factor. As a result, bacteria have evolved highly sophisticated mechanisms to selectively assimilate nitrogen sources when these are available. These mechanisms include the ability to fix molecular nitrogen or utilise assimilatory pathways, such as ammonium assimilation. Irrespective of which pathway is used, the result is the synthesis of the major intracellular nitrogen donors, glutamate and glutamine (Reitzer, 2003).

Nitrogen fixation and ammonium metabolism are both regulated in a coordinated response by the type and amount of nitrogenous compound available. This response involves a complex process with a network of proteins which are regulated by enzymes that modify these proteins post-translationally in response to nitrogen availability. In free-living nitrogen-fixing bacteria, an 
abundance of fixed nitrogen in the form of ammonium or other compounds such as nitrate or amino acids, is reported to affect nitrogen fixation by repressing either the synthesis of nitrogenase or its activity (Klugkist \& Haaker, 1984; Klassen et al., 2005). Excess ammonium can also inhibit the expression or activity of other pathways that utilise nitrogenous compounds, for instance glutamine synthetase (GS), a key enzyme that is utilised in the assimilation of ammonium (Fei et al., 2006). Notably, since ammonia is considered to be the centre of nitrogen assimilation, extracellular changes in the amount of available ammonium affect the intracellular concentration of glutamine which in turn, regulates GS activity.

Since the presence of ammonium in the growth medium and its effect on nitrogenase activity have been well studied, it is known that exogenous ammonium rapidly and reversibly inhibits nitrogenase activity in the cells of a variety of nitrogen-fixing microorganisms. Most microorganisms assimilate ammonium by one of two pathways, either via the glutamate dehydrogenase (GDH) pathway or the glutamine synthetase/glutamine oxoglutarate aminotransferase (GS-GOGAT) pathway. GOGAT is a key enzyme in the early stages of ammonia assimilation in bacteria and catalyses the reductive transamidation of the amido nitrogen from glutamine and $\alpha$-Ketoglutarate (AKG, also known as 2-Ketoglutarate or 2-Oxoglutarate) to form glutamate. The ammonia that enters this pathway can be supplied either by internal metabolic processes such as amino acid catabolism or through the reduction of external nitrogen sources such as atmospheric dinitrogen. In the presence of excess ammonium, the GDH pathway is preferentially induced and GDH assimilates ammonium, synthesising glutamate. Ammonium assimilation via GDH is associated with the repression and deactivation of GS, which is modified at the transcriptional and post-translational level in response to the activity of nitrogen sensor proteins. 
GS occurs in two forms, the adenylylated and deadenylylated forms, which have opposing effects on its activity. Both forms of GS affect the production of glutamine. When ammonium occurs in excess, GS is adenylylated in response to the activity of the nitrogen sensor, $\mathrm{P}_{\mathrm{II}}$, in its native form (Fig. 1.2). The $\mathrm{P}_{\mathrm{II}}$ protein is regulated by reversible uridylylation (Ninfa \& Atkinson, 2000) and itself occurs in two forms, the native form and the modified (uridylylated) form. Adenylylation of GS is catalysed by adenylyltransferase, the activity of which is governed by $\mathrm{P}_{\mathrm{II}}$. Under conditions of excess nitrogen, the native form is expressed, whereas the modified form is only expressed under nitrogenlimiting conditions. Uridylylated $\mathrm{P}_{\mathrm{II}}$ therefore stimulates deadenylylation of GS under nitrogen-fixing conditions whereas unmodified $\mathrm{P}_{\mathrm{II}}$ stimulates adenylylation of GS in cells not fixing nitrogen when ammonium is present. An increase in the degree of adenylylation of GS also correlates with the repression of nitrogenase synthesis and the coordinated induction of GDH synthesis. Upon deadenylylation of GS, these events are reversed and GDH is repressed (Kleiner \& Kleinschmidt, 1976). The post-translational modification of GS is governed by the nitrogen regulatory proteins $\mathrm{NtrC}$ and $\mathrm{P}_{\mathrm{II}}$ in response to the uridylylation of $\mathrm{P}_{\mathrm{II}}$ by uridylyltransferase. Uridylyltransferase is activated by AKG but inhibited by glutamine. An increase in the degree of adenylylation correlates with the repression of nitrogenase synthesis and an induction of GDH synthesis.

In the presence of low concentrations of ammonium or growth with a nitrogen source other than ammonium, for instance molecular nitrogen, the GDH pathway is repressed and the GS-GOGAT pathway is induced. In this pathway, GS assimilates ammonium whereas GOGAT synthesises glutamate. Therefore, under conditions of nitrogen fixation, nitrogen starvation results in the induction of the GS-GOGAT pathway which is associated with the derepression and activation of GS as well as the derepression of GOGAT. Consequently, maximal synthesis of glutamine occurs in a coordinated response to nitrogen limitation with the concomitant induction of proteins involved in transport and the catabolism of nitrogen sources. 


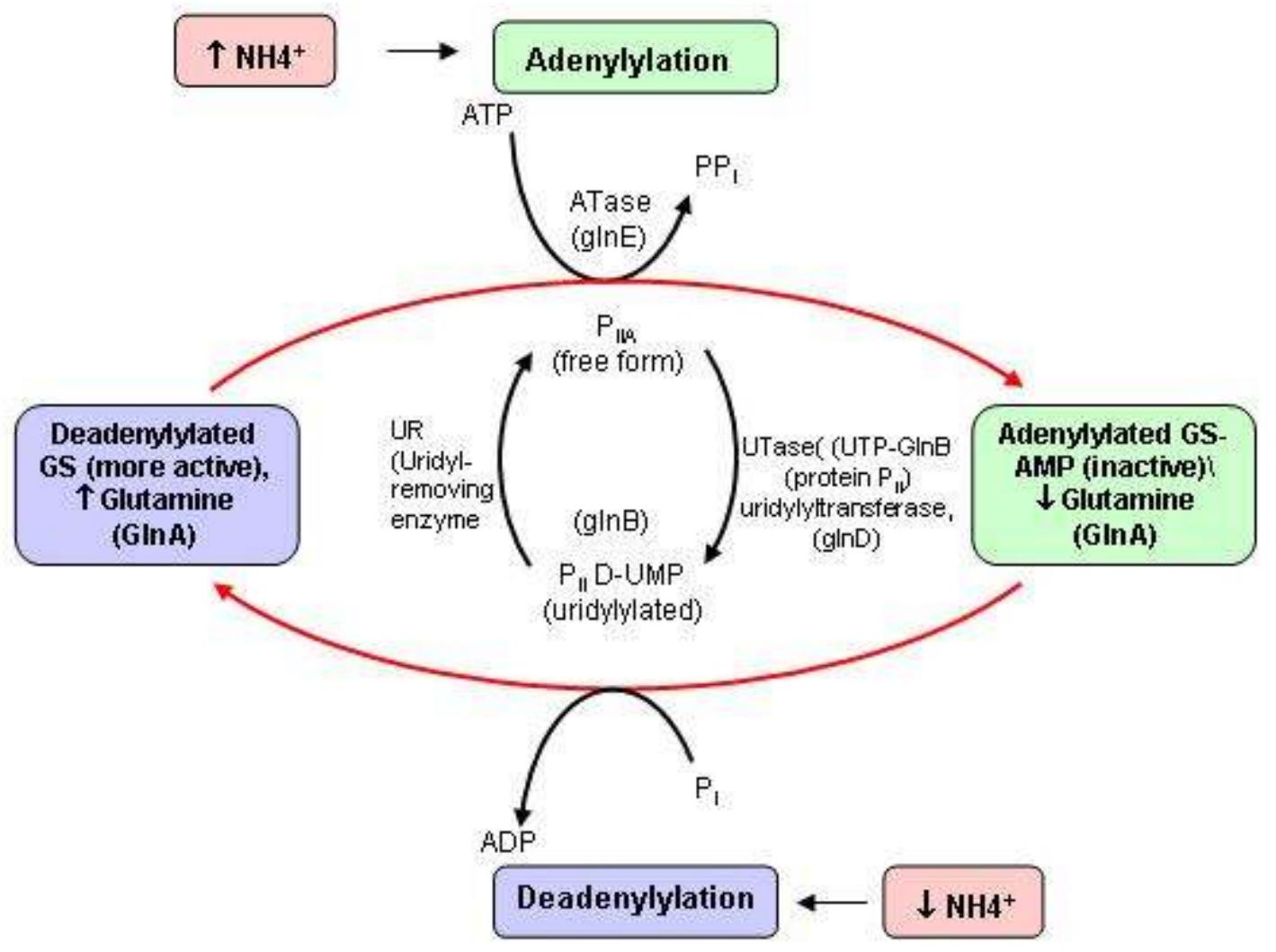

Figure 1.2 Schematic representation of adenylylation/deadenylylation of GS in response to ammonium status.

The adenylylation state of glutamine synthetase (GS) regulates its activity. The nitrogen regulating protein $P_{\text {II }}$ stimulates adenylylation of GS by means of adenylyltransferase (ATase) which catalyses the adenylylation and deadenylylation of GS. PIID-UMP stimulates the reverse reaction. Adapted from Foor et al., (1975) 


\subsubsection{PHA biosynthesis and bioplastics}

\subsubsection{Overview and commercial application}

Plastics are considered to be the most widely used man-made materials worldwide but have environmentally unfriendly properties. For this reason, the search for biodegradable plastics to replace conventional plastics has been particularly compelling (Anderson \& Dawes, 1990; Shi et al., 1999; De Oliveira et al., 2004; Sharma et al., 2007). The ability to produce "bioplastics" such as PHAs, is common to many bacteria and was first discovered in Bacillus megaterium by Lemoigne in 1925 (Lemoigne, 1926; Dawes \& Senior, 1973). Since then, more than 250 microorganisms have been identified that can produce PHAs (Lee, 1996; Steinbüchel \& Fuchtenbusch, 1998).

PHAs represent a class of natural polyesters that are biodegradable and have a broad range of uses (Anderson et al., 1990). These thermoplastics are widely considered to be of primary economic importance in a "sustainability" context, because of their similarities to conventional plastics and their complete biodegradability (Steinbüchel \& Fuchtenbusch, 1998). Although plants (Poirier et al., 1995; Mittendorf et al., 1999; Poirier et al., 1999) and yeast (Poirier et al., 2002) have been genetically modified in attempts to produce high yields of PHA, the focus for production applications has mainly been on bacteria (both wild type and genetically modified) because of their presumed greater potential for high productivity with growth on low-cost carbon substrates (Byrom, 1992). Despite the first industrial production of PHA in 1982 (Anderson \& Dawes, 1990), efforts to produce PHAs as substitutes for conventional polymers have historically been costly (Anderson \& Dawes, 1990; De Oliveira et al., 2004). Therefore, efforts are now focused on isolating microbes that are able to produce greater amounts of PHA at lower costs using more efficient fermentation and recovery processes (Shi et al., 1999). 
During the last few decades, increased awareness of environmental pollution through anthropogenic disturbances, such as discarded petrochemical plastics, has resulted in an increasing appreciation of the potential use of microorganisms to address problematic environmental issues. For this reason, the role of PHA-producing bacteria in their natural environment has come under the spotlight. Although the biological properties and biodegradability of PHAs are important, their production is based on renewable resources derived from complex carbon compounds in environments such as waste stream effluents containing mostly cellulose, but also polycyclic aromatic hydrocarbons and lignins (Peng et al., 1998). These environments are carbon-rich but otherwise nutrient-poor. Bacteria such as $\mathrm{Y} 88^{\mathrm{T}}$ that may naturally inhabit these waste streams, and are capable of remediating carbon compounds to produce bioproducts such as bioplastics, could therefore be used to enhance bioremediation.

\subsubsection{Bacterial PHA and the biosynthetic pathway}

Research to date suggests that bacterial PHA synthesis takes place in nutrientimbalanced environments, for instance in the presence of surplus carbon when elements such as $\mathrm{N}, \mathrm{P}, \mathrm{S}, \mathrm{O}$ or $\mathrm{Mg}$ are present in limiting quantities (Anderson \& Dawes, 1990; Steinbüchel \& Fuchtenbusch, 1998). Microorganisms investigated for their ability to produce PHA under carbon-excess, but otherwise limiting conditions, include Ralstonia eutropha, methylotrophs and pseudomonads. Less well documented are studies on microorganisms that do not require nutrient limitation but produce PHA during growth such as Alcaligenes latus, A. vinelandii and recombinant Escherichia coli (Wang \& Lee, 1997). Although only a few enzymes are considered to be specifically involved in PHA synthesis (Madison \& Huisman, 1999) there is a range of metabolic activities that influences the amount of PHA produced. Numerous factors, such as the carbon substrate, and its metabolic partitioning of carbon as well as the amounts of nutrients available under defined growth conditions, determine the type, quantity and quality of PHA that is synthesised (Shi et al., 1999). 
PHAs are synthesised in the form of granules that accumulate as cytoplasmic inclusion bodies in bacteria (Lee, 1996). These compounds apparently serve as carbon and energy reserves, as well as sinks for reducing equivalents (Dawes \& Senior, 1973; Pötter et al., 2004). Additionally, evidence supports PHA not simply as an inert storage polymer confined to bacteria, but as an interacting, solvating compound involved in various physiological functions, such as oligo3-hydroxybutyrates (5-80 subunits) that are found in human plasma as 'solubilising' oligomers (Reusch et al., 1992).

The physical properties of PHAs depend on their monomer composition and molecular weights. PHAs are polymers made up of linear monomers that possess the general formula illustrated in Fig. 1.3, where m can be 1-4 (Madison \& Huisman, 1999). However, most of the known PHAs identified to date comprise 3-hydroxyacids, where $m=1$. Differences in the alkyl substituents (" $R$ " in Fig.1.3) are known, e.g. epoxidated or halogenated forms have been reported as substituents (Madison \& Huisman, 1999). Variations in the alkyl substituents give rise to short-(SSC), medium-(MSC) and long-(LSC) chain length PHAs from hydroxyalkanoic acid monomers (Steinbüchel et al., 1992). The variability in the alkyl substituents, the position of the hydroxyl group or the modification of the side chains allows considerable variability in the structure of PHA. It is this diversity in structure that has enabled the varied exploitation of PHAs in commercial applications.

In order to better utilise PHA for commercial and industrial applications, a greater understanding of the structural aspects of these polymers, their physical state and the metabolic processes involved in regulation of their synthesis in the bacterial cell is needed (Anderson \& Dawes, 1990). The metabolism of PHA and the enzymes directly involved in its synthesis have been well described in many bacteria e.g. Ralstonia eutropha, Zoogloea ramigera, Aeromonas caviae, Azotobacter beijerinckii and Methylosinus trichosporium (Senior \& Dawes, 1973; Anderson \& Dawes, 1990; Kichise et al., 1999; Madison \& Huisman, 1999). 


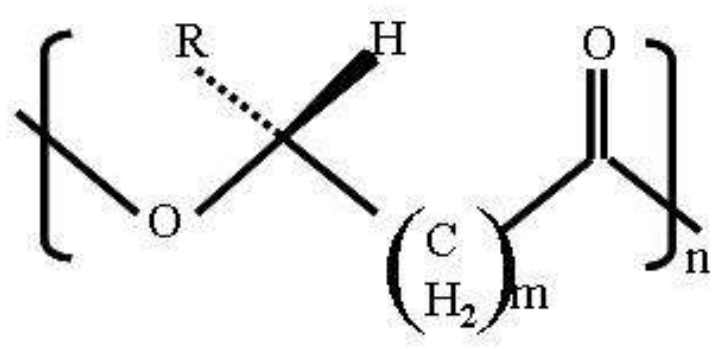

Figure 1.3 General structure of PHAs

For $\mathrm{m}=1$ and alkyl substituent $\mathrm{R}$ equals one of the following, hydrogen, methyl, ethyl, propyl, pentyl or nonyl, then the polymer formed is either poly(3-hydroxypropionate), poly(3-hydroxybutyrate), poly(3-hydroxyvalerate), poly(3-hydroxyhexanoate), poly(3-hydroxyoctanoate) or poly(3-hydroxydodecanoate) respectively. For $\mathrm{m}=2$ and alkyl substituent $\mathrm{R}$ equals hydrogen, then the polymer formed is poly(4-hydroxybutyrate). For $\mathrm{m}=3$ and alkyl substituent $\mathrm{R}$ equals hydrogen, then the polymer formed is poly(5-hydroxyvalerate). Adapted from Madison \& Huisman (1999). 
Investigations by Ritchie et al. (1971) followed by demonstrations that oxygen limitation rather than nitrogen limitation resulted in PHA accumulation in bacterial cells, gave impetus early to studies on the more complex underlying regulatory pathways of PHA (Senior \& Dawes, 1973).

The best understood PHA biosynthetic pathway was first described for a common form of this polymer containing poly(3-hydroxybutyric) acid (PHB) characterised in the chemolithoautotrophic bacterium R. eutropha (Sharma et al., 2007). This microorganism probably has the most well-studied metabolism of any organism that is capable of producing bioplastic (Pötter et al., 2004) and has undergone several name changes in the course of its characterisation due to its reclassification to different taxa (Reinecke \& Steinbüchel, 2009). Initially isolated as a member of the genus Hydrogenomonas and named H. eutropha, Strain H16 was subsequently renamed Alcaligenes eutropha H16 (Davis et al., 1969) followed by Ralstonia eutropha H16 (Yabuuchi et al., 1995). R. eutropha was later reclassified as Wautersia eutropha (Vaneechouette et al., 2004) and finally renamed Cupriavidus necator (Vandamme \& Coenye, 2004). R. eutropha and C. necator are currently the most commonly used appellations, with the former more frequently used (Reinecke \& Steinbüchel, 2009) and will therefore be referred to here as $R$. eutropha. Other bacteria known to possess similar plasticproducing properties to $R$. eutropha include members of the cyanobacteria (Sharma et al., 2007), methane-oxidising bacteria (Chu \& Alvarez-Cohen, 1998), halophilic bacteria (Quillaguaman et al., 2005) and nitrogen-fixing bacteria (Mandon et al., 1998; Pettinari et al., 2003). Although numerous PHA pathways have been elucidated, the current consensus is that four PHA synthetic pathways characterise the biosynthesis of all known bacterial PHAs (Steinbüchel \& Schlegel, 1991; Choi \& Lee, 1999).

The biosynthetic pathway of the PHB class of biopolymers is a three-step pathway utilising three major enzymes encoded by the phbCAB operon: $\beta$ Ketothiolase (PhbA) that catalyses the condensation of two molecules of acetyl- 
CoA to acetoacetyl-CoA, a NADPH-dependent acetoacetyl-CoA reductase (PhbB) and the key enzyme PHB synthase (PhaC) (Fig. 1.4). Although the generic PHA biosynthetic pathways are well described (Senior et al., 1972; Choi \& Lee, 1999), the particular enzymes, proteins and mechanisms of regulation implicated in PHA synthesis for different bacteria are the subjects of ongoing characterisation efforts (Lee et al., 1995; Sudesh et al., 2002; De Oliveira et al., 2004; Noda et al., 2005; Uchino \& Saito, 2006). More specifically, enzymes involved in both the synthesis and the degradation of PHA have gained increased attention as well as enzymes active at the PHA granule surface (Liebergesell et al., 1994; Pötter et al., 2004). Of particular interest are the PHA synthases of which the R. eutropha PhaC is known to be constitutively expressed (Kolibachuk et al., 1999; Chen et al., 2004), the PHA depolymerases (Kim et al., 2005), the phasins (Pötter et al., 2004) and the transcription factors involved in the regulation of the relevant genes (Pötter \& Steinbüchel, 2005). In R. eutropha, PHA synthase is currently the subject of intensive bioengineering efforts to generate enzymes with altered properties (Taguchi et al., 2002; Rehm, 2003; Taguchi \& Doi, 2004; Reinecke \& Steinbüchel, 2009). Additionally, the properties of phasins, which are PHA granule-associated proteins (Neumann et al., 2008) are of interest since they are known to constitute between at least three and five percent of the total cellular protein of PHB-accumulating bacteria (Reinecke \& Steinbüchel, 2009). Their major function is considered to involve the stabilisation of PHA granules, preventing coalescence of the granules within the cytoplasm as well as preventing hydrophobic proteins binding to the granules. PHA synthases, phasins, PHA depolymerases, and other proteins such as 3-hydroxybutyrate dehydrogenases all bind to the granules and are considered to be involved in PHA granule biogenesis or degradation (Pötter \& Steinbüchel, 2005). 


\section{NADPH}

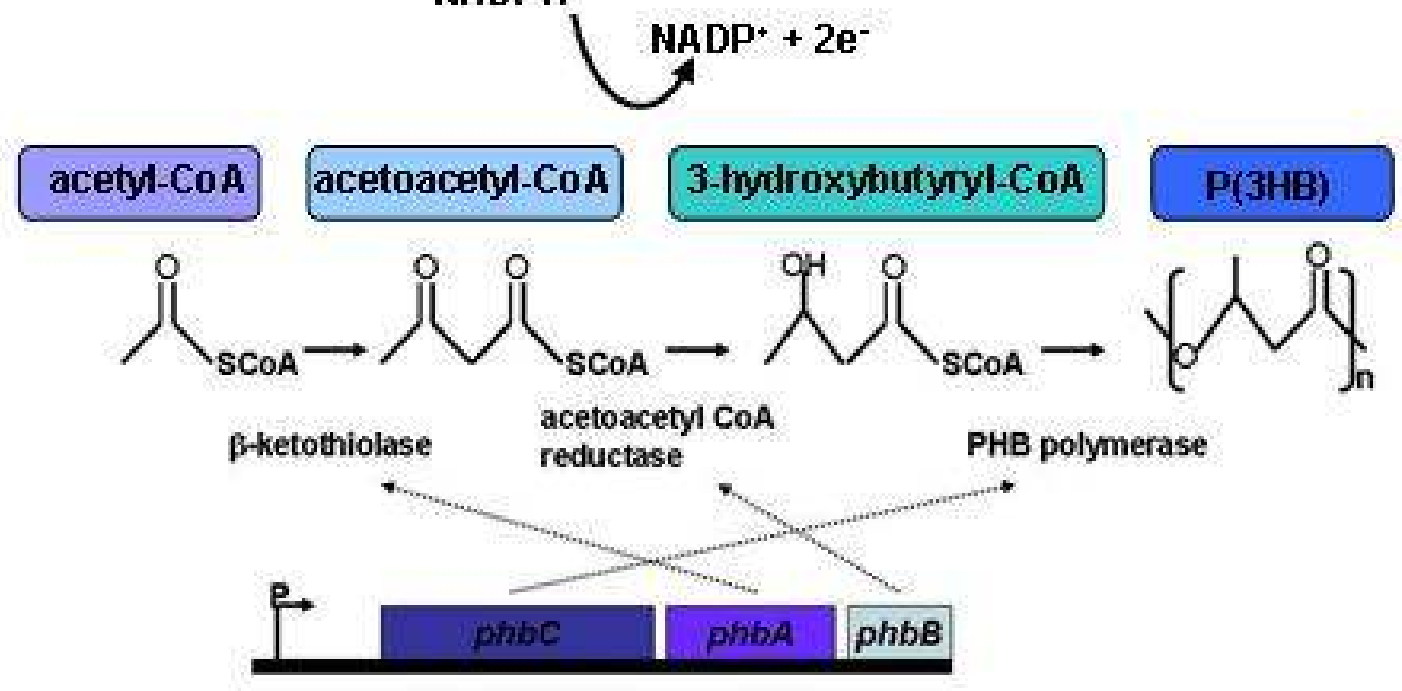

Figure 1.4. Biosynthetic pathway for $\mathrm{P}(3 \mathrm{HB})$

$\mathrm{P}(3 \mathrm{HB})$ is synthesised in a 3-step pathway by the successive action of $\beta$-Ketoacyl-CoA-thiolase ( $\beta$-Ketothiolase, acetyl-CoA C-acetyltransferase or PhbA), NADPH-dependent acetoacetyl-CoA reductase $(\mathrm{PhbB})$ and $\mathrm{P}(3 \mathrm{HB})$ polymerase $(\mathrm{PhbC})$. The 3 enzymes are encoded by the genes of the phbCAB operon. A promoter upstream of phbC transcribes the complete operon. Adapted from Madison \& Huisman (1999). 


\subsubsection{Carbon utilisation and partitioning}

\subsubsection{Central metabolism and its relationship to PHA biosynthesis}

The tricarboxylic acid (TCA) cycle is a core amphibolic pathway that plays two central roles in metabolism. First, the cycle is responsible for the complete oxidation of acetyl-CoA to $\mathrm{CO}_{2}$ and reducing equivalents used for ATP production and, second, it provides numerous chemical intermediates that are used in the biosynthesis of amino acids, among other key metabolites and biochemical "building blocks". Aerobic respiration, which involves TCA cycle activities, is central to the carbon flux that supports PHA biosynthesis via the key TCA cycle metabolite acetyl-CoA. Acetyl-CoA is produced from the glycolytic product pyruvate. Acetyl-CoA can enter the TCA cycle and is eventually oxidised to $\mathrm{CO}_{2}$. During this process, reducing equivalents are generated via the conversion of $\mathrm{NAD}^{+}$to $\mathrm{NADH}$. Since $\mathrm{NADH}$ is generated from both glycolysis and the TCA cycle, an excess of NADH occurs, which is then converted back to $\mathrm{NAD}^{+}$via electron transport and oxidative phosphorylation to produce ATP. Ubiquinones and cytochromes are components of the electron transport chain involved in oxidative phosphorylation and $\mathrm{O}_{2}$ is the final electron acceptor which is reduced to form $\mathrm{H}_{2} \mathrm{O}$. Alternatively, when ATP production is not at a premium acetyl-CoA and $\mathrm{NADH}$ can be channeled toward the production of other metabolites.

Bacteria can use at least three interrelated glucose catabolic pathways to metabolise glucose: the Embden-Meyerhof (EM) or main glycolytic pathway, the Entner-Doudoroff (ED) pathway (an exclusively prokaryotic alternative glycolytic pathway) and the oxidative pentose phosphate (OPP) pathway (used to generate pentose sugars and NADPH). The OPP and ED pathways differ from the EM pathway in that although they involve oxidation of glucose, their primary role is anabolic rather than catabolic. The NADPH yielded by the OPP and ED pathways carry electrons from the catabolic pathways to biosynthetic processes. The EM pathway yields two ATP and two NADH (equivalent to 6 
$\mathrm{ATP}, 3$ per $\mathrm{NADH}$ at $\Delta \mathrm{G}^{0}$, total energy yield therefore equivalent to $8 \mathrm{ATP}$ ) for every glucose molecule consumed. In comparison, the OPP and ED pathways yield reducing equivalents instead of ATP, with either two NADPH (total energy yield equivalent to $6 \mathrm{ATP}, 3$ per NADPH at $\Delta \mathrm{G}^{0}$ ), or one ATP plus one $\mathrm{NADH}$ and one NADPH (equivalent to $6 \mathrm{ATP}, 3$ per NADH and 3 per NADPH at $\Delta \mathrm{G}^{0}$, total energy yield therefore equivalent to $7 \mathrm{ATP}$ ) for every glucose molecule consumed in the OPP and ED pathways, respectively. The use of the ED and OPP pathways are therefore more costly in terms of energy production but provide NADPH for biosynthesis as well as the prevention of oxidative stress. In fact, even though the standard reduction potential of $\mathrm{NAD}^{+} / \mathrm{NADH}$ and $\mathrm{NADP}^{+} / \mathrm{NADPH}$ couples are equivalent, in the cell, the metabolic value of $\mathrm{NADPH}$ is higher because $[\mathrm{NADPH}]>\left[\mathrm{NADP}^{+}\right]$whereas $\left[\mathrm{NAD}^{+}\right]>[\mathrm{NADH}]$ resulting in inequalities in the cellular reduction potentials of these two pyridines. The NADPH/NADP+ couple is therefore a better electron donating system than the $\mathrm{NAD}^{+} / \mathrm{NADH}$ couple (Garret \& Grisham, 1999). Maintaining catabolic vs. anabolic processes via the production of intermediates and substrates for these activities requires interrelated metabolic processes many of which are species-specific and therefore remain the subject of continued investigation.

\subsubsection{Carbon flux and the regulation of PHA biosynthesis}

The regulation of PHA synthesis and the role of the key regulatory metabolite, acetyl-CoA, in the PHA biosynthetic pathways has been the subject of many studies (Moskowitz \& Merrick, 1969; Senior et al., 1972; Mandon et al., 1998; Madison \& Huisman, 1999). Acetyl-CoA can either be oxidised by the TCA cycle, or it can serve as a substrate for PHA synthesis (Oeding \& Schlegel, 1973). The ultimate fate of the acetyl-CoA formed depends on factors such as the availability of nutrients including excess carbon or limiting oxygen or nitrogen. These factors also influence the ratio of $\mathrm{NADH} / \mathrm{NAD}^{+}$produced by the TCA cycle. $\mathrm{NADH}, \mathrm{NAD}^{+}, \mathrm{NADPH}$ and $\mathrm{NADP}^{+}$are involved in energy metabolism, reductive biosynthesis and oxidation. Whereas NADH is the electron donor for 
the electron transport chain that generates ATP, NADPH is a key component in cellular antioxidant systems and is the reducing agent in anabolism (Rich, 2003). Although NADH seems to be the main electron donor, under conditions of oxidative stress NADPH-producing pathways are induced to replenish the NADPH pools (Vlamis-Gardikas, 2008).

In $R$. eutropha the $\mathrm{NADPH} / \mathrm{NADP}^{+}$ratio increases when limiting amounts of nitrogen, phosphorous or oxygen are available, thus promoting PHB synthesis. Under these conditions, cell growth is restricted (Choi \& Lee, 1999) and the increase in $\mathrm{NADPH} \mathrm{NADP}^{+}$ratio inhibits citrate synthase and isocitrate dehydrogenase. Consequently, acetyl-CoA does not enter the TCA cycle, but is instead available for conversion to acetoacetyl-CoA by $\beta$-Ketothiolase, the first enzyme in the PHB biosynthetic pathway. Conversely, when nitrogen, phosphorus and oxygen are sufficient, cell growth is no longer restricted and $\mathrm{NAD}(\mathrm{P}) \mathrm{H}$ can donate its reducing equivalents to the oxidative phosphorylation pathway, which results in a lower $\mathrm{NAD}(\mathrm{P}) \mathrm{H} / \mathrm{NAD}(\mathrm{P})^{+}$ratio. Furthermore, CoASH concentration increases as it is released by the entry of acetyl-CoA into the TCA cycle, which is inhibitory to $\beta$-Ketothiolase, thereby reducing the rate at which PHB is synthesised (Oeding \& Schlegel, 1973; Lee et al., 1995; Choi \& Lee, 1999).

Senior and Dawes (1971) proposed that PHB is not only a source of carbon and energy, but is also a sink for reducing equivalents and therefore could be considered a redox regulator within the cell. Shi et al., (1999) have demonstrated the importance of increased concentrations of, for instance, available NADPH as well as acetyl-CoA in achieving maximum PHB yields and redirecting metabolic fluxes in R. eutropha. More acetyl-CoA can be made available for consumption by effectively "blocking" the entry of acetyl-CoA into the TCA cycle. Thus by redirecting the carbon fluxes to another pathway, an increase in NADPH recycling can be achieved (Shi et al., 1999). 
Unlike non-diazotrophic PHA producers, $\mathrm{Y}^{\mathrm{T}} \mathrm{T}$ provides an opportunity to study metabolism under conditions of nitrogen fixation as well as PHA synthesis. These studies can elucidate underlying catabolic (TCA) vs. anabolic (PHA) pathways, and the role of culture conditions in influencing the utilisation of carbon (Fig. 1.5). For example, nitrogen fixation has been shown to compete with PHA accumulation in bacteroids of Rhizobium and Bradyrhizobium japonicum (Povolo et al., 1994). Y88 ${ }^{\mathrm{T}}$ therefore provides an opportunity to determine how a nitrogen fixer that accumulates PHA is able to maintain its core metabolic requirements yet balance competing metabolic activities such as nitrogen fixation and PHA accumulation. Understanding the interplay of the regulatory pathways of nitrogen fixation, carbon utilisation and PHA synthesis in $\mathrm{Y}^{8} 8^{\mathrm{T}}$ can elucidate how a diazotroph copes with varying environments. Glucose, with its central position in carbon and energy metabolism, is a useful carbon source to initiate the analysis of carbon flux in $\mathrm{Y}^{\mathrm{T}}$ to produce metabolites specific to its PHA biosynthetic pathway and the type of PHA produced under nitrogen-fixing conditions.

Metabolic carbon fluxes are central to PHA biosynthesis in that the carbon source determines the particular precursor metabolites that are produced (Ramsay et al., 1989; Muller et al., 1999; Wendisch et al., 2000; El-Mansi, 2005; Kolkman et al., 2005; Zhang et al., 2006). These precursors in turn determine the type and amount of PHA that is synthesised (Zhao \& Shimizu, 2003; Wolfe, 2005; El-Mansi et al., 2006). An understanding of these processes in pure culture may enable $\mathrm{Y}^{8} 8^{\mathrm{T}}$, or other sphingomonads to be exploited in a production environment to produce higher yields of PHA from renewable resources.

\subsection{Proteomic approaches for protein expression profiling}

Proteomics had its inception with the advent of a protein separation technique introduced independently by both O'Farrell (1975) and Klose (1975) and its subsequent use in the study of bacterial physiology (Herendeen et al., 1979). 


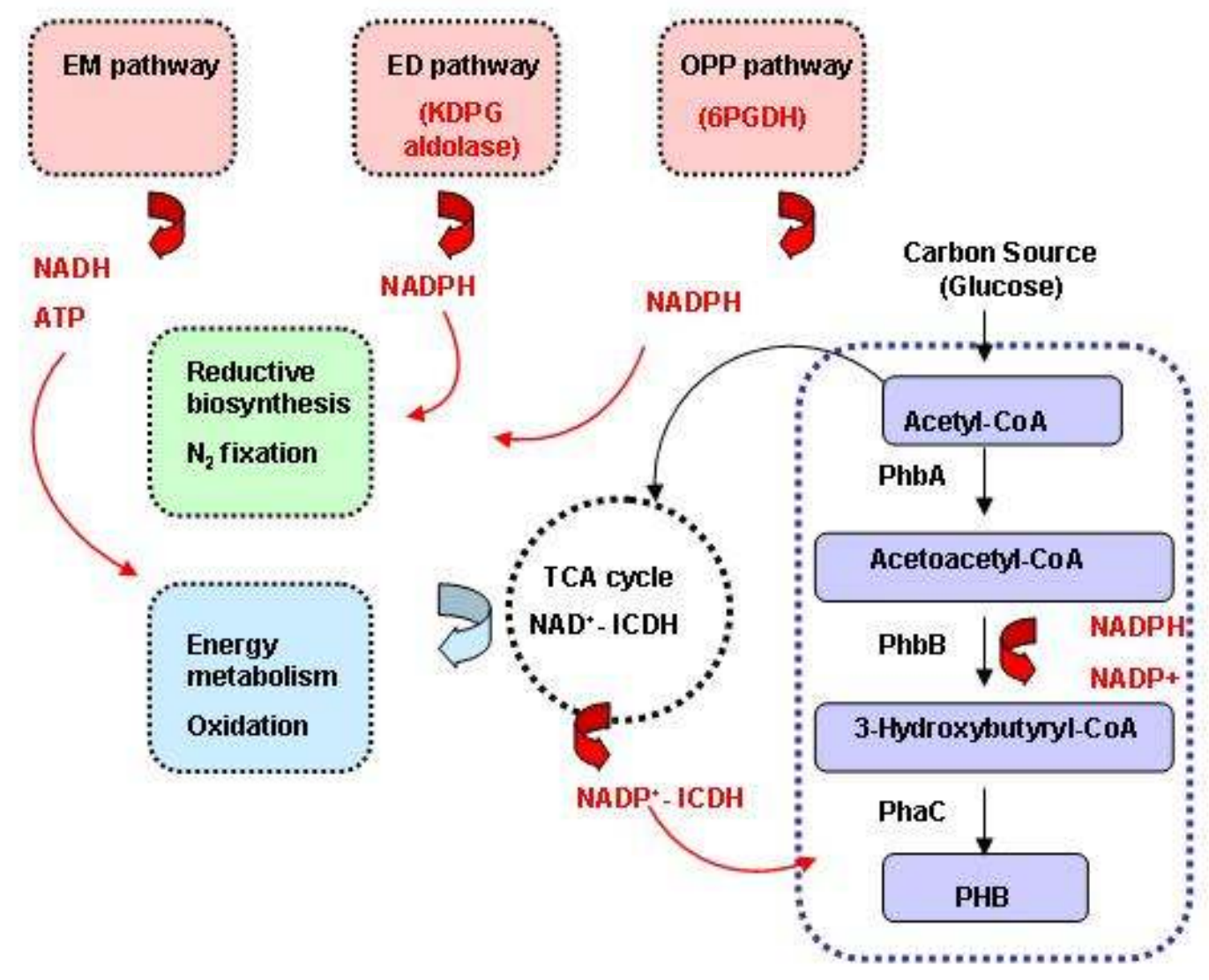

Figure 1.5 Schematic of NADH and NADPH production and utilisation via catabolic vs. anabolic pathways

$\mathrm{NADH}$ is produced and again consumed in catabolic pathways. NADPH couples catabolic to anabolic processes by carrying the reducing power released in certain catabolic sequences such as the two alternative glycolytic pathways, the ED and OPP pathways, to reductive biosynthetic pathways such as $\mathrm{N}_{2}$ fixation and $\mathrm{PHB}$ production. 
This separation technique was adopted as the classical proteomic approach and is based on protein separation using 2-D gel electrophoresis, in which proteins are resolved in the first dimension based on their isoelectric points and in the second based on their molecular masses, followed by protein identification and characterisation using MS. 2-D gel-based applications have since been shown to be particularly useful in studying bacterial proteomes under different growth conditions (Linn \& Losick, 1976; Reeh et al., 1977; Agabian \& Unger, 1978; Voigt et al., 2006).

Despite early advances in the use of proteomic applications, it was not until 1995 when the first genome sequence of the bacterium Haemophilus influenzae (Fleischmann et al., 1995) was published, that whole-genome protein identifications and functional genomics became possible. Since then, proteomics has advanced rapidly and has become an increasingly powerful tool used in molecular cell biology supported by the development of sophisticated technology such as multi-dimensional chromatography, MS and bioinformatics (Steen \& Mann, 2004). Since proteins are expressed in different combinations and levels during various stages of the life cycle of cells and under changing environmental conditions, the proteome, unlike the (relatively) static genome, must be dynamic and in constant flux. The use of proteomics throughout the past decade has assisted in characterising these differences and has therefore provided an improved understanding of cellular physiology (Hecker \& Volker, 2004). Whereas the genome sequence provides the "blueprint" of the cellular properties of a living cell, it is the proteome that brings a broader understanding of functional complexity to that sequence (Brotz-Oesterhelt et al., 2005; Kohler et al., 2005). Proteomics can therefore be used to investigate the biology of cells or organisms.

The term "proteomics" is loosely defined as the study of the set of proteins that is expressed throughout the lifetime of a cell and includes modifications of proteins that occur post-translationally (Takahashi et al., 2003). A more apt 
description of proteomics ideally involves the study of the identity and function of the proteins from a cell, tissue or organism at a given time or times, thus providing a snapshot of an expressed group of proteins for a given set of conditions. Since the proteome is highly dynamic, its composition reflects the physiological state of the specific sample studied (Jurat-Fuentes \& Adang, 2007).

Proteomic studies are now well advanced for diverse bacteria with extensive proteome coverage achieved for Escherichia coli (Han \& Lee, 2006) and Mycoplasma pneumoniae (Hecker \& Volker, 2004). Additionally, proteomic studies are increasingly being used to complement other molecular techniques such as microarrays ( $\mathrm{Hu}$ et al., 2006; Uttamchandani et al., 2006) to gain additional information on cellular processes. The use of proteomic techniques, particularly in protein expression profiling (Ellmark et al., 2006), provides a powerful tool to elucidate the expression patterns of proteins expressed under different environmental conditions. Moreover, the degree of expression of individual proteins can be determined (Kohler et al., 2005). Protein expression profiling is supported by 2-D gel-based proteomics used in combination with MS (Brotz-Oesterhelt et al., 2005) and can provide a proteomic view of cellular activities that can ultimately contribute information on basal cellular processes (Hecker, 2003; VanBogelen, 2003; Hecker \& Volker, 2004). As such, proteomics has proven to be useful in predicting the physiological states of bacterial cells, including their growth conditions, based on their "proteomic signatures" (VanBogelen, 2003; Voigt et al., 2004). These proteomic signatures can be used as indicators/predictors of the growth phase and related activities of actively growing cells. Additionally, predictions of other aspects of metabolism and physiology can also be made from the proteomic signatures of proteins involved in unrelated metabolic or regulatory activities.

Gel-free proteomic approaches have recently become popular (Linsen et al., 2006; Bosch et al., 2008) as they identify many proteins that are beneath the 
threshold of detection of gel-based methods (Roe \& Griffin, 2006). Gel-free proteomics is emerging as the preferred approach for quantitative proteomics (Haqqani et al., 2008) that uses methods such as stable-isotope labeling (Chen et al., 2008) and spectral counting (Bosch et al., 2008). Although the use of gel-free proteomic alternatives is particularly useful in identifying membrane (Wang et al., 2008) or low-abundance proteins as well as proteins with extreme pIs and/or molecular weights, 2-D gel-based approaches still remain popular as they complement gel-free alternatives (Hahne et al., 2008; Hecker et al., 2008).

The particular appeal of 2-D gels lies not only in the visualisation of proteins that have altered abundance, but in their ability to resolve post-translationally modified proteins into separate spots that can be individually measured. Conventional 2-D gel-based approaches can resolve thousands of proteins in a biological sample and provide fairly broad coverage of proteins from pI 3 to 11 and in the molecular weight range of approximately 1000 to 100,000. Despite the appeal of this technique to visualise altered protein abundance, its limitations include the under-representation of highly acidic or basic proteins as well as poor representation of hydrophobic proteins. Arguably, a key limitation is considered to be poor reproducibility across gels that hinders the comparison and interpretation of results (Clark \& Gutstein, 2008; Fuxius et al., 2008). For this reason, the use of 2-D DIGE, which aims to improve reproducibility, is often used instead of the conventional 2-D gel-based approach, including when comparing response to changes in the extracellular environment. Usually, the identification of approximately 300 cytosolic proteins using 2-D gel-based approaches combined with MS can be considered a reasonable starting point for physiological studies, providing the potential to analyse the regulation of metabolic pathways such as glycolysis or TCA cycle activities (Voigt et al., 2004). 2-D gel-based proteomics will therefore continue to be valuable for comparative physiological proteomics involving multiple samples, particularly where a quantitative measure of altered protein abundance is required. 


\subsection{Aims}

Since $\mathrm{Y} 88^{\mathrm{T}}$ grows largely in environments where nitrogen is naturally limiting but carbon is found in excess, it is potentially an ideal organism for the study of PHA production in a nitrogen-limiting environment. The first aim of this study was therefore to investigate the microbiology of $Y 88^{\mathrm{T}}$ to establish reproducible growth profiles for this organism under conditions of carbon-enrichment and both nitrogen-supplemented and nitrogen-depleted conditions in pure culture, batch flask mode. The effect of growth conditions on nitrogen fixation and PHA accumulation were examined.

The second aim of this study was to examine, the $Y 88^{\mathrm{T}}$ proteome to identify proteomic signatures of the physiological response of $\mathrm{Y}^{8} 8^{\mathrm{T}}$ cells to nitrogensupplemented and nitrogen-depleted conditions (representing the nonnitrogen-fixing and nitrogen-fixing physiological states of $\mathrm{Y}^{8} 8^{\mathrm{T}}$ respectively) in carbon-enriched media during PHA production. The aim was to identify the Y $88^{\mathrm{T}}$ proteins involved in nitrogen fixation and PHA accumulation and map any altered protein abundance in the underlying metabolic pathways to a given set of growth conditions. This would allow predictions to be made about which growth conditions promoted optimal PHA production in nitrogen-fixing $\mathrm{Y}^{8} 8^{\mathrm{T}}$ pure cultures.

The physiological response of Y88 ${ }^{\mathrm{T}}$ cells to different levels of DO (DOlow and $\mathrm{DO}^{\text {high}}$ ) at constant and changing $\mathrm{pH}$ was also examined during growth, biomass production, nitrogen fixation and PHA accumulation in nitrogensupplemented and nitrogen-depleted, carbon-enriched media. Since the nitrogenase enzyme is oxygen labile and consequently irreversibly inactivated by high levels of oxygen, the effect of oxygen concentration on the ability of Y $88^{\mathrm{T}}$ to fix nitrogen and accumulate PHA was examined. Proteomic signatures were used to predict the impact, if any, of different oxygen concentrations on the proteins involved in nitrogen fixation and PHA production. 
This study is the first combined microbiological and proteomic investigation of a novel, nitrogen-fixing, PHA-producing Novosphingobium strain and contributes to an understanding of the relationship between nitrogen fixation and PHA production in a family of bacteria that are proving useful in bioremediation efforts. Y88 ${ }^{\mathrm{T}}$ provides a suitable model to study the interplay of cellular metabolism, PHA synthesis and nitrogen fixation. Although many biotechnologically-based studies have been conducted on PHA-producing organisms, and many metabolic pathways have been described, most of these involved using mutant organisms with selectively engineered properties that enable optimisation of PHA yield. Y88 $8^{\mathrm{T}}$ provides a unique opportunity to study a novel organism that produces PHA under natural conditions necessitating nitrogen fixation. The findings of this study will also contribute to assessing optimal PHA accumulation in pure culture in a production environment. 


\section{Chapter 2: Materials and Methods}

\subsection{Microbiology}

The microbiology of $\mathrm{Y}^{2} 8^{\mathrm{T}}$ was investigated to establish a reproducible set of growth parameters before predictions about growth, nitrogen fixation and PHA accumulation could be tested. From these parameters, appropriate sampling times corresponding to the physiological state of the cells under desirable conditions of PHA accumulation and nitrogen fixation were established. This was done to promote consistency across all replicates and allow interpretation of the perturbations of the growth conditions that affect PHA production, to enable its optimisation. Therefore, minimal growth media with an excess of carbon substrate were formulated to determine the physiological response of Y88 ${ }^{\mathrm{T}}$ cells to either nitrogen-depleted or nitrogen supplemented conditions with sufficient carbon to support primary metabolism as well as PHA accumulation.

\subsubsection{Description of ${\mathrm{Y} 88^{\mathrm{T}}}^{\mathrm{T}}$}

$\mathrm{Y}^{\mathrm{T}} \mathrm{T}$ is a mesophilic, Gram-negative, obligate aerobe possessing diazotrophic properties that can accumulate the biopolymer PHA intracellularly. This bacterium belongs to the sphingomonad group of the Alphaproteobacteria yet is distinctly different from other Novosphingobia within this group due to its nitrogen-fixing capability. Y88 ${ }^{\mathrm{T}}$ was isolated at Scion in Rotorua, New Zealand from a pulp and paper-mill effluent culture bioreactor operating under nitrogen-limiting conditions (C:N ratio of 140:1) (Addison et al., 2007). Y88 ${ }^{\mathrm{T}}$ cells are non-sporulating, non-motile rods that form off-white to pale yellow colonies after 2-4 days on nutrient agar. The morphology of $\mathrm{Y}^{8} 8^{\mathrm{T}}$ colonies appears entire, convex and shiny with the centre of the colonies developing a deeper yellow pigmentation with time. $\mathrm{Y} 88^{\mathrm{T}}$ cells grow optimally on nutrient agar at $30^{\circ} \mathrm{C}$ and in minimal nitrogen-supplemented medium containing excess glucose as a carbon source. 


\subsubsection{Other bacterial isolates}

\subsubsection{Azotobacter vinelandii ICMP4036, Pseudomonas putida mt2 and Sphingomonas sp. WP01 (DSM 19371)}

In addition to $\mathrm{Y}^{8} 8^{\mathrm{T}}$, three other strains of bacteria were used for different aspects of the growth experiments. Two phylogenetically distant Gammaproteobacteria, Azotobacter vinelandii ICMP4036, a known nitrogen fixer, and Pseudomonas putida $\mathrm{mt} 2$, known to be incapable of nitrogen fixation, were selected for an interspecific comparison to $\mathrm{Y}^{8} 8^{\mathrm{T}}$. Both A. vinelandii and P. putida $\mathrm{mt} 2$ are known to synthesise PHA. The growth profiles of all three species were compared under conditions conducive to nitrogen fixation or ammonium assimilation, and PHA accumulation. The nitrogen-fixing and PHAaccumulating abilities of all three species were therefore investigated in parallel. The sphingomonad WP01, like Y88 ${ }^{\mathrm{T}}$, also belongs to the Alphaproteobacteria and was selected for an in-group comparison to $\mathrm{Y}^{8} 8^{\mathrm{T}}$, due to its similar ability to synthesise PHA. WP01, designated Sphingomonas sp. strain WP01 (DSM 19371) was isolated from a polycyclic aromatic hydrocarbon-contaminated soil at Waipa Mill, Rotorua, in New Zealand. No nitrogen-fixing genes have been identified in the recently sequenced WP01 genome (Strabala, Macdonald \& Liu, unpublished results). The growth profiles and PHA-accumulating abilities of both $\mathrm{Y} 88^{\mathrm{T}}$ and WP01 were examined.

\subsubsection{Growth conditions}

All experiments in this study were performed under sterile conditions with bacterial cells cultivated in batch mode, i.e. either in shaker flasks or in bioreactors. Batch cultivation makes use of a closed system in which all nutrients are in excess at the start of the cultivation relative to later phases of the growth process.

\subsubsection{Cell stocks, plate inoculation and pre-culture inocula}

Cells for all bacterial strains were maintained as freezer stocks on microbeads (Pro-lab Diagnostics, Nelson, New Zealand) placed in $2 \mathrm{~mL}$ cryogenic vials and 
stored at $-80^{\circ} \mathrm{C}$. When required, one vial was transferred from $-80^{\circ} \mathrm{C}$ storage and kept on ice during inoculation of the cells using the microbeads. For $\mathrm{Y}^{8} 8^{\mathrm{T}}$, P. putida mt2 and WP01 inoculation, a single bead was transferred onto a nutrient agar plate $(5 \mathrm{~g} / 250$ mL, Difco, Becton Dickinson \& Co., Franklin Lakes, NJ, USA) using an inoculation loop. For A. vinelandii, a single bead was transferred onto a plate count (PC) agar plate $(5 \mathrm{~g} / 250 \mathrm{~mL}$, Difco, Detroit, MI, USA). Inoculated nutrient agar plates were incubated at $30^{\circ} \mathrm{C}$ for 3 days to grow colonies of the appropriate size for inoculation into a nutrient growth broth (1 colony/5 mL growth medium with a final concentration of $2.5 \mathrm{~g}$ tryptone, $0.5 \mathrm{~g}$ glucose, $1.75 \mathrm{~g}$ yeast extract per litre of $\mathrm{MQ} \mathrm{H}_{2} \mathrm{O}$ ). Single colonies were individually selected and inoculated into a $50 \mathrm{~mL}$ polypropylene Falcon tube (Greiner Bio-one, Frickenhauser, Germany) containing $5 \mathrm{~mL}$ nutrient growth broth and cultivated for approximately $24 \mathrm{hr}$ in capped tubes in an orbital shaker incubator at $150 \mathrm{rpm}$.

\subsubsection{Shaker flask cultivation}

Batch cultivation was carried out in sterilised $250 \mathrm{~mL}$ (for pre-cultures) or $1 \mathrm{~L}$ Ehrlenmeyer flasks set up in replicate. Following overnight growth, a 2\% (v/v) inoculum was transferred to triplicate flasks by transferring $2 \mathrm{~mL} \mathrm{Y88^{ \textrm {T } }}$ cells from the starter culture in $50 \mathrm{~mL}$ polypropylene Falcon tubes to $100 \mathrm{~mL}$ minimal nitrogen medium (defined in Table 2.1 with respect to nitrogen source used) enriched with carbon substrate $\left(0.4 \mathrm{~g} \mathrm{KH}_{2} \mathrm{PO}_{4}, 0.1 \mathrm{~g} \mathrm{~K}_{2} \mathrm{HPO}_{4}, 0.2 \mathrm{~g}\right.$ $\mathrm{MgSO}_{4}, 0.1 \mathrm{~g} \mathrm{NaCl}, 5 \mathrm{~g}$ glucose, $0.05 \mathrm{~g}$ yeast extract, $0.1 \mathrm{~g} \mathrm{NH}_{4} \mathrm{Cl}, 10 \mathrm{mg} \mathrm{FeCl}$, 2 mg $\mathrm{Na}_{2} \mathrm{MoO}_{4} .2 \mathrm{H}_{2} \mathrm{O}$ per litre of $\mathrm{MQ} \mathrm{H} \mathrm{H}_{2} 0, \mathrm{pH}$ 7.2)(Cote \& Gherna, 1994). Cultures were cultivated for $24 \mathrm{hr}$ to equilibrate the cells in the minimal nitrogen medium before scaling up to the larger volume 1 L flasks. After $24 \mathrm{hr}$ of growth, a $2 \%(\mathrm{v} / \mathrm{v})$ inoculum was transferred to triplicate flasks (for independent samples) per experimental growth condition being tested by transferring $10 \mathrm{~mL}$ of the $\mathrm{Y}^{8} 8^{\mathrm{T}}$ pre-culture to each of the replicate $1 \mathrm{~L}$ Ehrlenmeyer flasks containing $500 \mathrm{~mL}$ of minimal nitrogen medium enriched with carbon substrate as before. The batch cultures were grown aerobically to the required $\mathrm{OD}_{600}$ obtained by monitoring growth throughout a $24 \mathrm{hr}$ growth period or $72 \mathrm{hr}$, 


\begin{tabular}{lll}
\hline \multicolumn{1}{c}{ Growth medium } & \multicolumn{1}{c}{ Available nitrogen in growth medium } & \multicolumn{1}{c}{ Physiological state of the cell } \\
\hline $\mathrm{NH}_{4}{ }^{+}$-free & None. $\mathrm{No} \mathrm{NH}_{4} \mathrm{Cl}$ supplemented & $\mathrm{Fix}^{\text {off }}$ (negative acetylene reduction) \\
$\mathrm{NH}_{4}{ }^{+}$-supplemented & $0.1 \mathrm{~g} / \mathrm{L} \mathrm{NH}_{4} \mathrm{Cl}$ supplemented, not depleted by time of sampling & $\mathrm{Fix}^{\text {off }}$ (negative acetylene reduction) \\
$\mathrm{NH}_{4}{ }^{+}$-depleted & $0.1 \mathrm{~g} / \mathrm{L} \mathrm{NH}_{4} \mathrm{Cl}$ supplemented, depleted by time of sampling & $\mathrm{Fix}^{\text {on }}$ (positive acetylene reduction) or \\
& & Fix $^{\text {off }}$ (decreased acetylene reduction but similar to Fix ${ }^{\text {on }}$ in terms of cell productivity) \\
\hline
\end{tabular}

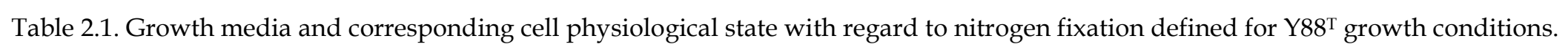


depending on the experimental design. $\mathrm{Y}^{8} 8^{\mathrm{T}}$ cells were cultivated at $30^{\circ} \mathrm{C}, 150$ rpm agitation in an orbital shaker incubator.

\subsubsection{Bioreactor cultivation}

Y88 ${ }^{\mathrm{T}}$ bioreactor batch cultivation was carried out in a Bioflo100 bioreactor (New Brunswick Scientific Co., Inc., New Brunswick, NJ, USA) consisting of two 1 L vessels set up in parallel. Each vessel contained $1 \mathrm{~L}$ of minimal nitrogen but carbon-enriched medium with a headspace of approximately $300 \mathrm{~mL}$. Y88 ${ }^{\mathrm{T}}$ cells were cultivated under a specific set of growth conditions according to the experimental design (Fig. 2.1). Each experiment was carried out in triplicate. A $2 \%(\mathrm{v} / \mathrm{v}$ ) inoculum was grown to comparable turbidity, measured with a PCcontrolled GBC spectrophotometer, model UV/VIS918 after removing $2 \mathrm{~mL}$ of culture at each sampling period over $24 \mathrm{hr}$ and diluting appropriately before transferring to a cuvette $(1 \mathrm{~cm}$ light path) with a syringe (see section 2.1.6.1). Ten $\mathrm{mL}$ of bacterial culture was removed and discarded prior to removing the 2 $\mathrm{mL}$ sample to prevent using cells considered to be the dead volume in the sampling tube. Bioreactor parameters controlled throughout the $24 \mathrm{hr}$ growth period were: agitation $(150 \mathrm{rpm})$, temperature $\left(30^{\circ} \mathrm{C}\right)$, dissolved $\mathrm{O}_{2}(\mathrm{DO})(10 \%$ $\mathrm{DO}, 50 \% \mathrm{DO})$ for the first set of oxygen experiments to determine differences between selected characteristics of $\mathrm{Y}^{8} 8^{\mathrm{T}}$ cells grown under DOlow and DOhigh conditions where the medium was allowed to acidify. For the second set of oxygen experiments to determine differences between selected characteristics of Y88 conditions $(10 \% \mathrm{DO}, 70 \% \mathrm{DO}$,$) at a constant \mathrm{pH}$, the bioreactor parameters controlled throughout $24 \mathrm{hr}$ growth were: agitation (150 rpm), temperature (30 C), $\mathrm{DO}(10 \% \mathrm{DO}, 70 \% \mathrm{DO})$ and $\mathrm{pH}=7.2 \pm 0.2$. The Bioflo110 bioreactor system was used in conjunction with the BioCommand Plus BioProcessing Software Version 3.30 for all bioreactor experiments. 


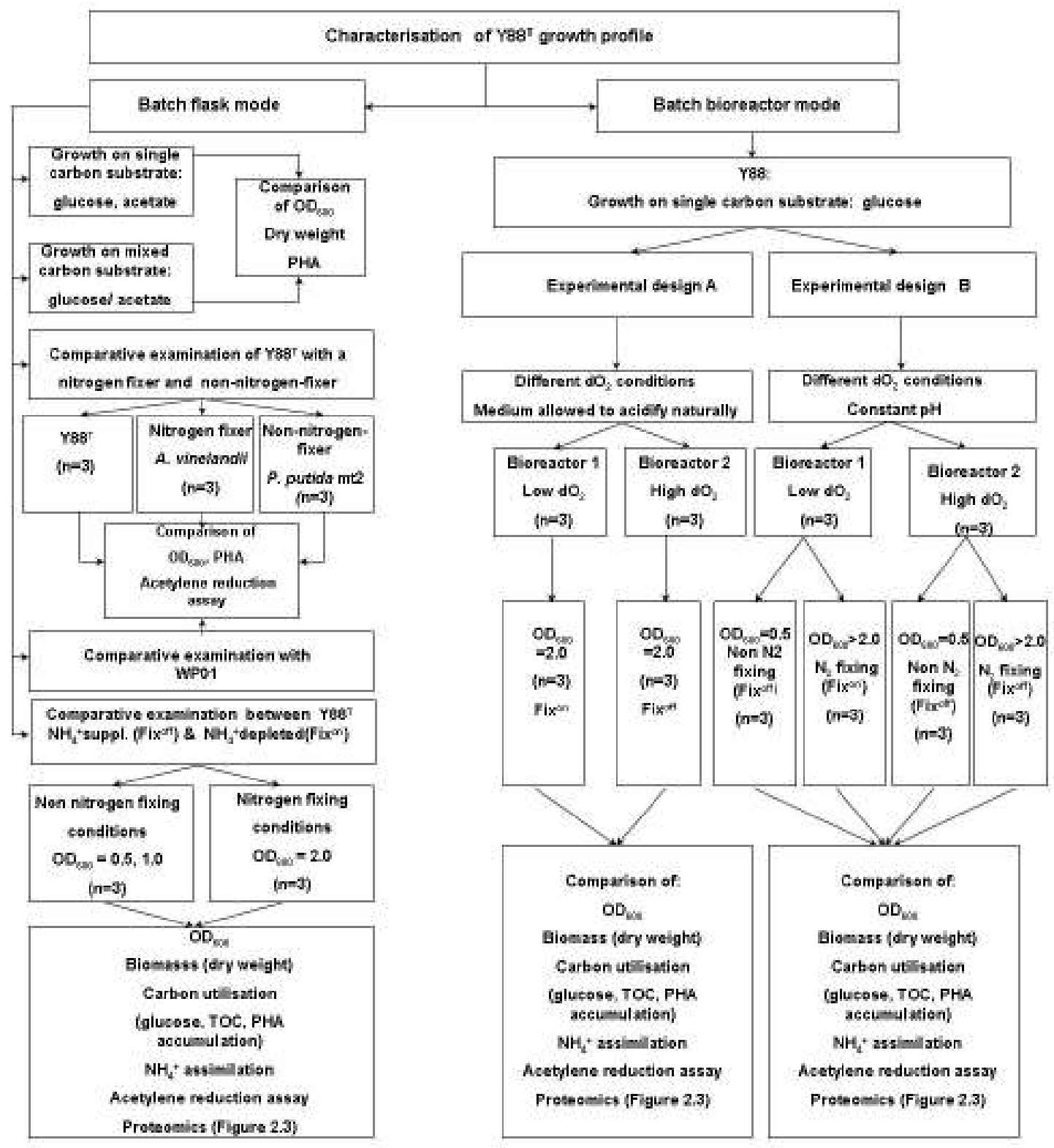

Figure 2.1. Schematic representation of workflow to investigate the microbiology of $\mathrm{Y}^{8} 8^{\mathrm{T}}$ growth, nitrogen assimilation, carbon utilisation and PHA accumulation under different growth conditions. 


\subsubsection{Optical density as an indicator of growth}

\subsubsection{Batch flask cultivation}

To evaluate growth, optical density $\left(\mathrm{OD}_{600}\right)$ was monitored over time. $\mathrm{Y} 88^{\mathrm{T}}$ was grown to lower cell densities $\left(\mathrm{OD}_{600}=0.5,1.0\right)$ and high cell density $\left(\mathrm{OD}_{600}=2.0\right)$ in batch flasks during a $24 \mathrm{hr}$ period. Each experiment was performed in triplicate. Two $\mathrm{mL}$ of $\mathrm{Y} 88^{\mathrm{T}}$ culture was taken at each sampling for each replicate and transferred to a $3 \mathrm{~mL}$ cuvette tube $\left(1 \mathrm{~cm}\right.$ light path). $\mathrm{OD}_{600}$ measurements after appropriate dilution to assay growth, were carried out using a PCcontrolled GBC spectrophotometer, model UV/VIS918. A blank, containing medium from a sterile stock was used to set the baseline reading. All $\mathrm{OD}_{600}$ measurements for each sample were carried out in duplicate and the average of each duplicate pair was determined. When the cells had reached the desired $\mathrm{OD}_{600}$, all the culture in a flask was centrifuged in $15 \mathrm{~mL}$ Falcon tubes.

\subsubsection{Batch bioreactor cultivation}

To evaluate growth, $\mathrm{OD}_{600}$ was determined in bioreactor cultivation. $\mathrm{Y}^{8} 8^{\mathrm{T}}$ was grown to high cell density $\left(\mathrm{OD}_{600}=2.0\right)$ under $\mathrm{DO}^{\text {low }}(10 \% \mathrm{DO})$ or DO $\mathrm{D}^{\text {high }}(50 \%$ or $70 \% \mathrm{DO})$ conditions during a $24 \mathrm{hr}$ period. Three independent biological replicates for each growth condition were generated. Culture sampling and $\mathrm{OD}_{600}$ measurements were carried out as described in section 2.1.4.1. When the cells had reached the desired $\mathrm{OD}_{600}$, all the culture in a flask was centrifuged into separate $15 \mathrm{~mL}$ Falcon tubes.

\subsubsection{Dry weights as an indicator of biomass}

The dry weight of each sample was determined as an indicator of biomass at specific stages of growth coinciding with Fix ${ }^{\text {on }}$ and Fix ${ }^{\text {off }}$ states of the cells (Table 2.1) under selected growth conditions. Fifteen $\mathrm{mL}$ samples of cultivated Y $88^{\mathrm{T}}$ cells were centrifuged at $1814 \times \mathrm{g}, 4{ }^{\circ} \mathrm{C}$, for $30 \mathrm{~min}$ and the spent medium supernatant was decanted carefully so as not to dislodge any cells. The cells were then centrifuged to ensure a tight pellet and $15 \mathrm{~mL}$ of $\mathrm{MQ} \mathrm{H}_{2} \mathrm{O}$ was added to the tube to rinse. The cells were again centrifuged and the $\mathrm{MQ} \mathrm{H}_{2} \mathrm{O}$ was 36 
decanted. Another $15 \mathrm{~mL}$ of $\mathrm{MQ} \mathrm{H}_{2} \mathrm{O}$ was added to the tube, which was centrifuged again. Following the second centrifugation, $14 \mathrm{~mL}$ of the supernatant was removed and $1 \mathrm{~mL}$ retained in the tube to resuspend the cells and facilitate transfer to aluminium foil containers. The foil containers had been tared and their masses documented, following which the containers were pre-dried in an oven at $105^{\circ} \mathrm{C}$ and stored in a desiccator to prevent moisture condensing on the containers and confounding the initial container weights. After transferring the wet cells to the aluminium foil containers, they were immediately placed in an oven at $105^{\circ} \mathrm{C}$. The containers were consecutively weighed in a microbalance (Mettler Toledo International Inc., UK) over several days until the weight had stabilised and at least three successive, constant weight values per sample were obtained. The third constant measured weight value for each sample was accepted as the final combined weight of the sample and foil. The tare of the foil container was subtracted from the final weight to derive the total dry weight of the cells per sample.

\subsubsection{Nitrogen utilisation assay}

\subsubsection{Determination of ammonium assimilation}

A Megazyme ammonia (rapid, manual format) assay kit (Megazyme International, Wicklow, Ireland) was used to determine the amount of ammonia in the culture medium of the growing $\mathrm{Y} 88^{\mathrm{T}}$ at specific time points (every $4 \mathrm{hr}$ ) over a $24 \mathrm{hr}$ period of growth. The principle of the assay is based on the presence of GDH and reduced NADPH in the medium. In the presence of GDH and NADPH, ammonia (in the form of $\mathrm{NH}_{4}{ }^{+}$) reacts with 2-oxoglutarate to form L-glutamic acid and $\mathrm{NADP}^{+}$. The amount of $\mathrm{NADP}^{+}$formed is stoichiometric with the amount of ammonia and the assay therefore measures the decrease in absorbance at $340 \mathrm{~nm}$ as the consumption of NADPH.

The assay was carried out according to the manufacturer's instructions with all samples measured in duplicate. Fifteen $\mathrm{mL}$ culture samples were centrifuged at $1814 \times \mathrm{g}$ to pellet the cells and the spent medium was decanted into another 
Falcon tube before filtering into a third Falcon tube using a $0.2 \mu \mathrm{m}$ Whatman filter (Global Science). The medium was subsequently filtered again using a fresh $0.2 \mu \mathrm{m}$ filter to ensure that no residual cells could contaminate the medium and give confounding values for the amount of $\mathrm{NH}_{4}^{+}$present in the medium at each time point. Before carrying out the assay, each sample was diluted with nine volumes of $\mathrm{MQ} \mathrm{H}_{2} \mathrm{O}$ to one volume of filtered sample. On completion of the assay, the results were multiplied by the dilution factor to determine the actual final amounts of $\mathrm{NH}_{4}{ }^{+}$in the medium at each time point. The final values were then subtracted from the known quantity of starting $\mathrm{NH}_{4}{ }^{+}$ supplemented as $\mathrm{NH}_{4} \mathrm{Cl}(0.1 \mathrm{~g} / \mathrm{L})$ in the medium, to establish how much $\mathrm{NH}_{4}{ }^{+}$ had been assimilated throughout a $24 \mathrm{hr}$ growth period.

\subsubsection{Acetylene reduction assay}

Acetylene $\left(\mathrm{C}_{2} \mathrm{H}_{2}\right)$ reduction is routinely used to estimate the activity of nitrogenase, as it is a good substrate for nitrogenase (Ludden, 2001). When $\mathrm{C}_{2} \mathrm{H}_{2}$ is reduced, it produces ethylene $\left(\mathrm{C}_{2} \mathrm{H}_{4}\right)$ that is relatively easy to quantify ( $\mathrm{Li}, 2002)$ using the $\mathrm{H}_{2}$-flame ionisation gas chromatography system (Hardy et al., 1968). $\mathrm{C}_{2} \mathrm{H}_{2}$ is a highly soluble gas that readily crosses the cell membrane. Although a much less soluble gas than $\mathrm{C}_{2} \mathrm{H}_{2}, \mathrm{C}_{2} \mathrm{H}_{4}$ still readily crosses the cell membrane and can accumulate in the gas phase above the cell suspension where it can be easily sampled and quantified by flame ionisation gas chromatography. Direct correlations can be made between $\mathrm{C}_{2} \mathrm{H}_{4}$ formation and nitrogenase activity as an indicator of nitrogen fixation. Theoretically, as few as 2 to 3 cells can produce sufficient $\mathrm{C}_{2} \mathrm{H}_{4}$ for detection by the $\mathrm{H}_{2}$-flame ionisation system. In Azotobacter, ethylene formation measured 0.02 pmol per hour per Azotobacter cell over a 1000-fold range of cell concentration (Hardy et al., 1968). Due to the extreme sensitivity by $\mathrm{H}_{2}$-flame ionisation to detect $\mathrm{C}_{2} \mathrm{H}_{4}$ formation, this technique was used to determine nitrogenase activity in $\mathrm{Y}^{\mathrm{T}}{ }^{\mathrm{T}}$ cells assayed for $\mathrm{C}_{2} \mathrm{H}_{2}$ reduction. 
The equation for the reaction forming $\mathrm{C}_{2} \mathrm{H}_{4}$ gas is as follows:

$\begin{array}{lcc}\mathrm{HC} \equiv \mathrm{CH}+2 \mathrm{H}^{+}+2 \mathrm{e}^{-} & \rightarrow & \mathrm{H}_{2} \mathrm{C}=\mathrm{CH}_{2} \\ \left(\mathrm{C}_{2} \mathrm{H}_{2}\right) & \text { nitrogenase } & \left(\mathrm{C}_{2} \mathrm{H}_{4}\right)\end{array}$

Y88 ${ }^{\mathrm{T}}$ cells were collected in $15 \mathrm{~mL}$ Falcon tubes and centrifuged at $4{ }^{\circ} \mathrm{C}$ for 30 min. Two replicates per sample were prepared for each $\mathrm{C}_{2} \mathrm{H}_{2}$ reduction assay as well as a positive (pure $\mathrm{C}_{2} \mathrm{H}_{4}$ ) and two negative (blank) controls. Cells were resuspended in $5 \mathrm{~mL}$ of culture supernatant and resuspended cells were transferred to $10 \mathrm{~mL}$ glass vials containing caps with rubber septums. The two blanks were prepared by using $5 \mathrm{~mL}$ of $\mathrm{MQ} \mathrm{H}_{2} \mathrm{O}$ instead of $\mathrm{Y}^{2} 8^{\mathrm{T}}$ cells. A gas bladder was prepared by evacuating as much air as possible. Approximately $200 \mathrm{~mL}$ of tap water was added to a $1 \mathrm{~L}$ conical flask and approximately $5 \mathrm{~mL}$ of calcium carbide $\left(\mathrm{CaC}_{2}\right)$ was added to generate $\mathrm{C}_{2} \mathrm{H}_{2}$ by the following reaction:

$$
\mathrm{CaC}_{2}+2 \mathrm{H}_{2} \mathrm{O} \rightarrow \mathrm{Ca}(\mathrm{OH})_{2}+\mathrm{C}_{2} \mathrm{H}_{2}
$$

After initiation of the reaction, the first $30 \mathrm{sec}$ of gas formed was vented. The bladder was then quickly connected to the rubber bung by means of silicone tubing and filled with $\mathrm{C}_{2} \mathrm{H}_{2}$ by attaching a syringe needle to the end of the tubing and pushing the needle through the bladder seal. The glass vials were prepared by sparging with argon for about $30 \mathrm{sec}$ to displace any $\mathrm{O}_{2}$ in the vial. After sparging with argon, $1 \mathrm{~mL} \mathrm{O}_{2}$ was injected into the vial to provide some $\mathrm{O}_{2}$ for the aerobic $\mathrm{Y}^{8} 8^{\mathrm{T}}$. To start the assay, $0.1 \mathrm{~mL}$ of $\mathrm{C}_{2} \mathrm{H}_{2}$ was then injected with a syringe into the vials. Five $\mathrm{mL}$ of resuspended $\mathrm{Y}^{\mathrm{T}}{ }^{\mathrm{T}}$ cells was subsequently added to the vials. Sealed vials were incubated in a $30^{\circ} \mathrm{C}$ water bath for $1 \mathrm{hr}$. Following incubation, approximately $6 \mathrm{~mL}$ of headspace gas was removed with a syringe and the syringe needle immediately plunged into a rubber bung to keep the sample sealed before injection into the gas chromatograph. $\mathrm{C}_{2} \mathrm{H}_{4}$ formed from $\mathrm{C}_{2} \mathrm{H}_{2}$ was analysed with a Pye Unicam Series 105 gas chromatograph using a Flame Ionisation Detector (FID) and a 
glass column (1.5 $\mathrm{m} \times 6.35 \mathrm{~mm}$ outer diameter and $4 \mathrm{~mm}$ inner diameter) filled with Porapak N (80/100 mesh), operated at $120^{\circ} \mathrm{C}$ and carrier gas nitrogen $\left(\mathrm{N}_{2}\right)$ at $20 \mathrm{~mL} / \mathrm{min}$. An HP 3393A integrator was used for quantitative analysis.

Headspace gas from a blank sample was injected into the chromatograph prior to the injection of any $Y 88^{\mathrm{T}}$ headspace gas sample and checked for a negative signal resulting from non-reduced $\mathrm{C}_{2} \mathrm{H}_{2}$. A second blank sample was injected at the end of the experiment to check for any false positive signal caused by carryover of residual $\mathrm{C}_{2} \mathrm{H}_{4}$ produced in any of the preceding $\mathrm{Y} 88^{\mathrm{T}}$ samples. The experimental results were only accepted if both blanks produced the expected negative $\mathrm{C}_{2} \mathrm{H}_{4}$ results. A positive control of $6 \mathrm{~mL}$ pure $\mathrm{C}_{2} \mathrm{H}_{4}$ gas from a $\mathrm{C}_{2} \mathrm{H}_{4}$ gas cylinder was injected to produce a positive $\mathrm{C}_{2} \mathrm{H}_{4}$ peak.

\subsubsection{Glucose utilisation}

\subsubsection{1 $\quad \mathrm{Y88}^{\mathrm{T}}$ growth on glucose and acetate}

Y88 ${ }^{\mathrm{T}}$ growth was investigated in batch flasks with glucose or acetate as carbon sources. PHA production, $\mathrm{OD}_{600}$ and biomass produced were monitored throughout the growth period. $\mathrm{Y}^{\mathrm{T}} 8^{\mathrm{T}}$ growth curves were generated from $\mathrm{OD}_{600}$ measurements of cells grown in the presence of glucose or acetate as a single carbon source or glucose and acetate in combination. For Y88 ${ }^{\mathrm{T}}$ growth using either glucose or acetate separately in a minimal nitrogen medium, equivalent amounts of carbon were used for each compound. Acetate concentrations were $5 \mathrm{mM}, 10 \mathrm{mM}, 20 \mathrm{mM}, 27 \mathrm{mM}$ or $81 \mathrm{mM}$. The equivalent amount of carbon in glucose was $1.9 \mathrm{mM}, 3.3 \mathrm{mM}, 6.8 \mathrm{mM}, 9 \mathrm{mM}$ or $27 \mathrm{mM}$. This allowed an evaluation of these two carbon sources at low or high concentrations, independent of each other and comparable in terms of the amount of initial carbon present in the medium. Biomass and PHA accumulation were also determined.

Additionally, Y88 ${ }^{\mathrm{T}}$ growth was examined in batch flasks on combinations of glucose and acetate as a mixed carbon source to determine whether any change 
in growth, cell yield and PHA accumulation could be detected as a consequence of growing in the presence of the mixed substrate, as compared to growth in the presence of either of these substrates alone. Since the purpose of growing the cells in the presence of a mixed substrate of glucose and acetate was to determine whether small amounts of glucose affected growth on acetate in any way, the mixed combinations of initial carbon substrate were as follows: 1.9 $\mathrm{mM}$ glucose /5 mM acetate, $3.3 \mathrm{mM}$ glucose/10 $\mathrm{mM}$ acetate, $1.9 \mathrm{mM}$ glucose/20 $\mathrm{mM}$ acetate and $3.3 \mathrm{mM}$ glucose $/ 20 \mathrm{mM}$ acetate. An additional $27 \mathrm{mM}$ glucose/27 $\mathrm{mM}$ acetate combination was used to compare the effect of excess glucose on acetate growth. All experiments were conducted in duplicate for each set of conditions being tested. The $\mathrm{pH}$ of the growth medium was determined at $0,8,12$ and $24 \mathrm{hr}$ post inoculation.

\subsubsection{Comparative growth of ${\mathrm{Y} 88^{\mathrm{T}}}^{\mathrm{T}}, A$. vinelandii and $P$. putida $\mathrm{mt} 2$ on glucose under ammonium-free, ammonium-supplemented or ammonium-depleted conditions}

Comparative growth of $\mathrm{Y}^{8} 8^{\mathrm{T}}$, A. vinelandii and P. putida $\mathrm{mt} 2$ was examined in parallel in batch flasks (3 per species) containing minimal nitrogen medium enriched with glucose as the sole carbon source. The ability of $Y 88^{\mathrm{T}}$ to fix nitrogen and accumulate PHA was investigated and compared with that of $A$. vinelandii. These experiments were carried out in two phases. Phase 1 investigated the ability of $\mathrm{Y}^{\mathrm{T}}$ to grow in nitrogen-free or nitrogensupplemented, carbon-enriched (5 g/L) medium. Since no data were available for $Y 88^{\mathrm{T}}$ growth in the presence of limiting glucose, triplicate controls containing the same medium but with less carbon $(1 \mathrm{~g} / \mathrm{L})$, were included to determine whether this lower concentration could be considered limiting in terms of growth and PHA production for $\mathrm{Y} 88^{\mathrm{T}}$. The activity of nitrogenase was examined under carbon excess, nitrogen-limiting and ammoniumsupplemented growth conditions and the masses of PHA accumulated under these conditions were determined. A. vinelandii was used as a positive nitrogenfixing, PHA-accumulating control and P. putida $\mathrm{mt} 2$ as a negative control. $\mathrm{OD}_{600}$ was measured at $0,8,12$ and 24 hr post-inoculation. $\mathrm{C}_{2} \mathrm{H}_{2}$ reduction assays were 
carried out on all three species when their growth reached maximum $\mathrm{OD}_{600}$. Nitrogenase activity in the cells was measured in the $\mathrm{C}_{2} \mathrm{H}_{2}$ reduction assays as an indicator of the ability to fix molecular nitrogen under conditions appropriate for nitrogen fixation.

Phase 2 investigated $Y 8^{\mathrm{T}}$ growth in batch flasks in duplicate for each set of conditions being tested to examine the ability of $Y 88^{\mathrm{T}}$ to fix nitrogen in the presence of excess carbon and determine the amount of PHA accumulated. Since it was uncertain when exactly in the growth phase $Y 88^{\mathrm{T}}$ accumulated PHA, two sampling points were selected at different cell densities representative of low or high cell density. Cells were harvested for assays of nitrogenase activity at $\mathrm{OD}_{600}$ of approximately 0.5 and 1.0 as well as an $\mathrm{OD}_{600}$ greater than 2.0 (undiluted). For these experiments, the masses of PHA, dry weights as an indicator of biomass, glucose utilisation and total organic carbon (TOC), acetic acid formation and ammonium assimilation were determined over a $72 \mathrm{hr}$ growth period. $\mathrm{C}_{2} \mathrm{H}_{2}$ reduction assays for nitrogenase activity were carried out at high cell densities at $22-24 \mathrm{hr}$ post-inoculation. An initial (0 hr post-inoculation) and final (72 hr post-inoculation) $\mathrm{pH}$ were recorded.

\subsubsection{Comparative growth of $\mathrm{Y}^{\mathrm{T}}{ }^{\mathrm{T}}$ and WP01 during PHA accumulation in the presence of a single carbon substrate}

$\mathrm{Y}^{\mathrm{T}}$ and WP01 were grown in batch flasks in triplicate to examine PHA accumulation in a minimal nitrogen medium with either glucose or acetate as the sole carbon source. For these experiments, the masses of PHA, dry weights as an indicator of biomass and $\mathrm{OD}_{600}$ were determined over a $72 \mathrm{hr}$ growth period.

\subsubsection{Total organic carbon as a measure of dissolved organic carbon}

An Elementar HiTOC analyser (Elementar, Hanau, Germany) and auto-injector was used to determine the total organic carbon (TOC) remaining in $\mathrm{Y}^{2} 8^{\mathrm{T}}$ culture media after $24 \mathrm{hr}$ of growth. Each sample was filtered twice with a $0.2 \mu \mathrm{m}$ filter to remove possible contaminating cells/substances. A stock solution of $1.083 \mathrm{~g}$ 
potassium hydrogen phthalate and $4.412 \mathrm{~g}$ of sodium carbonate was made up in $1000 \mathrm{~mL}$ of $\mathrm{MQ} \mathrm{H} \mathrm{H}_{2} \mathrm{O}$ and diluted to the appropriate standards $(500 \mathrm{~g} / \mathrm{L}, 250$ $\mathrm{g} / \mathrm{L}, 125 \mathrm{~g} / \mathrm{L}, 25 \mathrm{~g} / \mathrm{L})$. To ensure that the results would be within the acceptable range of the standards used, all samples were diluted 1:4 prior to analysis. Samples were added to $25 \mathrm{~mL}$ glass scintillation vials with a $10 \mathrm{~mm}$ magnetic stirrer that was placed in the bottom of each vial. All samples were analysed in duplicate. The difference between the total carbon (TC) and the total inorganic carbon (TIC) was calculated as the DOC present in each sample. The DOC amount was subtracted from the initial amount of total carbon supplemented in the growth medium at the start of the experiment. The difference between these two values was calculated to be the amount of carbon utilised in the presence of $\mathrm{Y}^{\mathrm{T}} 8^{\mathrm{T}}$ cells during growth over a $24 \mathrm{hr}$ period. A standard curve was generated from the standards used in the analysis.

\subsubsection{Enzyme assays}

\subsubsection{Glucose utilisation assay}

Glucose was measured using a Megazyme glucose assay (Megazyme International, Wicklow, Ireland) based on oxidation of glucose and measurement of the product $\mathrm{H}_{2} \mathrm{O}_{2}$ in a reaction catalysed by the enzyme peroxidase. The culture supernatant was filtered twice after centrifugation (1814 $\times \mathrm{g}, 4^{\circ} \mathrm{C}, 30 \mathrm{~min}$ ) through a $0.2 \mu \mathrm{m}$ filter and aliquots were incubated with the assay reagent at $40{ }^{\circ} \mathrm{C}$ for 15 min after 9x dilution with $\mathrm{MQ} \mathrm{H}_{2} \mathrm{O}$. Following incubation, spectrophotometric measurements were carried out on the reacted product at $510 \mathrm{~nm}$.

\subsubsection{Acetic acid formation assay}

Acetic acid formation was measured using a Megazyme (Wicklow, Ireland) Acetic Acid kit based on the use of acetyl-coenzyme A synthetase (ACS) to catalyse the reaction of acetic acid, ATP and CoA to give acetyl-CoA, AMP and pyrophosphate at room temperature. The culture supernatants used in the assays were prepared similarly to those in 2.1.10.1 above. The acetyl-CoA 
formed in the reaction reacts with oxaloacetate and $\mathrm{H}_{2} \mathrm{O}$ in the presence of citrate synthase to form citric acid and CoASH followed by catalysis of $\mathrm{NAD}^{+}$ dependent L-malate by L-malate dehydrogenase to form oxaloacetate and reduced NADH, the production of which is measured by absorbance at $340 \mathrm{~nm}$.

\subsubsection{PHA determination}

\subsubsection{PHA content in ${\mathrm{Y} 88^{\mathrm{T}}}^{\mathrm{P}}$ cells}

Duplicate $15 \mathrm{~mL}$ cultures were centrifuged at $1814 \times \mathrm{g}, 4{ }^{\circ} \mathrm{C}$ to sediment the cells which were then dried overnight and subjected to PHA gas chromatographic analysis (Riis \& Mai, 1988) to determine the amount and type of polymer that accumulated.

\subsubsection{Determination of polymer characteristics}

A CelLytic B Plus kit (Sigma) was used to extract PHA polymer from Y88 ${ }^{\mathrm{T}}$ cells for ${ }^{13} \mathrm{C}-\mathrm{NMR}$ analysis. The kit lysis buffer working solution (made up as specified in the manufacturer's instructions for protein extraction), readily disrupted the inclusion bodies in the cells, precipitating the inclusion body compound in the insoluble material. This compound was manually removed from the cell debris and subjected to ${ }^{13} \mathrm{C}-\mathrm{NMR}$, infrared spectroscopy and gas chromatography (Riis \& Mai, 1988).

\section{2 $\mathrm{Y}^{8} 8^{\mathrm{T}}$ whole genome sequencing and curation}

The $\mathrm{Y} 88^{\mathrm{T}}$ genome was shotgun sequenced using 454 Life Sciences (Branford, CT, USA) pyrosequencing to generate sequence reads with an average read length of 150 bases and an average sequence accuracy of $>99 \%$, resulting in approximately 99\% genome coverage. Contig assembly was performed at 454 Life Sciences using the Newbler contig assembly programme. The Y88 ${ }^{\mathrm{T}}$ genome was estimated to be approximately $4.5 \mathrm{Mb}$ of which $4.18 \mathrm{Mb}$ have been sequenced.

The Y88 ${ }^{\mathrm{T}}$ genomic sequence was subjected to a BLAST search of the GenEMBL non-redundant database at Scion, Rotorua. Gene annotations were assigned to 44 
identified open reading frames and used to create an in-house database that was used for protein identification from MS/MS data interpreted using MASCOT (Matrix Science, London, UK), (Strabala, Macdonald \& Liu, unpublished results).

\subsection{Proteomics}

A 2-D DIGE proteomic approach (Fig. 2.2) was used to examine the response of $\mathrm{Y}^{\mathrm{T}} 8^{\mathrm{T}}$ to conditions conducive to nitrogen fixation (represented by the Fix ${ }^{\text {on }}$ physiological state of the cell) or no nitrogen fixation (represented by the Fix off physiological state of the cell) in a carbon-enriched environment. MS of trypsinised protein from spots excised from Coomassie-stained 2-D DIGE gels, allowed the identification of $\mathrm{Y} 88^{\mathrm{T}}$ proteins with altered abundance under different growth conditions. Using this approach, the key physiological parameters of nitrogen fixation, growth, carbon utilisation and PHA accumulation were correlated with their corresponding proteomic signatures. Initially, a linear gradient in the $\mathrm{pH}$ 3-10 range was used to gain an overview of the total distribution of $Y 88^{\mathrm{T}}$ proteins under the tested growth conditions. For increased resolution and a more detailed overview of acidic and basic protein distribution, linear gradient $\mathrm{pH}$ 4-7 and $\mathrm{pH}$ 6-11 strips were used.

\subsubsection{Generation of samples for 2-D DIGE and LC-MS/MS analysis}

\subsubsection{2-D Gel Experimental Design 1}

$\mathrm{Y}^{\mathrm{T}} 8^{\mathrm{T}}$ samples for each 2-D DIGE experiment were cultivated in batch mode (flasks) in triplicate for each set of conditions and harvested at two optical densities corresponding to Fix ${ }^{\text {off }}\left(\mathrm{OD}_{600}=0.5,1.0\right)$ and Fix ${ }^{\text {on }}\left(\mathrm{OD}_{600}>2.0\right.$, $)$ states (Table 2.2). Two preparative and three analytical 2-D DIGE gels were used for each sample (Fig. 2.3). Each preparative gel comprised pooled samples for the three replicates representing the Fix ${ }^{\text {off }}$ state of the cell $\left(\mathrm{OD}_{600}=0.5\right)($ Fig. 2.3, A.1) and the Fix on state of the cell $\left(\mathrm{OD}_{600}>2.0\right.$, undiluted) (Fig. 2.3, A.2). The 2-D DIGE gels (Fig. 2.3) contained three samples, two of them randomly selected and representing a different Fix ${ }^{\text {on }}$ or Fix off state of the cell with the third 


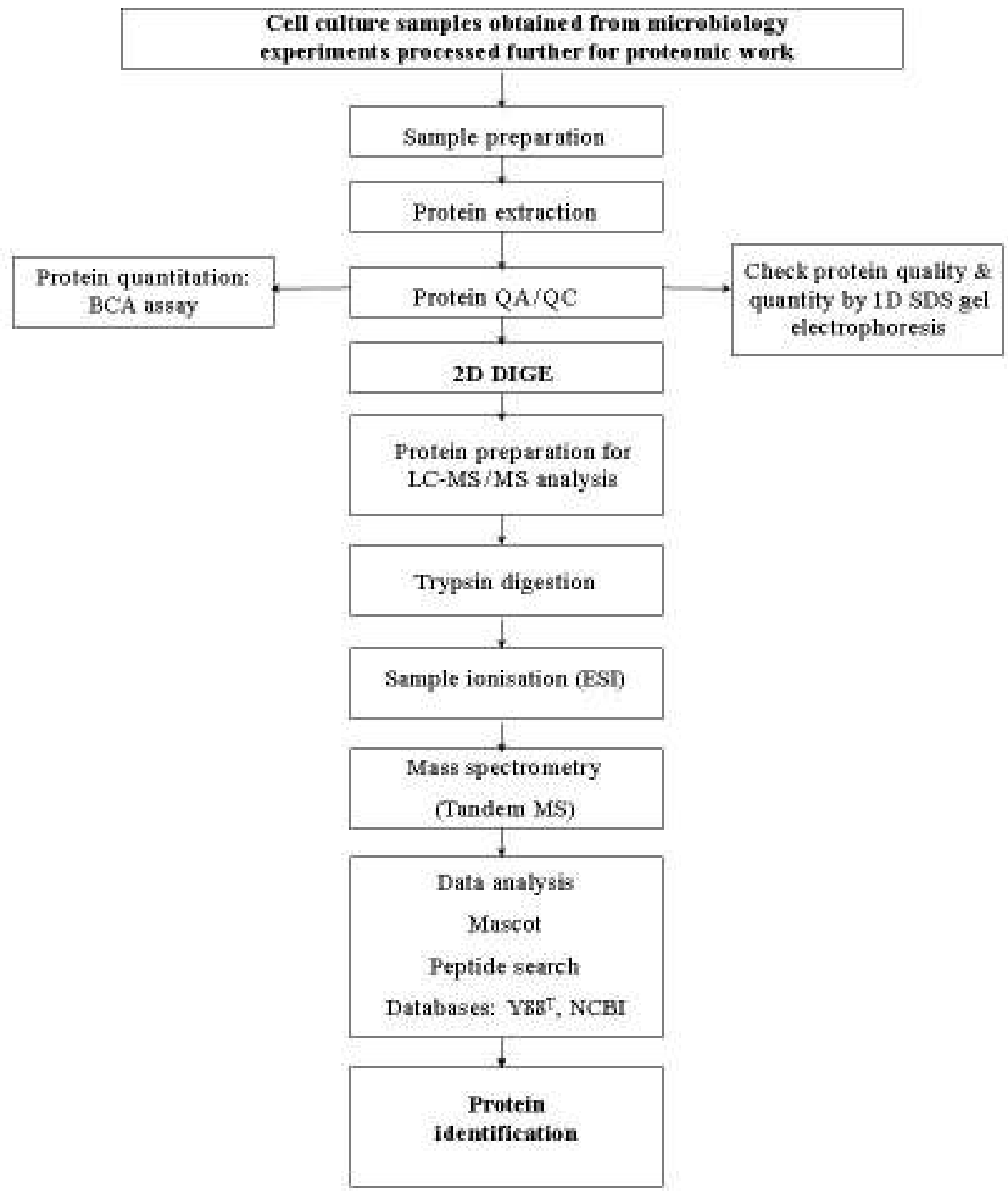

Figure 2.2. Schematic representation of workflow to investigate the proteome of $\mathrm{Y}^{8} 8^{\mathrm{T}}$ under different growth conditions. 


\section{Growth sampling phase/condition}

\begin{tabular}{|c|c|c|c|c|c|c|c|c|}
\hline \multirow[t]{3}{*}{ Chapter reference } & $\begin{array}{l}\text { Experimental } \\
\text { Design }\end{array}$ & $\underset{\text { free }}{\mathrm{NH}_{4}^{+}-}$ & $\begin{array}{c}\mathrm{NH}_{4}^{+}- \\
\text {supplemented }\end{array}$ & $\begin{array}{c}\mathrm{NH}_{4}^{+}- \\
\text {depleted }\end{array}$ & $\begin{array}{c}\mathrm{NH}_{4}^{+}- \\
\text {supplemented }\end{array}$ & $\begin{array}{c}\mathrm{NH}_{4}^{+}- \\
\text {depleted }\end{array}$ & $\begin{array}{c}\mathrm{NH}_{4}^{+}- \\
\text {supplemented }\end{array}$ & $\begin{array}{c}\mathrm{NH}_{4}^{+}- \\
\text {depleted }\end{array}$ \\
\hline & & $\mathrm{OD}_{600}=0.5$ & $O D_{600}=1.0$ & $\mathrm{OD}_{600}=2.0$ & $\mathrm{OD}_{600}=0.5$ & $O D_{600}=2.0$ & $O D_{600}=0.5$ & $O D_{600}=2.0$ \\
\hline & & & & & DO'low & DO low & DO ${ }^{\text {high }}$ & DO ${ }^{\text {high }}$ \\
\hline
\end{tabular}

Physiological state of cells

\begin{tabular}{|c|c|c|c|c|c|c|c|c|}
\hline Chapter 4, section 4.2.2.1 & 1 & Fix & & $\mathrm{Fix}^{\text {on }}$ & & & & \\
\hline Chapter 4 , section 4.2.2.2 & 2 & Fix & Fix $^{\text {off }}$ & Fix $^{\text {on }}$ & & & & \\
\hline Chapter 5 , section 5.2 .1 .3 & 3 (pH not controlled) & & & & Fix ${ }^{\text {off }}$ & Fix $^{\text {on }}$ & & \\
\hline $\begin{array}{l}\text { Chapter } 5 \text {, section } 5.2 .1 .4- \\
5.2 .1 .6\end{array}$ & $4(\mathrm{pH}$ controlled) & & & & Fix ${ }^{\text {off }}$ & $\mathrm{Fix}^{\text {on }}$ & Fix $^{\text {off }}$ & $\mathrm{Fix}^{\text {off }}{ }^{*}$ \\
\hline
\end{tabular}

Table 2.2. Physiological state of $Y 88^{\mathrm{T}}$ cells defined for a specific set of growth conditions.

Fix ${ }^{\text {off }}=$ negative acetylene reduction; Fix ${ }^{\text {on }}=$ positive acetylene reduction; Fix ${ }^{\text {off }}=$ decreased acetylene reduction but similar to Fix ${ }^{\text {on }}$ in terms of cell productivity.

Note in chapter 5 and thereafter, Fix ${ }^{\text {off }}{ }^{*}$ will be referred to as Fix ${ }^{\text {off. }}$ 

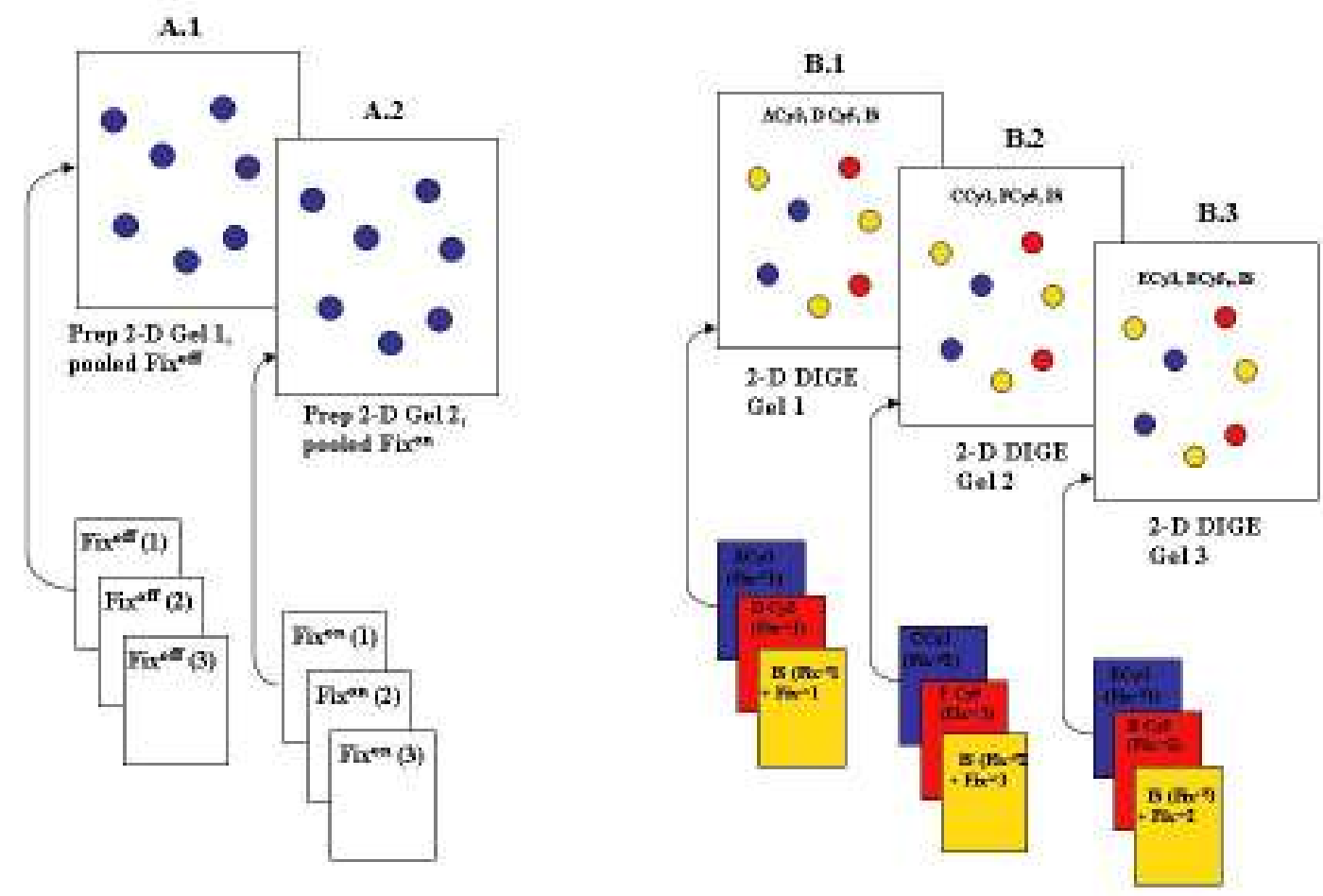

Figure 2.3. 2-D gel experimental design 1

(A) Preparative 2-D gels representing pooled replicate protein samples for $\mathrm{Y}^{8} 8^{\mathrm{T}}$ cells grown in ammonium-free medium in which the cells did not fix nitrogen (Fix ${ }^{\text {off }}$ state of the cells) (A.1) and a second gel representing pooled replicate protein samples for $\mathrm{Y}^{8} 8^{\mathrm{T}}$ cells grown in medium conducive to nitrogen fixation (Fix ${ }^{\text {on }}$ state of the cells) (A.2); (B) 2-D DIGE gels representing combinations of protein samples comprising, per gel, one sample (Fix off) labeled with CyDye 3 and the other sample (Fix $\left.{ }^{\circ}\right)$ with CyDye 5. An internal standard consisting of equal quantities of Fix ${ }^{\text {off }}$ and Fix ${ }^{\text {on }}$ was labeled with CyDye 2. The two different states of Fix ${ }^{\text {on }}$ and Fix ${ }^{\text {off }}$ resulted in 6 biological replicates (3 for each condition) resulting in 3 (B.1-B.3) 2-D DIGE analytical gels and 2 preparative 2-D gels (A.1, A.2). 
being a pooled sample of equal quantities of Fix on and Fix off samples representing the internal standard. The combination of samples for each of the two states of the cell were included on a gel with an internal standard allowing a comparison at the protein level of the physiological state (Fix ${ }^{\text {off }}$ and Fix ${ }^{\text {on }}$ ) of the cell under ammonium-free and ammonium-supplemented growth conditions respectively. Coomassie-stained protein spots were excised, reacted with trypsin to digest protein and analysed by MS to identify as many proteins as possible as well as to determine which, if any of these, were involved in nitrogen fixation and PHA accumulation under the selected growth conditions. Protein spots occurring on the gels at predicted isoelectric points and molecular weights for the nitrogenase enzymes and PHA accumulating proteins (based on relevant literature on these proteins from other bacteria) were targeted for analysis. Also selected were additional highly abundant proteins as well as low molecular weight basic and acidic protein spots since these are often of interest as bioactives. All spots picked were further processed for LC-MS/MS analysis.

\subsubsection{2-D Gel Experimental Design 2}

Y88 ${ }^{\mathrm{T}}$ samples for each 2-D DIGE experiment were cultivated in batch mode $(1 \mathrm{~L}$ Ehrlenmeyer flasks, working volume $500 \mathrm{~mL}$ ) in triplicate for each set of conditions and harvested at two optical densities corresponding to Fix off $\left(\mathrm{OD}_{600}=0.5\right)$, Fix ${ }^{\text {off }}\left(\mathrm{OD}_{600}=1,0\right)$ and Fix ${ }^{\circ}\left(\mathrm{OD}_{600}>2.0\right.$, undiluted) states (see conditions for Fix ${ }^{\text {off }}$ and Fix ${ }^{\text {on }}$ state of the cells for experimental design 2, Table 2.2). Three preparative and five analytical 2-D DIGE gels were generated (Fig. 2.4). Each preparative gel comprised pooled samples for the three replicates representing i) the Fix ${ }^{\text {off }}$ state of the cell $\left(\mathrm{OD}_{600}=0.5\right.$, Fig. 2.4, A.1), ii) the Fix off state of the cell $\left(\mathrm{OD}_{600}=1.0\right.$, Fig. 2.4, A.2) and the Fix on state of the cell $\left(\mathrm{OD}_{600}>2.0\right.$, undiluted, Fig. 2.4, A.3). The 2-D DIGE gels (Fig.2.4, B.1-B.5) contained three samples, two of them randomly selected and representing a different Fix on or Fix ${ }^{\text {off }}$ state of the cell as defined (Table 2.2, Experimental Design 2) with the third being a pooled sample of equal quantities of Fix on and Fix ${ }^{\text {off }}$ samples representing the internal standard. The combination of samples for each of the two states of the cell plus the internal standard included per 2-D 

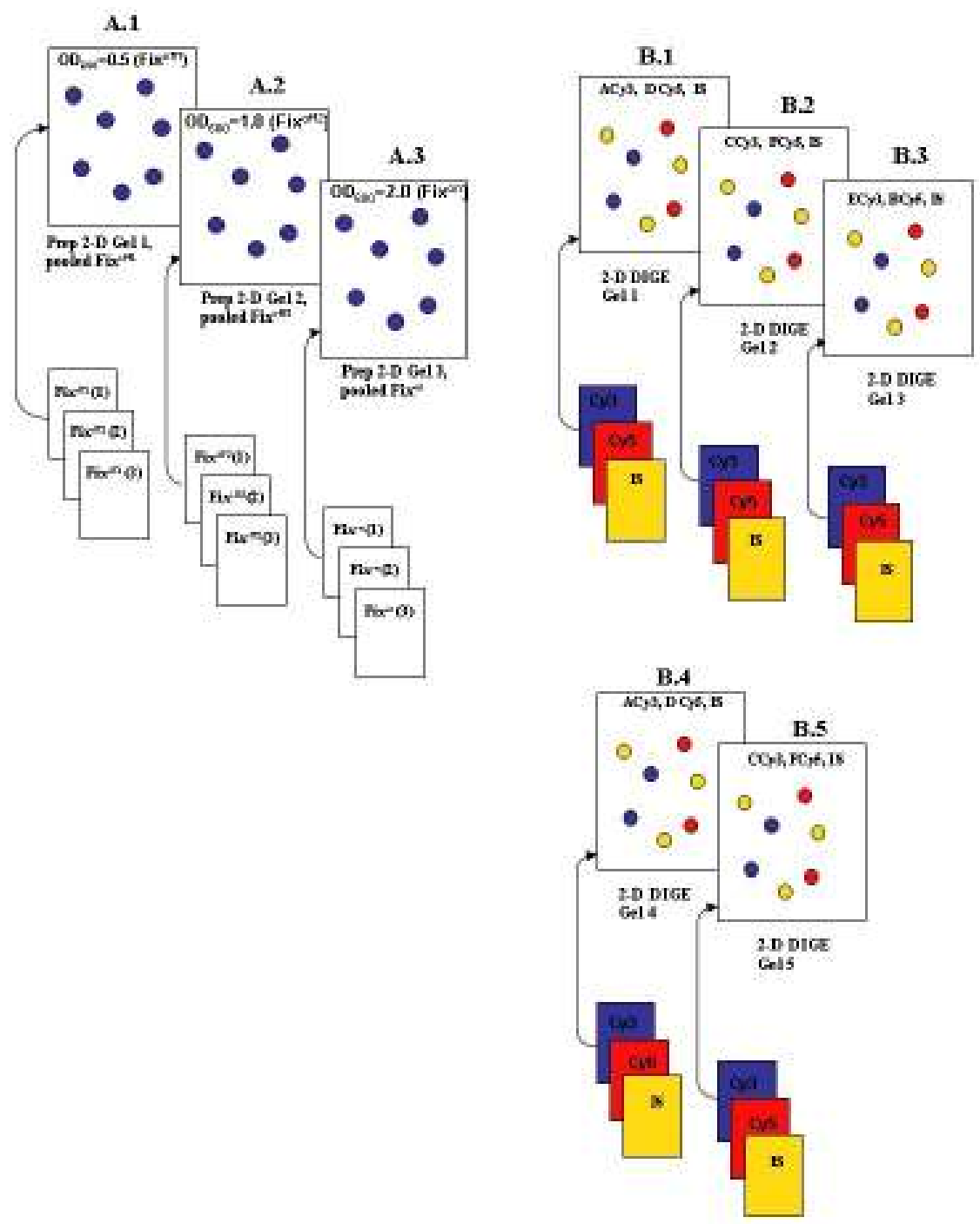

Figure 2.4. 2-D gel experimental design 2

(A) Preparative 2-D gels representing pooled replicate protein samples for cells grown to an $\mathrm{OD}_{600}=0.5$ in ammonium-supplemented medium in which cells did not fix nitrogen (Fix ${ }^{\text {off } 1 \text { ) }}$ (A.1), to an $\mathrm{OD}_{600}=1.0$ in ammonium supplemented medium in which cells did not fix nitrogen (Fix ${ }^{\text {off }}$ (A.2) and to an $\mathrm{OD}_{600}=2.0$ (A.3) in nitrogen-depleted medium in which cells fixed nitrogen. (B) 2-D DIGE gels representing combinations of two randomly selected samples, one from each state, per gel labeled with either CyDye 3 and or CyDye 5. An internal standard (IS) representing equal quantities of sample for each state of the two states of the cell was labeled with CyDye 2. Thus, for an experiment with three different conditions, 9 biological replicates were generated (3 for each condition) resulting in 5 (B.1-B.5) 2-D DIGE analytical gels and 3 preparative 2-D gels (A.1, A.2, A.3). 
DIGE gel, allowed a comparison at the protein level of the physiological state (Fix ${ }^{\text {off }}$ and Fix ${ }^{\text {on }}$ ) of the cell under ammonium-supplemented conditions during which $\mathrm{Y}^{\mathrm{T}}$ cells did not fix nitrogen and ammonium-depleted conditions during which Y88 ${ }^{\mathrm{T}}$ cells fixed nitrogen. Protein spots excised from the 2-D gels were processed as before (Section 2.3.1.1).

\subsubsection{2-D Gel Experimental Design 3}

Y88 ${ }^{\mathrm{T}}$ samples for each 2-D DIGE experiment were cultivated in parallel $1 \mathrm{~L}$ bioreactor vessels in batch mode for $24 \mathrm{hr}$ and repeated three times to generate three independent samples for each set of growth conditions representing the Fix off and Fix on state of $\mathrm{Y}^{\mathrm{T}} 8^{\mathrm{T}}$ cells (see Table 2.2, Experimental Design 3). Two preparative and three analytical 2-D DIGE gels were generated (Fig. 2.5). Each preparative gel comprised pooled samples for the three replicates representing i) the Fix ${ }^{\text {off }}$ state of the cell at high growth, DOhigh with $\mathrm{pH}$ not controlled and ii) the Fix ${ }^{\text {on }}$ state of the cell state at high growth, DOlow with $\mathrm{pH}$ not controlled. The 2-D DIGE gels (Fig.2.5, B.1-B.3) contained three samples, two of them randomly selected and representing a different Fix on or Fix off state of the cell (Table 2.2, Experimental Design 3) with the third being a pooled sample of equal quantities of Fix ${ }^{\text {on }}$ and Fix ${ }^{\text {off }}$ samples representing the internal standard. The combination of samples for each of the two states of the cell plus the internal standard included per 2-D DIGE gel, allowed a comparison at the protein level of the physiological state of the cell at high growth $\left(\mathrm{OD}_{600}=2.0\right)$ under ammonium-depleted conditions at DOhigh and DOlow respectively with $\mathrm{pH}$ not controlled. Protein spots excised from the 2-D gels were processed as before (Section 2.3.1.1).

\subsubsection{2-D Gel Experimental Design 4}

${\mathrm{Y} 88^{\mathrm{T}}}$ samples for each 2-D DIGE experiment, were cultivated in parallel $1 \mathrm{~L}$ bioreactor vessels in batch mode and repeated three times to generate three independent samples for each set of growth conditions representing the Fix ${ }^{\text {off }}$ or Fix ${ }^{\text {on }}$ state of ${\mathrm{Y} 88^{\mathrm{T}}}^{\mathrm{T}}$ cells (see Table 2.2, Experimental Design 4). Four preparative and six analytical 2-D DIGE gels were generated (Fig. 2.6). Each preparative gel 

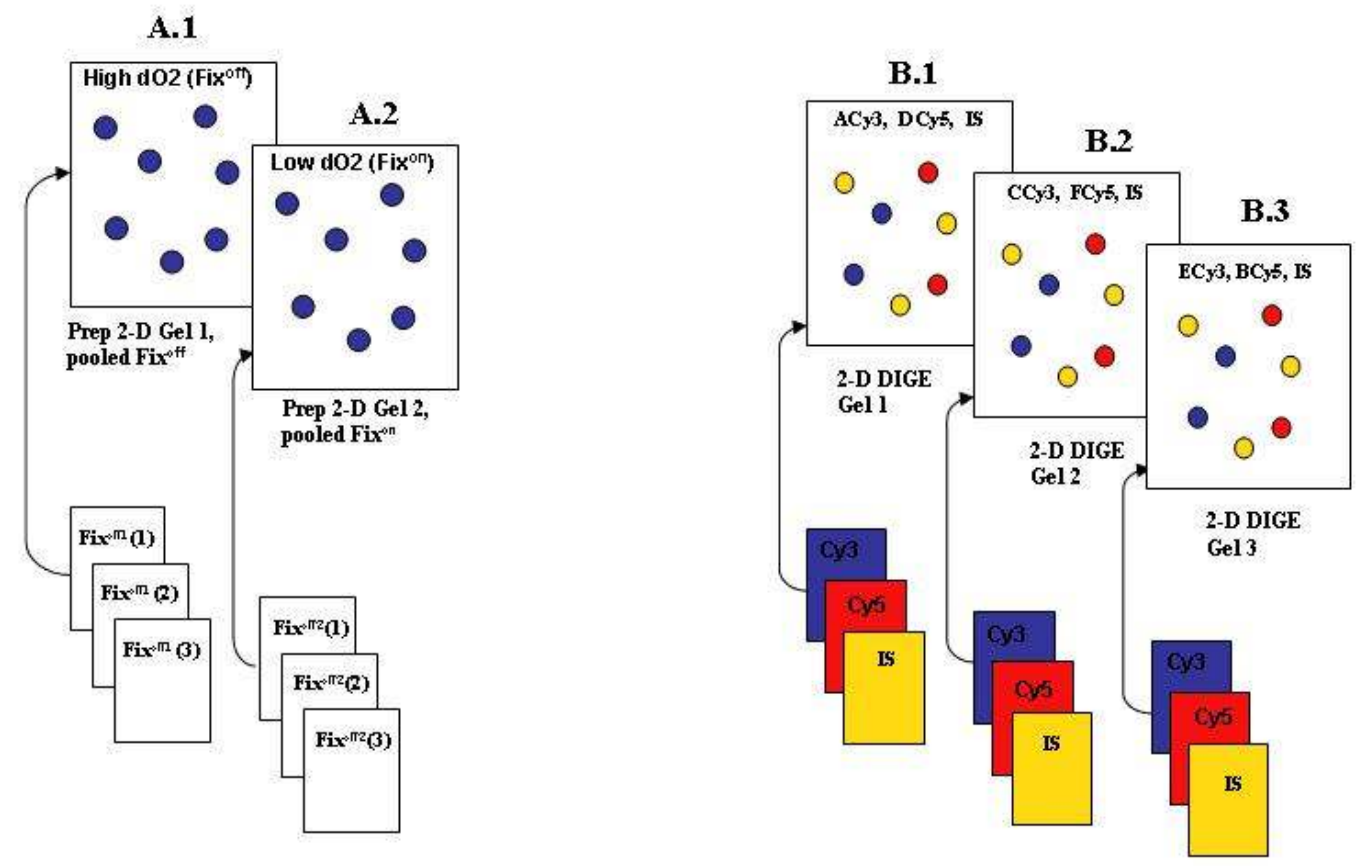

Figure 2.5. 2-D gel experimental design 3

(A) Preparative 2-D gels representing pooled replicate protein samples for $\mathrm{Y}^{8} 8^{\mathrm{T}}$ cells grown at DOhigh at an $\mathrm{OD}_{600}=2.0, \mathrm{pH}$ not controlled (Fix ${ }^{\text {off }}$ ) (A.1) and $\mathrm{DO}^{\text {low }}$ at an $\mathrm{OD}_{600}=2.0, \mathrm{pH}$ not controlled (Fixon) (A.2); (B) 2-D DIGE gels representing combinations of protein samples comprising, per gel, one sample from DOhigh labeled with CyDye 3 and one from DOlow with CyDye 5. An internal standard representing equal quantities of each of the two samples was labeled with CyDye 2. Thus, for an experiment with two different conditions, 6 biological replicates were generated (3 for each condition) resulting in 3 (B.1-B.3) 2-D DIGE analytical gels and 2 preparative 2-D gels (A.1, A.2). 

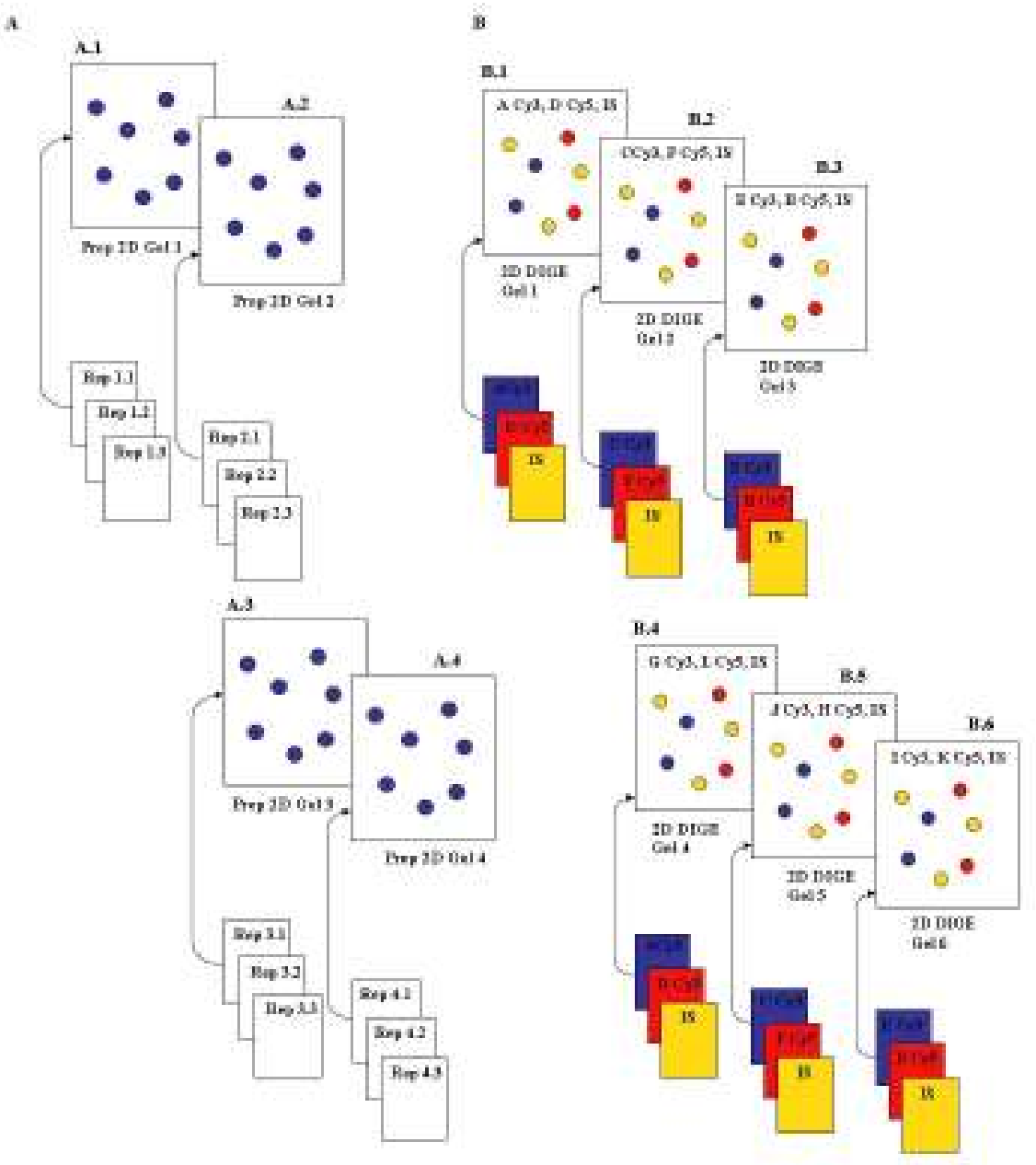

Figure 2.6. 2-D gel experimental design 4

(A) Preparative 2-D gels representing pooled replicate protein samples for $\mathrm{Y}^{8} 8^{\mathrm{T}}$ cells grown at DOhigh at an $\mathrm{OD}_{600}=0.5$ and 2.0, $\mathrm{pH}$ controlled (Fix ${ }^{\text {off }}$ state of the cells) (A.1) and DOlow at an $\mathrm{OD}_{600}=0.5$ and 2.0, $\mathrm{pH}$ controlled (Fix ${ }^{\text {on }}$ state of the cells) (A.1) and a second gel representing pooled replicate protein samples for the second state of the cells (A.2); (B) 2-D DIGE gels representing combinations of protein samples comprising, per gel, one sample (cell lysate) labeled with CyDye 3 and the other with CyDye 5 for each of the two states of the cell and an internal standard, labeled with CyDye 2. Thus, for an experiment with two different conditions, 6 biological replicates were generated (3 for each condition) resulting in 3 (B.1-B.3) 2-D DIGE gels and 2 preparative 2-D gels (A.1, A.2). For an experiment with 4 different conditions, 12 biological replicates were generated (3 for each condition) resulting in 6 (B.1-B.6) 2-D DIGE analytical gels and 4 (A.1-A.4) preparative 2-D gels. 
comprised pooled samples for the three replicates representing i) the Fix ${ }^{\text {off }}$ state of the cell at low growth, DOhigh with $\mathrm{pH}$ controlled and ii) the Fix ${ }^{\text {off }}$ state of the cell at high growth, DOhigh with $\mathrm{pH}$ controlled, iii) the Fix ${ }^{\text {off }}$ state of the cell at low growth, $\mathrm{DO}^{\text {low }}$ with $\mathrm{pH}$ controlled and iv) the Fix on state of the cell state at high growth, DOlow with $\mathrm{pH}$ controlled. Each 2-D DIGE gel (Fig.2.6, B.1-B.6) contained three samples, two of them randomly selected and representing a different Fix on or Fix ${ }^{\text {off }}$ state of the cell (Table 2.2, Experimental Design 4) with the third being a pooled sample of equal quantities of Fix on and Fix ${ }^{\text {off }}$ samples representing the internal standard. The combination of samples for each of the two states of the cell plus the internal standard included per 2-D DIGE gel, allowed a comparison at the protein level between the physiological state of the cell at low (ammonium-supplemented) and high (ammonium-depleted) growth at DOhigh and the physiological state of the cell at low (ammoniumsupplemented) and high (ammonium-depleted) growth at DOlow respectively with $\mathrm{pH}$ controlled. Protein spots excised from the 2-D gels were processed as before (Section 2.3.1.1).

\subsubsection{Sample preparation}

Care was taken to minimise differences between samples due to handling and preparation, ensuring consistency across all experiments for all conditions tested. For all proteomic analyses, $\mathrm{Y} 88^{\mathrm{T}}$ cell cultures were grown to a predetermined $\mathrm{OD}_{600}$ according to the experimental design in either batch flasks or bioreactors and harvested, using a $60 \mathrm{~cm}^{3}$ syringe attached to a sampling port. Particular care was taken to minimise the formation of air bubbles that could potentially introduce a bias for the $\mathrm{DO}^{\text {low }}$ or DOhigh oxygen results. Following harvesting, all samples were immediately incubated on ice and processed directly. At least $120 \mathrm{~mL}$ of culture for each protein sample was centrifuged at $1814 \times \mathrm{g}, 4{ }^{\circ} \mathrm{C}$, for $30 \mathrm{~min}$. Most of the spent medium was decanted, leaving behind approximately $1 \mathrm{~mL}$ of medium to resuspend the cells and facilitate transfer to $1.5 \mathrm{~mL}$ microcentrifuge tubes. Microcentrifuge tubes were tared and weighed before transferring the cells to the tubes. The cells were again centrifuged, this time in a microcentrifuge at 15,682 $\times \mathrm{g}$ and any 54 
remaining spent medium was removed with a pipetter, leaving only the cell pellet. Cell pellets were stored at $-20{ }^{\circ} \mathrm{C}$ until further processing for protein extraction.

\subsubsection{Protein extraction}

Total cellular protein was extracted using a CelLytic B Plus Kit (Sigma), known to be particularly useful in lysing Gram-negative bacteria. The kit contained a proprietary bacterial lysis reagent plus lysozyme, benzoase (an exogenous nuclease to minimise nucleic acid contamination in the protein extract) and a protease inhibitor cocktail (Sigma) to prevent the proteolytic breakdown of proteins. A minimum of $0.5 \mathrm{~g}$ (wet weight) per sample, equivalent to approximately 0.2-0.3 $\mathrm{g}$ (dry weight) of $\mathrm{Y}^{\mathrm{C}} 8^{\mathrm{T}}$ cells, was required when using the protein extraction CelLytic B Plus Kit to ensure sufficient protein for downstream analyses. This criterion was achieved by growing a $500 \mathrm{~mL}$ culture to an $\mathrm{OD}_{600}$ of greater than 0.5 , then centrifuging $60 \mathrm{~mL}$ of the culture per sample to obtain a cell pellet of approximately $0.5 \mathrm{~g}$. Since three replicates for each experimental condition were generated from growing cells in triplicate flasks, three independent protein samples were obtained for each condition being tested. A working solution comprising the bacterial lysis reagent $(5 \mathrm{~mL})$, lysozyme $(0.1 \mathrm{~mL})$, protease inhibitors $(0.05 \mathrm{~mL})$ and benzoase $(0.76 \mu \mathrm{L}=250$

units) was used to resuspend the cell pellet $(0.4 \mathrm{~mL}$ of working solution per 0.5 $\mathrm{g}$ cell pellet). The suspension was briefly vortexed (approximately $10 \mathrm{sec}$ ) and then mixed by repeatedly inverting for $10 \mathrm{~min}$ to ensure full extraction of the soluble proteins. The cell lysate was centrifuged at $15,682 \times \mathrm{g}, 4{ }^{\circ} \mathrm{C}$, for $5 \mathrm{~min}$ to pellet any insoluble material. The soluble proteins were transferred to a new microcentrifuge tube and the protein concentration for each extract was determined. Protein extracts were stored at $-20{ }^{\circ} \mathrm{C}$ until required for further protein analysis. 


\subsubsection{Protein quantitation}

\subsubsection{BCA protein assay}

All protein quantitation was carried out using the Bicinchoninic acid (BCA) kit (Pierce, Rockford). BCA is a stable and sensitive reagent that is highly specific for the detection of cuprous ion $\left(\mathrm{Cu}^{+}\right)$. When incubated with protein, a $\mathrm{Cu}^{2+}$ protein complex is formed which is reduced to $\mathrm{Cu}^{+}$under alkaline conditions. The reduction of $\mathrm{Cu}^{2+}$ to $\mathrm{Cu}^{+}$depends on the amount of protein present with more protein resulting in more $\mathrm{Cu}^{+}$being produced. A purple colour develops as a result of the chelation of one $\mathrm{Cu}^{+}$ion with two molecules of BCA. This $\mathrm{Cu}^{+} / \mathrm{BCA}$ complex is water soluble and exhibits a strong absorbance maximum at $562 \mathrm{~nm}$.

To quantitate the protein, a bovine serum albumin (BSA) standard curve was created for comparison to the experimental samples. BSA was diluted according to the manufacturer's instructions to give nine standards of varying BSA concentrations. Ten $\mu \mathrm{L}$ of each BSA standard was mixed with $190 \mu \mathrm{L}$ of BCA working solution made up as a 50:1 ratio of BCA to copper solution and incubated at $30{ }^{\circ} \mathrm{C}$ for $1 \mathrm{hr}$ alongside the experimental protein samples. The experimental protein samples were measured by diluting an aliquot of extracted protein five-fold, and then mixing $10 \mu \mathrm{L}$ of this diluted sample with $190 \mu \mathrm{L}$ BCA working solution. Following incubation, the absorbances were measured at $562 \mathrm{~nm}$ using a PC-controlled GBC spectrophotometer (model UV/VIS918). BSA concentrations were plotted with $A_{562}$ values to generate the standard curve and concentrations of the experimental samples were derived from this.

\subsubsection{Gel electrophoresis}

\subsubsection{Assessment of protein by 1-D SDS-PAGE}

An XCell Surelock ${ }^{\mathrm{TM}}$ Mini-Cell NuPAGE gel apparatus (Invitrogen, Carlsbad, CA) was used for 1-D SDS-PAGE of protein extracts to assess both the quality 
and quantity of the protein, as well as to gain a preliminary insight into any potential altered abundance in protein between growth conditions. Protein extracts were diluted four-fold ( $5 \mu \mathrm{L}$ of protein in $20 \mu \mathrm{L}$ of $\mathrm{MQ} \mathrm{H} \mathrm{H}_{2} \mathrm{O}$ ) and $20 \mu \mathrm{L}$ of the diluted extract was mixed with $20 \mu \mathrm{L}$ of $2 \times$ concentration reduced sample running buffer (100 mM DTT, $80 \mathrm{mM}$ Tris- $\mathrm{HCl} \mathrm{pH}$ 6.8, 2\% SDS, 10\% glycerol, bromophenol blue solution, made up to $25 \mathrm{~mL} \mathrm{MQ} \mathrm{H}_{2} \mathrm{O}$ ) to give a final concentration of $1 \times$ reduced sample running buffer. Aliquots of $0.5 \mathrm{~mL}$ were stored at $-20^{\circ} \mathrm{C}$. Five $\mu \mathrm{L}$ aliquots were electrophoresed at $200 \mathrm{~V}$ and $400 \mathrm{~mA}$ for 35 min. Protein separation was carried out using 10\% Novex pre-cast gels $(1.00$ $\mathrm{mm} \times 15$ wells) in $800 \mathrm{~mL}$ of $1 \times$ MES (diluted from a $20 \times$ stock solution $(50 \mathrm{mM}$ MES, $50 \mathrm{mM}$ Tris base, 0.1\% SDS, $1 \mathrm{mM}$ EDTA in $1000 \mathrm{~mL} \mathrm{MQ} \mathrm{H}_{2} \mathrm{O}$ ) running buffer. An unstained standard protein marker, Mark12 ${ }^{\mathrm{TM}}$ (Invitrogen), was used to estimate the molecular weights of the separated proteins.

\subsubsection{Gel washing, staining and destaining of 1-D gels}

Following electrophoresis, gels were removed from the gel cassettes and briefly rinsed in $\mathrm{MQ} \mathrm{H}_{2} \mathrm{O}$. Gels were then fixed in a solution of $40 \%$ acetic acid and $10 \%$ methanol in $\mathrm{MQ} \mathrm{H}_{2} \mathrm{O}$ for at least $15 \mathrm{~min}$. After rinsing twice in $\mathrm{MQ} \mathrm{H}_{2} \mathrm{O}$ for 2 min per rinse, gels were stained in colloidal Coomassie Brilliant Blue stain (Fluka; Sigma-Aldrich Group) which is an anionic triphenylmethane dye that binds noncovalently to the lysyl residues of proteins and has a detection limit of about one microgram of protein per spot. Any dye that is not bound to protein diffuses out of the gel during the destaining process. A $5 \% \mathrm{w} / \mathrm{v}$ stock solution of Coomassie Brilliant Blue G-250 (Fluka; Sigma-Aldrich Group) was used to make up a staining solution containing $10 \% \mathrm{w} / \mathrm{v} \quad\left(\mathrm{NH}_{4}\right)_{2} \mathrm{SO}_{4}, 1 \% \mathrm{v} / \mathrm{v}$ phosphoric acid and $2 \% \mathrm{v} / \mathrm{v}$ Coomassie Blue stock solution. All gels were incubated at room temperature in the stain solution on an orbital shaker at 40 rpm overnight. Gels were destained in $\mathrm{MQ} \mathrm{H}_{2} \mathrm{O}$ to remove excess stain and then photographed using a Canon EOS SLR digital camera. Gel images were saved as JPG files. 


\subsubsection{2-DE}

\subsection{Preparative gel sample preparation}

Protein in microbial extracts was precipitated with nine volumes of cold $100 \%$ acetone at $-20^{\circ} \mathrm{C}$ for a minimum of $2 \mathrm{hr}$. Precipitated protein was collected by centrifugation at $15,682 \times \mathrm{g}$ for $20 \mathrm{~min}$ at $4{ }^{\circ} \mathrm{C}$. The acetone was removed by decanting carefully and the pellet left to air dry for approximately $10 \mathrm{~min}$ at room temperature.

\subsection{Sample rehydration and loading onto IPG strip}

Protein (50 $\mu \mathrm{g}$ per sample) from three pooled technical replicates was resolubilised in rehydration buffer (2 $\mathrm{M}$ thiourea, $7 \mathrm{M}$ urea, 2\% (v/v) IPG buffer, $2 \%(\mathrm{w} / \mathrm{v})$ DTT, $4 \%(\mathrm{w} / \mathrm{v})$ CHAPS and a trace of bromophenol blue for pH 4-7 IPG strips; $2 \mathrm{M}$ thiourea, $7 \mathrm{M}$ urea, 1\% (v/v) IPG buffer (v/v), 2.5\% $(\mathrm{w} / \mathrm{v})$ DTT, 2\% (w/v) CHAPS, 5\% (v/v) glycerol, $10 \%(\mathrm{v} / \mathrm{v})$ isopropanol in $\mathrm{MQ} \mathrm{H}_{2} \mathrm{O}$ for $\mathrm{pH}$ 6-11 IPG strips) to a final volume of $125 \mu \mathrm{L}$ and incubated for $15 \mathrm{~min}$ at room temperature. Each sample was then centrifuged for $1 \mathrm{~min}$ at $15,682 \times \mathrm{g}$ to remove the insoluble material, and loaded onto either an Immobiline ${ }^{\mathrm{TM}}$ DryStrip (linear gradient) $7 \mathrm{~cm} \mathrm{pH} \mathrm{3-10,} \mathrm{pH} 4-7$ or $\mathrm{pH}$ 6-11 strip (GE Healthcare, Uppsala, Sweden) according to the experimental design. The sample was distributed across the length of the gel strip. Gel strips were placed gel side down in an Immobiline ${ }^{\mathrm{TM}}$ Drystrip Reswelling Tray (GE Healthcare, Uppsala, Sweden) with each gel strip covered with $3 \mathrm{~mL}$ of PlusOne DryStrip Cover Oil (GE Healthcare, Uppsala, Sweden). The gel strips were incubated overnight at room temperature.

\subsubsection{2-D DIGE}

\subsection{Sample preparation}

Protein in microbial extracts was precipitated with nine volumes of cold $100 \%$ acetone at $-20^{\circ} \mathrm{C}$ for a minimum of $2 \mathrm{hr}$. Precipitated protein was collected by centrifugation at $15,682 \times \mathrm{g}$ for $20 \mathrm{~min}$ at $4{ }^{\circ} \mathrm{C}$. The acetone was removed by decanting carefully and the pellet left to air dry for approximately $10 \mathrm{~min}$ at 
room temperature. The pellet was then solubilised in $2 \mu \mathrm{L}$ cell lysis buffer (30 mM Tris-Cl, $7 \mathrm{M}$ urea, $2 \mathrm{M}$ thiourea, $4 \%$ (w/v) CHAPS in MQ $\mathrm{H}_{2} \mathrm{O}$ ) to a final volume of $5 \mu \mathrm{g}$ protein $/ \mu \mathrm{L}$, providing $10 \mu \mathrm{g}$ total protein per sample required for each 2-D DIGE gel. The $\mathrm{pH}$ of each sample was tested to ensure a final $\mathrm{pH}$ after addition of lysis buffer of 7.5-8.5.

\subsection{Sample labeling}

Protein extracts were labeled for DIGE analysis using an Ettan DIGE minimal labeling kit (CyDye ${ }^{\mathrm{TM}}$ DIGE Fluor minimal dye) according to the manufacturer instructions (GE Healthcare, Uppsala, Sweden). Minimal labeling is stated to react with a single lysine per protein molecule (Marouga et al., 2005). CyDyes were reconstituted in dimethylformamide to a final concentration of $1 \mathrm{mM}$ working CyDye Fluor solution. Ten $\mu$ g protein per sample was labeled with 80 pmol of working CyDye Fluor solution, briefly vortexed (10 sec) and centrifuged for $5 \mathrm{sec}$ in a microcentrifuge to ensure collection of the solution at the bottom of the tube. Samples were incubated on ice for $30 \mathrm{~min}$ in the dark to minimise degradation and photo-bleaching of fluorescence dyes. Following incubation on ice, $1 \mu \mathrm{L}$ of $10 \mathrm{mM}$ lysine was added to each sample to stop the reaction. The solution was mixed well, centrifuged briefly (5 sec) and incubated on ice for $10 \mathrm{~min}$ in the dark.

\subsection{Sample mixing and loading onto IPG strip}

Each set of samples was loaded onto an IPG strip as determined by the experimental design (Fig. 2.1) following resolubilisation in rehydration buffer (see section 2.3.5.3.2). A total of $30 \mu \mathrm{g}$ protein $(10 \mu \mathrm{g}$ for each of two cell states and $10 \mu \mathrm{g}$ for the internal standard) was loaded per strip. To estimate the variability in sample handling, sample loading as well as the inherent variability in carrying out the 2-D DIGE technique, one sample was labeled with all three CyDyes (Cy2, Cy3 and Cy 5) separately. These were loaded onto one IPG strip. Initially, the $\mathrm{pH}$ 3-10 range was chosen to obtain an overview of total protein distribution. Subsequently, narrower 4-7 and 6-11 $\mathrm{pH}$ range strips were used to increase resolution of the protein spots on the gels, providing a 
more detailed overview of acidic $(\mathrm{pH} 4-7)$ and basic $(\mathrm{pH}$ 6-11) protein distribution.

\subsection{Sample rehydration}

Rehydration of protein samples were carried out as before (see section 2.3.5.3.2) and samples loaded onto an Immobiline ${ }^{\mathrm{TM}}$ DryStrip (linear gradient) $7 \mathrm{~cm} \mathrm{pH}$ 3-10, pH 4-7 or pH 6-11 strip (GE Healthcare, Uppsala, Sweden) as before according to the experimental design. The gel strips were incubated overnight at room temperature in the dark to minimise photo-bleaching of the fluorescence dyes.

\subsection{First dimension IEF}

After gel strip rehydration, each sample was subjected to IEF using either an IPGPhorTM IEF Unit ( $\mathrm{pH}$ 3-10, $\mathrm{pH}$ 4-7) or a Multiphor ${ }^{\mathrm{TM}}$ II Flatbed Electrophoresis Unit ( $\mathrm{pH}$ 6-11) according to manufacturer's (GE Healthcare, Uppsala, Sweden) recommended protocols (Table 2.3). During focusing of the IPG strips, the gel strips were protected from light by placing aluminium foil on the outside of the apparatus to minimise photo-bleaching of the fluorescence dyes. The same practice was applied to the buffer tank during SDS-PAGE.

\subsection{Protein Reduction}

On completion of IEF, each gel strip was placed in a reduction buffer $(50 \mathrm{mM}$ Tris, $6 \mathrm{M}$ urea, 30\% (v/v) glycerol, 2\% (w/v) SDS, 10 \% DTT in MQ $\mathrm{H}_{2} \mathrm{O}$ ) for 15 min to reduce protein disulfides to dithiols. Fifteen $\mathrm{mL}$ Falcon tubes (covered in aluminium foil to protect the gel strips from light and to minimise photobleaching of the fluorescence dyes) containing $10 \mathrm{~mL}$ of reduction buffer were used per gel strip and the tubes were placed on a rocker at room temperature to undergo reduction for $15 \mathrm{~min}$. Following reduction, the gel strips were removed 


\begin{tabular}{|c|c|c|c|c|c|c|c|}
\hline \multicolumn{4}{|c|}{ pH 3-10, pH 4-7 } & \multicolumn{4}{|c|}{ pH 6-11 } \\
\hline Step & Type & Voltage & Time (min) & Step & Type & Voltage & Time (min) \\
\hline 1 & Step and hold & $300 \mathrm{~V}$ & 30 & 1 & Gradient & 200 & 0.01 \\
\hline 2 & Gradient & $1000 \mathrm{~V}$ & 30 & 2 & Gradient & 3500 & 90 \\
\hline 3 & Gradient & $5000 \mathrm{~V}$ & 90 & 3 & Gradient & 3500 & 65 \\
\hline 4 & Step and hold & $5000 \mathrm{~V}$ & 25 & & & & \\
\hline
\end{tabular}

Table 2.3. Protocols for first dimension IEF focusing of protein

Protocols for first dimension IEF focusing of protein using IPG strips in the linear gradient $\mathrm{pH}$ 3-10 and $\mathrm{pH}$ 4-7 range on the IPGPhorTM IEF Unit and IPG strips in the linear gradient pH 6-11 range on the Multiphor ${ }^{\mathrm{TM}}$ II Flatbed Electrophoresis Unit (temperature $=10{ }^{\circ} \mathrm{C}$, current $=2 \mathrm{~mA}$, power $=5 \mathrm{~W})$. 
from the tubes and excess buffer was drained off each gel strip by turning each one on its side for all sides of the strip, blotting the edges on a lint-free laboratory wipe.

\subsection{Protein Alkylation}

After reduction, each gel strip was transferred to an alkylation buffer $(50 \mathrm{mM}$ Tris, $6 \mathrm{M}$ urea, 30\% (v/v) glycerol, 2\% (w/v) SDS, 2\% (w/v) iodoacetamide in $\mathrm{MQ} \mathrm{H}_{2} \mathrm{O}$ ) for $15 \mathrm{~min}$. Alkylation of the free cysteine thiols in the protein prevents disulfide bridges from reforming. Fifteen $\mathrm{mL}$ Falcon tubes were covered in aluminium foil to protect the gel strips from light so as to minimise photo-bleaching of the fluorescent dyes as well as to prevent degradation of the light-sensitive IAA. Each tube contained $10 \mathrm{~mL}$ of alkylation buffer per gel strip and the tubes were placed on a rocker to incubate at room temperature during alkylation.

\subsection{Second dimension protein separation}

The protein on each strip was subjected to second dimension separation in an XCell Surelock ${ }^{\mathrm{TM}}$ Mini-Cell NuPAGE gel apparatus (Invitrogen, Carlsbad, CA). Electrophoresis was carried out on each focused strip using 10\% Bis-Tris NuPAGE gels (Invitrogen, Carlsbad, CA), at $200 \mathrm{~V}, 400 \mathrm{~mA}$ constant for $1 \mathrm{hr}$ in $800 \mathrm{~mL}$ of running buffer ( $1 \times$ MOPS). Five hundred $\mu \mathrm{L}$ antioxidant (Invitrogen) was added to the upper chamber of the gel apparatus to maintain the protein in the reduced state during electrophoresis.

\subsubsection{Gel image acquisition}

Electrophoresed gels were rinsed in $\mathrm{MQ} \mathrm{H}_{2} \mathrm{O}$ and scanned using a Fuji FLA5000 Imaging System (FUJIFILM, Life Science). Each fluorescence dye was consecutively excited to avoid fluorescence "crosstalk" and scanned with the appropriate filter (Cy2, $473 \mathrm{~nm}$; Cy3, $520 \mathrm{~nm}$; Cy5, $600 \mathrm{~nm}$ ). After scanning, each gel image was analysed using the ImageQuant ${ }^{\mathrm{TM}}$ image analysis software (ImageQuant v5.2, Amersham Biosciences) to determine the limit of detection and the linear dynamic range. The volume review tool was used to determine 
whether the image exceeded or was below the linear dynamic range (Max. Val $>50,000)$. A lower or higher photomultiplier tube setting was selected to bring all the protein spots within the linear range where required.

\subsubsection{Gel Image analysis}

DeCyder 2-D image analysis software (ImageQuant v5.2, Amersham Biosciences) was used for all gel analyses. Gel images were aligned and cut to the region of interest using ImageQuant v5.2 Tools. Thereafter, each gel image was analysed using the DeCyder DIGE Differential In-gel Analysis (DIA) interface software (ImageQuant v5.2, Amersham Biosciences) with the optimal settings for spot detection and exclusion (estimated spot number set to 2500 spots). The selected parameters for spot detection and exclusion were also applied to the DeCyder DIGE Batch Processor (ImageQuant v5.2, Amersham Biosciences). All gels in a batch were processed and analysed under the same parameters and automatically matched. Individual protein patterns were assigned to groups dependent on the conditions they were representing as dictated by the experimental design.

Following batch processing of the gels, the complete batch was loaded into the DeCyder Biological Variation Analysis (BVA) software (ImageQuant v5.2, Amersham Biosciences). This software matches the different gel images across groups and provides statistical data on differential protein abundance levels between groups. Mismatches within the analysis were corrected manually by setting landmarks and adding spot matches. The groups of gels that had been assigned in the batch processor were compared and statistical $t$-test values were calculated. The obtained data were filtered according to the parameter set, with a threshold factor of two between the groups, a $t$-test value i) $p<0.01$ and the spot detected in at least $99 \%$ of the analysed protein patterns and (ii) $p<0.05$ and the spot detected in at least $95 \%$ of the analysed protein patterns. Despite this critical selection, each difference that was detected was further manually checked and where required, spots were rematched. All confirmed spots were marked and the gel image was captured in a screen shot. Analytical spot data, 
e.g. $t$-test values and the average ratios of the differences computed, were exported to a Microsoft Excel file together with the master numbers of the spots.

\subsubsection{Staining 2-D DIGE gels}

Electrophoresed preparative gels were rinsed briefly with $\mathrm{MQ} \mathrm{H}_{2} \mathrm{O}$ and soaked separately in fixative $(5 \%(\mathrm{v} / \mathrm{v})$ ethanol, $3 \%(\mathrm{v} / \mathrm{v})$ phosphoric acid) for at least one $\mathrm{hr}$, following which they were stained with Coomassie Brilliant Blue G-250 (Fluka; Sigma-Aldrich Group). Each gel was then separately washed three times for 30 min periods in $\mathrm{MQ} \mathrm{H}_{2} \mathrm{O}$. Following washing, each gel was separately stained by saturating with dye solution $\left(17 \%\right.$ (w/v) $\mathrm{NH}_{4} \mathrm{SO}_{4}, 34 \%$ (v/v) $\mathrm{MeOH}$, $3 \%(\mathrm{v} / \mathrm{v})$ phosphoric acid) and soaking the gel for at least one hr in this solution. After one hr of soaking, 0.06\% (w/v) Coomassie Brilliant Blue G-250 (Fluka; Sigma-Aldrich Group) was added and the gels were stained for 3-4 days.

\subsubsection{Protein spot picking}

Coomassie-stained protein spots were manually excised from the gels using a manual One Touch Plus Spot Picker (1.5 mm diameter, The Gel Company, San Francisco, California) and transferred to a sterile 96 Well V Bottom Polypropylene plate (Greiner Bio-One, Germany). Each gel spot corresponding to the particular spot number on a master gel (that was automatically assigned to the spot map with the highest number of detected spots) was recorded. Spot numbers were determined in the batch processor during batch analysis of the gel images.

\subsubsection{Protein preparation for LC-MS/MS analysis}

The protein in each spot was prepared for mass spectrometric analysis using the procedure as detailed in the remainder of this section.

\subsubsection{Destaining of excised gel spots}

All excised gel spots were washed twice in $100 \mu \mathrm{L}$ of $\mathrm{MQ} \mathrm{H}_{2} \mathrm{O}$ and destained by washing three times in $200 \mu \mathrm{L}$ of $50 \mathrm{mM} \mathrm{NH}_{4} \mathrm{HCO}_{3} / \mathrm{ACN}(1: 1)$ at $2 \mathrm{hr}$ intervals. 
Following dehydration, the gel pieces were rehydrated twice in $100 \mu \mathrm{L}$ ACN for $10 \mathrm{~min}$ at a time and then air dried in the laminar flow hood for $1 \mathrm{hr}$.

\subsubsection{In-gel reduction and alkylation of protein prior to LC-MS/MS analysis}

Once the gel pieces were destained, the protein in the gel pieces was reduced to ensure that all monothiols were maintained in a reduced state for tandem mass spectrometric analysis. To achieve reduction, approximately $10 \mu \mathrm{L}$ of $10 \mathrm{mM}$ DTT (enough to cover the gel piece containing a protein spot) was made up to a final concentration of $0.1 \mathrm{M} \mathrm{NH}_{4} \mathrm{HCO}_{3}$ and added to each well containing one gel spot. The gel pieces were then incubated at $56{ }^{\circ} \mathrm{C}$ for $30 \mathrm{~min}$. Following incubation, the samples were briefly centrifuged and excess liquid was removed by aspirating with a pipetter. Ten $\mu \mathrm{L}$ of $\mathrm{ACN}$ was then added to each well to shrink the gel piece. The gel pieces were centrifuged and the liquid was removed by aspirating with a pipetter. The gel pieces were dried in a vacuum centrifuge (Heraeus, Hanau, Germany) following which $50 \mu \mathrm{L}$ of $55 \mathrm{mM}$ iodoacetamide in a final concentration of $0.1 \mathrm{M} \mathrm{NH}_{4} \mathrm{HCO}_{3}$ was added to reswell the gel pieces. The gel pieces were incubated in the dark at room temperature for $20 \mathrm{~min}$. Following alkylation, the iodoacetamide solution was removed by aspirating with a pipetter and the gel pieces were then washed in 150-200 $\mu \mathrm{L}$ of $0.1 \mathrm{M}$ of $\mathrm{NH}_{4} \mathrm{HCO}_{3}$ for 15 min and centrifuged. The liquid was removed before adding $50 \mu \mathrm{L}$ of $\mathrm{ACN}$ to the gel pieces to shrink them. They were then centrifuged again, the liquid was removed by aspirating with a pipetter and the gel pieces dried in a vacuum centrifuge (Heraeus, Hanau, Germany).

\subsubsection{In-gel enzymatic digestion of protein}

The dried gel pieces were rehydrated in $2 \mu \mathrm{L}(12.5 \mathrm{ng} / \mu \mathrm{L})$ trypsin $(2.5 \mu \mathrm{g}$ of trypsin Modified Sequencing grade (Roche, Mannheim, Germany) in $50 \mu \mathrm{L}$ of $50 \mathrm{mM} \mathrm{NH} \mathrm{NHCO}_{3}$ ). An additional $10 \mu \mathrm{L}$ of $50 \mathrm{mM} \mathrm{NH}_{4} \mathrm{HCO}_{3}$ without trypsin was then added to the gel pieces and incubated on ice for approximately $1 \mathrm{hr}$. Once all the trypsin solution had been absorbed by the gel pieces, an additional $15 \mu \mathrm{L}$ of the same buffer $\left(50 \mathrm{mM} \mathrm{NH}_{4} \mathrm{HCO}_{3}\right.$ without trypsin) was added to 
maintain swelling of the gel during enzymatic digestion so that the trypsin could have maximum access to the protein. Digestion was carried out overnight in a $37^{\circ} \mathrm{C}$ water bath.

\subsubsection{Extraction of peptides following protein digestion}

Following overnight enzymatic digestion of the protein, $30 \mu \mathrm{L}$ of $25 \mathrm{mM}$ $\mathrm{NH}_{4} \mathrm{HCO}_{3}$ was added to the gel pieces and incubated in a $37^{\circ} \mathrm{C}$ water bath for 2 hr with shaking. The liquid was then transferred to a microcentrifuge tube (1 microfuge tube per sample well) to pool with all liquid subsequently collected from the corresponding well. To ensure maximum recovery of the digested peptides, enough ACN (1-2 times the volumes of the gel pieces) was added to the gel pieces and again incubated in a $37^{\circ} \mathrm{C}$ water bath for $1 \mathrm{hr}$ with shaking. All liquid was again transferred from the well to the corresponding microcentrifuge tube ( 1 per sample well) to pool with the previously collected liquid. Thereafter, approximately $40-50 \mu \mathrm{L}$ of $5 \%$ (v/v) formic acid was added to each well and was incubated for $2-3 \mathrm{hr}$ with shaking in a $37^{\circ} \mathrm{C}$ water bath. The liquid was transferred as before from the well to the corresponding microcentrifuge tube, pooling with the liquid previously collected. An additional quantity of ACN (1-2 times the volumes of the gel pieces) was again added to the gel pieces in the wells and incubated in a $37^{\circ} \mathrm{C}$ water bath for 30 min to $1 \mathrm{hr}$ with shaking. The liquid was then collected and transferred to the corresponding microcentrifuge tube (1 per sample well) and pooled with all previously collected liquid. All pooled extracts were dried to approximately 5 $\mu \mathrm{L}$ in a vacuum centrifuge.

\subsubsection{5 $\mathrm{C}_{18}$ membrane binding of peptides for reversed phase LC-MS/MS}

ZipTip $\mathrm{C}_{18}$ pipette tips (Millipore), appropriate for peptides and low molecular weight proteins, contain $\mathrm{C}_{18}$ beads that hydrophobically bind peptides via hydrophobic interactions. Maximum binding occurs in the presence of TFA $(0.1 \%(\mathrm{v} / \mathrm{v})$ or other ion-pairing agents. The binding of peptides to the membrane and subsequent elution of the peptides allows maximal recovery of peptides for MS analysis. The pooled, lyophilised peptide extracts for each 
sample (section 2.5.4) were resuspended in $10 \mu \mathrm{L}$ of $0.25 \%$ (v/v) TFA. Each Zip Tip $\mathrm{C}_{18}$ was then pre-wet with $0.25 \%(\mathrm{v} / \mathrm{v})$ TFA/50\% ACN by gently aspirating twice. After pre-wetting, each Zip Tip $C_{18}$ was equilibrated with $0.25 \%$ TFA by aspirating gently three times. To effect binding of peptides to the $\mathrm{C}_{18}$ beads, the pooled peptide extracts were gently aspirated repeatedly (30 times per sample). Once the peptides were bound, the Zip Tip $\mathrm{C}_{18}$ was rinsed with $0.25 \%$ TFA by again gently aspirating three times. To ensure efficient elution of peptides from the membrane, the peptides for each sample were eluted in $0.1 \%(\mathrm{v} / \mathrm{v})$ formic acid in 70\% ACN by aspirating 25 times. The eluted peptides were either stored at $-20{ }^{\circ} \mathrm{C}$ for later analysis or they were directly prepared for MS analysis. In either case, just prior to LC-MS/MS analysis, the peptides in each sample were diluted with $2 \%(\mathrm{v} / \mathrm{v})$ ACN, $0.1 \%(\mathrm{v} / \mathrm{v})$ formic acid to a final volume of $60 \mu \mathrm{L}$ for the $5 \mu \mathrm{L}$ sample loop. Each $60 \mu \mathrm{L}$ sample was transferred to a sample vial and loaded onto the carousel of the tandem MS for MS data acquisition.

\subsubsection{LC-MS/MS}

\subsubsection{Instrumentation}

A Dionex UltiMate 3000 LC system and a Thermo Finnigan LTQ mass spectrometer equipped with a nanospray ion source were used for all peptide analyses. The analytical column used was a $75 \mu \mathrm{m} \times 15 \mathrm{~cm}$ PepMap C18 (3 $\mu \mathrm{m}$, $300 \AA$, Dionex) with a constant flow rate of $200 \mathrm{~nL} / \mathrm{min}$. The following Merck (Merck Ltd.USA) HPLC grade solvents were used: $0.1 \%$ (v/v) formic acid (solvent A) ; 0.1\% (v/v) formic acid in 80\% (v/v) ACN (solvent B): 0\% - 20\% solvent B for $20 \mathrm{~min}$; $20 \%$ - 55\% solvent B for $40 \mathrm{~min}$; $55 \%$ - 100\% solvent B for 5 min; $100 \%$ solvent B for $5 \mathrm{~min} ; 100 \%$ to $0 \%$ solvent B for $2 \mathrm{~min}$. The LTQ was operated in data-dependent tandem MS mode where the three most abundant precursor ions detected in a single MS scan from m/z 400 to m/z 2000 were dynamically selected for subsequent MS/MS scans with the collisional energy set to $35 \%$, simultaneously incorporating the dynamic exclusion option to prevent re-acquisition of MS/MS spectra of the same peptides. 


\subsubsection{Data analysis and protein identification}

All acquired MS and MS/MS data were interpreted using MASCOT (Matrix Science, London, UK). The public database initially utilised was downloaded from the National Center for Biotechnology Information (http://www.ncbi.nlm.nih.gov/, 26/03/2007, Bacteria (Eubacteria), 4761919 sequences, 164309855 residues). Once the $\mathrm{Y}^{\mathrm{T}} 8^{\mathrm{T}}$ genome was sequenced, a $\mathrm{Y}^{\mathrm{T}}$ database was created in-house using ORF translated protein sequences. Since at the time of writing approximately $99 \%$ of the $\mathrm{Y}^{\mathrm{T}} 8^{\mathrm{T}}$ genome had been sequenced, all spectra were first searched against this ORF translated protein sequences database (Y88_ORFs 130208 (3912 sequences; 1254784 residues) and then repeated against the NCBI database to maximise the opportunity of peptide matches to some proteins homologous to those that might not yet be found in the $\mathrm{Y}^{\mathrm{T}} \mathrm{T}$ database. Searches were also repeated for all spectra previously searched against NCBI prior to establishing the Y88 ${ }^{\mathrm{T}}$ database.

All searches were carried out using a peptide mass tolerance of $1.2 \mathrm{Da}$ and a fragment ion tolerance of $0.6 \mathrm{Da}$, allowing for a fixed modification of cysteine carbamidomethylation and a variable modification of methionine oxidation. A maximum of two missed internal full trypsin cleavages was allowed (Elias et al., 2005). A peptide sequence that was uniquely matched to a protein was classified as a unique peptide. Proteins with two or more unique peptides having an individual Mascot score for each peptide MS/MS spectrum of at least 25 (although in most cases peptides were high-scoring with the lowest score of at least 40), were considered to be positive protein identifications. Any protein identified by a single unique peptide, had its corresponding MS/MS spectrum further manually inspected and validated (Chen et al., 2005).

Several filtered peptide sequences matched to multiple proteins. In some cases, this was due to the sequence similarities of the proteins resulting in proteins matched with the same peptide sequences into a protein group. Consequently, the protein group with greater than three peptide matches was also considered 
a positive identification and only a single protein from the group with either the largest sequence coverage or with representative annotation was reported (Bae et al., 2004).

In some cases, a high-scoring peptide did not have all peaks accounted for. In these instances, an error-tolerant search was carried out to determine if the mass difference was due to a possible post-translational amino-acid modification.

A decoy database consisting of reverse $\mathrm{Y} 88^{\mathrm{T}}$ ORF translated protein sequences was created. All spectra were searched against this decoy database to exclude the possibility of false positive protein identifications. The false discovery rate (false positive / (false positive plus true positive)) was set at $5 \%$. 


\section{Chapter 3: Microbiology of $\mathrm{Y88}^{\mathrm{T}}$}

\subsection{Introduction}

Preliminary work has shown that $\mathrm{Y} 88^{\mathrm{T}}$ accumulated PHA to $41 \pm 16 \%$ of its dry weight when grown in the presence of glucose (Addison et al., 2007). Since Y $88^{\mathrm{T}}$ was isolated from an environment where nitrogen is naturally limiting, but carbon is found in excess, it is potentially an ideal organism for the study of PHA production that is not constrained by nitrogen supply. The aim of this study was to investigate nitrogen and carbon utilisation as well as PHA production by $\mathrm{Y} 88^{\mathrm{T}}$ under conditions where the cells were either fixing nitrogen or not fixing nitrogen to determine whether PHA production had any dependence on nitrogen fixation. The growth profiles of $Y 88^{\mathrm{T}}$ under conditions of carbon enrichment, nitrogen supplementation and nitrogen depletion were examined. This study has shown that the type of PHA produced by Y88 ${ }^{\mathrm{T}}$, PHB, is accumulated intracellularly throughout the growth cycle to high levels of $80.5 \pm 7.4 \%(1.12 \mathrm{~g} / \mathrm{L})$ of the culture dry weight after $72 \mathrm{hr}$ in glucose-enriched minimal nitrogen medium. Predictable growth and lower variability in PHB concentrations was achieved. Also, PHB synthesis occurred independently of nitrogen fixation. A baseline was established for further investigation into the physiology of $\mathrm{Y}^{8} 8^{\mathrm{T}}$ at the protein level during PHB accumulation and nitrogen fixation.

\subsection{Results}

\subsection{1 ${\mathrm{Y} 88^{\mathrm{T}}}^{\mathrm{C}}$ cultivation in batch flasks}

\subsubsection{Growth in a glucose-enriched minimal nitrogen medium}

\subsection{Modeling $\mathrm{Y}^{\mathrm{T}}{ }^{\mathrm{T}}$ growth to the Gompertz model}

Y $88^{\mathrm{T}}$ growth in a glucose-enriched $(5 \mathrm{~g} / \mathrm{L}$, approximately $27 \mathrm{mM})$ minimal nitrogen medium $\left(0.1 \mathrm{~g} / \mathrm{L}\right.$, approximately $\left.2.8 \mathrm{mM} \mathrm{NH} \mathrm{Cl}_{4}\right)$ followed the predicted successive lag, growth and asymptotic phases of bacterial growth that 70 
are described by the Gompertz sigmoidal function (Zwietering et al., 1990). $\mathrm{Y}^{8} 8^{\mathrm{T}}$ growth curves were fitted with the Gompertz model using the Gompertz equation $\mathrm{Y}=\mathrm{N} 0+\mathrm{C}^{*} \exp \left(-\exp \left(\left(2.718^{*} \mu / \mathrm{C}\right)^{*}(\lambda-\mathrm{X})+1\right)\right) \quad(Z$ wietering et al., 1990). $\mathrm{Y}^{8} 8^{\mathrm{T}}$ growth, as determined by $\mathrm{OD}_{600}$ measurements at time points over $72 \mathrm{hr}$, showed a sigmoidal curve (Fig. 3.1), $\mathrm{R}^{2}=0.99$ for all three replicates (Table 3.1). All three replicates showed a very good fit of the model to the observed data, indicating that the parameter values are nearly precise and will have little variation. Although maximum growth was achieved by approximately $30 \mathrm{hr}$, the maximum (exponential) growth rate occurred between approximately 12-20 hr of growth (Fig. 3.1). Between 20-24 hr, growth was near linear. Early stationary phase was reached between $30-40 \mathrm{hr}$ post-inoculation.

\subsection{Biomass produced by $\mathrm{Y}^{\mathrm{T}}{ }^{\mathrm{T}}$}

Biomass as an indicator of growth was determined for $\mathrm{Y}^{\mathrm{T}}$ cells grown in glucose-enriched $(5 \mathrm{~g} / \mathrm{L})$, minimal nitrogen $(0.1 \mathrm{~g} / \mathrm{L})$ medium. Y88 ${ }^{\mathrm{T}}$ produced a maximum dry biomass of approximately $1.3 \mathrm{~g} / \mathrm{L}$ by $52 \mathrm{hr}$ with a linear increase in biomass between 20 to $44 \mathrm{hr}$ (Fig. 3.2). The greatest change in biomass between sampling intervals as well as the greatest rate of biomass production occurred between 20-28 hr with an increase of $0.423 \mathrm{~g} / \mathrm{L}$ at a rate of $0.05 \mathrm{~g} / \mathrm{hr}$ (Table 3.2). No measurable change in biomass occurred between 52-72 hr (Table $3.2)$.

The yield of biomass (grams of biomass produced per gram of glucose consumed) was more or less constant throughout the growth period with the exception of the $0-8 \mathrm{hr}$ growth interval. Although $\mathrm{OD}_{600}$ measurements showed a lag period of growth between $0-8 \mathrm{hr}$ (Fig. 3.2), the biomass measurements showed one of the highest rates of increase during this growth interval (Table 3.2). With the exception of the lag phase of growth (coinciding with the first two time points), a direct correlation exists between biomass and $\mathrm{OD}_{600}$ (Fig. 3.3). Both $\mathrm{OD}_{600}$ and biomass are therefore good predictors of $\mathrm{Y}^{\mathrm{T}} 8^{\mathrm{T}}$ growth, after the initial lag phase. 


\section{Growth curve of $\mathrm{Y}^{\mathrm{T}}{ }^{\mathrm{T}}$ fitted with Gompertz model}

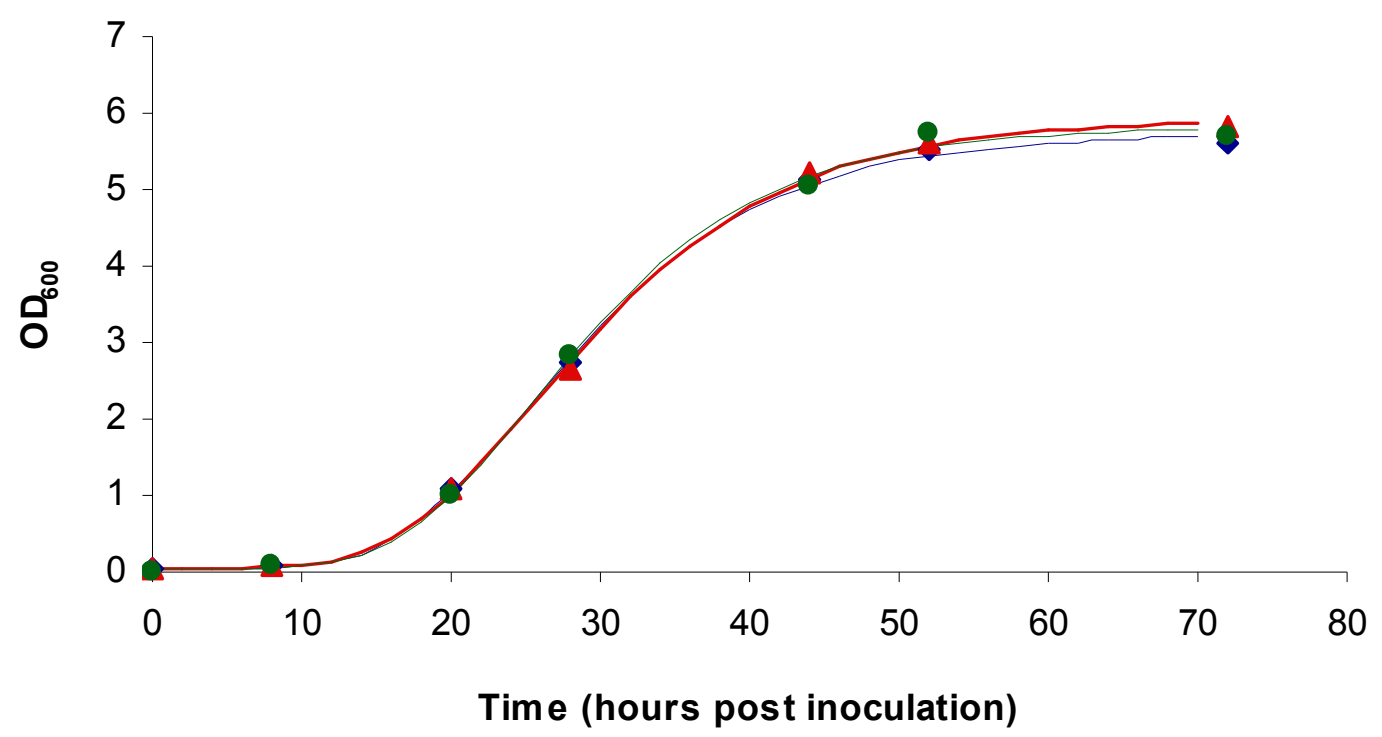

Figure 3.1 Y88 ${ }^{\mathrm{T}}$ growth data fitted to the Gompertz model

The Gompertz model used for bacterial growth shows the goodness-of-fit of the observed values (individual observed data points presented as coloured markers) to the predicted values (continuous coloured lines) for each replicate. Note that for each replicate, marker colour of observed values matches line colour of predicted values, $(n=3)$. 


\begin{tabular}{llc}
\hline \multicolumn{1}{c}{ '88 $^{\mathbf{T}}$} & \multicolumn{1}{c}{ Gompertz equation } & $\mathbf{R}^{\mathbf{2}}$ \\
\hline Replicate 1 & $\mathrm{y}=0.05585+5.667 * \exp (-\exp ((2.718 * 0.2312 / 5.667) *(16.12-\mathrm{x})+1))$ & 0.99 \\
Replicate 2 & $\mathrm{y}=0.062148+5.858226 * \exp (-\exp ((2.718 * 0.228818 / 5.858226) *(16.18539-\mathrm{x}))+1))$ & 0.99 \\
Replicate 3 & $\mathrm{y}=0.05384+5.774 * \exp (-\exp ((2.718 * 0.2394 / 5.774) *(16.42-\mathrm{x}))+1))$ & 0.99 \\
\hline
\end{tabular}

Table 3.1 Gompertz equations for $\mathrm{Y} 88^{\mathrm{T}}$ replicate growth curves

Gompertz equation $Y=N 0+C^{*} \exp \left(-\exp \left(\left(2.718^{*} \mu / C\right)^{*}(\lambda-X)+1\right)\right)$ describing the growth curve for each $\mathrm{Y}^{8} 8^{\mathrm{T}}$ replicate. $\mathrm{N} 0=\log$ (initial number of cells), $\mathrm{C}=$ difference between initial and final number of cells, $\lambda=$ delay before growth (same units as " $x$ "), $\mu=$ maximum specific growth rate, " $x$ "=time, " $y$ " $=\log$ (cell number). 


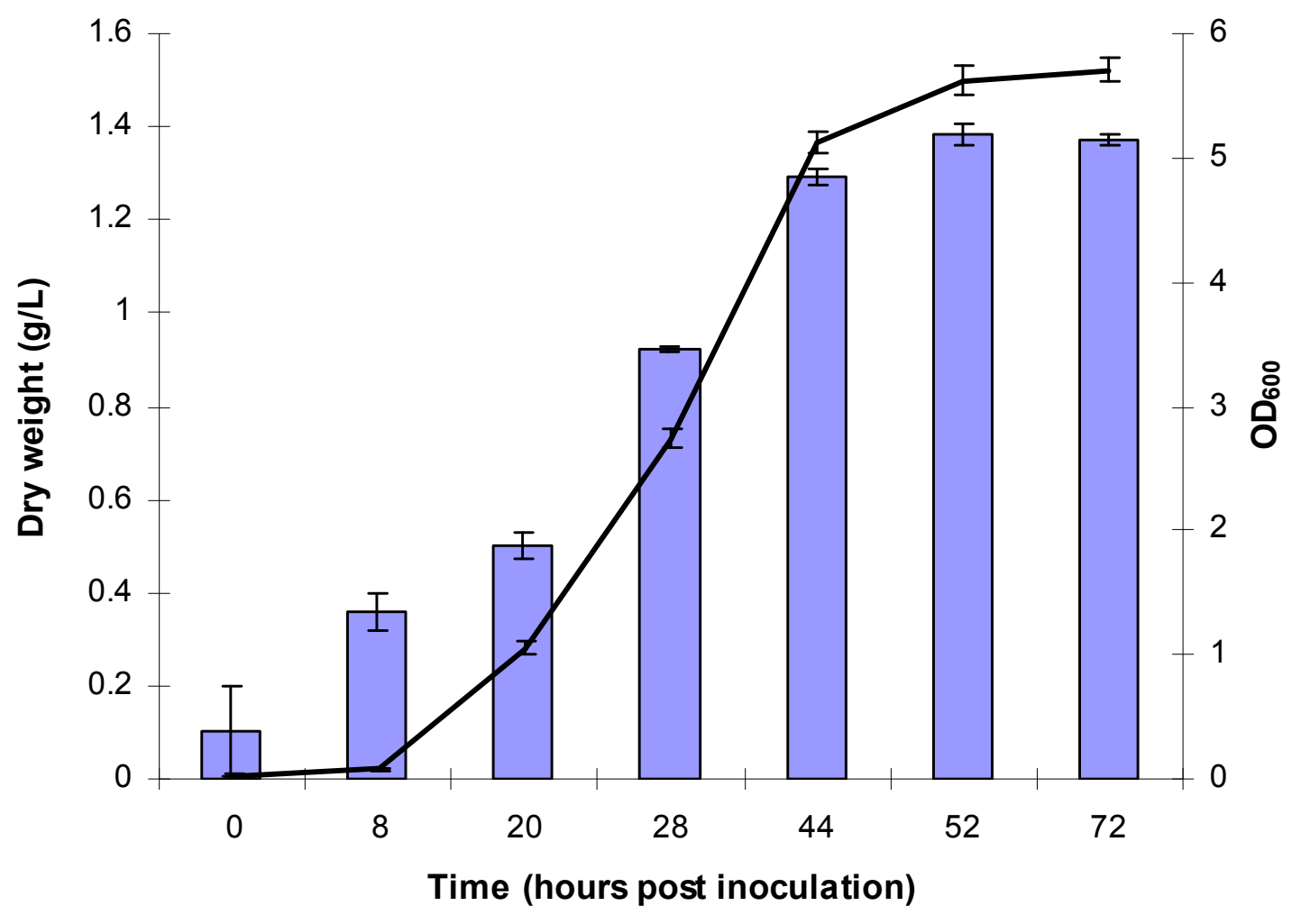

Figure $3.2 \mathrm{OD}_{600}$ and dry biomass produced by $\mathrm{Y}^{8} 8^{\mathrm{T}}$ in a glucose-enriched minimal nitrogen medium over $72 \mathrm{hr}$

$\mathrm{OD}_{600}$ (data points joined by lines; right y axis) and dry biomass (bars; left y axis) produced by $\mathrm{Y}^{8} 8^{\mathrm{T}}$ in a glucose-enriched minimal nitrogen medium over $72 \mathrm{hr}$ shows near linear growth and biomass production between 20-44 hr. Highest rate of biomass produced was between 20-28 hr. Error bars represent standard deviations, $(\mathrm{n}=3)$. 


\begin{tabular}{ccccc}
\hline $\begin{array}{c}\text { Time (hours post } \\
\text { inoculation) }\end{array}$ & $\begin{array}{c}\text { Dry biomass } \\
(\mathrm{g} / \mathrm{L})\end{array}$ & $\begin{array}{c}\text { Change in dry } \\
\text { biomass } \\
(\mathrm{g} / \mathrm{L})\end{array}$ & $\begin{array}{c}\text { Rate of change in } \\
\text { dried biomass } \\
(\mathrm{g} / \mathrm{L} / \mathrm{hr})\end{array}$ & $\begin{array}{c}\text { Yield in biomass } \\
\text { (g biomass/g glucose } \\
\text { consumed })\end{array}$ \\
\cline { 2 - 5 } & $0.103 \pm 0.09$ & $0.000 \pm 0.00$ & $0.000 \pm 0.00$ & $0.000 \pm 0.00$ \\
8 & $0.357 \pm 0.04$ & $0.254 \pm 0.12$ & $0.03 \pm 0.02$ & $3.31 \pm 0.93$ \\
20 & $0.500 \pm 0.03$ & $0.143 \pm 0.17$ & $0.01 \pm 0.01$ & $0.25 \pm 0.01$ \\
28 & $0.923 \pm 0.01$ & $0.423 \pm 0.04$ & $0.05 \pm 0.01$ & $0.27 \pm 0.00$ \\
44 & $1.29 \pm 0.017$ & $0.367 \pm 0.15$ & $0.02 \pm 0.01$ & $0.27 \pm 0.00$ \\
52 & $1.383 \pm 0.02$ & $0.093 \pm 0.03$ & $0.01 \pm 0.01$ & $0.28 \pm 0.00$ \\
72 & $1.373 \pm 0.01$ & $0.000 \pm 0.00$ & $0.000 \pm 0.00$ & $0.27 \pm 0.00$ \\
\hline
\end{tabular}

Table 3.2 Dry biomass (cumulative over $72 \mathrm{hrs}$ ), actual change in dry biomass (for each time interval separately), rate of change in dry biomass produced (for each time interval separately) and yield of biomass by $\mathrm{Y} 88^{\mathrm{T}}$ in a glucose-enriched minimal nitrogen medium. 


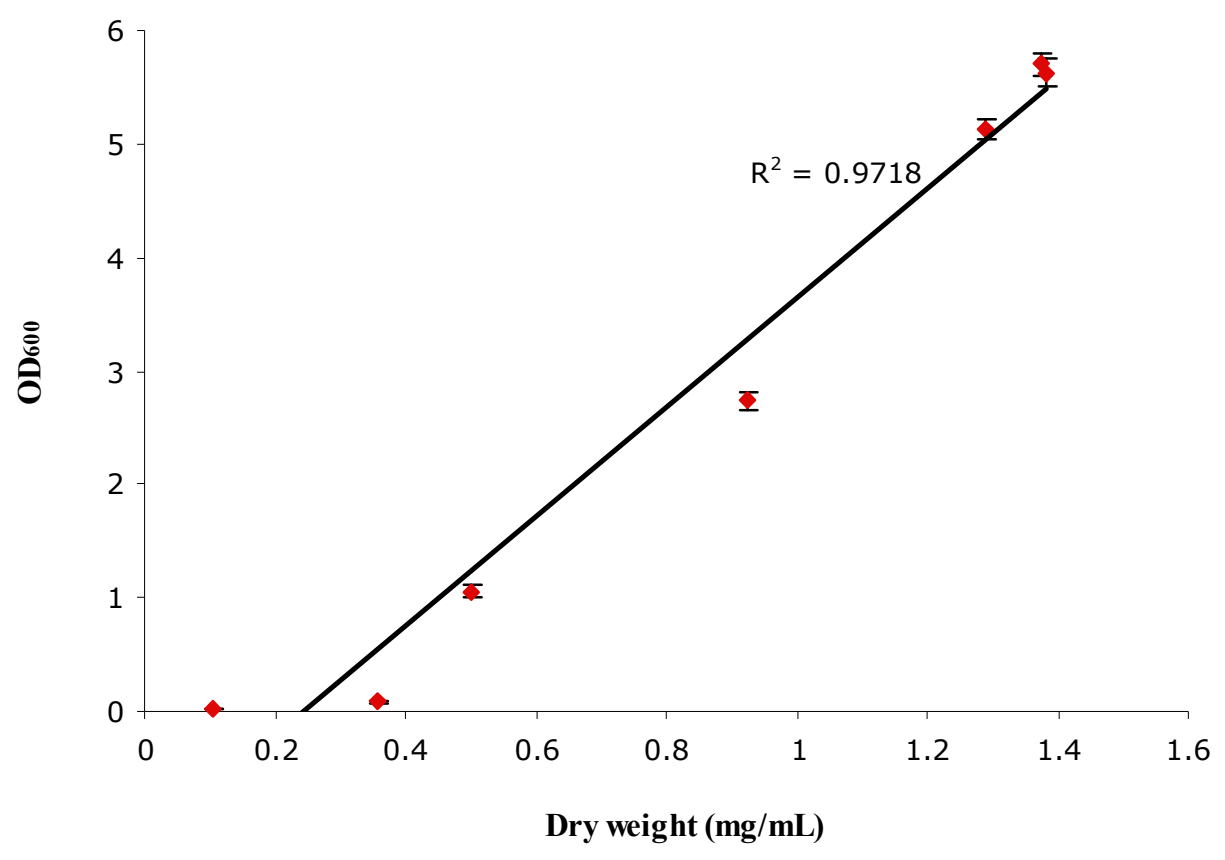

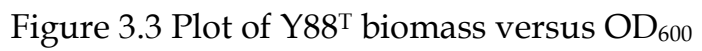

Error bars represent standard deviations, $(n=3)$. Note that the linear relationship breaks down in the initial stages of growth, as the cells are in lag phase to approximately eight hours of growth. See also Fig. 3.2. 


\subsubsection{2 ${\mathrm{Y} 88^{\mathrm{T}}}^{\mathrm{g}}$ growth and carbon substrate utilisation}

\subsection{Single substrate utilisation: glucose vs. acetate}

The ability of $Y 88^{\mathrm{T}}$ to utilise either glucose or acetate as its sole carbon substrate in a minimal nitrogen medium was investigated to determine whether there was a difference in the amount of biomass and PHA produced from each substrate and which of these carbon sources provided the best growth substrate. Concentrations of glucose and acetate supplemented in the medium contained the same amount of carbon on a molar basis. Different concentrations of each substrate ranging from low $(1.9 \mathrm{mM})$ to high $(27 \mathrm{mM})$ were used. Since $\mathrm{OD}_{600}$ and biomass were equally good predictors of $\mathrm{Y}^{\mathrm{T}} 8^{\mathrm{T}}$ growth (section 3.2.1.1.2), biomass was used as the measure of $Y 88^{\mathrm{T}}$ growth for this section.

$\mathrm{Y}^{\mathrm{T}}$ cells cultivated for $24 \mathrm{hr}$ on glucose as the sole carbon source achieved an overall higher growth for a given concentration of input carbon than those cultivated primarily on acetate (Fig. 3.4, see $20 \mathrm{mM} \mathrm{A}$, acetate; $6 \mathrm{mM} \mathrm{G}$, glucose). Growth on glucose resulted in acidification of the medium from an initial $\mathrm{pH}$ of 7.2 , to a final $\mathrm{pH}$ of 4.5. In contrast, during $\mathrm{Y}^{\mathrm{T}} 8^{\mathrm{T}}$ growth on acetate as the sole carbon source, the medium became more basic, from an initial $\mathrm{pH}$ of 7.2 to a final $\mathrm{pH}$ of 8.5. A dry biomass of approximately $1.125 \mathrm{~g} / \mathrm{L}$ was achieved for the highest concentration of glucose $(27 \mathrm{mM})$ compared to the highest biomass of approximately $0.2 \mathrm{~g} / \mathrm{L}$ achieved for $\mathrm{Y}^{\mathrm{T}}$ cells grown on $20 \mathrm{mM}$ acetate (Fig. 3.4). Biomass produced by $\mathrm{Y}^{\mathrm{T}} 8^{\mathrm{T}}$ after $24 \mathrm{hr}$ on $20 \mathrm{mM}$ acetate was therefore approximately one-fifth that of the biomass produced on $27 \mathrm{mM}$ glucose after the same time. Since $20 \mathrm{mM}$ acetate contains approximately $25 \%$ of the carbon that $27 \mathrm{mM}$ glucose contains and the amount of biomass produced on acetate is approximately $20 \%$ of that produced on glucose, Y $88^{\mathrm{T}}$ uses slightly less carbon if grown on glucose to achieve a similar amount of biomass on a carbon for carbon basis compared to growth on acetate. The amount of carbon converted to PHA differs significantly, however, depending on whether glucose or acetate is used as the carbon substrate. More carbon is used for PHA 


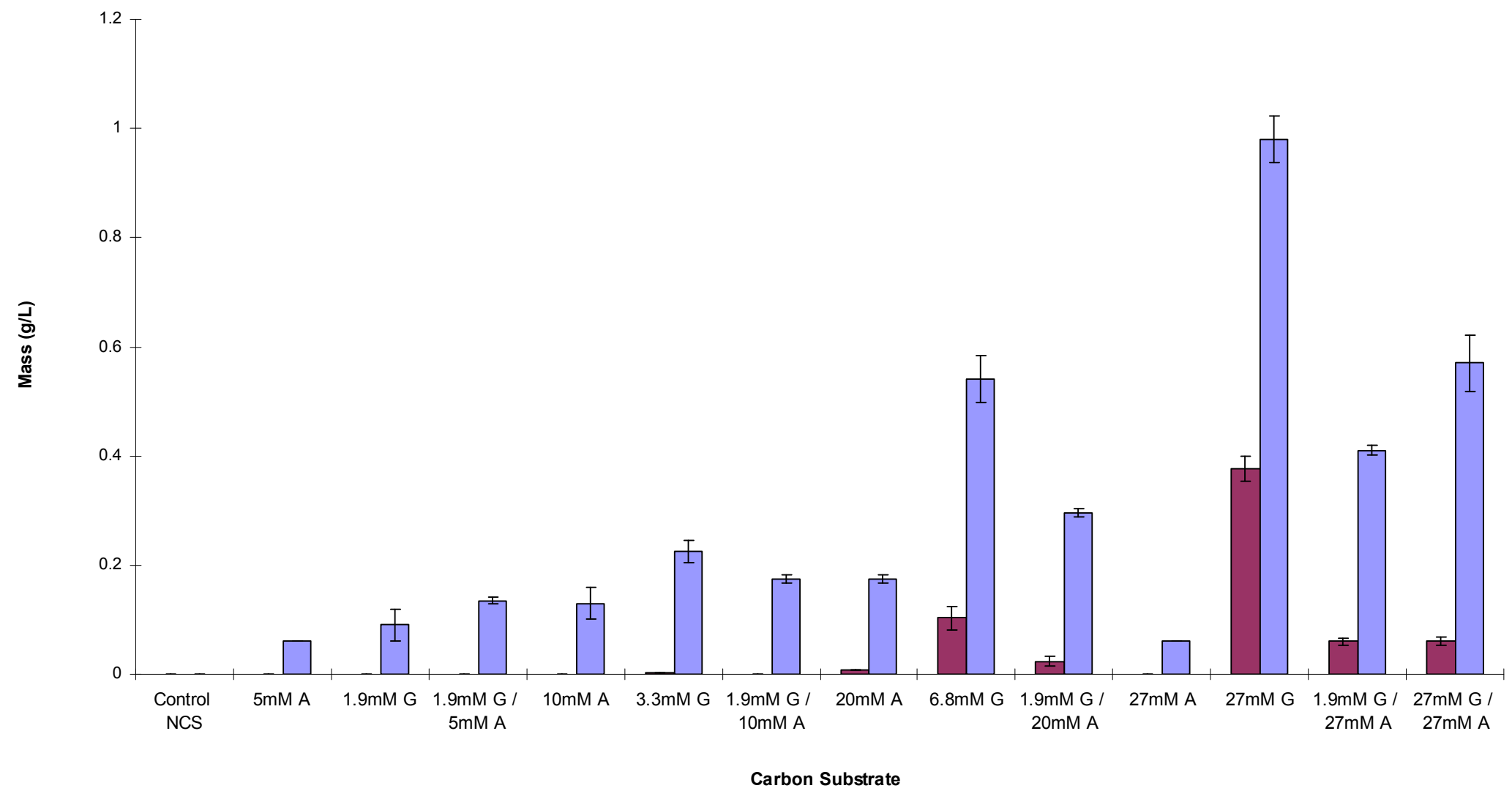

Figure 3.4. Total dry biomass and PHB mass produced by $Y 88^{\mathrm{T}}$ after $24 \mathrm{hr}$ growth in a minimal nitrogen medium with various carbon substrates

Total dry biomass (blue bars) and PHB mass (red bars) produced by Y88 ${ }^{\mathrm{T}}$ after 24 hr growth (left y axis) and 24 hr OD 600 measurements (bars outlined by dotted lines; right y axis) achieved in a minimal nitrogen medium enriched with a single carbon (C) substrate (glucose (G), acetate (A) ) or a mixed carbon substrate (G and A) . NCS=no carbon substrate in growth medium. Error bars represent standard deviations, $(n=2)$. 
production from glucose than that used from acetate since approximately $40 \%$ of the biomass produced by $\mathrm{Y} 88^{\mathrm{T}}$ in the glucose-enriched medium consisted of PHA whereas only $1.2 \%$ of the biomass produced by $\mathrm{Y}^{8} 8^{\mathrm{T}}$ in the acetateenriched medium $(0.01 \mathrm{~g} / \mathrm{L})$ consisted of PHA.

\subsection{Mixed substrate utilisation: glucose and acetate}

The ability of $Y 88^{\mathrm{T}}$ to utilise glucose and acetate as a mixed carbon source in a minimal nitrogen medium was investigated to determine the amount of biomass and PHA produced by $\mathrm{Y}^{8} 8^{\mathrm{T}}$ when cultivated in the presence of a combination of these two substrates. Comparisons were made between the amounts of biomass and PHA produced by $\mathrm{Y}^{\mathrm{T}}{ }^{\mathrm{T}}$ on the combined substrates and that produced under the same growth condition from a single carbon source. The aim was to determine whether the presence of a second carbon source in the growth medium would increase the amount of biomass and PHA produced by $\mathrm{Y}^{8} 8^{\mathrm{T}}$. Different concentrations of each substrate were used in combinations ranging from low $(1.9 \mathrm{mM})$ to high $(27 \mathrm{mM})$.

Y88 ${ }^{\mathrm{T}}$ cells cultivated on low amounts of glucose $(1.9 \mathrm{mM})$ in combination with 5 $\mathrm{mM}, 10 \mathrm{mM}$ or $20 \mathrm{mM}$ acetate as a mixed carbon source, achieved overall higher growth than $\mathrm{Y} 88^{\mathrm{T}}$ cells cultivated on the same concentrations of acetate alone (Fig. 3.4). Thus the addition of small amounts of glucose promoted $\mathrm{Y}^{\mathrm{T}} \mathrm{T}^{\mathrm{T}}$ growth in acetate-enriched media, as was particularly evident in the $1.9 \mathrm{mM}$ glucose/27 $\mathrm{mM}$ acetate combination. This combination showed superior biomass and PHB production to $27 \mathrm{mM}$ acetate alone, which itself was unable to achieve even the low biomass and PHB production of the $20 \mathrm{mM}$ acetate alone. An acetate concentration higher than $20 \mathrm{mM}$ as a sole substrate therefore appears to inhibit $\mathrm{Y}^{8} 8^{\mathrm{T}}$ cell growth. This conclusion was confirmed by demonstrating that $\mathrm{Y}^{8} 8^{\mathrm{T}}$ cells grown on $81 \mathrm{mM}$ acetate as a sole carbon substrate control showed no measurable growth.

Although a higher biomass (approximately $0.57 \mathrm{~g} / \mathrm{L}$ ) was obtained from growth on $27 \mathrm{mM}$ glucose/ $27 \mathrm{mM}$ acetate compared to that on $1.9 \mathrm{mM}$ 
glucose / $27 \mathrm{mM}$ acetate (approximately $0.4 \mathrm{~g} / \mathrm{L}$ ), minimal amounts of PHB (0.06 $\mathrm{g} / \mathrm{L}$ ) were produced in each case. These results demonstrate that the presence of $27 \mathrm{mM}$ acetate in the growth medium, irrespective of the high or low amounts of glucose present, inhibits PHB production (Fig. 3.4). Thus it appears that the additional glucose in these cultures was used by $\mathrm{Y}^{\mathrm{T}}$ as an energy source for growth rather than conversion into PHB. Therefore no benefit in terms of PHB production was derived from increasing the concentration of glucose in combination with $27 \mathrm{mM}$ acetate.

Growth on $1.9 \mathrm{mM}$ glucose/20 $\mathrm{mM}$ acetate resulted in PHB constituting approximately $10 \%$ of the cell dry weight, which was twice the PHB produced during growth on the $20 \mathrm{mM}$ acetate alone. However, the combination of 1.9 $\mathrm{mM}$ glucose/27 $\mathrm{mM}$ acetate resulted in approximately $15 \%$ of the biomass constituting PHB, which was approximately 33\% more PHB produced from 1.9 $\mathrm{mM}$ glucose $/ 20 \mathrm{mM}$ acetate. This translates into approximately $33 \%$ more PHB produced from roughly $26 \%$ more acetate thus the additional acetate resulted in a higher PHB production as long as a small amount of $1.9 \mathrm{mM}$ glucose was present in the culture medium. However, the overall amount of PHB produced was still low compared to that on $27 \mathrm{mM}$ glucose alone.

Y88 $8^{\mathrm{T}}$ cells cultivated on a mixed carbon substrate of $27 \mathrm{mM}$ glucose $/ 27 \mathrm{mM}$ acetate grew to a much lower biomass than that achieved on a single carbon source of $27 \mathrm{mM}$ glucose with approximately $40 \%$ less biomass than that produced on $27 \mathrm{mM}$ glucose alone. Dry biomass measurements determined for growth on $27 \mathrm{mM}$ glucose and acetate were approximately $0.6 \mathrm{~g} / \mathrm{L}$ with approximately $10 \%$ of the biomass composed of PHB $(0.06 \mathrm{~g} / \mathrm{L})$. Concomitant with the decreased total biomass, the amount of PHB produced during growth on the $27 \mathrm{mM}$ glucose/acetate combination was approximately $75 \%$ less than that produced during growth on $27 \mathrm{mM}$ glucose alone. These results suggest that acetate has a limiting effect on growth and PHB production at higher concentrations of combined glucose and acetate compared with growth and 
PHB produced from high concentrations of glucose alone. Since biomass and PHB production were consistently superior with glucose as the sole carbon source, all subsequent experiments were carried out with glucose as the sole carbon substrate.

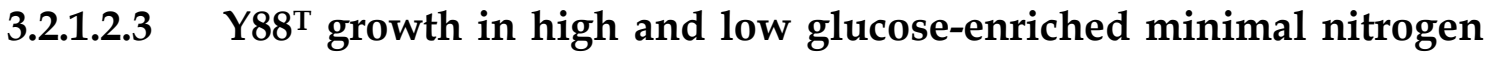 medium}

$\mathrm{Y}^{\mathrm{T}}$ growth was investigated in glucose-enriched media with either $5 \mathrm{~g} / \mathrm{L}$ of glucose (high glucose; HG) or $1 \mathrm{~g} / \mathrm{L}$ glucose (low glucose; LG) supplemented in the medium. The aim was to determine if carbon in the form of glucose is required in excess to produce high yields of PHB or whether similar yields can be achieved using a lower concentration of glucose. Also investigated was the question of whether a glucose concentration of $1 \mathrm{~g} / \mathrm{L}$ can be considered limiting to growth and PHB production in $\mathrm{Y}^{8} 8^{\mathrm{T}}$.

During the first $8 \mathrm{hr}$ of culture, growth kinetics on LG were similar to cells grown in HG (Fig. 3.5). After $8 \mathrm{hr}$, it was evident that growth on LG was becoming limited by low carbon supply with a biomass of only $0.04 \mathrm{~g} / \mathrm{L}$ attained after $24 \mathrm{hr}$. In comparison, Y88 ${ }^{\mathrm{T}}$ cells on HG grew exponentially between 8-24 hr and attained a biomass of $0.9 \mathrm{~g} / \mathrm{L}$ by $24 \mathrm{hr}$ (Figs. 3.5 and 3.6). Approximately $40 \%(0.34 \mathrm{~g} / \mathrm{L})$ of this biomass consisted of $\mathrm{PHB}$, whereas no PHB was produced during growth on LG after $24 \mathrm{hr}$ (Fig. 3.5). After $48 \mathrm{hr}, \mathrm{Y}^{\mathrm{T}} 8^{\mathrm{T}}$ cells on HG attained a biomass of $1.5 \mathrm{~g} / \mathrm{L}$ (Fig. 3.6). Approximately 66\% (1.1 g/L) of this biomass consisted of PHB (Fig. 3.6) whereas the cells grown on LG attained a biomass of $0.16 \mathrm{~g} / \mathrm{L}$ over the same period and still did not produce any PHB (Fig. 3.6). By 48 hr, Y88 ${ }^{\mathrm{T}}$ therefore achieved ten-fold less biomass on LG than on HG but consumed five-fold less glucose.

Final dry biomass measurements after $72 \mathrm{hr}$ showed that $\mathrm{Y} 88^{\mathrm{T}}$ cells grown on LG attained about $1 / 5$ the biomass $(0.3 \mathrm{~g} / \mathrm{L})$ of those grown on HG, which reached a final concentration of $1.5 \mathrm{~g} / \mathrm{L}$ (Fig. 3.6). Since five times more glucose was used at HG than at LG and five times more biomass was produced after 72 


\section{$\mathrm{Y}^{\top}{ }^{\top}$ growth in glucose-enriched minimal nitrogen medium}

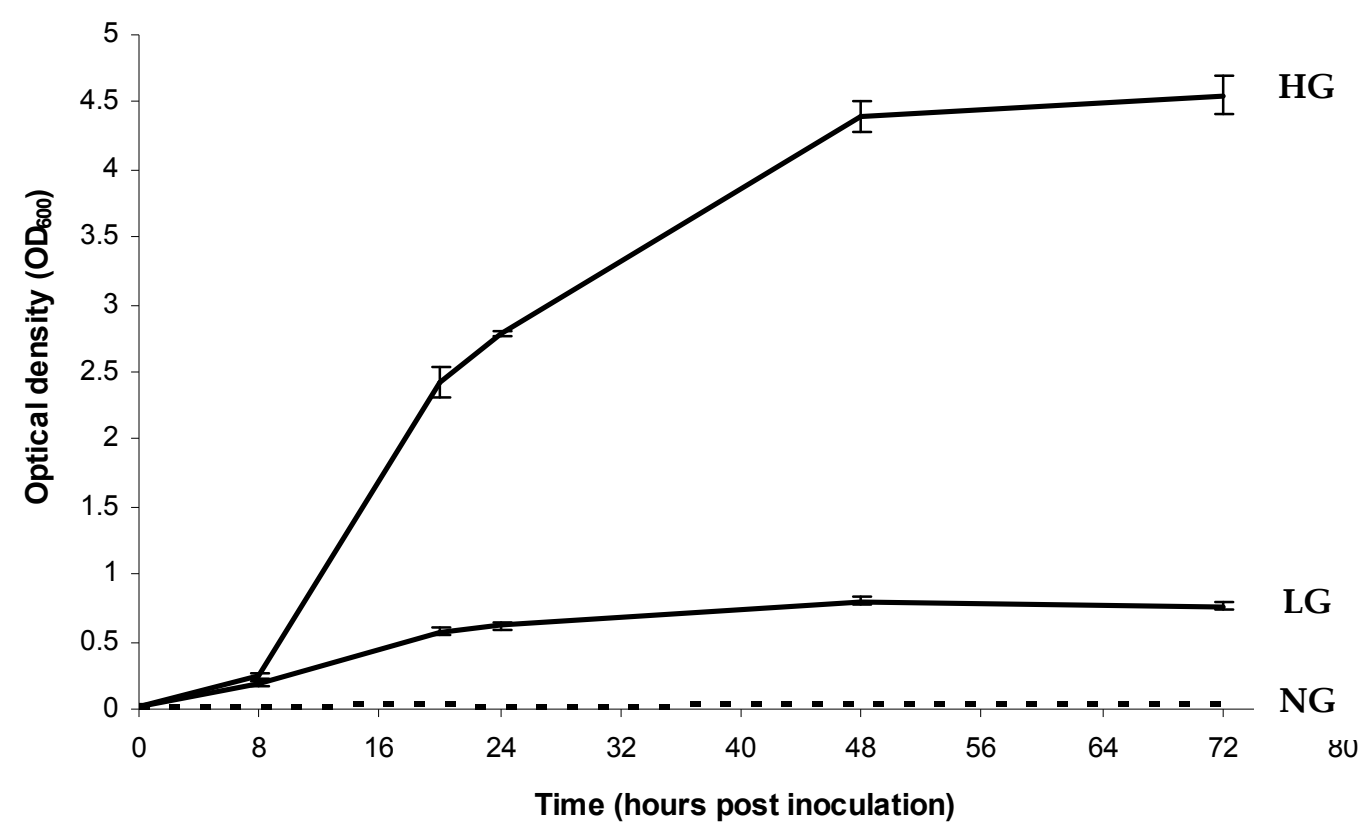

Figure 3.5 Comparative growth of $\mathrm{Y} 88^{\mathrm{T}}$ in high and low glucose minimal nitrogen media. Y88 ${ }^{\mathrm{T}}$ growth over $72 \mathrm{hr}$ in a glucose-enriched $(5 \mathrm{~g} / \mathrm{L})(\mathrm{HG})$ and low glucose $(1 \mathrm{~g} / \mathrm{L})(\mathrm{LG})$, minimal nitrogen $\left(0.1 \mathrm{~g} / \mathrm{L} \mathrm{NH}_{4} \mathrm{Cl}\right)$ medium, $(\mathrm{n}=3)$. A control $(\mathrm{NG})$ containing Y88 ${ }^{\mathrm{T}}$ cells but no glucose in the medium was included. Error bars represent standard deviations, $(n=2)$. 


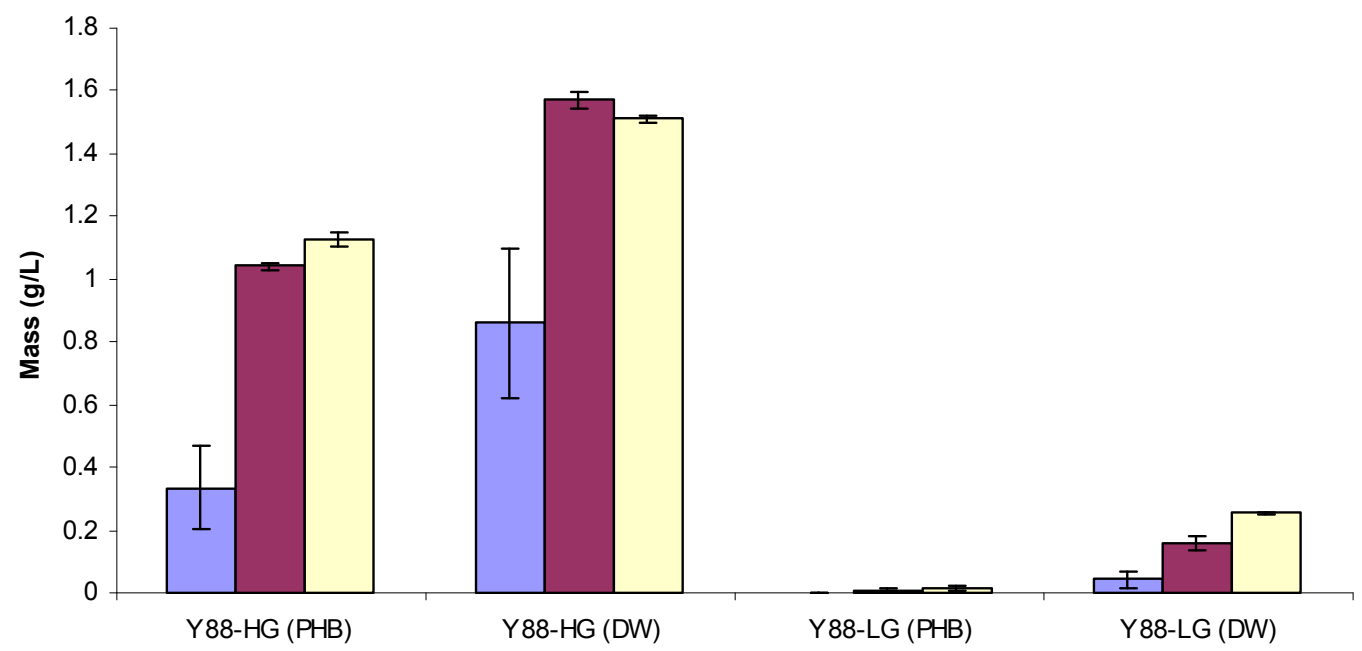

Figure 3.6 PHB and dry biomass produced by $\mathrm{Y}^{\mathrm{T}} 8^{\mathrm{T}}$ in high and low glucose minimal nitrogen medium

PHB and dry biomass (DW, g/L) produced by $\mathrm{Y}^{\mathrm{T}} 8^{\mathrm{T}}$ cultivated for $72 \mathrm{hr}$ in glucose-enriched (HG, 27mM) and low glucose (LG, 5.6mM) minimal nitrogen $\left(2.8 \mathrm{mM} \mathrm{NH}_{4} \mathrm{Cl}\right)$ medium. Bars represent time that cells were cultivated as follows: $24 \mathrm{hr}=$ blue, $48 \mathrm{hr}=$ maroon, $72 \mathrm{hr}=$ cream, $(n=3)$. 
$\mathrm{hr}$, a correlation exists between the amount of glucose supplied and the biomass produced. No such correlation was evident between glucose supplied and PHB produced since by $72 \mathrm{hr}$ on LG, Y $88^{\mathrm{T}}$ had not produced any measurable PHB. This suggests that the glucose supplied was used for energy requirements during growth and that the supply at $1 \mathrm{~g} / \mathrm{L}$ was insufficient to sustain both growth and PHB production.

Y88 ${ }^{\mathrm{T}}$ cells therefore require glucose in excess at the beginning of the growth phase to achieve high levels of PHB accumulation in the cells throughout the growth phase when grown under our laboratory conditions. Since approximately $1 \mathrm{~g} / \mathrm{L}$ glucose as a starting carbon substrate constrains biomass to low levels and is insufficient for PHB production during growth relative to the higher starting carbon substrate of $5 \mathrm{~g} / \mathrm{L}$, glucose at a starting concentration of $1 \mathrm{~g} / \mathrm{L}$ can be considered limiting to $\mathrm{Y}^{\mathrm{T}} 8^{\mathrm{T}}$ growth and PHB production.

Additional data (not shown) for $\mathrm{Y} 88^{\mathrm{T}}$ growth on $2 \mathrm{~g} / \mathrm{L}$ glucose (selected as an intermediate concentration between 1 and $5 \mathrm{~g} / \mathrm{L}$ ) confirmed that $\mathrm{Y}^{8} 8^{\mathrm{T}}$ produced $0.5 \mathrm{~g} / \mathrm{L}$ dry biomass after $24 \mathrm{hr}$. Of this, only $0.1 \mathrm{~g} / \mathrm{L}$ constituted PHB compared to the $0.34 \mathrm{~g} / \mathrm{L}$ PHB produced from $5 \mathrm{~g} / \mathrm{L}$ glucose. Thus 3.4-fold more PHB was produced from 2.5-fold more glucose at $5 \mathrm{~g} / \mathrm{L}$ than $2 \mathrm{~g} / \mathrm{L}$. Since $5 \mathrm{~g} / \mathrm{L}$ glucose gave a better PHB yield than either 1 or $2 \mathrm{~g} / \mathrm{L}$, the former concentration was selected for all subsequent growth experiments with glucose as carbon substrate.

\subsection{Composition of the PHB polymer produced by $\mathrm{Y}^{\mathrm{T}}$ from glucose}

The monomer composition of PHB produced by $\mathrm{Y}^{\mathrm{T}} 8^{\mathrm{T}}$ grown on a glucoseenriched $(5 \mathrm{~g} / \mathrm{L})$, nitrogen-limiting $(0.1 \mathrm{~g} / \mathrm{L} \mathrm{NH} 4 \mathrm{Cl})$ medium was confirmed by infrared spectroscopy and gas chromatography analysis to be 3hydroxybutyrate. ${ }^{13} \mathrm{C}-\mathrm{NMR}$ analysis determined the subunit structure of the PHB extract from Y88 cells (Fig. 3.7). The cell biomass of $\mathrm{Y}^{\mathrm{T}} 8^{\mathrm{T}}$ constitutes approximately $90 \%$ poly-( $\beta$-hydroxybutyrate) of the extracted product by weight. Transmission electron microscopy of $\mathrm{Y}^{\mathrm{T}} 8^{\mathrm{T}}$ cells confirmed that this 84 


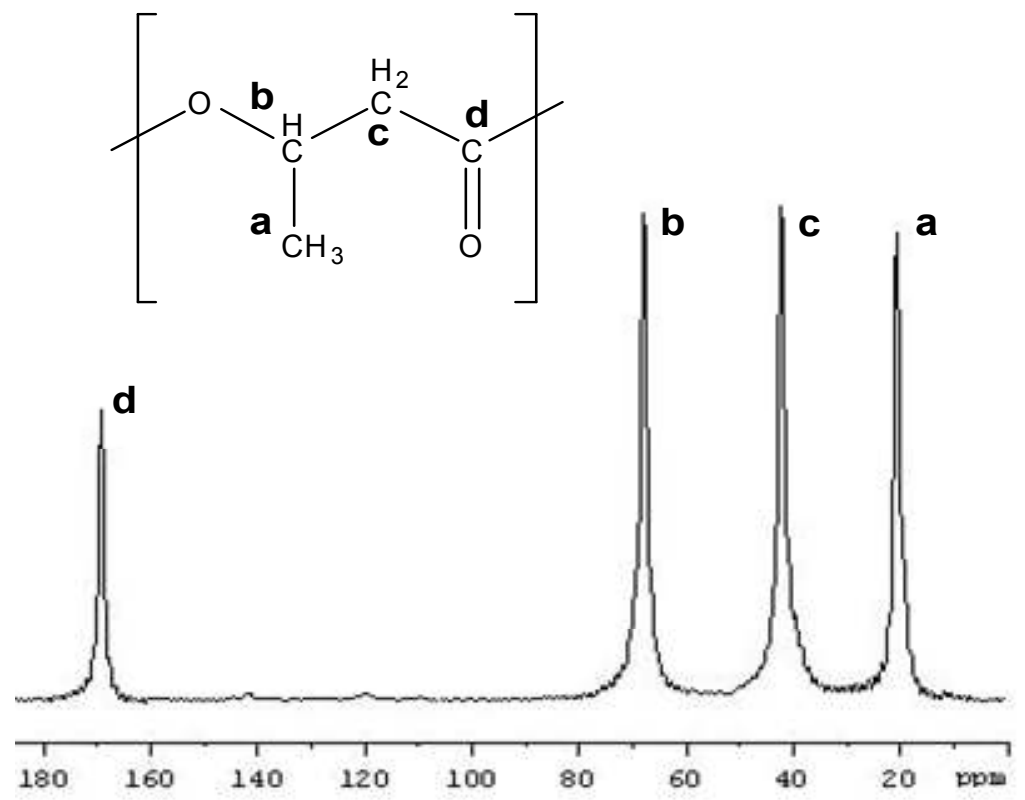

Figure $3.7^{13} \mathrm{C}-\mathrm{NMR}$ spectrum of PHB produced by $\mathrm{Y} 88^{\mathrm{T}}$.

Inset: PHA monomer structure with carbon atoms labeled corresponding to the NMR peaks they produce in the spectrum. 
bacterium accumulates PHB granules to a high percentage (80\%) in its cells (Fig. 3.8). Analysis of the extracted polymer by gel permeation chromatography (GPC) showed that $\mathrm{Y} 88^{\mathrm{T}}$ is able to synthesise a high molecular weight polymer of approximately 1.4 $\pm 0.2 \mathrm{MDa}$ when grown in our standard minimal nitrogen medium with excess glucose as the sole carbon source.

\subsubsection{Comparison between $\mathrm{Y}^{8} 8^{\mathrm{T}}$, A. vinelandii and P. putida $\mathrm{mt} 2$}

\subsubsection{Growth and nitrogen fixation in $\mathrm{NH}_{4}{ }^{+}$-free and $\mathrm{NH}_{4}{ }^{+}$-supplemented glucose-enriched media}

Y88 $8^{\mathrm{T}}$ growth in a minimal nitrogen medium enriched with glucose was investigated in parallel with two species from the Gammaproteobacteria: A. vinelandii (capable of fixing molecular nitrogen, positive control for nitrogen fixation) and P. putida $\mathrm{mt} 2$ (incapable of fixing molecular nitrogen, negative control for nitrogen fixation). To determine the effect that ammonium supplementation or the lack thereof has on $\mathrm{Y} 88^{\mathrm{T}}$ growth and nitrogen fixation during $24 \mathrm{hr}$ in a glucose-enriched medium, $\mathrm{Y}^{8} 8^{\mathrm{T}}$ growth was investigated under ammonium-free conditions and under conditions where ammonium initially supplemented in the medium $\left(0.1 \mathrm{~g} / \mathrm{L} \mathrm{NH}_{4} \mathrm{Cl}\right)$ was depleted and compared to that of $A$. vinelandii and P. putida $\mathrm{mt} 2 . \mathrm{C}_{2} \mathrm{H}_{2}$ reduction assays, to determine the activity of the nitrogenase enzyme required for nitrogen fixation, were carried out on cells from all three bacteria grown in ammonium-free and ammonium-supplemented media. Y88 ${ }^{\mathrm{T}}$ cells grew more poorly over a $24 \mathrm{hr}$ period in ammonium-free medium (Fig. 3.9) reflecting similar lower growth to that of A. vinelandii $\left(\mathrm{OD}_{600}<1.0\right)$, although the latter reached a higher $\mathrm{OD}_{600}$ than that for P. putida $\left.\mathrm{mt} 2 \mathrm{OD}_{600}<0.3\right)$ under the same growth conditions. $\mathrm{Y}^{8} 8^{\mathrm{T}}$ reached a maximum $\mathrm{OD}_{600}$ of approximately 0.7 by $24 \mathrm{hr}$ post-inoculation in ammonium-free medium (Fig. 3.9). Y88 $8^{\mathrm{T}}$ gave a negative $\mathrm{C}_{2} \mathrm{H}_{2}$ reduction assay for those cells grown in ammonium-free medium although $A$. vinelandii gave a positive $\mathrm{C}_{2} \mathrm{H}_{2}$ reduction assay under the same growth conditions (see section 3.2.2.2.1 for a more detailed description of the $\mathrm{C}_{2} \mathrm{H}_{2}$ reduction assay and results obtained). Under the same growth conditions, but with ammonium chloride 


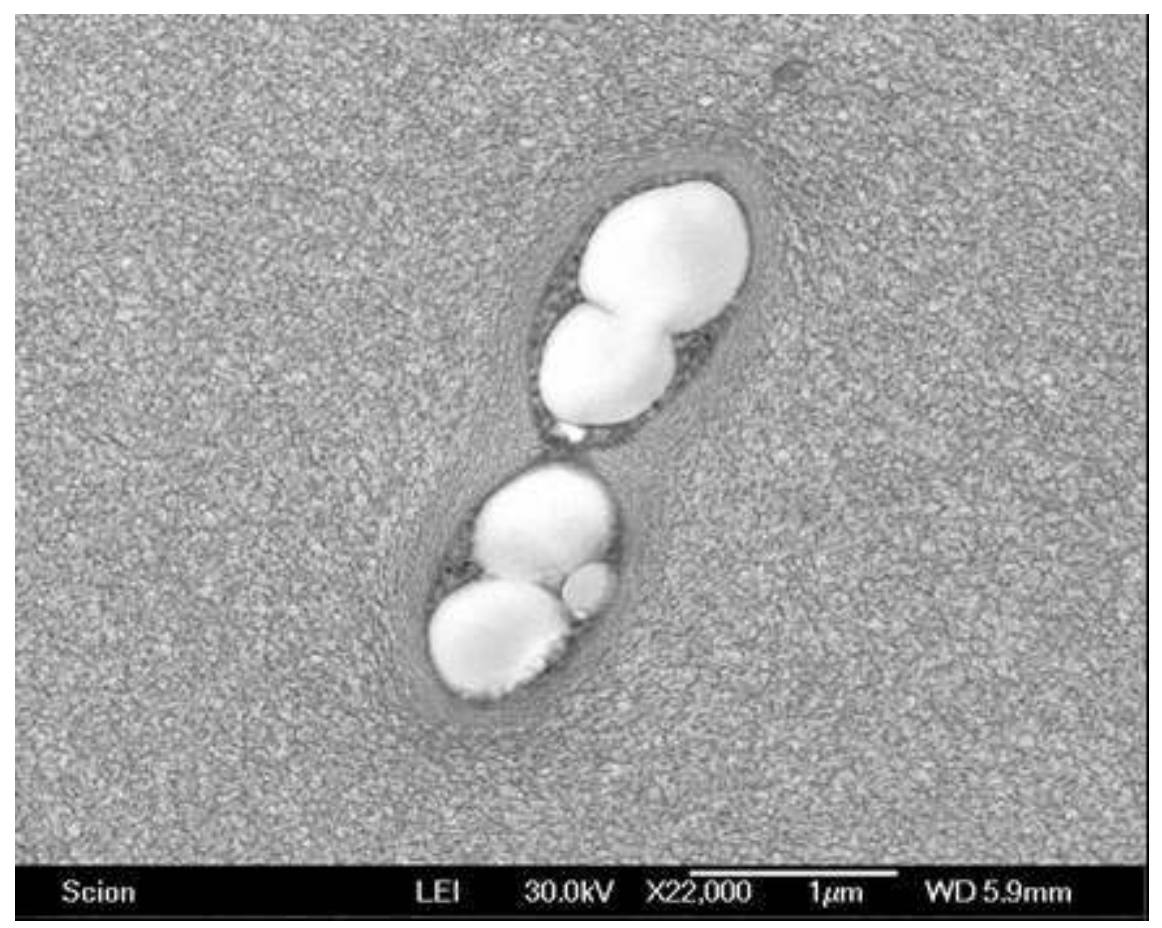

Figure 3.8 Transmission electron micrograph (TEM) of Y88 ${ }^{\mathrm{T}}$ cells containing PHB accumulated up to $48 \mathrm{hr}$ growth. 


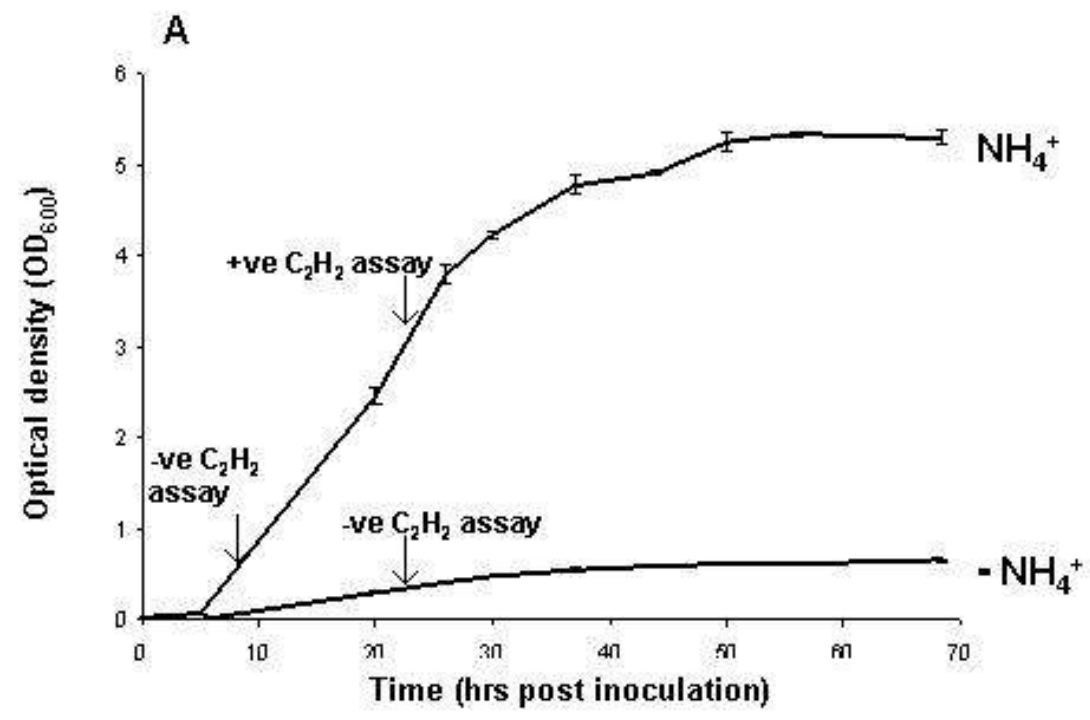

B

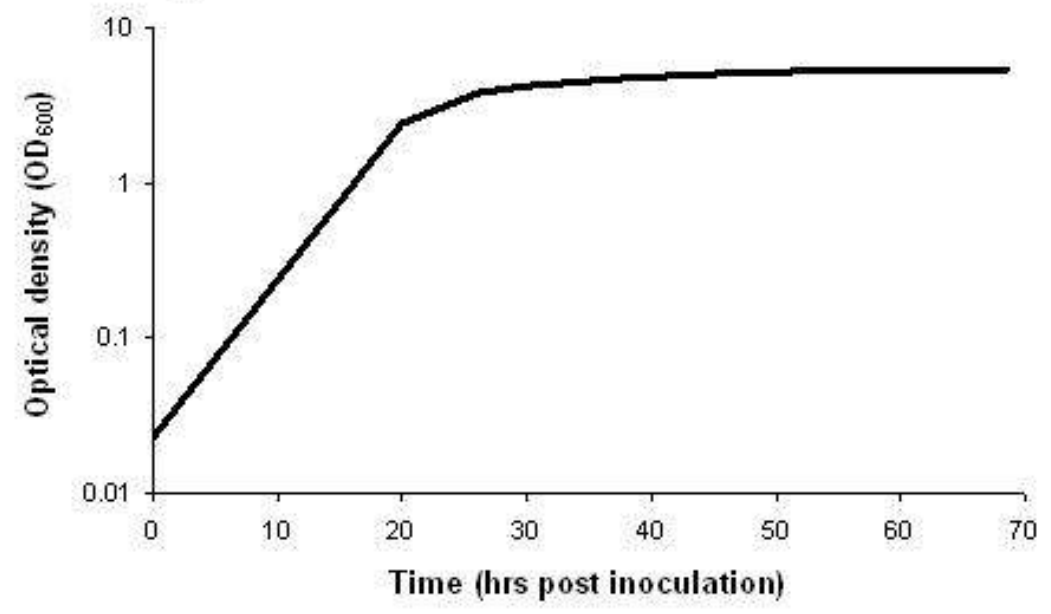

Figure $3.9{\mathrm{Y} 88^{\mathrm{T}}}$ growth in minimal nitrogen and nitrogen-free media.

(A) $\mathrm{Y}^{8} 8^{\mathrm{T}}$ growth $\left(\mathrm{OD}_{600}\right)$ measured over $72 \mathrm{hr}$ in a nitrogen -free $\left(-\mathrm{NH}_{4}{ }^{+}\right)$and in a minimal nitrogen $\left(0.1 \mathrm{~g} / \mathrm{L} \mathrm{NH}_{4} \mathrm{Cl}\right)\left(\mathrm{NH}_{4}^{+}\right)$medium. An $\mathrm{C}_{2} \mathrm{H}_{2}$ reduction assay to determine nitrogenase activity gave a negative result at $\mathrm{OD}_{600}=0.5$ (-ve $\mathrm{C}_{2} \mathrm{H}_{2}$ assay) for $\mathrm{Y}^{8} 8^{\mathrm{T}}$ cells grown under $\mathrm{NH}_{4}{ }^{+}$and $-\mathrm{NH}_{4}{ }^{+}$- conditions and a positive result at $\mathrm{OD}_{600}=2$ (+ve $\mathrm{C}_{2} \mathrm{H}_{2}$ assay) for $\mathrm{Y}^{2} 8^{\mathrm{T}}$ cells grown under $\mathrm{NH}_{4}{ }^{+}$conditions. (B) Growth curve of cells grown in $\mathrm{NH}_{4}{ }^{+}$medium fitted to a semi-log scale. Error bars represent standard deviations, $(\mathrm{n}=3)$. 
supplemented in the medium at $0.1 \mathrm{~g} / \mathrm{L}\left(2.2 \mathrm{mM} \mathrm{NH}_{4} \mathrm{Cl}\right.$ comprising $0.034 \mathrm{~g} / \mathrm{L}$ $\mathrm{NH}_{4}{ }^{+}$), Y88 ${ }^{\mathrm{T}}$ showed significantly higher growth over $24 \mathrm{hr}$ to either $A$. vinelandii or P. putida $\mathrm{mt} 2$. $\mathrm{Y}^{8} 8^{\mathrm{T}}$ showed a slow increase in $\mathrm{OD}_{600}$ during the first $8 \mathrm{hr}$, which is consistent with the lag phase of growth (Fig. 3.9). During this time, an ammonium assay determined that the ammonium initially supplemented in the medium showed no measurable change (Fig. 3.10). After the first $8 \mathrm{hr}$ of growth, ammonium was steadily depleted until no measurable ammonium remained in the medium by approximately $20 \mathrm{hr}$ of growth. Further monitoring of the ammonium in the medium showed no measurable change in concentration between 20-72 hr. Therefore, all the ammonium had been removed by $\mathrm{Y}^{\mathrm{T}} \mathrm{T}$ from the medium by $20 \mathrm{hr}$ (Fig. 3.10). Despite this, $\mathrm{Y}^{\mathrm{T}} 8^{\mathrm{T}} \mathrm{OD}_{600}$ increased steadily between 20-30 hr corresponding to mid to late log phase (Figs. 3.9 and 3.11). An $\mathrm{C}_{2} \mathrm{H}_{2}$ reduction assay gave a positive result for nitrogenase activity in cells harvested at $24 \mathrm{hr}$ following ammonium depletion in the cultures initially supplemented with ammonium, indicative of the cells fixing nitrogen (see chromatogram E in Fig. 3.14 and section 3.2.2.2.1 for a more detailed description of the $\mathrm{C}_{2} \mathrm{H}_{2}$ reduction assay results). Thus the only nitrogen available to the cells during that phase of growth was in the form of molecular nitrogen. In contrast, a negative result for nitrogenase activity in cells harvested at the same time from ammonium-free cultures was indicative of the cells not fixing nitrogen in these cultures. $\mathrm{Y}^{\mathrm{T}} \mathrm{OD}_{600}$ measurements in ammoniumsupplemented medium reached a maximum $\mathrm{OD}_{600}>5.0$ for all replicates $(n=3)$ by $35-40 \mathrm{hr}$ post-inoculation. At this stage, the cells had entered the stationary phase of growth (Figs. 3.9 and 3.11). The comparison between ammonium-free and ammonium-supplemented growth showed that $\mathrm{Y}^{\mathrm{T}} 8^{\mathrm{T}}$ cells attain high optical density and can fix nitrogen when ammonium is supplemented in the medium. In contrast, $\mathrm{Y}^{8} 8^{\mathrm{T}}$ cells grown in ammonium-free medium, only achieved a low relative $\mathrm{OD}_{600}$ (approximately 0.7 ) with no measurable nitrogenase activity, suggesting the cells were not able to give a positive acetylene reduction assay without ammonium added to the medium. Thus it appears that $\mathrm{Y} 88^{\mathrm{T}}$ cells require small amounts of ammonium to promote initial 


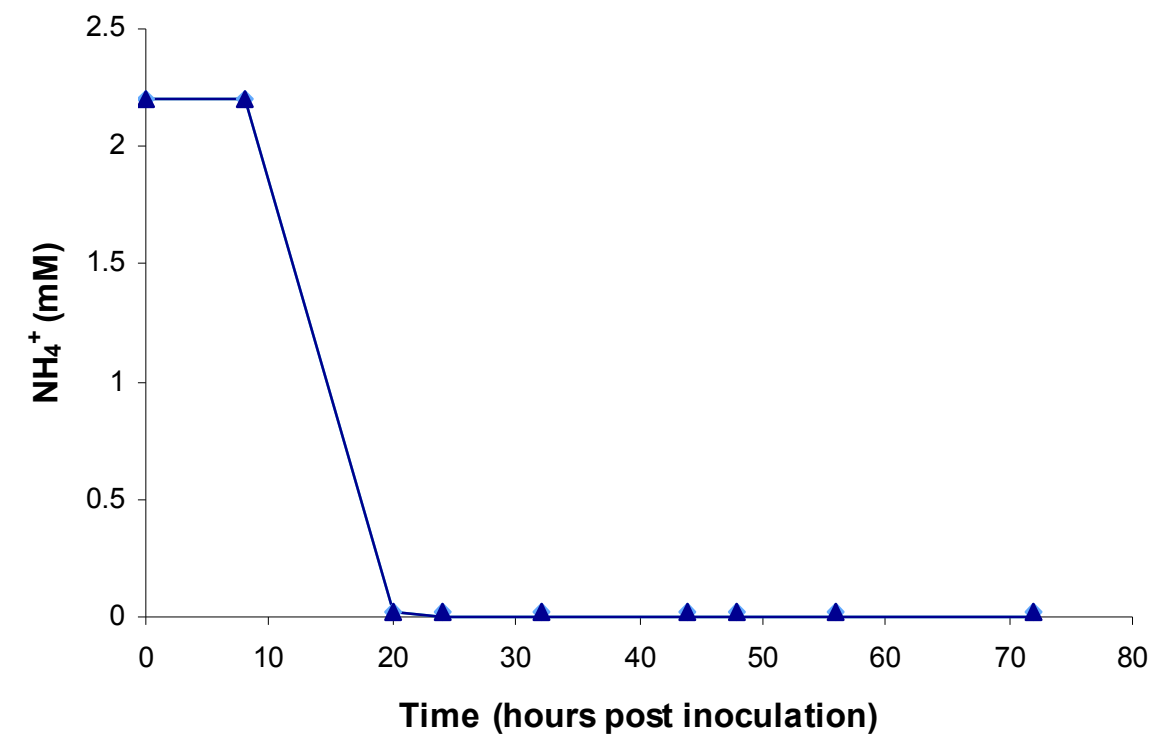

Figure 3.10 Ammonium utilisation by $\mathrm{Y} 88^{\mathrm{T}}$

Ammonium assimilation by $\mathrm{Y}^{8} 8^{\mathrm{T}}$ shows depletion of ammonium after $20 \mathrm{hrs}$ to almost undetectable levels with no change in ammonium concentrations thereafter, $(n=2)$. 


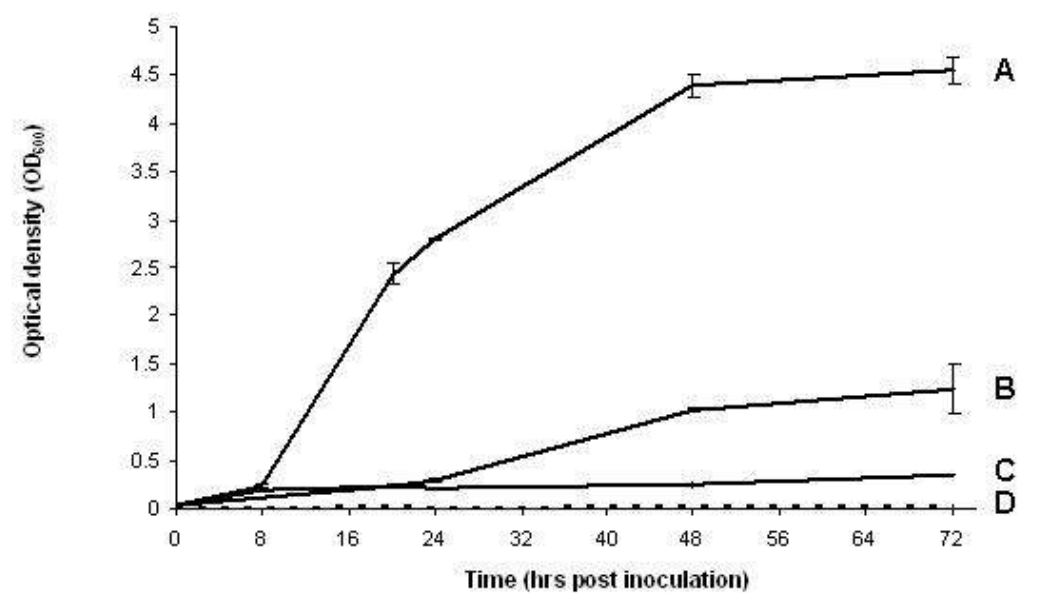

Figure 3.11 Comparative growth of $\mathrm{Y} 88^{\mathrm{T}}$, A. vinelandii, and P. putida $\mathrm{mt} 2$

Comparative growth of $\mathrm{Y}^{\mathrm{T}}$ (A), A. vinelandii (B) and P. putida $\mathrm{mt} 2$ (C) during $72 \mathrm{hr}$ in a glucose-enriched $(5 \mathrm{~g} / \mathrm{L})$, minimal nitrogen $\mathrm{NH}_{4} \mathrm{Cl}(0.1 \mathrm{~g} / \mathrm{L})$ medium, $(\mathrm{n}=3)$. A control (D) containing $\mathrm{Y}^{8} 8^{\mathrm{T}}$ cells but no glucose in the medium was included. Error bars represent standard deviations. 
cell growth and nitrogen fixation in batch culture.

\subsubsection{Growth, biomass and $\mathrm{PHB}$ production in $\mathrm{NH}_{4}{ }^{+}$-supplemented media}

Y88 ${ }^{\mathrm{T}}$ and $P$. putida mt2 showed superior growth after $24 \mathrm{hr}$ in an ammoniumsupplemented compared to their growth in an ammonium-free, glucoseenriched medium (as discussed above in section 3.2.2.1). Since A. vinelandii reached an $\mathrm{OD}_{600}$ of approximately 1.0 in the same ammonium-supplemented medium, this medium was used as the preferred medium to compare PHB accumulation, nitrogen fixation and biomass in these three species. Y88T, $A$. vinelandii (positive control for PHB accumulation) and P. putida mt2 (negative control for PHB accumulation which synthesises PHAs but not of the PHB type) were grown in a glucose-enriched minimal nitrogen $\left(0.1 \mathrm{~g} / \mathrm{L} \mathrm{NH} \mathrm{NH}_{4} \mathrm{Cl}\right.$ medium to determine how much biomass and PHB each strain could produce under standardised growth conditions. OD 600 , biomass and $\mathrm{PHB}$ produced by $\mathrm{Y} 88^{\mathrm{T}}$ and $A$. vinelandii under ammonium assimilatory and nitrogen-limiting conditions demonstrated the ability of these nitrogen-fixing bacteria to grow on glucose as a carbon substrate and convert it to PHB under these growth conditions (Figs. 3.12, 3.13). Although both nitrogen fixers displayed the ability to fix nitrogen under the tested growth conditions (Fig. 3.14), Y88 ${ }^{\mathrm{T}^{\prime}} \mathrm{S}$ ability to produce PHB was superior to that of $A$. vinelandii in a nitrogen-limiting, glucose-enriched growth medium as is evident from the higher PHB produced by $\mathrm{Y}^{\mathrm{T}}$ (Figs. 3.12, Fig. 3.13).

During the early lag phase of growth, little difference was evident among the cell densities of the three species with an $\mathrm{OD}_{600}$ of approximately 0.3 measured for all (Fig. 3.11). This lag phase coincided with the period during $Y 88^{\mathrm{T}}$ growth in which supplemented ammonium $\left(0.1 \mathrm{~g} / \mathrm{L} \mathrm{NH}_{4} \mathrm{Cl}\right.$ equivalent to $\left.2.8 \mathrm{mM}\right)$ showed no detectable depletion in the medium (see Fig. 3.10, Section 3.2.2.1). Following the lag phase of growth and by $24 \mathrm{hr}$ post inoculation, $\mathrm{Y}^{\mathrm{T}} 8^{\mathrm{T}}$ attained a dry biomass of approximately $0.9 \mathrm{~g} / \mathrm{L}$ (Fig. 3.12). Approximately $40 \%$ (0.34 


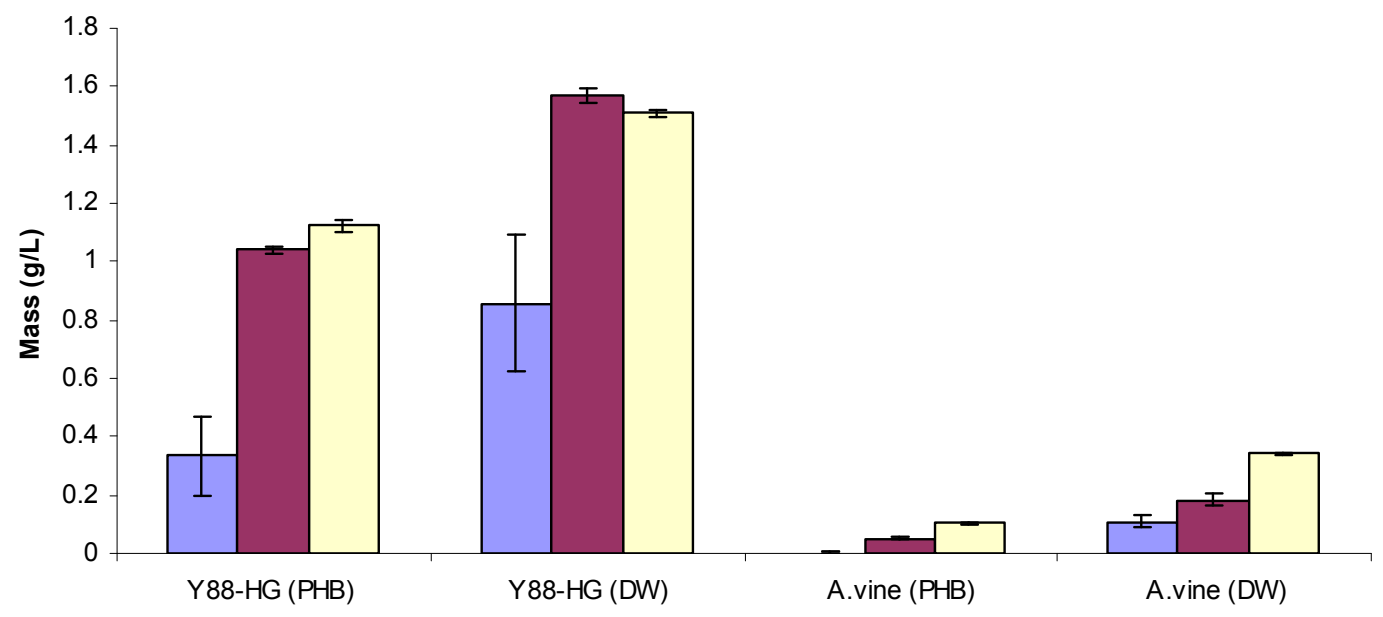

Figure 3.12 Comparative PHB mass and total dry biomass production by $\mathrm{Y}^{8} 8^{\mathrm{T}}$ and $A$. vinelandii $\mathrm{PHB}$ and dry biomass (dry weight (DW) produced by the nitrogen-fixing $\mathrm{Y} 88^{\mathrm{T}}$ and $A$. vinelandii (A. vine) when cultivated for $72 \mathrm{hr}$ in glucose-enriched $(27 \mathrm{mM})$ minimal nitrogensupplemented $\left(2.8 \mathrm{mM} \mathrm{NH}_{4} \mathrm{Cl}\right)$ medium. Bars represent time: $24 \mathrm{hr}=$ blue, $48 \mathrm{hr}=$ maroon, 72 $\mathrm{hr}=$ cream. Error bars represent standard deviations, $(\mathrm{n}=3)$. 


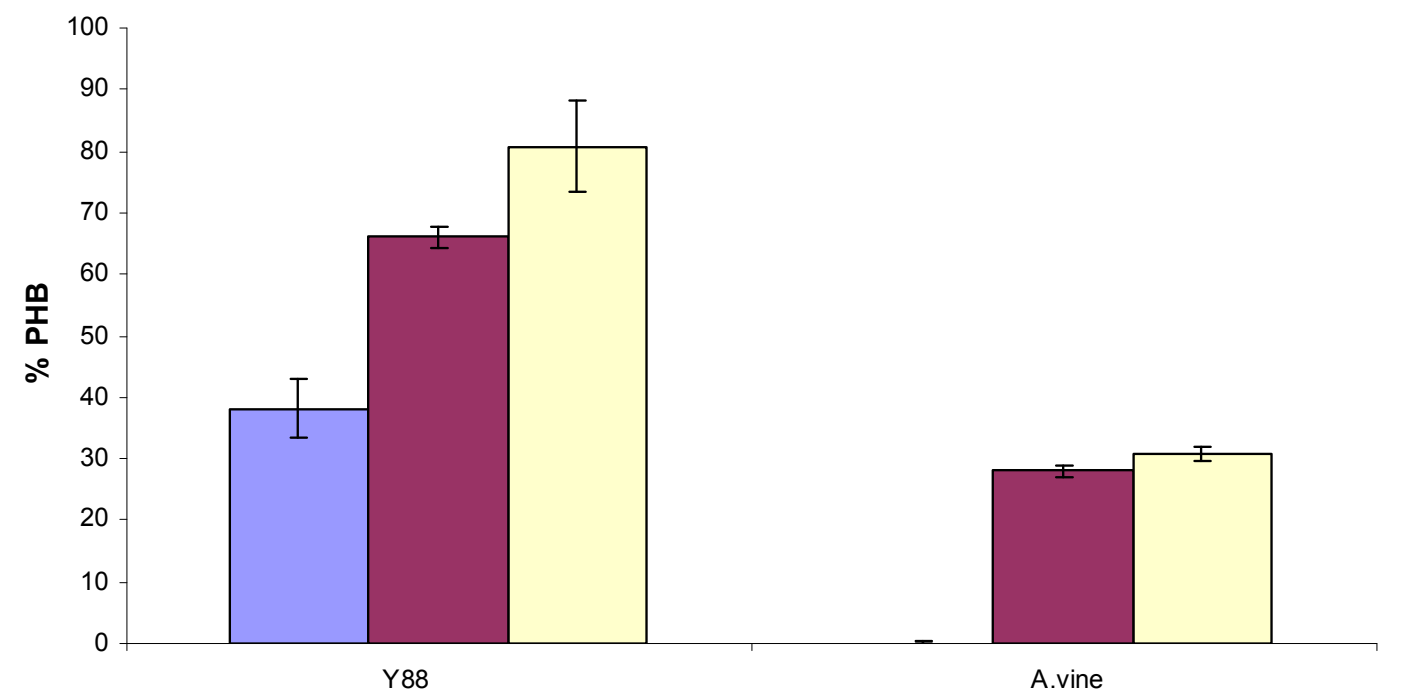

Figure 3.13 Comparative PHB production by $\mathrm{Y}^{8} 8^{\mathrm{T}}$ and A. vinelandii at 24, 48 and $72 \mathrm{hr}$.

Inter-specific comparison of PHB expressed as a percentage of dry biomass produced by the nitrogen-fixing $\mathrm{Y}^{8} 8^{\mathrm{T}}$ and $A$. vinelandii cultivated for $72 \mathrm{hr}$ in a glucose-enriched $(27 \mathrm{mM})$ minimal nitrogen-supplemented $\left(2.8 \mathrm{mM} \mathrm{NH}_{4} \mathrm{Cl}\right)$ medium. Bars represent time: $24 \mathrm{hr}=$ blue, $48 \mathrm{hr}=$ maroon, $72 \mathrm{hr}=$ cream. Error bars represent standard deviations, $(\mathrm{n}=3)$. 


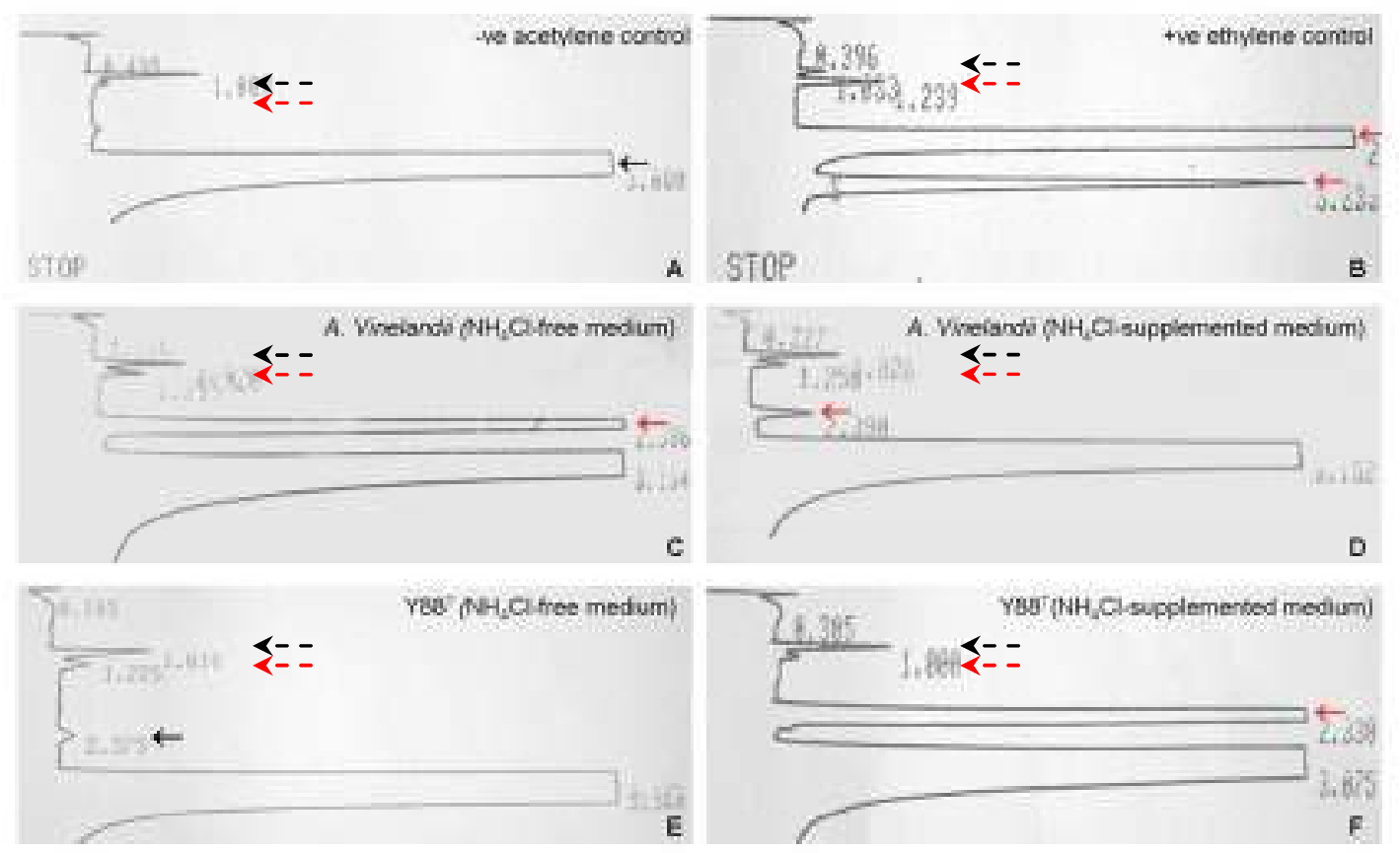

Figure 3.14 Acetylene reduction assays of $\mathrm{Y}^{8} 8^{\mathrm{T}}$ and $A$. vinelandii under various growth conditions

Representative chromatograms of $\mathrm{C}_{2} \mathrm{H}_{2}$ and ethylene peaks depicting inactive and active nitrogenase detected in $\mathrm{C}_{2} \mathrm{H}_{2}$ reduction assays. Red arrows (with solid lines) indicate positive ethylene peaks in positive ethylene control (B), Y88 $8^{\mathrm{T}}$ grown in ammonium-supplemented medium (F) and A. vinelandii grown in ammonium-free (C) and ammonium-supplemented (D) medium. Black arrows indicate $\mathrm{C}_{2} \mathrm{H}_{2}$ peak in negative $\mathrm{C}_{2} \mathrm{H}_{2}$ control (A) and the lack of an ethylene peak for $\mathrm{Y}^{8} 8^{\mathrm{T}}$ grown in ammonium-free (E) glucose-enriched medium. The representative chromatogram in each assay also has an argon peak (black arrows with broken lines) and an oxygen peak (red arrows with broken lines); $\mathrm{n}=2$ for $\mathrm{A}$ to $\mathrm{F}$ but only one representative chromatogram of each pair is shown. 
$\mathrm{g} / \mathrm{L}$ ) of the dry biomass consisted of PHB (Fig. 3.13). In comparison, A. vinelandii attained a dry biomass of $0.1 \mathrm{~g} / \mathrm{L}$ with $0.14 \%(0.0035 \mathrm{~g} / \mathrm{L})$ consisting of PHB (Fig. 3.13). For the same period of growth, P. putida $\mathrm{mt} 2$ produced 0.04 $\mathrm{g} / \mathrm{L}$ dry biomass but no PHB (data not shown).

After $48 \mathrm{hr}, \mathrm{Y}^{8} 8^{\mathrm{T}}$ attained a dry biomass of $1.5 \mathrm{~g} / \mathrm{L}$ compared to a dry biomass of $0.2 \mathrm{~g} / \mathrm{L}$ for A. vinelandii (Fig. 3.12). At this time, P. putida mt2 attained a dry biomass of $0.2 \mathrm{~g} / \mathrm{L}$, demonstrating how little growth $0.1 \mathrm{~g} / \mathrm{L} \mathrm{NH} \mathrm{N}_{4} \mathrm{Cl}$ can support for a confirmed non-nitrogen fixer. The amount of PHB produced by Y $88^{\mathrm{T}}$ after $48 \mathrm{hr}$ constituted $66 \%(1.04 \mathrm{~g} / \mathrm{L})$ of its dry biomass, whereas $A$. vinelandii produced 28\% (0.05 g/L) (Fig. 3.12) under these standardised growth conditions.

Between 48-72 $\mathrm{hr}$ post inoculation, $\mathrm{Y}^{\mathrm{T}} 8^{\mathrm{T}}$ produced no additional biomass growing to a final biomass of $1.5 \mathrm{~g} / \mathrm{L}$. Despite this lack of increase in biomass, $80 \%(1.125 \mathrm{~g} / \mathrm{L})$ of the dry biomass now consisted of PHB. In comparison for this same time period, dry biomass measurements for $A$. vinelandii showed an increase of more than $50 \%$ to $0.34 \mathrm{~g} / \mathrm{L}$ with $31 \%(0.11 \mathrm{~g} / \mathrm{L})$ of this biomass comprising PHB. P. putida $\mathrm{mt} 2$ reached a final dry biomass of $0.2 \mathrm{~g} / \mathrm{L}$ and produced no PHB.

These results confirm that $\mathrm{Y} 88^{\mathrm{T}}$ produced a greater biomass and PHB than the nitrogen-fixing, PHB-accumulating $A$. vinelandii under identical growth conditions. Y88 $8^{\mathrm{T}}$ produced up to $97 \%$ more $\mathrm{PHB}$ after $72 \mathrm{hrs}$ than $A$. vinelandii. Compared to A. vinelandii, which other authors have shown to produce up to $40 \%$ PHB (including 3-hydroxyvalerate) on glucose but with valerate added to the glucose as a precursor (Page et al., 1992; Pettinari et al., 2001), Y88 $88^{\mathrm{T}}$ has demonstrated a superior ability to produce PHB to high levels of its biomass under our standard growth conditions compared to another nitrogen fixer such as $A$. vinelandii under similar growth conditions. 


\subsection{Acetylene reduction assay}

${\mathrm{Y} 88^{\mathrm{T}}}$, A. vinelandii and P. putida $\mathrm{mt} 2$ cells were assayed for nitrogenase activity in cells cultivated in glucose-enriched medium for $24 \mathrm{hrs}$ either with or without supplemented ammonium. $\mathrm{Y}^{8} 8^{\mathrm{T}}$ cells cultivated in ammonium-free medium attained an $\mathrm{OD}_{600}$ equal to 0.7 by $24 \mathrm{hrs}$. A negative $\mathrm{C}_{2} \mathrm{H}_{2}$ reduction assay was obtained (Fig. 3.14E) despite its ability to fix molecular nitrogen, demonstrating the lack of assayable nitrogenase activity in $\mathrm{Y} 88^{\mathrm{T}}$ under growth conditions with no initial supplemented ammonium. In contrast, $A$. vinelandii cells grown in the ammonium-free medium to an $\mathrm{OD}_{600}$ of 1.0 at 24 hrs gave a positive $\mathrm{C}_{2} \mathrm{H}_{2}$ reduction assay (Fig. 3.14C). As expected, P. putida mt2, incapable of fixing molecular nitrogen, gave a negative $\mathrm{C}_{2} \mathrm{H}_{2}$ reduction assay at $24 \mathrm{hrs}$ and did not show any measurable growth during this period (chromatogram not shown).

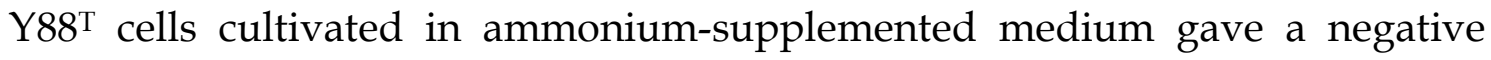
assay for nitrogenase activity at an $\mathrm{OD}_{600}=0.5$ but gave a positive assay for nitrogenase activity at $24 \mathrm{hr}$ when the cells reached a high $\mathrm{OD}_{600}(>2.0)$ (Fig. 3.14F). Under these same growth conditions, A. vinelandii cells gave a positive $\mathrm{C}_{2} \mathrm{H}_{2}$ reduction assay for nitrogenase activity but the peak was much smaller (Fig. 3.14D) compared to that obtained for $A$. vinelandii cells grown in the ammonium-free medium (Fig. 3.14C). P. putida $\mathrm{mt} 2$ cells grown in the ammonium-supplemented medium gave a negative $\mathrm{C}_{2} \mathrm{H}_{2}$ reduction assay as expected (chromatogram not shown).

The difference between $\mathrm{Y}^{8} 8^{\mathrm{T}}$ and $A$. vinelandii in their abilities to produce a positive ethylene peak when grown in ammonium-free medium is surprising given that both are capable of fixing nitrogen. Two points are noteworthy in this regard. First, $\mathrm{Y}^{\mathrm{T}} 8^{\mathrm{T}}$ cells gave a positive ethylene peak only when their $\mathrm{OD}_{600}$ was greater than approximately 1.4 in the ammonium-supplemented medium. At $\mathrm{OD}_{600}$ measurements less than 1.4, despite growing at a high rate, the cells always gave a negative $\mathrm{C}_{2} \mathrm{H}_{2}$ reduction assay, even when an equivalent cell biomass was used in the $\mathrm{C}_{2} \mathrm{H}_{2}$ reduction assays to compensate for the difference 
in the number of cells in the assays (data not shown). The switch to nitrogen fixation coincided with mid-log-phase growth, usually between 20 and $22 \mathrm{hr}$ post-inoculation and an $\mathrm{OD}_{600}$ greater than 1.4. Since $Y 88^{\mathrm{T}}$ never reached an $\mathrm{OD}_{600}$ of greater than 0.7 in the ammonium-free medium, this could have been a factor in producing the negative result, since any active nitrogenase may not have been present at detectable levels in the assay when measured at low $\mathrm{OD}_{600}$. Secondly, the results in this study suggest that the ability of $Y 88^{\mathrm{T}}$ to fix nitrogen relies on the presence of minimal amounts of available ammonium ion at low $\mathrm{OD}_{600}$ to initially promote growth. Thus in the absence of sufficient initial quantities of this supply, growth is restricted, as is the ability to initiate nitrogen fixation.

The ethylene peak produced by $\mathrm{Y}^{2} 8^{\mathrm{T}}$ in ammonium-supplemented medium (Fig. 3.14F) was much larger relative to that produced by A. vinelandii cells grown in parallel in the same medium (Fig. 3.14C). This result is not surprising considering that $A$. vinelandii experiences variable inhibition of nitrogenase activity by the addition of ammonium chloride (Laane et al., (1980). Thus, growth in our glucose-enriched medium supplemented with $0.1 \mathrm{~g} / \mathrm{L}$ of ammonium chloride, while favourable for $\mathrm{Y}^{8} 8^{\mathrm{T}}$ growth and nitrogen fixation, does not promote growth in A. vinelandii during the first 24 hrs post-inoculation in the same way that it does in $\mathrm{Y} 88^{\mathrm{T}}$. The addition of ammonium chloride to the growth medium therefore does not appear to have the same extended inhibitory effect on $Y 88^{\mathrm{T}}$ growth and nitrogenase activity as it does on $A$. vinelandii growth in our standard ammonium supplemented medium.

\subsubsection{Comparison between $\mathrm{Y}^{\mathrm{T}}{ }^{\mathrm{T}}$ and $\mathrm{WP01}$}

\subsection{Growth and PHB production}

The growth and PHB-producing abilities of $\mathrm{Y}^{8} 8^{\mathrm{T}}$ and WP01 were compared to determine which of these two PHB producers accumulated the most PHB when cultivated on glucose or acetate. This work was done primarily to examine the potential of these bacteria as PHB production strains. Although it was 
established in section 3.2.1.2.2 that $\mathrm{Y} 88^{\mathrm{T}}$ preferred glucose over acetate as a carbon substrate and produced more PHB when grown on glucose, it was of interest to determine whether another member within the same family produced similar amounts of PHB to $\mathrm{Y}^{2} 8^{\mathrm{T}}$ under the same glucose or acetateenriched growth conditions and to directly compare the two species side-byside. Also of interest was whether the ability of $Y 88^{\mathrm{T}}$ to fix molecular nitrogen conferred an advantage to produce higher levels of PHB on glucose and acetate than that produced by a phylogenetically similar PHB producer, WP01, lacking any nitrogen-fixing genes in its genome and therefore incapable of fixing molecular nitrogen (Strabala, Macdonald \& Liu, unpublished results).

$\mathrm{Y}^{\mathrm{T}}$ and WP01 were cultivated in parallel in either a glucose- or acetateenriched minimal nitrogen medium. For $\mathrm{Y}^{\mathrm{T}} 8^{\mathrm{T}}$ acetate growth, two different minimal nitrogen media were used: the same minimal nitrogen $\left(0.1 \mathrm{~g} / \mathrm{L} \mathrm{NH}_{4} \mathrm{Cl}\right.$ supplemented) medium used for all subsequent $Y 88^{\mathrm{T}}$ experiments in this study and the basal salts medium $(1 \times$ BSM) used in our laboratory as the standard WP01 growth medium. For WP01, three different media were used: the Y88 minimal nitrogen medium described above, basal salts medium ( $1 \times$ BSM) supplemented with $0.1 \mathrm{~g} / \mathrm{L} \mathrm{NH}_{4} \mathrm{Cl}$ and a variant of the $1 \times \mathrm{BSM}$ containing the same ingredients as the $1 \times$ BSM but with no added nitrogen source.

Cells cultivated in the glucose-enriched nitrogen-fixing medium (supplemented with $0.1 \mathrm{~g} / \mathrm{L} \mathrm{NH}_{4} \mathrm{Cl}$ ) attained a higher $\mathrm{OD}_{600}$ for $\mathrm{Y}^{\mathrm{T}}$ after $24 \mathrm{hr}$ than WP01 (Fig. 3.15). The dry biomass of $0.8 \mathrm{~g} / \mathrm{L}$ obtained for $\mathrm{Y}^{\mathrm{T}} 8^{\mathrm{T}}$ consisted of approximately $60 \%$ PHB $(0.47 \mathrm{~g} / \mathrm{L})$ whereas a lower dry biomass of $0.5 \mathrm{~g} / \mathrm{L}$ for WP01 consisted of 54\% (0.27 g/L) PHB (Fig. 3.16). The ability of Y88 to fix nitrogen therefore confers a growth advantage in a glucose-enriched minimal nitrogen medium, enabling it to attain a higher amount of biomass and PHB production than WP01 under the same growth conditions. 


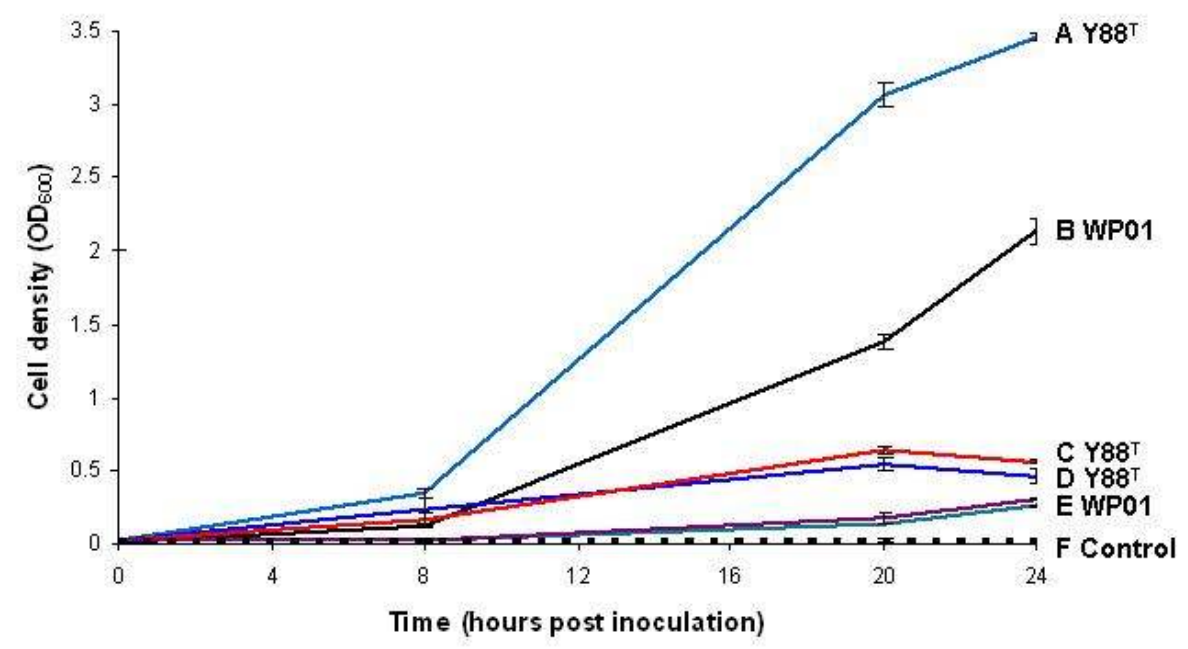

Figure 3.15 Growth of Y88 ${ }^{\mathrm{T}}$ and WP01 in a glucose-enriched, acetate-enriched and carbon-free medium

Comparative growth of $\mathrm{Y}^{8} 8^{\mathrm{T}}$ on glucose-enriched nitrogen-fixing medium (A), acetate-enriched nitrogen-fixing medium (C) and acetate-enriched 1x BSM (D) with WP01 on glucose-enriched nitrogen-fixing medium (B), acetate-enriched variant medium without supplemented nitrogen (E purple line) and acetate-enriched 1x BSM (E green line). Three negative controls included were mock inoculations in acetate-enriched 1x BSM medium and mock inoculations in acetateenriched nitrogen-fixing medium and WP01 cells in acetate-free 1x BSM medium. The three control growth curves are superimposed (F) due to no measurable growth for all. Error bars represents standard deviations, $\mathrm{n}=2$. 


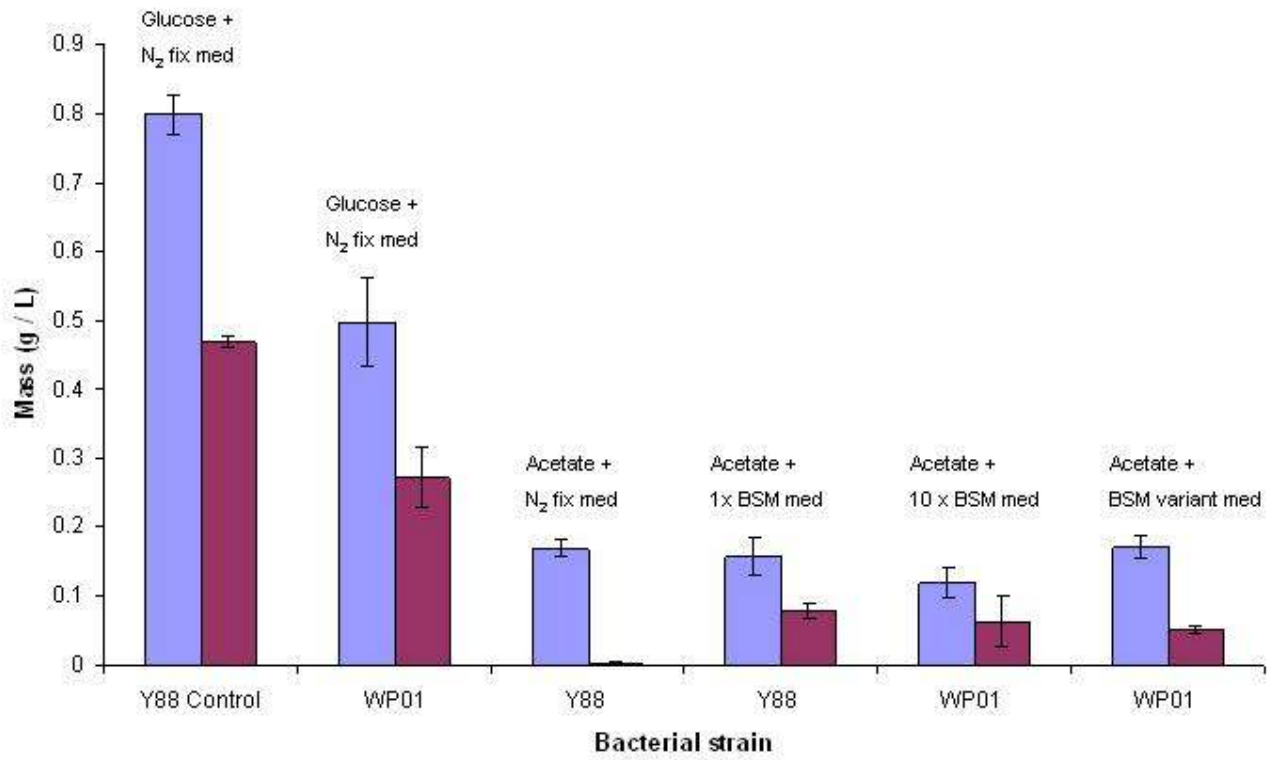

Figure 3.16 PHB and biomass produced by $\mathrm{Y}^{8} 8^{\mathrm{T}}$ and WP01 grown for $24 \mathrm{hr}$ in glucose-enriched nitrogen-fixing medium, acetate-enriched nitrogen-fixing medium, acetate-enriched 1x BSM and acetate-enriched variant 1x BSM with no nitrogen source

Blue bars $=$ dry biomass produced after $24 \mathrm{hr}$, maroon bars=PHB produced after $24 \mathrm{hr}$. Error bars represent standard deviations, $(\mathrm{n}=2)$. 
Y88 ${ }^{\mathrm{T}}$ cells cultivated in an acetate-enriched nitrogen-fixing medium and acetateenriched 1x BSM demonstrated that $\mathrm{Y}^{\mathrm{T}}$ achieved a similar $\mathrm{OD}_{600}$ of approximately 0.5 after $24 \mathrm{hr}$ and a similar dry biomass $(0.16 \mathrm{~g} / \mathrm{L})$ in both media (Fig. 3.16). Despite producing a similar biomass, 50\% of the dry biomass produced from Y88 ${ }^{\mathrm{T}}$ cells grown in $1 \times$ BSM consisted of PHB $(0.08 \mathrm{~g} / \mathrm{L})$ compared to only $1.3 \%(0.002 \mathrm{~g} / \mathrm{L})$ of the dry biomass produced from Y88 ${ }^{\mathrm{T}}$ cells grown in the nitrogen-fixing medium (Figs. $3.15 \& 3.16$ ). Thus for acetate growth, it would be beneficial to substitute the nitrogen-fixing medium I generally used for Y88T PHB production, for $1 \times$ BSM. Although use of this medium could boost $\mathrm{Y}^{\mathrm{T}} \mathrm{P}^{\mathrm{T}} \mathrm{PHB}$ production in an acetate-enriched environment, Y88 ${ }^{\mathrm{T}}$ cells produce a higher amount of PHB $(0.5 \mathrm{~g} / \mathrm{L})$ in glucose-enriched nitrogen-fixing medium than in acetate-enriched 1× BSM (0.08 g/L) after $24 \mathrm{hr}$.

Like Y88 ${ }^{\mathrm{T}}$, WP01 produced significantly less dry biomass and PHB (Fig. 3.16) in both acetate-enriched media compared with that produced in the glucoseenriched media. The amount of dry biomass produced by WP01 was similar to that produced by $\mathrm{Y}^{\mathrm{T}} 8^{\mathrm{T}}$ in $1 \times \mathrm{BSM}$ enriched with acetate. The amount of PHB produced by these sphingomonads in the acetate-enriched media did not differ significantly from each other.

For both $\mathrm{Y}^{\mathrm{T}}$ and WP01, a glucose-enriched minimal nitrogen medium promotes higher biomass production compared to acetate-enriched minimal nitrogen medium. Glucose is therefore the preferred carbon substrate for both $\mathrm{Y}^{\mathrm{T}}$ and WP01 rather than acetate, if achieving high amounts of PHB is desirable, since greater PHB production correlates with higher biomass in these bacteria under these experimental conditions. Furthermore, $\mathrm{Y}^{\mathrm{T}} 8^{\mathrm{T}}$ produces a higher amount of biomass and PHB than WP01 on glucose-enriched and acetate-enriched 1x BSM media, although in the latter medium the difference in PHB produced between the two strains is less pronounced. 


\subsubsection{Carbon and nitrogen utilisation by $\mathrm{Y}^{\mathrm{T}} \mathrm{T}$}

\subsection{Glucose assay results}

A glucose assay was carried out on $Y 88^{\mathrm{T}}$ cells grown in a glucose-enriched (5 g/L) minimal nitrogen (0.1 g/L) medium over $72 \mathrm{hr}$ (Fig. 3.17) with sampling times coinciding with different phases of growth during which i) ammonium supplied in the growth medium was being assimilated, ii) nitrogen fixation occurred as determined by a positive acetylene reduction assay and iii) the cells had reached stationary phase. The assay was carried out to characterise the rate at which $\mathrm{Y} 88^{\mathrm{T}}$ consumes glucose for each growth interval between sampling, as well as at which stage of the growth process most of the glucose is consumed. This assay was required to determine when the highest rate of glucose consumption occurred and if the rate at it was consumed correlated with the rate at which PHB was produced (see Fig. 3.18, blue bars, below).

Glucose assay results showed that $\mathrm{Y}^{\mathrm{T}}$ consumed glucose almost linearly between 10 and $30 \mathrm{hr}$ post inoculation and that most of the initial glucose supply of $27 \mathrm{mM}(5 \mathrm{~g} / \mathrm{L})$, had been depleted from the medium by $50 \mathrm{hr}$ (Fig. 3.17). The depletion of glucose from the medium correlated with the production of PHB being produced (Fig. 3.18). All the glucose was depleted by $72 \mathrm{hr}$.

\subsection{Total dissolved organic carbon (DOC) in spent medium}

The amount of total inorganic carbon (TIC) and DOC in the spent medium was determined during $\mathrm{Y}^{8} 8^{\mathrm{T}}$ growth on a glucose-enriched minimal nitrogen medium. This was to establish how much DOC remained in the growth medium following glucose depletion and PHB accumulation throughout the growth process.

The DOC results confirmed that more than $1 \mathrm{~g} / \mathrm{L}$ carbon, which equals $50 \%$ of the initial $2 \mathrm{~g} / \mathrm{L}$ of carbon in $5 \mathrm{~g} / \mathrm{L}$ of glucose, was removed from the medium 


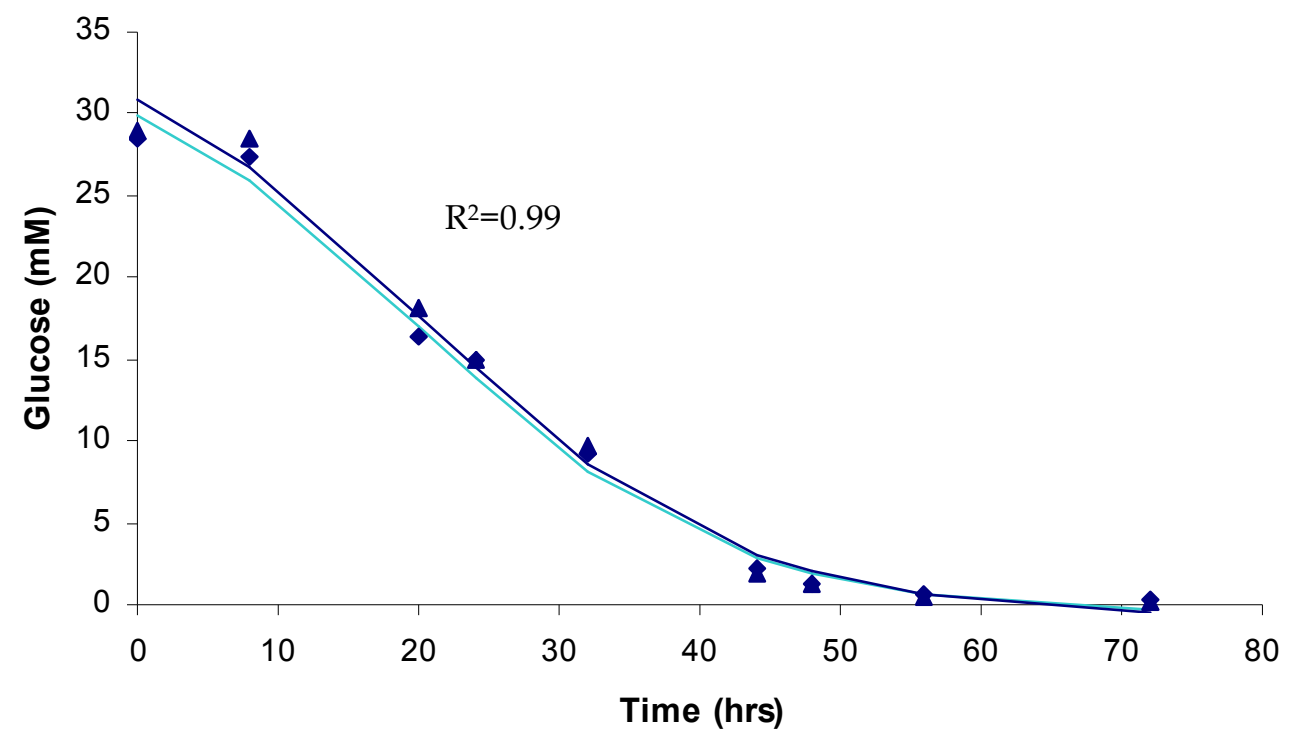

Figure 3.17 Glucose depletion by ${\text { Y } 88^{\mathrm{T}}}^{\mathrm{T}}$

Glucose remaining in the spent medium during $\mathrm{Y}^{\mathrm{T}} 8^{\mathrm{T}}$ growth over $72 \mathrm{hrs}$ in a carbon-enriched, minimal nitrogen medium, $(\mathrm{n}=2)$. 


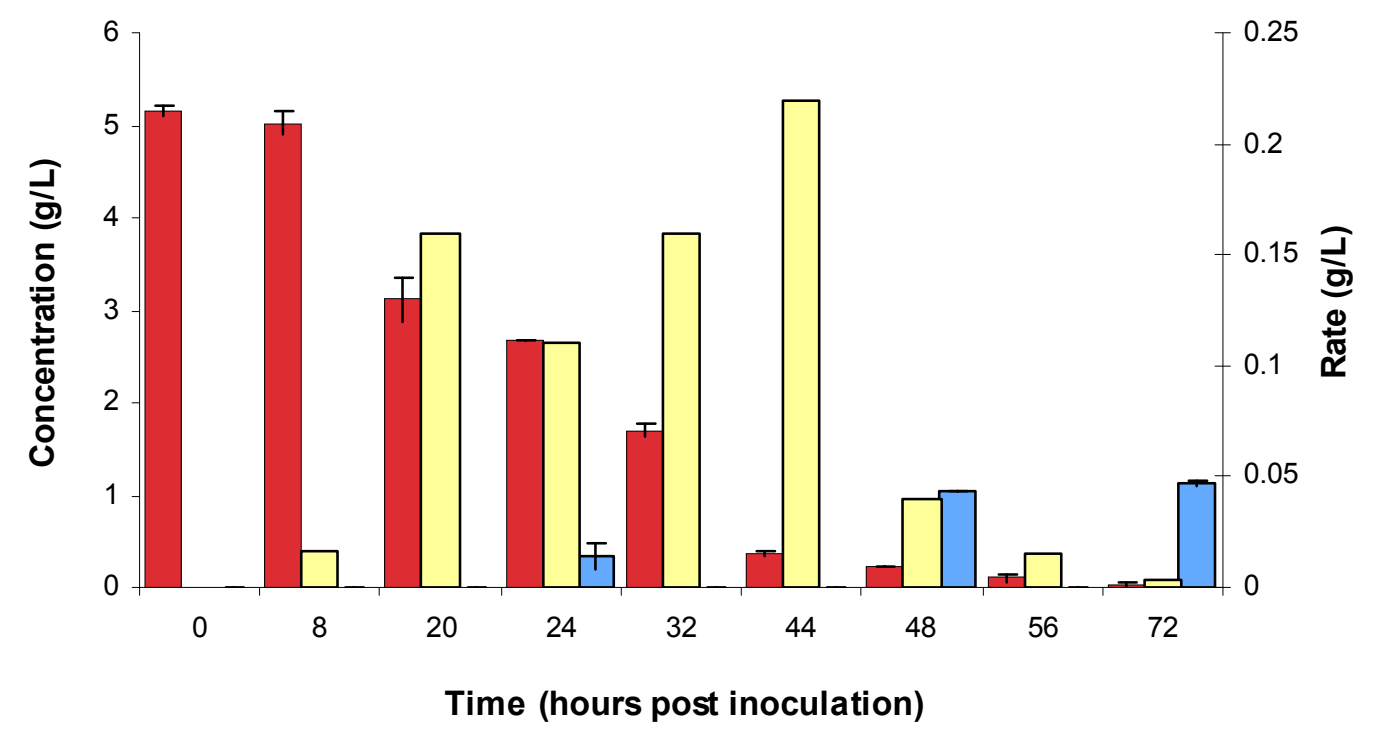

Figure 3.18 PHA production by $\mathrm{Y}^{8} 8^{\mathrm{T}}$ during glucose depletion

Glucose remaining in spent medium (red bars) during $\mathrm{Y} 88^{\mathrm{T}}$ consumption of glucose showing rate of glucose consumption (grams of glucose consumed per $\mathrm{hr}(\mathrm{g} / \mathrm{L} / \mathrm{hr})$ calculated for each time period between sampling (yellow bars) and the amount of PHB (blue bars) converted from glucose. Error bars represent standard deviations, n=2. Some error bars are not evident on graph due to small sampling errors. 
by $44 \mathrm{hr}$ (Fig. 3.19). The rate of carbon consumption by $\mathrm{Y}^{\mathrm{T}} 8^{\mathrm{T}}$ during the first $8 \mathrm{hr}$ of growth was $0.02 \mathrm{~g} / \mathrm{L} / \mathrm{hr}$. Between 8 and $20 \mathrm{hrs}$, the rate of carbon consumed increased slightly to $0.03 \mathrm{~g} / \mathrm{L} / \mathrm{hr}$. Between 20 and $28 \mathrm{hr}$, carbon was depleted at a rate of $0.08 \mathrm{~g} / \mathrm{L} / \mathrm{hr}$, corresponding to the mid to high log phase of growth when $\mathrm{Y}^{\mathrm{T}}$ cells are actively fixing nitrogen (as shown by a positive $\mathrm{C}_{2} \mathrm{H}_{2}$ reduction assay for nitrogenase activity). During the late log phase of growth and early stationary phase, carbon consumption by $\mathrm{Y}^{\mathrm{T}} 8^{\mathrm{T}}$ occurred at ate of $0.07 \mathrm{~g} / \mathrm{L} / \mathrm{hr}$. The highest rate of carbon consumption occurred between 44 and $48 \mathrm{hr}$ at a rate of $0.3 \mathrm{~g} / \mathrm{L} / \mathrm{hr}$. This coincided with the early- to mid- stationary phase, suggesting that although the cells were well past the highest rate of growth by then, an increased demand for carbon was presumably required to meet underlying metabolic demands of more cells after the growth spurt, in addition to other activities such as PHB production. Thus significantly more carbon is required during this period of the stationary phase than during any preceding stage of growth, including the mid to high log phase of growth when the cells were shown to fix nitrogen, a metabolically demanding activity, both for ATP production and reducing equivalents, which are produced via respiration.

\subsection{Ammonium assimilation}

Ammonium assimilation by $\mathrm{Y}^{\mathrm{T}} 8^{\mathrm{T}}$ during growth over $72 \mathrm{hr}$ on a glucoseenriched minimal nitrogen-supplemented $(0.1 \mathrm{~g} / \mathrm{L})$ medium was determined. The aim was to determine when ammonium becomes depleted in the medium as a result of $\mathrm{Y}^{8} 8^{\mathrm{T}}$ utilisation as well as identifying when the probable switch from ammonium assimilation to fixing nitrogen occurs. An ammonium assay was carried out on the spent medium at the same time intervals as that for which glucose and carbon were assayed. Ammonium assay results show that the ammonium supplemented in the medium at $0.1 \mathrm{~g} / \mathrm{L}$, was completely removed by $20 \mathrm{hr}$ growth with only minimal amounts at the limits of detection extant in the medium thereafter (Fig. 3.20). By $20 \mathrm{hr}, \mathrm{Y}^{\mathrm{T}} 8^{\mathrm{T}}$ cells had reached the $\log$ phase of growth and with no ammonium nitrogen available, Y88 ${ }^{\mathrm{T}}$ cells had to fix nitrogen to maintain an increase in $\mathrm{OD}_{600}$. A positive $\mathrm{C}_{2} \mathrm{H}_{2}$ reduction assay 106 


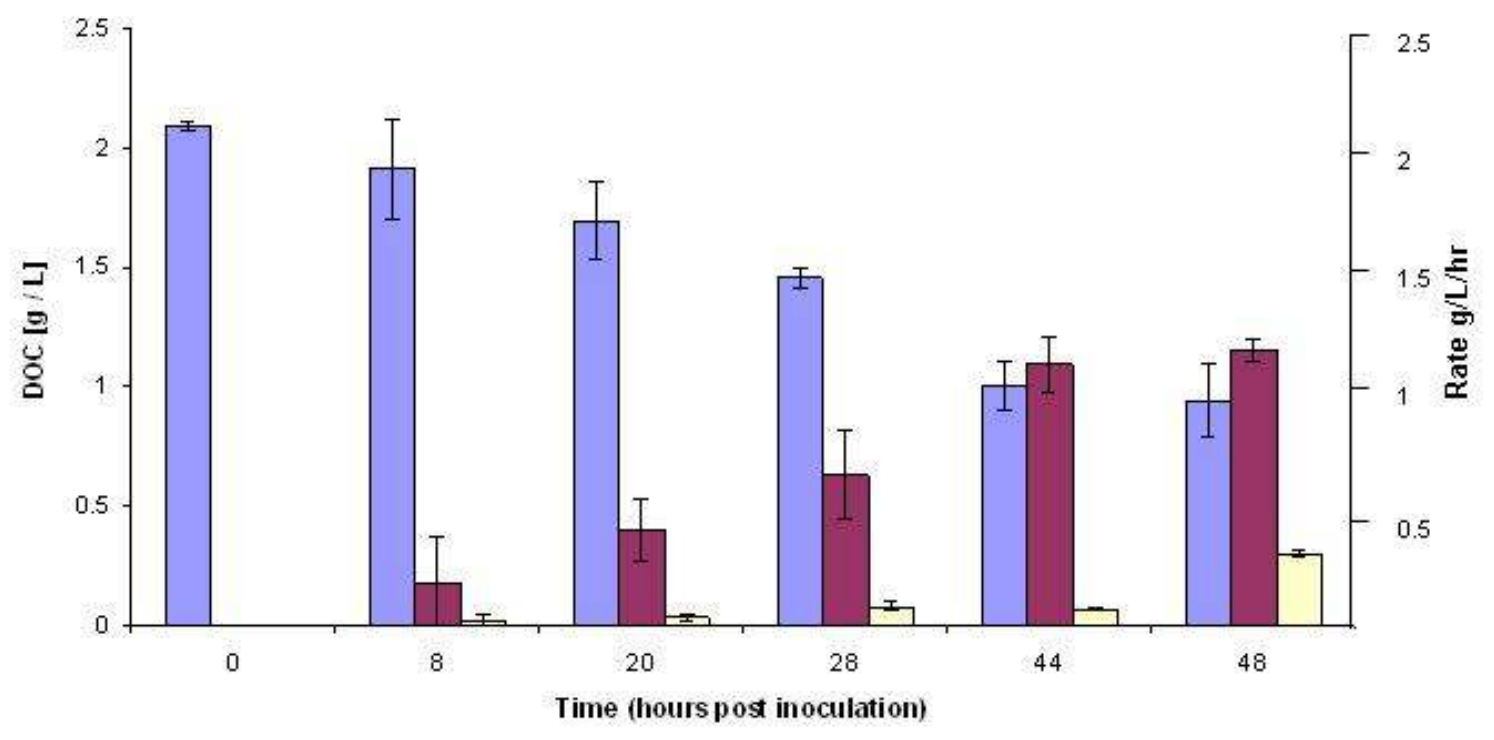

Figure 3.19 Total dissolved organic carbon (DOC) change during $\mathrm{Y}^{8} 8^{\mathrm{T}}$ growth

DOC removed (red bars) by $\mathrm{Y}^{\mathrm{T}} 8^{\mathrm{T}}$ from the glucose-enriched minimal nitrogen medium during $48 \mathrm{hr}$ growth. Blue bars=carbon remaining in medium, red bars=carbon utilised, yellow bars=the rate of carbon consumption. Error bars represent standard deviations, $(n=3)$. 


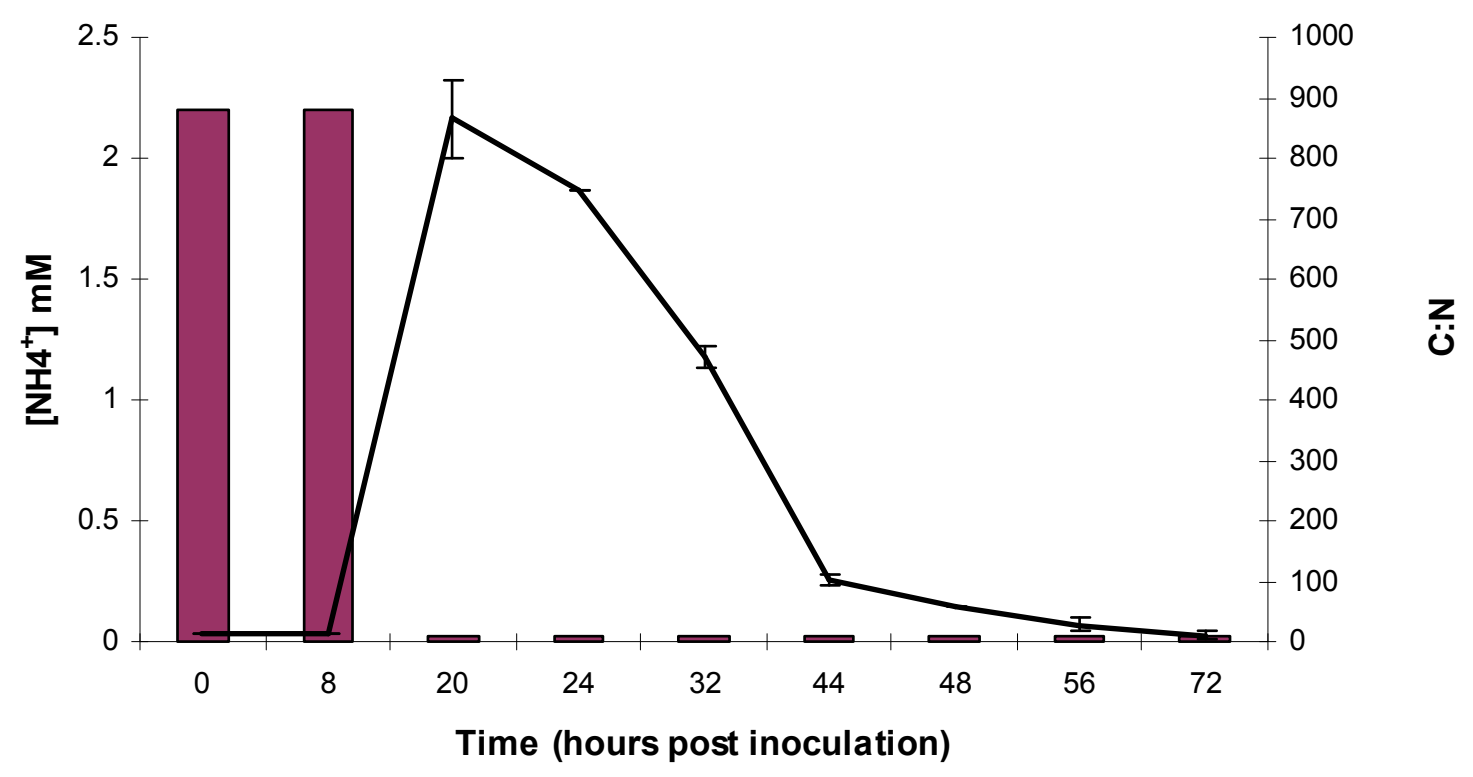

Figure 3.20 Change in C:N ratio during ammonium assimilation by $\mathrm{Y}^{8} 8^{\mathrm{T}}$

Ammonium remaining in medium (red bars, left y axis) during $Y 88^{\mathrm{T}}$ utilisation of glucose and the change in the C:N ratio (line graph, right y axis) during $72 \mathrm{hr}$ of growth. Error bars represent standard deviations, $(\mathrm{n}=2)$. 
at $24 \mathrm{hr}$ confirmed active nitrogenase in $\mathrm{Y}^{\mathrm{T}} 8^{\mathrm{T}}$ cells, indicative of nitrogen fixation by these cells at that stage of growth. The switch from ammonium assimilation to nitrogen fixation therefore occurs between 8-20 hr of growth although a positive $\mathrm{C}_{2} \mathrm{H}_{2}$ reduction assay is only obtained during 22-24 $\mathrm{hr}$ despite the cells growing exponentially at $20 \mathrm{hr}$.

\subsection{Change in carbon to nitrogen $(\mathrm{C}: \mathrm{N})$ ratio.}

The consumption of glucose and ammonium assimilation by $\mathrm{Y}^{\mathrm{T}}$ over $72 \mathrm{hr}$ changes the $\mathrm{C}: \mathrm{N}$ ratio in the medium during growth, which is known to affect the amount of PHB that is accumulated. The C:N ratio was therefore calculated from the amount of glucose and ammonium consumed.

During the first $8 \mathrm{hr}$ post-inoculation, very little change in the C:N ratio was evident (from approximately 13:1 to 12.5:1) (Figs. 3.20 and 3.21). From 8 to $20 \mathrm{hr}$, a significant change was observed with a high rate of glucose consumption (Fig. 3.21) and ammonium assimilation (Fig. 3.20). Ammonium nitrogen levels decreased to minimal levels during that time (Fig. 3.20) concomitant with a decrease in glucose by at least one-third of its original concentration. This change in glucose coincided with a dramatic change in ammonium levels (Fig. 3.20) to barely detectable levels which changed the C:N ratio from approximately $12.5: 1$ to $820: 1$ (Figs. 3.20 and 3.21). This change coincided with the early- to mid- log phase of growth. At $24 \mathrm{hr}$, when an $\mathrm{C}_{2} \mathrm{H}_{2}$ reduction assay gave a positive result for nitrogenase activity, the $C: N$ ratio showed a slight decline to 745:1. At $30 \mathrm{hr}$, the C:N ratio was 460:1, which was a decrease in the $\mathrm{C}: \mathrm{N}$ ratio approaching half that observed at $24 \mathrm{hr}$. Thereafter, the C:N ratio continued to decrease to $60: 1$ by $48 \mathrm{hr}$, coinciding with the highest rate of glucose removal (sections 3.2.1.7.1 and 3.2.1.7.2, Figs. 3.17 and 3.21). Although a 60:1 C:N ratio may still be considered high (Kostyál et al., 1997), relative to the C:N ratios obtained between 20 and $32 \mathrm{hr}$, it is much lower at $48 \mathrm{hr}$ which likely indicates a high rate of metabolic activity. Indeed, at this point, the decrease in the $\mathrm{C}: \mathrm{N}$ ratio in the medium correlates with the highest rate of $\mathrm{PHB}$ accumulation for $\mathrm{Y}^{8} 8^{\mathrm{T}}$ (see section 3.2.2.3.1). After $72 \mathrm{hr}$, the $\mathrm{C}: \mathrm{N}$ ratio was 


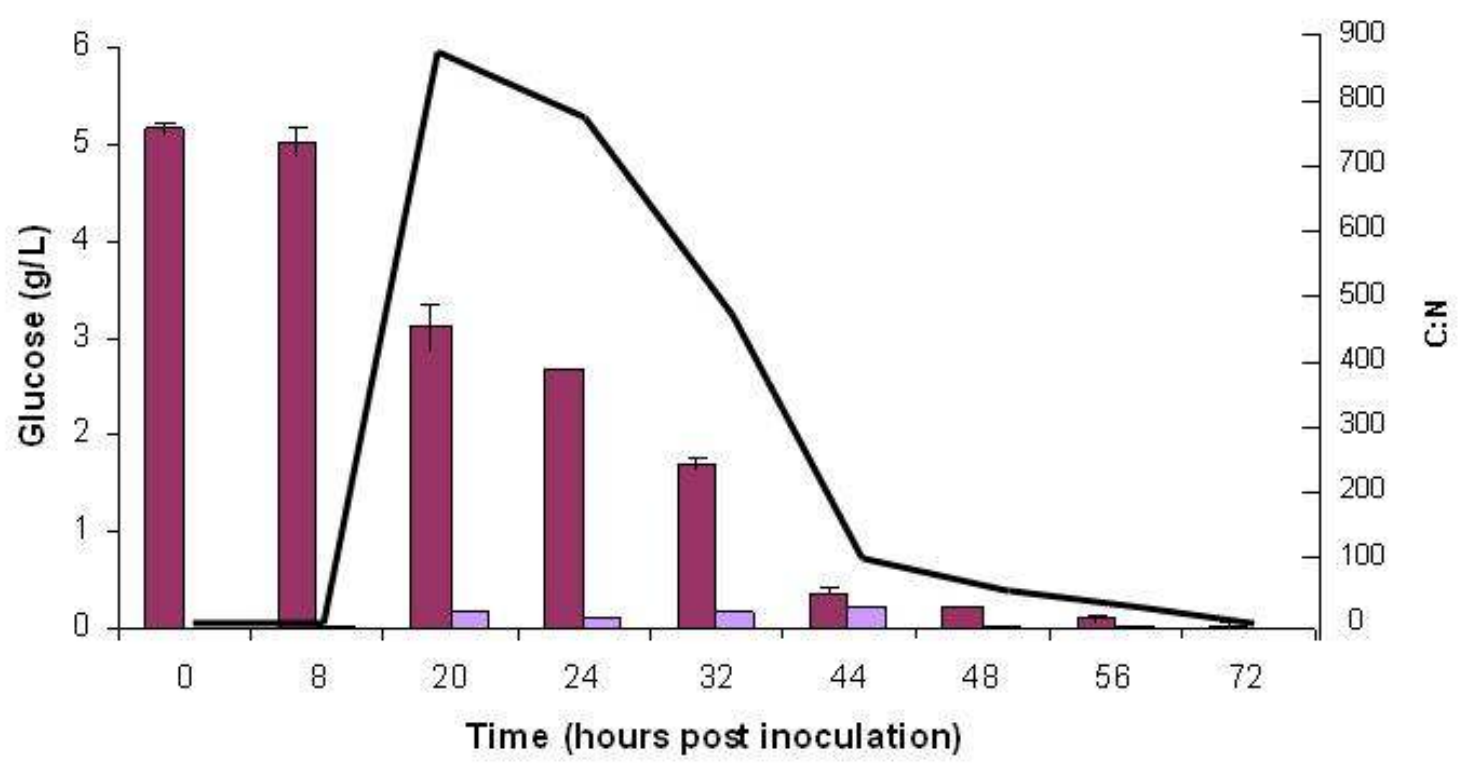

Figure 3.21 Y $88^{\mathrm{T}}$ glucose depletion: change in C:N ratio and rate of glucose depletion

Glucose remaining in spent medium (maroon bars; left y axis) during $\mathrm{Y}^{\mathrm{T}} 8^{\mathrm{T}}$ consumption of glucose, showing the rate of glucose consumption (grams of glucose consumed per $\mathrm{hr}$ calculated for each time period between sampling (blue bars) and the change in the C:N ratio during $72 \mathrm{hr}$ of growth (line graph; right y axis). Error bars represent the standard deviation, $(n=2)$. 
approximately 10:1, at which point approximately all the glucose had been utilised (Fig. 3.21).

\subsection{Acetic acid assay}

Since the $\mathrm{pH}$ of the growth medium acidifies to approximately 4.5 during $\mathrm{Y}^{2} 8^{\mathrm{T}}$ growth in a glucose-enriched minimal nitrogen medium, the possibility of any acetic acid buildup from glucose utilisation was considered. Growth on excess glucose under aerobic conditions causes the formation of acidic byproducts of which acetate is the most predominant (Luli \& Strohl, 1990). An acetic acid assay $(n=2)$, carried out to determine whether any acetic acid was present in the growth medium during $\mathrm{Y}^{8} 8^{\mathrm{T}}$ growth, showed that there are no detectable levels of acetic acid in the spent growth medium. An independent in-house analysis confirmed this result (M. Robinson, unpublished results). The decrease in $\mathrm{pH}$ could therefore not be attributed to the accumulation of acetic acid due to glucose-mediated aerobic acidogenesis.

Analysis of the extracellular biomass using gas chromatography revealed that during glucose-enriched growth, Y88 ${ }^{\mathrm{T}}$ produced an extracellular carbohydrate. Subsequent ${ }^{13} \mathrm{C}$ NMR ascertained that the carbohydrate consisted of two components likely to contain $\alpha$ - and $\beta$-carbon subunits of glucose (data not shown). Therefore, this carbohydrate is not likely to be the cause for the acidification of the media. Further ${ }^{13} \mathrm{C}$ NMR and ${ }^{1} \mathrm{H}$ NMR analysis is required to identify the type of carbohydrate produced by $\mathrm{Y} 88^{\mathrm{T}}$ in the extracellular environment likely to contribute to the acidification.

\subsection{Conversion of glucose to $\mathrm{PHB}$}

Accumulated PHB was detected in $\mathrm{Y}^{\mathrm{T}} 8^{\mathrm{T}}$ cells under all growth conditions tested in batch culture. Since the amount of glucose consumed by $\mathrm{Y}^{\mathrm{T}}$ and the amount of PHB produced was determined, it was possible to calculate the yield of PHB as well as the rate that glucose was being consumed and converted to PHB (Fig. 3.22, Table 3.3). The amount of PHB converted from glucose was determined at 20, 24, 48 and 72 hr with a three-fold increase in the amount of 


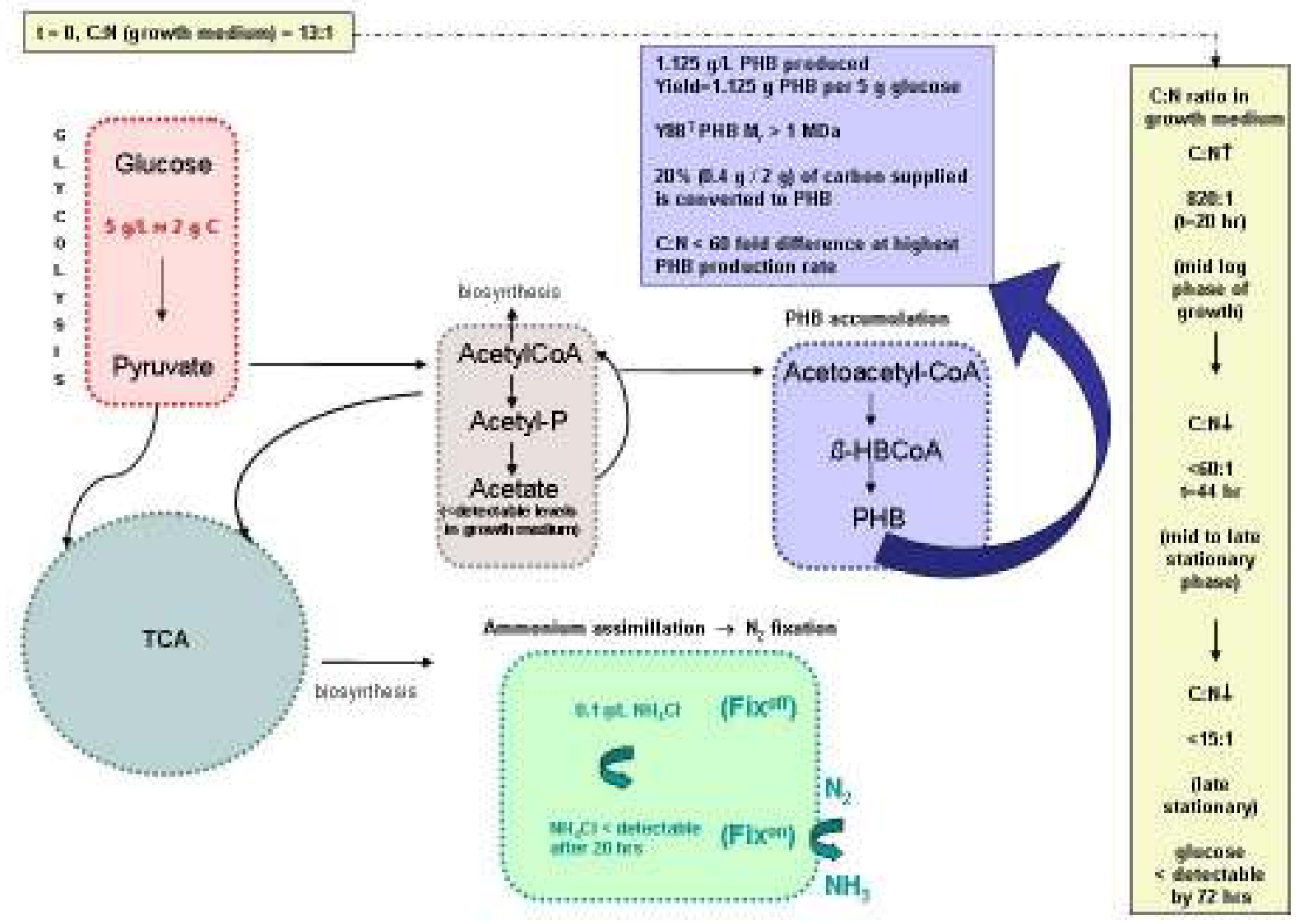

Figure 3.22 Schematic representation of glucose conversion to PHB and ammonium assimilation by Y88

Maximum amount of PHB accumulated, yield of PHB and percentage of carbon conversion to PHB calculated, are shown. Changes in the carbon to nitrogen ratio (C:N) during glucose utilisation, PHB accumulation and nitrogen fixation are indicated 


\begin{tabular}{|c|c|c|c|c|c|c|c|c|}
\hline $\begin{array}{l}\text { Time (hours } \\
\text { post } \\
\text { inoculation) }\end{array}$ & $\begin{array}{l}\text { Amount of glucose } \\
\text { remaining in medium }\end{array}$ & $\begin{array}{l}\text { Amount of glucose } \\
\text { removed from medium }\end{array}$ & $\begin{array}{l}\text { Amount of glucose } \\
\text { consumed between } \\
\text { each sampling period }\end{array}$ & $\begin{array}{l}\text { Rate of glucose } \\
\text { consumed }\end{array}$ & $\begin{array}{c}\text { Amount of PHA } \\
\text { produced }\end{array}$ & $\begin{array}{l}\text { Average Rate of } \\
\text { PHA produced }\end{array}$ & \multicolumn{2}{|c|}{ Yield of PHA } \\
\hline & $(\mathrm{g} / \mathrm{L})$ & $(\mathrm{g} / \mathrm{L})$ & $\mathrm{g} / \mathrm{L}$ & $\mathrm{g} / \mathrm{hr}$ & $\mathrm{g} / \mathrm{L}$ & $\mathrm{g} / \mathrm{hr}$ & $(w / w)$ & $\%$ \\
\hline 0 & $5.157 \pm 0.06$ & 0 & 0 & 0 & - & - & - & - \\
\hline 8 & $5.022 \pm 0.13$ & $0.135 \pm 0.06$ & 0.14 & 0.017 & - & - & - & - \\
\hline 20 & $3.114 \pm 0.23$ & $2.043 \pm 0.17$ & 1.9 & 0.16 & - & - & - & - \\
\hline 24 & $2.682 \pm 0.00$ & $2.475 \pm 0.06$ & 0.43 & 0.11 & $0.34 \pm 0.13$ & 0.014 & $0.14 \pm 0.00$ & 14 \\
\hline 32 & $1.701 \pm 0.06$ & $3.456 \pm 0.0$ & 0.98 & 0.16 & - & - & - & - \\
\hline 44 & $0.369 \pm 0.04$ & $4.788 \pm 0.1$ & 1.33 & 0.22 & - & - & - & - \\
\hline 48 & $0.216 \pm 0.00$ & $4.941 \pm 0.06$ & 0.15 & 0.04 & $1.04 \pm 0.01$ & 0.03 & $0.21 \pm 0.00$ & 21 \\
\hline 56 & $0.099 \pm 0.04$ & $5.058 \pm 0.06$ & 0.12 & 0.015 & - & - & - & - \\
\hline 72 & $0.036 \pm 0.03$ & $5.121 \pm 0.08$ & 0.06 & 0.004 & $1.125 \pm 0.02$ & 0.004 & $0.22 \pm 0.03$ & 22 \\
\hline
\end{tabular}

Table 3.3. Glucose consumed by $\mathrm{Y}^{\mathrm{T}} \mathrm{T}^{\mathrm{T}}$ during $72 \mathrm{hr}$ growth in a glucose-enriched minimal nitrogen medium

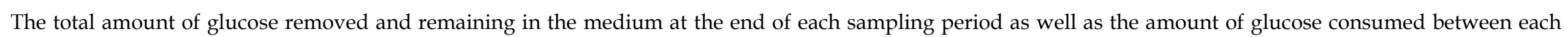

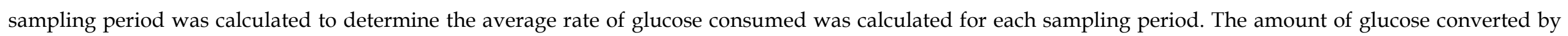

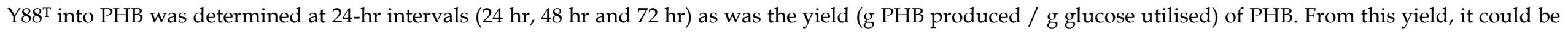

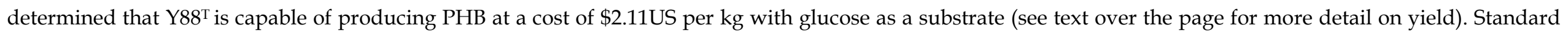
deviations are given, $(\mathrm{n}=2)$. 
PHB produced between 24 and $48 \mathrm{hr}$. A ten-fold increase in glucose consumption occurred between 20 and $44 \mathrm{hr}$ with the highest rate of glucose consumption between 32-44 hr (Table 3.3). Importantly, this peak glucose consumption rate did not correlate with growth rate or nitrogen fixation. Growth rate was maximal in the 22-24 time interval, when $Y 88^{\mathrm{T}}$ cells were also fixing nitrogen as indicated by a positive $\mathrm{C}_{2} \mathrm{H}_{2}$ reduction assay. A positive acetylene reduction assay was never obtained after $24 \mathrm{hr}$ of growth, indicating that the cells fixed nitrogen briefly, but ceased this activity in favour of PHB accumulation in later stages of growth. Notably, PHB production doubled from approximately $40 \%$ to $80 \%$ of the dry biomass between $24-72 \mathrm{hr}$ (Fig. 3.22) during which time nitrogen fixation had ceased, confirming that PHB production was not directly dependent on nitrogen fixation. Since the highest rate of $\mathrm{PHB}$ production occurred in the time interval following that during which the highest rate of glucose consumption occurred, this suggests a correlation between the highest rate of glucose consumption and its subsequent conversion to PHB. A final concentration of $1.125 \mathrm{~g} / \mathrm{L}$ PHB was produced by 72 hr from 5 grams of glucose initially supplemented in the growth medium. During this time, the C:N ratio in the medium decreased from 820:1 (after $20 \mathrm{hr}$ ) to 15:1 (after $72 \mathrm{hr}$ ). A final yield of $0.22 \mathrm{~g}$ PHB/g glucose was achieved. Therefore approximately $20 \%$ of the supplemented glucose is converted to PHB (Table 3.3, Fig. 3.22). The yield of PHB at $0.22 \mathrm{~g} / \mathrm{g}$ glucose therefore consists of $0.132 \mathrm{~g}$ carbon/g glucose used to make PHB. At a market price of US $\$ 0.44 / \mathrm{kg}$ of glucose, the cost of using glucose as a substrate for PHB production in $\mathrm{Y}^{\mathrm{T}} \mathrm{T}$ can be calculated as: (market price of glucose per kg) / (attainable yield of PHB) / 0.95 (unknown cost of adjustment to scale up from bench- to productionscale) (Webb et al., 2004). Thus factoring glucose in as a substrate, $\mathrm{Y}^{\mathrm{T}} \mathrm{c}$ can be used to produce PHB at a cost of US \$2.11 per $\mathrm{kg}$. Utilising glucose from lignocellulosic biomass, the cost is estimated to be less than US 50٪ per kg. (G. Lloyd-Jones, personal communication). These results should be taken into account in planning large-scale production of PHB from $\mathrm{Y}^{8} 8^{\mathrm{T}}$. 


\section{Chapter 4: "Proteomic signatures" for the Fix"on/Fix off physiology of $\mathrm{Y}^{\mathrm{T}}{ }^{\mathrm{T}}$ during PHA synthesis}

\subsection{Introduction}

"Proteomic signatures" are defined as a group or subset of proteins in a proteomic experiment that are characteristic of a specific physiological state or response (VanBogelen et al., 1999b). Proteins are identified as signatures by comparing protein profiles to identify proteins with altered abundance and mapping the altered state of the protein to a particular response. Proteomic signatures can be used as indicators of the growth phase of a cell population to predict the physiological state of cells (VanBogelen et al., 1999a; Voigt et al., 2004). Additionally, predictions can be made of other aspects of metabolism such as relating a protein to a specific pathway or function. For physiological studies, the examination of approximately 300 cytosolic proteins is considered to be a reasonable starting point to identify proteins that can be mapped as signatures to a particular state of the cell under specified growth conditions (Voigt et al., 2004).

The $\mathrm{Y}^{8} 8^{\mathrm{T}}$ proteome was examined using 2-D DIGE and MS to gain a direct assessment of proteins in terms of their presence and relative abundance in actively growing $\mathrm{Y}^{\mathrm{T}} 8^{\mathrm{T}}$ cells. 2-D DIGE allowed the visualisation of the response of the $\mathrm{Y} 88^{\mathrm{T}}$ proteome to conditions where no ammonium was supplemented in the growth medium, ammonium was supplemented at $0.1 \mathrm{~g} / \mathrm{L}$ and the supplemented ammonium was depleted. Proteomic signatures of nitrogenfixing and PHA-synthesising $\mathrm{Y}^{8} 8^{\mathrm{T}}$ cells showed that the abundance of the $\mathrm{Y} 88^{\mathrm{T}}$ nitrogenase enzyme was significantly altered at high $\mathrm{OD}_{600}$ (defined here as $\mathrm{OD}_{600}=2.0$ ) in response to a switch from ammonium assimilation to nitrogen fixation, but that PHA synthesis proteins undergo more subtle changes and occur in high abundance regardless of the growth conditions. Several proteins not usually associated with nitrogen fixation were coordinately upregulated 
during nitrogen fixation. Furthermore, this study supported a hypothesis that PHA synthesis in $\mathrm{Y}^{8} 8^{\mathrm{T}}$ is not dependent on nitrogen fixation.

\subsection{Results}

\subsubsection{DE}

Based on examination of the growth and metabolism of Y88 ${ }^{\mathrm{T}}$ (Chapter 3), it was expected that the Fix ${ }^{\text {on }}$ and Fix ${ }^{\text {off }}$ states (Table 2.2) would show differences in protein signatures reflecting the physiological state of the cell. Protein was extracted from $\mathrm{Y} 88^{\mathrm{T}}$ cells grown for $24 \mathrm{hr}$ in ammonium-free or ammoniumdepleted media, representing the Fix ${ }^{\text {off }}$ and Fix ${ }^{\text {on }}$ physiologies of cell growth, respectively. To assess the quality and quantity of $\mathrm{Y} 88^{\mathrm{T}}$ protein extracts for subsequent 2-D DIGE analysis, $\mathrm{Y}^{\mathrm{T}}{ }^{\mathrm{T}}$ extracts were first subjected to 1-DE to determine whether protein concentrations were appropriate for 2-D DIGE analysis. Also, 1-DE was used to determine if differences in protein expression could be observed in 1-DE protein bands between extracts representing the Fix ${ }^{\text {off }}$ or Fix ${ }^{\text {on }}$ states. Since protein was extracted from whole cell pellets obtained by centrifugation of cell cultures, total protein extracts comprised cytoplasmic as well as membrane-bound/associated proteins. Protein extracts were also obtained from the same cultures after $72 \mathrm{hr}$, both at this time point corresponding to the Fix off state when the cells were in stationary phase. These were compared with the $24 \mathrm{hr}$ samples to see if any differences in protein abundance and/or band patterns could be detected on 1-D gels. Total protein extracts were diluted four-fold and $5 \mu \mathrm{L}$ of soluble protein were subjected to 1DE under reducing conditions (Fig. 4.1).

Additionally, protein extracts were obtained at different optical densities representing the same two physiological states of the cells as before. Since growth to $\mathrm{OD}_{600}$ of 0.5 and 1.0 did not produce a positive $\mathrm{C}_{2} \mathrm{H}_{2}$ reduction assay, protein extracts from cells grown to these optical densities were considered to represent the Fix off state of the cells. Growth to an $\mathrm{OD}_{600}$ of 2.0 produced a positive $\mathrm{C}_{2} \mathrm{H}_{2}$ reduction assay, therefore protein extracts from cells grown to this $\mathrm{OD}_{600}$ were considered to represent the Fix ${ }^{\text {on }}$ state of the cells. Total protein 


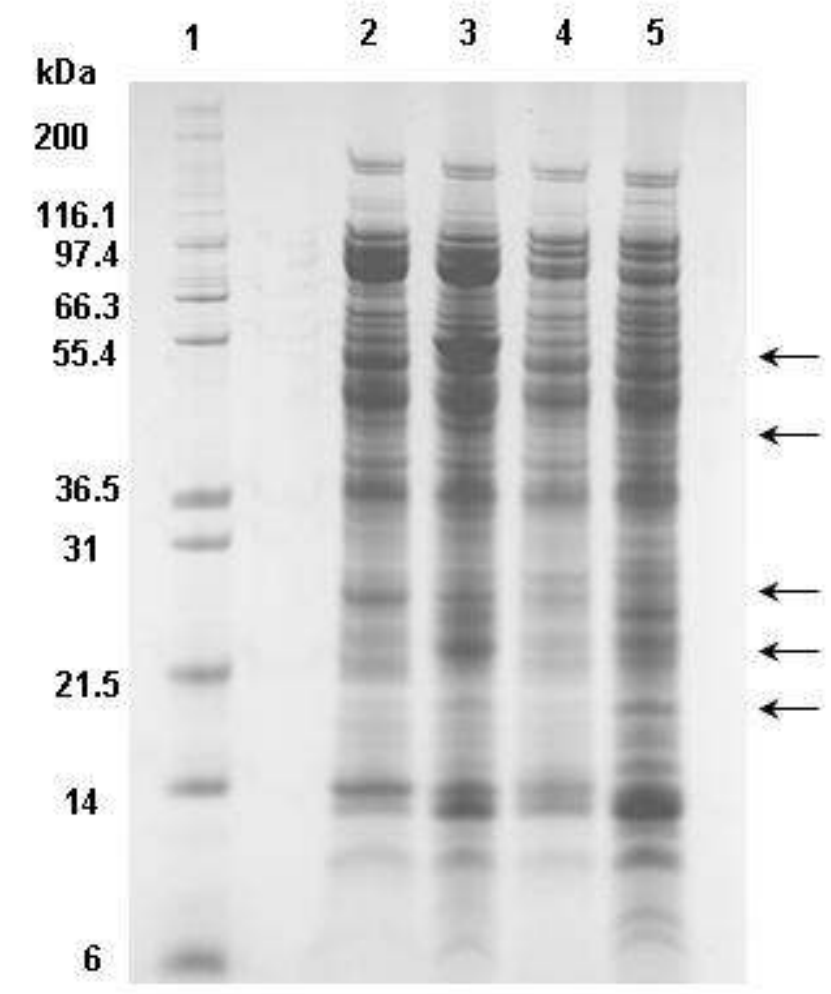

Figure 4.1 Coomassie-stained 1-DE gel showing comparison of $\mathrm{Y}^{8} 8^{\mathrm{T}}$ total protein extracts Lanes 2 and 4: total protein extracts representing the Fix off after $24 \mathrm{hr}$ (lane 2) and $72 \mathrm{hr}$ (lane 4) growth in ammonium-free media. Lane 3: total protein extract representing the Fix ${ }^{\text {on }}$ state after $24 \mathrm{hr}$ growth in ammonium-supplemented medium that had become depleted of ammonium ion. Lane 5: total protein extract from stationary phase cells representing Fixoff after $72 \mathrm{hr}$. Differences in protein band intensities for extracts representing different growth conditions are indicated by arrows. 
extracts were diluted four-fold, and $5 \mu \mathrm{L}$ of soluble protein were subjected to 1DE under reducing conditions (Fig. 4.2).

Differences were observed from 1-DE bands particularly at approximately 23 and $55.4 \mathrm{kDa}$ in the Fix on extracts representing $24 \mathrm{hr}$ growth (Fig. 4.1, lane 3). Differences in several other highly abundant bands were evident across similar extracts in the 10-100 kDa range. For example, differences in protein abundance were evident for bands at approximately 23 and $55.4 \mathrm{kDa}$ for cells grown to high $\mathrm{OD}_{600}$ (Fig. 4.2, lanes 2, 3, 8, 9, $\mathrm{OD}_{600}=2.0$ ) similar to those at the same $\mathrm{M}_{\mathrm{r}}$ in Fig. 4.1, lane 3, when compared to the corresponding band at $55.4 \mathrm{kDa}$ in cells grown to lower $\mathrm{OD}_{600}$ (Fig. 4.2, lanes 4 and $5\left(\mathrm{OD}_{600}=1.0\right)$, lanes 6 and 7 $\left(\mathrm{OD}_{600}=0.5\right)$. The bands at 23 and $55.4 \mathrm{kDa}$ that appeared in the protein extracts from cultures grown to high $\mathrm{OD}_{600}$ (Fig. 4.2, lanes 2, 3, 8, 9) as well as in the 24 hr extract (Fig. 4.1, lane 3) appear to be typical of the Fix on state of the cells since these extracts were from the same cultures that gave positive $\mathrm{C}_{2} \mathrm{H}_{2}$ reduction assays (Chapter 3). Proteins extracted from cultures grown to lower OD600 (Fig. 4.2 , lanes 4 to 7 ) showed similar band patterns and abundance to those obtained for cells grown in ammonium-free cultures that gave negative $\mathrm{C}_{2} \mathrm{H}_{2}$ reduction assays (Chapter 3). These 1-D protein profiles therefore appeared to be typical of the Fix off state of the cells.

\subsubsection{2-D/2-D DIGE}

\subsubsection{Differential protein abundance between the Fix ${ }^{\text {on }}$ and Fix ${ }^{\text {off }}$ physiologies of $\mathrm{Y88}^{\mathrm{T}}$ during PHA accumulation}

To visualise differences in protein abundance between $\mathrm{Y}^{\mathrm{T}} 8^{\mathrm{T}}$ cells grown in ammonium-free and ammonium-supplemented conditions, representative samples of $\mathrm{Y}^{8} 8^{\mathrm{T}}$ protein from each of the growth conditions were subjected to 2D DIGE analysis. The selected samples were similar in total protein concentration and 1DE band patterns for a particular growth condition but showed differences in band profiles across growth conditions. 


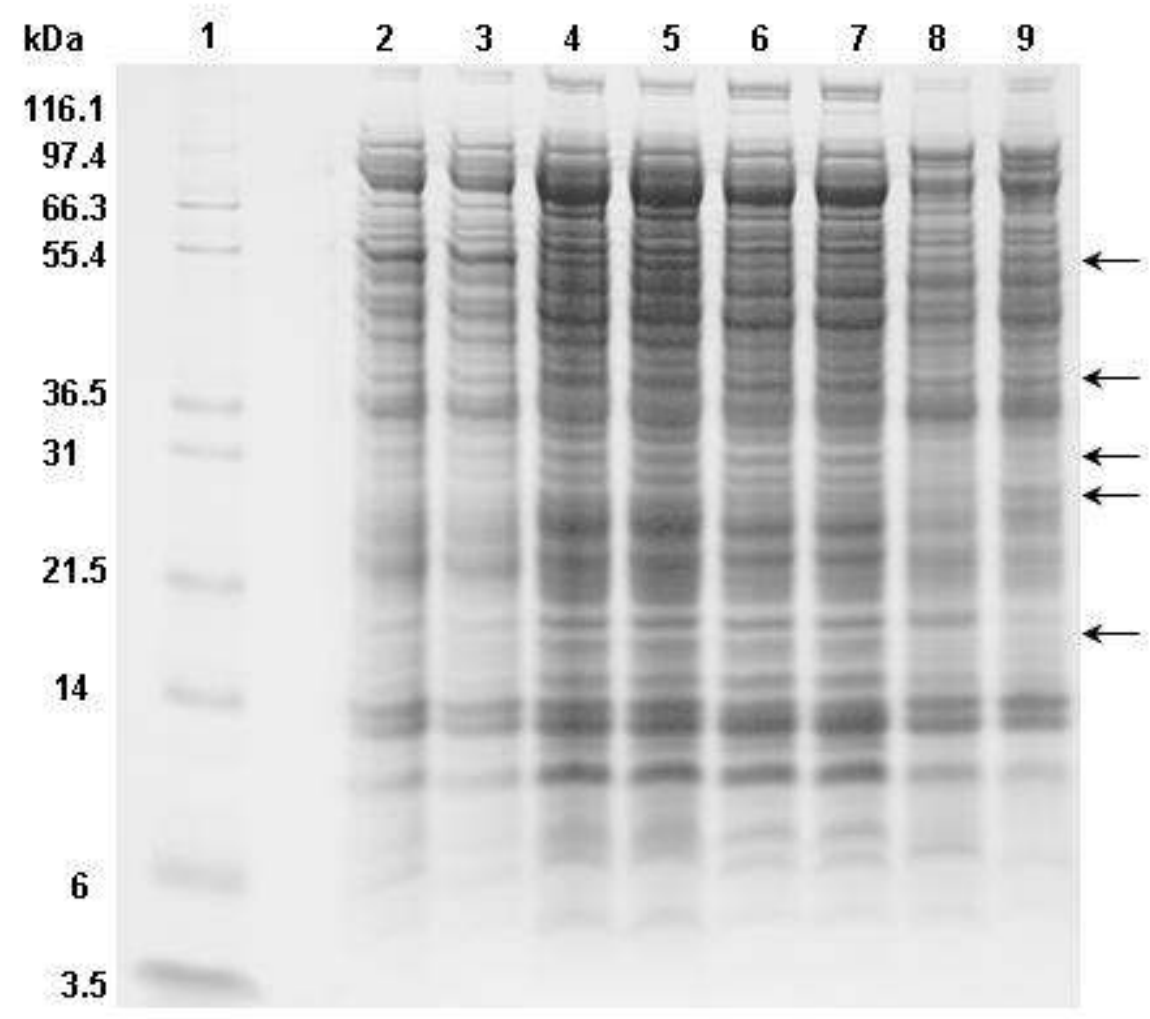

Figure 4.2.Total protein gel of $Y 88^{\mathrm{T}}$ at various stages of culture growth

Coomassie-stained 1-DE gel showing comparison of $Y 88^{\mathrm{T}}$ total protein extracts representing the Fix ${ }^{\text {off }}$ state at different optical densities $\left(\mathrm{OD}_{600}=0.5\right.$ (lanes 6, 7); $\mathrm{OD}_{600}=1.0($ lanes 4, 5) and the Fix ${ }^{\text {on }}$ state of the cells at $\mathrm{OD}_{600}=2.0$ (lanes 2, 3, 9); Fix off state (no $\mathrm{NH}_{4} \mathrm{Cl}$ ) after 24 hrs (lane 8). Observed differences in protein band intensities between the different physiological states are indicated by arrows. 
Since this was the first analysis of $\mathrm{Y} 88^{\mathrm{T}}$ proteins using 2-D DIGE, a master gel consisting of protein extracted from cells under ammonium-free (negative control) and ammonium-supplemented conditions (during which the ammonium was depleted and the cells switched from assimilating ammonium to fixing nitrogen) was generated using linear gradient $\mathrm{pH} 3-10$ strips for first dimension IEF. This $\mathrm{pH}$ range was chosen to obtain an overview of total protein distribution for the standard Fix on versus Fix off physiology to gauge whether i) ${\mathrm{Y} 88^{\mathrm{T}}}$ protein extracts were amenable to 2-D DIGE analysis, ii) the $\mathrm{Y}^{\mathrm{T}}$ proteome consisted of predominantly basic or acidic proteins and how well these proteins separated within the $\mathrm{pH}$ range selected and iii) whether protein differences for the selected growth conditions could be readily detected for $\mathrm{Y}^{\mathrm{T}} \mathrm{P}^{\mathrm{T}}$ using this type of analysis.

2-D DIGE of $\mathrm{Y}^{\mathrm{T}}$ extracts in the $\mathrm{pI}$ 3-10 range revealed in excess of 300 abundant proteins in the range 10-120 kDa (Fig. 4.3). These proteins represent only a small fraction of the $\mathrm{Y} 88^{\mathrm{T}}$ proteome as predicted from the $\mathrm{Y} 88^{\mathrm{T}}$ genome sequence. The presence of many proteins could therefore be masked by these abundant proteins or were below the set spot detection limit. Also proteins could be inadvertently excluded if they are outside the analytical window of $\mathrm{pI}$ 3-10 and 10-120 kDa. Several proteins showed altered abundance under both ammonium-free and ammonium-supplemented conditions. Several spots unique to each condition were detected. These included highly abundant proteins in particularly the 10-30 kDa range as well as higher molecular weight proteins in the 50-100 kDa range (Fig. 4.3). Although proteins were observed across the $\mathrm{pI}$ range, at least two-thirds of the $\mathrm{Y} 88^{\mathrm{T}}$ proteins were found within the neutral to acidic region of the gel (Fig. 4.3), corresponding to a pI range of between 4 and 7. Therefore, it was more appropriate to analyse subsequent samples using a narrower $\mathrm{pI}$ range of 4-7 that would allow greater resolution of these proteins, particularly some of those possibly masked beneath the more abundant proteins. 


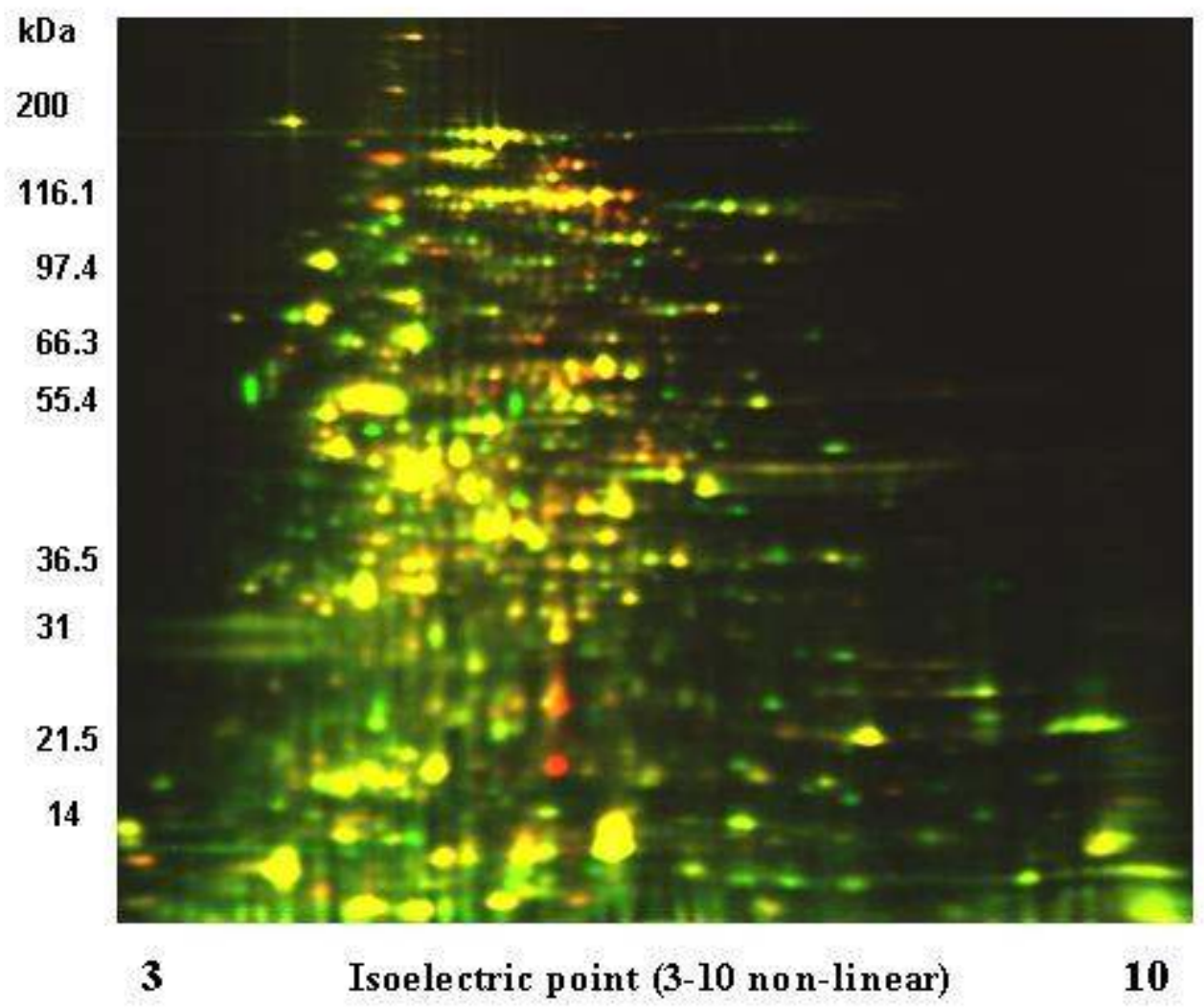

Figure 4.3 Overlay image of $\mathrm{Y}^{8} 8^{\mathrm{T}}$ protein profiles generated from minimally labeled pooled Fix ${ }^{\text {on }}$ and Fix off samples

(Cy2 - yellow), Fix ${ }^{\text {on }}$ (Cy3 - green) and Fix ${ }^{\text {off }}$ (Cy5 - red) samples showing differentially altered proteins in the linear gradient $\mathrm{pH}$ 3-10 range. Yellow=proteins unaltered for both the Fix on and Fix ${ }^{\text {off }}$ states of the cells; green=proteins with increased abundance for the Fix ${ }^{\text {on }}$ state of the cells; red=proteins with increased abundance for the Fix ${ }^{\text {off }}$ state of the cells. 
2-D DIGE using a linear gradient of $\mathrm{pH}$ 3-10 confirmed that $\mathrm{Y}^{\mathrm{T}} \mathrm{T}$ total protein extracts were amenable to such analysis and that differences in protein abundance were readily detected using this method. Given these results and that the majority of $\mathrm{Y}^{\mathrm{T}} 8^{\mathrm{T}}$ proteins appeared to be more acidic, subsequent samples were analysed using linear gradient $\mathrm{pH} 4-7$ strips to increase the resolution of proteins over this narrower acidic range, unless otherwise stated.

\subsubsection{Differential protein abundance at different optical densities for the Fix ${ }^{\text {on }}$ and Fix ${ }^{\text {off }}$ physiologies of Y88 $^{\mathrm{T}}$ during PHA accumulation}

2-D DIGE was carried out to examine the comparative response of the $\mathrm{Y}^{\mathrm{T}} \mathrm{P}^{\mathrm{T}}$ proteome to conditions of ammonium supplementation (Fix ${ }^{\text {off }}$ ) at $\mathrm{OD}_{600}$ of 0.5 and 1.0 relative to an $\mathrm{OD}_{600}$ of 2.0 under ammonium-depleted (Fix ${ }^{\circ}$ ) conditions. Samples were similar in protein concentration and 1-DE band patterns for a given $\mathrm{OD}_{600}$ but different across optical densities. Notably, all samples clearly showed PHA granules in the discarded cell debris following protein extraction from cells at low or high $\mathrm{OD}_{600}$, although differences in the amount of PHA were evident with a greater amount of PHA from cells grown to high $\mathrm{OD}_{600}$ (Chapter 3).

Comparison of the proteins in the pI 4-7 range for $\mathrm{Y}^{8} 8^{\mathrm{T}}$ cells for the Fix off and Fix ${ }^{\text {on }}$ states showed approximately a total of 200 protein spots irrespective of growth conditions. Approximately 80 proteins were observed to be highly abundant on each of the three gels (Figs. 4.4A, 4.4B and 4.5B). Of these, fortyeight were selected for initial analysis. Selection criteria included specific targeting of proteins predicted to have altered abundance between physiological states. Predicted $\mathrm{pI}$ and $\mathrm{M}_{\mathrm{r}}$ of proteins in public databases known to be involved in nitrogen fixation and PHA synthesis were used to target the most likely candidates, since at that time the $\mathrm{Y} 88^{\mathrm{T}}$ genome had not yet been sequenced. Additionally, several highly abundant proteins that appeared to be unaltered between physiological states were selected. 


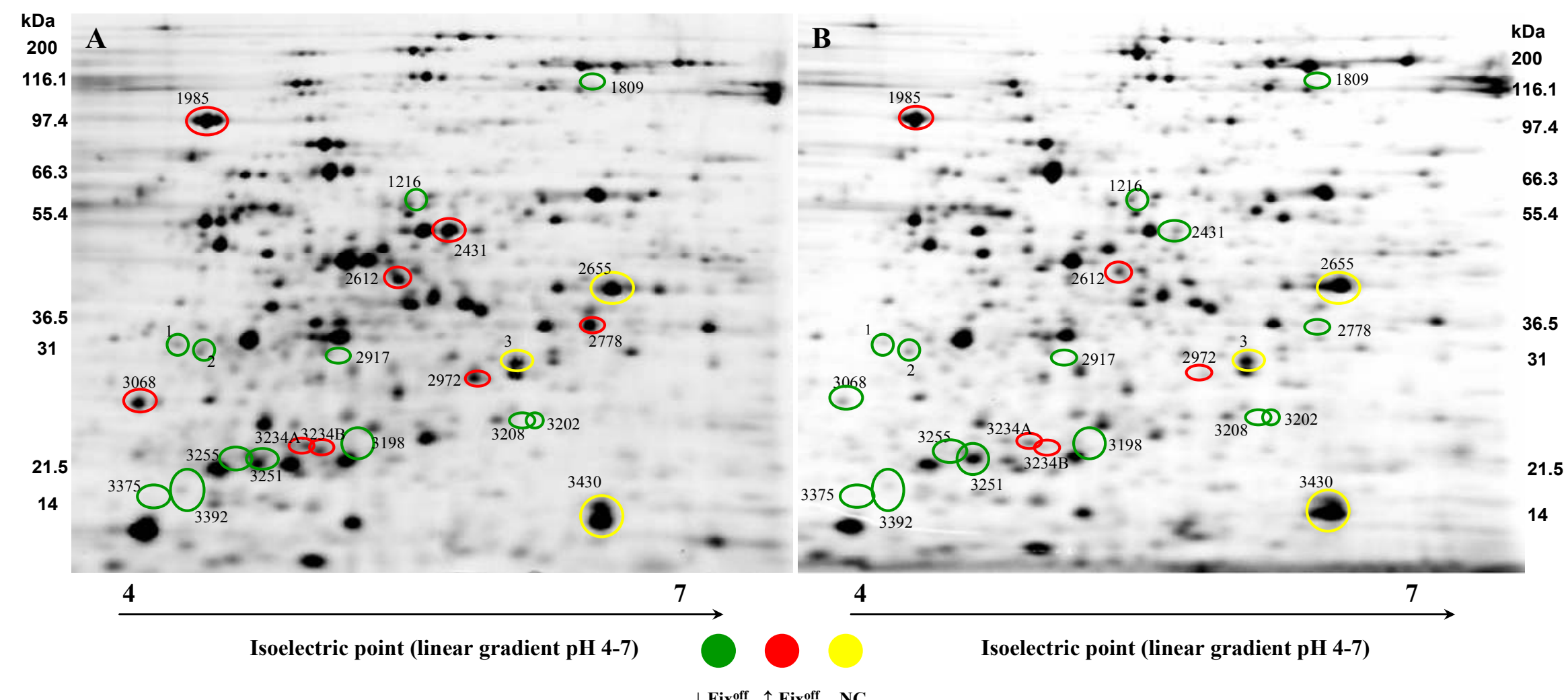

Figure 4.4 2-D DIGE (pI 4-7) profiles of Y88 ${ }^{\mathrm{T}}$ cells for the Fix off physiological state of the cells (A and B)

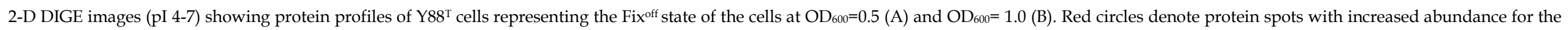

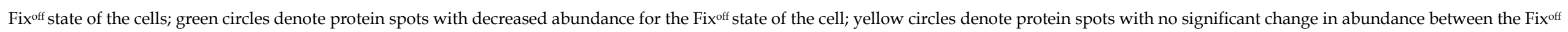

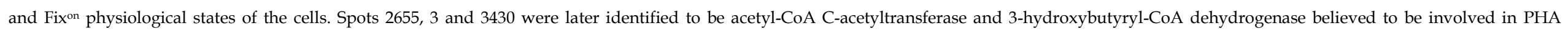
synthesis. Proteins identified corresponding to spot numbers in A and B that showed significant altered abundance are discussed in the text and are listed in Table 4.1, ( $=3$ ).

స్త్ర 


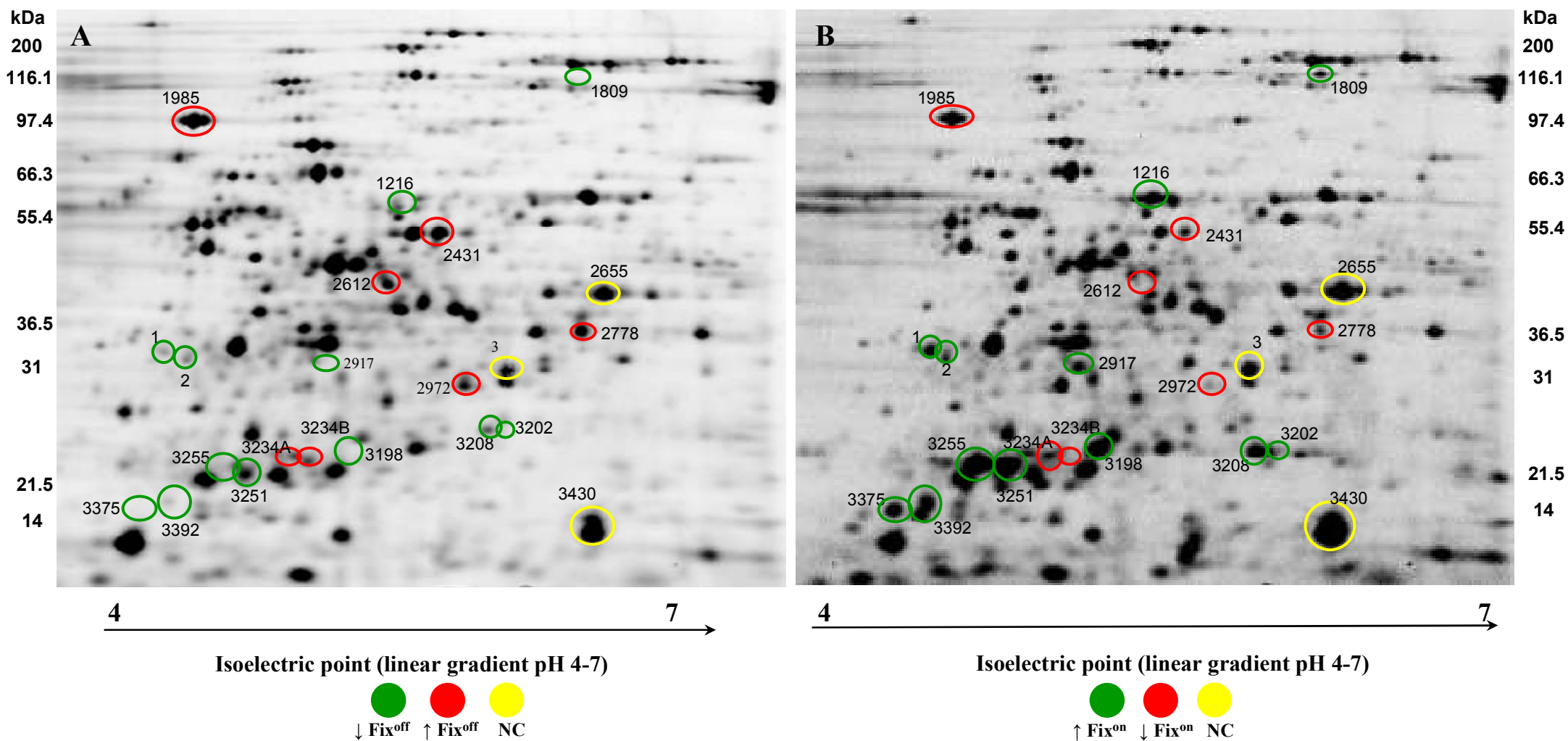

Figure 4.5. 2-D DIGE (pI 4-7) profiles of Y88 cells for the Fix off (A) and Fixon (B) physiological state of the cells

2-D DIGE images (pI 4-7) showing protein profiles of $\mathrm{Y}^{88^{\mathrm{T}}}$ cells representing the Fix off state of the cells at $\mathrm{OD}_{600}=0.5$ (A, repeated from previous page for ease of comparison with the Fix ${ }^{\text {on }}$ state) and the Fix ${ }^{\text {on }}$ state of the cells at $\mathrm{OD}_{600}=2.0$ (B). In A, red circles denote protein spots with increased abundance for the Fix off state of the cells and green circles denote protein spots with decreased abundance for the Fix ${ }^{\text {off }}$ state of the cells. In B, green circles denote protein spots with increased abundance for the Fix ${ }^{\text {on }}$ state of the cells and red circles denote protein spots with decreased abundance for the Fix ${ }^{\text {on }}$ state of the cells. Yellow circles in both A and B denote protein spots that show no change in abundance between the two physiological states. Spots 2655, 3 and 3430 were later identified to be acetyl-CoA C-acetyltransferase and 3-hydroxybutyryl-CoA dehydrogenase believed to be involved in PHA synthesis. Proteins identified corresponding to spot numbers in A and B that showed significant altered abundance are discussed in the text and are listed in Table 4.1, $(\mathrm{n}=3)$. 
Generally, there was good congruency between the experimental $\mathrm{pI}$ and $\mathrm{M}_{\mathrm{r}}$ and the theoretical $\mathrm{pI}$ and $\mathrm{M}_{\mathrm{r}}$ based on the $\mathrm{Y} 88^{\mathrm{T}}$ translated ORF sequences for most of the proteins selected for analysis, with a few exceptions. Furthermore, analysis of the 2-D DIGE gels showed very little change for the majority of proteins observed at low or high $\mathrm{OD}_{600}$, suggesting that the changes in extracellular nutrient availability and culture conditions had no visible effect on their abundance throughout growth, irrespective of whether the cells were assimilating ammonium or fixing nitrogen. This is not unexpected since many proteins would be involved in maintaining core metabolic activities within the cell and would not be expected to show significant changes.

Despite high similarity among protein profiles representing Fix on and Fix off physiological states, several proteins were either unique to a specific physiological state or showed altered abundance depending on growth conditions. For instance, proteins involved in nitrogen fixation were identified exclusively in extracts from cells grown to high $\mathrm{OD}_{600}$. Some of these are discussed in the following sections. Also, proteins usually associated with other physiological functions were coordinately upregulated with the nitrogen-fixing proteins, suggesting putative functional roles (discussed in the following sections) for these proteins in nitrogen recycling under nitrogen-depleted conditions when the cells have to fix nitrogen.

\subsection{Nitrogen-fixing and associated proteins}

Two spots (spots 3255 and 3198) corresponding to the homodimeric dinitrogenase reductase $(\mathrm{NifH})$, which together form component II of the hetero-oligomeric nitrogenase complex and are required for nitrogen fixation, were identified at approximately $23 \mathrm{kDa}$. One subunit had a pI of 4.7 (Fig. 4.5B, spot 3255), while the other had a pI of 5.2 (Fig. 4.5B, spot 3198). The protein spots of both subunits differed from the $31.8 \mathrm{kDa}$ and $\mathrm{pI} 4.9$ predicted from the $\mathrm{Y}^{8} 8^{\mathrm{T}}$ genome sequence, suggesting possible post-translational modification of this protein (see Chapter 6). NifH is known to be post-translationally modified by ADP-ribosylation in response to ammonium which would explain a 
difference in observed and predicted $\mathrm{M}_{\mathrm{r}}$ and $\mathrm{pI}$. However, since these subunits are upregulated at high $\mathrm{OD}_{600}$ representative of the nitrogen-fixing physiology of $\mathrm{Y}^{8} 8^{\mathrm{T}}$ at which point no ammonium is detected in the growth medium, this is unlikely. More likely is that the ADP-ribosylation response may be reversed under these conditions due to the depletion of ammonium in the medium. The differences between observed and predicted $\mathrm{M}_{\mathrm{r}}$ and $\mathrm{pI}$ may therefore be a response to some post-translational modification other than that associated with ADP-ribosylation. Both subunits showed altered abundance under ammonium-depleted conditions at high $\mathrm{OD}_{600}$ : the former was upregulated by approximately 16.7-fold (spot 3255, $t$-test $=0.01$, Table 4.1, Fig. 4.5B) and the latter was upregulated 10.5-fold (spot 3198, $t$-test=0.019) (Table 4.1). These subunits were among the most abundant spots on the gels representing nitrogen-fixing physiology. Note that the LC-MS/MS data supporting this and all subsequent protein identifications in this chapter are given in Table 4.2.

An abundant protein spot was evident at approximately $58 \mathrm{kDa}$ and pI 5.4 on the gel at high $\mathrm{OD}_{600}$ of 2.0 (Fig. 4.5B, spot 1216). This protein was later confirmed to be the NifK protein at its predicted $\mathrm{M}_{\mathrm{r}}$ and $\mathrm{pI}$. NifK (see following chapters) and constitutes part of the $\alpha_{2} \beta_{2}$-heterotetrameric component I (molybdenum iron $\beta$-subunit) of the nitrogenase complex and was more abundant for the Fix ${ }^{\text {on }}$ state relative to the Fix ${ }^{\text {off }}$ state. NifK was also identified in spot 2917 on the same gel and showed a 12-fold increase in abundance for the Fix ${ }^{\text {on }}$ state $(t$-test $=0.015)$. This spot is likely to be a NifK fragment as it occurred at a much lower $\mathrm{M}_{\mathrm{r}}$ and more acidic $\mathrm{pI}$ than expected from the $\mathrm{Y}^{\mathrm{T}} 8^{\mathrm{T}}$ genome sequence. Notably, the two NifH as well as the two NifK spots were absent from the profile of proteins representing the Fix ${ }^{\text {off }}$ state at $\mathrm{OD}_{600}$ of 0.5 and 1.0 (Figs. 4.4A, 4.4B). Given that these components are essential for nitrogenase activity, their absence on the gels representing growth to low $\mathrm{OD}_{600}$ suggests that at low growth, the presence of ammonium in the medium inhibits nitrogenase expression and thereby, its activity, explaining why $\mathrm{Y}^{8} 8^{\mathrm{T}}$ gives a negative $\mathrm{C}_{2} \mathrm{H}_{2}$ reduction assay in the presence of ammonium at low $\mathrm{OD}_{600}$ (see Chapter 3, Fig. 3.8). This effect is physiologically consistent with ammonium- 


\begin{tabular}{|c|c|c|c|c|c|c|c|}
\hline \multirow[t]{2}{*}{$\begin{array}{c}\text { Spot } \\
\text { number }\end{array}$} & \multirow[t]{2}{*}{ Protein ID } & \multicolumn{2}{|c|}{$\begin{array}{l}O D_{600}=0.5 / \\
O D_{600}=0.1\end{array}$} & \multicolumn{2}{|c|}{$\begin{array}{l}O D_{600}=2.0 / \\
O D_{600}=1.0\end{array}$} & \multicolumn{2}{|c|}{$\begin{array}{l}O D_{600}=0.5 / \\
O D_{600}=2.0\end{array}$} \\
\hline & & $\begin{array}{l}\text { Average } \\
\text { Ratio }\end{array}$ & $\begin{array}{l}\text { T-test } \\
\text { value }\end{array}$ & $\begin{array}{l}\text { Average } \\
\text { Ratio }\end{array}$ & $\begin{array}{l}\text { T-test } \\
\text { value }\end{array}$ & $\begin{array}{l}\text { Average } \\
\text { Ratio }\end{array}$ & $\begin{array}{l}\text { T-test } \\
\text { value }\end{array}$ \\
\hline 1985 & Chaperone DnaK (DnaK) & 2.25 & $0.003^{*}$ & - & - & - & - \\
\hline \multirow[t]{3}{*}{2778} & Ketol acid reductoisomerase ${ }^{a}$ & 2.78 & $0.004^{*}$ & -1.18 & 0.5 & 3.27 & $0.036^{\star *}$ \\
\hline & tryptophanyl-tRNA synthetase ${ }^{a}$ & 2.78 & $0.004^{*}$ & - & - & - & - \\
\hline & Glyceraldehyde-3-phosphate dehydrogenase ${ }^{a}$ & 2.78 & $0.004^{*}$ & - & - & - & - \\
\hline \multirow[t]{2}{*}{2972} & Translation elongation factor (Tuf) ${ }^{b}$ & 2.31 & $0.007^{*}$ & - & - & 3.62 & $0.006^{*}$ \\
\hline & Malate dehydrogenase ${ }^{b}$ & 2.31 & $0.007^{*}$ & - & - & 3.62 & $0.006^{*}$ \\
\hline 2431 & S-adenosylhomocysteine hydrolase (AdoHcy) & 4.16 & $0.02^{\star *}$ & - & - & 6.76 & $0.024^{\star *}$ \\
\hline 3208 & hypothetical protein Saro_2615 & -1.42 & 0.81 & 30.69 & $0.014^{* *}$ & -26.82 & $0.012^{*}$ \\
\hline \multirow[t]{2}{*}{3375} & OmpA/MotB ${ }^{c}$ & - & - & 18.56 & $0.019^{* *}$ & -12.1 & $0.02^{\star *}$ \\
\hline & Ribosomal protein $\mathrm{L} 7 / \mathrm{L} 12^{\mathrm{c}}$ & - & - & 18.56 & $0.019^{* *}$ & -12.1 & $0.02^{\star *}$ \\
\hline \multirow[t]{2}{*}{3392} & OmpA/MotB ${ }^{d}$ & - & - & 15.55 & $0.02^{\star *}$ & -12.24 & $0.019^{\star \star}$ \\
\hline & Ribosomal protein $L 7 / L 12^{d}$ & - & - & 15.55 & $0.02^{* *}$ & -12.24 & $0.019^{\star *}$ \\
\hline \multirow[t]{2}{*}{3202} & Translation elongation factor EF- $1 \alpha^{\varepsilon}$ & -1.42 & 0.81 & 7.43 & 0.081 & -10.57 & $0.007^{*}$ \\
\hline & $\begin{array}{l}\text { nitrogenase molybdenum-iron protein beta } \\
\text { chain (NifK) (fragment) }\end{array}$ & -1.42 & 0.81 & 7.43 & 0.081 & -10.57 & $0.007^{*}$ \\
\hline 2612 & S- adenosylmethionine (SAM) synthetase & - & - & - & - & 6.21 & $0.009^{*}$ \\
\hline 3255 & Dinitrogenase reductase $(\mathrm{NifH})$ & - & - & - & - & -16.7 & $0.01^{*}$ \\
\hline
\end{tabular}

Table 4.1 Y88 $8^{\mathrm{T}}$ proteins showing altered abundance in for the Fix off state $\left(\mathrm{OD}_{600}\right.$ of 0.5 and 1.0) compared to the Fix ${ }^{\text {on }}$ state $\left(\mathrm{OD}_{600}\right.$ of 2.0), identified using LC-MS/MS

Proteins identified in the same spots are marked with the same superscripts (a,b, c, d e). t-tests show significantly altered protein abundance at $99 \%$ confidence level $\left(^{*}\right)$ and at $95 \%$ confidence level (**) for a given $\mathrm{OD}_{600}$ pair. Unmarked $t$-test values represent altered proteins that did not attain the minimum $>2$-fold difference at $95 \%$ level of confidence. Positive average ratios denote enhanced protein abundance for $1^{\text {st }} \mathrm{OD}_{600}$ relative to $2^{\text {nd }} \mathrm{OD}_{600}$ in each $\mathrm{OD}_{600}$ pair; negative average ratios denote enhanced protein abundance for $2^{\text {nd }} \mathrm{OD}_{600}$ relative to $1^{\text {st }} \mathrm{OD}_{600}$ in each $\mathrm{OD}_{600}$ pair. Refer to Table 4.2 for supporting LC-MS/MS data for peptide matches to protein identifications that correspond to gel spot numbers in Table 4.1 and that are discussed in the body of the text throughout this chapter. Table 4.1 continued on next page. 


\begin{tabular}{|c|c|c|c|c|c|c|c|}
\hline \multirow[t]{2}{*}{$\begin{array}{c}\text { Spot } \\
\text { number }\end{array}$} & \multirow[t]{2}{*}{ Protein ID } & \multicolumn{2}{|c|}{$\begin{array}{l}O D_{600}=0.5 / \\
O D_{600}=0.1\end{array}$} & \multicolumn{2}{|c|}{$\begin{array}{l}O D_{600}=2.0 / \\
O D_{600}=1.0\end{array}$} & \multicolumn{2}{|c|}{$\begin{array}{l}O D_{600}=0.5 / \\
O D_{600}=2.0\end{array}$} \\
\hline & & $\begin{array}{l}\text { Average } \\
\text { Ratio }\end{array}$ & $\begin{array}{l}\text { T-test } \\
\text { value }\end{array}$ & $\begin{array}{l}\text { Average } \\
\text { Ratio }\end{array}$ & $\begin{array}{l}\text { T-test } \\
\text { value }\end{array}$ & $\begin{array}{l}\text { Average } \\
\text { Ratio }\end{array}$ & $\begin{array}{l}\text { T-test } \\
\text { value }\end{array}$ \\
\hline 3198 & Dinitrogenase reductase (NifH) & - & - & - & - & -10.5 & $0.02^{* *}$ \\
\hline 1809 & $\mathrm{NI}$ & - & - & - & - & -8.47 & $0.013^{*}$ \\
\hline 2917 & $\begin{array}{l}\text { Nitrogenase molybdenum beta chain } \\
\text { (NifK) fragment }\end{array}$ & 1.84 & 0.53 & 6.57 & 0.09 & -12.11 & $0.015^{\star \star}$ \\
\hline $3234 \mathrm{~A}$ & $\begin{array}{l}\text { ATP-dependent Clp protease, proteolytic } \\
\text { subunit (ClpP) }\end{array}$ & 2.42 & $0.037^{* *}$ & -1.36 & 0.095 & 3.28 & $0.015^{\star *}$ \\
\hline 3234B & isochorismatase & 2.42 & $0.037^{* *}$ & -1.36 & 0.095 & 3.28 & $0.015^{\star *}$ \\
\hline 3430 & phasin & -1.95 & 0.19 & 1.61 & 0.36 & -3.12 & 0.056 \\
\hline 3251 & hypothetical protein BRADO5426 & -2.39 & $0.05^{\star *}$ & -4.64 & $0.05^{\star *}$ & -1.94 & $0.05^{\star *}$ \\
\hline 1216 & $\begin{array}{l}\text { Nitrogenase molybdenum beta chain } \\
\text { (NifK) }\end{array}$ & -1.05 & 0.92 & 1.21 & 0.63 & 3.4 & $0.04^{* *}$ \\
\hline 1 & NifU & - & - & - & - & - & - \\
\hline 2 & $\begin{array}{l}\text { Electron-transfer flavoprotein } \alpha \text {-subunit } \\
\text { (FixB) }\end{array}$ & - & - & - & - & - & - \\
\hline & OmpA/MotB & - & - & - & - & - & - \\
\hline 3430 & Phasin & - & - & - & - & - & - \\
\hline
\end{tabular}

Table 4.1 (cont.) Y88 $8^{\mathrm{T}}$ proteins showing altered abundance in for the Fix ${ }^{\text {off }}$ state $\left(\mathrm{OD}_{600}\right.$ of 0.5 and 1.0) compared to the Fix ${ }^{\text {on }}$ state $\left(\mathrm{OD}_{600}\right.$ of 2.0), identified using LC-MS/MS

Proteins identified in the same spots are marked with the same superscripts (a, b, c, d e). t-tests show significantly altered protein abundance at $99 \%$ confidence level $\left(^{*}\right)$ and at $95 \%$ confidence level $\left.{ }^{* *}\right)$ for a given $\mathrm{OD}_{600}$ pair. Unmarked $t$-test values represent altered proteins that did not attain the minimum $>2$-fold difference at $95 \%$ level of confidence. Positive average ratios denote enhanced protein abundance for $1^{\text {st }} \mathrm{OD}_{600}$ relative to $2^{\text {nd }} \mathrm{OD}_{600}$ in each $\mathrm{OD}_{600}$ pair; negative average ratios denote enhanced protein abundance for $2^{\text {nd }} \mathrm{OD}_{600}$ relative to $1^{\text {st }} \mathrm{OD}_{600}$ in each $\mathrm{OD}_{600}$ pair. Refer to Table 4.2 for supporting LC-MS/MS data for peptide matches to protein identifications that correspond to gel spot numbers in Table 4.1 and that are discussed in the body of the text throughout this chapter. 


\begin{tabular}{|c|c|c|c|c|c|c|c|}
\hline Spot number & Protein ID & Unique peptides matched (peptide score) & $\mathbf{M}_{\mathrm{r}}$ & Score & $\begin{array}{l}\text { Queries } \\
\text { matched }\end{array}$ & pl & $\begin{array}{c}\text { Sequence } \\
\text { coverage (\%) }\end{array}$ \\
\hline \multirow[t]{2}{*}{1985} & Chaperone DnaK (DnaK) & $\begin{array}{l}\text { R.QAVTNPDNTIFAVK.R(93) } \\
\text { K.LGQAIYEK.E(81) }\end{array}$ & 67507 & 2706 & 70 & 4.77 & 22 \\
\hline & & $\begin{array}{l}\text { R.ADVDVIMIAPK.G(94) } \\
\text { R.VLEDIQAGR.F(69) }\end{array}$ & & & & & \\
\hline \multirow[t]{4}{*}{2778} & Ketol acid reductoisomerase ${ }^{a}$ & K.NFVLDNR.A(47) & 36252 & 988 & 29 & 5.57 & 15 \\
\hline & tryptophanyl-tRNA synthetase ${ }^{a}$ & $\begin{array}{l}\text { R.INLTDDADAIMQK.V(89) } \\
\text { R.SALDAILAK.G(66) }\end{array}$ & 36986 & 468 & 11 & 5.76 & 6 \\
\hline & Glyceraldehyde-3-phosphate dehydrogenase ${ }^{a}$ & $\begin{array}{l}\text { R.AVGEVLPELK.G(55) } \\
\text { K.VAINGFGR.I(47) }\end{array}$ & 36036 & 148 & 10 & 6 & 7 \\
\hline & & $\begin{array}{l}\text { K.LLDQGEAGDNVGALIR.G(112) } \\
\text { K.LIAPIAMDEGLR.F(71) } \\
\text { K.TTVTGVEMFR.K(72) }\end{array}$ & & & & & \\
\hline \multirow[t]{3}{*}{2972} & Translation elongation factor $(\text { Tuf })^{b}$ & K.VGDEVEIIGLKPTAK.T(69) & 43045 & 2263 & 117 & 5.16 & 32 \\
\hline & Malate dehydrogenase ${ }^{b}$ & $\begin{array}{l}\text { R.GGGGEIVALLK.T(93) } \\
\text { K.VVGMAGVLSAR.F(73) } \\
\text { K.ANLQVSVDAVK.E(71) } \\
\text { R.DDLLGINLK.V(58) }\end{array}$ & 33461 & 755 & 23 & 4.92 & 16 \\
\hline & & $\begin{array}{l}\text { R.TANLILDDGGDATMFALWGAR.V(138) } \\
\text { R.VEAGETLPEPANAEEIEFQR.A(97) } \\
\text { R.VVVTEIDPICALQAAMEGYEVVTMEEAVKR.A(92) } \\
\text { K.VACVAGFGDVGK.G(88) }\end{array}$ & & & & & \\
\hline 2431 & S-adenosylhomocysteine hydrolase (AdoHcy) & R.AEIAIAETEMPGLMALR.D(87) & 50877 & 580 & 19 & 5.33 & 66 \\
\hline
\end{tabular}

Table 4.2 LC-MS/MS peptide analysis of Y88 ${ }^{\mathrm{T}}$ proteins showing differential abundance for the Fix off state $\left(\mathrm{OD}_{600}\right.$ of 0.5 and 1.0$)$ compared to the Fix ${ }^{\circ}$ state $\left(\mathrm{OD}_{600}\right.$ of 2.0$)$

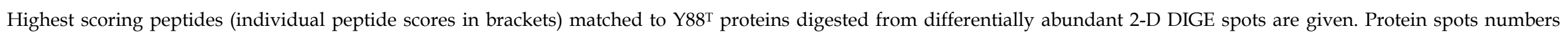

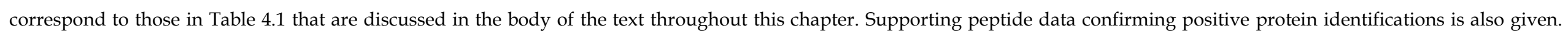
Continued on next page. 


\begin{tabular}{|c|c|c|c|c|c|c|c|}
\hline Spot number & Protein ID & Unique peptides matched (peptide score) & $\mathbf{M}_{\mathrm{r}}$ & Score & $\begin{array}{l}\text { Queries } \\
\text { matched }\end{array}$ & pl & $\begin{array}{c}\text { Sequence } \\
\text { coverage (\%) }\end{array}$ \\
\hline 3208 & hypothetical protein Saro_2615 & $\begin{array}{l}\text { K.AAYLQPNFSSTK.D(61) } \\
\text { K.TDFGEPFIK.V(46) }\end{array}$ & 29433 & 322 & 22 & 5.92 & 4 \\
\hline \multirow[t]{2}{*}{3375} & OmpA/MotB ${ }^{c}$ & $\begin{array}{l}\text { R.LEGQVGYLDAGNK.T(92) } \\
\text { K.TLNVDNQTITAVGGR.T(89) }\end{array}$ & 25899 & 697 & 12 & 7.03 & 11 \\
\hline & Ribosomal protein $L 7 / L 12^{\circ}$ & $\begin{array}{l}\text { K.LTVLEAADLAK.A(88) } \\
\text { R.AITSLGLTEAK.A(79) }\end{array}$ & 12683 & 552 & 11 & 4.65 & 43 \\
\hline \multirow[t]{2}{*}{3392} & OmpA/MotB ${ }^{d}$ & $\begin{array}{l}\text { R.LEGQVGYLDAGNK.T(80) } \\
\text { K.TLNVDNQTITAVGGR.T(91) } \\
\text { R.QTIPNDDYMIYQSR.T(68) }\end{array}$ & 25899 & 651 & 12 & 7.03 & 17 \\
\hline & Ribosomal protein $L 7 / L 12^{d}$ & $\begin{array}{l}\text { K.LTVLEAADLAK.A }(88) \\
\text { M.ADIAALVEELSK.L(94) } \\
\text { K.KIEEAGGTVEIK.X(78) } \\
\text { K.IEEAGGTVEIK.X(76) }\end{array}$ & 12683 & 1556 & 32 & 4.65 & 47 \\
\hline \multirow{3}{*}{3202} & & $\begin{array}{l}\text { K.LLDQGGEAGDNVGALIR.G(112) } \\
\text { K.LIAPIAMDEGLR.F(71) } \\
\text { K.TTVTGVEMFR.K(72) }\end{array}$ & & & & & \\
\hline & Translation elongation factor $\mathrm{EF}-1 \alpha^{\varepsilon}$ & K.VGDEVEIIGLKPTAK.T(69) & 43045 & 2263 & 117 & 5.16 & 32 \\
\hline & $\begin{array}{l}\text { nitrogenase molybdenum-iron protein beta chain } \\
\text { (NifK) })^{\text {(fragment) }}\end{array}$ & $\begin{array}{l}\text { R.LVDAIADSNAHIHGK.K(37) } \\
\text { R.VGFPIFDR.H(43) } \\
\text { R.DTGVPIR.V(44) }\end{array}$ & 58437 & 335 & 29 & 5.37 & 7 \\
\hline
\end{tabular}

Table 4.2 (cont.) LC-MS/MS peptide analysis of $\mathrm{Y}^{88^{\mathrm{T}}}$ proteins showing differential abundance for the Fix off state $\left(\mathrm{OD}_{600}\right.$ of 0.5 and 1.0$)$ compared to the Fixon state $\left(\mathrm{OD}_{600}\right.$ of 2.0$)$ Highest scoring peptides (individual peptide scores in brackets) matched to $\mathrm{Y} 88^{\mathrm{T}}$ proteins digested from differentially abundant 2-D DIGE spots are given. Protein spots numbers correspond to those in Table 4.1 that are discussed in the body of the text throughout this chapter. Supporting peptide data confirming positive protein identifications is also given. Continued on next page. 


\begin{tabular}{|c|c|c|c|c|c|c|c|}
\hline Spot number & Protein ID & Unique peptides matched (peptide score) & $\mathbf{M}_{\mathbf{r}}$ & Score & $\begin{array}{l}\text { Queries } \\
\text { matched }\end{array}$ & pl & $\begin{array}{l}\text { Sequence } \\
\text { coverage (\%) }\end{array}$ \\
\hline & & $\begin{array}{l}\text { K.GIMDTDGNWAPGVPEEVER.V(98) } \\
\text { K.ILQQLAADR.H(75) } \\
\text { K.NIVAAGLAHR.C(70) }\end{array}$ & & & & & \\
\hline 2612 & S- adenosylmethionine (SAM) synthetase & K.IIVDTYGGASPHGGGAFSGK.D(66) & 43503 & 2729 & 119 & 5.27 & 28 \\
\hline 3255 & Dinitrogenase reductase $(\mathrm{NifH})$ & K.STTSQNTLAALADLGQR.I(119) & 31.859 & 563 & 9 & 4.94 & 5 \\
\hline & & $\begin{array}{l}\text { R.CVESGGPEPGVGCAGR }(118) \\
\text { R.LGGLICNER.K(82) } \\
\text { R.DNIVQHAELR.R(83) }\end{array}$ & & & & & \\
\hline 3198 & Dinitrogenase reductase $(\mathrm{NifH})$ & K.AQEIYIVMSGEMMAMYAANNISK.G(74) & 31.859 & 9714 & 490 & 4.94 & 38 \\
\hline 1809 & $\mathrm{NI}$ & - & - & - & - & - & - \\
\hline 2917 & Nitrogenase molybdenum beta chain (NifK) fragment & $\begin{array}{l}\text { R.MYDGGTTLEEAGQAVHAR.A(54) } \\
\text { R.LAGVEIPDDLAKER.G(46) }\end{array}$ & 58437 & 192 & 13 & 5.37 & 7 \\
\hline $3234 \mathrm{~A}$ & $\begin{array}{l}\text { ATP-dependent Clp protease, proteolytic subunit } \\
\text { (ClpP) }\end{array}$ & $\begin{array}{l}\text { R.MNDLYVK.Y(47) } \\
\text { R.SFDIYSR.L(43) } \\
\text { R.GMASDIEIQAR.E(77) }\end{array}$ & 25292 & 730 & 37 & 4.92 & 13 \\
\hline 3234B & isochorismatase & $\begin{array}{l}\text { K.SIDATLLR.N(53) } \\
\text { K.LGGAYGLGITYAK.T(82) } \\
\text { R.TETYEHTTGIAR.K(72) }\end{array}$ & 23573 & 775 & 29 & 5.06 & 15 \\
\hline 3430 & phasin & $\begin{array}{l}\text { K.SQASFGELGEFAK.G(106) } \\
\text { K.LANEAFQPISNR.V(89) } \\
\text { K.ILSTGLQELGK.G(93) } \\
\text { K.HFDAAVAASS.N(73) } \\
\text { K.SAFETLTAEFK.D }(76)\end{array}$ & 33.963 & 12142 & 288 & 9.56 & 27 \\
\hline
\end{tabular}

Table 4.2 (cont.) LC-MS/MS peptide analysis of $\mathrm{Y}^{8} 8^{\mathrm{T}}$ proteins showing differential abundance for the Fix off state $\left(\mathrm{OD}_{600}\right.$ of 0.5 and 1.0$)$ compared to the Fix ${ }^{\text {on }}$ state (OD 600 of 2.0$)$

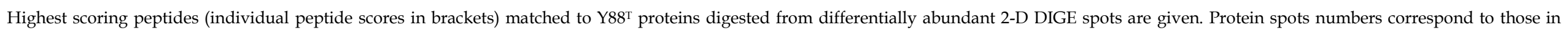




\begin{tabular}{|c|c|c|c|c|c|c|c|}
\hline Spot number & Protein ID & Unique peptides matched (peptide score) & $\mathbf{M}_{\mathbf{r}}$ & Score & $\begin{array}{l}\text { Queries } \\
\text { matched }\end{array}$ & pl & $\begin{array}{c}\text { Sequence } \\
\text { coverage (\%) }\end{array}$ \\
\hline 3251 & hypothetical protein BRADO5426 & $\begin{array}{l}\text { R.ISDTAFGTLEAAR.R(96) } \\
\text { M.SATTSPSLETVR.I(64) }\end{array}$ & 22861 & 450 & 11 & 4.93 & 15 \\
\hline 1216 & Nitrogenase molybdenum beta chain (NifK) & no high-scoring peptide data obtained ${ }^{*}$ & 58437 & - & - & 5.37 & - \\
\hline 1 & NifU & $\begin{array}{l}\text { R.TNGLTSIDEVTNYTK.A(107) } \\
\text { K.AGGGCSTCAEGIEGVLER.V(93) } \\
\text { K.NSGILEDADGVGDVGAISCGDALR.L(89) }\end{array}$ & 33542 & 4140 & 13 & 4.72 & 59 \\
\hline 2 & Electron-transfer flavoprotein $\alpha$-subunit (FixB) & $\begin{array}{l}\text { R.GVELGAVVMGDDR.A(99) } \\
\text { R.IVEYAPAIVEADIVTK.V(83) } \\
\text { K.LAEVLGAEYGGSRPLVQK.G(81) }\end{array}$ & 39443 & 3555 & 256 & 5.95 & 37 \\
\hline & OmpA/MotB & $\begin{array}{l}\text { K.TLNVDNQTITAVGGR.T(105) } \\
\text { R.LEGQVGYLDAGNK.T(98) } \\
\text { K.FAWQLIAGVR.A(90) } \\
\text { R.QTIPNDDYMIYQSR.T(86) }\end{array}$ & 25899 & 1655 & 44 & 7.03 & 30 \\
\hline 3430 & Phasin & $\begin{array}{l}\text { K.VALVFGQMNEPPGAR.A(116) } \\
\text { R.VALSGLTMAEYFR.D }(112) \\
\text { K.APEFIEQSTEAAILVTGIK.V(113) }\end{array}$ & 36948 & 5250 & 222 & 4.78 & 51 \\
\hline
\end{tabular}

Table 4.2 (cont.) LC-MS/MS peptide analysis of $Y^{8} 88^{\mathrm{T}}$ proteins showing differential abundance for the Fix off state $\left(\mathrm{OD}_{600}\right.$ of 0.5 and 1.0$)$ compared to the Fix ${ }^{\text {on }}$ state $\left(\mathrm{OD}_{600}\right.$ of 2.0$)$

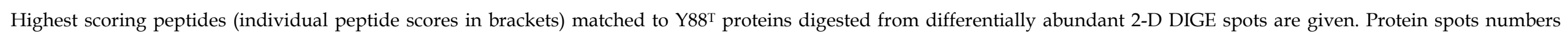

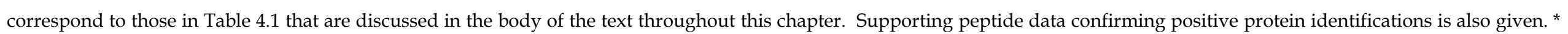

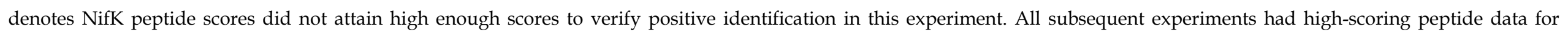
positive verification of NifK. 
mediated control of nitrogenase as previously demonstrated in A. vinelandii (Laane et al., 1980) in which ammonium chloride represses nitrogen fixation due to inhibition of the electron transport system to nitrogenase. However, the results presented here differ from those of Laane et al., (1980) in that these authors investigated the activity of the nitrogenase enzyme whereas our study investigated changes in the expression of the nitrogenase enzyme. In Y88 nitrogen fixation appears to be low due to lack of expression of the proteins themselves. Whether this lack of expression of the nitrogenase proteins in $\mathrm{Y}^{8} 8^{\mathrm{T}}$ is a consequence of the inhibition of the electron transport system to nitrogenase, is unknown. What is apparent is that whatever the constraint on the $\mathrm{Y}^{8 \mathrm{~T}}$ nitrogenase is, it is only removed at higher $\mathrm{OD}_{600}$ of greater than 1.0 once the ammonium has been depleted since at an $\mathrm{OD}_{600}$ of 1.0, NifHK are also absent from the gels (Fig. 4.4B).

Several other proteins known to be involved in nitrogen fixation displayed altered abundance at high $\mathrm{OD}_{600}$ under ammonium-depleted conditions relative to lower $\mathrm{OD}_{600}$ under ammonium-supplemented conditions. A highly abundant spot at approximately $23 \mathrm{kDa}$ on the high $\mathrm{OD}_{600}$ gel (Fix $\left.{ }^{\circ}\right)$ was identified as the hypothetical protein BRADO5426 (Fig. 4.5B, spot 3251). This protein showed a 2-fold difference in abundance between high $\left(\mathrm{OD}_{600}=2.0\right)$ and low $\mathrm{OD}_{600}$ $\left(\mathrm{OD}_{600}=0.5\right)$ and a 4.6-fold difference between $\mathrm{OD}_{600}=2.0$ and $\mathrm{OD}_{600}=1.0$ and may be implicated in some aspect of nitrogen fixation, since it is abundantly present for the Fix on state. Its exact function has yet to be elucidated. It is located in the $\mathrm{Y} 88^{\mathrm{T}}$ genome just upstream of nifU and nifW and the two subunits of the $\alpha / \beta$-heterodimeric electron transfer flavoprotein $(\mathrm{ETF})$, the electron transfer flavoprotein $\beta$ chain (FixA) and electron transfer flavoprotein $\alpha$ chain (FixB) as well as several other genes involved in nitrogen fixation. This gene cluster likely forms an operon that co-coordinates the switch from the Fix off to the Fix on state. The NifU protein was upregulated 3.7-fold $(t$-test $=0.09)$ in the Fix ${ }^{\text {on }}$ state (Fig. $4.5 \mathrm{~B}$, spot 1) relative to the Fix off states (Figs. 4.4A, 4.4B, spot 1). NifU is an assembly scaffold protein that plays a role (together with NifS) in the activation of the Fe and MoFe proteins required for maturation of the nitrogenase enzyme 
(Johnson et al., 2005). Similarly, FixB was upregulated for the Fix on state at the high $\mathrm{OD}_{600}$ of 2.0 (Fig. 4.5B, spot 2) relative to the Fix off states at lower OD 600 (0.5 and 1.0). This protein is considered to sustain nitrogen fixation by providing reducing equivalents to the nitrogenase complex (Finocchiaro et al., 1988; O'Neill et al., 1998; Edgren \& Nordlund, 2004; Scott \& Ludwig, 2004). At low $\mathrm{OD}_{600}$, the downregulation of this protein correlates with the absence of the nitrogenase metalloproteins for the Fix off state and is consistent with the ammonium depression hypothesis of nitrogenase as a consequence of ammonium uptake inhibiting the flow of reducing equivalents to nitrogenase, thereby inhibiting nitrogen fixation (Scott \& Ludwig, 2004). At a high OD 600 , the enhanced abundance of these proteins suggests a coordinated response whereby ammonium depletion results in a derepression of the operon transcribing these proteins, concomitantly promoting expression of the genes transcribing the nitrogenase metalloproteins and allowing nitrogen fixation to proceed.

\subsection{PHA synthesis and granule-associated proteins}

One of the three major enzymes involved in PHB synthesis, $\beta$-Ketothiolase (acetyl-CoA C-acetyltransferase, PhbA) was identified at 41 kDa (Figs. 4.4, 4.5; spot 2655) and was common to all physiologies. This protein showed very little change in abundance (1.3-fold) at $\mathrm{OD}_{600}$ of 2.0 (Fig. 4.5B) from that at lower $\mathrm{OD}_{600}$ although it possible to see this change in abundance on the gel. At a 1.3fold difference, $\mathrm{PhbA}$ was found to not be significantly different relative to its abundance at the lower $\mathrm{OD}_{600}$ of 0.5 ( $t$-test=0.37, Table 4.1, Fig. 4.5A) and an $\mathrm{OD}_{600}$ of $1.0(t$-test $=0.34$, Table 4.1, Fig. 4.4B) despite the presence of higher PHB content in the cells. Additionally, the PHB granule-associated protein, phasin (PhaP) was identified at approximately 13-14 kDa as the most abundant spot on the gel under all growth conditions (Figs. 4.4, 4.5, spot 3430). PhaP was most highly expressed under high $\mathrm{OD}_{600}$ of 2.0 for the Fix on state (Fig. 4.5B). BVA results confirmed an increase in PhaP abundance of 3.12-fold at a high $\mathrm{OD}_{600}$ of 2.0 compared to the low $\mathrm{OD}_{600}$ of $0.5(t$-test $=0.05$, Table 4.1$)$, and a 2 -fold $(t$-test $=$ 0.19 ) increase in abundance from an $\mathrm{OD}_{600}$ of 0.5 to 1.0 (Table 4.1). An increase in abundance of PhaP therefore occurred from low to high $\mathrm{OD}_{600}$ consistent 134 
with growth and PHB accumulation (Figs. 4.4, 4.5) but did not attain statistical significance at the $99 \%$ level of confidence.

Three points are notable in terms of increased PhbA and PhaP abundance throughout growth. First, the increase in PhbA, PhaP and $\mathrm{OD}_{600}$ occur concomitantly suggesting an interdependence of these two proteins from the early stages of growth and throughout changing growth conditions. Secondly, although changes in abundance occur with growth, both PhbA and PhaP are expressed at high levels even at low $\mathrm{OD}_{600}$. It would therefore take a huge increase in absolute abundance to achieve at least the two-fold difference in abundance required to attain statistical significance at a 99\% level of confidence. Thirdly, since PhaP was also highly expressed at the lower $\mathrm{OD}_{600}$ of 0.5 and 1.0, at which points no detectable nitrogen fixation occurred, these proteomic results augment the microbiology data by demonstrating that neither the presence nor the abundance of both $\mathrm{PhbA}$ and PhaP are dependent on nitrogen fixation. By inference, PHA synthesis is independent of nitrogen fixation.

\subsection{Stress-related proteins}

Several stress-related proteins were identified, of which two were upregulated for the Fix ${ }^{\text {off }}$ state. Chaperone DnaK (spot 1985) was upregulated 2.3-fold ( $t$ test $=0.0032$ ) at an $\mathrm{OD}_{600}$ of 0.5 (Fig. $4.4 \mathrm{~A}$, Table 4.1 ) relative to an $\mathrm{OD}_{600}$ of 1.0 (Fig. 4.4B). DnaK is the catalytic component of the DnaK chaperone system involved in a wide variety of biological processes such as protein folding, disassembly, disaggregation and translocation as well as targeting proteins for degradation (Bukau \& Horwich, 1998; Fink, 1999). Its higher abundance for the Fix off state of $\mathrm{Y}^{\mathrm{T}}{ }^{\mathrm{T}}$ cells coupled to its roles in disassembly and targeting proteins for degradation suggests that it may be upregulated in response to nitrogen turnover at lower $\mathrm{OD}_{600}$ when the cells are establishing themselves and starting to undergo higher rates of cell division. Additionally, DnaK has also been identified as a granule-associated protein in an $R$. eutropha phasin mutant strain (Pötter et al., 2004), as well as in E. coli expressing the phbCAB operon (Han et al., 2001). DnaK has been shown to enhance the specific activity of PHA synthase (Jossek et al., 1998) during granule formation and has also been shown 
to be upregulated as a result of stress to the cells caused by the accumulating PHA granules increasing in size and displacing the intracellular contents during PHA production (Hecker \& Volker, 2004; Tessmer et al., 2007). Given this latter role for DnaK, it could be expected that the abundance of this protein would be enhanced at higher PHA production. Its greater abundance at low $\mathrm{OD}_{600}$ when ammonium ion is available in the growth medium coupled to lower PHA production during the early stage of growth, therefore suggests that DnaK may play an increased role in protein turnover to accommodate an increase in the cells "scavenging" nitrogen and could be a link between nitrogen cycling and PHA accumulation in $\mathrm{Y}^{8} 8^{\mathrm{T}}$. Considering its role in cell stress, one other possibility for the enhanced abundance of DnaK at a lower $\mathrm{OD}_{600}$ of 0.5 when the cells would be experiencing a high rate of cell division, could be a cellular response to stress resulting from rapid metabolism.

Another stress response protein, ATP-dependent Clp protease, proteolytic subunit $(\mathrm{ClpP})$ was identified together with a second protein, isochorismatase. These proteins were picked as one spot since they did not completely resolve as individual spots on the $7 \mathrm{~cm}$ gels. Based on the observed pIs and $\mathrm{M}_{\mathrm{r}}$ of both spots compared with the pIs and $\mathrm{M}_{\mathrm{r}}$ predicted from the $\mathrm{Y} 88^{\mathrm{T}}$ genome sequence, it was possible to distinguish ClpP as spot 3234A and isochorismatase as spot 3234B (Figs. 4.5A, 4.5B). Isochorismatase was upregulated 3.3-fold ( $t$-test=0.015) for the Fix off state at low $\mathrm{OD}_{600}$ of 0.5 (Fig. 4.5A, spot 3234B) relative to a high $\mathrm{OD}_{600}$ of 2.0 (Fig. 4.5B). Isochorismatase belongs to the family of hydrolase enzymes and catalyses the second step in the overall enterobactin biosynthetic pathway as well as the first part of the pathway converting isochorismate, in the presence of water, to 2,3-dihydroxybenzoate and pyruvate. Isochorismatase is produced in E. coli during the biosynthesis of enterobactin, an iron-chelating product derived from chorismic acid and involved in the transport of iron from the bacterial environment into the cell cytoplasm (Hamano et al., 2006). Isochorismatase is also involved in the biosynthesis of the antimicrobial compound phenazine in pseudomonads and is considered to contribute to the persistence of pseudomonad infections by affording a competitive advantage to 
pseudomonads over other bacteria in its environment (Parsons et al., 2003). Its enhanced abundance in $\mathrm{Y}^{\mathrm{T}}$ at low $\mathrm{OD}_{600}$ of 0.5 (Fig. 4.4A) relative to the later stages of growth at an $\mathrm{OD}_{600}$ of 1.0 (Fig. 4.4B) or high $\mathrm{OD}_{600}$ of 2.0 (Fig. 4.5B), may be related to iron ion transport of the supplemented iron in the growth medium into the cells during early growth. Its downregulation at high $\mathrm{OD}_{600}$ may reflect the depletion of iron in the growth medium during nitrogen fixation since a high turnover rate of nitrogenase requires iron and increased demand for iron would result in depletion of the extracellular iron supply. Since isochorismatase is produced during enterobactin biosynthesis, its increased abundance in $\mathrm{Y}^{\mathrm{T}} \mathrm{T}$ cells during early growth was considered to possibly be related to enterobactin biosynthesis. However, this possibility was discounted in $\mathrm{Y}^{8} 8^{\mathrm{T}}$ since enterobactin biosynthesis is associated with limiting iron availability and during early growth of $\mathrm{Y}^{\mathrm{T}}{ }^{\mathrm{T}}$, more iron is available than at the later stages of growth. Consistent with this notion, only one enterobactin biosynthesis gene, ferric enterobactin esterase-related protein (Fes), was identified from the $\mathrm{Y} 88^{\mathrm{T}}$ ORF translated protein sequences.

ClpP showed enhanced abundance for the Fix ${ }^{\text {on }}$ state of the cells at high $\mathrm{OD}_{600}$ of 2.0 (Fig. 4.5B, spot 3243A) relative to the Fix ${ }^{\text {off }}$ state of the cells at lower $\mathrm{OD}_{600}$ of 0.5 and 1.0 (Figs. 4.5A, 4.4B). This protein forms part of the Clp protease complex that can function either as a proteolysis regulator or as a molecular chaperone. As a subunit of this complex, $\mathrm{ClpP}$ is important for the degradation of misfolded proteins generated when cells are exposed to stress. During stress, abnormal or misfolded proteins will accumulate in the cell due to denaturation and errors in biosynthesis (Gottesman, 1996). Cellular response to the accumulation of these proteins involves increasing the synthesis of molecular chaperones and proteases, the former to assist with the correct folding/refolding of proteins targeted for degradation and the latter to degrade the proteins that can not be folded (Schelin et al., 2002). In addition to eliminating abnormal proteins, proteolysis controls the level of naturally short-lived regulatory proteins and is therefore essential for cell homeostasis and optimal metabolic activity (Gottesman, 1996). The enhanced abundance of ClpP at a 
high $\mathrm{OD}_{600}$ of 2.0 in $\mathrm{Y}^{\mathrm{T}}$ cells fixing nitrogen may therefore be due to increased proteolysis of non-functional, short-lived regulatory proteins that may function in nitrogen cycling during nitrogen fixation. In $\mathrm{Y}^{8} 8^{\mathrm{T}}$, accumulated non-essential or non-functional proteins would place additional stress on cells already stressed by the competing energy intensive metabolic processes of nitrogen fixation and PHA accumulation, if these were not removed. A higher abundance of $\mathrm{ClpP}$ may therefore be required to ensure optimal nitrogen cycling and nitrogen-fixing activities as well as optimal functioning of PHA regulatory proteins.

\subsection{Other proteins}

Ketol acid reductoisomerase, tryptophanyl-tRNA synthetase and glyceraldehyde-3-phosphate dehydrogenase (NAD-dependent) were identified in the same spot (Figs. 4.4, 4.5; spot 2778). These three proteins co-migrated as a result of having similar $\mathrm{M}_{\mathrm{r}}$ and pIs (Table 4.1). Spot 2778 was more abundant (2.8-fold upregulated, $t$-test $=0.004$ ) at high $\mathrm{OD}_{600}$ of 2.0 (Fig. $4.5 \mathrm{~B}$ ) relative to the lower $\mathrm{OD}_{600}$ of 1.0 (Fig. 4.4B). It is unclear which of these proteins, if not all three, are responsible for this increase. What is clear is that this spot is present at $\mathrm{OD}_{600}=0.5$ (Figs. 4.4A, 4.5A), disappears from the gel at $\mathrm{OD}_{600}=1.0$ (Fig. 4.4B) and is again evident at $\mathrm{OD}_{600}=2.0$ (Fig. 4.5B). Ketol acid reductoisomerase is implicated in the synthesis of branched-chain amino acids, and such branchedchain amino acids as valine and isoleucine have been reported to induce the synthesis of phosphotransbutyrylase (YqiS), an enzyme which enhances PHB accumulation in Bacillus megaterium (Vazquez et al., 2003). Enhanced abundance of ketol acid reductoisomerase at high $\mathrm{OD}_{600}$ could therefore result from an increased demand for biosynthesis of these amino acids due to increased PHB synthesis. Tryptophanyl-tRNA synthetase is involved in protein biosynthesis and its upregulation at high $\mathrm{OD}_{600}$ could be related to increased protein synthesis of proteins required for nitrogen fixation and increased PHA production. NAD-dependent glyceraldehyde-3-phosphate dehydrogenase catalyses the conversion of glyceraldehyde-3-phosphate, the first 3-carbon metabolite of glycolysis, that is eventually used for PHB synthesis (Han \& Lee, 2003). An increase in abundance of glyceraldehyde-3-phosphate dehydrogenase 
at higher $\mathrm{OD}_{600}$ could be due to the greater demand for glyceraldehyde-3phosphate conversion to meet the increased demand of acetyl-coA and NADPH required for PHB synthesis (Han \& Lee, 2003).

Several proteins involved in protein synthesis and translation also showed altered abundance. Translation elongation factor and NAD-dependent malate dehydrogenase (comigrating in spot 2972, Figs. 4.4, 4.5) were upregulated 2.3fold ( $t$-test $=0.007$ ) at an $\mathrm{OD}_{600}$ of 0.5 (Fig. 4.4A) relative to that at an $\mathrm{OD}_{600}$ of 1.0 (Fig. 4.4B) and 3.6-fold ( $t$-test $=0.006$ ) relative to that at the highest $\mathrm{OD}_{600}$ of 2.0 (Fig. 4.5B, Table 4.1). Spot 3202, identified as elongation factor EF-1 $\alpha$, was upregulated 10.6-fold ( $t$-test $=0.0076$ ) at high $\mathrm{OD}_{600}$ (Fig. 4.5B) relative to that at the low $\mathrm{OD}_{600}$ of 0.5 (Fig. 4.5A). OmpA/MotB was identified in two highly abundant spots (Fig. 4.5B, spots 3392 and 3375) together with ribosomal protein L7/L12 at approximately $12 \mathrm{kDa}$ and pIs of 4.5 and 4.7 on the high $\mathrm{OD}_{600}$ gel (Fig. 4.5B). OmpA is a porin outer membrane protein present in the outer membrane of many Gram-negative bacteria whereas MotB is a flagellar torquegenerating protein and shares a conserved C-terminal domain with OmpA described as a peptidoglycan-anchoring domain (De Mot \& Vanderleyden, 1994). Baev et al. (2006) demonstrated that nitrogen limitation activates the nitrogen regulatory response (Ntr) which induces the expression of several operons including genes coding for outer membrane proteins involved in peptide transport. Expression of the porin ompA gene, amongst others, that encodes the protein OmpA, was enhanced under nitrogen-limiting conditions. These authors further demonstrated that OmpA, in conjunction with two other porins, plays an important role in peptide transport during nitrogen limitation. Spot 3392 was upregulated 15.6 -fold ( $t$-test $=0.02$ ) at high OD $_{600}$ (Fig. 4.5B) relative to the lower $\mathrm{OD}_{600}$ of 1.0 (Fig. 4.4B) and 12.3-fold ( $t$-test=0.019) relative to the $\mathrm{OD}_{600}$ of 0.5 . Spot 3375 was upregulated 18.6-fold ( $t$-test $\left.=0.019\right)$ at high $\mathrm{OD}_{600}$ of 2.0 (Fig. 4.5B) relative to that at an $\mathrm{OD}_{600}$ of 1.0 (Fig. 4.4B) and 12-fold ( $t$-test $=0.02$ ) relative to an $\mathrm{OD}_{600}$ of 0.5 (Fig. 4.5A, Table 4.1). High scoring peptide matches to OmpA/MotB in both spots made it difficult to ascertain which of the two OmpA/MotB proteins matched which spot. Y88 $8^{\mathrm{T}}$ has seven 
OmpA/MotB proteins. The upregulation of OmpA/MotB in $\mathrm{Y}^{\mathrm{T}}$ cells following ammonium depletion and during nitrogen fixation may be a response to low nitrogen levels in the cell or possibly increased cell membrane synthesis during nitrogen fixation.

Since $\mathrm{Y} 88^{\mathrm{T}}$ has only one gene encoding L7/L12 (based on the Y88 ${ }^{\mathrm{T}}$ genome, Scion in-house proprietary database) and the same high-scoring peptide matched each spot, this protein could have undergone post-translational modification, resulting in two charged isoforms of the same protein. Had the presence of the two spots been due to proteolysis, different peptides could have been expected to match uniquely to each spot and the proteins would have been observed at different molecular weights. This protein is absent from both the lower $\mathrm{OD}_{600}$ gels at corresponding $\mathrm{M}_{\mathrm{r}}$ and $\mathrm{pI}$ (Figs. 4.4A, 4.4B). Since the ribosomal protein L7/L12 plays an important role in mRNA-ribosome interactions and in the binding of several factors essential for accurate translation (Rosen et al., 2001), its enhancement and possible post-translational modification as observed at high $\mathrm{OD}_{600}$ may reflect an adaptive requirement of the cell for the rapid synthesis of a specific set of proteins required for increased growth rate during nitrogen fixation. Its induction from low to high $\mathrm{OD}_{600}$ reflects the shift from the Fix ${ }^{\text {off }}$ to the Fix on state of the cell and supports the notion that ribosomes play a role in sensing environmental changes as suggested by Rosen et al. (2001).

A hypothetical protein, Saro_2615 (spot 3208), showed highly altered abundance (26.8-fold) for the Fix ${ }^{\text {on }}$ state at high $\mathrm{OD}_{600}$ of 2.0 relative to the Fix ${ }^{\text {off }}$ state at lower $\mathrm{OD}_{600}$ of $0.5(t$-test $=0.01)$. This protein is considered to be a putative outer membrane protein but its function is yet to be elucidated. Its coordinated upregulation, together with the aforementioned OmpA/MotB, suggested in this study to possibly be a response to low nitrogen levels in Y88 ${ }^{\mathrm{T}}$, may reflect an enhanced nitrogen-sensing regulatory response that promotes nitrogen fixation. 
Spot 2612, identified as S-Adenosylmethionine (AdoMet) synthetase, which is known to play a central metabolic role in all organisms, was downregulated 6.21-fold ( $t$-test $=0.009$ ) at high $\mathrm{OD}_{600}$ (Fig. 4.5B) relative to that at the low $\mathrm{OD}_{600}$ of 0.5 (Fig. 4.5A). AdoMet synthetase is implicated in an intrinsic role in microbial secondary metabolism and the possible regulatory control of morphological differentiation (Okamoto et al., 2003). It catalyses the formation of AdoMet, which is the primary methyl group donor in biological systems and known to be involved in polyamine biosynthesis (Takusagawa et al., 1996). After donation of the methyl group from AdoMet to a methyl acceptor, SAdenosylhomocysteine (AdoHcy) is formed which is hydrolysed by AdoHcy hydrolase. The latter protein (identified in spot 2431) was shown to have a 4.2fold higher abundance at $\mathrm{OD}_{600} 0.5$ relative to 1.0 and a 6.8-fold decrease in abundance for the Fix ${ }^{\text {on }}$ state at $\mathrm{OD}_{600} 2.0$ relative to the Fix off state at $\mathrm{OD}_{600} 0.5$. Elevated levels of AdoMet synthetase are associated with increased levels of intracellular AdoMet (Okamoto et al., 2003). Another important function of AdoMet is its role as the sole donor of an aminopropyl group that is conjugated with putrescine to form the polyamine spermidine and then spermine (Chiang et al., 1996). This is of particular interest in the proteomic signature of $Y 88^{\mathrm{T}}$, since one of the distinguishing characteristics of sphingomonads from other Gram-negative bacteria is that they utilise homospermidine as the major polyamine (Busse et al., 2005). Although the function of homospermidine is unclear (Tholl et al., 1996), is has been implicated to have a functional role in nitrogen fixation and a role in nitrogen metabolism (Hamana et al., 1983). The coordinated upregulation of AdoMet synthetase and AdoHcy hydrolase in Y88 cells for the Fix off state is more likely to be a response either to nitrogen scavenging or the stress related to scavenging nitrogen since methylation of heat shock proteins by AdoMet is known to occur under stress (Chiang et al., 1996). Interestingly, AdoMet produces the autoinducer Al-2 that is implicated in a unique "universal" signal suggested to be used in bacterial communication (Schauder et al., 2001). 
Translation elongation factor and malate dehydrogenase were identified in the same protein spot (spot 2972), which was upregulated at OD600 0.5 (Fig. 4.4A) relative to $\mathrm{OD}_{600}$ of 1.0 (2.31-fold, $t$-test 0071, Fig. 4.4B, Table 4.1) and 2.0 (3.62fold, 0064, Fig. 4.5B, Table 4.1). These two proteins co-migrated so it is unclear which of these proteins, if not both, are responsible for this increase.

Three spots, two of which have yet to be identified, also show altered protein abundance. Spot 3208, formerly identified as hypothetical protein Saro_2615 which on closer inspection appeared to be two closely migrating spots rather than one, was later also identified as enoyl-CoA hydratase (see Appendix A, Fig. A.1, spot D11) an enzyme involved in fatty acid $\beta$-oxidation. It was highly upregulated 30.7-fold ( $t$-test=0.014, Appendix A, Fig. A.1) irrespective of

growth conditions at high $\mathrm{OD}_{600}$. Spot 2431 was upregulated 4.16-fold ( $t$ test=0.02) at an $\mathrm{OD}_{600}$ of 0.5 (Fig. 4.4A) relative to that at an $\mathrm{OD}_{600}$ of 1.0 (Fig. $4.4 \mathrm{~B})$ and 6.8 -fold $(t$-test $=0.024)$ relative to that at the highest $\mathrm{OD}_{600}$ of 2.0 (Fig. 4.5B). Spot 1809, yet to be identified, was upregulated 12-fold ( $t$-test $=0.013)$ at a high $\mathrm{OD}_{600}$ of 2.0 (Fig. 4.5B) for the Fix ${ }^{\text {on }}$ state relative to the low $\mathrm{OD}_{600}$ of 0.5 (Fig. 4.5A).

\subsection{Summary}

An examination of the $\mathrm{Y}^{\mathrm{T}} 8^{\mathrm{T}}$ proteome identified proteomic signatures for the Fix ${ }^{\text {off }}$ and Fix on states of $\mathrm{Y}^{8} 8^{\mathrm{T}}$ growth. The proteomic signature for the $\mathrm{Y} 88^{\mathrm{T}} \mathrm{Fix}$ on state included a number of nitrogen-fixing proteins which showed a clear upregulation in their abundance with a switch from assimilating extracellular ammonium to fixing nitrogen. Thus the presence of ammonium in the growth medium appeared to inhibit the expression of the genes encoding the $\mathrm{Y} 88^{\mathrm{T}}$ nitrogen-fixing proteins. The OmpA/MotB proteins included in this signature were similarly affected. The proteomic signature obtained for the Y88 ${ }^{\mathrm{T}}$ Fix ${ }^{\mathrm{n}}$ state contrasted with that for $\mathrm{Y}^{\mathrm{T}} \mathrm{T}^{\mathrm{PHA}}$ synthesis physiology, which showed no obvious effect of the presence or absence of ammonium. Therefore, PHA production appears to be independent of nitrogen fixation in $\mathrm{Y}^{8} 8^{\mathrm{T}}$. 
The coordinated upregulation of several proteins observed in the proteomic signature for $\mathrm{Y}^{\mathrm{T}} 8^{\mathrm{T}}$ nitrogen-fixing physiology that would not usually be associated with nitrogen fixation, suggests a functional role for these proteins initiated by ammonium-depleted conditions. Based on their general functions, these proteins could play a role in optimising metabolic activities as part of a coordinated response to changing nitrogen fixation and PHA activities, ensuring that the activity of specific regulatory proteins required for these functions is maintained to allow nitrogen fixation to proceed while maintaining high levels of PHA production. The nitrogenase enzyme is a case in point. The high turnover rate of nitrogenase during nitrogen fixation may result in the upregulation of proteins involved in protein degradation. The degraded protein products can be used to replenish the amino acids required for nitrogenase synthesis. Without the coordinated regulatory response of proteins that target other proteins for degradation, the increased demand for nitrogenase during nitrogen fixation could not be maintained and nitrogen fixation would not occur. 


\section{Chapter 5: The paradox of $\mathrm{Y88}^{\mathrm{T}}$ growth at high oxygen concentration}

\subsection{Introduction}

The MoFe nitrogenase enzyme is rapidly and irreversibly inactivated by oxygen (Staal et al., 2007). As an obligate aerobe, $\mathrm{Y}^{\mathrm{T}} 8^{\mathrm{T}}$ requires oxygen to support aerobic respiration and ATP synthesis to meet the high energy demands of nitrogen fixation and other cellular activities, yet it must prevent irreversible damage to its nitrogenase when growing under nitrogen-limiting conditions. To assess the possible effects of DO on the $\mathrm{Y} 88^{\mathrm{T}}$ nitrogenase enzyme, $\mathrm{Y} 88^{\mathrm{T}}$ cells were grown in parallel in bioreactors in which the DO concentrations were maintained at low $(10 \%$ DO) or high $(70 \%$ DO) levels. Proteomic analysis showed that the $\mathrm{Y} 88^{\mathrm{T}}$ nitrogenase enzyme was present at barely detectable levels under DOhigh conditions. Despite this fact and regardless of the vast differences in DO concentrations, the ability of $Y 88^{\mathrm{T}}$ to increase its biomass and produce high amounts of PHB was not affected. The yields of PHB produced under both oxygen concentrations were also similar to that produced by $\mathrm{Y}^{\mathrm{T}} \mathrm{T}$ grown in batch flasks (Chapter 3). These results indicate the versatility of $\mathrm{Y}^{\mathrm{T}} \mathrm{P}^{\mathrm{T}}$ as a PHB-producing nitrogen fixer that appears to have the ability to protect its nitrogenase (possibly through a conformational change) under adverse growth conditions.

\subsection{Results}

\subsubsection{Cultivation of ${\mathrm{Y} 88^{\mathrm{T}}}^{\mathrm{in}}$ a bioreactor at $\mathrm{DO}^{\text {low }}$ or $\mathrm{DO}^{\text {high }}$ concentrations}

\subsubsection{Growth and nitrogen utilisation}

The microbiology of $\mathrm{Y}^{8} 8^{\mathrm{T}}$ was investigated during batch cultivation for $24 \mathrm{hr}$ in parallel bioreactors with DO concentrations held constant at 10\% and 70\% DO in a glucose-enriched $(5 \mathrm{~g} / \mathrm{L})$ minimal nitrogen medium $\left(0.1 \mathrm{~g} / \mathrm{L} \mathrm{NH}_{4} \mathrm{Cl}\right)$ (see Chapter 2, section 2.1.4.2, Table 2.1 for experimental design and parameter details). $\mathrm{Y}^{\mathrm{T}} 8^{\mathrm{T}}$ attained similar high $\mathrm{OD}_{600}$ of approximately 2.0 at both DOlow 144 
and DOhigh concentrations after approximately $20 \mathrm{hr}$ (Fig. 5.1A). The amount of biomass produced was also similar (Fig. 5.1B) at both DO concentrations. Acetylene reduction assays carried out at low (0.5) or high (2.0) $\mathrm{OD}_{600}$ at both DO concentrations to determine whether the nitrogenase enzyme was active under these conditions, showed that $\mathrm{Y}^{\mathrm{T}} 8^{\mathrm{T}}$ cells grown in DOlow produced substantial amounts of ethylene, indicative of nitrogen fixation (Fig. 5.1C). In

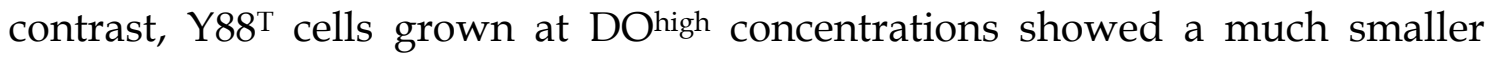
ethylene peak, indicative of decreased nitrogenase activity (Fig. 5.1D). Despite the presumable decrease in nitrogen fixation suggested by the smaller ethylene peak in the acetylene reduction assays for the cells grown at DOhigh, the cells grew similarly to those at DOlow with no difference in the amount of biomass produced by $\mathrm{Y}^{\mathrm{T}} 8^{\mathrm{T}}$ between $\mathrm{DO}^{\text {low }}$ and $\mathrm{DO}$ high conditions. At the time of the assay, only traces of nitrogen were measured in the spent medium for both DOlow and DOhigh conditions using the Kjeldahl method (Fig. 5.2). Independent verification of the removal of nitrogen from the growth medium by $Y 88^{\mathrm{T}}$ was also demonstrated by an ammonium assay. Also, the C:N ratios of total biomass of Y88 (Fig. 5.2, maroon triangles, blue squares on graph; Table 5.1) were similar for the cells grown at both concentrations of DO, suggesting that nitrogen (and carbon) changes in the cells were occurring similarly irrespective of DO concentrations. The nitrogen content from the total biomass produced during growth at both $\mathrm{DO}$ concentrations increased from $0.01 \mathrm{mg} / \mathrm{mL}$ to 0.03 $\mathrm{mg} / \mathrm{mL}$ after approximately $8 \mathrm{hr}$ growth (Fig. 5.3, Table 5.1), after which it was maintained at $0.03 \mathrm{mg} / \mathrm{mL}$ until the last sampling at $24 \mathrm{hr}$. Therefore, despite the ammonium being depleted from the medium during growth at both DO concentrations, the nitrogen content of the biomass was maintained at the same level for DOlow and DOhigh conditions.

Despite a much smaller ethylene peak for the DOhigh conditions (Fig. 5.1D) and the fact that the ammonium had been depleted from the growth medium (Fig. 5.2, Table 5.1), Y88 ${ }^{\mathrm{T}}$ cells at DOhigh showed no difference in total nitrogen levels or biomass to that at DOlow (Fig. 5.3, Table 5.1). Since a two-fold increase in biomass occurred between 16 and $24 \mathrm{hr}$ for $\mathrm{Y}^{8} 8^{\mathrm{T}}$ cells grown under both DO 
A

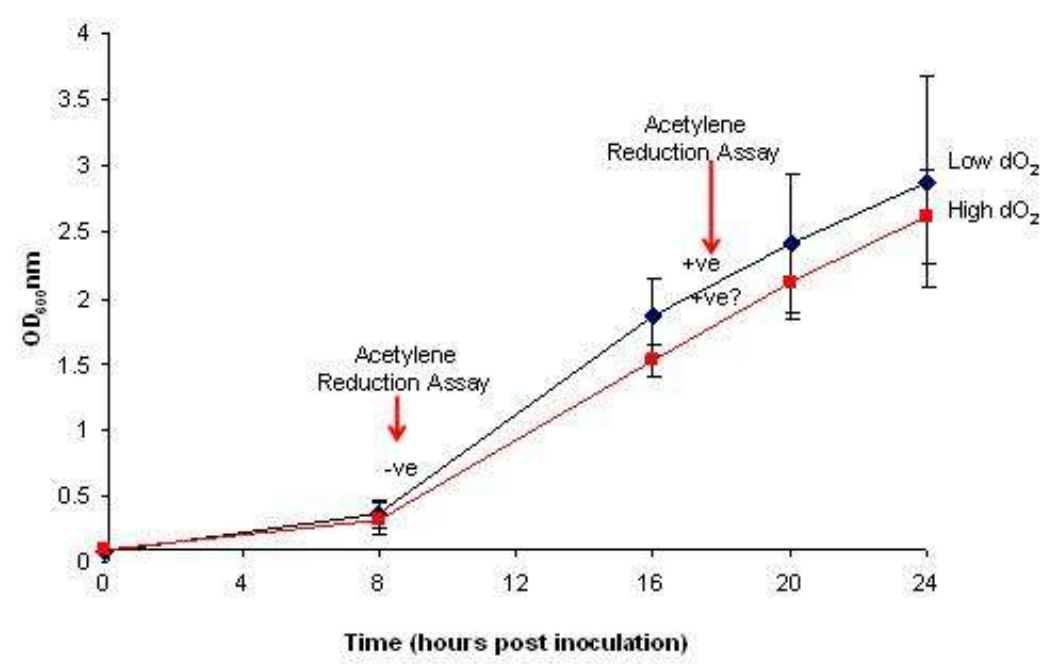

C
B

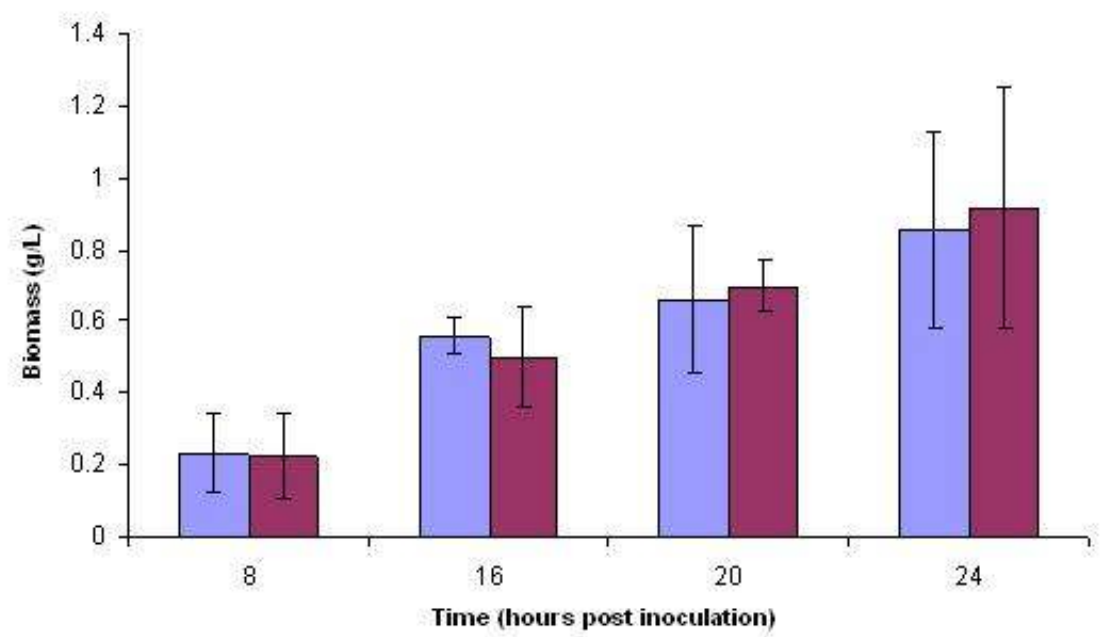

D

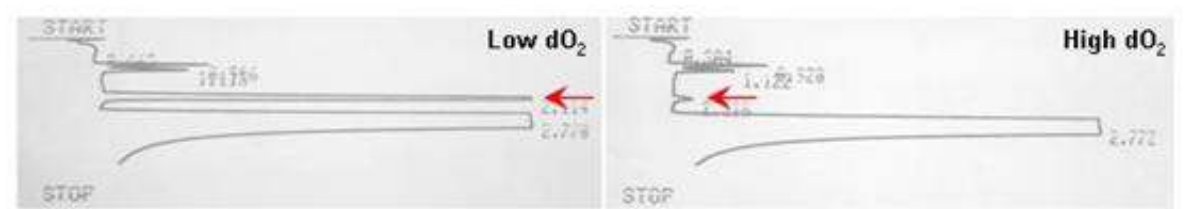

Figure $5.1 \mathrm{OD}_{600}$, biomass production and nitrogenase assays of Y88 ${ }^{\mathrm{T}}$ grown at DOlow or DOhigh for 24 hrs in a glucose-enriched, minimal nitrogen medium

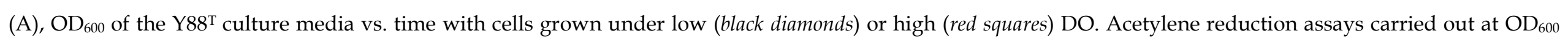

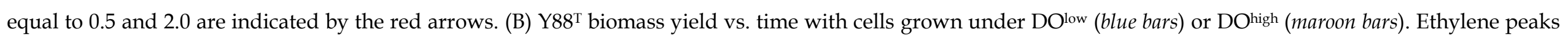

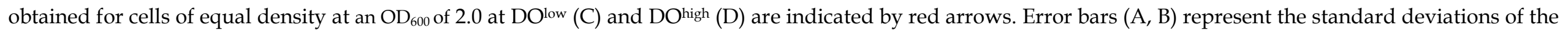
measurements, $(n=3)$. 


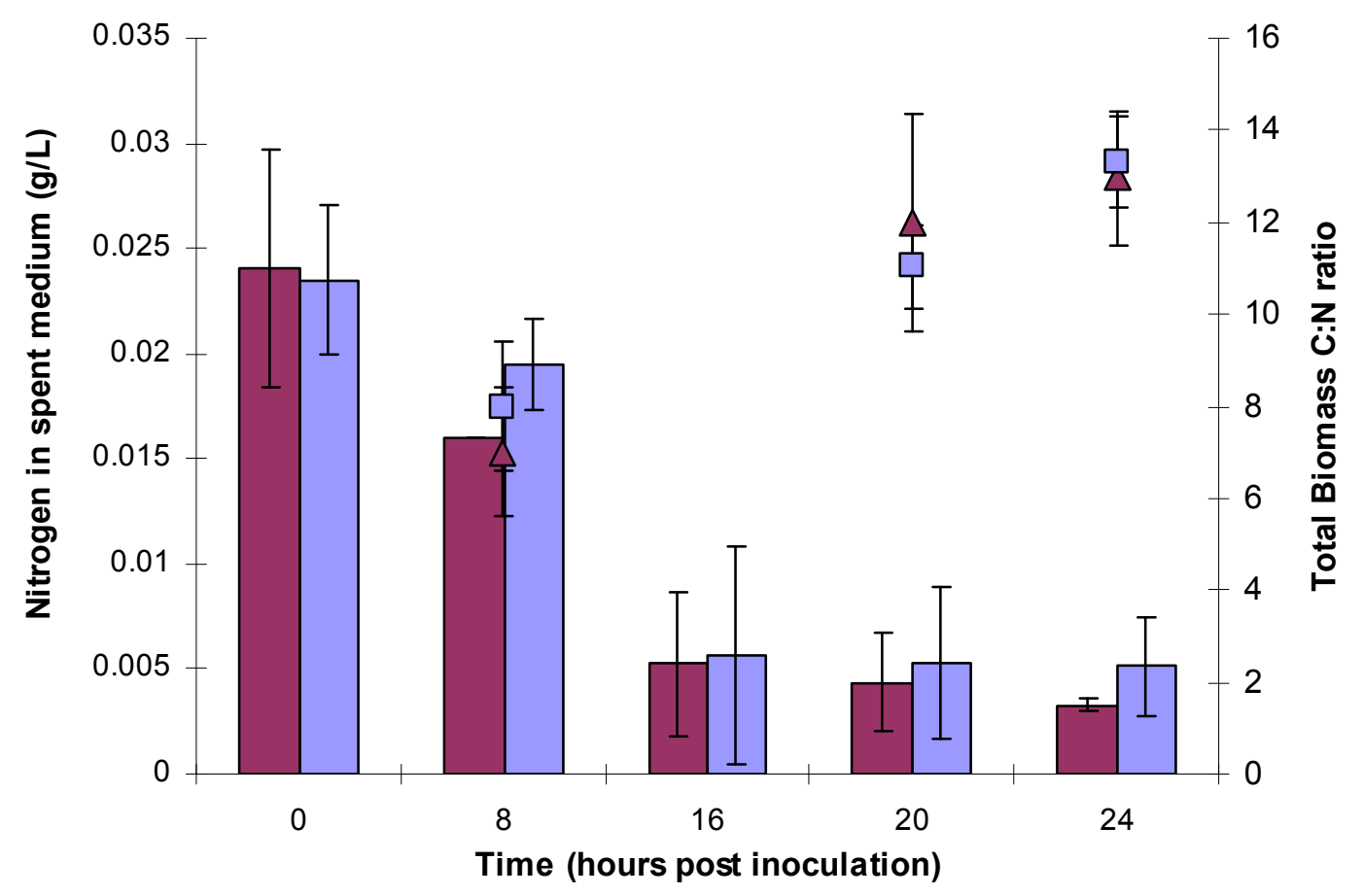

Figure 5.2 Total nitrogen (Kjeldahl) determined in the spent medium after removal of $\mathrm{Y}^{\mathrm{T}} 8^{\mathrm{T}}$ cells grown at $\mathrm{DO}^{\text {low }}$ or DOhigh

Total nitrogen content in spent medium from growth at DOlow (maroon bars) and DOhigh (blue bars) during $24 \mathrm{hr}$ growth. Biomass C:N ratios determined at 8, 20 and $24 \mathrm{hr}$ are represented by maroon triangles $\left(\mathrm{DO}^{\text {low }}\right)$ and blue squares $\left(\mathrm{DO}^{\text {high }}\right)$. Error bars represent standard deviations, $(n=2)$. 


\begin{tabular}{|c|c|c|c|c|c|c|c|c|c|c|c|c|}
\hline \multirow[t]{2}{*}{$\begin{array}{l}\text { Time } \\
\text { (hrs) }\end{array}$} & \multicolumn{2}{|c|}{ Total biomass C (g/L) } & \multicolumn{2}{|c|}{ Total biomass $N(g / L)$} & \multicolumn{2}{|c|}{ Biomass C:N } & \multicolumn{2}{|c|}{$\mathrm{NH}_{4}{ }^{+}$in spent medium } & \multicolumn{2}{|c|}{$\begin{array}{l}\text { Kjeldahl } N \text { (total) in spent } \\
\text { medium }(g / L)\end{array}$} & \multicolumn{2}{|c|}{ PHB (g/L) } \\
\hline & Do low & Do high & Do low & Do high & Do low & Do high & Do low & Do high & Do low & Do high & Do low & Do high \\
\hline 0 & $0.0302 \pm 0.006$ & - & $0.002 \pm 0.001$ & - & - & - & $0.0195 \pm 0.012$ & $0.0200 \pm 0.008$ & $0.024 \pm 0.006$ & $0.021 \pm 0.000$ & - & - \\
\hline 8 & $0.065 \pm 0.022$ & $0.051 \pm 0.017$ & $0.01 \pm 0.005$ & $0.01 \pm 0.002$ & $7 \pm 1.414$ & $8 \pm 1.414$ & $0.013 \pm 0.007$ & $0.0155 \pm 0.004$ & $0.016 \pm 0.000$ & $0.001 \pm 0.016$ & $0.023 \pm 0.010$ & $0.0241 \pm 0.013$ \\
\hline 12 & $0.382 \pm 0.168$ & $0.361 \pm 0.118$ & $0.04 \pm 0.014$ & $0.04 \pm 0.011$ & - & - & - & - & $0.005 \pm 0.003$ & $0.006 \pm 0.004$ & $0.334 \pm 0.024$ & $0.231 \pm 0.071$ \\
\hline 20 & $0.393 \pm 0.157$ & $0.375 \pm 0.107$ & $0.034 \pm 0.012$ & $0.03 \pm 0.008$ & $11.985 \pm 2.382$ & $12.31 \pm 0.898$ & $0.003 \pm 0.001$ & $0.003 \pm 0.000$ & $0.004 \pm 0.002$ & $0.007 \pm 0.003$ & $0.418 \pm 0.035$ & $0.312 \pm 0.140$ \\
\hline 24 & $0.452 \pm 0.059$ & $0.525 \pm 0.017$ & $0.04 \pm 0.001$ & $0.04 \pm 0.002$ & $12.956 \pm 1.476$ & $15.14 \pm 0.989$ & $0.002 \pm 0.001$ & $0.002 \pm 0.001$ & $0.003 \pm 0.000$ & $0.003 \pm 0.000$ & $0.555 \pm 0.052$ & $0.562 \pm 0.106$ \\
\hline
\end{tabular}

Table 5.1 Carbon and nitrogen content of $\mathrm{Y} 88^{\mathrm{T}}$ cells grown in glucose-enriched, nitrogen-limiting medium

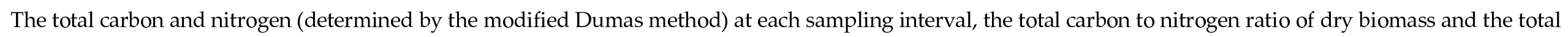

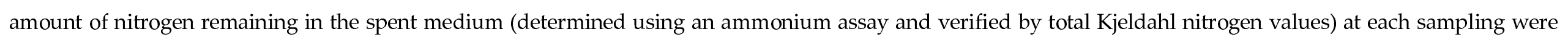

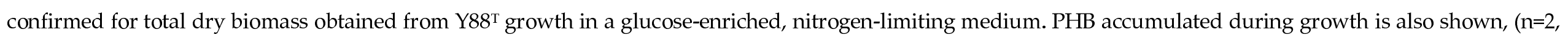
errors are standard deviations). 


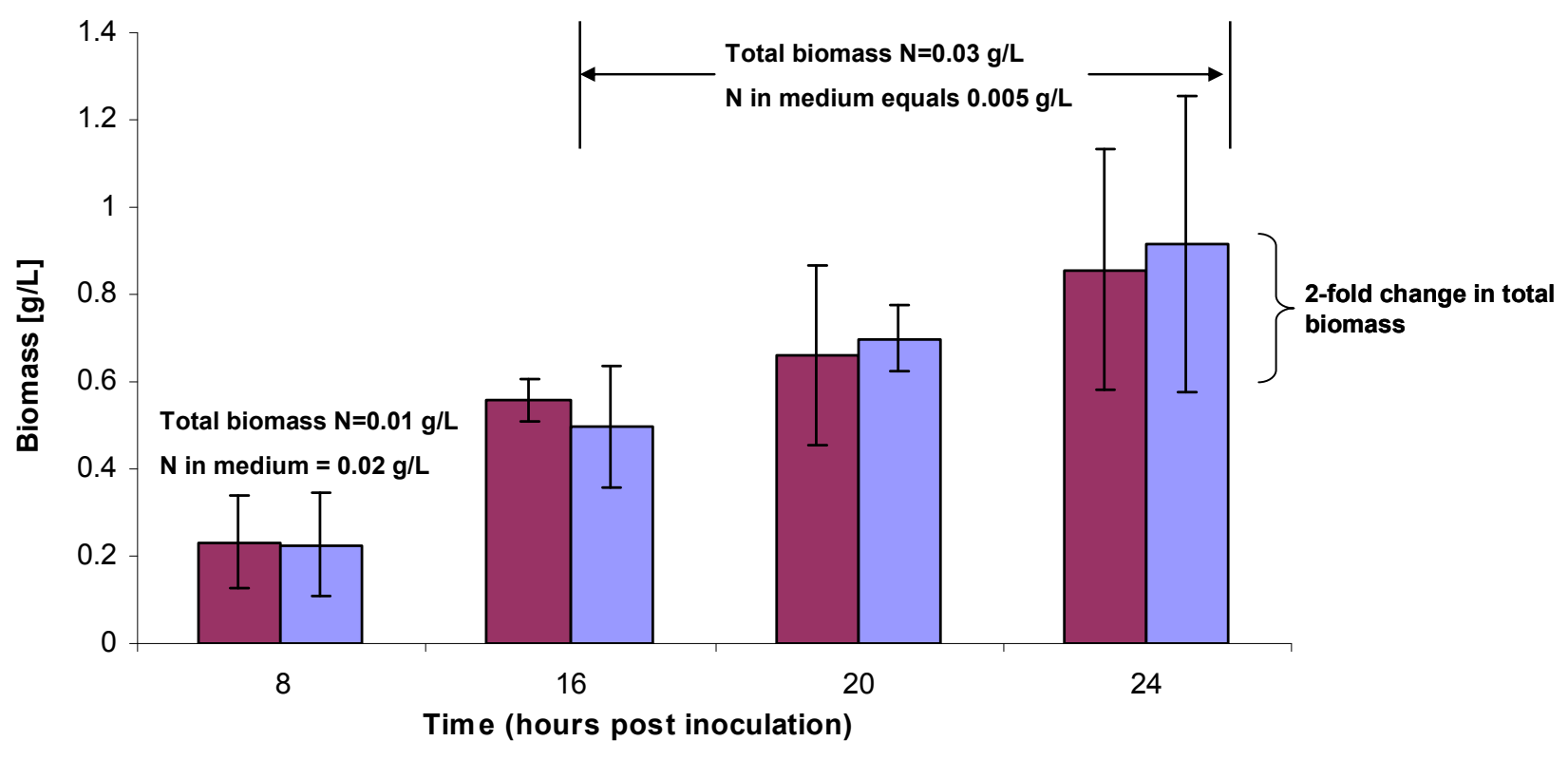

Figure 5.3 Change in total biomass nitrogen content with change in biomass during growth in nitrogen-depleted medium DOlow (maroon bars) and DOhigh (blue bars) during 24 hr growth. Error bars represent standard deviations, $(\mathrm{n}=2)$. 
conditions, during which time the nitrogen levels in the medium appeared to be too low to sustain growth without fixation, the cells at DOhigh appear to have fixed nitrogen similar to that at DOlow conditions.

The paradox of an increase in biomass and intracellular nitrogen content at DOhigh under nitrogen-depleted growth conditions, despite very little measurable nitrogenase activity to promote nitrogen fixation, suggests either that (i) the nitrogenase of $\mathrm{Y} 88^{\mathrm{T}}$ is sensitive to DOhigh and that an alternative mechanism is used by $\mathrm{Y}^{\mathrm{T}}$ at DOhigh to compensate for the loss of nitrogenase activity; (ii) an alternative mechanism is used by $\mathrm{Y}^{\mathrm{T}} 8^{\mathrm{T}}$ at $\mathrm{DO}$ high to prevent inactivation of its nitrogenase and allow nitrogenase activity to proceed albeit at a reduced rate; (iii) biomass increase is due to the synthesis and accumulation of an alternative byproduct such as an exopolysaccharide that requires more carbon but does not require much nitrogen, thereby still altering the C:N ratio. The latter explanation, however, does not fully account for the data as it does not explain the similar nitrogen content of $\mathrm{Y}^{\mathrm{T}} 8^{\mathrm{T}}$ cells at both DOhigh and DOlow. A ${ }^{15} \mathrm{~N}$ isotope labeling experiment, during which $\mathrm{Y}^{8} 8^{\mathrm{T}}$ cells could be grown under both DO conditions while sparging the headspace of the reactor with ${ }^{15} \mathrm{~N}$ gas and then determining the total cellular ${ }^{15} \mathrm{~N}$ content, would be one way of irrefutably confirming that nitrogen is fixed under both DOhigh and DOlow conditions. This would confirm the similar nitrogen content of Y88 ${ }^{\mathrm{T}}$ cells determined in these assays at both DO concentrations.

\subsubsection{PHB production and glucose utilisation}

The amount of PHB produced by Y88T in DOlow after $24 \mathrm{hr}$ was $0.6 \pm 0.05 \mathrm{mg} / \mathrm{ml}$, $(\mathrm{n}=2)$. The same amount of PHB $(0.6 \pm 0.1 \mathrm{mg} / \mathrm{ml}, \mathrm{n}=2)$ was produced by $\mathrm{Y}^{\mathrm{T}}$ after $24 \mathrm{hr}$ in DOhigh. Therefore, DOhigh had no effect on the total amount of PHB produced by $\mathrm{Y}^{8} 8^{\mathrm{T}}$ after $24 \mathrm{hr}$ when compared to that produced at DOlow for the same period of growth (Fig. 5.4). Glucose utilisation was similar in the early stages of growth at DOlow or DOhigh, although at $20 \mathrm{hr}$, this was not the case. Y $88^{\mathrm{T}}$ consumed more glucose at $20 \mathrm{hr}$ in DOhigh than in DOlow (Figs. 5.5, 5.6). In fact, the amount of glucose consumed by $24 \mathrm{hr}$ at DOhigh was approximately 1 $\mathrm{g} / \mathrm{L}$ whereas $1.6 \mathrm{~g} / \mathrm{L}$ was consumed for the same period of growth at DOhigh 150 


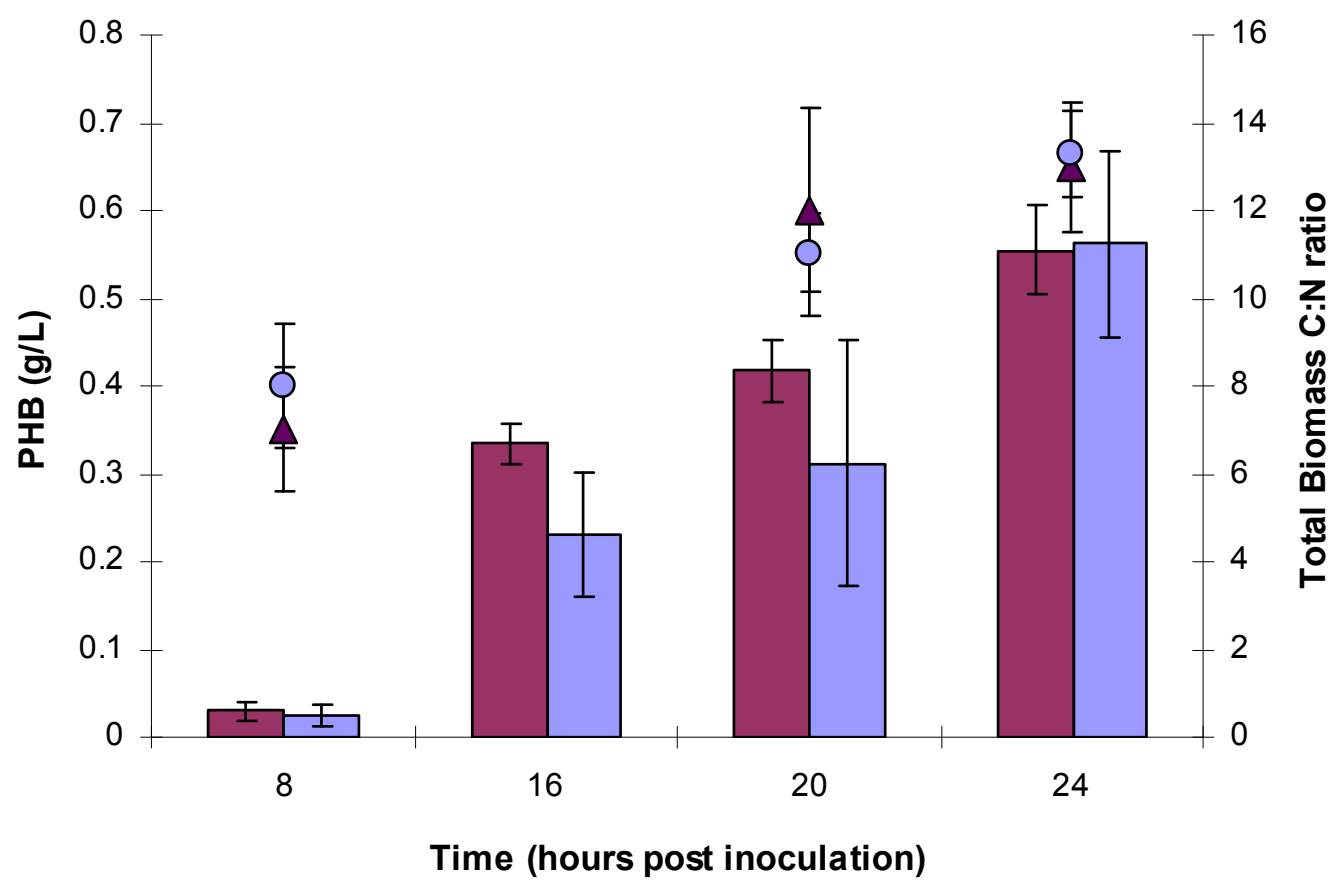

Figure 5.4 PHB produced by $\mathrm{Y}^{8} 8^{\mathrm{T}}$ at $\mathrm{DO}^{\text {low }}$ and $\mathrm{DO}$ high during changing $\mathrm{C}: \mathrm{N}$ ratios PHB produced during growth under DOlow (maroon bars) or DOhigh (blue bars) conditions over 24 $\mathrm{hr}$ in a glucose-enriched, minimal nitrogen medium. Biomass C:N ratios determined at timepoints throughout the growth period from cells grown at DO ${ }^{\text {low }}$ (represented by maroon triangles) and at $\mathrm{DO}^{\text {high }}$ (represented by blue circles), $(\mathrm{n}=2)$. 


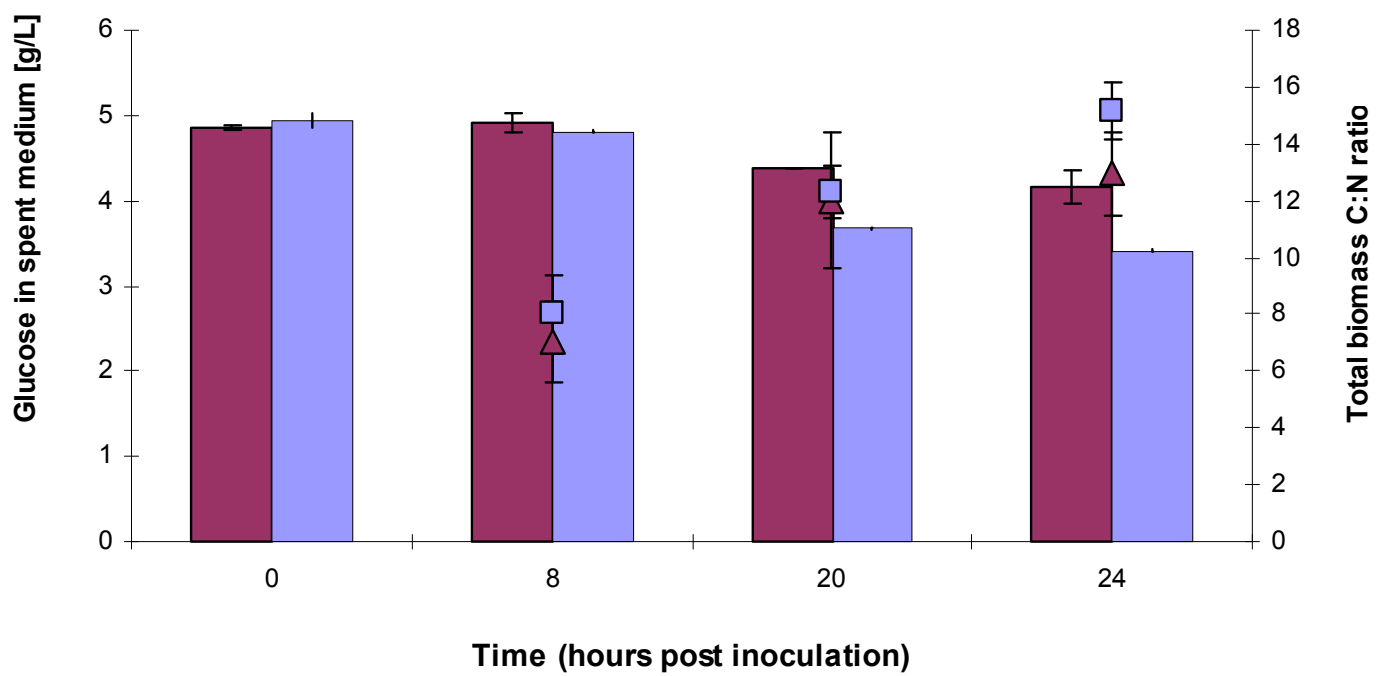

Figure 5.5 Glucose utilisation by $\mathrm{Y}^{2} 8^{\mathrm{T}}$ and change in C:N ratio

Glucose remaining in the spent medium following removal of $\mathrm{Y}^{8} 8^{\mathrm{T}}$ cells grown at DOlow (maroon bars) or DOhigh (blue bars) after $24 \mathrm{hr}$ of growth. Biomass C:N ratios determined at timepoints throughout the growth period are represented by maroon triangles (DOlow) and blue squares $(\mathrm{DO}$ high $),(\mathrm{n}=2)$. 


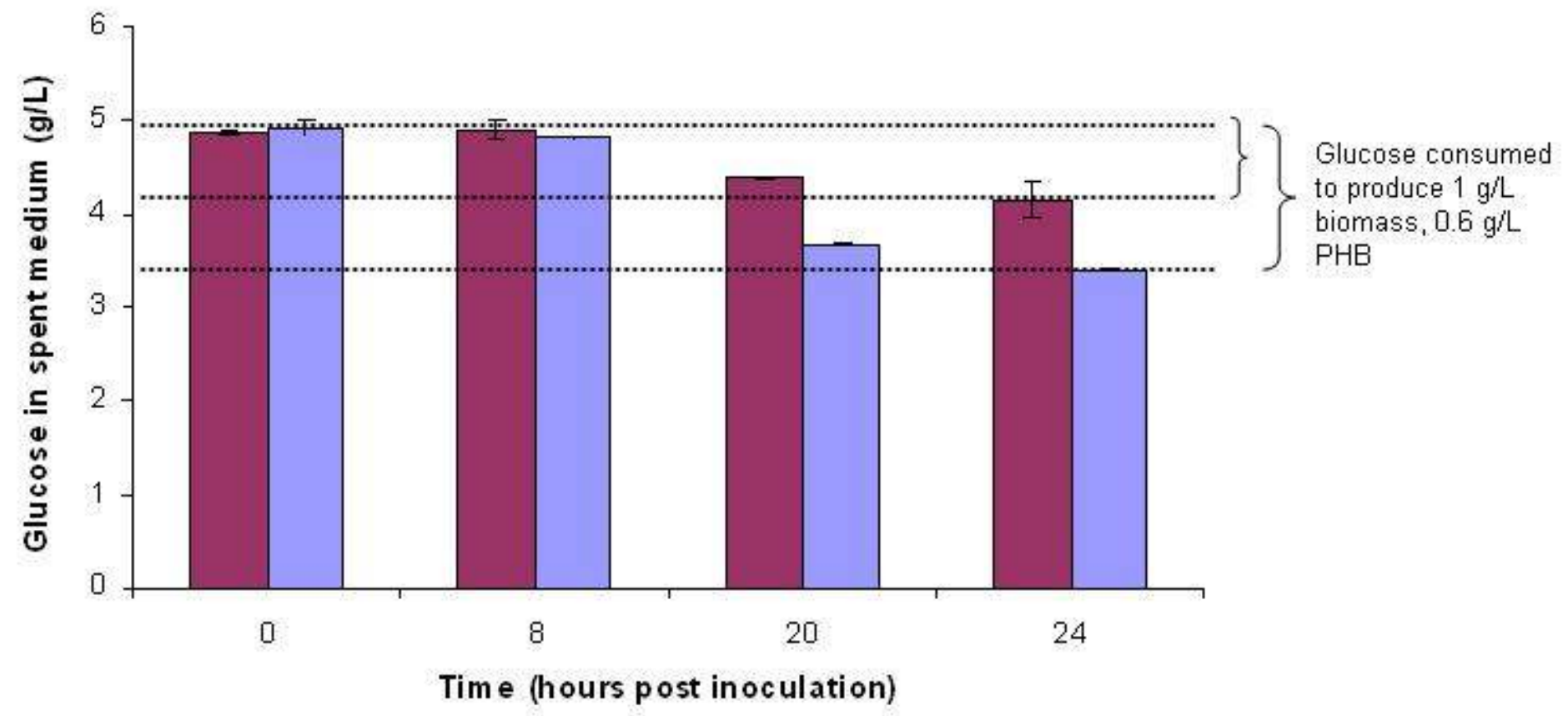

Figure 5.6 Glucose consumption by $\mathrm{Y}^{8} 8^{\mathrm{T}}$ showing inefficiency of glucose utilisation at DOhigh

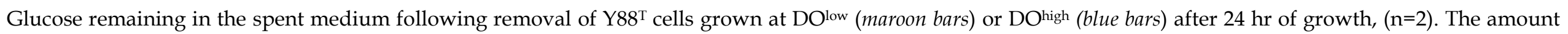
of glucose removed after $24 \mathrm{hr}$ at DOhigh was twice as much as that consumed for the same period at DOlow. Despite double the amount of glucose consumed at DOhigh, the same biomass $(1 \mathrm{~g} / \mathrm{L})$ in PHB $(0.6 \mathrm{~g} / \mathrm{L})$ was produced. 
(Fig. 5.6). Since biomass and PHB production were similar ( $1 \mathrm{~g} / \mathrm{L}$ biomass, 0.6 $\mathrm{g} / \mathrm{L} \mathrm{PHB}$ ) at both $\mathrm{DO}^{\text {high }}$ and $\mathrm{DO}^{\text {low }}$, it appears that at DOhigh, glucose utilisation was less efficient than at DOlow. Since the increased glucose consumption at DOhigh was not reflected in an increase in the amount of PHB produced, relative to that at DOlow at that stage of growth (Fig. 5.4), these results suggest that more glucose was likely being used to meet energy demands such as, for instance, higher respiration or the conversion to an additional byproduct other than PHB. Oxygen uptake rate at this stage of growth increased rapidly at DOhigh (consistent across triplicate experiments) relative to DOlow supporting this notion (Table 5.2). The similar amount of PHB produced irrespective of DO concentrations and efficiency of glucose utilisation, suggest that PHB synthesis in $\mathrm{Y}^{8} 8^{\mathrm{T}}$ is not limited by a changing supply of carbon or nitrogen during $24 \mathrm{hr}$ in a bioreactor, nor by $\mathrm{DO}^{\text {low }}$ or DOhigh concentrations at high growth.

\subsubsection{Comparison of protein profiles obtained for DOlow or DOhigh conditions at high cell densities $\left(\mathrm{OD}_{600}=2.0\right)$}

\subsection{Acidic proteins}

2D DIGE was used to visualise the $\mathrm{Y} 88^{\mathrm{T}}$ proteins and differences in their abundance resulting from growth at $\mathrm{DO}^{\text {low }}$ or DOhigh. Examination of the proteins in the $\mathrm{pI} 4-7$ range for $\mathrm{Y}^{8} 8^{\mathrm{T}}$ cells grown at DOlow or DOhigh showed approximately 200 protein spots for both states of the cells with approximately 80 of these occurring in high abundance (Fig. 5.7). Ninety-six protein spots were selected from these gels for analysis, most of which were not differentially expressed. Thirty-two protein spots showed statistically significant difference in abundance between the different DO states in the pI 4-7 range. Since Y88 continued to increase in biomass (refer back to Fig. 5.1B) despite producing a very small ethylene peak at DOhigh (Fig. 5.1D), emphasis in this section is placed on the examination of the statistically significant differentially expressed proteins between $\mathrm{DO}^{\text {high }}$ and $\mathrm{DO}^{\text {low }}$ growth conditions in an attempt to explain this apparent paradox. 


\begin{tabular}{lcc}
\hline DO condition & \multicolumn{1}{c}{ Sparging oxygen level } \\
\hline Maintain $\mathrm{DO}^{\text {low }}\left(\right.$ low $\left.\mathrm{OD}_{600}\right)$ & $\begin{array}{c}\text { Equation for the line fitted } \\
\text { to oxygen demand data }\end{array}$ & $\begin{array}{c}\text { Total (accumulative) Input } \\
\text { oxygen over 24 hrs (L) }\end{array}$ \\
\cline { 2 - 3 } Maintain $\mathrm{DO}^{\text {high }}\left(\right.$ low $\left.\mathrm{OD}_{600}\right)$ & $y=21.59 x-1.71$ & $1857.63 \pm 683.98$ \\
Maintain $\mathrm{DO}^{\text {low }}\left(\right.$ high $\left.\mathrm{OD}_{600}\right)$ & $y=30.53 x-5.21$ & $2928.36 \pm 924.31$ \\
Maintain $\mathrm{DO}^{\text {high }}\left(\right.$ high $\left.\mathrm{OD}_{600}\right)$ & $y=44.2 x-10.03$ & $18278.96 \pm 1734.41$ \\
& $y=108.22 x-40.05$ & $28303.39 \pm 1102.66$ \\
\hline
\end{tabular}

Table 5.2 Oxygen input to meet the demand of $\mathrm{Y}^{8} 8^{\mathrm{T}}$ cells and maintain set DO levels constant during $\mathrm{Y}^{8} 8^{\mathrm{T}}$ growth in a glucose-enriched, nitrogen-fixing medium in bioreactors

The amount of oxygen that was required to maintain DO levels constant and to meet the respiratory requirements of $\mathrm{Y}^{8} 8^{\mathrm{T}}$ cells during growth in the bioreactors at DOlow and DOhigh is shown. During the first 9 hours of growth, there was little difference in the maximum amount of oxygen required to maintain set levels at the two DO levels. Between 9 to 24 hrs, a much higher amount of input oxygen was required to meet the respiratory requirements of $Y 88^{\mathrm{T}}$ cells grown at DOhigh compared to $\mathrm{Y}^{8} 8^{\mathrm{T}}$ cells grown at DOlow. This is confirmed by the slope of the line for a trendline fitted through the input oxygen data under the different DO conditions. 


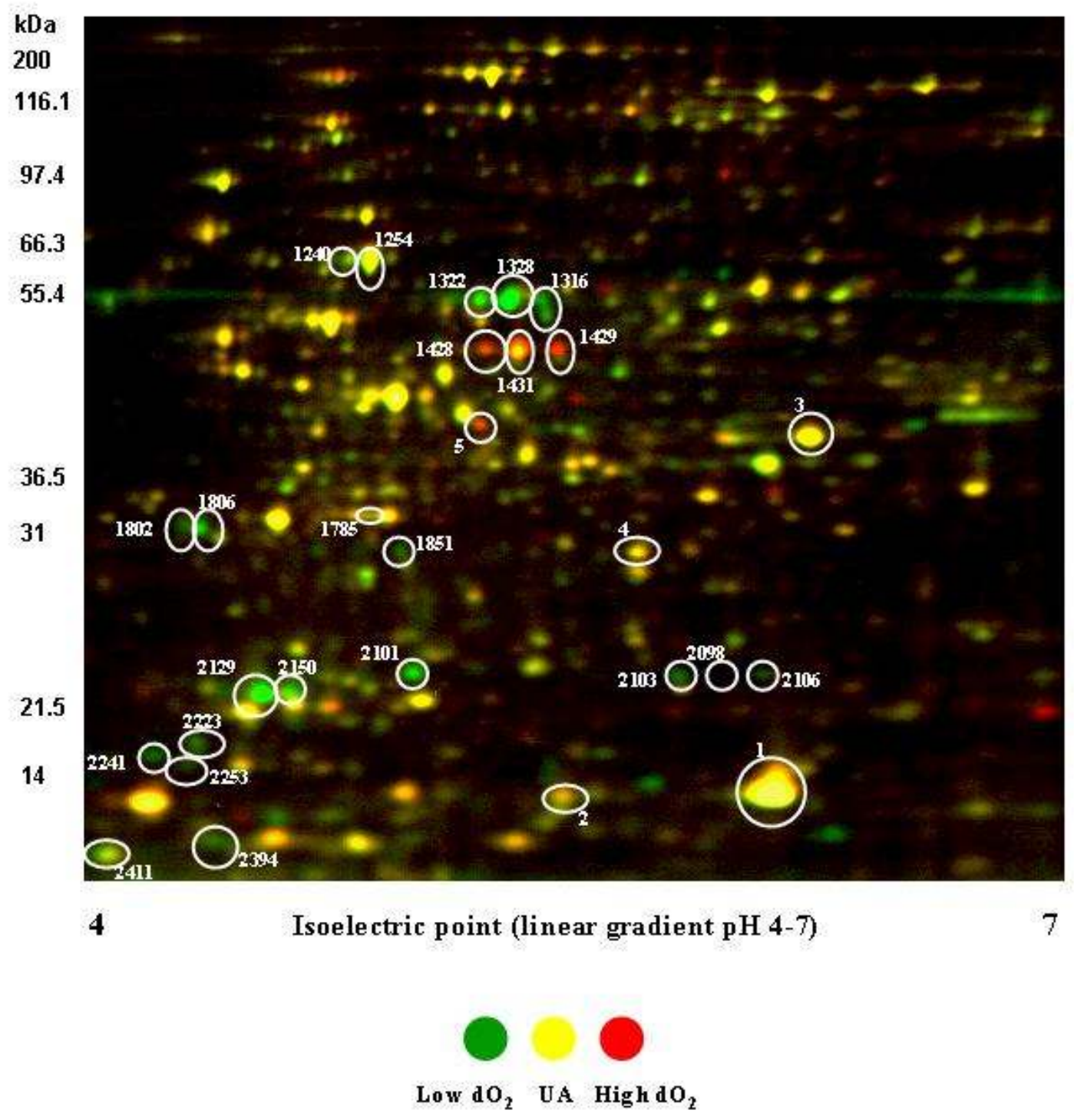

Figure 5.7 Overlay image of $\mathrm{Y}^{8} 8^{\mathrm{T}}$ protein profiles generated from minimally labeled samples showing differential protein abundance under $\mathrm{DO}^{\text {low }}$ or $\mathrm{DO}^{\text {high, }}$, uncontrolled $\mathrm{pH}$ conditions in the linear gradient $\mathrm{pH}$ 4-7 range

Pooled (Cy2 - yellow), DOlow (Cy3 - green) or DOhigh (Cy5 - red) samples are overlaid. UA (yellow) =unaltered abundance: proteins expressed similarly in both states of the cells at DOlow or DOhigh; $\mathrm{DO}^{\text {High }}$ (red): proteins either unique to or more abundant in the cells at DOHigh; DOlow (green): proteins either unique to or more abundant in the cells at DOlow. Spot numbers represent proteins determined by BVA analysis to have significantly altered abundance between the two DO concentrations, with the exception of spots 1 through 5 which did not show statistically different altered abundance $(n=3)$. Spots selected for analysis were those likely to be involved in the nitrogen-fixing and PHB pathways based on predicted pI and molecular weight, as well as some spots with altered abundance that are not usually associated with these pathways. Spot numbers correspond to protein identifications in Table 5.3. 


\subsection{Nitrogen-fixing proteins}

The $\beta$-subunit of nitrogenase component I, NifK, was identified in a spot at approximately 56kDa (spot 1328) that had 6.8-fold enhanced abundance ( $t$ test $=0.01$ ) at DOlow relative to DOhigh (Figs. 5.7, 5.8A, Table 5.3). Its position on the gel was consistent with the $\mathrm{M}_{\mathrm{r}}$ and $\mathrm{pI} 5.4$ predicted from the $\mathrm{Y}^{\mathrm{T}} 8^{\mathrm{T}}$ translated ORFs. NifK was barely detectable at the corresponding $\mathrm{M}_{\mathrm{r}}$ and $\mathrm{pI}$ on the gel at DOhigh (see corresponding spot 1328, Fig. 5.8B).

Two forms of the homodimeric dinitrogenase reductase $(\mathrm{NifH})$ subunits were seen on the gels at approximately 23 and $24 \mathrm{kDa}$ and were more abundant at DOlow. One subunit had a pI of 4.7 (Figs. 5.7, 5.8A, spot 2129) and showed a 3fold increase $(t$-test $=0.026)$ in abundance at DOlow. The second subunit had a $\mathrm{pI}$ of 5.2 (Figs. 5.7, 5.8A, spot 2101 and showed a 4.5 -fold increase $(t$-test $=0.01)$ in abundance at DOlow. These two forms were present at different abundance under DOlow conditions. Their observed $\mathrm{M}_{\mathrm{r}}$ differed from that predicted (31.8 $\mathrm{kDa}$ ) as did the pI 4.9 predicted from the $\mathrm{Y} 88^{\mathrm{T}} \mathrm{NifH}$ conceptual translation, suggesting possible post-translational modification of this protein as mentioned previously (Chapter 4, section 4.2.2.2.1). The difference in abundance of each subunit is consistent with the notion that each may be differently modified post-translationally for the nitrogen-fixing state, or that at least one is modified even if the other is not. It is known that when conditions are unfavourable for nitrogen fixation, such as in the presence of ammonium, one subunit of the homodimeric $\mathrm{NifH}$ protein is inactivated by the addition of an ADP-ribose group from $\mathrm{NAD}^{+}$to an arginine residue on the subunit, thereby preventing nitrogen fixation (Nordlund \& Ludden, 2004; Huergo et al., 2006). Once the ammonium is exhausted from the medium, the ADP-ribose group is removed from the NifH subunit. Although ADP-ribosylation of dinitrogenase reductase plays a significant role in the regulation of nitrogenase activity, it is not the only mechanism of such regulation (Zhang et al., 1996). The post-translational modification of NifH in Anabaena sp. (Durner et al., 1994; Durner \& Böger, 1995) was found to not be ADP-ribosylated as in Rhodospirillum rubrum (Ludden et al., 1989; Martin \& Reinhold-Hurek, 2002). The fact that the two homodimeric 
A

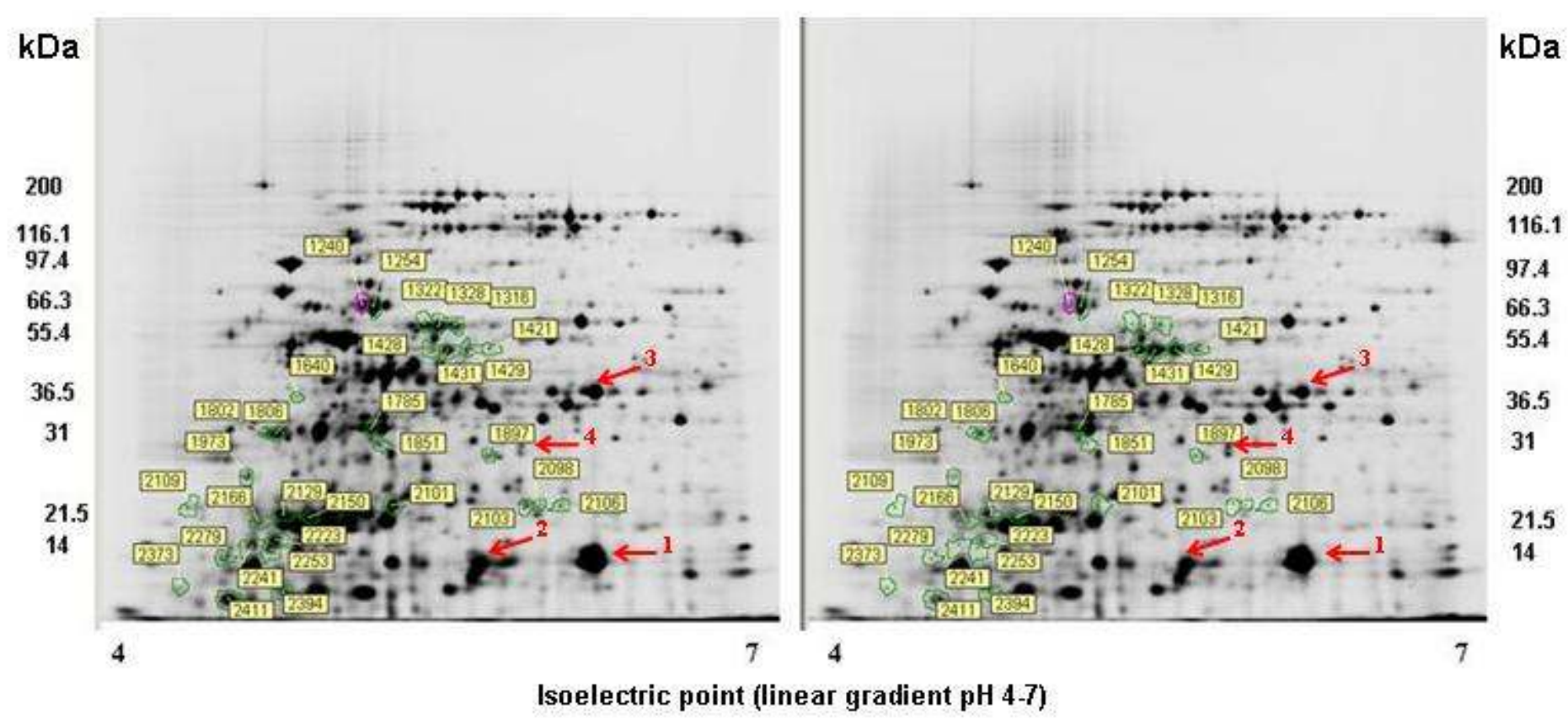

Figure 5.8 2-D DIGE images ( $\mathrm{pI} 4-7$ ) showing protein profiles of $\mathrm{Y}^{8} 8^{\mathrm{T}}$ cells grown to high $\mathrm{OD}_{600}(2.0)$ under ammonium-depleted conditions at $\mathrm{DO}^{\text {low }}$ or DOhigh concentrations, $\mathrm{pH}$ not controlled.

(A) DOlow gel, (B) DOhigh gel. Spot numbers (excluding those marked by red arrows) represent proteins determined by BVA analysis to have significantly altered abundance between the two DO concentrations. Spot numbers correspond to protein identifications in Table 5.3. Spots marked by red arrows represent PHB synthesis proteins: $1=\mathrm{PhaP}, 2=\mathrm{PhaP}, 3=\mathrm{PhbB}, 4=\mathrm{PhbA},(\mathrm{n}=3)$. 


\begin{tabular}{|c|c|c|c|c|c|c|c|c|c|}
\hline Spot number & Protein ID & \multicolumn{2}{|c|}{$\mathrm{Do}^{\text {low }} / \mathrm{Do}^{\text {high }}$} & $\begin{array}{l}\text { Highest scoring unique peptides } \\
\text { matched (peptide score) }\end{array}$ & $\mathbf{M}_{\mathbf{r}}$ & Score & $\begin{array}{l}\text { Queries } \\
\text { matched }\end{array}$ & pl & $\begin{array}{l}\text { Sequence } \\
\text { coverage (\%) }\end{array}$ \\
\hline & & $\begin{array}{l}\text { Average } \\
\text { Ratio }\end{array}$ & $t$-test value & & & & & & \\
\hline \multirow[t]{3}{*}{1240} & Chaperonin GroEL & 3.42 & $0.030^{\star *}$ & K.ALAGLTGANEDQTR.G(87) & 57484 & 571 & 29 & 5.09 & 12 \\
\hline & & & & K.EGVITVEEAK.G(61) & - & - & - & - & - \\
\hline & & & & K.SVAAGINPMDLK.R(57) & - & - & - & - & - \\
\hline \multirow[t]{4}{*}{$1254^{*}$} & Chaperonin GroEL & 3.36 & $0.035^{\star *}$ & K.ALAGLTGANEDQTR.G(85) & 57484 & 3666 & 170 & 5.09 & 20 \\
\hline & & & & K.SVAAGINPMDLK.R(63) & - & - & - & - & - \\
\hline & & & & K.VIEDLKGR.S(38) & - & - & - & - & - \\
\hline & & & & K.LAGGVAVIK.V(64) & - & - & - & - & - \\
\hline \multirow[t]{8}{*}{1316} & GMP synthase & 3.26 & $0.003^{*}$ & R.IVAVSDGAPFAVIADDTR.K (101) & 57278 & 243 & 15 & 5.43 & 12 \\
\hline & & & & R.LGEAEQVVGLFR.N (71) & - & - & - & - & - \\
\hline & & & & R.ELGLPDIFVGR.H (48) & - & - & - & - & - \\
\hline & & & & K.LIANFVR.H (43) & - & - & - & - & - \\
\hline & $\begin{array}{l}\text { Glycine dehydrogenase (decarboxylating)/ } \\
\text { ribosomal protein L9 }\end{array}$ & 3.26 & $0.003^{*}$ & R.IDLAALLER.L(79) & 55278 & 186 & 4 & 5.34 & 6 \\
\hline & & & & K.AALDQFIAAMR.D(68) & - & - & - & - & - \\
\hline & prolyl-tRNA synthetase & & & R.IDLAALLER.L(79) & 58055 & 125 & 4 & 5.39 & 4 \\
\hline & & & & K.AALDQFIAAMR.D(68) & - & - & - & - & - \\
\hline 1322 & D-3-phosphoglycerate dehydrogenase (PGDH) & 7.52 & $0.023^{* *}$ & R.VTVGTDEGEK.A (45) & 56092 & 93 & 6 & 5.44 & 3 \\
\hline \multirow[t]{2}{*}{1328} & Nitrogenase molybdenum beta-chain (NifK) & 6.75 & $0.011^{*}$ & R.MYDGGTTLEEAGQAVHAR.A(109) & 58437 & 17167 & 983 & 5.37 & 49 \\
\hline & & & & K.VEYTILGDNSDVWDTPTDGEFR.M(84) & - & - & - & - & - \\
\hline
\end{tabular}

Table 5.3 2-D DIGE protein spot analysis (pH 4-7) and LC-MS/MS analysis of protein from cells grown at DOlow or DOhigh

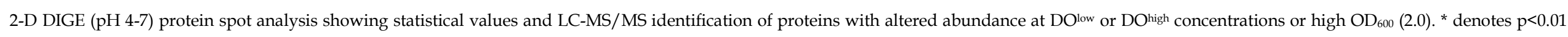

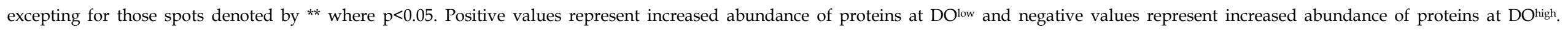
ज़ํ

$\mathrm{NI}=$ protein not identified. See body of the text throughout section 5.2.1.3 for discussion of these proteins. Table 5.3 continued on next page. 


\begin{tabular}{|c|c|c|c|c|c|c|c|c|c|}
\hline \multirow[t]{2}{*}{$\begin{array}{c}\text { Spot } \\
\text { number }\end{array}$} & \multirow[t]{2}{*}{ Protein ID } & \multicolumn{2}{|c|}{ Do ow/Do $o^{\text {high }}$} & \multirow[t]{2}{*}{$\begin{array}{l}\text { Highest scoring unique peptides matched } \\
\text { (peptide score) }\end{array}$} & \multirow[t]{2}{*}{$\mathbf{M}_{\mathrm{r}}$} & \multirow[t]{2}{*}{ Score } & \multirow[t]{2}{*}{$\begin{array}{l}\text { Queries } \\
\text { matched }\end{array}$} & \multirow[t]{2}{*}{ pl } & \multirow[t]{2}{*}{$\begin{array}{c}\text { Sequence } \\
\text { coverage } \\
(\%)\end{array}$} \\
\hline & & $\begin{array}{c}\text { Average } \\
\text { Ratio }\end{array}$ & $\begin{array}{l}t \text {-test } \\
\text { value }\end{array}$ & & & & & & \\
\hline \multirow[t]{2}{*}{1328} & Nitrogenase molybdenum beta-chain (NifK) & 6.75 & $0.011^{*}$ & K.MQDLFDSSPFGAGCK.A(95) & 58437 & 17167 & 983 & 5.37 & 49 \\
\hline & & & & R.ATISMQEFCTEK.T(72) & - & - & - & - & - \\
\hline 1421 & $\mathrm{NI}$ & -3.02 & $0.034^{\star *}$ & - & - & - & - & - & - \\
\hline \multirow[t]{2}{*}{1428} & S-adenosylhomocysteine (AdoHcy) hydrolase & -2.97 & $0.007^{*}$ & K.VACVAGFGDVGK.G(80) & 50877 & 788 & 38 & 5.33 & 20 \\
\hline & & & & R.DEFGPTQPLK.G(47) & - & - & - & - & - \\
\hline 1429 & $\mathrm{NI}$ & -2.86 & $0.008^{*}$ & - & - & - & - & - & - \\
\hline \multirow[t]{8}{*}{1431} & S-adenosylhomocysteine (AdoHcy) hydrolase & -2.65 & $0.010^{*}$ & R.TANLILDDGGDATMFALWGAR.V(138) & 50877 & 14979 & 631 & 5.33 & 66 \\
\hline & & & & R.VVVTEIDPICALQAAMEGYEVVTMEEAVKR.A(92) & - & - & - & - & - \\
\hline & & & & R.VEAGETLPEPANAEEIEFQR.A(97) & - & - & - & - & - \\
\hline & & & & R.AEIAIAETEMPGLMALR.D(87) & - & - & - & - & - \\
\hline & histidyl-tRNA synthetase & & & R.IDDFLTAEAQDFFGR.V(100) & - & - & - & - & - \\
\hline & & & & K.VLAGLSLADGAPR.W(86) & - & - & - & - & - \\
\hline & & & & R.VTSGLDAAGVAWTR.S(97) & - & - & - & - & - \\
\hline & & & & R.SLGETTDVVSK.E(85) & - & - & - & - & - \\
\hline 1640 & $\mathrm{NI}$ & 2.01 & $0.043^{* *}$ & - & - & - & - & - & - \\
\hline \multirow[t]{4}{*}{1785} & fructose-biphosphate aldolase & 2.14 & $0.010^{*}$ & K.NNGIIASFSR.A(64) & 32291 & 132 & 17 & 5.06 & 5 \\
\hline & & & & R.ALLEDLR.H(32) & - & - & - & - & - \\
\hline & translation elongation factor TS & & & K.TPIAQVVEAAGK.A(54) & 32125 & 121 & 26 & 5.09 & 3 \\
\hline & & & & R.IVAVSDGAPFAVIADDTR.K(89) & - & - & - & - & - \\
\hline
\end{tabular}

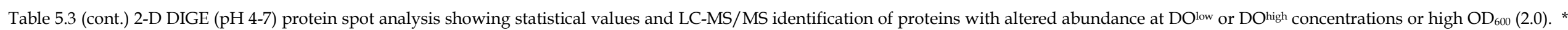

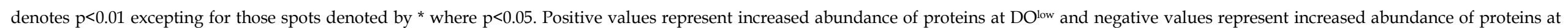
DOhigh. NI=protein not identified. See body of the text throughout section 5.2.1.3 for discussion of these proteins. Table 5.3 continued on next page. 


\begin{tabular}{|c|c|c|c|c|c|c|c|c|c|}
\hline \multirow[t]{2}{*}{$\begin{array}{c}\text { Spot } \\
\text { number }\end{array}$} & \multirow[t]{2}{*}{ Protein ID } & \multicolumn{2}{|c|}{$\mathrm{Do}^{\mathrm{low}} / \mathrm{Do}^{\text {high }}$} & \multirow[t]{2}{*}{$\begin{array}{l}\text { Highest scoring unique peptides } \\
\text { matched (peptide score) }\end{array}$} & \multirow[t]{2}{*}{$\mathbf{M}_{\mathrm{r}}$} & \multirow[t]{2}{*}{ Score } & \multirow[t]{2}{*}{$\begin{array}{l}\text { Queries } \\
\text { matched }\end{array}$} & \multirow[t]{2}{*}{ pl } & \multirow[t]{2}{*}{$\begin{array}{c}\text { Sequence } \\
\text { coverage }(\%)\end{array}$} \\
\hline & & $\begin{array}{l}\text { Average } \\
\text { Ratio }\end{array}$ & $\begin{array}{l}t \text {-test } \\
\text { value }\end{array}$ & & & & & & \\
\hline \multirow[t]{7}{*}{1802} & Nifu & 3.08 & $0.018^{* *}$ & R.TNGLTSIDEVTNYTK.A(107) & 33542 & 864 & 123 & 4.72 & 59 \\
\hline & & & & K.AGGGCSTCAEGIEGVLER.V(93) & - & - & - & - & - \\
\hline & & & & R.VNAEMVAEGALAPER.A(91) & - & - & - & - & - \\
\hline & & & & R.DGGDCELVDVEGNR.V(85) & - & - & - & - & - \\
\hline & & & & R.APAKPLTNLQK.I(65) & - & - & - & - & - \\
\hline & & & & K.VDEPSQTISDAR.F(72) & - & - & - & - & - \\
\hline & & & & K.CFGIDEGMIER.T(59) & - & - & - & - & - \\
\hline \multirow[t]{4}{*}{1806} & Electron transfer flavoprotein beta-subunit & 3.94 & $0.009^{*}$ & R.GVELGAVVMGDDR.A(99) & 39443 & 3555 & 256 & 5.95 & 37 \\
\hline & & & & R.DLAGAVATTLR.T(96) & - & - & - & - & - \\
\hline & & & & R.IVEYAPAIVEADIVTK.V(83) & - & - & - & - & - \\
\hline & & & & K.LAEVLGAEYGGSRPLVQK.G(81) & - & - & - & - & - \\
\hline \multirow[t]{2}{*}{1851} & Chaperonin GroEL & 11.52 & 0.009 & K.EGVITVEEAK.G(45) & 57484 & 202 & 10 & 5.09 & 5 \\
\hline & & & & K.SVAAGINPMDLK.R(50) & & & & & \\
\hline 1897 & $\mathrm{NI}$ & 2.04 & $0.045^{\star *}$ & - & - & - & - & - & - \\
\hline \multirow[t]{5}{*}{2101} & dinitrogenase reductase & 4.47 & $0.013^{*}$ & R.CVESGGPEPGVGCAGR.G(118) & 31859 & 380 & 59 & 4.94 & 38 \\
\hline & & & & K.STTSQNTLAALADLGQR.I(112) & - & - & - & - & - \\
\hline & & & & K.LGTQLIHFVPR.D(66) & - & - & - & - & - \\
\hline & & & & R.DNIVQHAELR.R(61) & - & - & - & - & - \\
\hline & & & & R.LGGLICNER.Q(60) & - & - & - & - & - \\
\hline 2103 & $\mathrm{NI}$ & 12.46 & $0.005^{*}$ & - & - & - & - & - & - \\
\hline
\end{tabular}

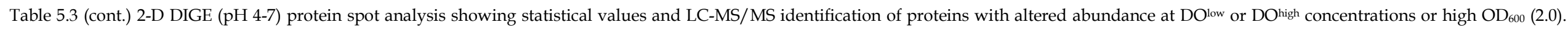

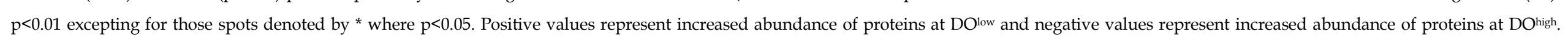
ڤ̆

$\mathrm{NI}=$ protein not identified. See body of the text throughout section 5.2.1.3 for discussion of these proteins. Table 5.3 continued on next page. 


\begin{tabular}{|c|c|c|c|c|c|c|c|c|c|}
\hline \multirow[t]{2}{*}{$\begin{array}{c}\text { Spot } \\
\text { number }\end{array}$} & \multirow[t]{2}{*}{ Protein ID } & \multicolumn{2}{|c|}{ Do low $/ D o^{\text {high }}$} & \multirow[t]{2}{*}{$\begin{array}{l}\text { Highest scoring unique peptides matched } \\
\text { (peptide score) }\end{array}$} & \multirow[t]{2}{*}{$\mathbf{M}_{\mathrm{r}}$} & \multirow[t]{2}{*}{ Score } & \multirow[t]{2}{*}{$\begin{array}{l}\text { Queries } \\
\text { matched }\end{array}$} & \multirow[t]{2}{*}{ pl } & \multirow[t]{2}{*}{$\begin{array}{c}\text { Sequence } \\
\text { coverage } \\
(\%)\end{array}$} \\
\hline & & $\begin{array}{l}\text { Average } \\
\text { Ratio }\end{array}$ & $\begin{array}{l}t \text {-test } \\
\text { value }\end{array}$ & & & & & & \\
\hline 2106 & $\mathrm{NI}$ & 6.46 & $0.011^{*}$ & - & - & - & - & - & - \\
\hline 2109 & $\mathrm{NI}$ & 5.38 & $0.011^{*}$ & - & - & - & - & - & - \\
\hline \multirow[t]{4}{*}{2129} & dinitrogenase reductase & 2.8 & $0.026^{* *}$ & R.CVESGGPEPGVGCAGR.G(120) & 31859 & 4864 & 151 & 4.94 & 32 \\
\hline & & & & K.STTSQNTLAALADLGQR.I(118) & - & - & - & - & - \\
\hline & & & & R.DNIVQHAELR.R(66) & - & - & - & - & - \\
\hline & & & & R.LGGLICNER.Q(65) & - & - & - & - & - \\
\hline \multirow[t]{5}{*}{2150} & hypothetical protein BRAD05426 & 7.85 & $0.002^{*}$ & R.ISDTAFGTLEAAR.R(100) & 22861 & 4004 & 108 & 4.93 & 58 \\
\hline & & & & K.ETLELVDVDKNDVK.K(92) & - & - & - & - & - \\
\hline & & & & K.VAAFTAAYPELSYEDGVAAMGPVR.N(68) & - & - & - & - & - \\
\hline & & & & M.SATTSPSLETVR.I(64) & - & - & - & - & - \\
\hline & & & & K.IPVLVGYLHNFAWLK.D(50) & - & - & - & - & - \\
\hline \multirow[t]{5}{*}{$2166^{*}$} & alkyl hydroperoxide reductase & 2.03 & $0.034^{* *}$ & K.FVDLTDADIAGK.W(97) & 20864 & 10135 & 373 & 4.79 & 66 \\
\hline & & & & K.WEEGEATLAPSIDLVGK.I(93) & - & - & - & - & - \\
\hline & & & & R.GTFVVDPDGVIQLVEITPEGVGR.N(88) & - & - & - & - & - \\
\hline & & & & R.EGVGLADR.G(67) & - & - & - & - & - \\
\hline & & & & K.AWHDSSAAIAK.I(64) & - & - & - & - & - \\
\hline 2223 & $\mathrm{NI}$ & 5.78 & $0.012^{*}$ & - & - & - & - & - & - \\
\hline \multirow[t]{3}{*}{2241} & OmpA/MotB ${ }^{d}$ & 5.61 & $0.01^{*}$ & K.YNLGLSAR.R(50) & 11983 & 963 & 81 & 5.76 & 21 \\
\hline & & & & K.AFGEANPR.V(56) & - & - & - & - & - \\
\hline & & & & R.VPTADGVR.E(46) & - & - & - & - & - \\
\hline
\end{tabular}

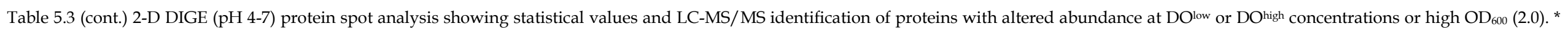

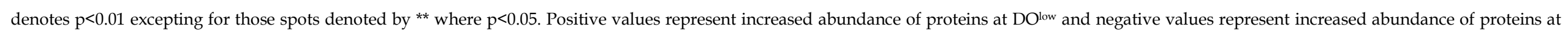
DOhigh. NI=protein not identified. See body of the text throughout section 5.2.1.3 for discussion of these proteins. Table 5.3 continued on next page 


\begin{tabular}{|c|c|c|c|c|c|c|c|c|c|}
\hline \multirow[t]{2}{*}{$\begin{array}{l}\text { Spot } \\
\text { number }\end{array}$} & \multirow[t]{2}{*}{ Protein ID } & \multicolumn{2}{|c|}{ Do low $/ \mathrm{Do}^{\text {high }}$} & \multirow[t]{2}{*}{$\begin{array}{l}\text { Highest scoring unique peptides } \\
\text { matched (peptide score) }\end{array}$} & \multirow[t]{2}{*}{$\mathbf{M}_{\mathbf{r}}$} & \multirow[t]{2}{*}{ Score } & \multirow[t]{2}{*}{$\begin{array}{l}\text { Queries } \\
\text { matched }\end{array}$} & \multirow[t]{2}{*}{ pl } & \multirow[t]{2}{*}{$\begin{array}{l}\text { Sequence } \\
\text { coverage (\%) }\end{array}$} \\
\hline & & $\begin{array}{l}\text { Average } \\
\text { Ratio }\end{array}$ & $\begin{array}{l}t \text {-test } \\
\text { value }\end{array}$ & & & & & & \\
\hline \multirow[t]{2}{*}{2241} & OmpA/MotB ${ }^{\mathrm{d}}$ & 5.61 & $0.01^{*}$ & K.TLNVDNQTITAVGGR.T(89) & 25899 & 674 & 12 & 7.03 & 11 \\
\hline & & & & R.LEGQVGYLDAGNK.T(92) & - & - & - & - & - \\
\hline \multirow[t]{2}{*}{2241} & Ribosomal protein $L 7 / L 12^{d}$ & & & R.AITSLGLTEAK.A(79) & 12683 & 533 & 11 & 4.65 & 28 \\
\hline & & & & K.LTVLEAADLAK.A & - & - & - & - & - \\
\hline \multirow[t]{4}{*}{2253} & OmpA/MotB ${ }^{\mathrm{e}}$ & 10.32 & $0.013^{*}$ & K.TLNVDNQTITAVGGR.T(89) & - & - & - & - & - \\
\hline & & & & R.LEGQVGYLDAGNK.T(92) & - & - & - & - & - \\
\hline & Ribosomal protein $\mathrm{L} 7 / \mathrm{L} 12^{\mathrm{e}}$ & & & R.AITSLGLTEAK.A(79) & - & - & - & - & - \\
\hline & & & & K.LTVLEAADLAK.A & - & - & - & - & - \\
\hline \multirow[t]{6}{*}{1} & Phasin & - & - & K.ILSTGLQELGKGYATEGK.S(95) & 33963 & 8163 & 295 & 9.56 & 40 \\
\hline & & & & K.TPTELLEKQSALLR.K(90) & - & - & - & - & - \\
\hline & & & & K.SQASFGELGEFAK.G(87) & - & - & - & - & - \\
\hline & & & & K.GNVEALVESTK.I(85) & - & - & - & - & - \\
\hline & & & & K.ILSTGLQELGK.G(84) & - & - & - & - & - \\
\hline & & & & K.LANEAFQPISNR.V(78) & - & - & - & - & - \\
\hline 2279 & $\mathrm{NI}$ & 5.31 & $0.014^{*}$ & - & - & - & - & - & - \\
\hline 2373 & $\mathrm{NI}$ & 3.64 & $0.001^{*}$ & - & - & - & - & - & - \\
\hline 2394 & $\mathrm{NI}$ & 3.02 & $0.005^{\star}$ & - & - & - & - & - & - \\
\hline 2411 & $\mathrm{NI}$ & 3.04 & $0.027^{\star *}$ & - & - & - & - & - & - \\
\hline \multirow[t]{4}{*}{2} & Phasin & - & - & K.SQASFGELGEFAK.G(85) & 33963 & 3862 & 131 & 9.56 & 34 \\
\hline & & & & K.LANEAFQPISNR.V(71) & - & - & - & - & - \\
\hline & & & & K.GNVEALVESTK.I(81) & - & - & - & - & - \\
\hline & & & & K.SAFETLTAEFK.D(63) & - & - & - & - & - \\
\hline
\end{tabular}

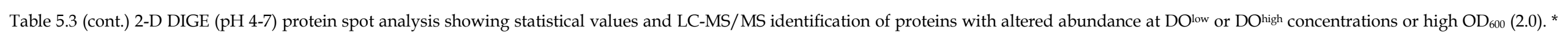

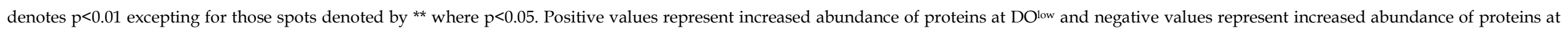
DOhigh. NI=protein not identified. See body of the text throughout section 5.2.1.3 for discussion of these proteins. Continued on next page.

Бे 


\begin{tabular}{|c|c|c|c|c|c|c|c|c|c|}
\hline \multirow[t]{2}{*}{$\begin{array}{c}\text { Spot } \\
\text { number }\end{array}$} & \multirow[t]{2}{*}{ Protein ID } & \multicolumn{2}{|c|}{ Do ${ }^{\text {low }} / \mathrm{Do}^{\text {high }}$} & \multirow[t]{2}{*}{$\begin{array}{l}\text { Highest scoring unique peptides matched } \\
\text { (peptide score) }\end{array}$} & \multirow[t]{2}{*}{$\mathbf{M}_{\mathrm{r}}$} & \multirow[t]{2}{*}{ Score } & \multirow[t]{2}{*}{$\begin{array}{l}\text { Queries } \\
\text { matched }\end{array}$} & \multirow[t]{2}{*}{ pl } & \multirow[t]{2}{*}{$\begin{array}{l}\text { Sequence } \\
\text { coverage (\%) }\end{array}$} \\
\hline & & $\begin{array}{l}\text { Average } \\
\text { Ratio }\end{array}$ & $\begin{array}{l}t \text {-test } \\
\text { value }\end{array}$ & & & & & & \\
\hline \multirow[t]{2}{*}{3} & $\begin{array}{l}\text { Acetyl-CoA C-acetyltransferase ( } \beta \text { - } \\
\text { Ketothiolase) }\end{array}$ & & & R.SGVAAEKFDR.V(79) & 41038 & 530 & 15 & 5.18 & 14 \\
\hline & & & & R.AMGTFAQDTANAYQLTR.E(73) & - & - & - & - & - \\
\hline \multirow[t]{2}{*}{4} & 3-Hydroxybutyryl-CoA dehydrogenase & & & K.IVAADAEAALSR.I(86) & 30939 & 175 & 10 & 5.42 & 22 \\
\hline & & & & K.VLAPQAILASNTSSIPITR.M(51) & - & - & - & - & - \\
\hline \multirow[t]{2}{*}{5} & S-Adenosylmethionine synthetase (AdoMet) & & & K.GIMDTDGNWAPGVPEEVER.V(86) & 43392 & 210 & 5 & 5.27 & 10 \\
\hline & & & & K.NIVAAGLAHR.C(49) & _- & - & _- & - & - \\
\hline
\end{tabular}

Table 5.3 (cont.) 2-D DIGE (pH 4-7) protein spot analysis showing statistical values and LC-MS/MS identification of proteins with altered abundance at DOlow or DOhigh concentrations or high $\mathrm{OD}_{600}(2.0)$.

* denotes $\mathrm{p}<0.01$ excepting for those spots denoted by ** where $\mathrm{p}<0.05$. Positive values represent increased abundance of proteins at DOlow and negative values represent increased abundance of proteins at DOhigh. NI=protein not identified. Spot numbers 3, 4 and 5 (Fig. 5.7) showed altered abundance but were determined by BVA analysis not to be significantly altered. See body of the text throughout section 5.2.1.3 for discussion of these proteins. 
NifH subunits of $\mathrm{Y}^{8} 8^{\mathrm{T}}$ are observed at different pIs for the nitrogen-fixing state (when the ADP-ribose group would have already been removed if either of them had been ADP-ribosylated to begin with), suggests a possible different post-translational modification in this instance. Gallon et al., (2000) proposed that Gloeothece nitrogenase is subject to modification by palmitoylation rather than by ADP-ribosylation. Palmitoylation is an important reversible posttranslational lipid modification of proteins that provides a mechanism for binding cytosolic proteins to membranes, segregating proteins to microdomains or mediating protein-protein interaction (Gallon et al., 2000; Basu, 2004). Since this mechanism is reversible, de-palmitoylation and re-palmitoylation could provide a mechanism whereby these processes are regulated (Basu, 2004). Notably, the NifH subunits were barely visible on the gel at DOhigh suggesting a different regulatory mechanism to that at DOlow that results in a decrease in abundance at DOhigh.

The NifU protein (spot 1806) showed a 3.1-fold increase $(t$-test $=0.018)$ in abundance at DOlow relative to DOhigh (Figs. 5.7, 5.8A, Table 5.3). At DOhigh, NifU was coordinately downregulated with both the NifK and NifH components of nitrogenase. It is possible that this protein plays a regulatory role in negative feedback of $\mathrm{Y}^{8} 8^{\mathrm{T}}$ nitrogenase enzyme expression at DOhigh, since inactivation of NifU has been shown to affect the activity of both nitrogenase components (Dos Santos et al., 2004). The proteomic signature obtained at DOlow with respect to the NifK, NifH and NifU proteins is consistent with that obtained for the Fix on state of $\mathrm{Y}^{\mathrm{T}}$ cells at high $\mathrm{OD}_{600}$ (Chapter 4). The decreased abundance of these proteins at DOhigh is consistent with the decreased nitrogenase activity shown in the acetylene reduction assays for the Fix ${ }^{\text {off }}$ state of $\mathrm{Y}^{8 \mathrm{~T}}$ cells at lower OD 600 (Chapter 4).

Electron transfer flavoprotein $\beta$-subunit (ETF-FixB subunit of the ETF-FixAB protein) (spot 1802) showed a 3.9-fold increase $(t$-test $=0.001)$ in abundance at DO $^{\text {low }}$ (Figs. 5.7, 5.8). Functionally, in bacteria (and eukaryotes), ETF is a soluble one- or two-electron carrier that couples various flavoprotein dehydrogenases 
(one acting oxidatively, the other reductively) via transient formation of alternately ETF-oxidized and ETF-reduced binary complexes (Scott \& Ludwig, 2004). ETF-FixAB is specifically required for dinitrogenase complex activity (Tsai \& Saier, 1995) and is only expressed when nitrogenase is also expressed (Edgren \& Nordlund, 2004; Sarma \& Emerich, 2006).

Hypothetical protein BRADO5426 (spot 2150, Figs. 5.7, 5.8) was 8-fold more abundant $(t$-test $=0.002)$ at DOlow relative to DOhigh. At DOhigh, this protein was barely visible on the gel at the corresponding $\mathrm{pI}$ and $\mathrm{M}_{\mathrm{r}}$. Its coordinated enhanced abundance for the Fix on state of $\mathrm{Y}^{\mathrm{T}}{ }^{\mathrm{T}}$ cells at DOlow suggests a possible regulatory role in some aspect of nitrogen fixation (suggested in Chapter 4).

\subsection{PHA-accumulating proteins}

Several PHB synthesis proteins were abundantly expressed at DOlow and DOhigh. PhbB was identified in spot 4 (Fig. 5.7) and like PhbA (spot 3, Fig. 5.7) was not significantly altered between the different cell states representing $\mathrm{Y}^{8} 8^{\mathrm{T}}$ physiology at DOlow and DOhigh. A PHB granule-associated protein, PhaP, was identified in spots 1 and 2 at approximately $14 \mathrm{kDa}$ and pIs of approximately 5.8 and 6.1 respectively (Figs. 5.7, 5.8). PhaP was observed to be the most highly abundant protein on all gels for all growth conditions. The $\mathrm{M}_{\mathrm{r}}$ and pIs of both spots differed significantly from the predicted $\mathrm{M}_{\mathrm{r}}$ and $\mathrm{pI}$ of the $\mathrm{Y} 88^{\mathrm{T}}$ phasin. Unlike R. eutropha, which is reported to have four phasins (Neumann et al., 2008), Y88 ${ }^{\mathrm{T}}$ has only one phasin predicted from the $\mathrm{Y} 88^{\mathrm{T}}$ genome to be $33.9 \mathrm{kDa}$ and have a $\mathrm{pI}$ of 9.56. Since the same high-scoring peptides were identified in each case (Table 5.3), the spots were considered not to be degradation products of the same protein. Spots identified to be the same protein with similar $M_{r}$ but different pI, are suggested to represent isoforms with potential posttranslational modifications (Büttner et al., 2001; Rosen et al., 2004; Zhu et al., 2005). These findings will be discussed in greater detail in Chapter 6. 


\subsection{Other proteins}

GroEL was upregulated 3.4-fold at DOlow compared to DOhigh in two adjacent spots with the same $M_{\mathrm{r}}$ but slightly different pIs of 5.07 and 5.09, spot 1240 and 1254 ( $t$-test $=0.03$ and 0.034 respectively) and 11.52 -fold $(t$-test $=0.009)$ in spot 1851 (Fig. 5.7). The enhanced abundance of two adjacent spots at the same $M_{r}$ is consistent with one of the spots possibly representing a phosphorylated form of the same protein. As a molecular chaperone, GroEL (together with DnaK) is mainly known for its essential role in core physiological responses (Lemos et al., 2007), participating in, amongst other things, a variety of cellular processes such as protein folding and preventing misfolded proteins aggregating, protein translocation as well as the assembly and disassembly of protein complexes. A lesser known role of GroEL is its involvement in the nitrogen fixation system where it fulfills both regulatory and structural functions and is required for the correct folding of NifA (Govezensky et al., 1991). It has also been shown that upon heat shock, a fraction of GroEL is phosphorylated with this modification enhancing the capacity of GroEL to bind to certain unfolded proteins (Sherman \& Goldberg, 1992; Sherman \& Goldberg, 1994). The capacity of GroEL to be phosphorylated is consistent with an additional, possibly phosphorylated form induced in $\mathrm{Y}^{\mathrm{T}}$ cells (spot 1240, Fig. 5.7) at DO ${ }^{\text {low }}$ in addition to the enhanced abundance of the native form of the $\mathrm{Y}^{\mathrm{T}} 8^{\mathrm{T}}$ GroEL (spot 1254) at DOlow during nitrogen fixation. The lack of this potentially phosphorylated form on the gels at $\mathrm{DO}$ high is consistent with the low to undetectable levels of all nitrogenase components compared to that at DOlow. It is therefore conceivable that a phosphorylated form of GroEL may be induced during nitrogen fixation to increase the binding affinity of GroEL for one or more of the nitrogen-fixing proteins, ensuring correct folding of these proteins as part of the nitrogenase assembly system and thereby regulation of nitrogen fixation in Y88 .

GMP synthase (spot 1316) showed a 3.3-fold ( $t$-test 0.003 ) increase in abundance at DOlow compared to DOhigh. GMP synthase is involved in nucleotide biosynthesis and is an amidotransferase that catalyses the amination of xanthosine $5^{\prime}$-monophosphate to form GMP in the presence of glutamine and 
ATP (Nakamura et al., 1995). Glutamine hydrolysis produces the necessary amino group, while ATP hydrolysis provides the energy to drive the reaction. Ammonia can also serve as an amino group donor (Nakamura et al., 1995). Additionally, glycine dehydrogenase, ribosomal protein L9 and prolyl-tRNA synthetase were identified in what appeared to be the same spot as GMP synthase (spot 1316, Fig. 5.7), although on magnification of the gel image it was evident that three separate spots existed (Fig. 5.9, see *). Due to their close comigration, it was impossible to excise them as individual spots, so they were excised as one spot. Ribosomal protein L9 is considered to serve as a "molecular strut" most likely playing a role in ribosome assembly and/or maintaining the catalytically active conformation of ribosomal RNA (Lillemoen et al., 1997). Prolyl-tRNA synthetase is one of 20 aminoacyl-tRNA synthetases that catalyse the attachment of an amino acid to its cognate transfer RNA molecule. All four proteins in spot 1316 play some role in core metabolic processes of nucleotide, amino acid or ribosome (and thus protein) synthesis. High-scoring peptide matches to each of them ensured their inclusion as positive identifications since it was probable that due to their similar $\mathrm{M}_{\mathrm{r}}$ and pIs (Table 5.3), they had comigrated. Due to their mutual proximity, it was unclear which, if not all, of these proteins contributed to the increased abundance of this spot. Since the increase in abundance at DOlow coincided with nitrogen fixation, any or all of them may be implicated in some aspect of RNA/DNA repair or synthesis or amino acid synthesis to replenish requisite proteins for specialised activities such as nitrogen fixation.

Fructose-bisphosphate aldolase (Fba1p) and translation elongation factor Ts (EF-Ts) were both identified in spot 1785 and showed a 2.1-fold increase ( $t$ test $=0.01$ ) in abundance at DOlow. These two spots migrated as adjacent spots in a "string" formation with four other spots. Due to their proximity on the $7 \mathrm{~cm}$ gels, it was difficult to excise the spot detected by BVA analysis to be altered from the more abundant protein spot that showed no altered abundance between the two DO conditions. Based on $\mathrm{pI}$ and the previous identification of the larger spot as EF-Ts, it was possible to determine that the upregulated spot 

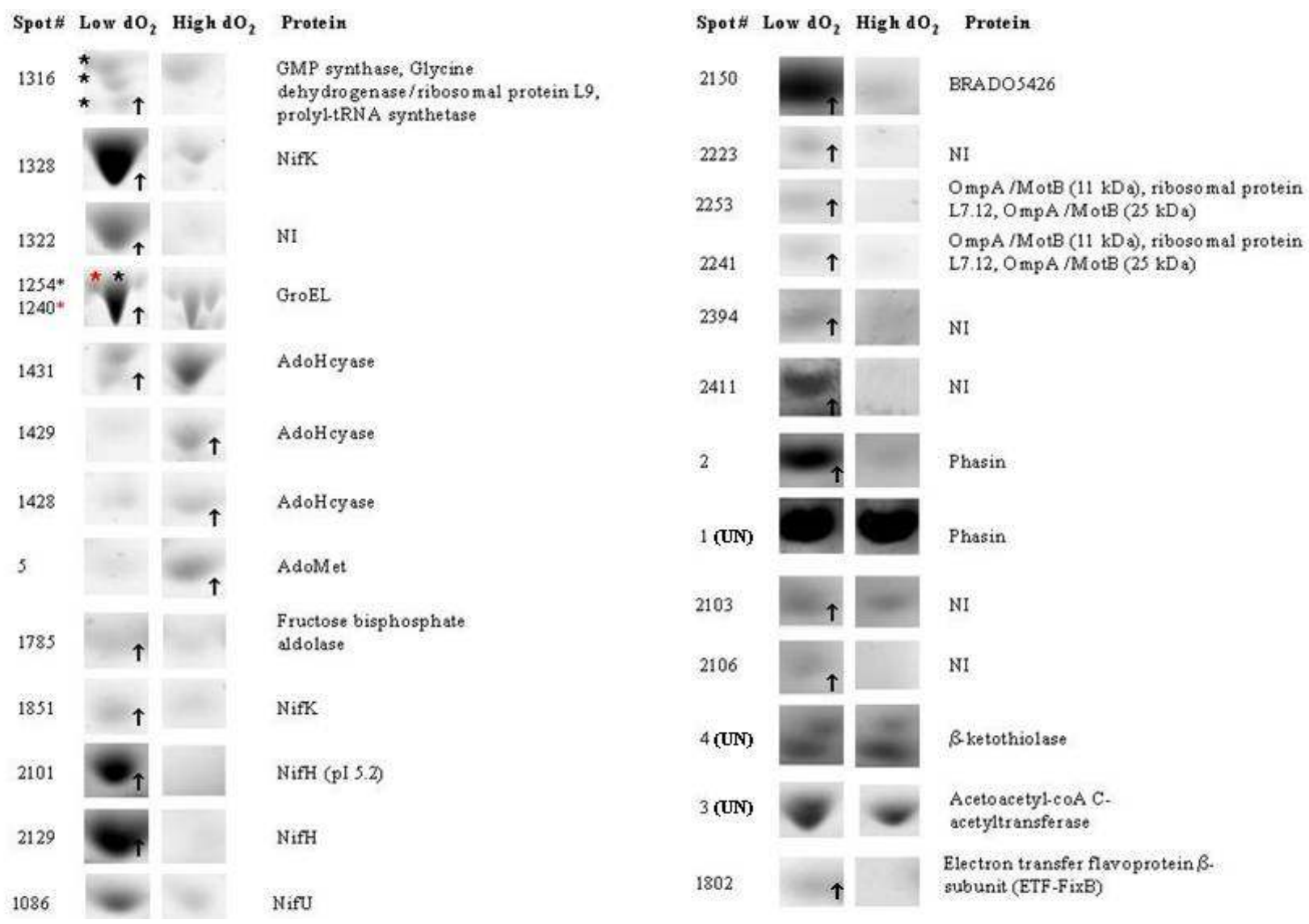

Figure 5.9 Magnification of the protein spots from 2-D DIGE pH 4-7 gels that showed altered abundance between DOlow and DOhigh under constant $\mathrm{pH} 7$ conditions in the growth medium.

Arrows denote those proteins with increased abundance at DOlow (left spot in each pair of spots) or DOhigh (right spot in each pair of spots). Spots with no arrows $\vec{\sigma}$ were determined by BVA analysis to be unaltered (UN) between DOlow and DOhigh. See body of the text throughout section 5.2.1.3 for discussion of these proteins. 
was indeed Fba1p. This protein is required for glycolysis and gluconeogenesis and catalyses the cleavage of fructose-1,6-bisphosphate into glyceraldehyde-3phosphate and dihydroxyacetone phosphate (Fitzgerald-Hughes et al., 2007). Enhanced abundance of this protein in $\mathrm{Y}^{\mathrm{T}} \mathrm{T}$ may signify increased energy requirements during nitrogen fixation. Notably, KDPG aldolase (also known as 2-dehydro-3-deoxyphosphogluocnate aldolase which is unique to the ED pathway, see spot number C2, Chapter 8, Appendix A.1, Fig. A.1) and 6phosphogluconate dehydratase, two diagnostic enzymes of the ED pathway were also abundant on the gels irrespective of DO conditions. It therefore appears that $\mathrm{Y} 88^{\mathrm{T}}$ may utilise more than one pathway to catabolise glucose.

S-Adenosylhomocysteine hydrolase (AdoHcyase) was identified in three adjacent spots: 1428, 1429 and 1431 (Figs. 5.7, 5.8, 5.9). All showed a 3-fold increase in abundance at DOhigh ( $t$-test $=0.006,0.008,0.01$ respectively). Based on their similar $M_{r}$ but different pIs (Figs. 5.7, 5.8), spots 1428 and 1429 may possibly be phosphorylated forms of the native AdoHcyase in spot 1429. AdoHcyase is a ubiquitous enzyme that plays a pivotal role in methylationbased processes by maintaining the intracellular balance between AdoHcy and S-Adenosyl-L-methionine (AdoMet). AdoHcy is the product of all AdoMetdependent biological transmethylations. About 95\% of AdoMet is reported to be used for transmethylation reactions that result in the formation of AdoHcy and is subsequently hydrolysed by AdoHcyase to form adenosine and homocysteine (Merali et al., 2000). AdoHcyase is the only known enzyme to catalyse the breakdown of AdoHcy (Turner et al., 2000) which if accumulated, can potentially be toxic to the cell (James et al., 2002). Since the accumulation of AdoMet is known to be significantly affected by DO as well as nitrogen source and pH (Yu et al., 2003), this would cause an imbalance between AdoMet and AdoHcy if not effectively regulated. It is therefore possible that the potentially phosphorylated forms of AdoHcyase on the gels at DOhigh are induced to cope with increased activity of AdoHcy at DOhigh levels. This is supported by the fact that AdoHcyase was also upregulated at the same $M_{r}$ but different $\mathrm{pI}$ (from that considered to be the $\mathrm{pI}$ of the native form of AdoHcyase) at low OD600 for the 
Fix off state, where DO was not controlled (Chapter 4). Phosphorylation of AdoHcyase may therefore serve to increase the activity of this protein under DOhigh to modulate AdoHcy and maintain the balance between AdoHcy and AdoMet. Since AdoMet is known to be significantly affected by DO, nitrogen source or $\mathrm{pH}$ as mentioned above (Yu et al., 2003), in $\mathrm{Y}^{8} 8^{\mathrm{T}}$, nitrogen availability, DOhigh, $\mathrm{pH}$, or a combination of all three during growth under nitrogen-limiting and DOhigh conditions may affect the balance between AdoHcy and AdoMet. Consequently, a heightened response by AdoHcyase to maintain this balance may be the reason for the observed increase in abundance as well as its appearance in three different spots at similar $\mathrm{M}_{\mathrm{r}}$ but different $\mathrm{pI}$.

In addition to the positive identification of AdoHcyase in spots 1428 and 1429, the third spot (spot 1431) matched to histidyl-tRNA synthetase as well as AdoHcyase. Since histidyl-tRNA synthetase may have co-migrated with AdoHcyase, it is unclear which of these two proteins, if not both, is responsible for the increase in abundance in spot 1431. Similar to prolyl-tRNA synthetase (spot 1316 mentioned above), histidyl-tRNA is one of the 20 aminoacyl-tRNA synthetases that catalyse the attachment of an amino acid to its cognate transfer RNA molecule and its upregulation in $\mathrm{Y}^{8} 8^{\mathrm{T}}$ is likely to be associated with increased protein synthesis.

Alkyl hydroperoxide reductase (AhpC) was identified in spot 2166 with a 2-fold increase in abundance $(t$-test $=0.03)$ at $\mathrm{DO}^{\text {low }}$. This protein migrated at a similar $\mathrm{M}_{\mathrm{r}}$ but slightly lower $\mathrm{pI}$ than the unaltered AhpC protein identified in spot C6 (see Appendix A, Fig. A.1), which showed similar abundance at both high and DOlow concentrations. AhpC confers resistance to alkyl hydroperoxides that are produced in response to oxidative stress, by reducing these compounds to alcohols (Storz et al., 1990). Reactive oxygen intermediates are continuously produced in any aerobically metabolising cell and need to be dealt with continuously to avoid damage to DNA, RNA, proteins, and lipids. AhpC is also iron-regulated and proposed to be expressed at a significantly higher level in cells grown under iron-limiting conditions than in iron-sufficient conditions 
(Baillon et al., 1999). Since iron is known to participate in the production of reactive oxygen intermediates via the Fenton reaction (Storz et al., 1990), the increased abundance of $\mathrm{AhpC}$ under iron-limiting conditions appears to be counterintuitive given that it is required to protect against iron-generated free radical production. With respect to $\mathrm{Y}^{\mathrm{T}}{ }^{\mathrm{T}}$ growth under nitrogen-depleted conditions, AhpC may be enhanced in $\mathrm{Y}^{8} 8^{\mathrm{T}}$ cells at DOlow due to the increased iron requirements for the highly abundant nitrogen fixation apoenzymes. Consequently, AhpC may be induced to protect the cells against the Fenton reaction under these growth conditions.

Additionally, the production of AhpC has been coupled to the activation of iron acquisition mechanisms such as those in E. coli that control superoxide dismutase (SOD) by means of the iron-responsive gene regulator Fur (Niederhoffer et al., 1990). Notably, under nitrogen-depleted growth at DOlow and DOhigh, SOD was always abundant on the gels and showed no altered state between nitrogen-depleted growth conditions. Again, because of the iron requirements of nitrogen fixation proteins such as NifH, NifK and NifU (involved in the synthesis of the Fe-S cluster of nitrogenase (Schilke et al., 1999)), it is likely that the increased abundance of the isoform of AhpC is related to the activation of iron acquisition mechanisms required to maintain nitrogenase activity. Although enhanced abundance of AhpC is observed during nitrogen fixation at DOlow, a basal level of AhpC was evident for both DOlow or DOhigh conditions, since the $20 \mathrm{kDa}$ native AhpC protein and a $16 \mathrm{kDa}$ isoform (confirmed to be two separate gene products based on the $\mathrm{Y}^{\mathrm{T}}{ }^{\mathrm{T}}$ genome) of this protein were present in equal abundance for both DO conditions at their deduced $\mathrm{M}_{\mathrm{r}}$ and pIs. The similar abundance of these proteins irrespective of DO concentration, suggests that a background level of oxidative stress proteins may be required for $\mathrm{Y}^{\mathrm{T}} 8^{\mathrm{T}}$ growth under conditions requiring increased amounts of iron.

Two highly abundant spots (spots 2241 and 2253, Figs. 5.7, 5.8) were evident at acidic pIs of 4.7 and 5.0 at approximately $12 \mathrm{kDa}$. Spot 2241 showed a 5.6-fold 
$(t$-test $=0.01)$ increase in abundance at DOlow, whereas spot 2253 showed a 10.3fold $(t$-test $=0.01)$ increase in abundance at DOlow. Two OmpA/MotB proteins encoded by two separate genes based on the $\mathrm{Y} 88^{\mathrm{T}}$ genome, and ribosomal protein L7/L12 appear to have co-migrated in each of these spots. The $\mathrm{M}_{\mathrm{r}}$ of the two OmpA/MotB proteins was 11.9 and 25.9. Their respective pIs were 5.76 and 7.03. Ribosomal protein L7/L12 is predicted to be $12.7 \mathrm{kDa}$ and have a pI of 4.7. The same set of OmpA/MotB and ribosomal L7/L12 proteins was identified with unique peptide matches to both spots. Manual validation of all peptide matches suggested that any of the three proteins were equally likely to be the correct identification in both spots. Despite the $25 \mathrm{kDa} O m p A / M o t B$ protein having high-scoring peptides, the predicted $\mathrm{pI}$ of 7.03 and $\mathrm{M}_{\mathrm{r}}$ for this protein were both higher than that for the observed spot. Therefore, the 11.9 $\mathrm{kDa}$ OmpA/MotB protein and the $12 \mathrm{kDa}$ ribosomal protein L7/L12 were the more likely candidates represented in these spots. It was also considered that the $25 \mathrm{kDa}$ OmpA/MotB protein may have been degraded and a fragment of this may have co-migrated with the other two proteins but this was discounted since the same unique, high-scoring peptides for this protein matched both spots. Alternatively, the $25 \mathrm{kDa}$ protein could be processed post-translationally by cleavage, which would explain its migration at a much lower $M_{r}$ and $p I$ than predicted. Since the same migration pattern was evident in $\mathrm{Y}^{\mathrm{T}}$ cells for all protein samples representing the Fix on state (for both batch flasks and bioreactors), this suggests directed processing of this protein posttranslationally during nitrogen fixation.

\subsection{Basic proteins}

Based on the $\mathrm{pH}$ 4-7 2-D gels, a major portion of the $\mathrm{Y} 88^{\mathrm{T}}$ proteome seemed to comprise more acidic proteins. A more detailed profile of the Y88 ${ }^{\mathrm{T}}$ basic proteome was obtained to determine whether any additional proteins could be mapped to differences in the response of $Y 88^{\mathrm{T}}$ to different DO concentrations. 2D DIGE was used to visualise the more basic proteins in the linear gradient $\mathrm{pI}$ 6-11 range. Comparison of the proteins in the linear gradient pI 6-11 range for $\mathrm{Y}^{\mathrm{T}}$ cells grown at DOlow or DOhigh showed approximately 70 protein spots with about 30 of these present in high abundance (Fig. 5.10). Of these, only six 
A

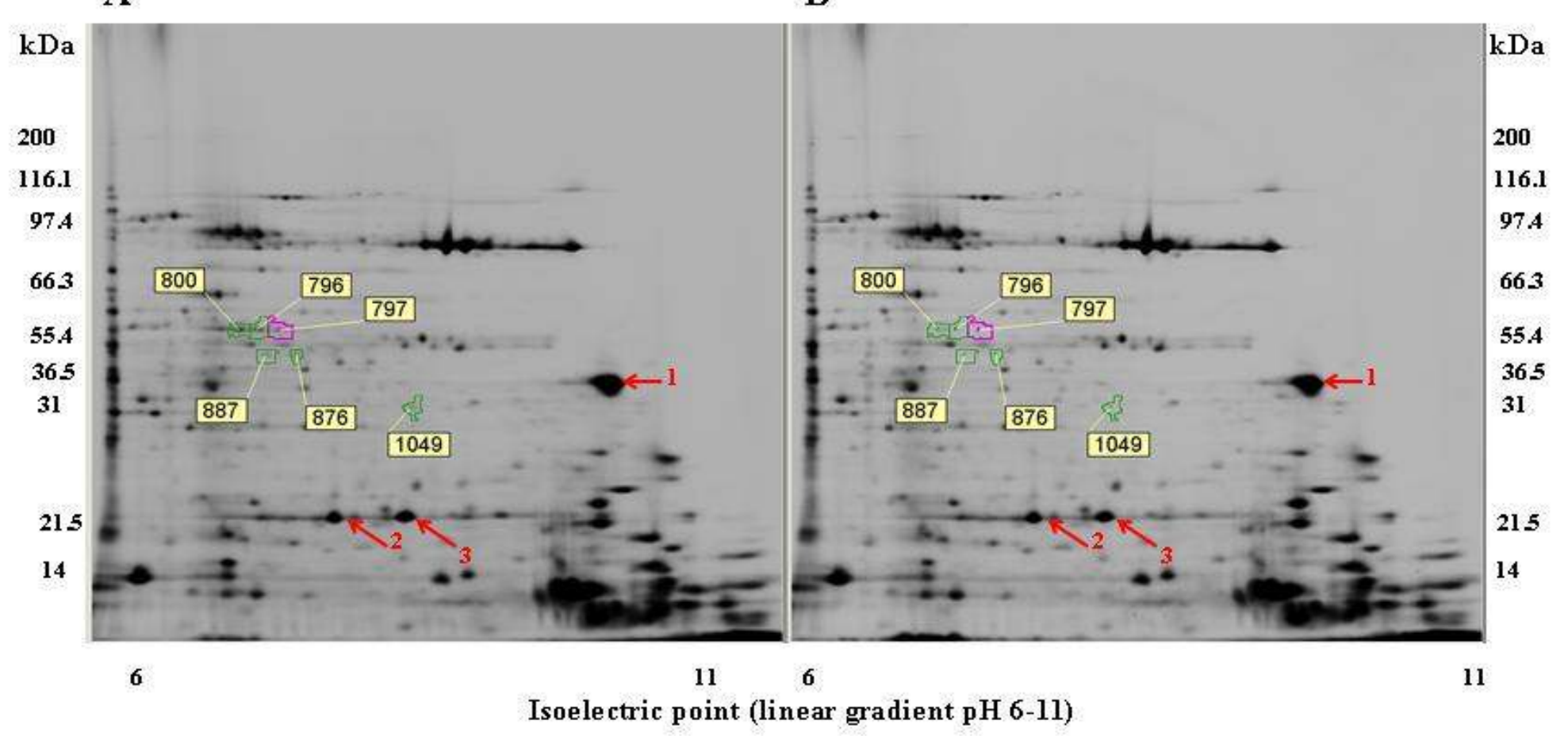

Figure 5.10 2-D DIGE images (pI 6-11) showing protein profiles of $\mathrm{Y}^{8} 8^{\mathrm{T}}$ cells grown to high $\mathrm{OD}_{600}(2.0)$ at DOlow or DOhigh concentrations, $\mathrm{pH}$ not controlled (A) DOlow; (B) DOhigh. Spot numbers (excluding those marked by red arrows) represent proteins determined by BVA analysis to have significantly altered abundance between the two DO concentrations. Spots marked by red arrows represent PHB synthesis proteins PhaP (spot 1) and two potential forms of PhbB with different pIs (spots 2,3), (n=3) 
(discussed in the following sections, see also Table 5.4) showed statistically significant altered abundance. In addition to those displaying altered abundance, 10 of the most abundant proteins that showed no change were selected for further analysis.

\subsection{Nitrogen fixation proteins}

The $\alpha$-subunit of dinitrogenase (component I), NifD (spot 800, Fig. 5.10), showed a 14-fold increase in abundance $(t$-test $=0.01)$ relative to DOhigh. This 56 $\mathrm{kDa}$ protein was identified on the gel for the $\mathrm{pH}$ 6-11 range (spot 800) and had a predicted $\mathrm{pI}$ of 6.3. Despite this predicted $\mathrm{pI}$, NifD was never observed on any gels in the $\mathrm{pH}$ 4-7 range. It was only ever identified on $\mathrm{pH}$ 6-11 gels for the Fix ${ }^{\text {on }}$ state at DOlow and migrated at a more basic pI (approximately 7.2) than that predicted from the $\mathrm{Y} 88^{\mathrm{T}}$ genome sequence. Although it was observed at its predicted $\mathrm{M}_{\mathrm{r}}$, a distinct $\mathrm{pI}$ shift from the conceptual protein sequence suggests that this protein may be modified post-translationally during nitrogen fixation. It is well established that nitrogenase activity is regulated by post-translational modification of the NifH Fe component of nitrogenase (Ludden \& Roberts, 1989; Martin \& Reinhold-Hurek, 2002; Huergo et al., 2006). However, there is no apparent precedent in the literature that $\mathrm{NifD}$ is subject to post-translational modification. This provides the first evidence that a NifD protein may be posttranslationally modified.

\subsection{PHB synthesis proteins}

Two PHB synthesis associated proteins were identified in the pI 6-11 range: PhaP (spot 1(UN), Fig. 5.9) and PhbB (spots 2 and 3, Fig. 5.9, Table 5.4). PhbB catalyses the second step in the PHB biosynthetic pathway. Both PhaP and $\mathrm{PhbB}$ were expressed at similar abundance irrespective of DO concentrations. PhaP was observed at its expected $\mathrm{M}_{\mathrm{r}}$ and $\mathrm{pI}$ as predicted from the $\mathrm{Y} 88^{\mathrm{T}}$ genome but the appearance of $\mathrm{PhbB}$ in two separate spots differing in $\mathrm{pI}$ but at the same $\mathrm{M}_{\mathrm{r}}$, suggests a $\mathrm{pI}$ shift for this protein indicative of an additional, potentially phosphorylated, isoform. 


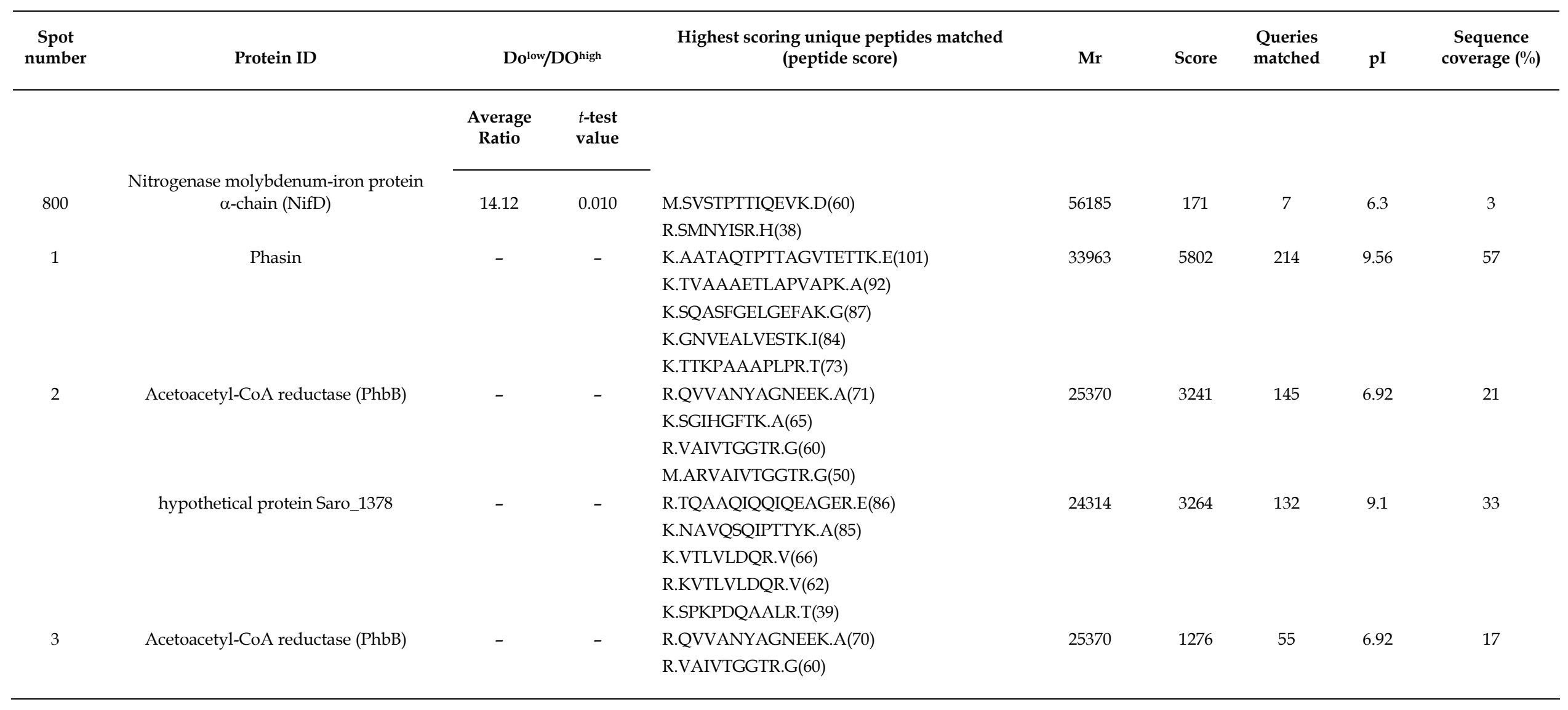

Table 5.4 2-D DIGE protein spot analysis showing statistical values and LC-MS/MS identification of proteins with altered abundance at high OD ${ }^{600}(2.0)$, and $\mathrm{pH}$ not controlled at DOlow or

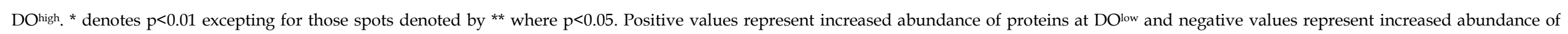

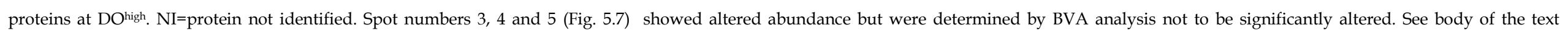
throughout section 5.2.1.3 for discussion of these proteins. 
Notably, PhaP was previously identified in two spots at approximately $14 \mathrm{kDa}$, well away from its predicted $33.96 \mathrm{kDa}$, but at different pIs (see previous section 5.2.1.3.3), suggesting that two different isoforms of the protein exist, at least one of which is additionally post-translationally modified. Numerous high-scoring peptide matches to PhaP in this spot on the $\mathrm{pH}$ 6-11 gel found at the predicted $\mathrm{M}_{\mathrm{r}}$ and $\mathrm{pI}$ for this protein, not only confirmed the genome prediction of a non-canonical phasin protein with an $\mathrm{N}$-terminus rich in alanine, proline and lysine residues, but also confirmed additional unique peptide matches to the N-terminus that had not previously been matched by any of the former peptides for the two phasin isoforms identified on the $\mathrm{pH}$ 4-7 gels ( $\mathrm{n}=8$ independent gels). The additional peptide matches to the N-terminus increased the sequence coverage to account for almost the entire protein sequence for PhaP. This suggests that the form of PhaP observed on the $\mathrm{pH}$ 6-11 gels may be the precursor of the other two forms observed on the $\mathrm{pH} \mathrm{4-7} \mathrm{gels,}$ the amino terminal segment of which is cleaved to produce the $13 \mathrm{kDa}$ phasin isoforms. The implications of these findings are discussed in Chapter 6.

\subsection{Other}

Several additional spots were determined to be significantly altered between DOlow or DOhigh conditions in the pI 6-11 range. None of these spots yielded positive identifications due to insufficient quantities of protein.

\subsubsection{Comparison of protein profiles obtained for DOlow or DOhigh conditions at high cell densities $\left(\mathrm{OD}_{600}=2.0\right), \mathrm{pH}$ controlled}

\subsection{Acidic proteins}

The batch flask and bioreactor experiments (Chapter 4, Chapter 5, Section 5.1.2.5.2) carried out to compare protein profiles for the physiological states of Y88 ${ }^{\mathrm{T}}$ cells during growth at $\mathrm{DO}^{\text {low }}$ or DOhigh conditions did not have the $\mathrm{pH}$ of the medium controlled. Consequently, Y88 ${ }^{\mathrm{T}}$ glucose-mediated growth resulted in acidification of the medium. To determine the effect, if any, of $\mathrm{pH}$ on the abundance of those proteins identified in the proteomic signatures for the Fix on and Fix ${ }^{\text {off }}$ states, the growth experiments were repeated in the bioreactors at DOlow and DOhigh but with $\mathrm{pH}$ controlled at 7.0 for the duration of the 
experiment. 2-D DIGE was carried out for different combinations of low or high $\mathrm{OD}_{600}$ and $\mathrm{DO}^{\text {low }}$ or DOhigh concentrations under $\mathrm{pH}$-controlled conditions as determined by the experimental design (see Chapter 2, Tables 2.1, 2.2) to take into account all possible effects of growth and DO concentrations within the existing growth parameters. Ninety-six protein spots were selected for analysis, which included those proteins determined to be statistically altered under DOlow or DOhigh conditions with $\mathrm{pH}$ controlled as well as many of those that showed no altered abundance. The goal was to attempt to identify as many proteins as possible in underlying metabolic pathways to obtain a more complete profile of the $\mathrm{Y}^{8} 8^{\mathrm{T}}$ proteome and more representative protein signatures for the specified growth conditions.

The number of proteins showing statistically significant differences in abundance between different DO concentrations with $\mathrm{pH}$ not controlled compared to different DO concentrations with $\mathrm{pH}$ controlled at $7.02 \pm 0.2$, was dramatically reduced. Previously, 38 proteins showed altered abundance between $\mathrm{DO}^{\text {low }}$ and $\mathrm{DO}^{\text {high }}$ conditions with $\mathrm{pH}$ not controlled with 32 of these in the $\mathrm{pH}$ 4-7 range (Fig. 5.8) and six in the $\mathrm{pH}$ 6-11 range (Fig. 5.10). Under the same DO conditions but with $\mathrm{pH}$ controlled, this number was reduced to seven for $\mathrm{pH}$ 4-7 DIGE (Figs. 5.11, 5.12) and from six (Fig. 5.10) to three for $\mathrm{pH}$ 6-11 DIGE (see section 5.2.1.5.4 below), suggesting that changes of many of these proteins may be regulated or affected by $\mathrm{pH}$, not DO. Despite these changes, the proteins signatures for nitrogen fixation and PHB synthesis showed similar profiles to those detected in previous experiments (sections 5.2.1.3, 5.2.1.4). Since the proteomic signatures for the different DO concentrations were highly altered once the medium was prevented from naturally acidifying, $\mathrm{pH}$ clearly had an effect on many proteins with the exception of the core nitrogen-fixing proteins and PHB synthesis/associated proteins.

\subsection{Linear gradient $\mathrm{pH}$ 4-7 range}

Several proteins showed altered abundance for the two DO states, with seven proteins that showed statistically significant changes. These included three proteins (spots 1249, 2038 and 2136) that had not previously shown any change 


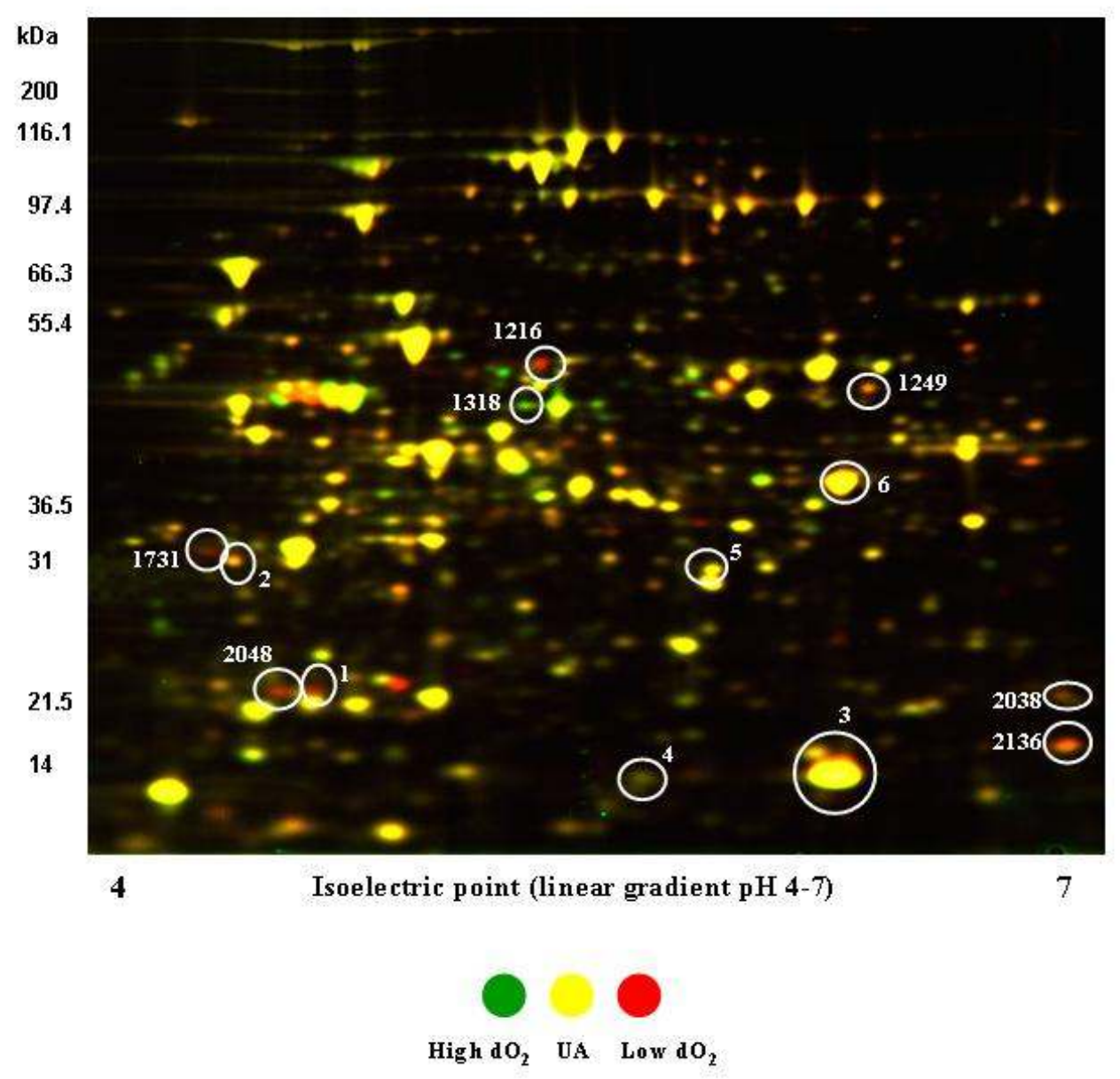

Figure 5.11 Overlay image of $\mathrm{Y}^{\mathrm{T}} 8^{\mathrm{T}}$ protein profiles generated from minimally labeled samples showing differential protein abundance under $\mathrm{DO}^{\text {low }}$ or DOhigh, constant $\mathrm{pH} 7$ conditions in the linear gradient $\mathrm{pH}$ 4-7 range

Pooled (Cy2 - yellow), DOlow (Cy3 - green) or DOhigh (Cy5 - red) samples are overlaid. Overlay image of $\mathrm{Y}^{8} 8^{\mathrm{T}}$ protein profiles generated from minimally labeled pooled (Cy2 - yellow), DOlow (Cy3 - green) or DOhigh (Cy5 - red) samples showing differential protein abundance in the linear gradient pH 4-7 range. Yellow $(\mathrm{UE})=$ proteins expressed similarly in both states of the cells at $\mathrm{DO}^{\text {low }}$ or $\mathrm{DO}^{\text {high}}$, red $\left(\mathrm{AE} \mathrm{DO}^{\text {low }}\right)=$ proteins unique to the state of the cells at $\mathrm{DO}^{\text {low }}$, green $(\mathrm{AE}$ DOhigh) $=$ proteins unique to the state of the cells at DOhigh. Spot numbers (excluding spots 1, 2, 3, 4, 5 and 6) represent proteins determined by BVA analysis to have significantly altered abundance between the two DO concentrations. Spots 1 and 2 showed altered abundance but were outside the BVA filter thresholds. Spots 3, 4, 5 and 6 are involved in PHB synthesis. Spots 1249, 2038 and 2136 that showed significant change in abundance under $\mathrm{pH}$ controlled conditions, did not show altered abundance when $\mathrm{pH}$ was not controlled. Spots selected for analysis were those likely to be involved in the nitrogen-fixing and PHB pathways based on predicted pI and molecular weight, as well as some spots with altered abundance that are not usually associated with these pathways. 


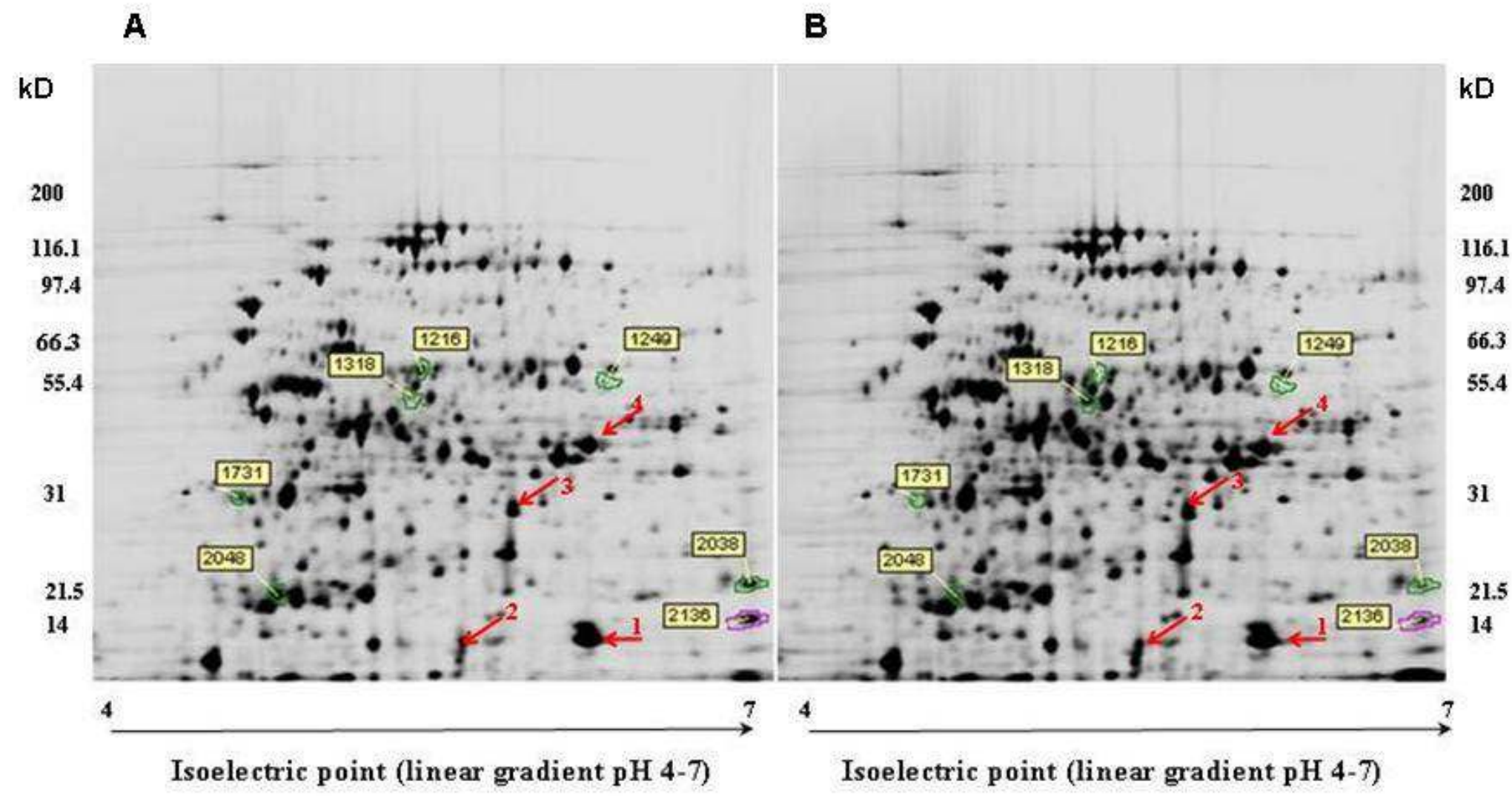

Figure 5.12. 2D DIGE images ( $\mathrm{pI} 4-7$ ) showing protein profiles of $\mathrm{Y}^{\mathrm{T}} 8^{\mathrm{T}}$ cells grown to a high $\mathrm{OD}_{600}(2.0)$ under ammonium-depleted conditions at DOlow or DOhigh at constant $\mathrm{pH}$

(A) DOlow; (B) DOhigh. Spot numbers represent proteins determined by BVA analysis to have significantly altered abundance between the two DO concentrations. 
(Figs. 5.11, 5.12, 5.13). With both DO and pH controlled, proteomic signatures for DOlow or DOhigh differed from those determined for DOlow or DOhigh with $\mathrm{pH}$ of the medium not controlled.

\subsection{Nitrogen fixation proteins}

The NifK protein (spot 1216) showed significant altered abundance between the two DO conditions under controlled $\mathrm{pH}$ conditions. As before, NifK was identified at $58 \mathrm{kDa}$ and pI 5.4 and showed a greater than 4-fold increase in abundance $(t$-test $=0.019)$ at DOlow relative to DOhigh $($ Table 5.5, Figs. 5.11, 5.13). This protein was once again detected at very low levels at the corresponding $M_{r}$ and $\mathrm{pI}$ on the gel at DOhigh (see corresponding spot 1216, Figs. 5.12B, 5.13).

The fact that DOhigh results in decreased abundance of nitrogenase is not unexpected given the susceptibility of nitrogenase to oxygen (Staal et al., 2007). What is surprising is that this low level of NifK may represent a still-active form of the protein based on a very low level of nitrogenase activity detected in the acetylene reduction assay (see Fig. 5.1D at the beginning of this chapter). Similarly, the abundance of the NifH protein (spot 2048, Figs. 5.11, 5.12B, 5.13) was altered at DOhigh, showing a 2.5-fold $(t$-test $=0.033)$ decrease in abundance of this component of the nitrogenase enzyme at DOhigh conditions. Again, this subunit of the nitrogenase enzyme was barely visible on the gel at DOhigh compared to the highly abundant spots evident at the same $\mathrm{M}_{\mathrm{r}}$ and $\mathrm{pI}$ on the gel at DOlow. Considering the obvious abundance of spot 2048 at $\mathrm{DO}^{\text {low }}$ but its huge decrease in abundance to only barely detectable levels on the gel at DOhigh, it is surprising that BVA analysis determined only a 2.5-fold difference in abundance between the two. Nevertheless, the spot was highly downregulated as evident on the gels at DOhigh suggesting an effect of $\mathrm{DO}^{\text {high }}$ on dinitrogenase. Despite its downregulation at DOhigh, NifH, like NifK may still be present at very low levels under DOhigh conditions.

Notably, only one form of NifH was visible at pI 4.7 on the gel at DOlow with $\mathrm{pH}$ controlled instead of the two forms previously observed at different $\mathrm{pIs}$ and $\mathrm{M}_{\mathrm{r}}$ with $\mathrm{pH}$ not controlled. Thus at constant exposure to DOlow, with the 


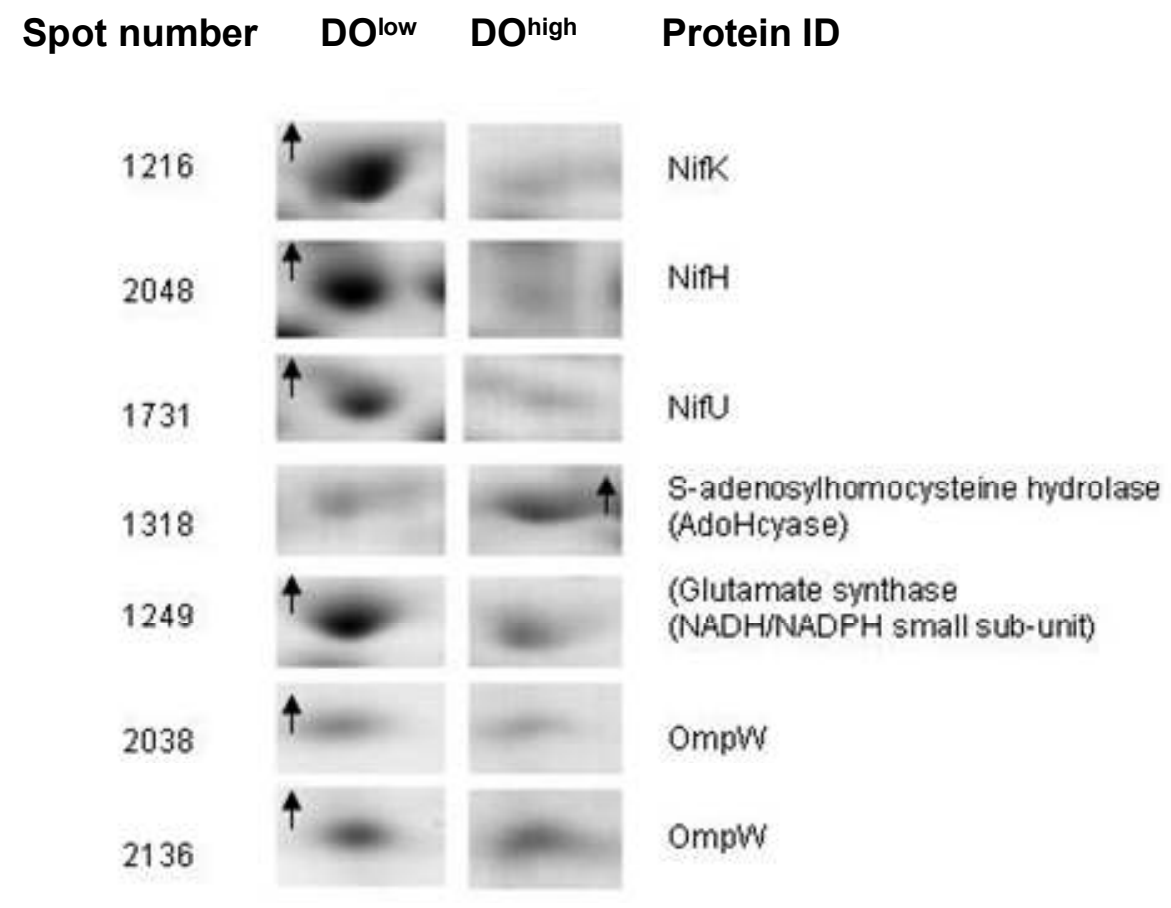

Figure 5.13 Magnification of the protein spots from 2-D DIGE pH 4-7 gels that showed altered abundance between $\mathrm{DO}^{\text {low }}$ and DOhigh under constant $\mathrm{pH} 7$ conditions in the growth medium. Arrows denote increased abundance for the protein under DOlow or DOhigh conditions. 


\begin{tabular}{|c|c|c|c|c|c|c|c|c|c|}
\hline \multirow[t]{2}{*}{$\begin{array}{l}\text { Spot } \\
\text { number }\end{array}$} & \multirow[t]{2}{*}{ Protein ID } & \multicolumn{2}{|c|}{$\mathrm{Do}^{\text {low }} / \mathrm{DO}^{\text {high }}$} & \multirow[t]{2}{*}{$\begin{array}{l}\text { Highest scoring unique peptides matched } \\
\text { (peptide score) }\end{array}$} & \multirow[t]{2}{*}{$\mathbf{M}_{\mathbf{r}}$} & \multirow[t]{2}{*}{ Score } & \multirow[t]{2}{*}{$\begin{array}{l}\text { Queries } \\
\text { matched }\end{array}$} & \multirow[t]{2}{*}{ pl } & \multirow[t]{2}{*}{$\begin{array}{c}\text { Sequence } \\
\text { coverage (\%) }\end{array}$} \\
\hline & & $\begin{array}{l}\text { Average } \\
\text { Ratio }\end{array}$ & $\begin{array}{l}t \text {-test } \\
\text { value }\end{array}$ & & & & & & \\
\hline \multirow[t]{5}{*}{1216} & Dinitrogenase (NifK) & 4.3 & $0.019^{* *}$ & R.MYDGGTTLEEAGQAVHAR.A(109) & 58437 & 13674 & 708 & 5.37 & 44 \\
\hline & & & & K.MQDLFDSSPFGAGCK.A(95) & & & & & \\
\hline & & & & K.INFLGGFDGYTVGNTR.E(95) & & & & & \\
\hline & & & & K.VEYTILGDNSDVWDTPTDGEFR.M(84) & & & & & \\
\hline & & & & R.ATISMQEFCTEK.T(72) & & & & & \\
\hline \multirow[t]{3}{*}{1249} & $\begin{array}{l}\text { Glutamate synthetase (NADP/NADPH), small } \\
\text { subunit }\end{array}$ & 2.13 & $0.015^{\star *}$ & R.VTGENDVTGLECVR.V (80) & 52955 & 150 & 16 & 5.89 & 12 \\
\hline & & & & R.FAMEFLTQQNK.R(65) & & & & & \\
\hline & & & & QEVPGSEFTLK.A (51) & & & & & \\
\hline \multirow[t]{3}{*}{1318} & S-adenosylmethionine (SAM) synthetase & -2.13 & $0.045^{\star *}$ & K.GIMDTDGNWAPGVPEEVER.V (86) & 43503 & 130 & 14 & 5.27 & 10 \\
\hline & & & & K.NIVAAGLAHR.C(49) & & & & & \\
\hline & & & & R.TDLVADLK.A(49) & & & & & \\
\hline \multirow[t]{5}{*}{1731} & NifU & 2.52 & $0.040^{* *}$ & R.TNGLTSIDEVTNYTK.A(107) & 33542 & 3630 & 98 & 4.72 & 59 \\
\hline & & & & K.AGGGCSTCAEGIEGVLER.V(93) & & & & & \\
\hline & & & & K.NSGILEDADGVGDVGAISCGDALR.L(89) & & & & & \\
\hline & & & & R.DGGDCELVDVEGNR.V(85) & & & & & \\
\hline & & & & K.VDEPSQTISDAR.F(72) & & & & & \\
\hline
\end{tabular}

Table 5.5 2-D DIGE protein spot analysis ( $\mathrm{pH} 4-7)$ and LC-MS/MS analysis of protein from cells grown at DOlow or DOhigh at constant $\mathrm{pH}$ and high OD 600 (2.0)

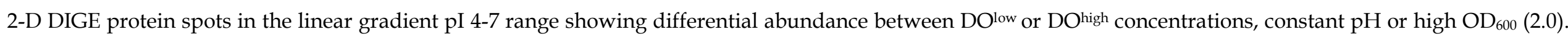

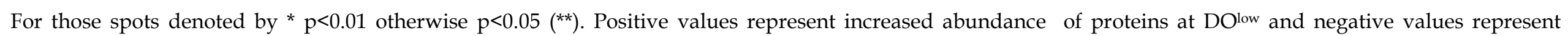
increased abundance of proteins at DOhigh. Table 5.5 continued on next page.

$\stackrel{\infty}{\infty}$ 


\begin{tabular}{|c|c|c|c|c|c|c|c|c|c|}
\hline \multirow[t]{2}{*}{$\begin{array}{l}\text { Spot } \\
\text { number }\end{array}$} & \multirow[t]{2}{*}{ Protein ID } & \multicolumn{2}{|c|}{ Do low $/ \mathrm{DO}^{\text {high }}$} & \multirow[t]{2}{*}{$\begin{array}{l}\text { Highest scoring unique peptides } \\
\text { matched (peptide score) }\end{array}$} & \multirow[t]{2}{*}{$\mathbf{M}_{\mathbf{r}}$} & \multirow[t]{2}{*}{ Score } & \multirow[t]{2}{*}{$\begin{array}{l}\text { Queries } \\
\text { matched }\end{array}$} & \multirow[t]{2}{*}{ pl } & \multirow[t]{2}{*}{$\begin{array}{l}\text { Sequence } \\
\text { coverage }(\%)\end{array}$} \\
\hline & & $\begin{array}{c}\text { Average } \\
\text { Ratio }\end{array}$ & $\begin{array}{l}t \text {-test } \\
\text { value }\end{array}$ & & & & & & \\
\hline \multirow[t]{2}{*}{2038} & Outer membrane protein $\mathrm{W}(\mathrm{OmpW})$ & 2.24 & $0.003^{*}$ & K.LLATGVLADGNIDTVR.S(94) & 25096 & 251 & 6 & 9.1 & 4 \\
\hline & & & & K.TPYSLTFDAK.K(71) & & & & & \\
\hline \multirow[t]{5}{*}{2048} & Dinitrogenase reductase $(\mathrm{NifH})$ & 2.5 & $0.033^{*}$ & R.CVESGGPEPGVGCAGR.G(120) & 31859 & 4200 & 123 & 4.94 & 32 \\
\hline & & & & K.STTSQNTLAALADLGQR.I(118) & - & - & - & - & - \\
\hline & & & & R.QTDKELELAESLAK.K (85) & - & - & - & - & - \\
\hline & & & & K.ELELAESLAK.K(70) & - & - & - & - & - \\
\hline & & & & R.DNIVQHAELR.R(66) & - & - & - & - & - \\
\hline \multirow[t]{2}{*}{2136} & Outer membrane protein $\mathrm{W}(\mathrm{OmpW})$ & 2.12 & $0.012^{*}$ & K.LLATGVLADGNIDTVR.S(94) & 25096 & 851 & 16 & 9.1 & 10 \\
\hline & & & & K.TPYSLTFDAK.K(71) & - & - & - & - & - \\
\hline
\end{tabular}

Table 5.5 2-D DIGE protein spot analysis ( $\mathrm{pH} 4-7)$ and LC-MS/MS analysis of protein from cells grown at DOlow or DOhigh at constant pH, high OD 600 (2.0)

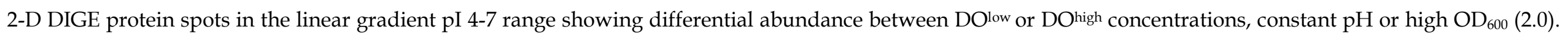

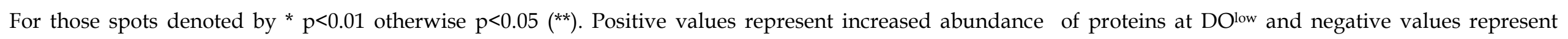
increased abundance of proteins at DOhigh. 
extracellular medium maintained at $\mathrm{pH} 7$, the appearance of $\mathrm{NifH}$ was altered at DOlow and the two forms that were previously evident (Chapter 4 and Chapter 5, Figs. 5.7, 5.8A, spots 2129 and 2101), were no longer observed as two distinct, abundant spots on the 2-D gels (spot 2048, Figs. 5.11, 5.12A). Of the two spots previously observed, the spot considered to be the more basic NifH form (spot 2101, Figs. 5.7, 5.8A) became barely visible on the gel. This suggests that it may have been differently regulated when the growth medium was maintained at a neutral $\mathrm{pH}$ and it may have migrated to another position on the gel. Alternatively, the two spots could have resolved into the one, more acidic spot observed. Thus the former presence of the more basic NifH form could be attributed to the change brought about by the more acidic growth medium. Its former presence at a higher-than-predicted pI and/or higher $\mathrm{M}_{\mathrm{r}}$ (by about 1000 Da) than that of the more acidic form (spot 2129, Figs. 5.7, 5.8A; spot 2048, Figs. 5.11, 5.12A), may have been due to some possible post-translational modification as a result of the more acidic growth conditions as previously discussed (section 5.2.1.3). Its disappearance from the corresponding $\mathrm{pI}$ and $\mathrm{M}_{\mathrm{r}}$ on the gels at DOlow for the neutral growth conditions suggests some modification that may have caused a shift in $\mathrm{pI}$ or $\mathrm{M}_{\mathrm{r}}$. Despite the altered NifH profile for the $\mathrm{pH}$ controlled, DOlow conditions compared to the same conditions but with $\mathrm{pH}$ not controlled, the activity of the nitrogenase enzyme was clearly not affected by the change in this form of $\mathrm{NifH}$, since a positive acetylene reduction assay was obtained for $\mathrm{Y}^{8} 8^{\mathrm{T}}$ cells grown under controlled $\mathrm{pH}, \mathrm{DO}{ }^{\text {low }}$ conditions. Since NifH functions as a homodimer, it is conceivable that all the NifH was therefore reduced to a single spot under neutral growth conditions. Growth at acidic $\mathrm{pH}$ therefore appears to result in an intracellular response with the modification of a key component of the $\mathrm{Y}^{8} 8^{\mathrm{T}}$ nitrogenase under acidic growth conditions, a finding for which there is no apparent precedent in the literature.

The NifU protein (spot 1731) showed a 2.5-fold ( $t$-test=0.04) increase in abundance at $\mathrm{DO}^{\text {low }}$ relative to DOhigh (Figs. 5.11, 5.12A, Table 5.5). At DOhigh, it was coordinately downregulated with the NifK and $\mathrm{NifH}$ components of 
nitrogenase. It is possible that this protein plays a regulatory role in negative feedback of nitrogenase enzyme activity at $\mathrm{DOhigh}$ whether $\mathrm{pH}$ is controlled or not, since decreased abundance of NifU occurred regardless of $\mathrm{pH}$. NifU has been shown to affect the activity of both nitrogenase components (Dos Santos et al., 2004). The proteomic signature obtained with respect to NifK and NifU at DOlow with $\mathrm{pH}$ controlled is consistent with that previously obtained for the nitrogen-fixing state of $\mathrm{Y}^{\mathrm{T}}$ cells at high $\mathrm{OD}_{600}$ in which $\mathrm{pH}$ was not controlled (Chapter 4). The coordinated decrease in abundance of the nitrogen-fixing proteins at $\mathrm{DO}^{\text {high }}$ and controlled $\mathrm{pH}$ is consistent with their decrease for the Fix ${ }^{\text {off }}$ state of $\mathrm{Y}^{8} 8^{\mathrm{T}}$ cells at lower $\mathrm{OD}_{600}$ (Chapter 4). Therefore, $\mathrm{pH}$ had no visible

effect on NifK and NifU abundance, although it may have had an anomalous effect on NifH abundance, at least for the more basic form of NifH, despite apparently not having an effect on nitrogenase activity.

\subsection{Nitrogen assimilation}

The small subunit of NADPH-dependent glutamate synthase (also known as GOGAT), was identified on the gels at DOlow concentration (spot 1249, Figs. $5.11,5.12,5.13)$ and showed a $>2$-fold change in abundance ( $t$-test $=0.015)$ relative to DOhigh concentrations (Table 5.5). This protein was observed at the predicted $53 \mathrm{kDa}$ but at a greater $\mathrm{pI}$ than expected ( $\mathrm{pI}=6.4$ compared to the expected $\mathrm{pI}$ of 5.9) from the $\mathrm{Y}^{\mathrm{T}} \mathrm{P}^{\mathrm{T}}$ genome prediction. GOGAT (NADPH- or $\mathrm{NADH}$-dependent) is a key enzyme in the early stages of ammonia assimilation in bacteria that catalyses the reductive transamidation of the amido nitrogen from glutamine and 2-oxoglutarate to form glutamate. The ammonia that enters this pathway can be supplied either by internal metabolic processes such as amino acid catabolism, or through the reduction of external nitrogen sources such as atmospheric dinitrogen. Most bacteria use NADPH-dependent GOGAT, although some are reported to show NADH-dependent activity (Dincturk \& Knaff, 2000). NADPH-dependent GOGAT in bacteria consists of two different subunits, the larger of which shows considerable similarity to the ferredoxin-dependent enzymes. 
The identification of NADPH-dependent GOGAT on Y88 ${ }^{\mathrm{T}}$ gels at DOlow, suggests that $\mathrm{Y} 88^{\mathrm{T}}$ presumably use the NADPH-dependent form of GOGAT as the electron donor for the two-electron conversion of glutamine to glutamate. Since the ammonia supplemented in the medium was depleted by the time the Y $88^{\mathrm{T}}$ cells were harvested for protein extraction, the abundance of NADPHdependent GOGAT at DOlow concentrations must be due to the assimilation of ammonium produced intracellularly as a consequence of the reduction of external atmospheric dinitrogen. The decreased abundance of this protein at DOhigh is consistent with the decreased ethylene peak in the acetylene reduction assays at DOhigh as well as the decreased abundance of the nitrogen-fixing proteins on the 2-D gels. The altered abundance of NADPH-dependent GOGAT at $\mathrm{DO}^{\text {low }}$ or $\mathrm{DO}$ high may reflect the ability of $\mathrm{Y}^{\mathrm{T}} 8^{\mathrm{T}}$ to establish hierarchical cascades of protein abundance in response to nitrogen limitation.

AdoHcyase (spot 1318) showed a greater than 2-fold difference $(t$-test $=0.045)$ at DOhigh relative to DOlow. Its role in balancing AdoHcy and AdoMet, an ubiquitous cofactor in protein enzymes that is mainly involved in transmethylation, transsulfuration and polyamine synthesis (Cochrane \& Strobel, 2008), was previously described (Chapter 5, section 5.2.1.3.4). Since nitrogen source, $\mathrm{pH}$ and DO have been shown to have significant effects on accumulation of AdoMet (Yu et al., 2003), the increased abundance of a potentially phosphorylated form of AdoHcyase at DOhigh with $\mathrm{pH}$ controlled is consistent with its former increased abundance for DOhigh conditions (Chapter 5, section 5.2.1.3.4) where $\mathrm{pH}$ was not controlled. Thus, irrespective of $\mathrm{pH}$, this protein appears to be abundant at DOhigh as a presumably more phosphorylated form similar to that observed for the Fix off state (Chapter 4).

The outer membrane porin protein OmpW was identified in two spots (spots 2136,2038 ) both of which showed greater than 2-fold increase in abundance (spot 2038, $t$-test=0.003; spot 2136, $t$-test $=0.01$ ) at DOlow relative to DO ${ }^{\text {high }}$ (Table 5.5). The identification of this protein in both spots at different $M_{r}$ but the same pI suggests that one isoform could be post-translationally modified, possibly by glycosylation, a modification that is does not change the $\mathrm{pI}$ of the protein but 
does change its $\mathrm{M}_{\mathrm{r}}$. Bacterial outer membrane proteins (OMPs) are known to play important roles in the cell's adaptive response to environmental conditions (Nikaido, 1999; Lin et al., 2002) and OmpW has been shown to be expressed under stress conditions, such as low aeration, elevated temperature or high salt concentration (Nandi et al., 2005; Hong et al., 2006). The increased abundance of this protein at DOlow regardless of the growth state of the cell (see later Sections 5.2.1.5.7, 5.2.1.6.2) suggests that its altered abundance in $\mathrm{Y}^{\mathrm{T}} 8^{\mathrm{T}}$ may be a response to low aeration.

Several outer membrane proteins were identified in spots that showed no altered abundance on the gels for both $\mathrm{DO}^{\text {low }}$ and DOhigh at controlled $\mathrm{pH}$ (see Appendix 3). A TonB-dependent siderophore receptor, additional TonBdependent receptors and a TolB-like protein were identified in eight other spots on the gels. TonB-dependent receptors are outer membrane proteins known for, amongst other roles, the active transport of iron siderophore complexes in Gram-negative bacteria. Due to the high insolubility of $\mathrm{Fe}(\mathrm{III})$ in aerobic conditions, many Gram-negative bacteria produce small iron-chelating compounds called siderophores under iron-limiting conditions (Moeck \& Coulton, 1998). TonB-dependent receptors function as receptors for these "ferrisiderophores". The increased abundance of a TonB-dependent siderophore receptor at DOlow is consistent with the acquisition of iron uptake that may be required for the iron-sulfur cluster of nitrogenase utilised during nitrogen fixation. At DOhigh, the decreased abundance of this protein suggests a decreased requirement for iron, consistent with what would be expected for decreased iron requirements when the iron-dependent nitrogenase enzyme and accessory proteins are not present at such high abundance under DOhigh conditions. The upregulation of this OMP together with the coordinated upregulation of the porin TonB-dependent siderophore receptor suggests a functional role for these OMPs in iron uptake and transport across the periplasm during nitrogen fixation. 


\subsection{Basic proteins}

\subsection{Nitrogen-fixing proteins}

Three spots showed altered abundance in the $\mathrm{pI}$ 6-11 range between $\mathrm{DO}^{\text {low }}$ and DOhigh in which culture $\mathrm{pH}$ was controlled. As in the uncontrolled $\mathrm{pH}$ experiments, NifD (spot 880, Fig. 5.14, Table 5.6) showed a higher abundance at DOlow although the 2.4-fold increase in abundance $(t$-test $=0.005)$ under $\mathrm{pH}$ controlled conditions between DOlow and DOhigh was much lower than the 14fold difference determined between these two DO levels with $\mathrm{pH}$ not controlled (Section 5.2.1.4.1). Thus controlling $\mathrm{pH}$ resulted in a smaller difference in abundance of this protein. Once again, NifD was observed only on the pH 6-11 gels at its predicted $\mathrm{M}_{\mathrm{r}}$ but at a $\mathrm{pI}$ of 7.2 rather than its predicted $\mathrm{pI}$ of 6.3 . As a result of this second set of independent, replicate experiments which confirms the presence of NifD again at a higher than predicted pI, it seems likely that the Y88 ${ }^{\mathrm{T}}$ NifD may be post-translationally modified as previously suggested (Section 5.2.1.4.1).

\subsection{PHB synthesis proteins}

Irrespective of $\mathrm{DO}^{\text {low }}$ or DOhigh conditions with $\mathrm{pH}$ controlled, the proteins involved in PHB synthesis (Fig. 5.14, spots 1 through to 3; Table 5.6) previously observed in the $\mathrm{pH}$ 6-11 range for $\mathrm{DO}^{\text {low }}$ or DOhigh with $\mathrm{pH}$ not controlled (Fig. 5.10), were once again observed at the same $\mathrm{pI}$ and $\mathrm{M}_{\mathrm{r}}$ as before. Once again there was no significant change in their abundance. The abundance of these proteins remained consistently high irrespective of growth at $\mathrm{DO}^{\text {low }}$ or $\mathrm{DO}$ high or whether the growth medium was more acidic or neutral.

\subsection{Other proteins}

Spot 1784 (Fig. 5.14) identified as OmpW (and previously identified in spot 2136, Fig. 5.12) showed a 2.3-fold increase at DOlow at approximately $14 \mathrm{kDa}$ and pI 6.4 (Table 5.6). Since the abundance of OmpW was unaltered between

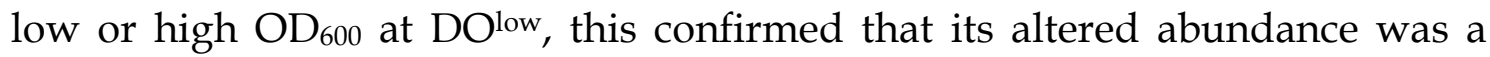
response to $\mathrm{DO}^{\text {low }}$ conditions at constant $\mathrm{pH}$. Peptide matches to this protein were the same as those in spots 2036 (at a higher $M_{r}$ ) and spots 2136 (the same 
A

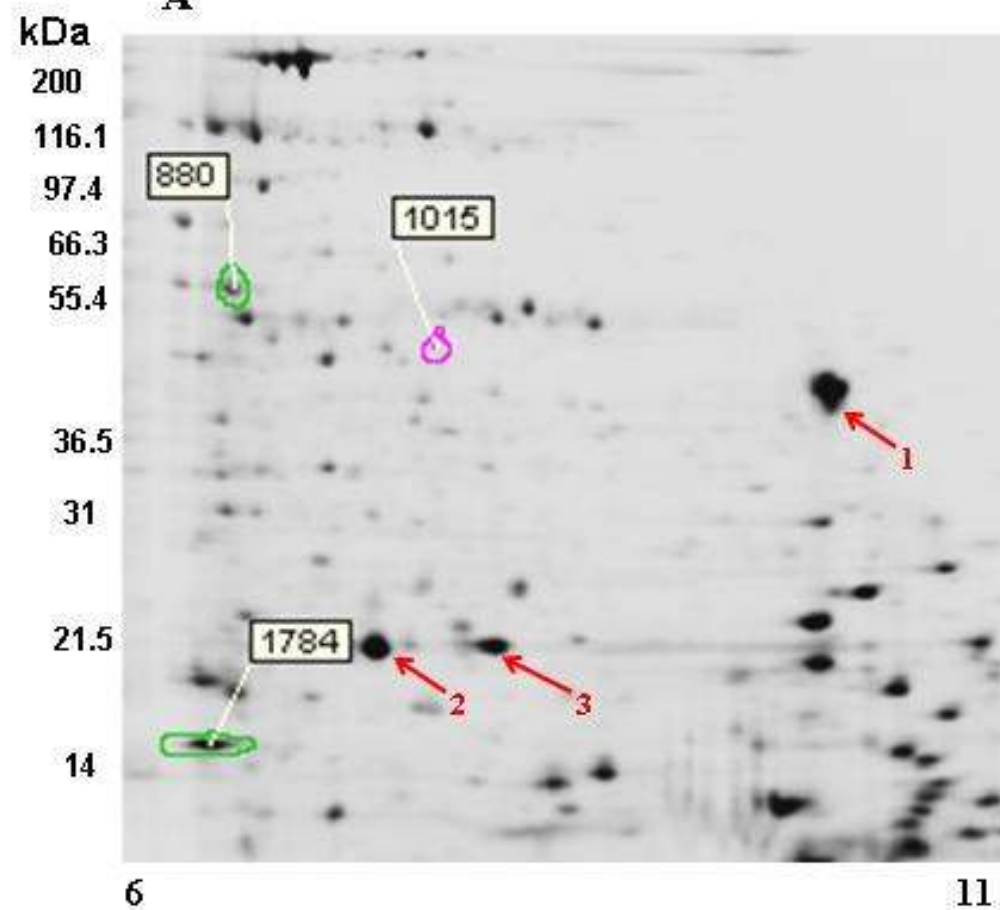

B

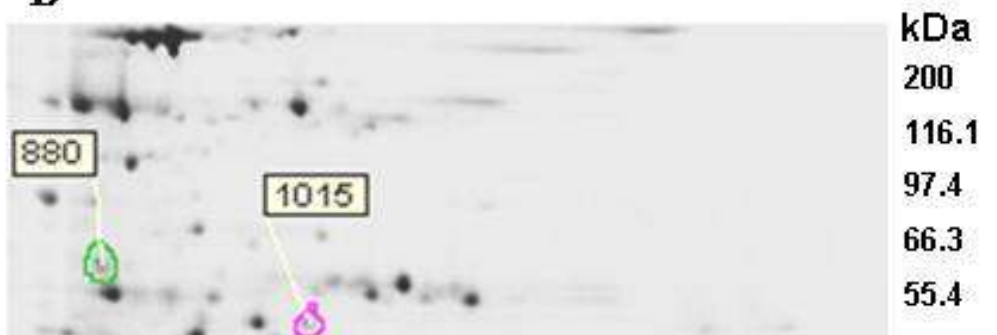

116

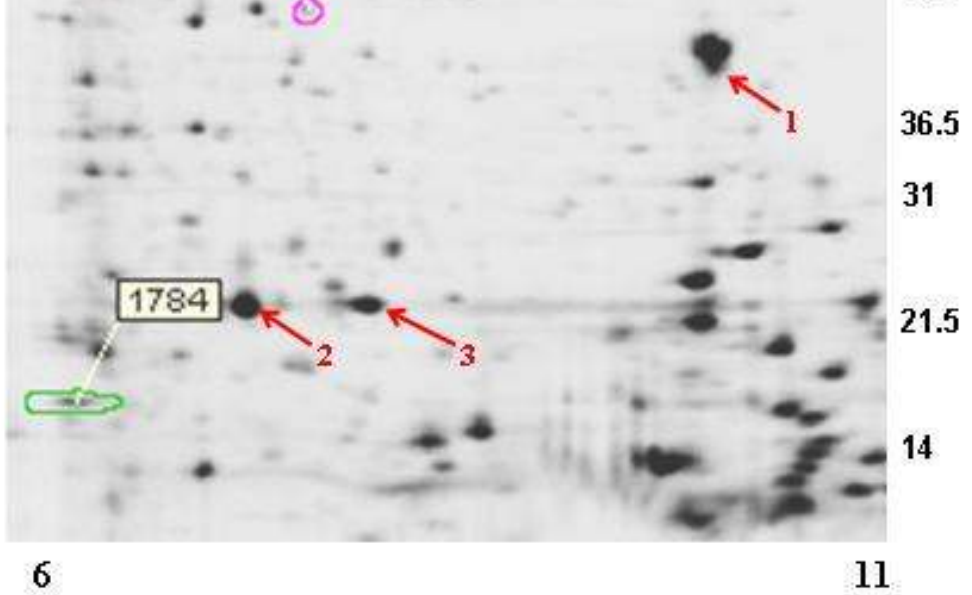

11

Isoelectric point (linear gradient pH 6-11)

Figure 5.14 2-D DIGE images for the linear gradient pI 6-11 range showing protein profiles of $\mathrm{Y}^{\mathrm{T}}{ }^{\mathrm{T}}$ cells grown to a high $\mathrm{OD}_{600}$ at $\mathrm{DO}^{\text {low }}$ or $\mathrm{DO}$ high at constant $\mathrm{pH} 7$. Cells were grown to an $\mathrm{OD}_{600}$ of approximately 2.0 under DOlow (A) or DOhigh (B) conditions. Spot numbers (excluding those marked with red arrows) represent proteins determined by BVA analysis to have significantly altered abundance between the two DO concentrations. Spots marked by red arrows represent PHB synthesis proteins PhaP (spot 1 ) and two potential forms of PhbB with different pIs (spots 2, 3), (n=3). 


\begin{tabular}{|c|c|c|c|c|c|c|c|c|c|}
\hline \multirow[t]{2}{*}{$\begin{array}{l}\text { Spot } \\
\text { number }\end{array}$} & \multirow[t]{2}{*}{ Protein ID } & \multicolumn{2}{|c|}{$\mathrm{Do}^{\text {low }} / \mathrm{DO}^{\text {high }}$} & \multirow[t]{2}{*}{$\begin{array}{l}\text { Highest scoring unique peptides } \\
\text { matched (peptide score) }\end{array}$} & \multirow[t]{2}{*}{$\mathbf{M}_{\mathbf{r}}$} & \multirow[t]{2}{*}{ Score } & \multirow[t]{2}{*}{$\begin{array}{l}\text { Queries } \\
\text { matched }\end{array}$} & \multirow[t]{2}{*}{ pl } & \multirow[t]{2}{*}{$\begin{array}{c}\text { Sequence } \\
\text { coverage (\%) }\end{array}$} \\
\hline & & $\begin{array}{l}\text { Average } \\
\text { Ratio }\end{array}$ & $\begin{array}{l}t \text {-test } \\
\text { value }\end{array}$ & & & & & & \\
\hline \multirow[t]{2}{*}{880} & Nitrogenase molybdenum-iron protein a-chain (NifD) & 2.39 & $0.010^{*}$ & M.SVSTPTTIQEVK.D(60) & 56185 & 171 & 7 & 6.3 & 3 \\
\hline & & & & R.SMNYISR.H(38) & - & - & - & - & - \\
\hline 1015 & $\mathrm{NI}$ & -3.49 & $0.016^{\star *}$ & - & - & - & - & - & - \\
\hline \multirow[t]{2}{*}{1784} & Outer membrane protein (OmpW) & 2.32 & $0.032^{* *}$ & K.LLATGVLADGNIDTVR.S(92) & 25096 & 735 & 13 & 9.1 & 10 \\
\hline & & & & K.TPYSLTFDAK.K(71) & - & - & - & - & - \\
\hline
\end{tabular}

Table 5.6 2-D DIGE protein spot analysis (pH 6-11) and LC-MS/MS analysis of protein from cells grown at DOlow or DOhigh at constant $\mathrm{pH}$

2-D DIGE analysis of protein spots in the linear gradient pI 6-11 range that were determined by BVA analysis to be significantly altered between DOlow or DOhigh concentrations at constant $\mathrm{pH}$ or high $\mathrm{OD}_{600}(2.0)$. For those spots denoted by ${ }^{*} \mathrm{p}<0.01$ otherwise $\left.\mathrm{p}<0.05{ }^{* *}\right)$. Positive values represent increased abundance of proteins at DOlow and negative values represent increased abundance of proteins at DOhigh. NI=protein not identified. 
$M_{r}$ ) on the pI 4-7 gels (Fig. 5, 12). Since this protein occurred at the same $M_{r}$ at the extreme $\mathrm{pH} 7$ end of the $\mathrm{pH} 4-7$ gel (spot 2136, Fig. 5.12) and then again at the same $\mathrm{M}_{\mathrm{r}}$ between $\mathrm{pH}$ 6-7 on the $\mathrm{pH}$ 6-11 gel (spot 1784, Fig. 5.14), this was clearly an overlap of the same protein in the corresponding section of the two different $\mathrm{pI}$ ranges.

Spot 1015 (Fig. 5.14) showed a 3.5-fold decrease (Table 5.6) at DOhigh at approximately $50 \mathrm{kDa}$ and $\mathrm{pI}$ 7.5. No identification could be obtained for this spot due to its very low abundance.

\subsubsection{Comparison of protein profiles obtained for DOlow or DOhigh conditions at low cell densities $\left(\mathrm{OD}_{600}=0.5\right), \mathrm{pH}$ controlled}

To determine whether the altered abundance of $Y 88^{\mathrm{T}}$ proteins between DOlow or DOhigh conditions were due to the differences in sustained DO levels at high $\mathrm{OD}_{600}$ or whether they were part of the regulatory network of changes associated with changes from low to high growth, proteomic signatures were obtained for $\mathrm{Y}^{8} 8^{\mathrm{T}}$ cells subjected to different DO concentrations at the low $\mathrm{OD}_{600}$ of 0.5 .

\subsection{Acidic proteins}

As with extracts from cells grown to $\mathrm{OD}_{600}=2.0$, approximately 200 protein spots were present in the linear gradient pI 4-7 range (Fig. 5.15). Of these, approximately 70 occurred in high abundance. BVA analysis determined that six proteins were significantly altered between $\mathrm{DO}^{\text {low }}$ and $\mathrm{DO}^{\text {high }}$ at low $\mathrm{OD}_{600}$. Three of these were the same proteins that previously showed altered abundance between DOlow and DOhigh at high $\mathrm{OD}_{600}$. Since at low $\mathrm{OD}_{600}$, ammonium would still have been available in the medium, it was not surprising that no nitrogen fixation proteins were expressed with either DOlow or DOhigh.

AdoHcyase was identified in two adjacent spots, 1318 and 1326 (Fig. 5.15), both of which were upregulated at DOhigh with a 2.4-fold increase in abundance in spot $1318(t$-test $=0.01)$ and a 2.5 -fold increase in abundance in spot $1326(t$ - 


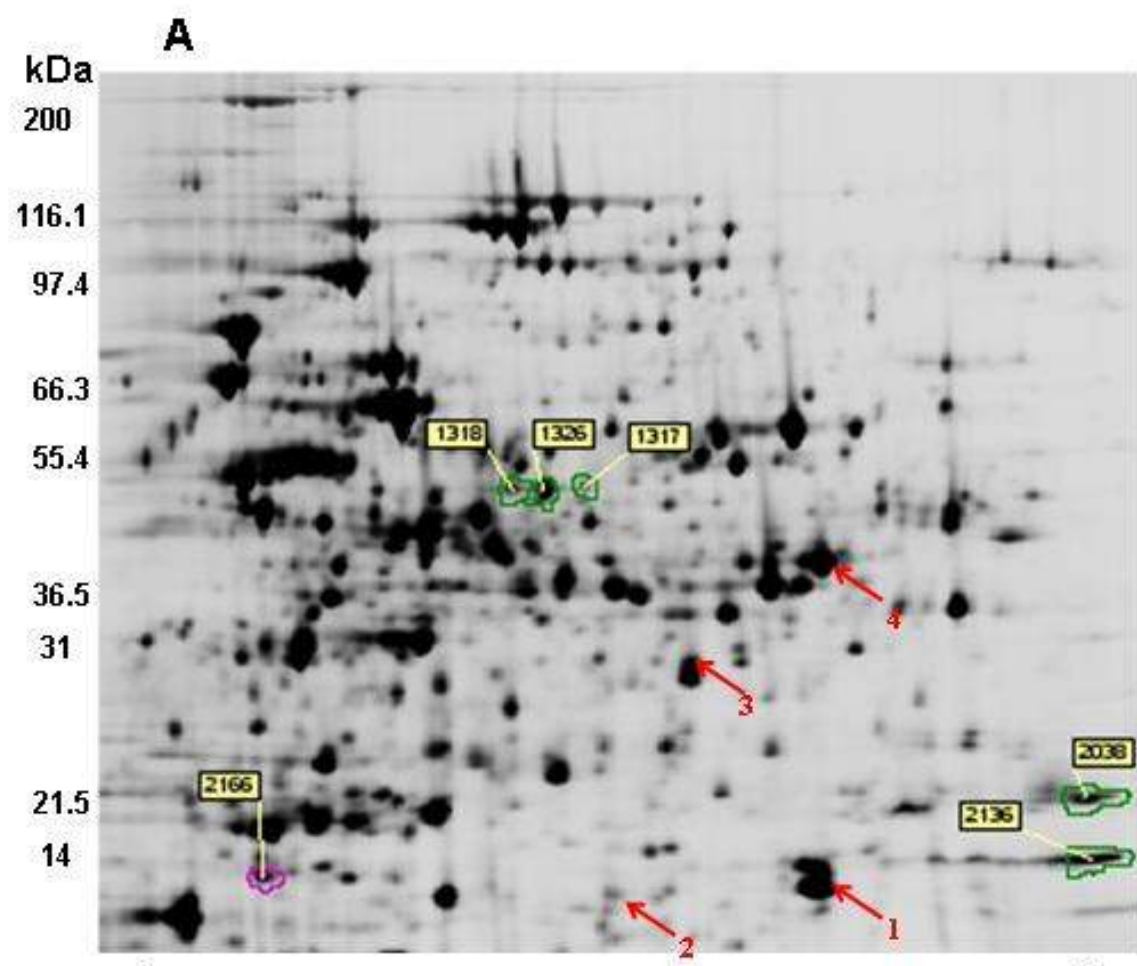

4

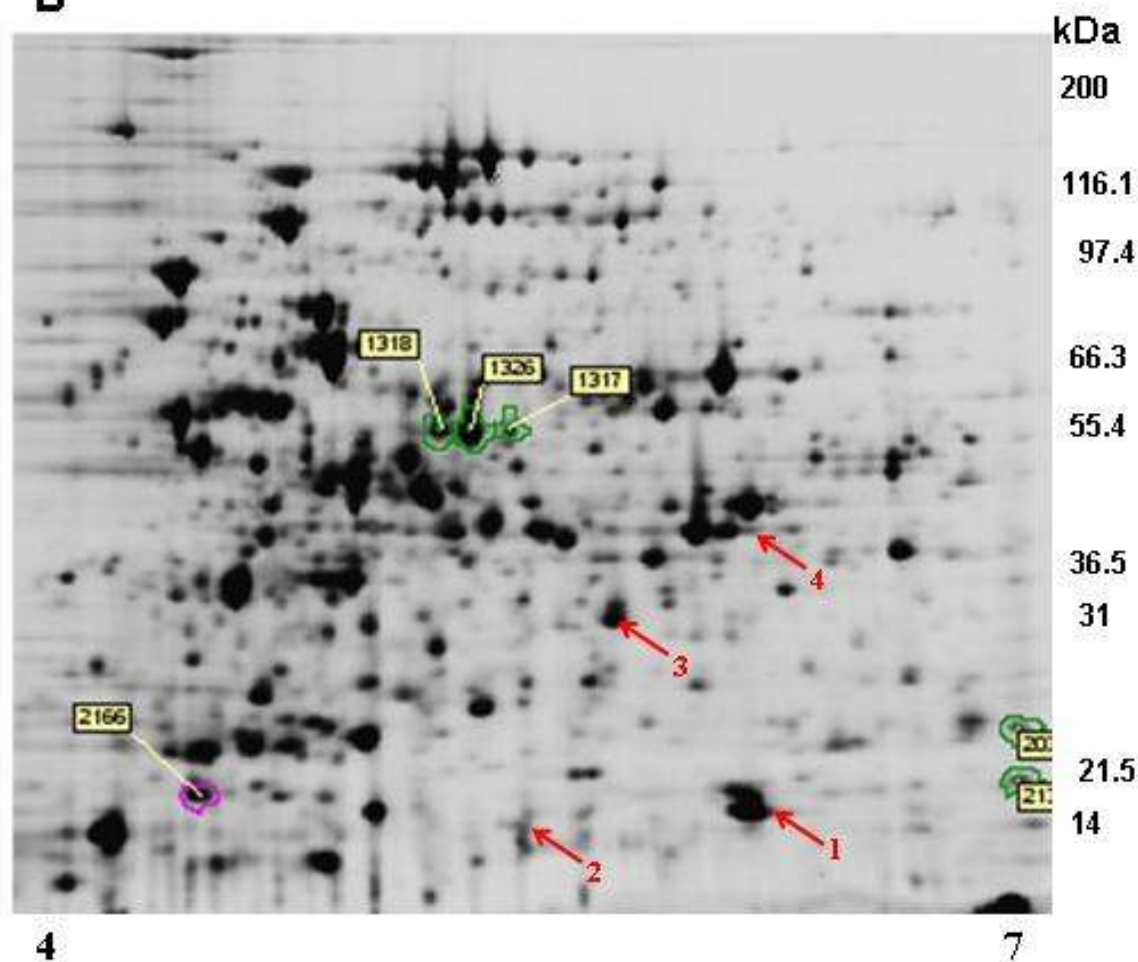

Isoelectric point (linear gradient $\mathrm{pH}$ 4-7)

Figure 5.15 2-D DIGE images (pI 4-7) showing protein profiles of $\mathrm{Y}^{8} 8^{\mathrm{T}}$ cells grown to a low $\mathrm{OD}_{600}$ under ammonium-depleted conditions at DOlow or DOhigh at constant $\mathrm{pH} 7$

Cells were grown to an $\mathrm{OD}_{600}$ of 0.5 under DOlow $(\mathrm{A})$ or DOhigh $(\mathrm{B})$ conditions. Spot numbers (excepting those marked with red arrows) represent proteins determined by BVA analysis to have significantly altered abundance between the two DO concentrations. Spots 1 through 4 represent PHB synthesis proteins. ॐ 
test=0.003) (Table 5.7). A third spot (spot 1317) in this "train" of spots was only tentatively identified as AdoHcyase (one peptide matched in 3 separate experiments). Since this protein is upregulated at both high and low growth at DOhigh regardless of the $\mathrm{pH}$, its altered abundance can be attributed to a response to DOhigh. The fact that it appears in two adjacent spots at the same $\mathrm{Mr}_{\mathrm{r}}$ but slightly different pIs, suggests that spot 1318 may be a phosphorylated form of the protein appearing in spot 1326 as discussed before (Chapter 5 section 5.2.1.3.4). The same can be said for spot 1317. Notably, AdoHcyase was expressed at higher abundance on all gels representing the Fix ${ }^{\text {off }}$ state relative to those for the Fix on state, regardless of extracellular $\mathrm{pH}$ or DO conditions. Thus the enhanced abundance of AdoHcyase generally may be related to the nitrogen source since nitrogen source is known to affect the accumulation of AdoMet (Yu et al., 2003). The induction of phosphorylated forms of AdoHcyase in $\mathrm{Y}^{8} 8^{\mathrm{T}}$ may be more related to DOhigh concentrations.

\subsection{Basic proteins}

Only one spot was determined by BVA analysis to be significantly altered in the linear gradient pI 6-11 range at low $\mathrm{OD}_{600}$ and at $\mathrm{DO}^{\text {low }}$ compared to that at low $\mathrm{OD}_{600}$ but at DOhigh (Fig.5.16, Table 5.8). Spot 1784, previously identified to be OmpW, was 2.8-fold more abundant $(t$-test=0.034) at low OD 600 for the state of the cells at DOlow relative to DOhigh (Table 5.8, Fig. 5.16). Once again, peptide matches to this protein confirmed that OmpW identified in spot 1784 was the same protein identified in spot 2036 on the pI 4-7 gel (Section 5.2.1.5.7 and Fig. $5.14)$.

PhaP and PhbB were once again observed to be abundant at the same $\mathrm{pI}$ and $\mathrm{M}_{\mathrm{r}}$ in two spots (Fig. 5.16) as in the profile of PHB synthesis proteins observed in the linear gradient $\mathrm{pH}$ 6-11 range for low $\mathrm{OD}_{600}$ or high $\mathrm{OD}_{600}$ at $\mathrm{DO}^{\text {low }}$ or DOhigh with pH controlled (Figs. 5.14). Spot 1 had high-scoring peptide matches to PhaP. Spots 2 and 3 had high-scoring peptide matches to PhbB. The peptides matching spot 1 (Fig. 5.16) matched the entire PhaP sequence predicted from the $\mathrm{Y} 88^{\mathrm{T}}$ genome which included peptide matches across the entire N-terminus 


\begin{tabular}{|c|c|c|c|c|c|c|c|c|c|}
\hline \multirow[t]{2}{*}{$\begin{array}{l}\text { Spot } \\
\text { number }\end{array}$} & \multirow[t]{2}{*}{ Protein ID } & \multicolumn{2}{|c|}{$\mathrm{Do}^{\text {low }} / \mathrm{DO}^{\text {high }}$} & \multirow[t]{2}{*}{$\begin{array}{l}\text { Highest scoring unique peptides matched } \\
\text { (peptide score) }\end{array}$} & \multirow[t]{2}{*}{$\mathbf{M}_{\mathbf{r}}$} & \multirow[t]{2}{*}{ Score } & \multirow[t]{2}{*}{$\begin{array}{l}\text { Queries } \\
\text { matched }\end{array}$} & \multirow[t]{2}{*}{ pl } & \multirow[t]{2}{*}{$\begin{array}{l}\text { Sequence } \\
\text { coverage }(\%)\end{array}$} \\
\hline & & $\begin{array}{l}\text { Average } \\
\text { Ratio }\end{array}$ & $\begin{array}{l}t \text {-test } \\
\text { value }\end{array}$ & & & & & & \\
\hline 1317 & $\mathrm{NI}$ & -2.88 & $0.023^{\star *}$ & - & - & - & - & - & - \\
\hline \multirow[t]{2}{*}{1318} & $\begin{array}{l}\text { Adenosylhomocysteinase (S- } \\
\text { adenosylhomocysteine hydrolase, AdoHcy) }\end{array}$ & -2.39 & $0.011^{*}$ & K.VACVAGFGDVGK.G(80) & 50877 & 788 & 38 & 5.33 & 20 \\
\hline & & & & R.DEFGPTQPLK.G(47) & - & - & - & - & - \\
\hline \multirow[t]{3}{*}{1326} & $\begin{array}{l}\text { Adenosylhomocysteinase (S- } \\
\text { adenosylhomocysteine hydrolase, AdoHcy) }\end{array}$ & -2.52 & $0.0027^{* *}$ & R.TANLILDDGGDATMFALWGAR.V(138) & 50877 & 14979 & 631 & 5.33 & 66 \\
\hline & & & & R.VVVTEIDPICALQAAMEGYEVVTMEEAVKR.A(92) & - & - & - & - & - \\
\hline & & & & R.VEAGETLPEPANAEEIEFQR.A(97) & - & - & - & - & - \\
\hline 2038 & OmpW & 2.17 & $0.0019^{*}$ & R.AEIAIAETEMPGLMALR.D(87) & 25096 & 851 & 16 & 9.1 & 10 \\
\hline \multirow[t]{2}{*}{2136} & OmpW & 2.14 & $0.017^{\star *}$ & K.LLATGVLADGNIDTVR.S(94) & 25096 & 251 & 6 & 9.1 & 4 \\
\hline & & & & K.TPYSLTFDAK.K(71) & & & & & \\
\hline \multirow[t]{2}{*}{2166} & $\begin{array}{l}\text { Alkyl hydroperoxide reductase/ Thiol specific } \\
\text { antioxidant/ Mal allergen (AhpC) }\end{array}$ & -2.01 & $0.02^{*}$ & K.ATAEGNEAVQSADYFAGK.K(83) & 16726 & 465 & 21 & 4.84 & 23 \\
\hline & & & & M.TIAVGDKLPDVK.L(62) & - & - & - & - & - \\
\hline
\end{tabular}

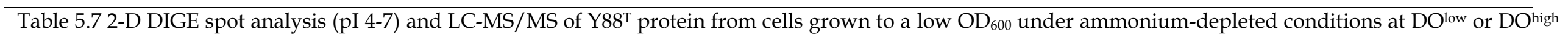
at constant $\mathrm{pH} 7$.

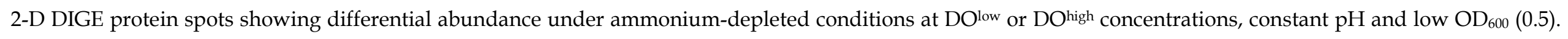

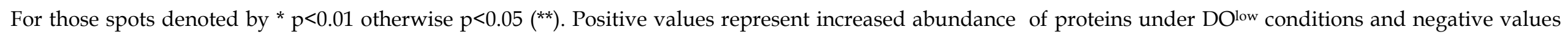
जे represent increased abundance of proteins under DOhigh conditions. 
A

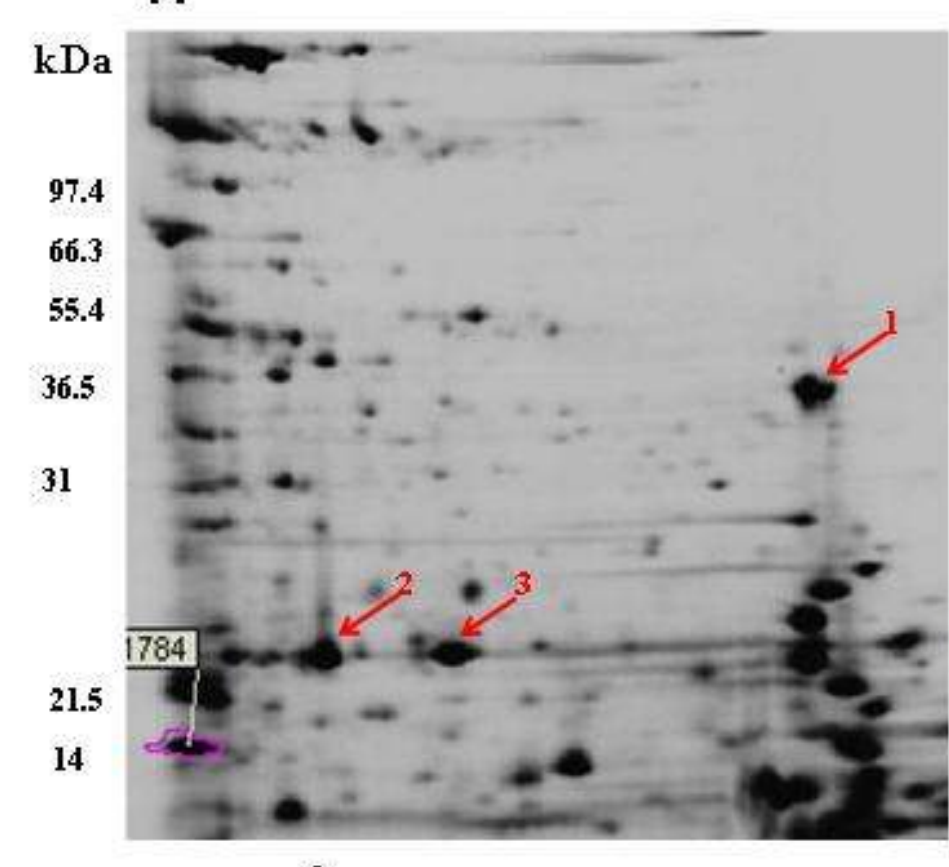

6
B

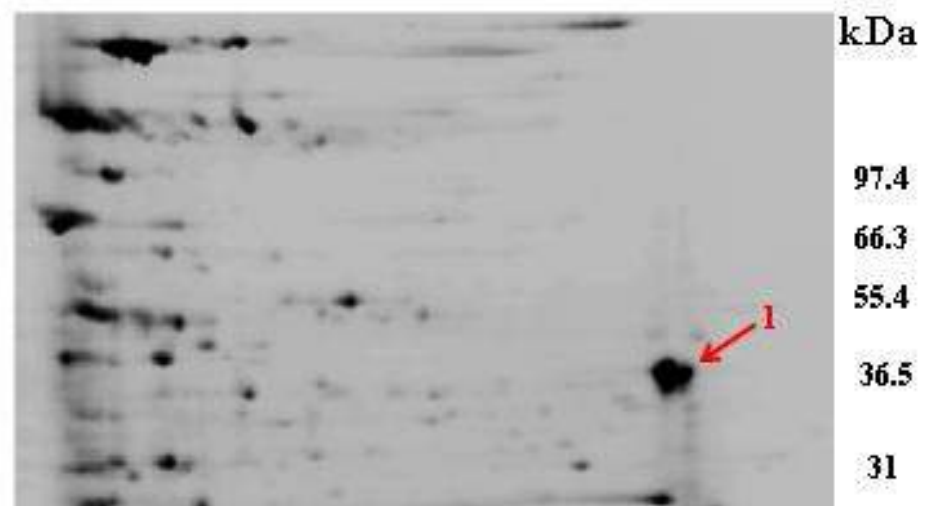

116

11

Isoe lec tric point (linear gradient $\mathrm{p}$ H 6-11)

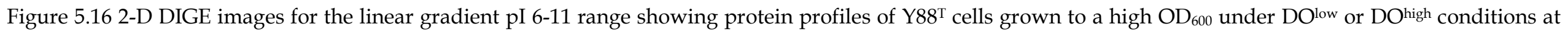
constant $\mathrm{pH} 7$.

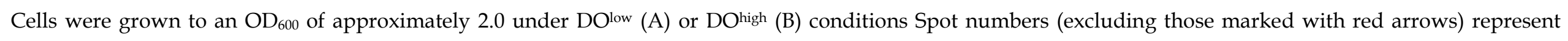

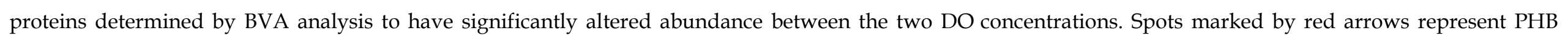
synthesis proteins PhaP (spot 1) and two potential forms of PhbB with different pIs (spots 2, 3), $(n=3)$. 


\begin{tabular}{|c|c|c|c|c|c|c|c|c|c|}
\hline \multirow[t]{2}{*}{ Spot number } & \multirow[t]{2}{*}{ Protein ID } & \multicolumn{2}{|c|}{$\mathrm{Do}^{\text {low }} / \mathrm{DO}^{\text {high }}$} & \multirow[t]{2}{*}{$\begin{array}{l}\text { Highest scoring unique peptides matched } \\
\text { (peptide score) }\end{array}$} & \multirow[t]{2}{*}{$\mathbf{M}_{\mathrm{r}}$} & \multirow[t]{2}{*}{ Score } & \multirow[t]{2}{*}{$\begin{array}{l}\text { Queries } \\
\text { matched }\end{array}$} & \multirow[t]{2}{*}{ pl } & \multirow[t]{2}{*}{$\begin{array}{l}\text { Sequence } \\
\text { coverage (\%) }\end{array}$} \\
\hline & & $\begin{array}{l}\text { Average } \\
\text { Ratio }\end{array}$ & $\begin{array}{l}t \text {-test } \\
\text { value }\end{array}$ & & & & & & \\
\hline \multirow[t]{2}{*}{1784} & OmpW & 2.18 & $0.034^{* *}$ & K.LLATGVLADGNIDTVR.S(94) & 25096 & 851 & 16 & 9.1 & 10 \\
\hline & & & & K.TPYSLTFDAK.K(71) & - & - & - & - & - \\
\hline
\end{tabular}

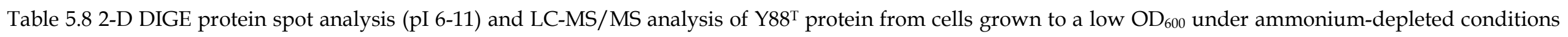
at $\mathrm{DO}^{\text {low }}$ or DOhigh at constant $\mathrm{pH} 7$

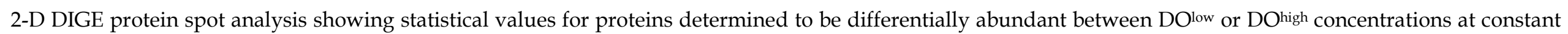

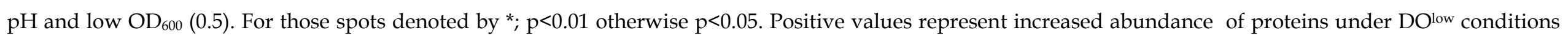
and negative values represent increased abundance of proteins under DOhigh conditions. 
and C-terminus. The peptides matching the N-terminus segment of this high $\mathrm{M}_{\mathrm{r}}$ form of PhaP were unique to this spot and were never matched in the lower $\mathrm{M}_{\mathrm{r}}$ form at the more acidic pI. The relevance of these findings is discussed in Chapter 6.

\subsection{Summary}

The proteomic signatures described for $\mathrm{Y}^{8} 8^{\mathrm{T}}$ nitrogen fixation and $\mathrm{PHB}$ accumulation confirmed that there was no coordinated regulation of PHB and nitrogen-fixing proteins in $\mathrm{Y} 88^{\mathrm{T}}$. The microbiology of $\mathrm{Y}^{8} 8^{\mathrm{T}}$ confirms that $\mathrm{Y} 88^{\mathrm{T}}$ produces copious amounts of PHB irrespective of DO concentrations, changing nitrogen concentrations in the culture supernatant, $\mathrm{pH}$ conditions, and assayable acetylene reduction assay or an alternative mechanism for nitrogenase activity.

Concomitantly, PHB synthesis proteins and phasins occurred in high abundance on all gels irrespective of the growth conditions or whether cells were at low $\mathrm{OD}_{600}$ or high $\mathrm{OD}_{600}$. Since these proteins are among the most abundant proteins on the gel at all times, core metabolic activities appear to support PHB production regardless of the growth conditions. Consistent with this, essentially all the proteins that show unaltered abundance are associated with core carbon metabolism. Those that that did show altered abundance, such as the OmpA or OmpW proteins, may be involved in specialised activities associated with membrane changes and/or iron regulation that may be heightened under conditions conducive to nitrogen fixation. Others, such as AdoHcyase, may have increased regulated activity related to stress under higher DO conditions.

The proteins involved in nitrogen fixation were all abundant at DOlow but showed decreased abundance at DOhigh. Consistent with the nitrogenase enzyme's lability under high oxygen concentrations, in $\mathrm{Y}^{8} 8^{\mathrm{T}}$, the different nitrogenase components were present at extremely low abundance at DOhigh, which correlates with the decreased ethylene peak observed at DOhigh (Fig. 5.1D). Thus, it cannot be ruled out that there is a residual level of nitrogenase 198 
activity in these cells. Whether any possible remaining nitrogenase activity is sufficient to sustain very low levels of nitrogen fixation is not certain. Nonetheless, despite this decrease in nitrogenase activity, $\mathrm{Y}^{\mathrm{T}} 8^{\mathrm{T}}$ apparently continued to accumulate similar amounts of $\mathrm{PHB}$ and fixed nitrogen irrespective of DO concentrations. Interestingly, examination of the $\mathrm{Y}^{8} 8^{\mathrm{T}}$ genome revealed that $Y 88^{\mathrm{T}}$ possesses a gene encoding the NifW protein that is considered to be a part of the oxygen-protection complex that may involve the reversible inactivation of nitrogenase via a conformational change, thereby protecting the enzyme from oxygen (Moshiri et al., 1995; Kim \& Burgess, 1996; Lee et al., 1998; Ureta \& Nordlund, 2002); however, this gene product was never identified proteomically. Irrespective of the mechanism that may result in a low level of nitrogenase at DOhigh concentration, nitrogen levels are no different relative to those at DOlow, nor is PHB production limited. This is evident despite the fact that at DOhigh, Y88 ${ }^{\mathrm{T}}$ uses glucose less efficiently although the increased consumption of glucose may be part of a more efficient oxygen protective mechanism in promoting increased respiration (Post et al., 1983) and subsequent carbon dioxide production. 


\section{Chapter 6: Bioinformatic analysis of post-translational modifications and primary and secondary structure of selected $\mathrm{Y}^{8} 8^{\mathrm{T}}$ nitrogenase and $\mathrm{PHB}$ synthesis proteins}

\subsection{Introduction}

Proteins can be post-translationally modified in a large number of ways. These modifications can be identified using various mass spectrometric techniques (Larsen \& Roepstorff, 2000; Reinders et al., 2004; Rosen et al., 2004; Ekman et al., 2008; Philmus et al., 2008). Generally, a difference in a protein's observed $M_{r}$ and/or $\mathrm{pI}$ on 2-D gels relative to its predicted $\mathrm{M}_{\mathrm{r}}$ and/or $\mathrm{pI}$ is suggestive of one or more potential modifications. For instance, proteins migrating at lower than expected $\mathrm{M}_{\mathrm{r}}$ are often the result of truncation of their $\mathrm{C}$ - or N-termini. Likewise, pI shifts of protein spots to more acidic isoelectric points on 2-D gels can be caused by protein phosphorylation.

The identification of the nitrogenase and phasin proteins of $\mathrm{Y}^{\mathrm{T}} \mathrm{T}$ on 2-D gels with unpredicted migration positions (Chapter 5) suggested that these proteins may be modified in a way that changed their isoelectric points and their molecular weights, resulting in mobility shifts. Given the differences in migration patterns of the $\mathrm{Y}^{\mathrm{T}} 8^{\mathrm{T}} \mathrm{NifH}, \mathrm{NifD}$ and phasin proteins from in silico predictions based on the $Y 88^{\mathrm{T}}$ genome sequence, it was hypothesised that there may be primary and/or secondary structure differences that may explain these anomalies. In an attempt to identify any possible modification(s) in the $\mathrm{Y}^{8} 8^{\mathrm{T}}$ nitrogenase and phasin that could explain the 2-D gel migration anomalies, their sequences were compared to orthologous proteins in a phylogenetic analysis to map known modification sites from other species that were potentially conserved in $\mathrm{Y}^{8} 8^{\mathrm{T}}$. MS peptide data were then examined for evidence of similar modifications in these $\mathrm{Y} 88^{\mathrm{T}}$ proteins. The significance of the potential modifications in terms of the biology of $Y 88^{\mathrm{T}}$ was also considered. 
Analysis of the protein sequences of the $Y 88^{\mathrm{T}}$ nitrogenase and phasin determined that: i) NifK (nitrogenase component I $\beta$-subunit), NifD (nitrogenase component I $\alpha$-subunit) and $\mathrm{NifH}$ (nitrogenase component II) contain highly conserved sequences, including amino acid residues known to be integral to Fe-S cluster assembly and thought to be the site of nitrogenase reduction during nitrogen fixation; ii) a peptide match from the $\mathrm{NifH}$ protein observed at higher $\mathrm{M}_{\mathrm{r}}$ and $\mathrm{pI}$ than the predicted $\mathrm{Y}^{\mathrm{T}} 8^{\mathrm{T}} \mathrm{NifH}$ protein under acidic growth conditions was a sequence known to be highly conserved and modified post-translationally in other nitrogen-fixing bacteria (Section 6.2.1.1) (Pope et al., 1985; Ekman et al., 2008); iii) the $\mathrm{Y}^{8} 8^{\mathrm{T}} \mathrm{NifH}$ may be susceptible to a different type of modification to those generally observed in other nitrogen-fixing bacteria; iv) the $\mathrm{Y} 88^{\mathrm{T}}$ phasin has a low complexity, 199 amino acid alanine- and proline-rich N-terminal segment that is not found in phasins of most other PHA-producing bacteria, but is similar to four other sphingomonad phasins, suggesting that this may be a distinguishing feature of this family (Section 6.2.2.1); v) the $\mathrm{Y} 88^{\mathrm{T}}$ phasin may be modified post-translationally, resulting in cleavage of the 199 amino acid N-terminus as well as two potentially modified forms with lower $\mathrm{M}_{\mathrm{r}}$ and different pIs to that of the predicted $\mathrm{Y} 88^{\mathrm{T}}$ phasin; vi) the $\mathrm{Y} 88^{\mathrm{T}}$ phasin has several amphipathic $\alpha$-helices in its C-terminal half, a feature that has been identified in other phasins and is suggested here to be the reason why no common PHA-binding domain has been reported in phasins generally.

\subsection{Results}

\subsubsection{Amino acid sequence analysis of the nitrogenase protein of $\mathrm{YB8}^{\mathrm{T}}$}

\subsubsection{NifH}

A CLUSTALW (1.83) multiple sequence alignment of the $\mathrm{Y}^{\mathrm{T}} \mathrm{N} \mathrm{NifH}$ protein sequence with $20 \mathrm{NifH}$ sequences from other bacteria, (Table 6.1, Fig. 6.1), showed highly conserved regions spanning the entire sequence among all the $\mathrm{NifH}$ sequences examined. The most highly conserved portion of the NifH sequence, CVESGGPEPGVGCAGR (Fig. 6.1, amino acid sequence 


\begin{tabular}{|c|c|c|}
\hline Accession number & Species & $\begin{array}{c}\text { Truncated species name as } \\
\text { it appears in NifH sequence } \\
\text { alignment }\end{array}$ \\
\hline ref|YP_001600720.1| & $\begin{array}{l}\text { Gluconacetobacter diazotrophicus } \\
\text { PAl } 5\end{array}$ & Gluco \\
\hline ref | NP_659736.1| & Rhizobium etli CFN 42 & Ensifermexicanus \\
\hline emb|CAD31326.1। & Mesorhizobium loti & Meso \\
\hline gb | ACF19771.1। & Aminobacter sp. BA135 & Aminobactersp \\
\hline ref | NP_659736.1 | & Rhizobium etli CFN 42 & Rhizobiumsp \\
\hline gb |ACF19777.1। & Mesorhizobium sp. ML105 & Meso2 \\
\hline $\mathrm{gb}|\mathrm{ACM} 01736.1|$ & Rhodobacter sphaeroides KD131 & Rhodobacterspaeroides \\
\hline gb |AAB02342.1 | & Azospirillum brasilense & Azosp \\
\hline gb | ABG74606.1 | & Sinorhizobium fredii & Sinorhizobiumfredii \\
\hline gb | AAG60754.1 | AF322012_59 & $\begin{array}{l}\text { Bradyrhizobium japonicum } \\
\text { USDA } 110\end{array}$ & Bradylia \\
\hline gb |ACF15255.1। & Bradyrhizobium yuanmingense & Bradyyuan \\
\hline gb |ACF15253.1। & Bradyrhizobium elkanii & Bradyrhizobiumelkanii \\
\hline gb|ACI23531.1| & Bradyrhizobium canariense & Bradcana \\
\hline gb|ACI46147.1| & Azorhizobium doebereinerae & Azorhizobiumdoebereinerae \\
\hline NA & & Y88 \\
\hline gb|AAT06095.1। & Burkholderia sp. Br3469 & Burkholderiasp \\
\hline dbj|BAE71134.1 | & Sphingomonas azotifigens & Sphinogazob \\
\hline gb|ABP79021.1| & $\begin{array}{l}\text { Pseudomonas stutzeri } \\
\text { A1501 }\end{array}$ & Pseudomonasstut \\
\hline gb | ABU49158.1 | & Azotobacter vinelandii & Azoto \\
\hline emb|CAD56230.1। & Paenibacillus durus & Paenibacillus \\
\hline gb|AAX73206.21 & Paenibacillus massiliensis & Paenibacillusmaa \\
\hline
\end{tabular}

Table 6.1 Bacterial species names and the corresponding abbreviated names in the NifH alignment with Y88 ${ }^{\mathrm{T}}$ (Fig. 6.1).

No accession number (NA) yet for $\mathrm{Y}^{8} 8^{\mathrm{T}}$. P. durus and P. massiliensis (dinitrogenase MoFe-alpha component) are outgroup sequences. 


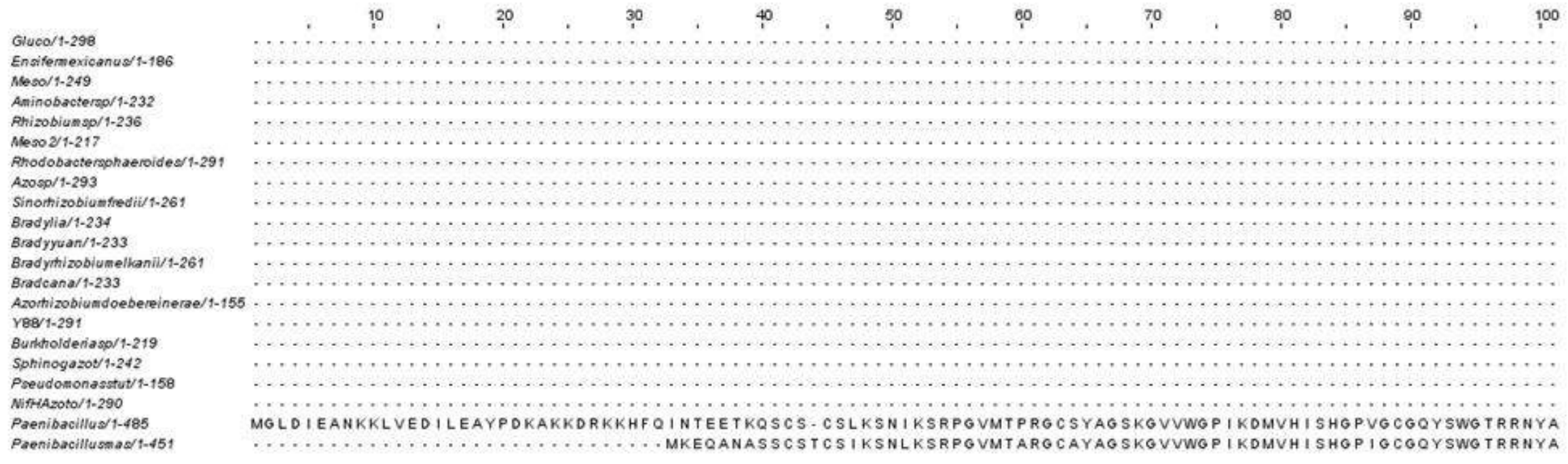

Conservation

Quality

Consensus

Figure 6.1 CLUSTALW (1.83) multiple sequence alignment of the $\mathrm{Y}^{8} 8^{\mathrm{T}} \mathrm{NifH}$ protein sequence with $20 \mathrm{NifH}$ sequences from other bacteria (Table 6.1)

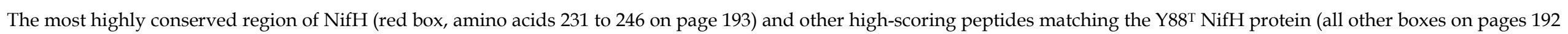

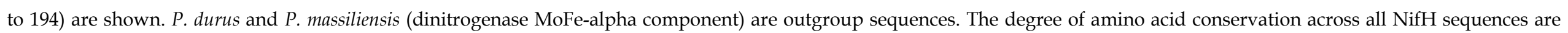

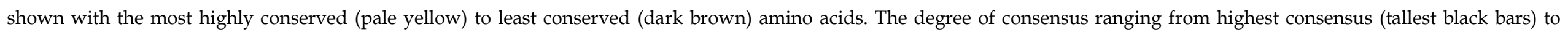

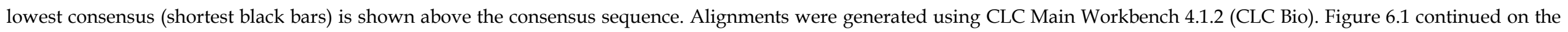
following page. See Table 6.1 for full species names. 


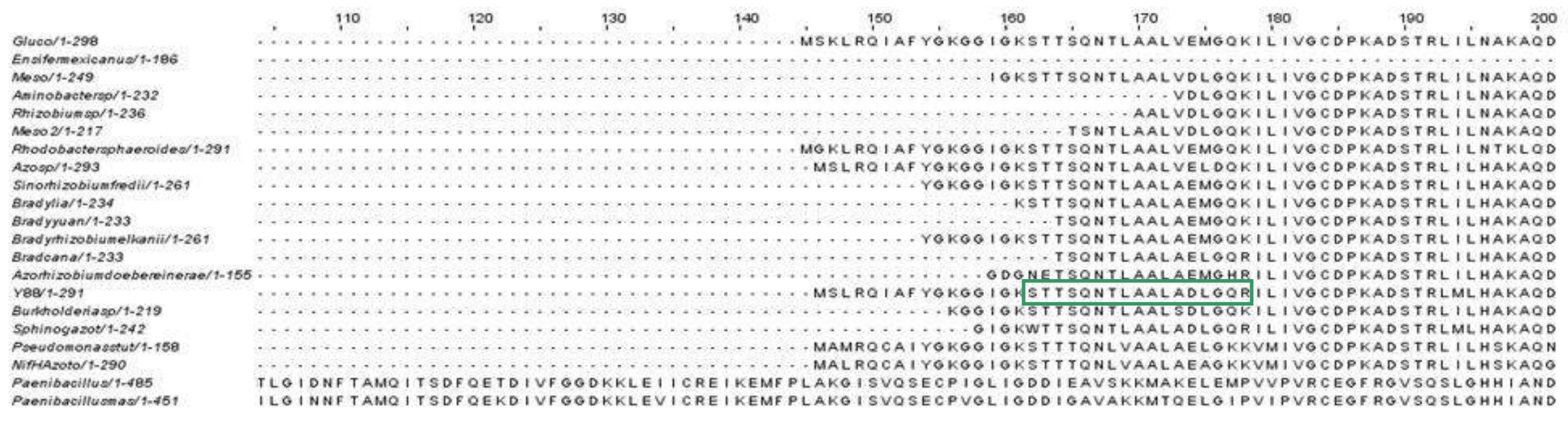

Conservation

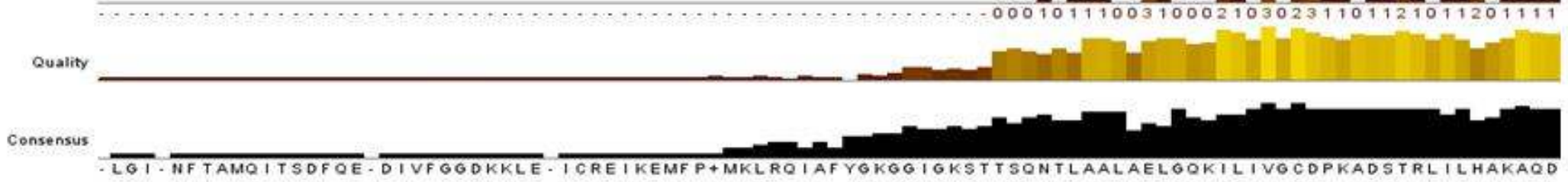

Figure 6.1 (cont.) CLUSTALW (1.83) multiple sequence alignment of the Y88 NifH protein sequence with 20 NifH sequences from other bacteria (Table 6.1)

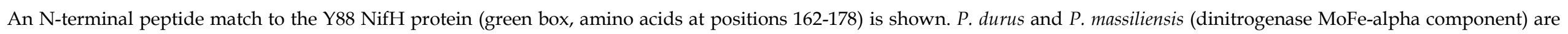

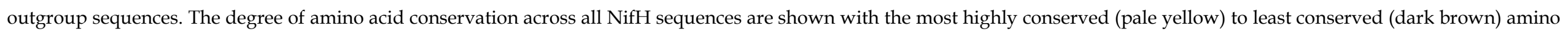

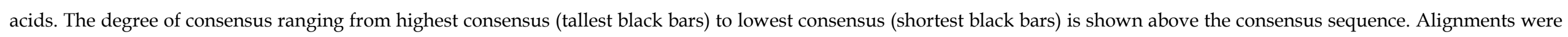
generated using CLC Main Workbench 4.1.2 (CLC Bio). Figure 6.1 continued on the following page. See Table 6.1 for full species names. 


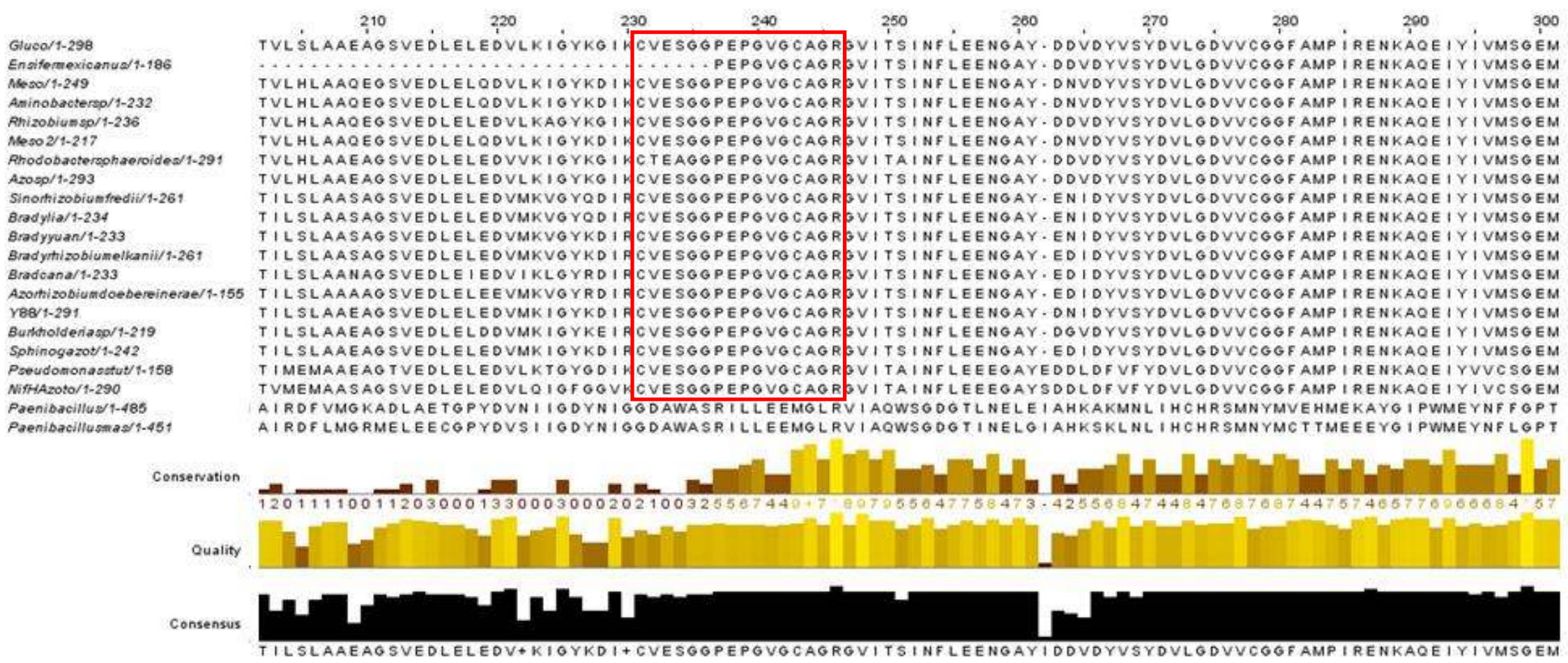

Figure 6.1 (cont.) CLUSTALW (1.83) multiple sequence alignment of the Y88 NifH protein sequence with 20 NifH sequences from other bacteria (Table 6.1)

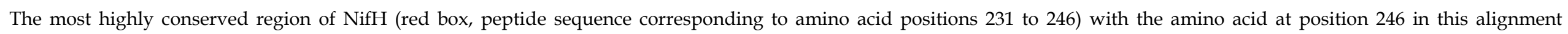

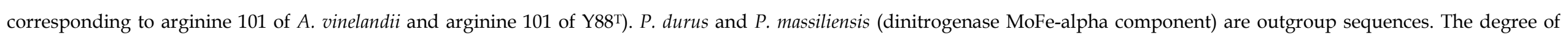

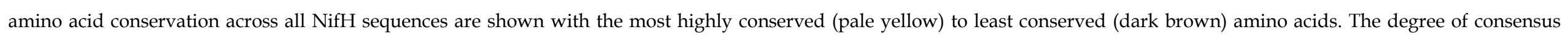

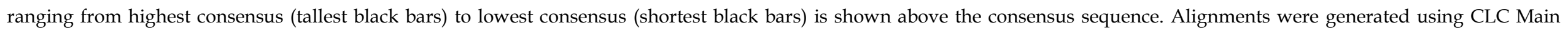
Workbench 4.1.2 (CLC Bio). Figure 6.1 continued on the following page. See Table 6.1 for full species names. 


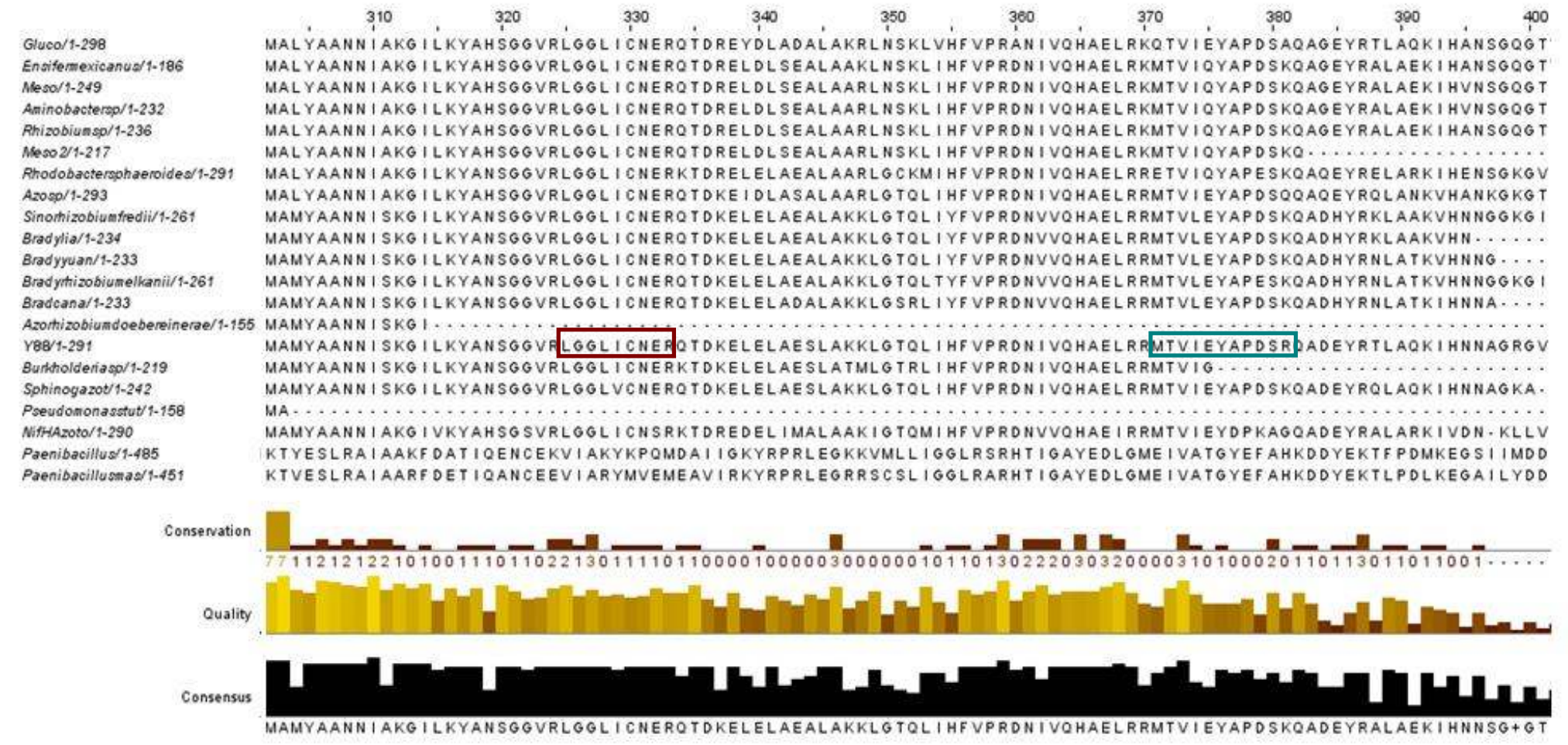

Figure 6.1 (cont.) CLUSTALW (1.83) multiple sequence alignment of the Y88 NifH protein sequence with 20 NifH sequences from other bacteria (Table 6.1)

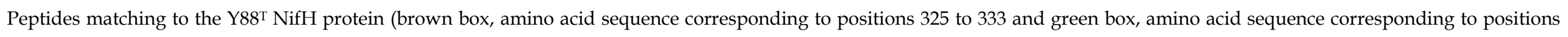

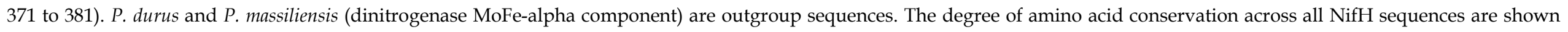

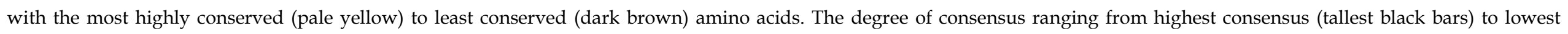

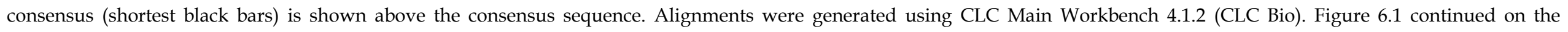
following page. See Table 6.1 for full species names. 


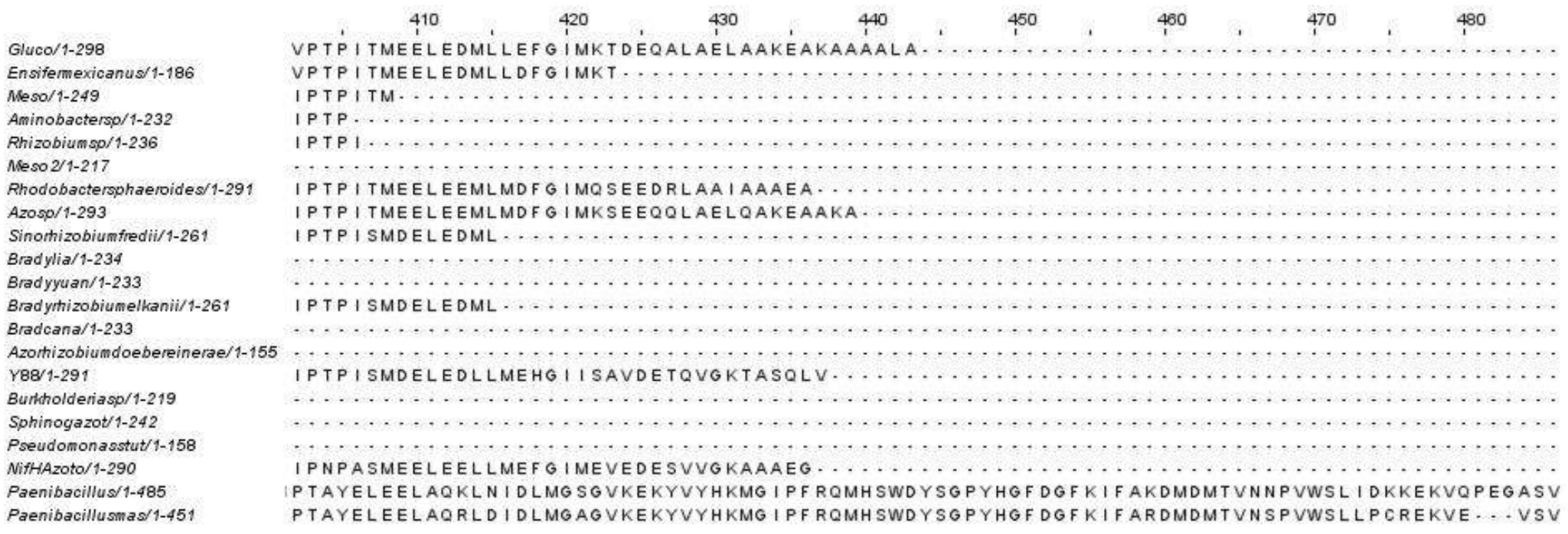

Conservation

Quality

Consensus

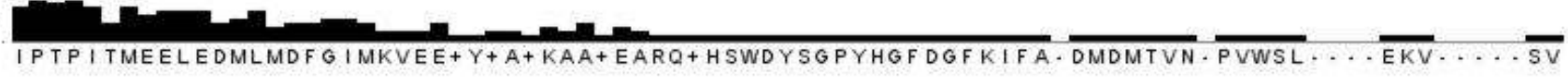

Figure 6.1 (cont.) CLUSTALW (1.83) multiple sequence alignment of the Y88 $\mathrm{NifH}$ protein sequence with $20 \mathrm{NifH}$ sequences from other bacteria (Table 6.1)

C-terminus amino acids are shown to ensure complete sequences of the relevant species are represented in the alignment. P. durus and P. massiliensis (dinitrogenase MoFe-alpha component) are outgroup sequences. The degree of amino acid conservation across all NifH sequences are shown with the most highly conserved (pale yellow) to least conserved (dark brown) amino acids. The degree of consensus ranging from highest consensus (tallest black bars) to lowest consensus (shortest black bars) is shown above the consensus sequence. Alignments were generated using CLC Main Workbench 4.1.2 (CLC Bio). See Table 6.1 for full species names. 
corresponding to positions 231 to 246 in this alignment, with the C-terminus arginine known to be susceptible to ADP-ribosylation, at position 246), was shown to be positioned close to the active site of nitrogenase (Georgiadis et al., 1992; Ekman et al., 2008). This conserved segment was of particular interest because coincidentally it corresponded perfectly to the highest-scoring peptide matched in the $\mathrm{Y}^{\mathrm{T}} \mathrm{NifH}$ protein in the MS analysis (Chapter 5, Table5.1, Chapter 6, Fig. 6.1, red box at amino acid positions 231 to 246).

This peptide sequence is reported to be perfectly conserved in most sequenced nitrogenase proteins (Ekman et al., 2008), which was found to be the case for all $\mathrm{NifH}$ sequences examined in this study, with the exception of Paenibacillus sp. (Fig. 6.1, last two sequences in the alignment). In Y88 ${ }^{\mathrm{T}}$, the Arg101 at the Cterminus of this peptide corresponds to Arg100 in A. vinelandii (Li, 2002) as well as Arg101 in Rhodospirillum rubrum and is the site of activity-regulating ADPribosylation in R. rubrum (Pope et al., 1985) and many other (Ekman et al., 2008), but not all (Durner et al., 1994), nitrogen-fixing bacteria.

Error-tolerant spectral analysis of unassigned candidate peptides matched to CVESGGPEPGVGCAGR in Mascot suggested several potential modifications consistent with the mobility shifts observed for NifH. One such modification biochemically identified in NifH is palmitoylation (Gallon et al., 2000). Theoretically, the peptide carrying a modification would have a higher mass in the modified protein than the peptide in the unmodified protein and the mass difference would allow identification and location of the modification (Ekman et al., 2008). Based on the molecular weight and pI differences of the two NifH forms (Chapter 4, Fig. 4.5, spots 3198, 3255; Chapter 5, Fig. 5.5, spots 2101, 2129), modification of CVESGGPEPGVGCAGR by acylation was considered. Despite the approximately 500 Da difference between the two forms corresponding to two possible palmitoylations (each equal to $238 \mathrm{Da}$ ), an error-tolerant search did not detect this type of modification on CVESGGPEPGVGCAGR in Y88 ${ }^{\mathrm{T}}$. In bacteria, palmitoylation is usually observed only on lysine and on N-terminal cysteines following post-translational signal peptide cleavage (Ekman et al., 
2008). Since the N-terminal cysteine in CVESGGPEPGVGCAGR is the result of a trypsin digestion, not a signal peptide cleavage, the modification of the $\mathrm{N}$ terminal cysteine on CVESGGPEPGVGCAGR is unlikely. The possibility that this modification does exist on another peptide or in combination with another modification (Gallon et al., 2000), also cannot be ruled out since not all peptides spanning the entire $\mathrm{Y}^{8} 8^{\mathrm{T}} \mathrm{NifH}$ sequence were matched.

The potential difference in $\mathrm{M}_{\mathrm{r}}$ between the two NifH forms does correspond to one possible ADP-ribosylation (equal to $541 \mathrm{Da}$ ). That Arg101 in Y88 ${ }^{\mathrm{T}}$ may therefore be ADP-ribosylated also cannot be ruled out, since this amino acid was never accounted for in the spectrum for this peptide. Two possible reasons for the unaccounted Arg101 were considered. First, since the enzyme trypsin was used to digest the protein during protein preparation for MS and cleaves Cterminal to arginine (or lysine), any modification of Arg101 would potentially block this cleavage, resulting in a peptide with a much higher molecular weight (Ekman et al., 2006) than that observed in the spectrum. Secondly, the mass of arginine is $174 \mathrm{Da}$ and the MS parameter set limits for peak detection are between 200 and $2000 \mathrm{Da}$. Arginine may therefore not be accounted for in the spectrum (for ion trap data) since its mass is below the mass cutoff and is outside this $\mathrm{m} / \mathrm{z}$ range of interest.

Despite the lack of detection of the arginine in the CVESGGPEPGVGCAGR spectrum, it is nonetheless tempting to rule out this modification for the high $\mathrm{M}_{\mathrm{r}}$ form of $\mathrm{NifH}$ protein because ADP-ribosylation inhibits nitrogenase activity (Pope et al., 1985) yet nitrogen fixation was demonstrated by $\mathrm{Y}^{\mathrm{T}}$ (in an acetylene reduction assay). The higher $M_{r}$ more basic form may represent a portion of the NifH pool that may be modified in an alternative way to that of ADP-ribosylation, but may have a similar effect rendering it catalytically inactive under aerobic conditions of growth (Gallon et al., 2000). This was suggested to be the case in the Azolla cyanobiont (Ekman et al., 2008) where approximately $25 \%$ of the $\mathrm{NifH}$ pool was suggested to be modified by means of ADP-ribosylation and consequently inactive, as well as possibly targeted for 
degradation. An alternative type of modification of $\mathrm{NifH}$ would explain the presence of the higher $M_{r}$ form for the nitrogen-fixing state of the cell but further experimentation is required to establish if this is the case. In Y88 ${ }^{\mathrm{T}}$, any potential modification may be a consequence of the lower $\mathrm{pH}$ of the medium, since this higher $\mathrm{M}_{\mathrm{r}}$ more basic form is absent from the $\mathrm{pH} 4-7$ gels representing the Fix ${ }^{\text {on }}$ state of the cells at DOlow and a neutral growth medium.

An error-tolerant search of the high-scoring peptide STTSQNTLAALADLGQR (Fig. 6.1, green box) revealed a possible modification of this peptide, resulting in a higher mass. However, the mass difference between the potentially modified and unmodified peptides did not account for the mobility shift of approximately 500 Da observed between the two NifH forms on the 2-D gels.

Although the NifH protein is modified by ADP-ribosylation in R. rubrum, (Pope et al., 1985) more recently other modifications such as palmitoylation, acetylation and other, as yet, unidentified modifications have been suggested to regulate NifH in other bacterial species (Gallon et al., 2000; Ekman et al., 2008). Based on these precedents, one must also consider that the $\mathrm{Y} 88^{\mathrm{T}} \mathrm{NifH}$ may be modified in yet a different way in response to changes in culture growth conditions that would explain the two different forms of $\mathrm{NifH}$ for the Fix on state of the cells at DOlow and at a more acidic growth medium.

\subsubsection{NifK and NifD proteins}

The Y88 ${ }^{\mathrm{T}}$ NifK and NifD protein sequences were examined in a CLUSTALW (1.83) multiple sequence alignment with 16 NifK ( $\beta$-subunit) and NifD ( $\alpha$ subunit) sequences from other Alphaproteobacteria, as well as the $\gamma$ proteobacterium $A$. vinelandii as an outgroup (Fig. 6.2). A. vinelandii was chosen for comparison because its nitrogenase is well studied and understood biochemically (Dean et al., 1990; Kent et al., 1990; Peters et al., 1997; Li, 2002). Sequence analysis revealed that the $\mathrm{Y} 88^{\mathrm{T}} \mathrm{NifK}$ and NifD proteins were highly conserved relative to these 16 species. The conserved amino acid residues of interest are discussed below and highlighted in sequence alignments of the NifK and NifD proteins of $Y 88^{\mathrm{T}}$ with those of $A$. vinelandii (Fig. 6.2). 


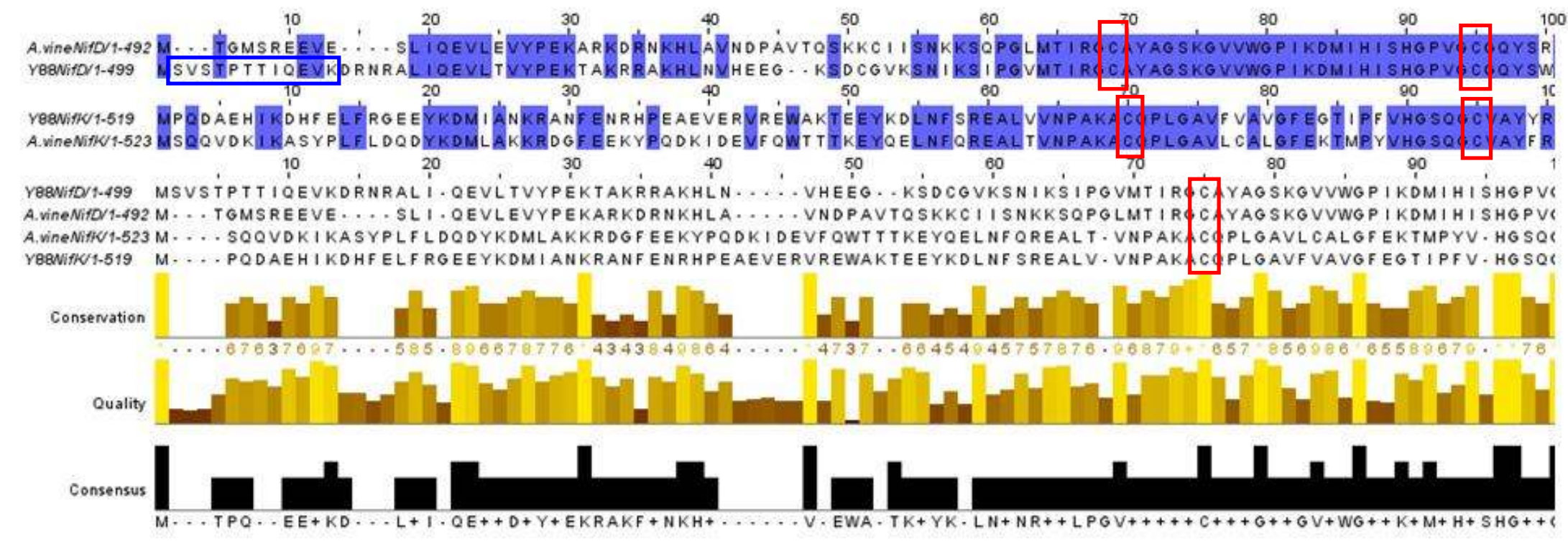

Figure 6.2 CLUSTALW (1.83) multiple sequence alignment of the Y88 NifD and NifK protein sequences with the A. vinelandii NifD and NifK sequences

Highly conserved NifDK amino acids (red boxes) and peptides matching the Y88 $8^{\mathrm{T}}$ NifD protein (blue boxes) and the Y88 ${ }^{\mathrm{T}}$ NifK protein (green boxes) are shown. $A$. vine $\mathrm{NifD} / 1-492=$ A. vinelandii $\mathrm{NifD}$ protein sequence; A.vineNifK/1-523 = A. vinelandii NifK protein sequence; Y88NifD $/ 1-499=\mathrm{Y} 88^{\mathrm{T}} \mathrm{NifD}$ protein sequence; Y88NifK/1-519 $=$ Y88 $8^{\mathrm{T}}$ NifK protein sequence. Blue shaded amino acids are conserved across NifD of $A$. vinelandii and $\mathrm{Y}^{\mathrm{T}} 8^{\mathrm{T}}$ in the first two rows of sequences from top of the page and across NifK of $A$. vinelandii and $Y 88^{\mathrm{T}}$ in the third and fourth rows of sequences from top of the page. The degree of amino acid conservation across NifDK for both A. vinelandii and $\mathrm{Y} 88^{\mathrm{T}}$ are shown for the bottom four rows of sequences with the most highly conserved (pale yellow) to least conserved (dark brown) amino acids. The degree of consensus ranging from highest consensus (tallest black bars) to lowest consensus (shortest black bars) is shown above the

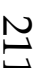




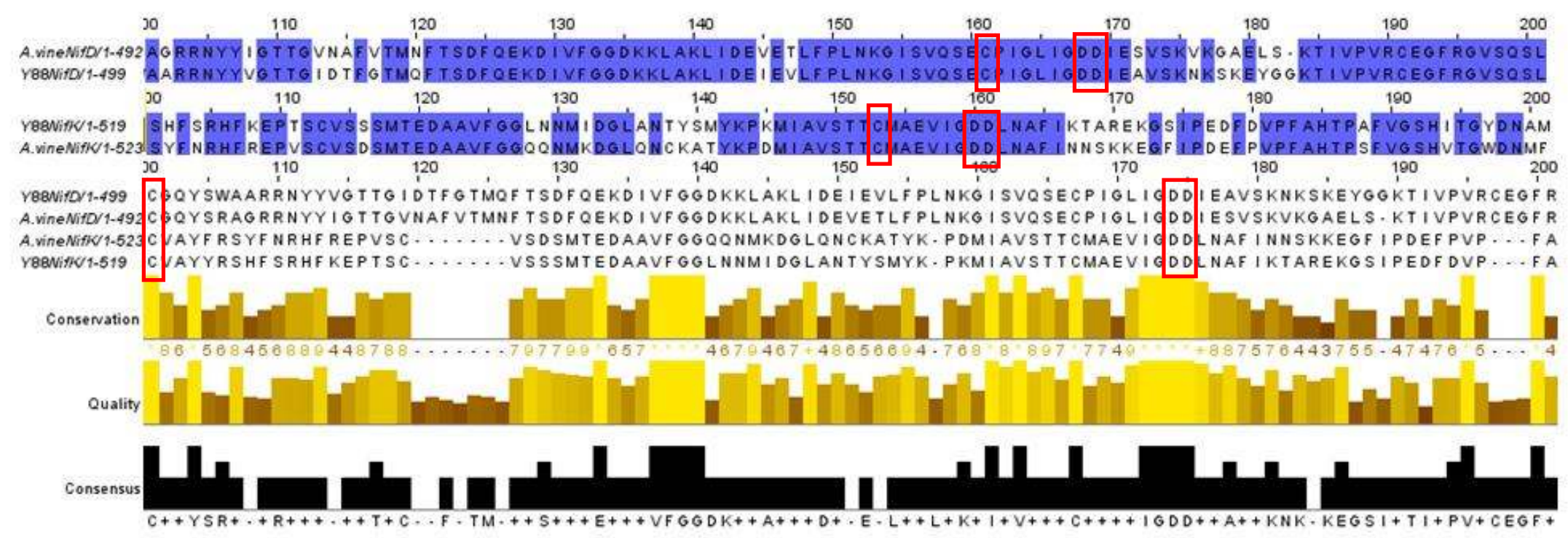

Figure 6.2 (cont.) CLUSTALW (1.83) multiple sequence alignment of the Y88 $8^{\mathrm{T}}$ NifD and NifK protein sequences with the A. vinelandii NifD and NifK sequences Highly conserved NifDK amino acids (red boxes) and peptides matching the Y88 $8^{\mathrm{T}}$ NifD protein (blue boxes) and the Y88 ${ }^{\mathrm{T}}$ NifK protein (green boxes) are shown. $A$. vine NifD/1-492 = A. vinelandii NifD protein sequence; A.vineNifK/1-523 $=$ A. vinelandii NifK protein sequence; $\mathrm{Y}_{88 \mathrm{NifD}} / 1-499=\mathrm{Y} 88^{\mathrm{T}} \mathrm{NifD}$ protein sequence; $\mathrm{Y} 88 \mathrm{NifK} / 1-519=\mathrm{Y} 88^{\mathrm{T}} \mathrm{NifK}$ protein sequence. Blue shaded amino acids are conserved across NifD of $A$. vinelandii and $\mathrm{Y} 88^{\mathrm{T}}$ in the first two rows of sequences from top of the page and across NifK of $A$. vinelandii and $Y 88^{\mathrm{T}}$ in the third and fourth rows of sequences from top of the page. The degree of amino acid conservation across NifDK for both A. vinelandii and $\mathrm{Y}^{8} 8^{\mathrm{T}}$ are shown for the bottom four rows of sequences with the most highly conserved (pale yellow) to least conserved (dark brown) amino acids. The degree of consensus ranging from highest consensus (tallest black bars) to lowest consensus (shortest black bars) is shown above the consensus sequence. Fig. 6.2 continued on the following page. Alignments were generated using CLC Main Workbench 4.1.2 (CLC Bio). 


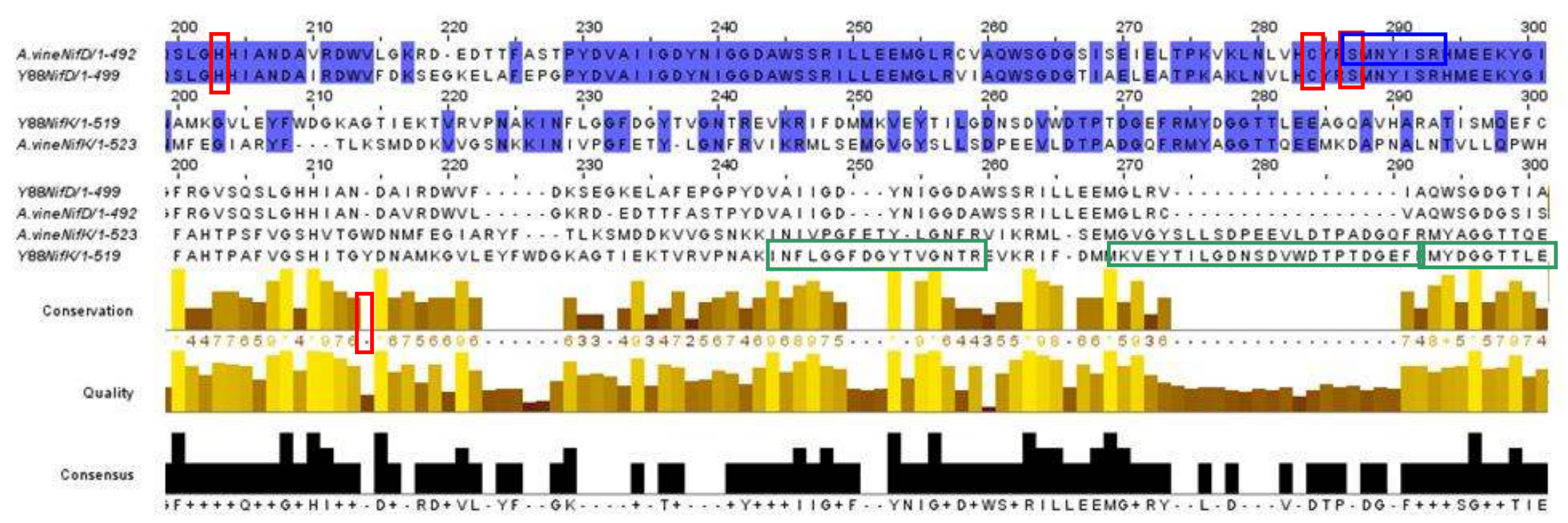

Figure 6.2 (cont.) CLUSTALW (1.83) multiple sequence alignment of the Y88 $8^{\mathrm{T}}$ NifD and NifK protein sequences with the A. vinelandii NifD and NifK sequences

Highly conserved NifDK amino acids (red boxes) and peptides matching the Y88 ${ }^{\mathrm{T}} \mathrm{NifD}$ protein (blue box) and the Y88 ${ }^{\mathrm{T}} \mathrm{NifK}$ protein (green boxes) are shown. $A$. vineNifD/1-492 = A. vinelandii $\mathrm{NifD}$ protein sequence; A.vineNifK/1-523 = A. vinelandii NifK protein sequence; Y88NifD/1-499 = Y88 ${ }^{\mathrm{T}} \mathrm{NifD}$ protein sequence; Y88NifK/1-519 $=$ Y88 $8^{\mathrm{T}}$ NifK protein sequence. Blue shaded amino acids are conserved across NifD of $A$. vinelandii and $\mathrm{Y}^{8} 8^{\mathrm{T}}$ in the first two rows of sequences from top of the page and across NifK of A. vinelandii and $\mathrm{Y} 88^{\mathrm{T}}$ in the third and fourth rows of sequences from top of the page. The degree of amino acid conservation across NifDK for both $A$. vinelandii and $\mathrm{Y}^{8 \mathrm{~T}}$ are shown for the bottom four rows of sequences with the most highly conserved (pale yellow) to least conserved (dark brown) amino acids. The degree of consensus ranging from highest consensus (tallest black bars) to lowest consensus (shortest black bars) is shown above the consensus sequence. Fig. 6.2 continued on the following page. Alignments were generated using CLC Main Workbench 4.1.2 (CLC Bio). 


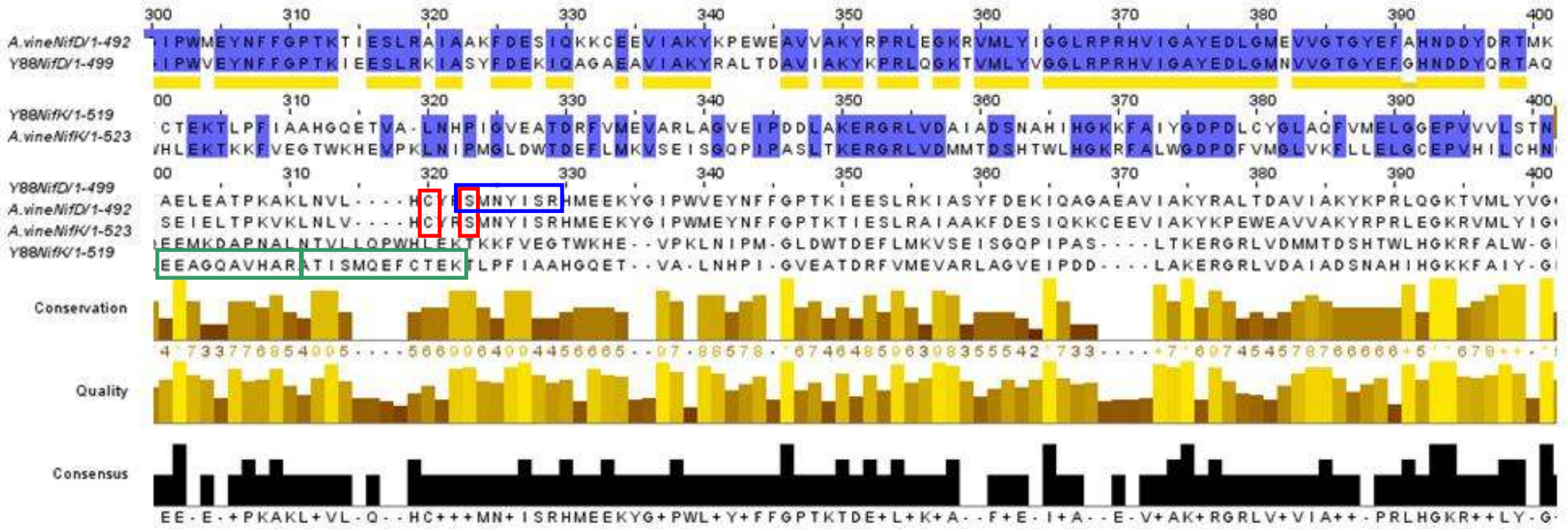

Figure 6.2 (cont.) CLUSTALW (1.83) multiple sequence alignment of the Y88 $8^{\mathrm{T}} \mathrm{NifD}$ and NifK protein sequences with the A. vinelandii NifD and NifK sequences Highly conserved NifDK amino acids (red boxes) and peptides matching the $Y 88^{\mathrm{T}}$ NifD protein (blue box) and the Y88 $8^{\mathrm{T}}$ NifK protein (green boxes) are shown. $A$. vine NifD/1-492 = A. vinelandii NifD protein sequence; A.vineNifK/1-523 $=$ A. vinelandii NifK protein sequence; $Y 88$ NifD $/ 1-499=\mathrm{Y} 88^{\mathrm{T}} \mathrm{NifD}$ protein sequence; Y88NifK/1-519 $=$ Y $88^{\mathrm{T}} \mathrm{NifK}$ protein sequence. Blue shaded amino acids are conserved across NifD of $A$. vinelandii and $\mathrm{Y} 88^{\mathrm{T}}$ in the first two rows of sequences from top of the page and across NifK of $A$. vinelandii and $Y 88^{\mathrm{T}}$ in the third and fourth rows of sequences from top of the page. The degree of amino acid conservation across NifDK for both A. vinelandii and $\mathrm{Y}^{8} 8^{\mathrm{T}}$ are shown for the bottom four rows of sequences with the most highly conserved (pale yellow) to least conserved (dark brown) amino acids. The degree of consensus ranging from highest consensus (tallest black bars) to lowest consensus (shortest black bars) is shown above the consensus sequence. Fig. 6.2 continued on the following page. Alignments were generated using CLC Main Workbench 4.1.2 (CLC Bio). 


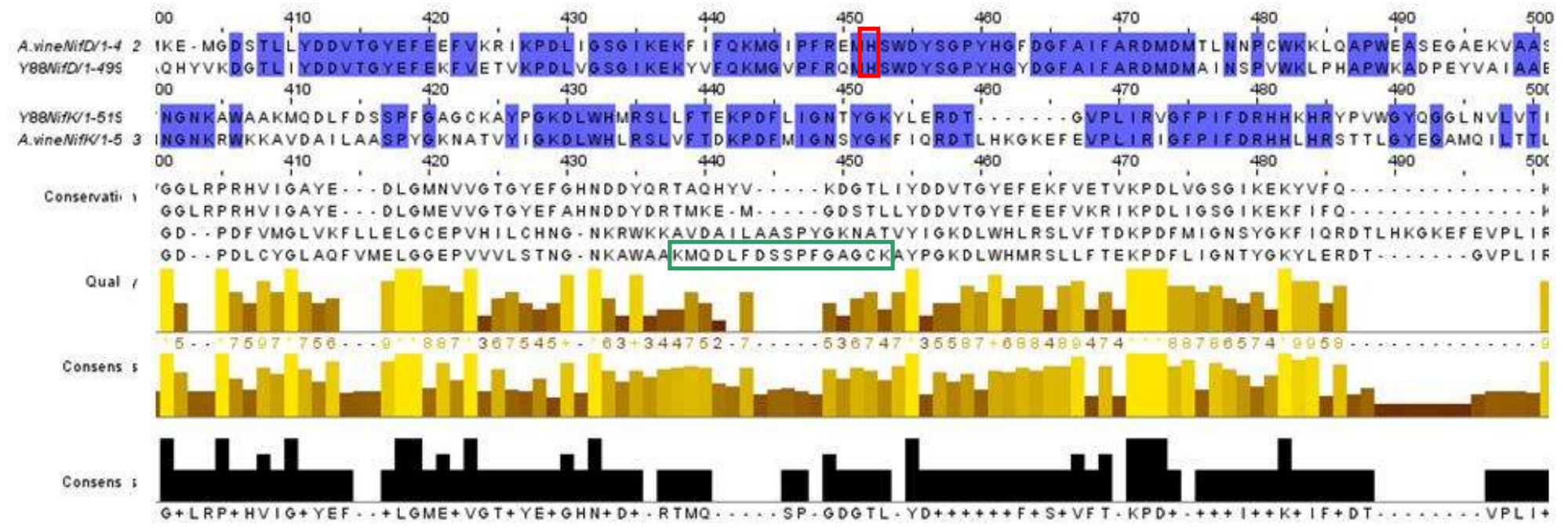

Figure 6.2 (cont.) CLUSTALW (1.83) multiple sequence alignment of the Y88 ${ }^{\mathrm{T}} \mathrm{NifD}$ and NifK protein sequences with the $A$. vinelandii NifD and NifK sequences Highly conserved NifDK amino acids (red boxes) and peptides matching the $\mathrm{Y} 88^{\mathrm{T}}$ NifD protein (blue boxes) and the Y88 ${ }^{\mathrm{T}}$ NifK protein (green boxes) are shown. $A$. vineNifD/1-492 = A. vinelandii NifD protein sequence; A.vineNifK/1-523 = A. vinelandii NifK protein sequence; $\mathrm{Y} 88 \mathrm{NifD} / 1-499=\mathrm{Y} 88^{\mathrm{T}} \mathrm{NifD}$ protein sequence; Y88NifK/1-519 $=$ Y $88^{\mathrm{T}}$ NifK protein sequence. Blue shaded amino acids are conserved across NifD of $A$. vinelandii and $\mathrm{Y}^{\mathrm{T}} 8^{\mathrm{T}}$ in the first two rows of sequences from top of the page and across NifK of A. vinelandii and $\mathrm{Y} 88^{\mathrm{T}}$ in the third and fourth rows of sequences from top of the page. The degree of amino acid conservation across NifDK for both A. vinelandii and $\mathrm{Y}^{8} 8^{\mathrm{T}}$ are shown for the bottom four rows of sequences with the most highly conserved (pale yellow) to least conserved (dark brown) amino acids. The degree of consensus ranging from highest consensus (tallest black bars) to lowest consensus (shortest black bars) is shown above the consensus sequence. Fig. 6.2 continued on the following page. Alignments were generated using CLC Main Workbench 4.1.2 (CLC Bio). 


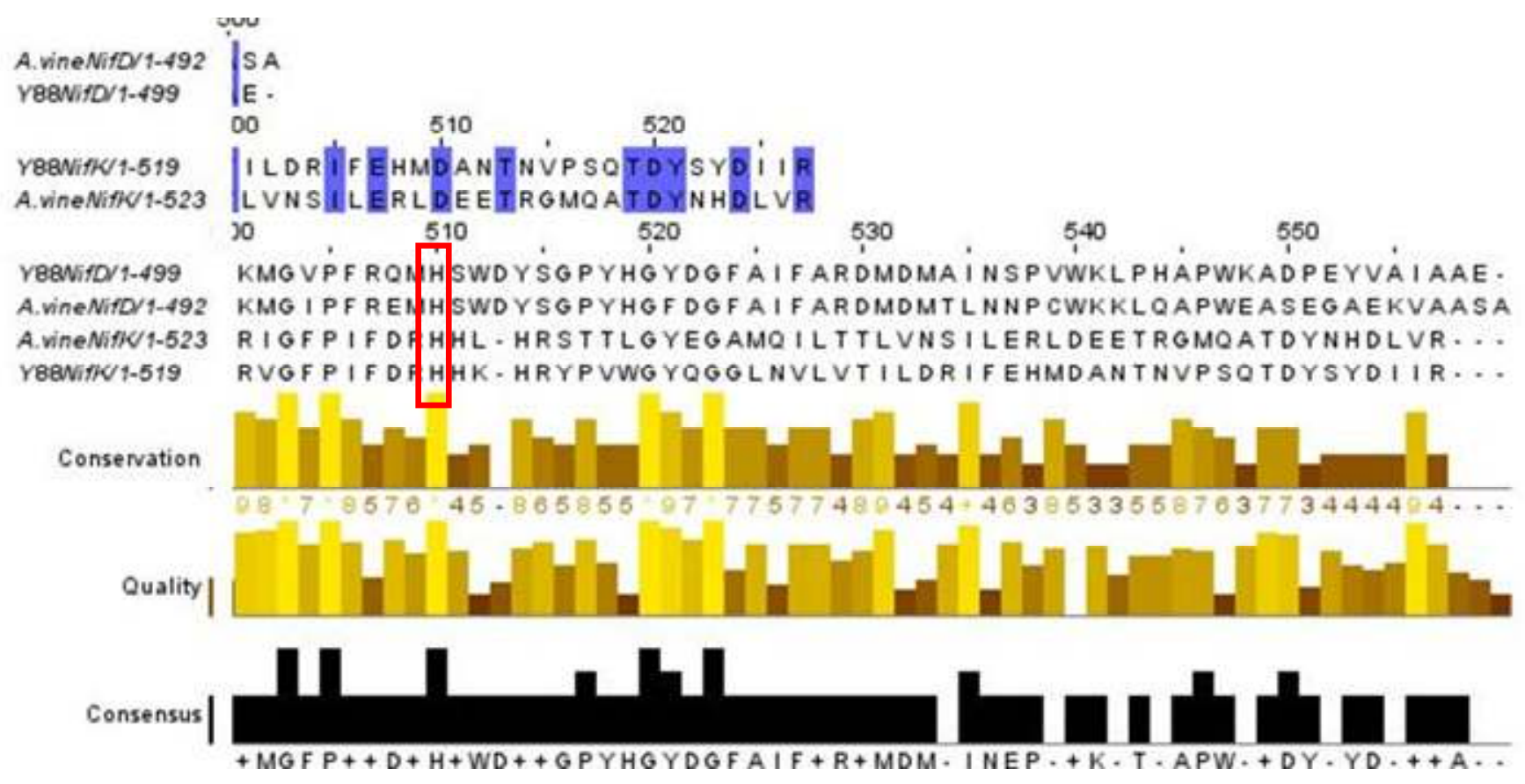

Figure 6.2 (cont.) CLUSTALW (1.83) multiple sequence alignment of the Y88 ${ }^{\mathrm{T}} \mathrm{NifD}$ and NifK protein sequences with the $A$. vinelandii NifD and NifK sequences showing the highly conserved key amino acids (red boxes) and peptides matching the Y88 $8^{\mathrm{T}} \mathrm{NifD}$ protein (blue boxes) and the $\mathrm{Y} 88^{\mathrm{T}} \mathrm{NifK}$ protein (green boxes). $A$. vineNifD/1-492 = A. vinelandii NifD protein sequence; A.vineNifK/1-523 = A. vinelandii NifK protein sequence; Y88NifD/1-499 = Y88 NifD protein sequence; Y88NifK/1-519 $=$ Y $88^{\mathrm{T}}$ NifK protein sequence. Blue shaded amino acids are conserved across NifD of $A$. vinelandii and Y88 ${ }^{\mathrm{T}}$ in the first two rows of sequences from top of the page and across NifK of A. vinelandii and $\mathrm{Y}^{\mathrm{T}} \mathrm{T}$ in the third and fourth rows of sequences from top of the page. The degree of amino acid conservation across NifDK for both $A$. vinelandii and $\mathrm{Y}^{8 \mathrm{~T}}$ are shown for the bottom four rows of sequences with the most highly conserved (pale yellow) to least conserved (dark brown) amino acids. The degree of consensus ranging from highest consensus (tallest black bars) to lowest consensus (shortest black bars) is shown above the consensus sequence. Alignments were generated using CLC Main Workbench 4.1.2 (CLC Bio). Alignments were generated using CLC Main Workbench 4.1.2 (CLC Bio). 
Amino acid residues corresponding to A. vinelandii $\alpha$-subunit Cys275 and $\alpha$ subunit His442 (amino acid positions 284 and 452 respectively in A. vinelandii NifD alignment with $\mathrm{Y}^{8} 8^{\mathrm{T}}$ but positions 320 (red box) and 510 (red box) respectively in alignment with both NifDK, Fig. 6.2) that are required for all FeMo protein activities, were identified as Y88 $\alpha$ Cys282 and $\alpha H i s 450$ respectively (Fig. 6.2, red boxes at amino acid positions 284 and 510 respectively). Additionally, substitution of A. vinelandii $\alpha$ His442 (amino acid position 452 in alignment with $Y 88^{\mathrm{T}}$ ) with Asn has been shown to completely inactivate MoFe activity and in A. vinelandii, $\alpha$ His442 appears to play a major role in anchoring the cofactor to the NifD polypeptide (Brigle et al., 1985). A. vinelandii $\alpha$ His195, $\alpha$ Cys275, and $\alpha$ Ser278 (Fig. 6.2, amino acid positions 203, 284 and 287 respectively) which are involved in proton delivery to the $A$. vinelandii FeMo cofactor (Pham \& Burgess, 1993; Dilworth et al., 1998; Fisher et al., 2000), were identified as $\mathrm{Y}^{8} 8^{\mathrm{T}} \alpha \mathrm{His} 202$, $\alpha \mathrm{Cys} 282$ (mentioned above) and $\alpha$ Ser285 respectively (Fig. 6.2, red boxes at amino acid positions 203, 284 and 287 respectively). Also, A. vinelandii $\alpha$ Asp161, $\alpha$ Asp162, $\beta$ Asp160 and $\beta$ Asp161 (Fig. 6.2, amino acid positions 168, 169, 160, 161 respectively), reported to all be strictly conserved in the MoFe protein primary sequences of at least five nitrogen-fixing species (Peters et al., 1995) were conserved at sites $\alpha$ Asp166 and $\alpha$ Asp167 in the Y88 ${ }^{\mathrm{T}}$ NifD sequence and at $\beta$ Asp160 and $\beta$ Asp161 in the NifK predicted protein sequence (Fig. 6.2, red boxes at same amino acid positions 168, 169, 160, 161 respectively). Six A. vinelandii cysteine residues, $\alpha$ Cys62, $\alpha C y s 88, \alpha$ Cys154 and $\beta$ Cys70, $\beta$ Cys95 and $\beta$ Cys153 Fig. 6.2, amino acid positions $69,95,161,70,95,153$ respectively), reported to be the sites through which the MoFe P-cluster is covalently coordinated to the MoFe protein in A. vinelandii ( $\mathrm{Li}, 2002)$ were also conserved in $\mathrm{Y}^{8} 8^{\mathrm{T}}$ at $\alpha \mathrm{Cys} 67, \alpha \mathrm{Cys} 93, \alpha \mathrm{Cys} 159$, $\beta$ Cys70, $\beta$ Cys95 and $\beta$ Cys153, respectively (Fig. 6.2, red boxes at amino acid positions $69,95,161,70,95,153$ respectively).

Close inspection of all peptide matches to the $\mathrm{Y} 88^{\mathrm{T}} \mathrm{NifD}$ and NifK protein sequences (Fig. 6.2, blue and green boxes) to determine if any peptides may 
have been modified at the conserved amino acids mentioned above, which could either explain a pI shift or why the abundance of these proteins was altered at DOhigh concentrations, showed that only one of these peptides, SMNYISR, spanned any of the conserved amino acids of interest in the NifD sequence (Fig. 6.2, blue box, amino acid positions 323 to 329). An error-tolerant spectral analysis of unmatched spectra did not account for any potential modification of this peptide that could explain a $\mathrm{pI}$ shift of the NifD protein to a more basic position on the 2-D gel. That NifD in particular may still be susceptible to post-translational modification cannot be ruled out, since only two peptides matched this protein (Fig.6.2; blue boxes amino acid positions 2 to 13 and 323 to 329) and only one of them, SMNYISR, as mentioned before, spanned any portion of the $\mathrm{Y} 88^{\mathrm{T}}$ sequence that included any of the key amino acids identified from $A$. vinelandii to be conserved and essential to nitrogenase activity. The first serine in the peptide SMNYISR corresponds to $\alpha$ Ser275 in $A$. vinelandii and to $\alpha$ Ser278 in Y88 ${ }^{\mathrm{T}}$ (Fig. 6.2, red box at amino acid position 323 in this sequence alignment).

The second peptide, SVSTPTTIQEVK (Fig. 6.2, amino acid positions 2 to 13), that was matched to NifD was identified in an error-tolerant search to potentially be modified either at the C-terminal lysine or the internal glutamine. Since the mass difference was $0.04 \mathrm{Da}$, this mass difference was below the set limit of the mass error tolerance, thus a modification of this amino acid could be ruled out.

\subsubsection{Protein and peptide analysis of the $\mathrm{Y}^{8} 8^{\mathrm{T}}$ phasin}

\subsubsection{Proteomics of the three $\mathrm{Y} 88^{\mathrm{T}}$ phasin isoforms}

The full-length $\mathrm{Y}^{\mathrm{T}} 8^{\mathrm{T}}$ phasin predicted from the $\mathrm{Y} 88^{\mathrm{T}}$ genome sequence was observed at its predicted $34 \mathrm{kDa}$ and pI of 9.6 on the basic gels (Chapter 5, spot 1, Figs. 5.10, 5.14) compared to the two "truncated" $13 \mathrm{kDa}$ forms at acidic pIs (6.9 and 7.2) (Chapter 5, spots 1 and 2, Fig. 5.8). Several peptides that matched different parts of the alanine- and proline-rich N-terminal segment (Chapter 5 , spot 1, Figs. 5.10, 5.14; Chapter 6, Fig. 6.3, black boxed sequences) were never 


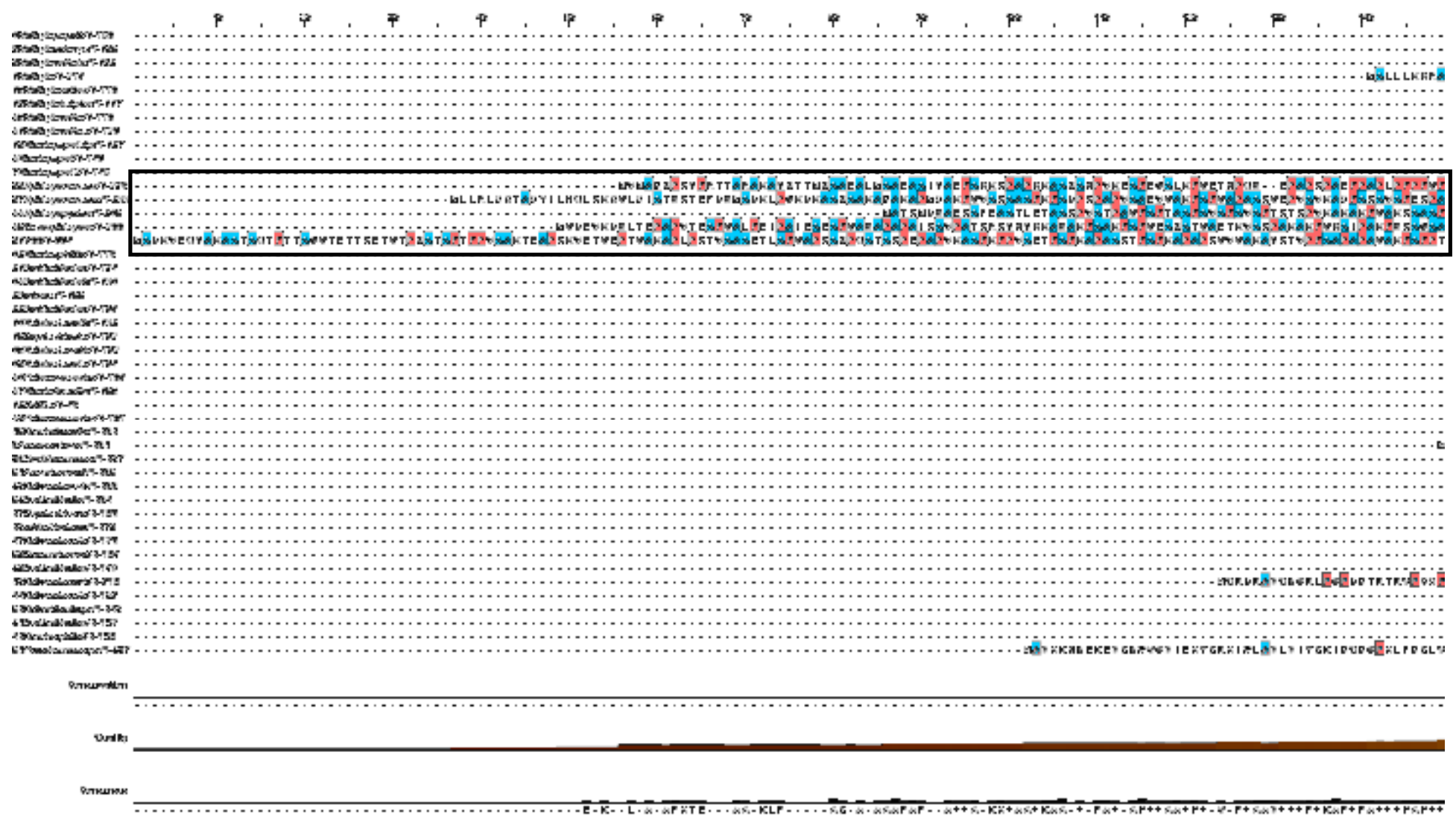

Figure 6.3 CLUSTALW (1.83) multiple sequence alignment of the Y88 $8^{\mathrm{T}}$ phasin protein with representative phasin sequences randomly selected from Genbank (Table 6.2)

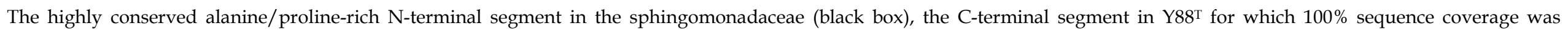

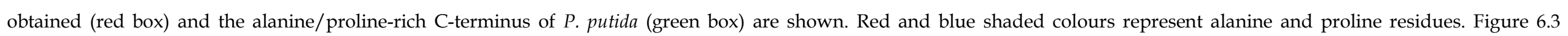

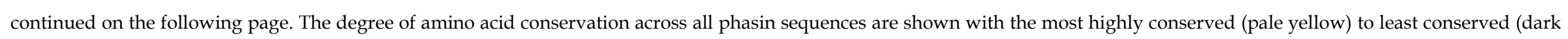

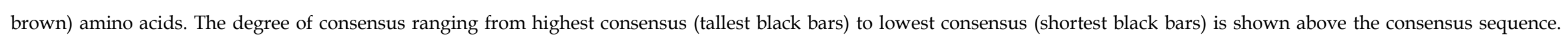




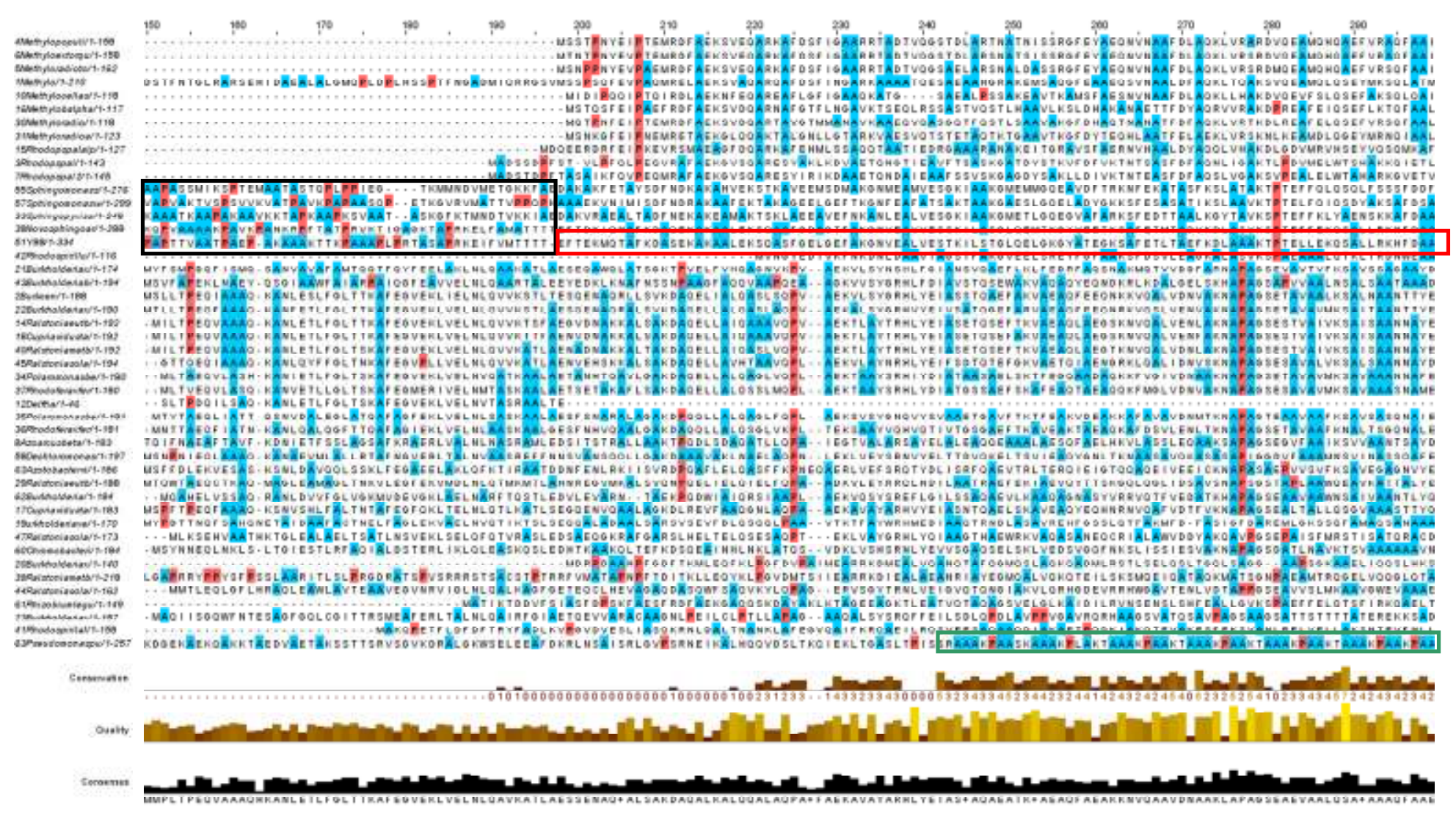

Figure 6.3 (cont.) CLUSTALW (1.83) multiple sequence alignment of the Y88 ${ }^{\mathrm{T}}$ phasin protein with representative phasin sequences randomly selected from Genbank (Table 6.2)

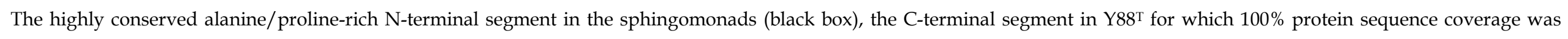

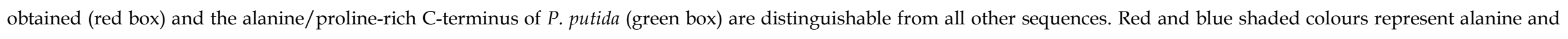

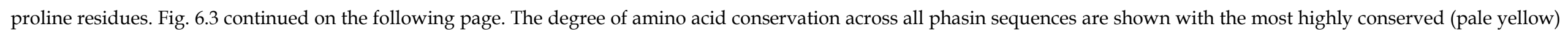

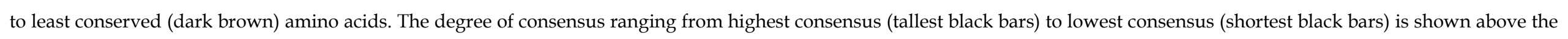
consensus sequence. Alignments were generated using CLC Main Workbench 4.1.2 (CLC Bio). See Table 6.2 for full species names. 


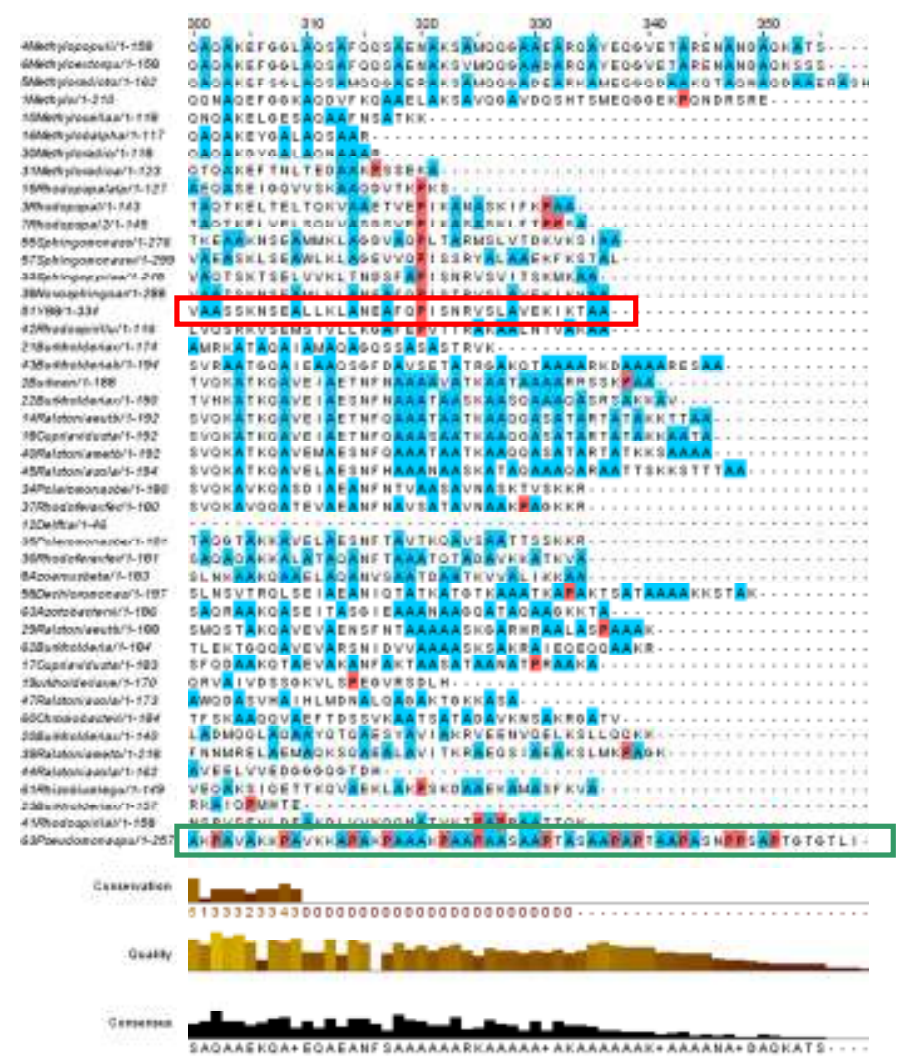

Figure 6.3 (cont.) CLUSTALW (1.83) multiple sequence alignment of the Y88 The highly conserved alanine/proline-rich N-terminal segment in the sphingomonads (black box previous page), the C-terminal segment in Y88 for which $100 \%$ protein sequence coverage was obtained (red box continued from previous page to this page) and the alanine/proline-rich C-terminus of $P$. putida (green box continued from previous page to this page) are distinguishable from all other sequences. Red and blue shaded colours represent alanine and proline residues. The degree of amino acid conservation across all phasin sequences are shown with the most highly conserved (pale yellow) to least conserved (dark brown) amino acids. The degree of consensus ranging from highest consensus (tallest black bars) to lowest consensus (shortest black bars) is shown above the consensus sequence. Alignments were generated using CLC Main Workbench 4.1.2 (CLC Bio). See Table 6.2 for full species names. 
observed in the two lower $\mathrm{M}_{\mathrm{r}}$ forms (Chapter 5, Fig. 5.8, spots 1 and 2). Peptides matching the C-terminal portion of the predicted $\mathrm{Y} 88^{\mathrm{T}}$ phasin from the two lower $\mathrm{M}_{\mathrm{r}}$ forms (Chapter 5, Figs. 5.8, spots 1 and 2; Chapter 6, Fig. 6.3, green boxed sequence) were also observed in the C-terminus of the higher $\mathrm{M}_{\mathrm{r}}$ basic form. The occurrence of these peptides derived from corresponding protein spots on all gels supports the notion that the lower $\mathrm{M}_{\mathrm{r}}$ forms of the $\mathrm{Y} 88^{\mathrm{T}}$ phasin are not artefacts of degradation or mobility. The difference in $M_{r}$ between the high $\mathrm{M}_{\mathrm{r}}$ form and the perceived modified forms corresponds to this "lost" segment. The observed low $\mathrm{M}_{\mathrm{r}}$ phasins may be post-translationally modified by site-specific cleavage at the N-terminal end of Met192 or Met203 in the Y88 phasin sequence (Fig. 6.3) or may be directly translated, either from an internal ribosome initiation site, or from an alternative phasin transcript.

\subsubsection{Phasin protein sequence alignments}

Examination of the CLUSTALW (1.83) multiple sequence alignment of the Y88 phasin protein sequence with 45 phasin sequences taken from Genbank (Table 6.2, Fig. 6.3) showed that the $\mathrm{Y}^{\mathrm{T}} 8^{\mathrm{T}}$ phasin has a distinctive, low-complexity, mainly alanine and proline-rich N-terminal segment, similar in composition only to corresponding N-termini in the four other known sphingomonad phasin sequences examined (Fig. 6.3, black box). This 199 amino acid segment corresponds to the difference in $\mathrm{M}_{\mathrm{r}}$ between the expected $33.9 \mathrm{kDa}$ native form and the two $13 \mathrm{kDa}$ forms, so the $\mathrm{N}$-terminal portion may be cleaved posttranslationally. Notably, only the sphingomonad phasins had a similar Nterminal segment, although $P$. putida had an alanine/proline-rich segment at its C-terminus (Fig. 6.3, red box). Many of the phasin sequences examined had an alanine-rich segment C-terminal to the "core" phasin sequence, similar to that reported for R. eutropha (Neumann et al., 2008), but none of these alanines was conserved across all the sequences examined, reflecting the general sequence heterogeneity among the phasins.

To eliminate the possibility of overlooking potentially incorrectly annotated phasin sequences, a TBLASTN analysis of the $Y 88^{\mathrm{T}}$ phasin protein sequence against the NCBI non-redundant database was carried out. This analysis 


\begin{tabular}{|c|c|c|}
\hline Accession number & Species & $\begin{array}{l}\text { Truncated species name } \\
\text { as it appears in phasin } \\
\text { sequence alignment }\end{array}$ \\
\hline gb|ACB80653.1| & Methylobacterium populi BJ001 & Methylopopuli \\
\hline gb|ABY30954.1| & Methylobacterium extorquens PA1 & Methyloextorqu \\
\hline gb| ACB27545.1 | & Methylobacterium radiotolerans JCM 2831 & Methyloradioto \\
\hline gb|ACA18624.1| & Methylobacterium sp. 4-46 & Methylo \\
\hline gb|ACK51275.1| & Methylocella silvestris BL2 & Methylocellas \\
\hline gb| ACB80343.1 | & Methylobacterium populi BJ001 & Methylobalpha \\
\hline gb| ACB26322.1 | & Methylobacterium radiotolerans JCM 2831 & Methyloradio \\
\hline gb|ACA19562.1| & Methylobacterium sp. 4-46 & Methyloradioa \\
\hline ref|NP_949474.1| & Rhodopseudomonas palustris CGA009 & Rhodopspalalp \\
\hline gb|ACF03108.1| & Rhodopseudomonas palustris TIE-1 & Rhodopspal \\
\hline gb| ABJ07987.1| & Rhodopseudomonas palustris BisA53 & Rhodopspal \\
\hline gb|EAT09637.1| & Sphingomonas sp. SKA58 & Sphingomonass \\
\hline gb|ABQ67229.1। & Sphingomonas wittichii RW1 & Sphingomonasw \\
\hline gb|ABF52225.1| & Sphingopyxis alaskensis RB2256 & Sphingopyxisa \\
\hline gb| ABD24947.1 | & Novosphingobium aromaticivorans DSM 12444 & Novosphingoar \\
\hline NA & Novosphingobium nitrogenifigens $\mathrm{Y}^{8} 8^{\mathrm{T}}$ & $Y 88^{\mathrm{T}}$ \\
\hline gb| ABC23614.1 | & Rhodospirillum rubrum ATCC 11170 & Rhodospirillu \\
\hline gb|ABE33652.1| & Burkholderia xenovorans LB400 & Burkholderiax \\
\hline gb|ABB09697.1| & Burkholderia sp. 383 & Burkholderiab \\
\hline ref $\mid Y P_{-}$625781.1 $\mid$ & Burkholderia cenocepacia AU 1054 & Burkcen \\
\hline gb|ABE31411.1| & Burkholderia xenovorans LB400 & Burkholderiax \\
\hline gb | AAC78327.1| & Ralstonia eutropha H16 & Ralstoniab \\
\hline emb |CAQ69257.1| & Cupriavidus taiwanensis & Cupriavidust \\
\hline gb|ABF08086.1| & Ralstonia metallidurans $\mathrm{CH} 34$ & Ralstonia metb \\
\hline ref |YP_002254539.1 | & Ralstonia solanacearum MolK2 & Ralstoniasola \\
\hline gb|ABE45002.1 | & Polaromonas sp. JS666 & Polaromonasbe \\
\hline gb|ABD69864.1 | & Rhodoferax ferrireducens T118 & Rhodoferaxfer \\
\hline gb|ABX37371.1| & Delftia acidovorans SPH-1 & Delftia \\
\hline gb|ABE44227.1| & Polaromonas sp. JS666 & Polaromonasbe \\
\hline $\mathrm{gb}|\mathrm{ABD} 70831.1|$ & Rhodoferax ferrireducens T118 & Rhodoferaxfer \\
\hline
\end{tabular}

Table 6.2 Bacterial species names and the corresponding truncated names in the order of appearance in the list of phasin sequences in the alignment with $\mathrm{Y}^{8} 8^{\mathrm{T}}$ (Fig. 6.2).

No accession number (NA) is yet available for $\mathrm{Y}^{8} 8^{\mathrm{T}}$. 


\begin{tabular}{|c|c|c|}
\hline Accession number & Species & $\begin{array}{c}\text { Truncated species name } \\
\text { as it appears in phasin } \\
\text { sequence alignment }\end{array}$ \\
\hline ref |YP_935317.1 | & Azoarcus sp. BH72 & Azoarcusbeta \\
\hline gb|AAZ48152.1। & Dechloromonas aromatica $\mathrm{RCB}$ & Dechloromonas \\
\hline gb|ACO78555.1 $\mid$ & Azotobacter vinelandii $\mathrm{DJ}$ & Azotobactervi \\
\hline gb|AAP85954.1 | & Ralstonia eutropha H16 & Ralstoniaeutb \\
\hline ref $\left|Z P \_02382729.1\right|$ & Burkholderia ubonensis Bu & Burkholderia \\
\hline ref | YP_002005766.1| & Cupriavidus taiwanensis & Cupriavidusta \\
\hline $\mathrm{gb}|\mathrm{ABE} 35627.1|$ & Burkholderia xenovorans LB400 & Burkholderiaxe \\
\hline gb|EAP73279.1। & Ralstonia solanacearum UW551 & Ralstoniasola \\
\hline gb|AAQ59041.1। & Chromobacterium violaceum ATCC 12472 & Chromobacteri \\
\hline gb| ABE35234.1 | & Burkholderia xenovorans LB400 & Burkholderiax \\
\hline gb|ABF11905.1| & Ralstonia metallidurans CH34 & Ralstoniametb \\
\hline ref | YP_002254322.1 | & Ralstonia solanacearum MolK2 & Ralstoniasola \\
\hline gb| ACI53681.1 | & $\begin{array}{l}\text { Rhizobium leguminosarum bv. trifolii } \\
\text { WSM2304 }\end{array}$ & Rhizobiumlegu \\
\hline $\mathrm{gb}|\mathrm{ABE} 31092.1|$ & Burkholderia xenovorans LB400 & Burkholderiax \\
\hline gb| ABC24078.1 | & Rhodospirillum rubrum ATCC 11170 & Rhodospirilal \\
\hline gb|AAD02215.1 $\mid$ & Pseudomonas putida & Pseudomonaspu \\
\hline
\end{tabular}

Table 6.2 (cont.) Bacterial species names and the corresponding truncated names in the order of appearance in the list of the phasin sequences in the alignment with $\mathrm{Y}^{\mathrm{T}}{ }^{\mathrm{T}}$ (Fig. 6.2). 
confirmed that no other phasins, with the exception of the sphingomonad phasins, had this low-complexity, alanine/proline-rich segment. A 1000 iteration neighbour-joining bootstrap phylogenetic analysis (CLC Main Workbench 4.1.2, CLC Bio) confirmed the grouping of the $\mathrm{Y}^{8} 8^{\mathrm{T}}$ phasin exclusively with the four other known sphingomonad phasins with 100\% bootstrap values (Fig. 6.4). The alanine/proline-rich $\mathrm{N}$-terminal segment first determined for $\mathrm{Y}^{8} 8^{\mathrm{T}}$ in this study therefore appears to be unique among the sphingomonads (Fig. 6.4).

Bioinformatic secondary structure analysis of the $\mathrm{Y} 88^{\mathrm{T}}$ phasins revealed that the two $13 \mathrm{kDa}$ phasins and the C-terminal segment of the $34 \mathrm{kDa}$ phasin from Met203 to the end of the sequence are predicted to be composed almost entirely of $\alpha$-helices (Fig. 6.5A). Secondary structure predictions for the $13 \mathrm{kDa} R$. eutropha phasin (PhaP1) by Neumann et al., (2008) also predicted mainly $\alpha$ helical domains across the entire phasin sequence that these authors suggest may be implicated in the binding of the entire R. eutropha PhaP1 to the PHB granule. Although there is little absolute sequence conservation among the phasins, the proteins are structurally very similar in that they all comprise amphipathic $\alpha$-helices (Pötter et al., 2005). This structure is consistent with the role of these proteins in binding the large hydrophobic PHA granules while providing a hydrophilic solvent face, presumably to maintain the overall solubility of the PHA granule. Helical wheel analyses of phasins from $\mathrm{Y}^{\mathrm{T}} 8^{\mathrm{T}}$ in this study (Fig. 6.6) and R. eutropha (Fig.6.7), predict that the common portions of both the R. eutropha and $\mathrm{Y} 88^{\mathrm{T}}$ phasins (Figs. 6.5A, 6.5B) are amphipathic (Figs 6.6. 6.7). The predicted amphipathicity may explain the lack of an identified conserved, specific PHA-binding domain in the R. eutropha phasin. It seems likely from its predicted amphipathic helical structure that the phasin binds PHA relatively non-specifically through simple hydrophobic interactions, while providing a soluble solvent interface on the other sides of these predicted $\alpha$ helices. 


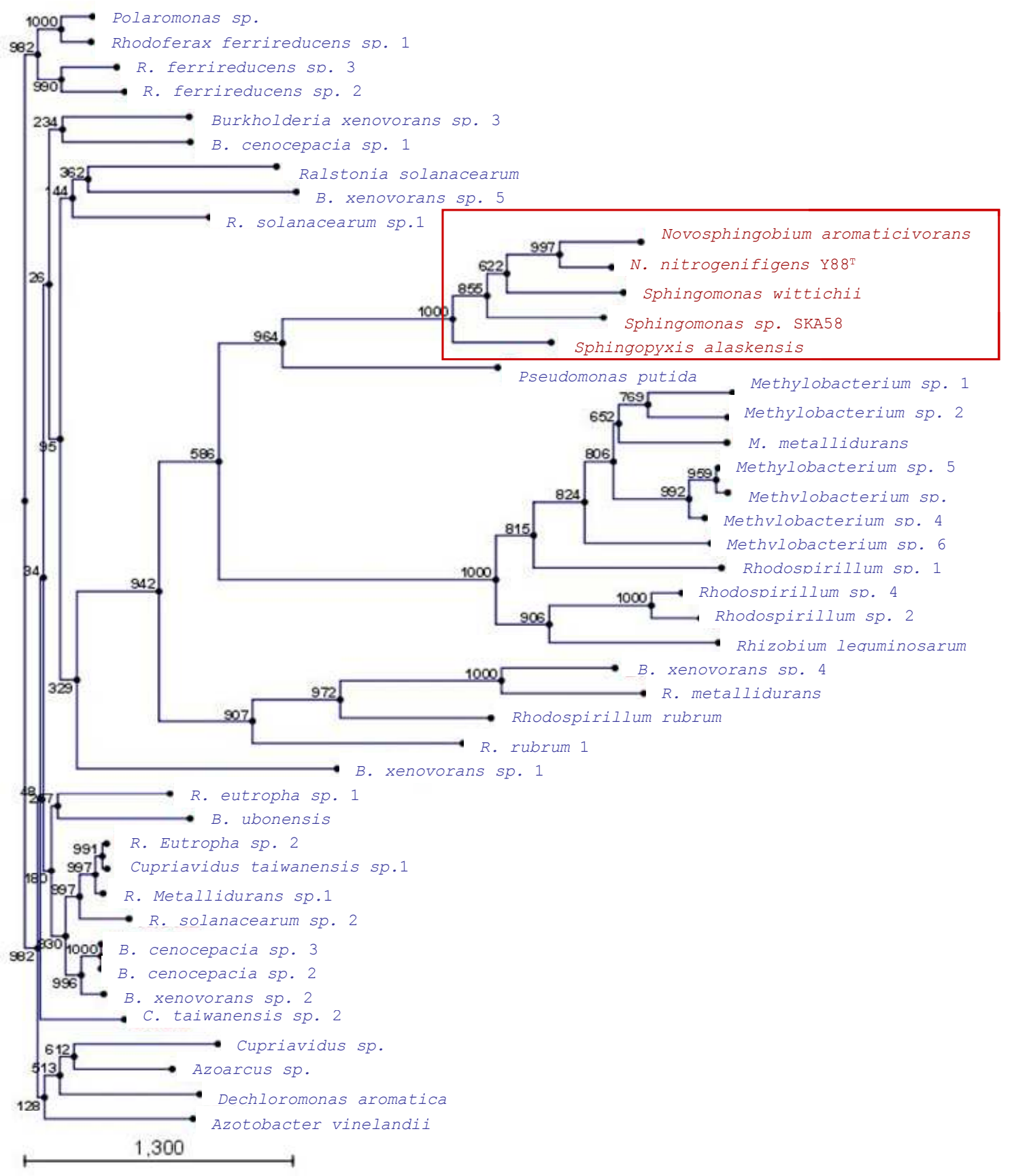

Figure 6.4 Neighbour-joining bootstrap analysis of the $\mathrm{Y}^{8} 8^{\mathrm{T}}$ phasin with 44 phasins from Genbank.

The phylogenetic grouping of the sphingomonad phasins are highlighted (red box). Bootstrap values from 1000 iterations are given at the nodes of each branch. Phylogenetic tree was generated using CLC Main Workbench 4.1.2 (CLC Bio). Branch lengths are given in terms of expected number of substitutions per amino acid site. 1,300 therefore translates to 1.300 (default setting is a comma and needs to be converted to a point) which means that in this tree, branch lengths are based on 1.3 number of substitutions per amino acid site. 
A

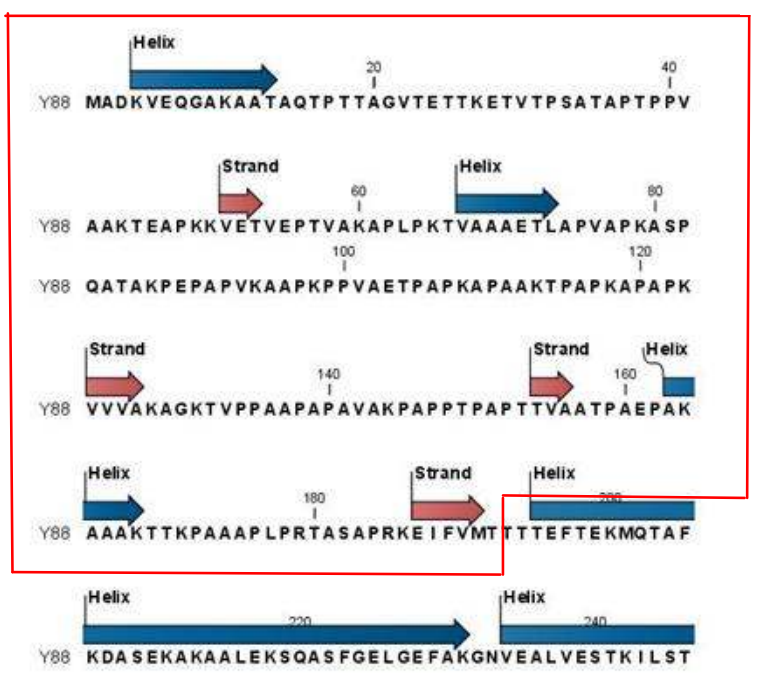

Y88 GLOELGKGYATEGKSAFETLTAEFKDLAAAKTPTELLEKaS

Y88

Y88 $\underset{\text { KIKTAA }}{\stackrel{\text { Hellx }}{\longrightarrow}}$
B

Helix

R. eutropha MT OWTAEQC TKAOMA GLE AMA GL TNKVLE GFEKVMDL

Helix

Helix

R. eutropha NLQTMKMT LAHNREGVMKAL'SV' '́NPQELI IELQIELLFQ

R. eutropha PAADKVLEYRRQLHDILAATRAEFEK IAEVQYTTSKG

Helix

Helix

R. eutropha QLQGLIDSAVSNAPSGS TAPLAAWQEAVKATTALYES

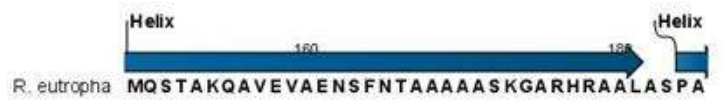

R. eutropha

Figure 6.5 Secondary structure predictions for the $\mathrm{Y} 88^{\mathrm{T}}$ and R. eutropha phasins.

The $\mathrm{Y} 88^{\mathrm{T}}(\mathrm{A})$ and R. eutropha (B) phasins showing the additional N-terminal, low complexity, alanine/proline-rich portion of the $\mathrm{Y} 88^{\mathrm{T}}$ phasin (A; red box) that is N common to the sphingomonads. Secondary structure predictions were generated using CLC Main Workbench 4.1.2 (CLC Bio). 


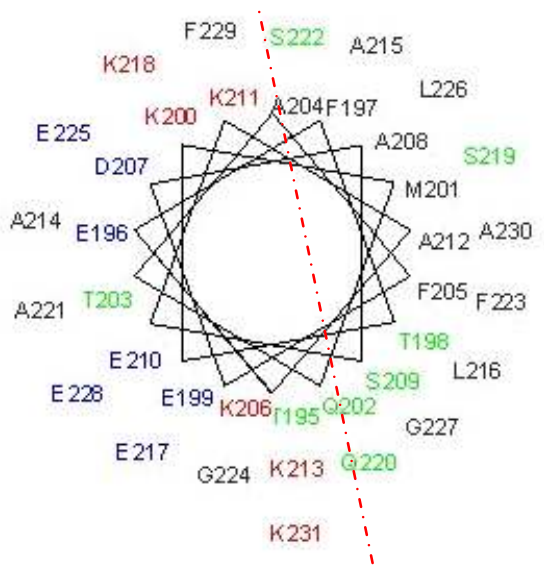

D

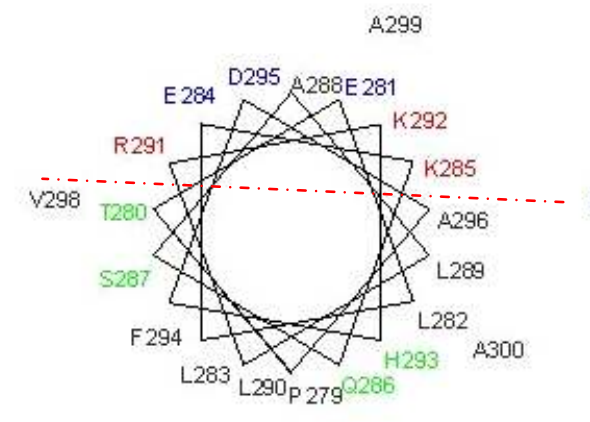

A.297
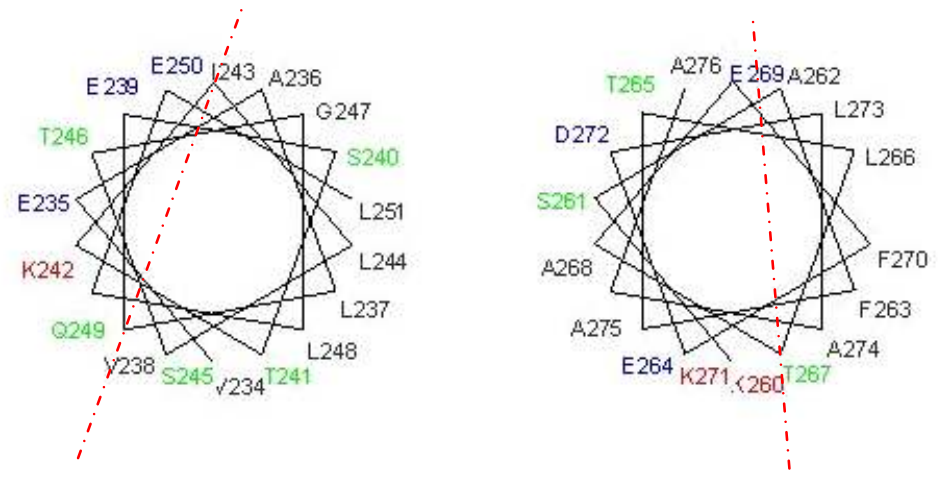

E

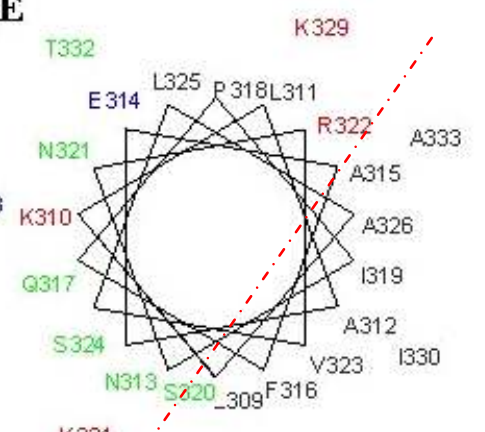

K331 $\because \quad V_{327}$

Figure 6.6 Helical wheel predictions of the $Y 88^{\mathrm{T}}$ phasin

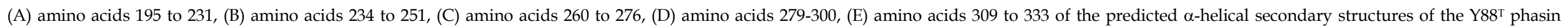

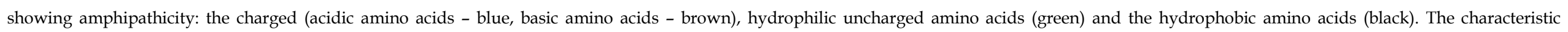
hydrophobic "face" of each structure is apparent to the right of the red line (A, B, C, E) and below the red line (D). Helical wheel diagrams were generated using WinPep 3.01 (Hennig, 1999). 
A

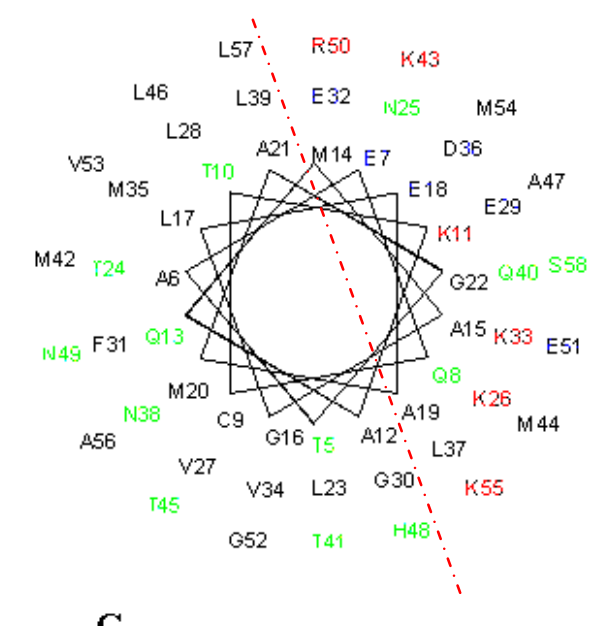

C

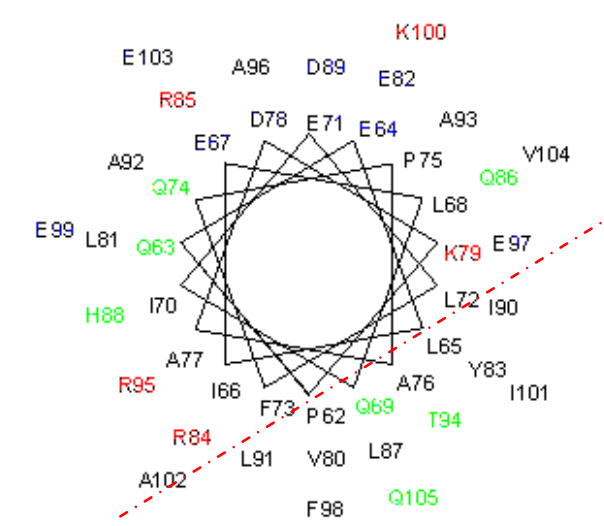

B

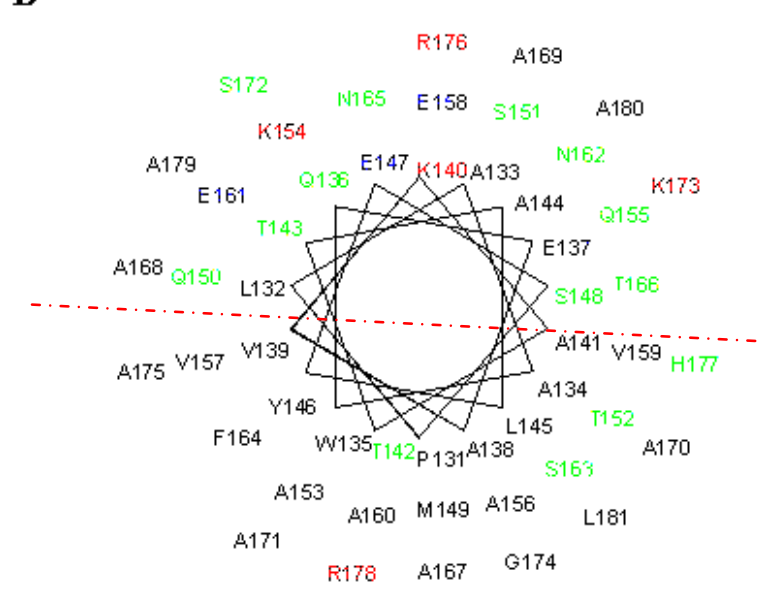

D

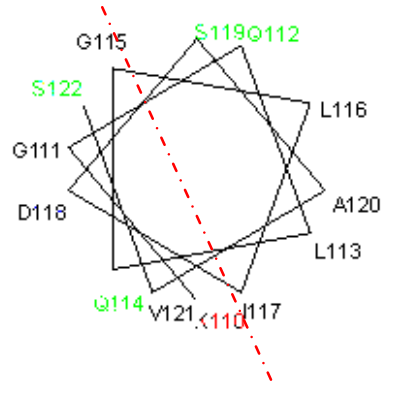

Figure 6.7 Helical wheel predictions of the R. eutropha phasin

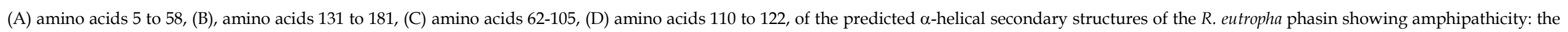

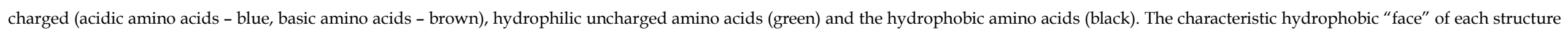

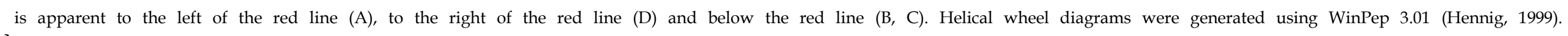


Not surprisingly, given the high proline (an amino acid residue well known to disrupt secondary structure) content of the N-terminal segment of the $34 \mathrm{kDa}$ phasin in $\mathrm{Y} 88^{\mathrm{T}}$, this portion of the $\mathrm{Y} 88^{\mathrm{T}}$ phasin shows very little predicted $\alpha$ helical secondary structure in stark contrast to the C-terminal segment. Secondary structure predictions for the other four sphingomonads examined in this study also predicted almost no $\alpha$-helical secondary structure for the $\mathrm{N}$ terminal portions of their phasins also consistent with the proline-rich primary sequences. Once again, secondary structure for the C-terminal portions of the phasins from these sphingomonads showed almost entirely amphipathic $\alpha$ helical structure similar to that of $Y 88^{\mathrm{T}}$ and $R$. eutropha. Thus the sphingomonad N-terminal segment may serve a separate functional role to the "core" phasin. This idea is supported by the facts that i) the low $M_{r}$ forms appear to be perfectly functional phasins by all known relevant criteria $\left(M_{r}\right.$, sequence homology, secondary structure, amphipathicity), yet ii) the high $\mathrm{M}_{\mathrm{r}}$ form of the $\mathrm{Y}^{\mathrm{T}}{ }^{\mathrm{T}}$ phasin is as abundant as the lower $\mathrm{M}_{\mathrm{r}}$ forms, regardless of acidic or neutral growth conditions and iii) the N-terminal sequence is conserved among the known sphingomonads. It is possible that the N-terminal alanine/prolinerich segment may also be involved in binding of the phasin to the PHB granule. It is possible that this high $\mathrm{M}_{\mathrm{r}}$ form of phasin may play some role in the copious quantities of $\mathrm{PHB}$ produced by $\mathrm{Y}^{8} 8^{\mathrm{T}}$ regardless of the growth conditions in this study, the high molecular weight of the PHB polymers, or both, perhaps by altering the polymer conformation within the granule. Alternatively, since Y88 has only one phasin gene compared to the four identified in R. eutropha, the "additional" alanine/proline-rich N-terminus in the high $\mathrm{M}_{\mathrm{r}}$ form may have a functional role analogous to, but not yet defined for the additional phasins in $R$. eutropha. 


\section{Chapter 7: Summary and Discussion}

\subsection{Y88 : Microbiology, Nitrogen Fixation and Carbon Utilisation}

The capacity to fix nitrogen is characteristic of sphingomonads such as Sphingomonas azotifigens and S. trueperi, but in the main, studies on nitrogen fixation in the sphingomonads, and particularly the Novosphingobia, are lacking. Additionally, the intracellular accumulation of PHA is not well understood in the genus Sphingomonas (Godoy et al., 2003). The intracellular PHA content of only four sphingomonads, Sphingopyxis chilensis, Sphingopyxis alaskensis, Sphingomonas sp. and $N$. aromaticivorans, had been described in any detail prior to a recent study of $Y 88^{\mathrm{T}}$ (Addison et al., 2007). More importantly for this work, studies on the combined ability of bacteria to both accumulate PHA and fix nitrogen are generally lacking and those that have been published have generally focused on the Rhizobia. Of the 13 Novosphingobium species described, the combined capabilities of PHB production and nitrogen fixation appears, at the time of writing, to be unique to $\mathrm{Y} 88^{\mathrm{T}}$.

$\mathrm{Y}^{8} 8^{\mathrm{T}}$ growth was investigated under optimal conditions for nitrogen fixation and PHB accumulation in a minimal nitrogen medium in batch mode with glucose as the preferred carbon source. A reproducible growth profile for Y88T was achieved for growth conditions at $30^{\circ} \mathrm{C}$. Under these conditions, $\mathrm{Y}^{8} 8^{\mathrm{T}}$ grew in a glucose-enriched environment, fixed nitrogen and produced PHB, the size of which exceeded 1,000,000 Da (Chapter 3). This finding is of particular significance because high molecular weight biopolymers such as PHB are desirable from a commercial standpoint to produce higher quality PHAs, as well as from an environmental standpoint as biodegradable replacements for conventional plastics. Y88 ${ }^{\mathrm{T}}$ naturally produces a PHB that exceeds the upper range of 50,000 to $1,000,000$ Da generally produced by bacteria (Madison \& Huisman, 1999). The type (precursor monomer) and molecular weight produced by bacteria varies and is dependent on the species and the carbon source utilised. Y $88^{\mathrm{T}}$ produces high concentrations of PHB with glucose as its 
carbon source, and can do so irrespective of $\mathrm{DO}^{\text {low }}$ or DOhigh concentrations and within a $\mathrm{pH}$ window at least between $\mathrm{pH} 4.5$ and 7.2. PHB production in batch culture by $\mathrm{Y} 88^{\mathrm{T}}$ occurred irrespective of whether or not the cells fixed nitrogen.

Y88 ${ }^{\mathrm{T}}$ also synthesised an extracellular polysaccharide during PHB production. Such polysaccharides are generally considered disadvantageous from a biotechnological standpoint, since they shunt carbon away from PHA and thus decrease PHA yields (Madison \& Huisman, 1999). Despite Y88 $8^{\mathrm{T}}$ producing an exopolysaccharide (confirmed by ${ }^{13} \mathrm{C}-\mathrm{NMR}$ analysis), it still produced up to $80 \%$ of its dry weight as PHB.

Y88 ${ }^{\mathrm{T}}$ proteomic profiles, as expected, included a majority of proteins that showed no significant difference in abundance between growth conditions. In the following sections patterns of protein change are interpreted as indicators of change in physiological state, and potentially also as indicators of change in rate although generally, it is necessary to validate such hypotheses. Proteins that were not detected on the 2-D gels are also expected to participate in $\mathrm{Y}^{\mathrm{T}} \mathrm{P}^{\mathrm{T}}$ function although below the level of detection by 2-D DIGE in this study.

\subsection{Y88 $^{\mathrm{T}}$ growth profiles}

$\mathrm{Y}^{\mathrm{T}} 8^{\mathrm{T}}$ showed reproducible growth, nitrogen fixation and PHB production in a glucose-enriched, minimal nitrogen, medium. Comparisons of Y88 ${ }^{\mathrm{T}}$ with the nitrogen-fixing, PHB-producing, A. vinelandii and the PHB-producing WP01, demonstrated superior growth and PHB by $\mathrm{Y}^{\mathrm{T}} 8^{\mathrm{T}}$ in a glucose-enriched minimal nitrogen medium in batch culture. Initial supplementation of the medium with ammonium promoted the early growth of $\mathrm{Y}^{8} 8^{\mathrm{T}}$. Nitrogenase activity was not detected in the presence of added ammonium as determined by acetylene reduction assays (Chapter 3). Proteomic signatures for $Y 88^{\mathrm{T}}$ during ammoniumsupplemented growth included the absence of the nitrogenase proteins on the 2-D gels (Chapter 4). Once the cells had exhausted the ammonium in the medium, $\mathrm{Y}^{\mathrm{T}} \mathrm{T}$ began fixing nitrogen, as determined by i) acetylene reduction assays, ii) the accumulation of nitrogen above that provided by initial culture conditions (Chapter 5) and iii) confirmed by proteomic analysis (Chapters 4,5) 232 
with the nitrogenase enzymes detected on the 2-D gels. Without the initial nitrogen supplemented in the form of ammonium, Y88 ${ }^{\mathrm{T}}$ growth was lower than that in medium supplemented with small amounts of ammonium, despite its ability to fix molecular nitrogen. $\mathrm{Y}^{\mathrm{T}} 8^{\mathrm{T}}$ therefore requires small amounts of supplemented nitrogen that can be in the form of ammonium in batch culture upon inoculation to initiate and achieve high growth. One possible explanation for such a phenomenon might be that during early growth following inoculation, the initial DO concentration in the medium may be too high to allow the bacteria to immediately fix nitrogen and they must initially deplete the DO in the batch cultures through respiration. A certain initial amount of growth that is dependent on supplemented ammonium may be required to achieve this. Alternatively, a quorum sensing mechanism may also play a role in nitrogen fixation (Brelles-Mariño \& Bedmar, 2001). Given the oxygen lability of nitrogenase, there may be strength in numbers for the bacteria in nitrogen fixation because of the protective effects of extracellular polysaccharides used by aerobic nitrogen fixers (Dong et al., 2002) and quorum sensing provides a mechanism by which the cells could recognise when favourable conditions were present.

Y88 ${ }^{\mathrm{T}}$ growth in batch culture allowed an examination of glucose utilisation, ammonium assimilation and nitrogen fixation as well as the response of the $\mathrm{Y}^{\mathrm{T}}$ proteins to the growth conditions in culture. Moreover, growth in bioreactors allowed examination of the differential responses of $Y 88^{\mathrm{T}}$ to controlled $\mathrm{DO}^{\text {low }}$ and $\mathrm{DO}^{\text {high }}$ at different $\mathrm{pH}$ during changes in the nitrogen source in glucose-enriched medium. Across the various growth conditions, Y $88^{\mathrm{T}}$ assimilated similar amounts of nitrogen and carbon except under DOhigh conditions, where the cells consumed more glucose. This increased glucose consumption did not contribute to increased intracellular carbon levels, since $\mathrm{C}: \mathrm{N}$ ratios and biomass were similar across all growth conditions examined. Increased respiration at DOhigh growth is a possible explanation for this apparent contradiction. Alternatively, the "missing" carbon may have been utilised for exopolysaccharide production, a common oxygen protective 
mechanism among aerobic nitrogen-fixing bacteria. Consistent with this hypothesis, ${ }^{13} \mathrm{C}$ NMR analysis of extracellular material from cell pellets of bacteria grown under high oxygen conditions revealed a spectrum consistent with a carbohydrate, likely consisting of glucose subunits (as mentioned in Chapter 3).

The similarity of the C:N ratio in cells grown in both $\mathrm{DO}^{\text {low }}$ and DOhigh conditions, despite the depletion of the ammonium in the medium, suggested that nitrogen fixation was occurring even under $\mathrm{DO}$ high conditions. A greatly decreased, but still detectable acetylene peak observed for growth under DOhigh meant that this hypothesis could not be ruled out. Thus, $\mathrm{Y} 88^{\mathrm{T}}$ may have a mechanism of oxygen protection that still enables it to fix enough nitrogen to maintain cellular processes, despite downregulation of its nitrogenase under DOhigh conditions. Additional work is required to better understand $\mathrm{Y}^{8} 8^{\mathrm{T}}$ growth and metabolism under DOhigh conditions.

Comparative analysis of the $\mathrm{Y}^{8} 8^{\mathrm{T}}$ proteomic signatures revealed notable differences between the nitrogen-fixing physiology of the cell (ammoniumdepleted conditions, "Fix ${ }^{{ }^{n} \text { ") }}$ and ammonium-assimilatory physiology (ammonium-supplemented conditions, "Fix ${ }^{\text {off" }}$ ). Proteins directly involved in and associated with nitrogen fixation (see section 7.3.2) constituted most of the proteins that showed increased abundance for the Fix ${ }^{\text {on }}$ state. The abundance of these proteins was similar for the Fix ${ }^{\text {on }}$ state in batch flasks and in bioreactors at

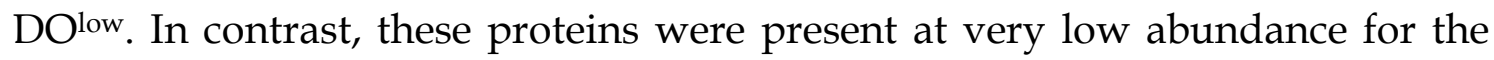
Fix ${ }^{\text {off }}$ state in batch flask culture as well as batch bioreactor culture under DOhigh concentrations. The number of proteins apparently specific to the Fix on state under controlled DO conditions decreased from 38 in the proteomic signatures for growth in acidic media to 10 in the proteomic signatures for growth in neutral media (Chapter 5, Section 5.2.1.5, Figs 5.6, 5.10, Chapter 7, see following section), suggesting that the observed changes in abundance of these proteins was due to the $\mathrm{pH}$ of the growth medium rather than a response to nitrogen depletion in the media. Consistent with this notion, this subset of proteins did 
not include those directly involved in nitrogen fixation (Chapter 5, Fig. 5.6, 5.10).

\subsection{Nitrogen metabolism}

\subsubsection{Assimilation of ammonium}

In free-living nitrogen-fixing prokaryotes, an abundance of fixed nitrogen in the form of ammonium or other compounds such as nitrate or amino acids is reported to affect nitrogen fixation by inhibiting either the synthesis or the activity of nitrogenase (Klugkist \& Haaker, 1984; Klassen et al., 2005). Nitrogen fixation and ammonium metabolism are regulated in a coordinated response to the type and amount of nitrogenous compound available. This response involves a network of proteins that are regulated by post-translational modifications in response to nitrogen availability.

It is well known that exogenous ammonium rapidly and reversibly inhibits nitrogenase activity in a variety of nitrogen-fixing bacteria. In contrast, the ammonium ions produced from the reduction of molecular nitrogen by nitrogenase are assimilated directly into anabolic cellular processes beginning with amino acid synthesis via the coordinated activities of GS and GOGAT. The activity of GS is controlled by the nitrogen source of the growth medium and is high in media in which the nitrogen source is growth-rate limiting and low in media containing an excess of ammonium. Extracellular ammonium is incorporated into glutamine, which in turn regulates GS activity indirectly via product inhibition through the nitrogen regulatory proteins $\mathrm{NtrC}$ and $\mathrm{P}_{\mathrm{II}}$ (Ninfa \& Atkinson, 2000). The GS-GOGAT system links nitrogen metabolism with carbon metabolism, as GS catalyses the incorporation of newly fixed free ammonium into glutamine, and GOGAT transfers the glutamine amide nitrogen to the AKG carbon skeleton resulting in the formation of two molecules of glutamate (Hodges, 2002). In this system, the intracellular glutamine concentration is the critical regulatory point for the cell in sensing its carbon to nitrogen ratio (Hodges, 2002). 
In bacteria, GOGAT occurs as two distinct isoforms: ferredoxin (Fd)-GOGAT and NADPH-GOGAT, the latter of which is an $\alpha / \beta$ heterodimer. In $Y 88^{\mathrm{T}}$, GS and the $\beta$-subunit of NAPDH-GOGAT were present on all 2-D gels examined irrespective of the growth conditions. A two-fold increase in NADPH-GOGAT abundance at $\mathrm{DO}^{\text {low }}$ relative to $\mathrm{DO}$ high concentrations may suggest an increased assimilation of ammonium as a consequence of higher levels of nitrogen fixation at DOlow, consistent with the larger ethylene peak observed in the acetylene reduction assay under these growth conditions (Chapter 5).

Two types of GS are known: GS type I (GSI) and GS type II (GSII) (Darrow \& Knotts, 1977). Analysis of the $Y 88^{\mathrm{T}}$ genomic sequence confirms the presence of genes for both these proteins. Examination of $\mathrm{Y}^{\mathrm{T}} 8^{\mathrm{T}}$ 2-D gels revealed four abundant adjacent GSI spots (under all growth conditions examined) that migrated at similar $\mathrm{M}_{\mathrm{r}}$ but at different pIs. GSII was never identified from any of the gels. This array of GSI proteins is indicative of some form of posttranslational modification. Such modifications of a protein are often a means to regulate enzyme activity. In other species, GSI is usually modified by adenylylation under microaerobic, ammonium-excess growth conditions, which reversibly inactivates GS and results in a downregulation of GSII (Rao et al., 1978). In $Y 88^{\mathrm{T}}$, the abundance of GSI did not appear to be significantly altered by the switch from Fix ${ }^{\text {off }}$ to Fix ${ }^{\text {on }}$ nor by the cells growing in DOhigh. These observations may be consistent with an adenylylation regulatory mechanism, which alters the protein's activity, but not its abundance. Furthermore, the 329 Da difference in size of such a modification might not be detectable, given the abundance and relatively high $\mathrm{M}_{\mathrm{r}}$ of GSI. However, adenylylation cannot explain the pI differences of the four GSI isoforms, since monoadenylylation at a specific tyrosine residue is the basis of the regulation (Selao et al., 2008) and thus the modification does not alter the protein charge. The differences in pI of the proteins suggest that the modifications are from low $\mathrm{M}_{\mathrm{r}}$ charged adducts. The nature of these adducts and their functional significance has yet to be elucidated. 


\subsubsection{Nitrogen fixation in $\mathrm{Y}^{\mathrm{T}} \mathrm{T}$}

Control of nitrogen fixation involves regulatory networks that are still not fully understood (Selao et al., 2008). Although synthesis of the nitrogenase enzyme is known to be under tight transcriptional regulation in all nitrogen-fixing bacteria studied (Martinez-Argudo et al., 2004), in certain bacteria such as R. rubrum, it is also regulated at the metabolic level through the GS/GOGAT system. The proteomic signatures of $\mathrm{Y} 88^{\mathrm{T}}$ in the Fix on state suggest that the nitrogen regulatory system in this organism enables the induction of nitrogenase with no concomitant change in abundance of proteins such as GS and PII under both Fix ${ }^{\text {on }}$ and Fix ${ }^{\text {off }}$ states.

In the Fix ${ }^{\text {on }}$ state at high $\mathrm{OD}_{600}$, the increased abundance of the $\mathrm{Y}^{8} 8^{\mathrm{T}}$ nitrogenase apoproteins (NifDHK) together with proteins known to be involved in the formation and maturation of the nitrogenase apoproteins (NifU) and electron transfer to the nitrogenase complex (electron transfer flavoprotein, ETF-FixAB) suggests that these proteins may form part of a cluster of nitrogen-fixing and accessory proteins that are coordinately regulated to sustain high levels of nitrogenase activity. Their increased abundance is consistent with the large ethylene peaks observed in the nitrogenase assays (Chapters 3, 5). The coordinated increased abundance of ETF-FixAB for the Fix ${ }^{\text {on }}$ state suggests a possible role in supplying reductants to the energy-demanding nitrogenase reaction (Selao et al., 2008). The coordinated decreased abundance of ETFFixAB for the Fix ${ }^{\text {off }}$ state together with NifU is significant in that a decreased supply of reductants from ETF-FixAB may result in the requirements for nitrogenase activity not being met. This would explain the observed coordinated decrease in abundance of the cluster of nitrogen-fixing proteins since less electron transfer may result in reduced nitrogenase turnover requiring less NifU to support a decreased rate of nitrogenase synthesis.

The two forms of $\mathrm{Y}^{8} 8^{\mathrm{T}} \mathrm{NifH}$ identified at different $\mathrm{M}_{\mathrm{r}}$ and pIs are consistent with two NifH forms observed in a Gloeothece cyanobacterium (Gallon et al., 2000), R. rubrum (Selao et al., 2008) and an Azolla cyanobiont (Ekman et al., 
2008). In Anabaena and R. rubrum, one of these forms is known to result from ADP-ribosylation. In contrast, ADP-ribosylation cannot account for the second Y88 ${ }^{\mathrm{T}}$ isoform observed on 2-D gels. Although the difference in $\mathrm{M}_{\mathrm{r}}$ between the two $\mathrm{Y}^{\mathrm{T}} \mathrm{\textrm {T }}$ NifH forms matched the difference that would be expected from the addition of an ADP-ribosyl adduct, examination of the mass spectrum of the peptide containing the site of ADP-ribosylation, the Arg101 residue, did not reveal any evidence for this modification. Palmitoylation of the same conserved peptide is suggested to be the modification found in Gloeothece and Azolla (Gallon et al., 2000; Ekman et al., 2008), but not only was no evidence for this modification found in the Y88 ${ }^{\mathrm{T}}$ MS data, such a modification is also not consistent with the difference in $\mathrm{M}_{\mathrm{r}}$ and $\mathrm{pI}$ observed for the two NifH forms in $\mathrm{Y}^{8} 8^{\mathrm{T}}$. Therefore the $\mathrm{Y} 8^{\mathrm{T}} \mathrm{NifH}$ may be modified differently to NifH proteins from other species.

Notably, the more basic, higher $\mathrm{M}_{\mathrm{r}}$ form of $\mathrm{NifH}$ was barely discernable on 2-D gels for the $\mathrm{Y}^{\mathrm{T}} 8^{\mathrm{T}} \mathrm{Fix}{ }^{\text {on }}$ state at DOlow in neutral growth medium. Despite this apparent decreased abundance, nitrogenase activity was not affected, as similar ethylene peaks were obtained in the acetylene reduction assays for cells grown under both acidic and neutral growth conditions at $\mathrm{DO}^{\text {low }}$. The more basic form of NifH observed may therefore be an inactive, possibly modified form that is targeted for degradation as suggested to be the case for the modified form in Gloeothece and Azolla (Gallon et al., 2000; Ekman et al., 2008). The nature of any potential modification is unclear and requires more detailed biochemical analysis.

The reduced abundance of the $\mathrm{Y}^{\mathrm{T}}$ NifHDK at DOhigh concentrations irrespective of $\mathrm{pH}$ suggests that, like nitrogenase from most bacteria, the $\mathrm{Y}^{\mathrm{T}} \mathrm{P}^{\mathrm{T}}$ nitrogenase appears to be sensitive to DOhigh levels. However, despite decreased abundance of the $\mathrm{Y} 88^{\mathrm{T}}$ nitrogenase under such conditions, it appears that there may still be sufficient nitrogenase to support growth since $\mathrm{OD}_{600}$, biomass and $\mathrm{C}: \mathrm{N}$ ratios were similar regardless of the $\mathrm{DO}$ concentrations. Alternative nitrogenase enzymes that are insensitive to DOhigh are utilised by 
some nitrogen-fixing species (Zhao et al., 2006). Such a hypothesis was considered for $\mathrm{Y} 88^{\mathrm{T}}$, but examination of its genome revealed no candidates for a homologue to such an alternative nitrogenase. However, the $\mathrm{Y} 88^{\mathrm{T}}$ genome sequence did reveal the presence of a gene encoding the nitrogenase-stabilising protein, NifW. NifW is considered to be a part of the oxygen-protection complex that involves the reversible inactivation of nitrogenase via a conformational change, thereby protecting the enzyme from oxygen (Moshiri et al., 1995; Kim \& Burgess, 1996; Lee et al., 1998). Such a reversible protection mechanism for the nitrogenase enzyme might explain the apparent paradox between the decreased abundance of the NifHDK at DOhigh and the continued growth of the cells, as a small proportion of nitrogenase may cycle in and out of the active state, thus supporting growth.

\subsection{Central metabolism, energy and cellular redox state}

Key proteins involved in the ED pathway, EM pathway and OPP glucose catabolic pathways such as KDPG aldolase (a diagnostic enzyme of the ED pathway), glyceraldehyde-3-phosphate dehydrogenase (G3P), fructose-1,6bisphosphate aldolase (a key enzyme of the EM pathway), enolase, phosphoglycerate kinase, 6-phosphogluconate dehydrogenase (6PGDH, a diagnostic enzyme for the OPP pathway) and 6-phosphogluconate dehydratase, amongst others, detected on all the 2-D gels irrespective of the growth conditions suggest that $\mathrm{Y} 88^{\mathrm{T}}$ utilises three interrelated catabolic pathways to metabolise glucose. Of these enzymes, two EM pathway enzymes, glyceraldehyde-3-phosphate (G3P) dehydrogenase and fructose-1,6bisphosphate aldolase were the only proteins to show altered abundance: G3P dehydrogenase increased at low growth and fructose-1,6-bisphosphate aldolase increased at high growth combined with DOlow. Since the proteins from these three pathways generally were present on all 2-D gels regardless of physiological state, they presumably are required to meet metabolic demands. The apparent differential abundance of fructose-1,6-bisphosphate aldolase and G3P dehydrogenase may suggest that there is differential control of the EM pathway. 
Based on proteomic profiling of $\mathrm{Y}^{\mathrm{T}} 8^{\mathrm{T}}$ growth on glucose-enriched, ammoniumsupplemented and ammonium-depleted media, $\mathrm{Y}^{\mathrm{T}}$ appears to have the ability to shunt glucose through the OPP and ED pathways. In Y88 ${ }^{\mathrm{T}}$, 6PGDH and KDPG aldolase were always abundantly expressed regardless of low or high growth and DOlow or DOhigh concentrations, together with another enzyme of the ED pathway, 6-phosphogluconate dehydratase.

The metabolic fates of glucose in the three pathways are different, but yield complementary byproducts of importance to the cell. Ignoring the fate of the carbon for the moment, the EM pathway yields two ATP and two NADH for every glucose molecule processed. In contrast, the OPP and ED pathways yield reducing equivalents instead of ATP, with either two NADPH, or one NADH and one NADPH for every glucose molecule processed in the OPP and ED pathways, respectively (Fig. 7.1). The OPP and ED pathways are therefore costly in terms of energy production. The question thus arises as to what benefit is derived from the utilisation of alternative pathways that result in decreased energy production? Certainly, the OPP pathway is required as the principal source of NADPH for anabolic biochemistry. Coupled with $\mathrm{NADP}^{+}$-dependent isocitrate dehydrogenase, another major route to NADPH, detected under all Y88 ${ }^{\mathrm{T}}$ growth conditions, it would appear that the cells are well-geared toward the production of NADPH. However, it is not as simple to explain the presence of the ED pathway enzymes, since this pathway is only $50 \%$ as efficient as the OPP pathway in producing NADPH as well as 50\% less efficient than the EM pathway in producing ATP (Tauro et al., 1986). It is possible that one of the intermediates in the ED pathway is required as a substrate for a different aspect of metabolism in $\mathrm{Y}^{8} 8^{\mathrm{T}}$, but as it appears that the ED pathway generally serves simply as an alternate oxidative route to pyruvate (Fig. 7.1) (Peekhaus \& Conway, 1998), it might be important for the production of some amino acids after conversion to malate or oxaloacetate via carboxylation reactions. It seems unlikely that the ED pathway would be required by $\mathrm{Y}^{\mathrm{T}} 8^{\mathrm{T}}$ for $\mathrm{NADH}$ production given a highly active aerobic metabolism. However, the ED pathway also generates NADPH, albeit half less than that of the OPP pathway, and it is 


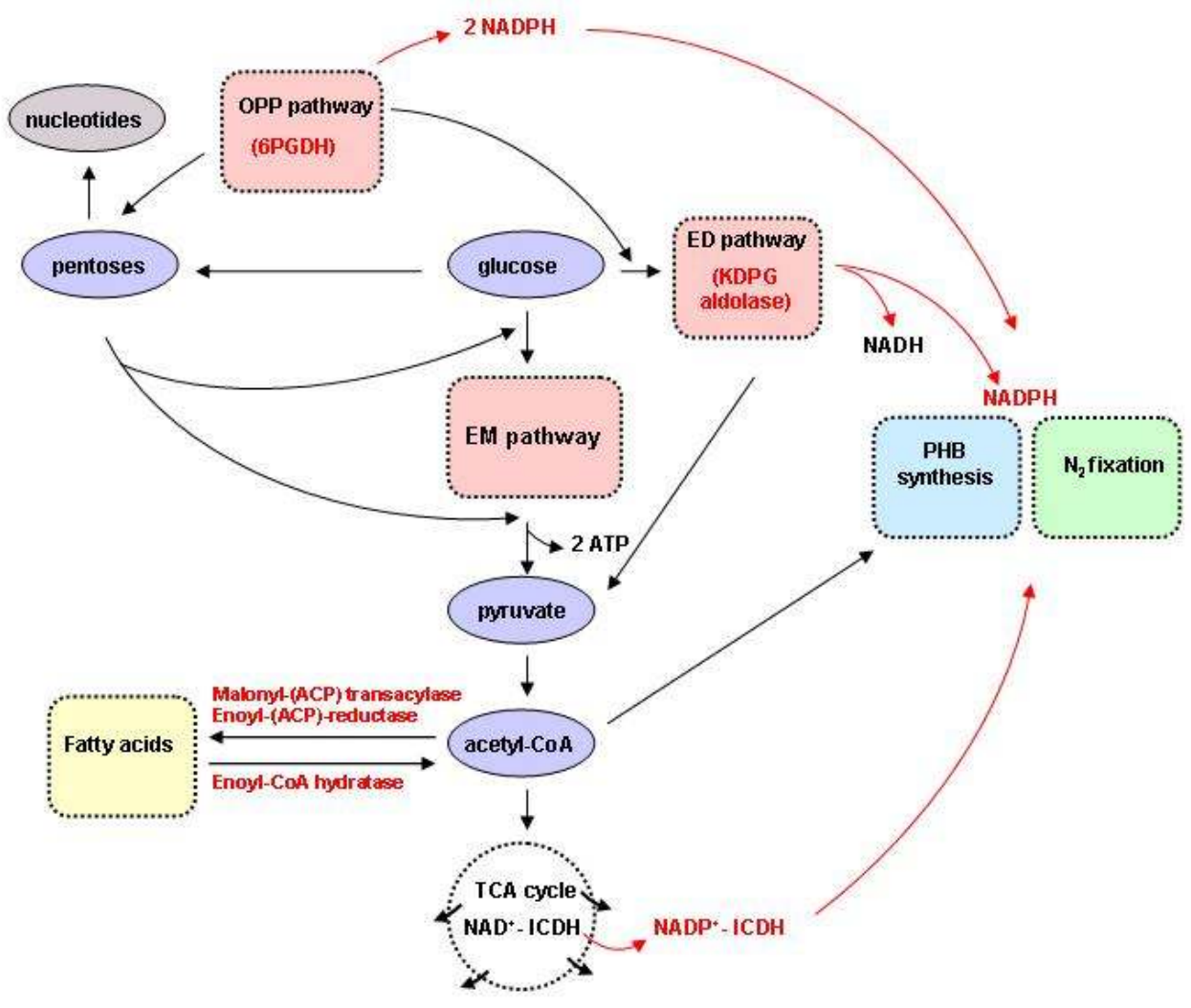

Figure 7.1 Schematic of proposed carbon and reducing equivalent pathways relating to central metabolism, nitrogen fixation and PHB accumulation in $\mathrm{Y}^{8} 8^{\mathrm{T}}$.

Proposed pathways for PHB and reducing equivalents $\mathrm{PHB}$ pathway in $\mathrm{Y}^{\mathrm{T}} 8^{\mathrm{T}}$ including possible alternative routes to PHB production, based on proteomic identification of enzymes (red) involved in the relevant pathways. Carbon pathways are shown as black solid lines and reducing equivalent pathways are shown as red solid lines. 
possible that it is in this aspect that the ED pathway is required by $\mathrm{Y} 88^{\mathrm{T}}$, due to requirement for NADPH possibly unmet by other metabolic means. One possible circumstance that maximal quantities of NADPH might be required for is in cellular responses to oxidative stress. As an aerobic organism, $\mathrm{Y}^{\mathrm{T}} 8^{\mathrm{T}}$ generates NADH from the TCA cycle, which is the initial electron donor to the oxidative phosphorylation electron transport chain. Passage of electrons through the oxidative phosphorylation electron transport chain results in the formation of toxic byproducts in the form of reactive oxygen species (ROS) such as superoxide $\left(\mathrm{O}_{2}{ }^{\left.-{ }^{-}\right)}\right.$and $\mathrm{H}_{2} \mathrm{O}_{2}$. Singh et al., (Singh et al., 2007) suggested that increased synthesis of NADPH and decreased synthesis of NADH is a protective response against oxidative stress in Pseudomonas fluorescens through mechanisms associated with regeneration of reduced glutathione and recharging protective enzymes including catalase, glutathione peroxidase and SOD. Under highly oxidative conditions, an imbalance in NADH/NADPH ratio can occur, resulting in an "oxidative milieu", a condition conducive to cellular dysfunction and the expression of enzymes that promote NADPH production, primarily glucose-6-phosphate dehydrogenase (G6PDH), NADP+dependent isocitrate dehydrogenase and malic enzyme induced to counteract this condition (Singh et al., 2007). Therefore, in growth under highly oxidising conditions, one might expect increased abundance of enzymes involved in $\mathrm{NADPH}$-producing pathways in $\mathrm{Y}^{8} 8^{\mathrm{T}}$.

In this study, none of the key enzymes involved in NADPH production such as the $\mathrm{NADP}^{+}$-dependent isocitrate dehydrogenase or G6PDH that produces most of the NADPH (Marino et al., 2007; Singh et al., 2007) showed altered abundance under any conditions. Consistent with the apparent lack of an induced oxidative response at DOhigh similar amounts of SOD were observed on 2-D gels at both DOlow and DOhigh concentrations. However, the possibility that $\mathrm{DO}^{\text {high }}$ may be stressful to the cells at least in early growth is suggested by the two-fold differential abundance of alkyl hydroperoxide reductase, known to be produced under oxidative stress, between $\mathrm{DO}^{\text {low }}$ and DOhigh concentrations at low growth. In $\mathrm{Y} 88^{\mathrm{T}}$, a highly reductive environment promoted in a glucose- 
enriched environment by high levels of NADPH produced by expression of the different glucose catabolic pathways, may be the reason why an apparently minimal induced oxidative response to DOhigh is evident.

If oxidative stress cannot explain the need for multiple NADPH-producing pathways, what other possible physiological basis might this observation have? Under the growth conditions used in these experiments, $\mathrm{Y}^{8} 8^{\mathrm{T}}$ is essentially constitutively producing PHA and nitrogen fixation is required after the initial ammonium supply is depleted. Therefore, demand for NADPH would be essentially constant and $\mathrm{Y}^{8} 8^{\mathrm{T}}$ may be utilising these pathways, including the ED pathway, to meet this demand (Fig. 7.1). This model assumes that substrate flux through the OPP pathway and $\mathrm{NADP}^{+}$-dependent isocitrate dehydrogenase becomes limiting for NADPH production. Activation of the ED pathway would provide another route to NADPH, albeit a less efficient one. If such a hypothesis proved correct, improvement of reductive flux through the OPP pathway and/or $\mathrm{NADP}^{+}$-dependent isocitrate dehydrogenase could be biotechnological targets for improvement of the organism as a bioplastic producer. Regardless, it appears that under the growth conditions used in these experiments, $\mathrm{Y}^{8} 8^{\mathrm{T}}$ must distribute its glucose among these pathways and maintain a high metabolic flux to meet its energy and redox demands, likely explaining the essentially omnipresence of $\mathrm{NADP}^{+}$-dependent isocitrate dehydrogenase, the enzymes from the EM and OPP pathways, and possibly the ED pathway.

\subsection{PHB production}

Several interesting phenomena were observed in the $\mathrm{Y} 88^{\mathrm{T}}$ proteomic signatures that may explain the abundance of PHB-related proteins observed on all 2-D gels irrespective of growth conditions. Enzymes involved in the PHB synthesis pathway via acetyl-CoA ( $\beta$-Ketothiolase and NADPH-dependent acetoacetylCoA reductase), were observed at constant high abundance on all 2-D gels regardless of growth conditions. Acetoacetyl-CoA reductase, which catalyses the second reaction in the PHB biosynthesis pathway, was observed as two forms at the same $\mathrm{M}_{\mathrm{r}}$ but different pIs on the Y88 ${ }^{\mathrm{T}}$ 2-D gels. Examination of the 
Y88 ${ }^{\mathrm{T}}$ genome confirmed only one gene encoding this protein and therefore the second form is likely due to post-translational processing. Bacteria that naturally produce PHB also synthesise phasin, a protein which is known to cover the surface of PHB granules (Wieczorek et al., 1995; Pötter et al., 2004; Neumann et al., 2008), stabilise the granules and prevent the coalescence of separated granules in the cytoplasm and nonspecific binding of other proteins to the hydrophobic granule surfaces (Neumann et al., 2008). Despite Y88T possessing only one gene encoding a phasin protein, three forms of the $\mathrm{Y}^{\mathrm{T}} \mathrm{T}$ phasin were present at different $\mathrm{M}_{\mathrm{r}}$ and pIs suggesting post-translational processing (Chapter 6). The Y88 ${ }^{\mathrm{T}}$ more basic low $\mathrm{M}_{\mathrm{r}}$ form was the most abundant protein on all 2-D gels under all growth conditions whereas the more acidic low $\mathrm{M}_{\mathrm{r}}$ form was a minor component under neutral growth conditions but highly abundant during acidic growth. The Y88 ${ }^{\mathrm{T}}$ phasin appears to differ from the $R$. eutropha phasins in possessing a low-complexity, alanine- and proline-rich N-terminal segment which is absent from the $\mathrm{Y}^{\mathrm{T}} 8^{\mathrm{T}}$ lower $\mathrm{M}_{\mathrm{r}}$ forms as well as in R. eutropha and all known phasins from other species, excluding the sphingomonads. This N-terminal segment was found to be exclusive to all the sphingomonads examined (Chapter 6). The higher $\mathrm{M}_{\mathrm{r}}$ form observed only on the basic 2-D gels, was also highly abundant under all growth conditions. The presence of the three forms of the $\mathrm{Y} 88^{\mathrm{T}}$ phasin on all 2-D gels at high growth is consistent with the high amount of PHB produced and the presence of high levels of phasin in $\mathrm{Y}^{\mathrm{T}}$ may therefore affect the amount of $\mathrm{PHB}$ produced. Thus all three forms may be implicated in the ability of $Y 88^{\mathrm{T}}$ to produce high concentrations of PHB irrespective of the growth conditions since phasin is known to affect the size and number of PHB granules in the cell in $R$. eutropha H16 (Kuchta et al., 2007). The role of the R. eutropha H16 phasin (PhaP1) has also been linked to PHB degradation and is therefore important in PHB accumulation. Interestingly, 3-hydroxybutyryl-CoA dehydrogenase, involved in the degradation of $\mathrm{PHB}$, was present on all 2-D gels at unaltered abundance, irrespective of growth conditions, like the PHB synthesis enzymes. 
Although $\mathrm{Y}^{\mathrm{T}} 8^{\mathrm{T}}$ produces more $\mathrm{PHB}$ at later stages of growth and during the stationary phase, high concentrations of PHB were evident throughout the growth cycle. No significant change in the abundance of phasin was observed between $\mathrm{DO}^{\text {high }}$ and $\mathrm{DO}^{\text {low }}$ for both the acidic or neutral conditions. However, a significant increase in abundance for all three forms of the $\mathrm{Y}^{\mathrm{T}}{ }^{\mathrm{T}}$ phasin was detected between high and low $\mathrm{OD}_{600}$ during acidic growth. Also, a significant increase in abundance between low and high growth was determined for the more acidic, lower $\mathrm{M}_{\mathrm{r}}$ form at DOlow for the Fix on state, although this was not the case for low and high growth at DOhigh during growth in neutral medium.

Interestingly, enoyl-CoA hydratase, an enzyme involved in fatty acid $\beta$ oxidation, showed significantly increased abundance at high growth relative to low growth at DOlow concentrations in the neutral growth medium, which was the case regardless of DO concentration. The higher abundance of enoyl-CoA hydratase in the later stages of growth may indicate a redirection of carbon metabolism from growth-related activities (i.e., cell membrane synthesis) to carbon storage (i.e., PHB) (Fig. 7.2) as the cultures approach stationary phase (Tsuge et al., 2000). Other fatty acid metabolic enzymes, such as enoyl-(acylcarrier-protein) reductase, which catalyses a key regulatory step in the fatty acid biosynthesis pathway, were present on the $\mathrm{Y}^{8} 8^{\mathrm{T}}$ 2-D gels, as was malonyl CoA-acyl carrier protein (ACP) transacylase, but neither of these proteins showed altered abundance. The latter of these two enzymes catalyses the transfer of the malonyl moiety from ACP to CoASH, in so doing converting (R)3-hydroxyacyl-ACP to the corresponding CoA derivative. This enzyme links fatty acid de novo biosynthesis to PHB production (Rehm et al., 1998) but whether or not this relationship holds in $\mathrm{Y}^{\mathrm{T}} 8^{\mathrm{T}}$ is unknown (Fig. 7.2).

The detected proteins are therefore consistent with functions of biosynthetic pathways geared to apparently maximise PHB production. This raises the question: why are such high levels of PHB required if PHB is essentially an energy reservoir and glucose is present in excess in batch culture? PHAs are often synthesised when one or more other nutrients are limiting. However, 


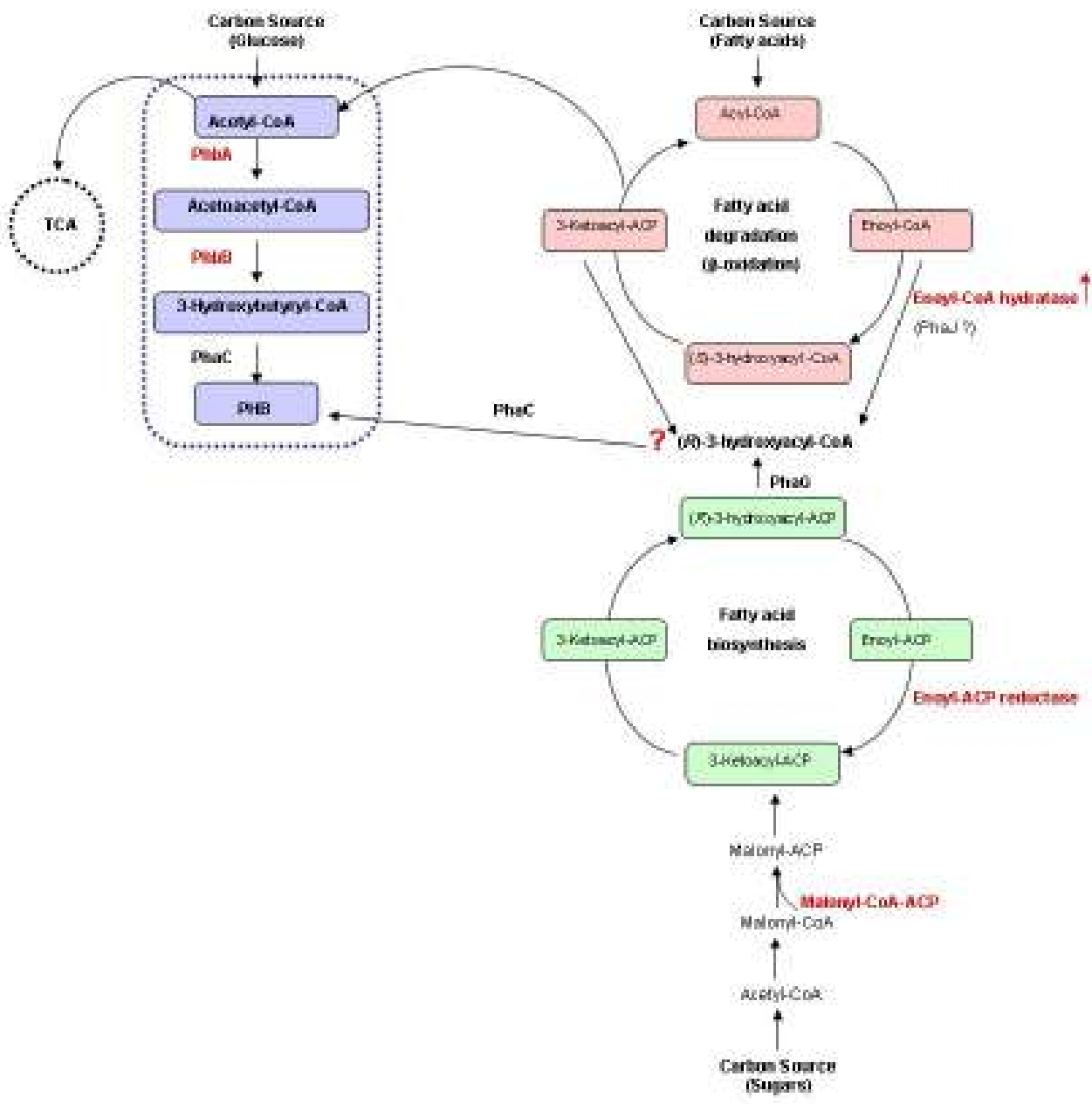

Figure 7.2 Schematic of proposed PHB pathway in Y88 $8^{\mathrm{T}}$ including possible alternative routes to PHB production, based on proteomic identification of enzymes (red) involved in the relevant pathways. Adapted from Tsuge et al., (2002). 
Y88 $^{\mathrm{T}}$ synthesises $\mathrm{PHB}$ despite growth in medium which supports culture growth, so a nutrient limitation response is unlikely. The Novosphingobia, including $\mathrm{Y} 88^{\mathrm{T}}$, are generally found in soil and aqueous environments where substrates like glucose (in free form) are presumably not generally found in abundance. Indeed, species from this genus, such as N. aromaticivorans, harbour genes that enable them to metabolise unusual carbon substrates. As mentioned previously, Y88 ${ }^{\mathrm{T}}$ was isolated from a pulp mill waste stream and glucose, although readily utilisable by $\mathrm{Y}^{8} 8^{\mathrm{T}}$, may not be the predominant carbon substrate in this environment. Thus, the explanation for $\mathrm{Y}^{\mathrm{T}}$ converting glucose to PHB may simply be an ecological one, which confers a competitive advantage to the species. In other words, $\mathrm{Y} 88^{\mathrm{T}}$, upon encountering a rich supply of glucose, may simply be metabolically geared to convert it to PHB in times of "feast" to quickly sequester the glucose away from competitors for later use in times of "famine". Such growth substrate conversion to confer competitive advantage is not unprecedented (Serafim et al., 2004), but further work is required to elucidate the basis for this biotechnologically useful phenomenon.

\subsection{Amino acid and nucleic acid metabolism proteins}

Enzymes catalysing the biosynthesis of various amino acids and nucleic acids as well as those known to be involved in protein repair and degradation were detected on the Y88 ${ }^{\mathrm{T}}$ 2-D gels (Table 7.1). By and large, these enzymes did not vary in their abundance. Their unaltered states possibly reflect their "housekeeping" roles in cellular function.

Another protein observed, saccharopine dehydrogenase, is an intriguing hit to an Arabidopsis protein and appears to be multifunctional since it is also involved in lysine catabolism (Zhu et al., 2001).

\subsection{Outer membrane proteins}

Different outer membrane proteins showed altered abundance for the acidic growth conditions (OmpA/MotB) compared to the neutral growth conditions $(\mathrm{OmpW})$ at high growth and DOlow. Additionally, MotA/TolQ/ExbB proton channel protein was present at constant abundance for the DOlow and DOhigh, 


\section{Enzyme}

\section{Cellular Function}

L-Isoaspartate-(D-aspartate) O-
methyltransferase
polyribonucleotide nucleotidyltransferase
DNA polymerase III beta subunit
dihydroorotate oxidase
phosphoserine aminotransferase
ס-Glutamyl phosphate reductase
homoserine dehydrogenase
phenylalanyl-tRNA synthetase, a-subunit
saccharopine dehydrogenase

repair non-enzymatically damaged protein

RNA processing and mRNA degradation

DNA Replication

pyrimidine biosynthesis

serine and pyridoxine biosynthesis

proline biosynthesis

amino acid biosynthesis

protein synthesis

lysine catabolism, carbon/energy supply

Table 7.1 Y88 ${ }^{\mathrm{T}}$ enzymes involved in protein and nucleic acid synthesis that showed unaltered states irrespective of the growth conditions. 
acidic and neutral conditions. These proteins may play a role in exopolysaccharide export or the transport of peptides across the membrane and their altered appearance may be related to the osmolality of the culture medium as suggested for E. coli (Han \& Lee, 2003). They may therefore alter certain aspects of the outer membrane permeability of $\mathrm{Y}^{\mathrm{T}} 8^{\mathrm{T}}$ with increase in cell density and at DOlow conditions under acidic or neutral growth conditions as suggested by the altered abundance of porin proteins.

\subsection{Other}

$\mathrm{Y}^{\mathrm{T}}$ proteomic profiles included a majority of proteins that showed no significant difference in abundance between growth conditions. The fact that many proteins show visually detectable alterations in abundance but are not determined by BVA analysis to have significantly altered abundance does not imply that these changes lack biological significance. Each 2-D DIGE gel is essentially a "snapshot" of the protein state at the moment of culture sampling and the differences observed between two sampling points reflect only the physiological states of the cells at those moments. Proteins that show more subtle alterations in abundance may show differences above the BVA threshold at other sampling times. Essentially, these changes are likely indicative of constantly changing physiological conditions that presumably mask small transient changes maintaining cellular functions related to general and more specialised pathways, such as PHB production.

\subsection{Future prospects}

The work described here has highlighted important proteins involved in and associated with the major core metabolic, nitrogen fixation and PHB synthesis pathways as well as possible alternative pathways to increase PHB production. This work provides important direction for future studies of PHB production in nitrogen-fixing bacteria. Particular proteins detected here could be the focus of investigations for biochemical characterisation to verify function, to examine regulatory details of expression and to measure specific enzyme activities in full-scale PHB production systems (Wilmes et al., 2008). Also, this project provides structural and functional insight into $\mathrm{Y}^{\mathrm{T}} 8^{\mathrm{T}}$ nitrogen fixation and $\mathrm{PHB}$ 
production in batch culture. Further work directed toward optimising $Y 88^{\mathrm{T}}$ growth in continuous culture would be advantageous from a production scale perspective to maintain $\mathrm{Y}^{8} 8^{\mathrm{T}}$ in a steady state of continuous $\mathrm{PHB}$ production.

The data from this work suggest the possibility that $Y 88^{\mathrm{T}}$ may prove to be a useful production strain in pure culture. Experiments on PHB synthesis and extraction from large-scale cultures for the purpose of testing the PHB for its usefulness in manufacturing processes are underway (A-M Smit, G Lloyd-Jones \& A. Fernyhough, unpublished results). Biotechnological improvement of Y88 as a potential production strain is another possibility and several targets for improvement of the strain are noted here. Regardless of the outcome of such experiments, the concept of the use of a nitrogen-fixing PHA-producing bacterium either as a low cost means of converting waste streams to a useful product or as a production strain in pure culture has been shown to be plausible here.

The ubiquity of key proteins such as the $\mathrm{Y} 88^{\mathrm{T}}$ phasin, regardless of growth conditions, suggests that the PHB synthesis capability of $\mathrm{Y}^{8} 8^{\mathrm{T}}$ is highly robust and that, unlike many other PHB-producing bacteria, $\mathrm{Y}^{\mathrm{T}}{ }^{\mathrm{T}}$ is capable of producing PHB under a wide range of conditions. Phasin abundance appeared to be positively correlated to the quantity of intracellular PHB, which accumulated most rapidly in the late stages of growth. Based on these observations, maintenance of $\mathrm{Y} 88^{\mathrm{T}}$ cells in a state of growth akin to late log phase could allow for continuous optimal production of PHB. In a production environment, phasin has the potential to be utilised as a biomarker to maintain the cells in such a state and maximisation of phasin expression would presumably correlate with the maximisation of PHB accumulation.

Further studies using recombinant E. coli and the Y88 beneficial in determining the functional role of phasins and their role in PHB production. In this regard, in situ experiments involving antibody probing and immunogold detection of the $\mathrm{Y}^{8} 8^{\mathrm{T}}$ phasin (with and without the 
sphingomonad-specific N-terminus) to determine where in the cell the intact phasin and the truncated phasin are located, may reveal the functional significance, if any, of the N-terminal segment of the $\mathrm{Y}^{\mathrm{T}} 8^{\mathrm{T}}$ phasin in $\mathrm{PHB}$ production, and for sphingomonads in general.

Further studies on the $\mathrm{Y} 88^{\mathrm{T}}$ nitrogenase, in particular the NifH apoprotein, is required to determine whether the $\mathrm{Y}^{8} 8^{\mathrm{T}} \mathrm{NifH}$ undergoes post-translational modification as established for several other nitrogen fixers and what the functional significance, if any, of this would be. Furthermore, ${ }^{15} \mathrm{~N}$ isotope labeling experiments to trace the incorporation of nitrogen in the cell during DOhigh growth conditions, thereby increasing the nitrogen content in the cell and confirming that nitrogen fixation occurs irrespective of DOhigh, will irrefutably confirm whether or not nitrogenase is active or inactive under DOhigh. An alternative option would be to monitor the amount of nitrogenase present throughout the growth process by employing immunoblotting at different times corresponding to that period of growth when $\mathrm{Y}^{8} 8^{\mathrm{T}}$ is known to fix nitrogen and not to fix nitrogen.

Currently, international focus in biotechnology has shifted to producing nextgeneration biofuels using engineered microorganisms to produce fossil fuel replacements (Keasling \& Chou, 2008). A more far-reaching implication of understanding the role of $\mathrm{Y}^{8} 8^{\mathrm{T}}$ proteins in the PHB synthetic pathway is the prospect of the development of bioproducts other than PHB. Since Y88 ${ }^{\mathrm{T}}$ has the ability to naturally produce PHB to high levels in its cells, excess amounts of the 4-carbon intermediate, 3-hydroxybutyryl-CoA, generated in the initial steps of the PHB synthetic pathway, could be redirected through metabolic engineering to produce a "next-generation" biofuel such as butanol (Keasling \& Chou, 2008). Additionally, the use of early intermediates in the synthesis of alternative PHAs with varying alkyl groups or chain lengths, offer the potential of even more carbon-rich biofuels with improved properties over biobutanol. The natural propensity of $\mathrm{Y}^{8} 8^{\mathrm{T}}$ to metabolise glucose to preferentially produce $\mathrm{PHB}$ offers a substantial biotechnological advantage in that the metabolic 
engineering of this microorganism can focus on what to do with the high quantities of its early synthetic precursors, be it to make bioplastic or biofuel. Although this study initially set out to understand the interplay of PHA accumulation and nitrogen fixation of $\mathrm{Y}^{\mathrm{T}} 8^{\mathrm{T}}$ to enhance bioremediation processes, the real value of this organism may thus lie in its potential in pure culture as a production strain for reduced-cost biomaterials. 


\section{Chapter 8 Appendices}

8.1 Appendix A Additional proteins (following six pages) not all discussed in chapters 4-7 identified by Mascot-based searches of LC-MS/MS data.

Supporting peptide data confirming positive identifications are shown. Protein identifications represent proteins at DOlow / DOhigh, constant $\mathrm{pH}$, linear range $\mathrm{pH}$ 4-7. See 2-D preparative gel (Fig. A.1 below) for spots matching identified proteins and corresponding spots in this table.

\begin{tabular}{|c|c|c|c|c|c|c|c|}
\hline $\begin{array}{c}\text { Spot } \\
\text { number }\end{array}$ & Protein ID & $\begin{array}{l}\text { Two highest scoring unique peptides } \\
\text { (peptide score) }\end{array}$ & $\mathrm{Mr}$ & Score & $\begin{array}{l}\text { Queries } \\
\text { matched }\end{array}$ & pl & $\begin{array}{l}\text { Sequence } \\
\text { coverage }\end{array}$ \\
\hline \multirow[t]{2}{*}{ A1 } & Nitrogenase molybdenum-iron beta chain & R.LAGVEIPDDLAK.E(65) & 58444 & 127 & 15 & 5.37 & 9 \\
\hline & & R.FVMEVAR.L(46) & & & & & \\
\hline \multirow[t]{5}{*}{ A2 } & glutamyl-tRNA(Gln) amidotransferase, B subunit & K.MLETGDAPGSIVER.E (76) & 54554 & 178 & 5 & 5.25 & 8 \\
\hline & & R.ADVNVSVR.R (70) & & & & & \\
\hline & pyridine nucleotide-disulphide oxidoreductase, class-II, active site & M.PILDAATTAQLK.A(78) & 55268 & 347 & 21 & 5.31 & 12 \\
\hline & & R.MDLAQIVAK.L(53) & & & & & \\
\hline & GMP synthase & K.TFIDVFEEEAR.Q (30) & 57278 & & & 5.43 & 2 \\
\hline A3 & D-3-phosphoglycerate dehydrogenase & R.VTVGTDEGEK.A (45) & 56092 & 93 & 6 & 5.44 & 3 \\
\hline \multirow[t]{4}{*}{ A4 } & hypothetical protein BRADO5426 & R.ISDTAFGTLEAAR.R (85) & 22861 & 187 & 5 & 4.93 & 18 \\
\hline & & M.SATTSPSLETVR.I (72), & & & & & \\
\hline & Inorganic diphosphatase & R.SPFVPGAVVR.A (43) & 20089 & 90 & 5 & 4.9 & 10 \\
\hline & & R.IVVEAIER.E (39) & & & & & \\
\hline \multirow[t]{4}{*}{ A5 } & nitrogenase iron protein & K.STTSQNTLAALADLGQR.I(86) & 31859 & 205 & 16 & 4.94 & 20 \\
\hline & & R.LGGLICNER.Q(63) & & & & & \\
\hline & GrpE protein & R.DILSVADNLAR.A (66) & 20712 & 63 & 1 & 4.86 & 5 \\
\hline & Inorganic diphosphatase & R.SPFVPGAVVR.A (35) & 20089 & 337 & 47 & 4.9 & 5 \\
\hline \multirow[t]{6}{*}{ A6 } & glutamine synthetase & R.LVPGFEAPVLLAYSAR.N (81) & & & & & \\
\hline & & K.ALNAFTNPTTNSYK.R (70) & & & & & \\
\hline & Glucose-6-phosphate isomerase & R.QLFEGETINNTEGR.A (76), & 42356 & 198 & 3 & 178 & 15 \\
\hline & & R.AAFADLVYTQALGCQTR.A (73) & & & & & \\
\hline & chaperonin GroEL & R.AAVEEGIVTGGGTALLYATK.A (103) & 57484 & 198 & 3 & 5.09 & 7 \\
\hline & & K.LENVTLGMLGQAK.K (89) & & & & & \\
\hline \multirow[t]{5}{*}{ A7 } & glutamine synthetase, type I & R.INDEEIEWVDLR.F (72) & 52156 & 331 & 10 & 4.94 & 23 \\
\hline & & K.GGYFPVAPVDSLVDIR.G (70) & & & & & \\
\hline & anthranilate synthase component I & R.LAEAIELAR.Q (71) & 54709 & 68 & 1 & 4.93 & 4 \\
\hline & & R.LIADTETPVGAALK.L (68) & & & & & \\
\hline & glutamyl-tRNA(GIn) amidotransferase, A subunit & M.TNLTEFGIAAIR.D (69) & 52826 & & & 4.92 & 2 \\
\hline \multirow[t]{2}{*}{ A8 } & glutamine synthetase, type I & R.INDEEIEWVDLR.F (66), , & 52156 & 262 & 10 & 4.94 & 25 \\
\hline & & K.ALNAFTNPTTNSYK.R (64) & & & & & \\
\hline \multirow[t]{4}{*}{ A9 } & glutamine synthetase, type I & K.AINAFTNPTTNSYK.R (75) & 54554 & 178 & 5 & 5.25 & 8 \\
\hline & & R.LVPGFEAPVLLAYSAR.N (73) & & & & & \\
\hline & glutamine synthetase, type I & K.IDDIELPTNSNR.V (69) & 52267 & 125 & 12 & 4.94 & 15 \\
\hline & & K.GGYFPVAPVDSLVDIR.G (61) & & & & & \\
\hline \multirow[t]{2}{*}{ A10 } & Argininosuccinate synthase & K.GQALVVGR.K (59) & 45192 & 79 & 3 & 5.37 & 5 \\
\hline & & R.GIESITLDR.G (46) & & & & & \\
\hline \multirow[t]{4}{*}{ A11 } & translation elongation factor $\mathrm{Tu}$ & K.GSALAALEGRDDAIGKDSIK.E (52) & 43045 & 129 & 6 & 5.16 & 11 \\
\hline & & R.KLLDQGEAGDNVGALIR.G (45) & & & & & \\
\hline & 3-isopropylmalate dehydrogenase & K.GLANPMATILSAAMLLR.H (84) & 37267 & 112 & 3 & 5.19 & 7 \\
\hline & & R.TLADGILGR.D (42) & & & & & \\
\hline \multirow[t]{3}{*}{ A12 } & oxidoreductase, 2OG-Fe(II) oxygenase family & R.MAVAADLGK.A(50) & 39009 & 138 & 6 & 5.07 & 2 \\
\hline & Ribonucleoside-diphosphate reductase & R.LFQAFVQER.D (56) & 41366 & 71 & 2 & 4.99 & 4 \\
\hline & & R.NLLTQIFR.F (44) & & & & & \\
\hline
\end{tabular}




\begin{tabular}{|c|c|c|c|c|c|c|c|}
\hline $\begin{array}{c}\text { Spot } \\
\text { number }\end{array}$ & Protein ID & $\begin{array}{l}\text { Two highest scoring unique peptides } \\
\text { (peptide score) }\end{array}$ & $\mathrm{Mr}$ & Score & $\begin{array}{l}\text { Queries } \\
\text { matched }\end{array}$ & pl & $\begin{array}{l}\text { Sequence } \\
\text { coverage }\end{array}$ \\
\hline \multirow[t]{3}{*}{ B1 } & NifU & R.TNGLTSIDEVTNYTK.A(110) & 33542 & 1139 & 29 & 4.72 & 22 \\
\hline & & R.VNAEMVAEGALAPER.A(82) & & & & & \\
\hline & OmpA/MotB & K.YNLGLSAR.R (39) & 11983 & 48 & 2 & 5.76 & 7 \\
\hline \multirow[t]{4}{*}{ B2 } & electron transfer flavoprotein, alpha subunit & K.LGAAIGASR.A(60) & 31153 & 141 & 3 & 4.8 & 14 \\
\hline & & R.AAVDAGYVPNDYQVGQTGK.I(50) & & & & & \\
\hline & OmpA/MotB & K.YNLGLSAR.R (45) & 11983 & 96 & 6 & 5.76 & 37 \\
\hline & & R.NASVQSYLTAHGIPAAEIATK.A (38) & & & & & \\
\hline \multirow[t]{3}{*}{ B3 } & translation elongation factor $\mathrm{Tu}$ & K.LIAPIAMDEGLR.F (58) & 42934 & 77 & 3 & 5.16 & 10 \\
\hline & & R.TVGSGVVSK.I (44) & & & & & \\
\hline & OmpA/MotB & K.YNLGLSAR.R (42) & 11983 & 96 & 6 & 5.76 & 18 \\
\hline \multirow[t]{2}{*}{ B4 } & adenosylhomocysteinase & K.VACVAGFGDVGK.G(80) & 50877 & 788 & 38 & 5.33 & 20 \\
\hline & & R.DEFGPTQPLK.G(47) & & & & & \\
\hline B5 & putative glutaredoxin family protein & R.GEFVGGCDIVR.E (47) & 12194 & 48 & 1 & 4.55 & 9 \\
\hline B6 & OmpA/MotB & K.YNLGLSAR.R (43) & 11983 & 77 & 5 & 5.76 & 7 \\
\hline \multirow[t]{3}{*}{ B7 } & Uspa & K.DAGLVVMGLFGK.S (71) & 27836 & 266 & 7 & 5.03 & 16 \\
\hline & & R.KGTIAATIEDFAR.E(68) & & & & & \\
\hline & 4-diphosphocytidyl-2C-methyl-D-erythritol kinase & R.LPVAAGLGGGSADAGAIFR.L (141) & 28778 & 141 & 1 & 5.08 & 7 \\
\hline \multirow[t]{2}{*}{ B8 } & hypothetical protein Saro_2615 & K.AAYLQPNFSSTK.D(58) & 29433 & 267 & 14 & 5.92 & 7 \\
\hline & & K.TDFGEPFIK.V(33) & & & & & \\
\hline \multirow[t]{2}{*}{ B9 } & 3-oxoacid CoA-transferase, subunit A & R.AGGAGIPGFYTK.T (60) & 25869 & 143 & 4 & 5.43 & 9 \\
\hline & & R.MIVGSPYDKK.I (41) & & & & & \\
\hline \multirow[t]{2}{*}{ B10 } & Phasin & K.SQASFGELGEFAK.G (91) & 33963 & 438 & 16 & 9.56 & 24 \\
\hline & & K.SAFETLTAEFK.D (74) & & & & & \\
\hline \multirow[t]{3}{*}{ B11 } & ribosomal protein $\mathrm{L} 7 / \mathrm{L} 12$ & K.LTVLEAADLAK.A (83) & 12683 & 323 & 9 & 4.65 & 24 \\
\hline & & K.IEEAGGTVEIK.X (78) & & & & & \\
\hline & Phasin & K.SQASFGELGEFAK.G (67) & 33963 & 233 & 5 & 9.56 & 3 \\
\hline \multirow[t]{8}{*}{ B12 } & ribosomal protein $\mathrm{L} 7 / \mathrm{L} 12$ & K.LTVLEAADLAK.A (74) & 12683 & 422 & 12 & 4.65 & 28 \\
\hline & & R.AITSLGLTEAK.A (66) & & & & & \\
\hline & pyruvate dehydrogenase & K.TLADLAQVTEMK.T (75) & 20244 & & & 5.12 & 6 \\
\hline & protein of unknown function DUF179 & R.AEGIDPSHLVAATGR.A (34) & 19809 & & & 5.07 & 8 \\
\hline & protein-L-isoaspartate(D-aspartate) O-methyltransferase & R.VLVIGKPGAYLAAVTAK.V(47) & 20640 & 64 & 2 & 5.03 & 12 \\
\hline & & R.AMIESQLR.V(44) & & & & & \\
\hline & ribosomal protein L7/L12 & K.LTVLEAADLAK.A (80) & 12683 & & & 4.65 & 8 \\
\hline & translation elongation factor Tu & K.TTLTAAITK.V (47) & 43045 & & & 5.16 & 2 \\
\hline \multirow[t]{5}{*}{$\mathrm{C} 2$} & protein-L-isoaspartate(D-aspartate) O-methyltransferase & R.VLVIGKPGAYLAAVTAK.V (59) & 20640 & 64 & 2 & 5.03 & 12 \\
\hline & & R.AMIESQLR.V (44) & & & & & \\
\hline & Inorganic diphosphatase & R.SPFVPGAVVR.A (46) & 20089 & & & 4.9 & 9 \\
\hline & 2-dehydro-3-deoxyphosphogluconate aldolase/4-hydroxy-2-oxoglutarate & R.ILHTPMR.Y (26) & & & & & \\
\hline & aldolase & K.GEPDVVAIEAAAR.A (61) & 20779 & & & 5.15 & 6 \\
\hline \multirow[t]{5}{*}{ C3 } & nitrogen regulatory protein $\mathrm{P}$-II & K.IFVLDLASATR.I (89) & & & & & \\
\hline & & K.GQTEIYR.G (46) & & & & & \\
\hline & nitrogen regulatory protein $\mathrm{P}$-II & K.IFVLDLASATR.I (87), & 12090 & 236 & 5 & 5.13 & 30 \\
\hline & & R.EALSGLGVAGMTVSEVK.G (76) & & & & & \\
\hline & Inorganic diphosphatase & R.SPFVPGAVVR.A (41) & 20089 & & & 4.9 & 5 \\
\hline \multirow[t]{6}{*}{$\mathrm{C} 4$} & isocitrate dehydrogenase & K.VQNPIVEIDGDEMTR.I (66) & & & & & \\
\hline & & R.LIDDMVASALK.W (61) & & & & & \\
\hline & isocitrate dehydrogenase, NADP-dependent & K.YYDLSVQNR.D (62) & 46087 & 114 & 3 & 5.28 & 8 \\
\hline & & R.LIDDMVASALK.W (60) & & & & & \\
\hline & & K.VKNPIVELDGDEMTR.I (56) & & & & & \\
\hline & Methionine adenosyltransferase & R.HSGAAPFLEPDAK.S (37) & 43503 & & & 5.27 & 3 \\
\hline
\end{tabular}




\begin{tabular}{|c|c|c|c|c|c|c|c|}
\hline $\begin{array}{c}\text { Spot } \\
\text { number }\end{array}$ & Protein ID & $\begin{array}{l}\text { Two highest scoring unique peptides } \\
\text { (peptide score) }\end{array}$ & $\mathrm{Mr}$ & Score & $\begin{array}{l}\text { Queries } \\
\text { matched }\end{array}$ & $\mathrm{pl}$ & $\begin{array}{l}\text { Sequence } \\
\text { coverage }\end{array}$ \\
\hline \multirow[t]{3}{*}{ C5 } & alkyl hydroperoxide reductase/ Thiol specific antioxidant/ Mal allergen & K.GIDEVACTAVNDPFVMK.A (67) & & & & & \\
\hline & alkyl hydroperoxide reductase/ Thiol specific antioxidant/ Mal allergen [ & K.ALGLVLDGSGFGLGQR.G (84) & 16726 & 141 & 5 & 4.84 & 36 \\
\hline & & K.GVDEIACTAVNDPFVMK.A (75) & & & & & \\
\hline \multirow[t]{3}{*}{ C6 } & chromosome segregation protein SMC & R.LSDLTSEIR.R (75) & & & & & \\
\hline & alkyl hydroperoxide reductase/ Thiol specific antioxidant/ Mal allergen & K.FVDLTDADIAGK.W (87) & 20864 & 278 & 8 & 4.79 & 17 \\
\hline & & K.LKPFANTAFYQGK.F (44) & & & & & \\
\hline \multirow[t]{4}{*}{$\mathrm{C7}$} & inorganic pyrophosphatase & K.KSGALFVDR.L (67) & & & & & \\
\hline & Inorganic diphosphatase & K.ESGALFVDR.I (67) & 20089 & 163 & 8 & 4.9 & 30 \\
\hline & & R.VGTWGGAEDAR.R (59) & & & & & \\
\hline & Electron transfer flavoprotein beta-subunit & R.TALAMGADR.A (32) & 26104 & 32 & 1 & 5.5 & 3 \\
\hline \multirow[t]{3}{*}{$\mathrm{C} 8$} & pantoate--beta-alanine ligase & MSPATLLR.S (58) & & & & & \\
\hline & isochorismatase hydrolase & K.SIDATLLR.N (63) & 23573 & 157 & 7 & 5.06 & 11 \\
\hline & & R.TETYEHTTGIAR.K (57) & & & & & \\
\hline \multirow[t]{3}{*}{ C9 } & ATP-dependent Clp protease proteolytic subunit 3 & R.GMASDIEIQAR.E (75) & & & & & \\
\hline & isochorismatase hydrolase & K.SFSGPMFEEVTAPFPGK.A (66) & 23573 & 86 & 3 & 5.06 & 10 \\
\hline & ATP-dependent Clp protease, proteolytic subunit ClpP & R.GMASDIEIQAR.E (66) & 25292 & 67 & 1 & 4.92 & 4 \\
\hline \multirow[t]{6}{*}{$\mathrm{C} 10$} & ATP-dependent Clp protease, proteolytic subunit ClpP & R.GMASDIEIQAR.E (76) & & & & & \\
\hline & & R.SFDIYSR.L (29) & & & & & \\
\hline & transaldolase, putative & K.IGADVITAPPAVIK.G (58) & 23406 & 74 & 2 & 5.19 & 11 \\
\hline & & K.AGATFVSPFVGR.H (47) & & & & & \\
\hline & $\begin{array}{l}\text { ATP-dependent Clp protease, proteolytic subunit ClpP } \\
\text { 2-dehydro-3-deoxyphosphogluconate aldolase/4-hydroxy-2-oxoglutarate }\end{array}$ & R.GMASDIEIQAR.E (71) & 25292 & 72 & 1 & 4.92 & 4 \\
\hline & aldolase & K.GEPDVVAIEAAAR.A (67) & 20779 & 129 & 3 & 5.15 & 6 \\
\hline C11 & possible glycosyltransferase & R.SLVDGVTAQLFR.D (49) & & & & & \\
\hline \multirow[t]{4}{*}{$\mathrm{C} 12$} & translation elongation factor $\mathrm{Tu}$ & K.LLDQGEAGDNVGALIR.G (85) & 43045 & 401 & 12 & 5.16 & 11 \\
\hline & & K.LIAPIAMDEGLR.F (67) & & & & & \\
\hline & enoyl-(acyl-carrier-protein) reductase & R.VLASELGGQGIR.V (113) & 29160 & 139 & 7 & 5.45 & 7 \\
\hline & & K.VMADLAVR.W (48) & & & & & \\
\hline \multirow[t]{8}{*}{ D2 } & GMP synthase & R.IVAVSDGAPFAVIADDTR.K (101) & 57278 & 243 & 15 & 5.43 & 12 \\
\hline & & R.LGEAEQVVGLFR.N (71) & & & & & \\
\hline & prolyl-tRNA synthetase & K.GVPLVLEIGGR.D(64) & 57944 & 181 & 4 & 5.39 & 4 \\
\hline & & K.ALVSQSVFDEK.V(61) & & & & & \\
\hline & Glycine dehydrogenase (decarboxylating) & R.IDLAALLER.L (79) & 55278 & 127 & 4 & 5.34 & 6 \\
\hline & & K.AALDQFIAAMR.D (68) & & & & & \\
\hline & ribosomal protein L9 & K.GVPLVLEIGGR.D (67) & 58055 & & & 5.39 & 4 \\
\hline & & K.ALVSQSVFDEK.V (62) & & & & & \\
\hline \multirow[t]{2}{*}{ D2 } & translation elongation factor $\mathrm{Tu}$ & K.LLDQGEAGDNVGALIR.G (86) & 43045 & 591 & 19 & 5.16 & 25 \\
\hline & & R.QVGVPALVVYMNK.V (77) & & & & & \\
\hline \multirow[t]{3}{*}{ D3 } & DNA polymerase III, beta subunit & R.KLPDGSQVSLETADNR.M(100) & 39096 & 126 & 9 & 4.9 & 9 \\
\hline & nucleotide sugar dehydrogenase & K.QLLANYSEVPQNLIR.A(85) & 43208 & 1280 & 33 & 5.07 & 22 \\
\hline & & R.LGTEQVIFSPEFLR.E(82) & & & & & \\
\hline \multirow[t]{3}{*}{ D4 } & aspartate kinase & K.VSVLIDSDETELAVR.V (87) & 44608 & 174 & 4 & 4.99 & 5 \\
\hline & & K.ISVVGVGMR.S (54) & & & & & \\
\hline & translation elongation factor $\mathrm{Tu}$ & K.LIAPIAMDEGLR.F (58) & 43045 & 119 & 4 & 5.16 & 8 \\
\hline \multirow{3}{*}{ D5 } & hydro-lvases. Fe-S type tartrate/fumarate subfamily alpha region & K.TTVTGVEMFR.K (55) & & & & & \\
\hline & 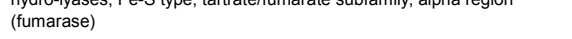 & K.DAIAQILTNSR.M (78) & 55452 & 119 & 4 & 5.76 & 9 \\
\hline & & R.GPQTDIER.L (58) & & & & & \\
\hline \multirow{3}{*}{ D6 } & peptidase M16-like & K.ASDGNAQDLR.V (47) & 103631 & & & 5.75 & 1 \\
\hline & aldehyde dehydrogenase $(\mathrm{NAD+})$ & K.NLLVSYSPK.A (53) & & & & & \\
\hline & chloroacetaldehyde dehydrogenase & R.FENFIGGK.W (50) & 56306 & 135 & 9 & 5.56 & 7 \\
\hline \multirow{5}{*}{ D7 } & & K.NLLVSYSPK.K (41) & & & & & \\
\hline & hydro-lyases, Fe-S type, tartrate/fumarate subfamily, alpha region & K.DAIAQILTNSR.M (60) & 55452 & & & 5.76 & 4 \\
\hline & trigger factor & K.VPGEFVANDDFAK.Q (73) & 55114 & 296 & 8 & 4.71 & 18 \\
\hline & & R.FIPGFEEQLVGVK.A (71) & & & & & \\
\hline & cell division protein FtsZ & R.AIANPLLDGVSMQGAK.G (73) & 51291 & & & 4.65 & 7 \\
\hline
\end{tabular}




\begin{tabular}{|c|c|c|c|c|c|c|c|}
\hline $\begin{array}{c}\text { Spot } \\
\text { number }\end{array}$ & Protein ID & $\begin{array}{l}\text { Two highest scoring unique peptides } \\
\text { (peptide score) }\end{array}$ & $\mathrm{Mr}$ & Score & $\begin{array}{l}\text { Queries } \\
\text { matched }\end{array}$ & $\mathrm{pl}$ & $\begin{array}{l}\text { Sequence } \\
\text { coverage }\end{array}$ \\
\hline \multirow[t]{4}{*}{ D8 } & ribose-phosphate pyrophosphokinase & K.LVANLITTAGADR.V (92) & 33700 & 538 & 16 & 5.55 & 27 \\
\hline & & K.ELVITDSILPTEATR.E (88) & & & & & \\
\hline & succinyl-CoA synthetase, alpha subunit & R.KGSVGVVSR.S (66) & 30663 & 296 & 29 & 5.54 & 21 \\
\hline & & K.IGIMPGSIFR.K (61) & & & & & \\
\hline \multirow[t]{7}{*}{ D9 } & probable 3-hydroxybutyryl-coa dehydrogenase protein & K.IVAADAEAALSR.I (86) & 30939 & 175 & 10 & 5.42 & 22 \\
\hline & & K.VLAPQAILASNTSSIPITR.M (51) & & & & & \\
\hline & succinyl-CoA synthetase, alpha subunit & R.KGSVGVVSR.S (64) & 30663 & 202 & 18 & 5.54 & 9 \\
\hline & & M.SILVNKDTK.V (38) & & & & & \\
\hline & ribose-phosphate pyrophosphokinase & K.LVANLITTAGADR.V (92) & 33700 & 90 & 1 & 5.55 & 4 \\
\hline & UDP-glucose pyrophosphorylase & K.AVFPVAGLGTR.F(56) & 32293 & 141 & 5 & 5.64 & 3 \\
\hline & Nucleotidyl transferase & K.AVFPVAGLGTR.F (58) & 32404 & & & 5.62 & 3 \\
\hline \multirow[t]{3}{*}{ D10 } & putative glutathione S-transferase YghU & R.AVGAPENQLR.E (49) & 33744 & 94 & 7 & 5.35 & 9 \\
\hline & & R.LLHVLDTQLGK.S (34) & & & & & \\
\hline & succinyl-CoA synthetase, alpha subunit & R.KGSVGVVSR.S (47) & 30663 & & & 5.54 & 3 \\
\hline \multirow[t]{2}{*}{ D11 } & Enoyl-CoA hydratase/isomerase & K.AFAAFEADPDQR.C (60) & 28551 & 75 & 2 & 5.44 & 7 \\
\hline & & K.FGQPEVK.L (40) & & & & & \\
\hline \multirow[t]{2}{*}{ D12 } & fumarase & K.DAIAQILTNSR.M (68) & 55452 & 197 & 11 & 5.76 & 10 \\
\hline & & R.ASVLTDPAFTR.R (50) & & & & & \\
\hline \multirow[t]{2}{*}{ E1 } & Hypothetical, possible membrane & R.IGLAKTLR.R (47) & & & & & \\
\hline & & R.LGIAARDR.D (47) & & & & & \\
\hline \multirow[t]{2}{*}{ E1 } & Dihydrolipoamide dehydrogenase & K.VTGAEVKDGK.A (46) & 49056 & 93 & 4 & 5.63 & 6 \\
\hline & & K.VGKFPMLANSR.A (37) & & & & & \\
\hline \multirow[t]{6}{*}{ E2 } & phosphoribosylformylglycinamidine cyclo-ligase & R.LLIDHLIEPTR.I (51) & 39054 & 126 & 12 & 4.92 & 12 \\
\hline & & R.VIAGIAEGCR.I (44) & & & & & \\
\hline & translation elongation factor $\mathrm{Tu}$ & K.LLDQGEAGDNVGALIR.G (92) & 43045 & 197 & 4 & 5.16 & 7 \\
\hline & & K.LIAPIAMDEGLR.F (60) & & & & & \\
\hline & fructose-1,6-bisphosphatase, class II & R.VTEAAAIGASR.L (90) & 34829 & 113 & 4 & 4.89 & 8 \\
\hline & & K.AADAAAVEAMR.A (80) & & & & & \\
\hline \multirow[t]{4}{*}{ E3 } & malonyl CoA-acyl carrier protein transacylase & K.VGMGADLAAASAVAR.E (93) & 32504 & 372 & 15 & 5.05 & 13 \\
\hline & & R.AFVFPGQGSQK.V (61) & & & & & \\
\hline & two component LuxR family transcriptional regulator & R.AVQASTVGLDATGR.M (62) & 33664 & 88 & 2 & 5.12 & 2 \\
\hline & fructose-1,6-bisphosphatase, class II & R.VTEAAAIGASR.L (88) & 34829 & 84 & 3 & 4.89 & 3 \\
\hline \multirow[t]{2}{*}{ E4 } & biotin synthase [Novosphingobium aromaticivorans DSM 12444] gb|ABD2! & K.LLTAANAGDDADSAMFAR.L (83) & 38806 & 211 & 7 & 5.26 & 11 \\
\hline & & K.IDDIEFVR.T (58) & & & & & \\
\hline \multirow[t]{5}{*}{ E4 } & NADH:flavin oxidoreductase/NADH oxidase & R.LLDDYALAAENAK.K (76) & 39525 & 156 & 5 & 5.19 & 8 \\
\hline & & R.ILMAPLTR.G (34) & & & & & \\
\hline & Myo-inositol-1-phosphate synthase & R.GFIVADAPEATK.E (64) & 39788 & 123 & 3 & 5.11 & 5 \\
\hline & & R.VLSSLFGAR.G (57) & & & & & \\
\hline & succinyl-CoA synthetase, beta subunit & K.EVNLSVPLVVR.L (50) & 42798 & & & 5.36 & 4 \\
\hline \multirow[t]{7}{*}{ E5 } & S-adenosylmethionine synthetase & K.GIMDTDGNWAPGVPEEV R.V(74) & 43392 & 210 & 6 & 5.27 & 9 \\
\hline & & K.NIVAAGLAHR.C(48) & & & & & \\
\hline & isocitrate dehydrogenase, NADP-dependent & R.DATADQITIDSANAIK.E (99) & 46087 & & & 5.28 & 8 \\
\hline & & R.LIDDMVASALK.W (73) & & & & & \\
\hline & Methionine adenosyltransferase & K.GIMDTDGNWAPGVPEEVER.V (86) & 43503 & 210 & 5 & 5.27 & 10 \\
\hline & & K.NIVAAGLAHR.C (49) & & & & & \\
\hline & NADH dehydrogenase I, D subunit & K.LLNVEVPLR.A (44) & 46315 & 62 & 2 & 5.36 & 2 \\
\hline \multirow[t]{4}{*}{ E6 } & isocitrate dehydrogenase, NADP-dependent & R.LIDDMVASALK.W (76) & 46087 & 215 & 10 & 5.28 & 8 \\
\hline & & K.YYDLSVQNR.D (59) & & & & & \\
\hline & GTP-binding protein TypA & R.FSVNDSPFAGR.E (65) & 67658 & 65 & 1 & 5.08 & 1 \\
\hline & Methionine adenosyltransferase & K.ILQQLAADR.H (62) & & 95 & 2 & & \\
\hline \multirow[t]{2}{*}{ E7 } & chaperonin GroEL (Class 1 heat-shock protein chaperonin) & K.ALAGLTGANEDQTR.G(96) & 57484 & 1226 & 72 & 5.09 & 12 \\
\hline & & K.AAGVIDPTK.V(45) & & & & & \\
\hline \multirow[t]{4}{*}{ E8 } & malate dehydrogenase, NAD-dependent & R.GGGGEIVALLK.T (85) & 33461 & 289 & 16 & 4.92 & 14 \\
\hline & & K.VVGMAGVLDSAR.F (79) & & & & & \\
\hline & translation elongation factor $\mathrm{Tu}$ & K.LIAPIAMDEGLR.F (65) & 43045 & 311 & 17 & 5.16 & 10 \\
\hline & & R.TVGSGVVSK.I (45) & & & & & \\
\hline
\end{tabular}




\begin{tabular}{|c|c|c|c|c|c|c|c|}
\hline $\begin{array}{c}\text { Spot } \\
\text { number }\end{array}$ & Protein ID & $\begin{array}{l}\text { Two highest scoring unique peptides } \\
\text { (peptide score) }\end{array}$ & $\mathrm{Mr}$ & Score & $\begin{array}{l}\text { Queries } \\
\text { matched }\end{array}$ & pl & $\begin{array}{l}\text { Sequence } \\
\text { coverage }\end{array}$ \\
\hline \multirow[t]{11}{*}{ E9 } & translation elongation factor Tu & R.TVGSGVVSK.I (56) & 43045 & 120 & 6 & 5.16 & 8 \\
\hline & & K.GSALAALEGR.D (44) & & & & & \\
\hline & malate dehydrogenase, NAD-dependent & R.GGGGEIVALLK.T (58) & 33461 & 141 & 5 & 4.92 & 6 \\
\hline & & K.VIEIALDDTAK.A (45) & & & & & \\
\hline & putative xylose isomerase-like protein & R.LPADPFAR.R (43) & 32468 & & & 4.92 & 6 \\
\hline & protein of unknown function DUF28 [ & K.ALGEAEGVK.L (36) & 26975 & & & 4.97 & 3 \\
\hline & OmpA/MotB & K.AFGEANPR.V (48) & 11983 & 166 & 8 & 5.76 & 38 \\
\hline & & R.NASVQSYLTAHGIPAAEIATK.A (40) & & & & & \\
\hline & alcohol dehydrogenase superfamily, zinc-containing & R.FGMTDFLNTR.G (58) & 43051 & 74 & 2 & 5.5 & 4 \\
\hline & & R.TALEACHR.G (42) & & & & & \\
\hline & beta-ketothiolase & M.SDVFLLSAAR.T (87) & 40702 & 88 & 2 & 5.7 & 2 \\
\hline \multirow[t]{5}{*}{ E11 } & OmpA/MotB & K.TLNVDNQTITAVGGR.T (84) & 25899 & 57 & 3 & 7.03 & 11 \\
\hline & & R.LEGQVGYLDAGNK.T (35) & & & & & \\
\hline & OmpA/MotB & K.YNLGLSAR.R (44) & 11983 & 60 & 3 & 5.76 & 14 \\
\hline & & K.AFGEANPR.V (42) & & & & & \\
\hline & alcohol dehydrogenase superfamily, zinc-containing & R.AAVAFEPK.K (42) & 43051 & 82 & 2 & 5.5 & 5 \\
\hline \multirow[t]{3}{*}{ E12 } & Acetyl-CoA C-acetyltransferase & R.SGVAAEKFDR.V (79) & 41038 & 530 & 15 & 5.8 & 14 \\
\hline & & R.AMGTFAQDTANAYQLTR.E (73) & & & & & \\
\hline & hypothetical protein Saro_1919 & K.GGIDADKDR.V (48) & 46531 & 69 & 3 & 8.37 & 2 \\
\hline \multirow[t]{5}{*}{$\mathrm{F} 1$} & hypothetical protein Saro_1919 & R.ITEQGLSTGALK.A (80) & 46531 & 102 & 4 & 8.37 & 5 \\
\hline & & R.RFPGEAVR.I (38) & & & & & \\
\hline & cobalt chelatase, pCobS small subunit & R.VLVAEYYQR.V (52) & 36373 & 62 & 2 & 5.34 & 5 \\
\hline & & K.LTLLDQNR.V (37) & & & & & \\
\hline & 4-hydroxy-3-methylbut-2-enyl diphosphate reductase & K.SDLLIVVGAR.N (55) - 1 good peptide & 35135 & 54 & 1 & 5.34 & 3 \\
\hline \multirow[t]{4}{*}{$\mathrm{F} 2$} & phosphoserine aminotransferase & K.EGAAYDIAGYR.D (67) & 41426 & 201 & 7 & 5.33 & 8 \\
\hline & & K.VLGGEGGHGVIILGPR.A (44) & & & & & \\
\hline & succinyl-CoA synthetase, beta subunit & K.LSFDSNALYR.H (63) & 42798 & 178 & 4 & 5.36 & 5 \\
\hline & Z-oxoglutarate dehydrogenase, $ヒ 2$ component, dinydrolipoamide & M.DGQLLVLDAK.L (61) & & & & & \\
\hline \multirow[t]{2}{*}{ F3 } & succinyltransferase & K.LGFMSFFAK.A (33) & 42939 & 69 & 20 & 5.37 & 8 \\
\hline & & K.AACLALKDIPAVNAR.I (24) & & & & & \\
\hline \multirow[t]{3}{*}{ F4 } & translation elongation factor $\mathrm{Tu}$ & K.LLDQGEAGDNVGALIR.G (91) & 43045 & 334 & 8 & 5.16 & 9 \\
\hline & 2-oxoglutarate dehydrogenase, E2 component, dihydrolipoamide & R.QVGVPALVVYMNK.V (66) & & & & & \\
\hline & 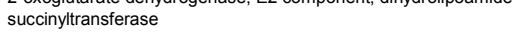 & R.AVLEYGIDPATVK.G (54) & 42939 & 52 & 2 & 5.37 & 3 \\
\hline \multirow[t]{2}{*}{ F5 } & TonB-dependent receptor & R.DYSACSLASATK.C (74) & 107722 & 201 & 8 & 6.02 & 4 \\
\hline & & K.SVAPVTSINNEDIK.T (62) & & & & & \\
\hline \multirow[t]{6}{*}{ F6 } & succinate CoA transferase & K.VMDAAAAASLIK.S(72) & 55310 & 246 & 8 & 5.79 & 8 \\
\hline & & R.NAYISIFMAPSTAK.G(64) & & & & & \\
\hline & Acetyl-CoA hydrolase & K.VMDAAAAASLIK.S (74) & 55421 & & & 5.79 & 8 \\
\hline & & R.NAYISIFMAPSTAK.G (66) & & & & & \\
\hline & ATP synthase F1, alpha subunit & K.AIDALVPIGR.G (57) & 55106 & & & 5.84 & 8 \\
\hline & & R.DSKDLGDATK.A (53) & & & & & \\
\hline \multirow[t]{4}{*}{ F7 } & Electron-transferring-flavoprotein dehydrogenase & K.GAVMGVATGDMGVAR.D (59) & 59647 & 143 & 7 & 5.89 & 10 \\
\hline & & K.YTLFAEGAR.G (56) & & & & & \\
\hline & ATP synthase $F 1$, alpha subunit & R.ADILAEIR.D (57) & 55106 & 148 & 5 & 5.84 & 3 \\
\hline & & K.AIDALVPIGR.G (50) & & & & & \\
\hline F8 & glutathione S-transferase-like & R.SHPVLAPSAGK.V (45) & 24700 & & & 5.64 & 4 \\
\hline \multirow[t]{2}{*}{ F9 } & Phasin & K.ILSTGLQELGK.G (81) & 33963 & 233 & 5 & 9.56 & 13 \\
\hline & & K.SQASFGELGEFAK.G (78) & & & & & \\
\hline $\mathrm{f} 10$ & transcriptional regulator, ModE family & M.SVATSGGAPR.A (46) & 16037 & & & 5.27 & 6 \\
\hline \multirow[t]{2}{*}{ F11 } & ribosomal protein L9 & R.AASNAGHLYGSVSVR.D(102) & 21643 & 5027 & 247 & 4.84 & 76 \\
\hline & & R.IEKLGTIGDEVTVK.D(69) & & & & & \\
\hline \multirow[t]{6}{*}{ F12 } & adenylate kinases & R.TAAQAESLDGILASR.G (91) & 23112 & 192 & 5 & 5.08 & 19 \\
\hline & & K.TAPILPIYEAR.G (44) & & & & & \\
\hline & $\mathrm{NADH}$-quinone oxidoreductase, $\mathrm{E}$ subunit & R.SAVMPLLDLAQR.Q(69) & 24975 & 172 & 9 & 5.16 & 9 \\
\hline & & R.YLDMPIIR.V(30) & & & & & \\
\hline & ribosomal protein L9 & K.LGTIGDEVTVK.D (69) & 21643 & 167 & 9 & 4.84 & 19 \\
\hline & & MQIILLER.I (55) & & & & & \\
\hline
\end{tabular}




\begin{tabular}{|c|c|c|c|c|c|c|c|}
\hline $\begin{array}{c}\text { Spot } \\
\text { number }\end{array}$ & Protein ID & $\begin{array}{l}\text { Two highest scoring unique peptides } \\
\text { (peptide score) }\end{array}$ & $\mathrm{Mr}$ & Score & $\begin{array}{c}\text { Queries } \\
\text { matched }\end{array}$ & pl & $\begin{array}{l}\text { Sequence } \\
\text { coverage }\end{array}$ \\
\hline \multirow[t]{3}{*}{ G1 } & peptidyl-prolyl cis-trans isomerase, cyclophilin type & K.LVLSLDSGDVVIK.L (91) & 16756 & 324 & 6 & 5.84 & 16 \\
\hline & Phasin & K.SQASFGELGEFAK.G (82) & 33963 & & & 9.56 & 6 \\
\hline & NADH-quinone oxidoreductase, E subunit [ & R.SAVMPLLDLAQR.Q (62) & 25086 & 114 & 3 & 5.16 & 5 \\
\hline \multirow[t]{2}{*}{ G2 } & translation elongation factor Ts [Novosphingobium aromaticivorans DSM 1 & 1K.TPIAQVVEAAGK.A (91) & 32125 & 551 & 24 & 5.09 & 29 \\
\hline & & K.ENALLSQLFVMDNK.T (77) & & & & & \\
\hline \multirow[t]{6}{*}{ G3 } & translation elongation factor Ts & R.TAAEGLVGVAVAGTK.G (103) & 32125 & 114 & 4 & 5.09 & 12 \\
\hline & & K.IALVDYVR.F (41) & & & & & \\
\hline & putative sugar decarboxylase & R.AVSNFLSQALTNGK.L (59) & 36947 & & & 5.11 & 10 \\
\hline & & R.CTESLLFEMHR.T (37) & & & & & \\
\hline & translation elongation factor Tu & K.GSALAALEGR.D (45) & 43045 & & & 5.16 & 5 \\
\hline & & R.DDAIGKDSIK.E (39) & & & & & \\
\hline \multirow[t]{4}{*}{ G4 } & glyceraldehyde-3-phosphate dehydrogenase, type I & R.VPTPNVSVVDLTFVPK.R (81) & 36036 & 231 & 13 & 6 & 24 \\
\hline & & R.AAAMSMIPTTTGAAR.A (69) & & & & & \\
\hline & transcriptional regulator, Lacl family protein & R.MLVDLLTR.R (52) & 33561 & 58 & 2 & 5.79 & 2 \\
\hline & putative sugar decarboxylase & R.AVSNFLSQALTNGK.L (48) & 36947 & & & 5.11 & 4 \\
\hline \multirow[t]{3}{*}{ G5 } & succinyl-CoA synthetase, beta subunit & K.LNGEFPANFLDVGGGATK.E (69) & 42798 & 361 & 11 & 5.36 & 16 \\
\hline & & R.LYVTDGVDIAK.E (62) & & & & & \\
\hline & Aspartate-semialdehyde dehydrogenase, USG-1 related & R.EMLNILAER.E (33) & 38621 & & & 5.68 & 2 \\
\hline \multirow[t]{2}{*}{ G6 } & DNA-directed RNA polymerase, alpha subunit & R.VLLSSLQGAAVTSIR.I (94) & 38947 & 302 & 11 & 4.94 & 18 \\
\hline & & K.NDNIIYIGDLVQK.T (73) & & & & & \\
\hline \multirow[t]{5}{*}{ G7 } & molybdenum cofactor synthesis domain-containing protein [Caulobacter $\mathrm{sF}$ & FR.IVGLPGNPSSALVTAR.L(68) & 41264 & 114 & 2 & 4.97 & 4 \\
\hline & Phosphoglycerate kinase & R.EDLNVPMADGK.V (50) & 41203 & & & 4.97 & 11 \\
\hline & Molybdopterin binding domain:MoeA, N-terminal, domain I and II:MoeA, C. & K.TLDDIADVTGK.A (43) & & & & & \\
\hline & terminal, domain IV & R.IVGLPGNPSSALVTAR.L (70) & 41375 & & & 4.97 & 4 \\
\hline & putative oxidoreductase & R.MAVAADLGK.A (50) & 39120 & & & 5.07 & 2 \\
\hline \multirow[t]{2}{*}{ G8 } & glutamate synthases, NADH/NADPH, small subunit & R.VTGENDVTGLECVR.V (80) & 52955 & 326 & 18 & 5.89 & 18 \\
\hline & & R.FAMEFLTQQNK.R (65) & & & & & \\
\hline \multirow[t]{3}{*}{ G9 } & glutamate synthases, NADH/NADPH, small subunit & R.AVDEALMGVSELPR.X (58) & 52955 & 75 & 2 & 5.89 & 4 \\
\hline & & R.NAGDDEIR.A (44) & & & & & \\
\hline & nitrogen regulatory protein $\mathrm{P}-\|$ & R.EALSGLGVAGMTVSEVK.G (77) & 12090 & 266 & 8 & 5.13 & 25 \\
\hline \multirow[t]{3}{*}{ G10 } & chaperonin Cpn10 & K.TAGGIIIPDSAK.E (73) & 10262 & 317 & 14 & 5.12 & 59 \\
\hline & & K.VSGEDLLIMK.E (65) & & & & & \\
\hline & nitrogen regulatory protein $\mathrm{P}-\|$ & R.EALSGLGVAGMTVSEVK.G(70) & 11979 & 70 & 1 & 5.14 & 15 \\
\hline \multirow[t]{2}{*}{ G11 } & Nucleoside-diphosphate kinase & K.MLEEAGLR.V (49) & 15516 & 79 & 4 & 5.12 & 19 \\
\hline & & R.TFSIIKPDATRR.N (27) & & & & & \\
\hline \multirow[t]{4}{*}{ G12 } & Aspartate-semialdehyde dehydrogenase, USG-1 related & K.GAALNAVQIAELLGR.R (68) & 38621 & 173 & 9 & 5.68 & 14 \\
\hline & & R.EMLNILAER.E (45) & & & & & \\
\hline & Amine dehydrogenase & R.GFVQAGTGVYDSATGK.Y (77) & 42431 & 113 & 2 & 5.75 & 8 \\
\hline & & K.AQMTMLTYTGLVYTAK.L (73) & & & & & \\
\hline \multirow[t]{5}{*}{$\mathrm{H} 2$} & Tyrosine transaminase & R.INIAGLTTGNIEK.F (83) & 47192 & 261 & 8 & 5.96 & 12 \\
\hline & & R.VGAFYAVTSDADALAR.A (73) & & & & & \\
\hline & hypothetical protein Saro_1919 & R.EYVAYLQAIDAR.R (80) & 46531 & 319 & 17 & 8.37 & 11 \\
\hline & & K.TLLVSAMLGQNAYSAK.D (72) & & & & & \\
\hline & Aspartate-semialdehyde dehydrogenase, USG-1 related & R.AIFVGDPVEPK.K (38) & 38621 & 38 & 1 & 5.68 & 3 \\
\hline \multirow[t]{4}{*}{$\mathrm{H} 2$} & translation elongation factor Ts & K.ENALLSQLFVMDNK.T (102) & 32125 & 385 & 13 & 5.09 & 24 \\
\hline & & K.ALDETGGDFEAAVDALR.A (94) & & & & & \\
\hline & Fructose-bisphosphate aldolase & K.EILAQLDALPEGTQVMLK.L (94) & 32291 & 179 & 5 & 5.06 & 13 \\
\hline & & K.GFIAALDQSGGSTPK.A (75) & & & & & \\
\hline \multirow[t]{9}{*}{$\mathrm{H} 3$} & S-adenosylhomocysteine hydrolase & K.VACVAGFGDVGKGSAASLR.N(89) & 50877 & 158 & 4 & 5.33 & 6 \\
\hline & & K.SADYENHVYVLPK.H(74) & & & & & \\
\hline & threonine synthase & K.IMQPFVGDSLTPER.L(75) & 50463 & 910 & 79 & 5.35 & 6 \\
\hline & & R.LLFDAAGR.D(42) & & & & & \\
\hline & hypothetical protein Saro_1190 & K.VACVAGFGDVGK.G (79) & 50877 & & & 5.33 & 9 \\
\hline & & R.IFDWDDGSGR.T (69) & & & & & \\
\hline & translation elongation factor Ts & R.TAAEGLVGVAVAGTK.G (95) & 32125 & 118 & 5 & 5.09 & 12 \\
\hline & & K.TPIAQVVEAAGK.A (41) & & & & & \\
\hline & acetyl-CoA carboxylase, biotin carboxylase & K.AAFGDATVYLEK.Y (44) & 49787 & 44 & 1 & 5.53 & 2 \\
\hline
\end{tabular}




\begin{tabular}{|c|c|c|c|c|c|c|c|}
\hline $\begin{array}{c}\text { Spot } \\
\text { number }\end{array}$ & Protein ID & $\begin{array}{l}\text { Two highest scoring unique peptides } \\
\text { (peptide score) }\end{array}$ & Mr & Score & $\begin{array}{l}\text { Queries } \\
\text { matched }\end{array}$ & pl & $\begin{array}{l}\text { Sequence } \\
\text { coverage }\end{array}$ \\
\hline \multirow[t]{2}{*}{$\mathrm{H} 4$} & malate dehydrogenase, NAD-dependent & K.IALIGAGNIGGTLAHLAAQK.E (86) & 33461 & 506 & 16 & 4.92 & 33 \\
\hline & & K.VIEIALDDTAK.A (80) & & & & & \\
\hline \multirow[t]{2}{*}{ H5 } & ketol-acid reductoisomerase & R.YSISNTAEYGDITTGPR.L (113) & 36252 & 274 & 8 & 5.57 & 14 \\
\hline & & R.ADVDVIMIAPK.G (71) & & & & & \\
\hline \multirow[t]{6}{*}{ H6 } & UDP-glucose pyrophosphorylase & K.AVFPVAGLGTR.F (83) & 32293 & 151 & 4 & 5.64 & 8 \\
\hline & & R.SDMAADVR.A(70) & & & & & \\
\hline & Nucleotidyl transferase & K.AVFPVAGLGTR.F (71) & 32404 & 720 & 26 & 5.62 & 6 \\
\hline & & R.SDMAADVR.A (66) & & & & & \\
\hline & ketol-acid reductoisomerase & R.ADVDVIMIAPK.G (61) & 36141 & 108 & 3 & 5.57 & 3 \\
\hline & & R.VLEDIQAGR.F (50) & & & & & \\
\hline \multirow[t]{2}{*}{$\mathrm{H} 7$} & putative nucleotide di-P-sugar epimerase or dehydratase & R.GMVGGAIVR.K (42) & 35012 & 97 & 14 & 5.76 & 8 \\
\hline & & R.KLMDVAR.L (41) & & & & & \\
\hline \multirow[t]{2}{*}{$\mathrm{H} 8$} & cysteine synthases & R.VLGFNYDTGER.Y (60) & 32414 & 217 & 7 & 9.52 & 14 \\
\hline & & MKADSVLATIGK.T (59) & & & & & \\
\hline \multirow[t]{2}{*}{ H9 } & Peptidase S1C, Do & R.IQPLSDDLAASLGLPK.R (93) & 51818 & 355 & 11 & 6.06 & 15 \\
\hline & & R.TGEFVQAVEPAQGAAK.A (88) & & & & & \\
\hline $\mathrm{H} 10$ & aldehyde dehydrogenase & K.AFVSYSQTTLDER.K (70) & 50471 & 123 & 7 & 5.24 & 5 \\
\hline H11 & chaperonin GroEL & K.LENVTLGMLGQAK.K (91) & 57484 & 341 & 10 & 5.09 & 16 \\
\hline \multirow[t]{4}{*}{$\mathrm{H} 12$} & Phosphopyruvate hydratase & $\begin{array}{l}\text { K.AGDGTTTATVLAQAIVR.E (79) } \\
\text { R.SGETEDSTIADLAVATNCGQIK.T } \\
\text { (114) }\end{array}$ & 45276 & 400 & 29 & 4.75 & 23 \\
\hline & & K.GLATAVGDEGGFAPNLSSTR.D (98) & & & & & \\
\hline & chaperonin GroEL & K.LENVTLGMLGQAK.K (89) & 57484 & 194 & 7 & 5.09 & 6 \\
\hline & & K.SVAAGINPMDLK.R (52) & & & & & \\
\hline & phosphoribosylamine--glycine ligase & K.KGGLIAGIDAAQADGAK.V (46) & 44602 & & & 4.8 & 3 \\
\hline \multirow[t]{2}{*}{ J1 } & OmpW & K.LLATGVLADGNIDTVR.S(94) & 25096 & 251 & 6 & 9.1 & 4 \\
\hline & & K.TPYSLTFDAK.K(71) & & & & & \\
\hline J2 & DNA-directed RNA polymerase, alpha subunit & R.LQLSATGPGEVR.A(70) & 38947 & 219 & 6 & 4.94 & 3 \\
\hline \multirow[t]{2}{*}{ J3 } & heat shock protein $\mathrm{Hsp} 90$ & K.SDITSEEYTDFYR.S(95) & 68507 & 1597 & 52 & 4.94 & 19 \\
\hline & & R.EMIQESPLLSAIR.K(75) & & & & & \\
\hline $\mathrm{J} 4$ & phosphoserine aminotransferase & K.EGAAYDIAGYR.D(81) & 41426 & 623 & 54 & 5.33 & 29 \\
\hline \multirow[t]{2}{*}{ J5 } & Chaperone DnaK (Class 1 heat-shock protein molecular chaperone) & K.MLGQFDLVGIPAAR.R(113) & 68013 & 10913 & 320 & 4.79 & 45 \\
\hline & & K.KAIEGGDTDEINAK.A(112) & & & & & \\
\hline \multirow[t]{2}{*}{ J6 } & trigger factor (prolyl isomerase) & K.LVVPVSDAEVDEAVAR.I(102) & 55114 & 6669 & 216 & 4.71 & 43 \\
\hline & & K.AAAEETPAGEAGEATEEAAPK.K(103) & & & & & \\
\hline \multirow[t]{2}{*}{ J7 } & NusA antitermination factor & R.AELLAIANAVASEK.M(90) & 61419 & 420 & 11 & 4.73 & 3 \\
\hline & & R.ALEALER.R(56) & & & & & \\
\hline \multirow[t]{2}{*}{ J8 } & Saccharopine dehydrogenase & K.TNIGDIATGTK.D(72) & 44496 & 1333 & 44 & 4.92 & 11 \\
\hline & & K.AVLPEPASLGATTK.G(72) & & & & & \\
\hline \multirow[t]{2}{*}{ J9 } & Pyruvate, phosphate dikinase & R.TFGDAANPLLVSVR.S(93) & 96595 & 1290 & 41 & 5.04 & 11 \\
\hline & & R.AIFEAALDVAQK.S(85) & & & & & \\
\hline \multirow[t]{2}{*}{ J10 } & translation elongation factor $\mathrm{G}$ & K.YCVQSIIDR.L(67) & 76577 & 2113 & 133 & 4.94 & 17 \\
\hline & & R.LSAEDPSFR.V(63) & & & & & \\
\hline
\end{tabular}




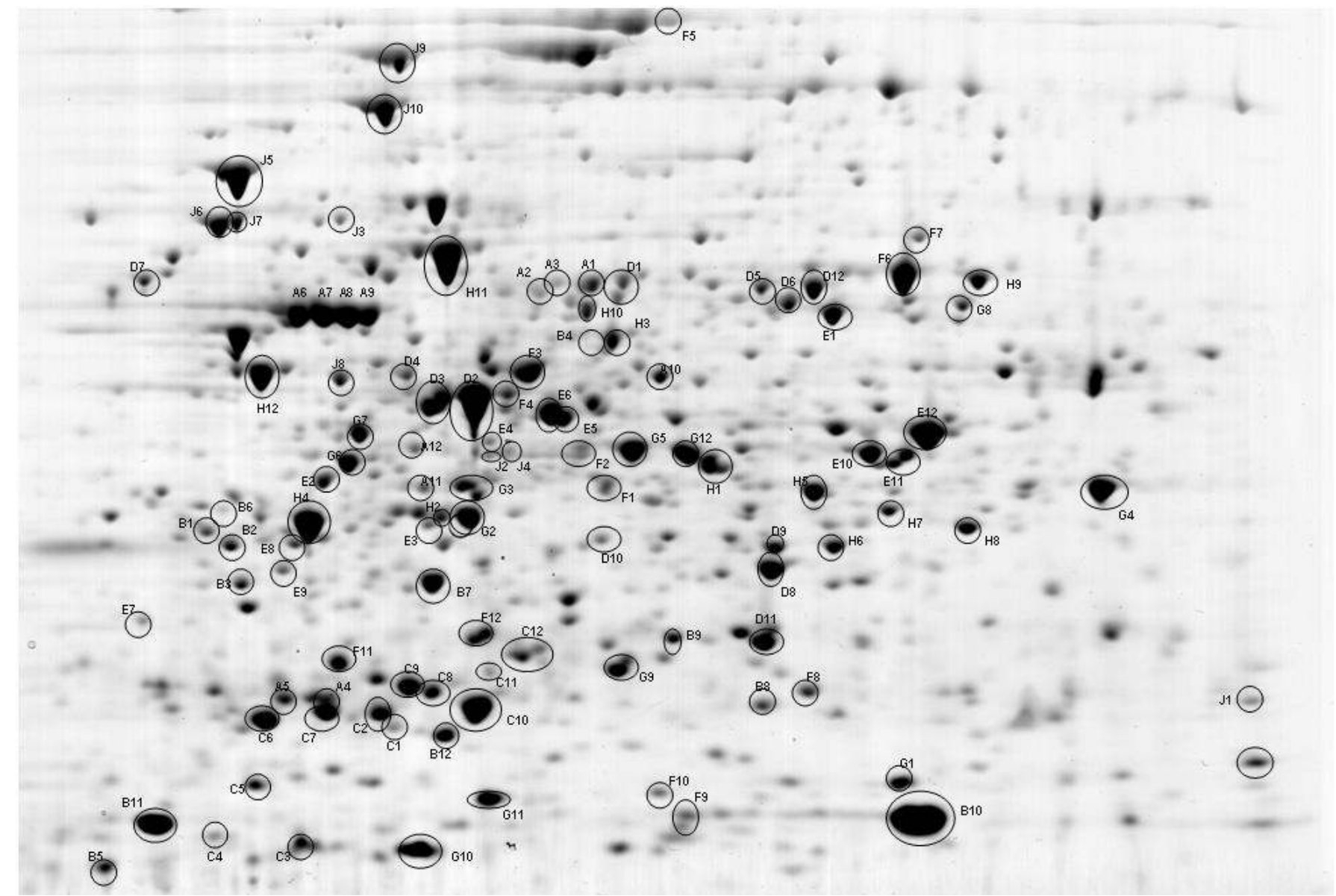

8.2 Figure A.1 A representative 2-D preparative gel showing additional proteins identified in the $\mathrm{pH}$ 4-7 linear range and 6-100 kDa range using LC-MS/MS and not all discussed in chapters 4-7.

Spot numbers match spots represented in 8.1 (previous pages). Mass spec data and peptide matches are given in 8.1, Appendix A table. 


\subsection{Appendix B Additional protein identifications not all discussed in Chapters 4-7.}

Protein identifications represent proteins at low / high $\mathrm{dO}_{2}$, constant $\mathrm{pH}$ in the $\mathrm{pH}$ 6-11 linear range.

\begin{tabular}{|c|c|c|c|c|c|c|c|}
\hline $\begin{array}{c}\text { Spot } \\
\text { number }\end{array}$ & Protein ID & $\begin{array}{l}\text { Two highest scoring unique peptides } \\
\text { (peptide score) }\end{array}$ & $\mathrm{Mr}$ & Score & $\begin{array}{l}\text { Queries } \\
\text { matched }\end{array}$ & $\mathrm{pl}$ & $\begin{array}{l}\text { Sequence } \\
\text { coverage }\end{array}$ \\
\hline \multirow[t]{2}{*}{$\mathrm{J} 11$} & Endoribonuclease L-PSP & K.YQSNPGALILDGAEVK.A(94) & 18095 & 2311 & 67 & 9.02 & 43 \\
\hline & & K.LDFAGANEGFK.Q(82) & & & & & \\
\hline \multirow[t]{2}{*}{ K1 } & amine oxidase, flavin-containing & K.SLNAGALDTAVTAEDK.A(127) & 58264 & 220 & 16 & 8.65 & 7 \\
\hline & & K.VQILEFQNR.A(44) & & & & & \\
\hline \multirow[t]{2}{*}{ K2 } & ribosomal protein $\mathrm{L} 10$ & R.NLGMTVAQSTALR.T(86) & 17838 & 792 & 19 & 9.13 & 20 \\
\hline & & K.ALATMPSLDELR.A(59) & & & & & \\
\hline \multirow[t]{2}{*}{ К3 } & ribosomal protein S5 & R.ATFDALQEQTSPK.S(96) & 25190 & 2732 & 77 & 10.16 & 36 \\
\hline & & R.AVFESLGVHDVVTK.S(94) & & & & & \\
\hline \multirow[t]{2}{*}{ K4 } & translation initiation factor IF-2 & K.AGDTLEVFEVEER.A(83) & 95265 & 660 & 20 & 8.48 & 8 \\
\hline & & K.VGDIFVVGTQSGR.V(85) & & & & & \\
\hline \multirow[t]{2}{*}{ K5 } & 6-phosphogluconate dehydratase & R.AAYLDLIDR.A(70) & 64604 & 561 & 19 & 6.26 & 6 \\
\hline & & R.EDAPAPIQAMGVGR.E(69) & & & & & \\
\hline \multirow[t]{2}{*}{ K6 } & ribosomal protein L6 & R.TLVSNLMTGVTEGYTK.T(120) & 19366 & 3216 & 60 & 9.77 & 33 \\
\hline & & K.TPDNTTVLISGIDK.Q(96) & & & & & \\
\hline K7 & succinate dehydrogenase and fumarate reductase iron-sulfur protein & K.SELDPSLTFR.R(57 & 30625 & 99 & 3 & 7.59 & 3 \\
\hline \multirow[t]{2}{*}{$\mathrm{k} 8$} & Dihydroorotate oxidase & R.MGFNNDGSEAVAQR.L(90) & 36996 & 540 & 11 & 9.64 & 6 \\
\hline & & R.GVSQTPIFLK.L(61) & & & & & \\
\hline \multirow[t]{2}{*}{ К9 } & ribosomal protein S9 & R.LVINQPFQVAGR.D(60) & 18796 & 925 & 51 & 10.31 & 30 \\
\hline & & K.GGGLSGQAGAVK.H(54) & & & & & \\
\hline \multirow[t]{2}{*}{ K10 } & ribosomal protein L11 & K.DLNANDIDQATK.I(81) & 15303 & 1668 & 86 & 9.68 & 28 \\
\hline & & R.SQLAAIAEAK.M(74) & & & & & \\
\hline \multirow[t]{2}{*}{ K11 } & ribosomal protein L17 & K.KLFEVLAER.Y(71) & 15927 & 2167 & 162 & 9.86 & 39 \\
\hline & & R.NMSAALIKHEQITTTLPK.A(53) & & & & & \\
\hline \multirow[t]{6}{*}{ K12 } & ribosomal protein L24 & K.VVVGGVNIATR.H(86) & 11329 & 2523 & 117 & 10.28 & 67 \\
\hline & & R.FEAPLHVSK.V(49) & & & & & \\
\hline & Glycine hydroxymethyltransferase & R.SPFVTSGIR.L(56) & 47410 & 2534 & 86 & 6.13 & 16 \\
\hline & & R.SGIILTNDEDLAK.K(58) & & & & & \\
\hline & Citrate synthase I & R.SGTLGPDVVDIR.K(75) & 48054 & 1007 & 46 & 6.13 & 10 \\
\hline & & R.IFILHADHEQNASTSTVR.L(60) & & & & & \\
\hline \multirow[t]{2}{*}{ M1 } & ribosomal protein $\mathrm{L} 5$ & K.GKYDVEIAQAMQAK.F(69) & 21946 & 5455 & 323 & 9.45 & 28 \\
\hline & & K.VQTAAAEMEK.I(54) & & & & & \\
\hline \multirow[t]{2}{*}{ M2 } & ribosomal protein $\mathrm{L} 3$ & K.AEVPLKAEVAEFR.V(79) & 26075 & 2834 & 185 & 9.71 & 10 \\
\hline & & R.TQQNLEIVR.T(66) & & & & & \\
\hline \multirow[t]{2}{*}{ M3 } & inosine-5'-monophosphate dehydrogenase & K.AAMGYTGSATIEDLR.H(109) & 51851 & 1413 & 34 & 6.57 & 14 \\
\hline & & K.ISGIPVVEASGK.L(72) & & & & & \\
\hline \multirow[t]{2}{*}{ M4 } & 2-oxoglutarate dehydrogenase, E1 component & R.LLSDINGASDAETR.K(112) & 103902 & 1330 & 39 & 6.86 & 7 \\
\hline & & K.VVYDLFEAR.D(55) & & & & & \\
\hline \multirow[t]{2}{*}{ M5 } & TonB-dependent siderophore receptor & R.TTDAGGFVSNVGIK.R(107) & 83919 & 2076 & 39 & 6.98 & 15 \\
\hline & & K.SGYGSYYADSSR.T(95) & & & & & \\
\hline \multirow[t]{2}{*}{ M6 } & Pyruvate kinase & R.IAAQVEADNAYNAR.I(97) & 53208 & 1228 & 25 & 8.29 & 11 \\
\hline & & K.ILATVGPASSSPEMLEK.L(81) & & & & & \\
\hline M7 & ribosomal protein $\mathrm{L} 10$ & R.NLGMTVAQSTALR.T(86) & 17838 & 2204 & 71 & 9.13 & 21 \\
\hline & & K.ALATMPSLDELR.A(59) & & & & & \\
\hline M8 & ribosomal protein L18 & K.AAGITAVVFDR.G(78) & 12559 & 591 & 13 & 11.3 & 18 \\
\hline & & K.SIGSNVDAAVK.V(81) & & & & & \\
\hline M9 & ribosomal protein S8 & R.NGLGITIVSTPR.G(70) & 13477 & 100 & 2 & 10.32 & 9 \\
\hline & & K.YFEGQPAIK.H(48) & & & & & \\
\hline M10 & TonB-dependent receptor & R.TPSLQIESSFGR.T(94) & 84231 & 1282 & 28 & 6.88 & 9 \\
\hline & & R.VATGYLGPAVQDR.V(90) & & & & & \\
\hline M11 & TolB-like & R.LTNTPGINIGGSFSPDGR.K(104) & 51546 & 1185 & 32 & 8.29 & 15 \\
\hline & & R.FITNGQATALTPR.Y(90) & & & & & \\
\hline M12 & Acetyl-CoA C-acetyltransferase & M.AQFSASDPVVILSYAR.T(113) & 41038 & 5479 & 119 & 5.8 & 43 \\
\hline & & R.AMGTFAQDTANAYQLTR.E(105) & & & & & \\
\hline
\end{tabular}




\begin{tabular}{|c|c|c|c|c|c|c|c|}
\hline $\begin{array}{c}\text { Spot } \\
\text { number }\end{array}$ & Protein ID & $\begin{array}{l}\text { Two highest scoring unique peptides } \\
\text { (peptide score) }\end{array}$ & $\mathrm{Mr}$ & Score & $\begin{array}{l}\text { Queries } \\
\text { matched }\end{array}$ & $\mathrm{pl}$ & $\begin{array}{l}\text { Sequence } \\
\text { coverage }\end{array}$ \\
\hline \multirow[t]{2}{*}{ P1 } & malate dehydrogenase, NAD-dependent & K.VIEIALDDTAK.A(75) & 33461 & 4535 & 184 & 4.92 & 36 \\
\hline & & K.VVGMAGVLDSAR.F(87) & & & & & \\
\hline \multirow[t]{2}{*}{ P2 } & Ompw & K.LLATGVLADGNIDTVR.S(94) & 25096 & 851 & 16 & 9.1 & 10 \\
\hline & & K.TPYSLTFDAK.K(71) & & & & & \\
\hline \multirow[t]{2}{*}{1} & Phasin & K.AATAQTPTTAGVTETTK.E(86) & 33963 & 1295 & 419 & 9.56 & 55 \\
\hline & & K.SQASFGELGEFAK.G(85) & & & & & \\
\hline \multirow[t]{2}{*}{2} & Acetoacetyl-CoA reductase & R.GIGEAISLALKEQGR.Q(98) & 25370 & 8382 & 339 & 6.92 & 47 \\
\hline & & R.QVVANYAGNEEK.A(73) & & & & & \\
\hline \multirow[t]{4}{*}{3} & hypothetical protein Saro_1378 & R.TQAAQIQQIQEAGER.E(112) & 24314 & 9327 & 274 & 9.1 & 49 \\
\hline & & K.AQIQAQIQPLVAK.Y(93) & & & & & \\
\hline & Acetoacetyl-CoA reductase & K.AFTEATGIPTVR.W(80) & 25370 & 539 & 12 & 6.92 & 22 \\
\hline & & R.QVVANYAGNEEK.A(47) & & & & & \\
\hline
\end{tabular}




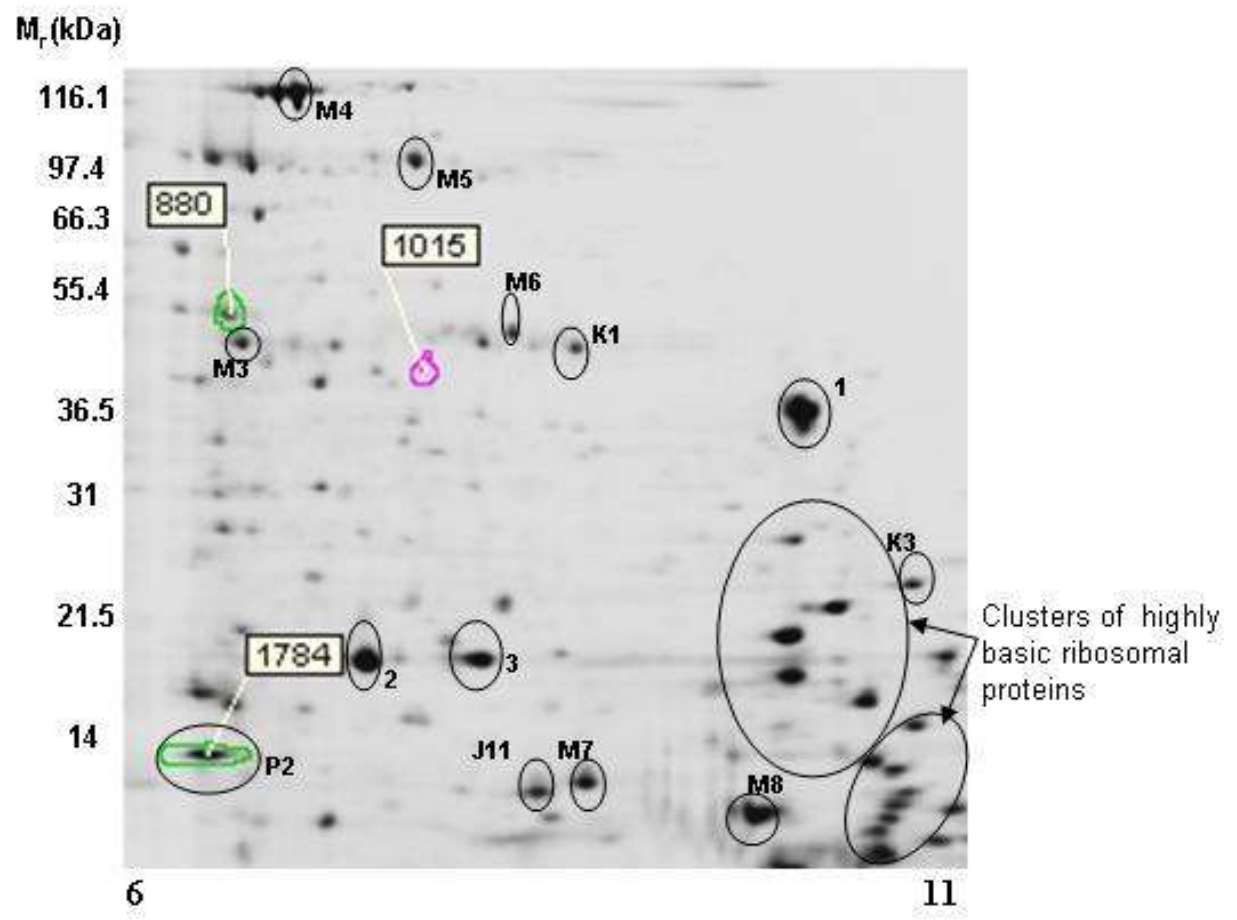

Isoelectric point (linear gradient $\mathrm{pH}$ 6-11)

8.4 Figure B.1. A representative 2-D DIGE gel showing additional proteins identified in the pH 6-11 linear range using LC-MS/MS and not all discussed in chapters 4-7.

Spot numbers correspond to the spot numbers represented in the previous table. The green circles represent proteins with increased abundance for one physiological state and the pink circle represents the protein with increased abundance for the opposing physiological state as determined by BVA analysis. 


\subsection{Appendix C Additional protein identifications not all discussed in Chapters 4-7.}

Protein identifications represent proteins at low / high dO2, $\mathrm{pH}$ not controlled, linear range $\mathrm{pH}$ 4-7.

\begin{tabular}{|c|c|c|c|c|c|c|}
\hline Protein ID & $\begin{array}{l}\text { Two highest scoring unique peptides } \\
\text { (peptide score) }\end{array}$ & Mr & Score & $\begin{array}{l}\text { Queries } \\
\text { matched }\end{array}$ & pl & $\begin{array}{l}\text { Sequence } \\
\text { coverage }\end{array}$ \\
\hline \multirow[t]{3}{*}{ chaperonin GroEL } & K.VGGATEVEVK.E(72) & 57484 & 571 & 29 & 5.09 & 6 \\
\hline & K.SVAAGINPMDLK.R(53) & & & & & \\
\hline & K.LAGGVAVIK.V(47) & & & & & \\
\hline \multirow[t]{4}{*}{ chaperonin GroEL } & K.ALAGLTGANEDQTR.G(85) & 57484 & 3666 & 170 & 5.09 & 20 \\
\hline & K.SVAAGINPMDLK.R(63) & & & & & \\
\hline & K.VIEDLKGR.S(38) & & & & & \\
\hline & K.LAGGVAVIK.V(64) & & & & & \\
\hline \multirow[t]{3}{*}{ chaperonin GroEL } & K.ALAGLTGANEDQTR.G(87) & 57484 & 2302 & 91 & 5.09 & 12 \\
\hline & K.EGVITVEEAK.G(61) & & & & & \\
\hline & K.SVAAGINPMDLK.R(57) & & & & & \\
\hline NifU & K.VDEPSQTISDAR.F(83) & 33542 & 522 & 13 & 4.72 & 3 \\
\hline ATP synthase $F 1$, beta subunit & R.TIAMDSTDGLTR.G(68) & 51090 & 522 & 13 & 4.82 & 2 \\
\hline NifU & K.VDEPSQTISDAR.F(73) & 33542 & 334 & 10 & 4.72 & 3 \\
\hline ATP synthase F1, beta subunit & R.TIAMDSTDGLTR.G(68) & 51090 & 94 & 2 & 4.82 & 2 \\
\hline OmpA/MotB & R.VPTADGVR.E(46) & 11983 & 70 & 12 & 5.76 & 14 \\
\hline \multirow[t]{2}{*}{ phasin } & K.GNVEALVESTK(84) & 33852 & 9708 & 319 & 9.56 & 23 \\
\hline & K.ILSTGLQELGK.G(81) & & & & & \\
\hline \multirow[t]{2}{*}{ Fructose-bisphosphate aldolase } & K.NNGIIASFSR.A(64) & 32291 & 147 & 17 & 5.06 & 5 \\
\hline & R.ALLEDLR.H(32) & & & & & \\
\hline \multirow[t]{2}{*}{ chaperonin GroEL } & K.EGVITVEEAK.G(45) & 57484 & 216 & 9 & 5.09 & 5 \\
\hline & K.SVAAGINPMDLK.R(50) & & & & & \\
\hline nitrogenase molybdenum-iron protein beta chain & R.FVMEVAR.L(41) & 44210 & 110 & 65 & 5.37 & 1 \\
\hline hypothetical protein BRADO5426 & M.SATTSPSLETVR.I(61) & & & & & \\
\hline \multirow[t]{2}{*}{ alkyl hydroperoxide reductase/ Thiol specific antioxidant/Mal allergen } & R.EGVGLADR.G(45) & 20864 & 169 & 21 & 4.79 & 7 \\
\hline & R.NAEELVR.K(47) & & & & & \\
\hline alkyl hydroperoxide reductase/ Thiol specific antioxidant/ Mal allergen & R.NAEELVR.K(48) & 20864 & 168 & 19 & 4.79 & 7 \\
\hline \multirow[t]{2}{*}{ nitrogenase iron protein } & R.LGGLICNER.Q(68) & 31859 & 397 & 45 & 4.94 & 12 \\
\hline & K.YANSGGVR.L(42) & & & & & \\
\hline \multirow[t]{3}{*}{ chaperonin Cpn10 } & K.TAGGIIIPDSAK.E(83) & 10262 & 4116 & 440 & 5.12 & 64 \\
\hline & K.VSGEDLLIMK.E(80) & & & & & \\
\hline & K.EKPAEGEIVAVGTGTR.A(48) & & & & & \\
\hline \multirow[t]{2}{*}{ Superoxide dismutase } & R.TNTAIEGTELADK.S(78) & 22197 & 577 & & 5.22 & 10 \\
\hline & K.NVRPDYLK.Q(33) & & & & & \\
\hline \multirow[t]{2}{*}{ 2-keto-3-deoxy-phosphogluconate aldolase } & R.TPAGLEAIR.A(86) & 20668 & 480 & 21 & 5.16 & 7 \\
\hline & R.VLEVTLR.T(39) & & & & & \\
\hline \multirow[t]{4}{*}{ ribosomal protein L7/L12 } & K.IEEAGGTVEIK.X(81) & 12683 & 2687 & 164 & 4.65 & 43 \\
\hline & R.AITSLGLTEAK.A(77) & & & & & \\
\hline & K.IQVIKEVR.A(61) & & & & & \\
\hline & K.AEAEDIKK.K(50) & & & & & \\
\hline \multirow[t]{3}{*}{ alkyl hydroperoxide reductase/ Thiol specific antioxidant/ Mal allergen } & K.FVDLTDADIAGK.W(83) & 20864 & 1291 & 168 & 4.79 & 14 \\
\hline & R.EGVGLADR.G(72) & & & & & \\
\hline & R.NAEELVR.K(48) & & & & & \\
\hline \multirow[t]{2}{*}{$\begin{array}{l}\text { 2-oxoglutarate dehydrogenase, E2 component, dihydrolipoamide } \\
\text { succinyltransferase }\end{array}$} & K.EDVIAAAAQAK.A(90) & 42828 & 1199 & 89 & 5.37 & 14 \\
\hline & K.EAIEEPTR.L(39) & & & & & \\
\hline \multirow[t]{4}{*}{ glyceraldehyde-3-phosphate dehydrogenase, type I } & R.AAAMSMIPTTTGAAR.A(99) & 36036 & 2281 & 112 & 6 & 17 \\
\hline & R.AVGEVLPELK.G(68) & & & & & \\
\hline & R.VLISAPAK.N(43) & & & & & \\
\hline & K.VAINGFGR.I(44) & & & & & \\
\hline \multirow[t]{2}{*}{ ATP synthase $F 1$, alpha subunit } & R.VVDALGNPIDGK.G(88) & 55106 & 2051 & 128 & 5.84 & 14 \\
\hline & R.DSKDLGDATK.A(72) & & & & & \\
\hline \multirow[t]{2}{*}{ Acetyl-CoA hydrolase } & K.VMDAAAAASLIK.S(72) & 55421 & 1396 & 35 & 5.79 & 8 \\
\hline & R.IQNGIGGSGDFAR.N(65) & & & & & \\
\hline nitrite and sulphite reductase $4 \mathrm{Fe}-4 \mathrm{~S}$ region & R.VAEFSDQVAR.R & & & & 5.83 & 8 \\
\hline \multirow[t]{2}{*}{ aromatic amino acid aminotransferase } & R.TGDGATPVFK.A(66) & 47081 & 416 & 20 & 5.97 & 6 \\
\hline & R.AMANGATIAR.A(52) & & & & & \\
\hline
\end{tabular}




\begin{tabular}{|c|c|c|c|c|c|c|}
\hline Protein ID & $\begin{array}{l}\text { Two highest scoring unique peptides } \\
\text { (peptide score) }\end{array}$ & Mr & Score & $\begin{array}{l}\text { Queries } \\
\text { matched }\end{array}$ & pl & $\begin{array}{l}\text { Sequence } \\
\text { coverage }\end{array}$ \\
\hline \multirow[t]{2}{*}{ aspartate-semialdehyde dehydrogenase } & R.AIFVGDPVEPK.K(64) & 38510 & 332 & 24 & 5.68 & 12 \\
\hline & K.KILDPAVK.V(38) & & & & & \\
\hline \multirow[t]{4}{*}{ isocitrate dehydrogenase, NADP-dependent } & K.TIEAEAAHGTVTR.H(104) & 46087 & 1267 & 51 & 5.28 & 14 \\
\hline & R.LIDDMVASALK.W(72) & & & & & \\
\hline & K.YYDLSVQNR.D(56) & & & & & \\
\hline & K.CATITPDEAR.V(43) & & & & & \\
\hline MotA/TolQ/ExbB proton channel & .MLIQTLAAAATSAAPQNK.F(48) & 26220 & 169 & 23 & 9.47 & 10 \\
\hline \multirow[t]{2}{*}{ 2,3,4,5-tetrahydropyridine-2,6-dicarboxylate $\mathrm{N}$-succinyltransferase } & R.ADVTPASADVR.E(66) & 28970 & 492 & 20 & 5.34 & 7 \\
\hline & K.TGINELLRD.-(41) & & & & & \\
\hline Nucleoside-diphosphate kinase & R.DIMGATNPANADAGTIR.K(104) & 15516 & 2463 & 258 & & \\
\hline \multirow[t]{4}{*}{ type I phosphodiesterase/nucleotide pyrophosphatase } & R.AVTAGTVTVGTGR.F(100) & 58770 & 2369 & 115 & 6.18 & 16 \\
\hline & K.TAIEENEAVDK.V(68) & & & & & \\
\hline & R.LNQQALPQAAR.A(72) & & & & & \\
\hline & R.AQFTGGLAR.L(52) & & & & & \\
\hline \multirow[t]{2}{*}{ TonB-dependent receptor, plug } & K.TDASFVVNGR.L(65) & 86259 & & & 6.44 & 6 \\
\hline & R.GIVPFDQNQTAR.D(48) & & & & & \\
\hline \multirow[t]{2}{*}{ Polyribonucleotide nucleotidyltransferase } & K.VLEIDNR.G(36) & 83008 & 738 & 46 & 5.34 & 3 \\
\hline & R.ANALNAAR.D(75) & & & & & \\
\hline glutamine synthetase, type I & K.ALNAFTNPTTNSYK.R(81) & 52267 & 648 & 59 & 4.94 & 7 \\
\hline aconitate hydratase 1 & K.AAAQFGDISR.L(43) & 96728 & 43 & 1 & 5.32 & 1 \\
\hline \multirow[t]{5}{*}{ trigger factor } & R.SEPLAAAQLR.A(73) & 55114 & 2309 & 158 & 4.71 & 17 \\
\hline & K.NFADAGEDAVAK.D(68) & & & & & \\
\hline & MQIVETSNEGLK.R & & & & & \\
\hline & MQIVETSNEGLKR.A & & & & & \\
\hline & R.APLYEDK.V(41) & & & & & \\
\hline \multirow[t]{2}{*}{ Chaperone DnaK } & K.AIEGGDTDEINAK.A(92) & 68013 & 987 & 62 & 4.79 & 4 \\
\hline & K.VIENSEGAR.T(70) & & & & & \\
\hline \multirow[t]{3}{*}{ ATP synthase $F 1$, beta subunit } & R.TIAMDSTDGLTR.G(78) & 51090 & 1189 & 56 & 4.82 & 10 \\
\hline & K.IGLFGGAGVGK.T(61) & & & & & \\
\hline & K.VIDLLAPYAK.G(40) & & & & & \\
\hline \multirow[t]{2}{*}{ Saccharopine dehydrogenase } & K.TNIGDIATGTK.D(76) & 44496 & 692 & 46 & 4.92 & 10 \\
\hline & K.AVLPEPASLGATTK.G(53) & & & & & \\
\hline \multirow[t]{2}{*}{ Inorganic diphosphatase } & R.IVVEAIER.E(58) & 20089 & 337 & 47 & 4.9 & 14 \\
\hline & R.SPFVPGAVVR.A(54) & & & & & \\
\hline protein-L-isoaspartate(D-aspartate) O-methyltransferase & K.LGAVLADGGR.I(80) & 20751 & 1143 & 66 & 5.02 & 21 \\
\hline & R.AMIESQLR.V(38) & & & & & \\
\hline Inorganic diphosphatase & R.SPFVPGAVVR.A(48) & 20089 & 284 & 52 & 4.9 & 10 \\
\hline & R.IVVEAIER.E(34) & & & & & \\
\hline $\begin{array}{l}\text { 2-dehydro-3-deoxyphosphogluconate aldolase/4-hydroxy-2-oxoglutarate } \\
\text { aldolase }\end{array}$ & R.TPAGLEAIR.A(64) & 20779 & 246 & 23 & 5.15 & 7 \\
\hline & R.VLEVTLR.T(35) & & & & & \\
\hline ribosomal protein L9 & K.LGTIGDEVTVK.D(73) & 21643 & 2063 & 106 & 4.85 & 51 \\
\hline & R.IEAENAAR.R(64) & & & & & \\
\hline & R.AASNAGHLYGSVSVR.D(55) & & & & & \\
\hline & R.VALHPEVAVTVK.A(47) & & & & & \\
\hline nitrogenase molybdenum-iron protein alpha chain & M.SVSTPTTIQEVK.D(60) & 56185 & 171 & 7 & 6.3 & 3 \\
\hline & R.SMNYISR.H(38) & & & & & \\
\hline phasin & K.AATAQTPTTAGVTETTK.E(101) & 33963 & 5802 & 214 & 9.56 & 57 \\
\hline & K.TVAAAETLAPVAPK.A(92) & & & & & \\
\hline & K.SQASFGELGEFAK.G(87) & & & & & \\
\hline & K.GNVEALVESTK.I(84) & & & & & \\
\hline & K.TTKPAAAPLPR.T(73) & & & & & \\
\hline TonB-dependent receptor & K.ADAGDAGSAIIVTAK.T(108) & 89707 & 1742 & 67 & 6.66 & 12 \\
\hline & R.SATAVTGAEIQK.I(76) & & & & & \\
\hline & K.NYSVYPIAPR.Q(57) & & & & & \\
\hline TonB-dependent receptor, plug & R.SQTFNSFSPEVVR.S(85) & 86259 & 1166 & 39 & 6.44 & 12 \\
\hline & K.TDASFVVNGR.L(73) & & & & & \\
\hline & R.GIVPFDQNQTAR.D(57) & & & & & \\
\hline Acetoacetyl-CoA reductase & R.QVVANYAGNEEK.A(71) & 25370 & 3241 & 145 & 6.92 & 21 \\
\hline & K.SGIHGFTK.A(65) & & & & & \\
\hline & R.VAIVTGGTR.G(60) & & & & & \\
\hline & M.ARVAIVTGGTR.G(50) & & & & & \\
\hline hypothetical protein Saro_1378 & R.TQAAQIQQIQEAGER.E(86) & 24314 & 3264 & 132 & 9.1 & 33 \\
\hline & K.NAVQSQIPTTYK.A(85) & & & & & \\
\hline & K.VTLVLDQR.V(66) & & & & & \\
\hline & R.KVTLVLDQR.V(62) & & & & & \\
\hline & K.SPKPDQAALR.T(39) & & & & & \\
\hline Acetoacetyl-CoA reductase & R.QVVANYAGNEEK.A(70) & 25370 & 1276 & 55 & 6.92 & 17 \\
\hline & R.VAIVTGGTR.G(60) & & & & & \\
\hline ribosomal protein L18 & K.SIGSNVDAAVK.V(60) & 12559 & 170 & 7 & 11.3 & 11 \\
\hline
\end{tabular}




\section{References}

Addison S. L., Foote S., Reid N., Lloyd-Jones G., Novosphingobium nitrogenifigens sp. nov., a polyhydroxyalkanoate-accumulating diazotroph isolated from a New Zealand pulp and paper wastewater. Int J Syst Evol Microbiol 2007, 57, 2467-2471.

Agabian N., Unger B., Caulobacter crescentus cell envelope: effect of growth conditions on murein and outer membrane protein composition. J Bacteriol 1978, $133,987-994$.

Anderson A. J., Dawes E. A., Occurrence, metabolism, metabolic role, and industrial uses of bacterial polyhydroxyalkanoates. Microbiol Rev 1990, 54, 450472.

Anderson A. J., Haywood G. W., Dawes E. A., Biosynthesis and composition of bacterial poly(hydroxyalkanoates). Int J Biol Macromol 1990, 12, 102-105.

Auman A. J., Speake C. C., Lidstrom M. E., nifH sequences and nitrogen fixation in type I and type II methanotrophs. Appl Environ Microbiol 2001,67, 4009-4016.

Bae T.-J., Kim M.-S., Kim J.-W., Kim B.-W., et al., Lipid raft proteome reveals ATP synthase complex in the cell surface. Proteomics 2004, 4, 3536-3548.

Baev M., Baev D., Jansco Radek A., Campbell J., Growth of Escherichia coli MG1655 on LB medium: monitoring utilization of amino acids, peptides, and nucleotides with transcriptional microarrays. Appl Microbiol Biotechnol 2006, 71, 317-322. 
Baillon M., van Vliet A., Ketley J., Constantinidou C., Penn C., An ironregulated alkyl hydroperoxide reductase $(\mathrm{AhpC})$ confers aerotolerance and oxidative stress resistance to the microaerophilic pathogen Campylobacter jejuni. J Bacteriol 1999, 181, 4798-4804.

Barrios A. F. G., Zuo R., Hashimoto Y., Yang L., et al., Autoinducer 2 Controls Biofilm Formation in Escherichia coli through a Novel Motility Quorum-Sensing Regulator (MqsR, B3022). J Bacteriol 2006, 188, 305-316.

Bastiaens L., Springael D., Wattiau P., Harms H., et al., Isolation of adherent polycyclic aromatic hydrocarbon (PAH)-degrading bacteria using PAH-sorbing carriers. Appl Environ Microbiol 2000, 66, 1834-1843.

Basu J., Protein palmitoylation and dynamic modulation of protein function. Curr Sci (Bangalore) 2004, 87, 214-217.

Bosch G., Skovran E., Xia Q., Wang T., et al., Comprehensive proteomics of Methylobacterium extorquens AM1 metabolism under single carbon and nonmethylotrophic conditions. Proteomics 2008, 8, 3494-3505.

Brelles-Mariño G., Bedmar E. J., Detection, purification and characterisation of quorum-sensing signal molecules in plant-associated bacteria. J Biotechnol 2001, 91, 197-209.

Brigle K. E., Newton W. E., Dean D. R., Complete nucleotide sequence of the Azotobacter vinelandii nitrogenase structural gene cluster. Gene 1985, 37, 37-44.

Brotz-Oesterhelt H., Bandow J. E., Labischinski H., Bacterial proteomics and its role in antibacterial drug discovery. Mass Spectrom Rev 2005, 24, 549-565.

Bukau B., Horwich A. L., The Hsp70 and Hsp60 Chaperone Machines. Cell 1998, $92,351-366$. 
Burris R. H., Nitrogenases. J Biol Chem 1991, 266, 9339-9342.

Burris R. H., Roberts G. P., Biological nitrogen fixation. Annu Rev Nutr 1993, 13, 317-335.

Busse H., Hauser E., Kämpfer P., Description of two novel species, Sphingomonas abaci sp. nov. and Sphingomonas panni sp. nov. Int J Syst Evol Microbiol 2005, 55, 2565-2569.

Büttner K., Bernhardt J., Scharf C., Schmid R., et al., A comprehensive twodimensional map of cytosolic proteins of Bacillus subtilis. Electrophoresis 2001, 22, 2908-2935.

Byrom D., Production of Poly- $\beta$-hydroxybutyrate: Poly- $\beta$-hydroxyvalerate Copolymers. FEMS Microbiol Rev 1992, 103, 247-250.

Chen H., Talaty N. N., Takats Z., Cooks R. G., Desorption electrospray ionization mass spectrometry for high-throughput analysis of pharmaceutical samples in the ambient environment. Anal Chem 2005, 77, 6915-6927.

Chen J. Y., Liu T., Zheng Z., Chen J. C., Chen G. Q., Polyhydroxyalkanoate synthases PhaC1 and PhaC2 from Pseudomonas stutzeri 1317 had different substrate specificities. FEMS Microbiol Lett 2004, 234, 231-237.

Chen N., Sun W., Deng X., Hao Y., et al., Quantitative proteome analysis of HCC cell lines with different metastatic potentials by SILAC. Proteomics 2008, 8, $5108-5118$.

Chiang P., Gordon R., Tal J., Zeng G., et al., S-Adenosylmethionine and methylation. FASEB J 1996, 10, 471-480. 
Choi J., Lee S., High-level production of poly(3-hydroxybutyrate-co-3hydroxyvalerate) by fed-batch culture of recombinant Escherichia coli. Appl Environ Microbiol 1999, 65, 4363-4368.

Chu K. H., Alvarez-Cohen L., Effect of nitrogen source on growth and trichloroethylene degradation by methane-oxidizing bacteria. Appl Environ Microbiol 1998, 64, 3451-3457.

Clark B. N., Gutstein H. B., The myth of automated, high-throughput twodimensional gel analysis. Proteomics 2008, 8, 1197-1203.

Cochrane J. C., Strobel S. A., Riboswitch effectors as protein enzyme cofactors. RNA 2008, 14, 993-1002.

Cote R., Gherna R., in: Gerhardt, P., Murray, R., Wood, W., Kreig, N., (Eds.), Methods for general and molecular bacteriology, ASM Press, Washington, DC 1994, pp. 155-178.

Darrow R. A., Knotts R. R., Two forms of glutamine synthetase in free-living root-nodule bacteria. Biochem Biophys Res Commun 1977, 78, 554-559.

Davis D., Doudoroff M., Stanier R., Mandel M., Proposal to reject the genus Hydrogenomonas: taxonomic implications. Int J Syst Bacteriol 1969, 19, 375-390.

Davis J. B., Coty V. F., Stanley J. P., Atmospheric Nitrogen Fixation by MethaneOxidizing Bacteria. J Bacteriol 1964, 88, 468-472.

Dawes E. A., Senior P. J., The role and regulation of energy reserve polymers in micro-organisms. Adv Microb Physiol 1973, 10, 135-266.

De Mot R., Vanderleyden J., The C-terminal sequence conservation between OmpA-related outer membrane proteins and MotB suggests a common function in both gram-positive and gram-negative bacteria, possibly in the 
interaction of these domains with peptidoglycan. Mol Microbiol 1994, 12, 333334.

De Oliveira V. C., Maeda I., Delessert S., Poirier Y., Increasing the carbon flux toward synthesis of short-chain-length--medium-chain-length polyhydroxyalkanoate in the peroxisome of Saccharomyces cerevisiae through modification of the beta-oxidation cycle. Appl Environ Microbiol 2004, 70, 56855687.

Dean D. R., Setterquist R. A., Brigle K. E., Scott D. J., et al., Evidence that conserved residues Cys-62 and Cys-154 within the Azotobacter vinelandii nitrogenase MoFe protein $\alpha$-subunit are essential for nitrogenase activity but conserved residues His-83 and Cys-88 are not. Mol Microbiol 1990, 4, 1505-1512.

Dilworth M. J., Eady R. R., Eldridge M. E., The vanadium nitrogenase of Azotobacter chroococcum. Reduction of acetylene and ethylene to ethane. Biochem J 1988, 249, 745-751.

Dilworth M. J., Eldridge M. E., Eady R. R., The molybdenum and vanadium nitrogenases of Azotobacter chroococcum: effect of elevated temperature on $\mathrm{N}_{2}$ reduction. Biochem J 1993, 289 (Pt 2), 395-400.

Dilworth M. J., Fisher K., Kim C.-H., Newton W. E., Effects on Substrate Reduction of Substitution of Histidine-195 by Glutamine in the $\alpha$-Subunit of the MoFe Protein of Azotobacter vinelandii Nitrogenase. Biochemistry 1998, 37, 1749517505.

Dincturk H., Knaff D., The evolution of glutamate synthase. Mol Biol Rep 2000, $27,141-148$. 
Dong Z., Zelmer C. D., Canny M. J., McCully M. E., et al., Evidence for protection of nitrogenase from $\mathrm{O}_{2}$ by colony structure in the aerobic diazotroph Gluconacetobacter diazotrophicus. Microbiology 2002, 148, 2293-2298.

Dos Santos P. C., Smith A. D., Frazzon J., Cash V. L., et al., Iron-sulfur cluster assembly: NifU-directed activation of the nitrogenase Fe protein. J Biol Chem 2004, 279, 19705-19711.

Drozd J., Tubb R., Postgate J., A chemostat study of the effect of fixed nitrogen sources on nitrogen fixation, membranes and free amino acids in Azotobacter chroococcum. J Gen Microbiol 1972, 73, 221-232.

Durner J., Böger P., Ubiquitin in the Prokaryote Anabaena variabilis. J Biol Chem $1995,270,3720-3725$.

Durner J., Böhm I., Hilz H., Böger P., Posttranslational modification of nitrogenase. Eur J Biochem 1994, 220, 125-130.

Eady R., in: Gibson, A. H., Newton, W. E., (Eds.), Current perspectives in nitrogen fixation, Australian Academy of Science, Canberra 1981, pp. 172-181.

Edgren T., Nordlund S., The fix ABCX genes in Rhodospirillum rubrum encode a putative membrane complex participating in electron transfer to nitrgenase. $J$ Bacteriol 2004, 186, 2052-2060.

Ekman M., Tollbäck P., Bergman B., Proteomic analysis of the cyanobacterium of the Azolla symbiosis: identity, adaptation, and NifH modification. J Exp Bot 2008, 59, 1023-1034.

Ekman M., Tollback P., Klint J., Bergman B., Protein expression profiles in an endosymbiotic cyanobacterium revealed by a proteomic approach. Mol PlantMicrobe Interact 2006, 19, 1251-1261. 
El-Mansi M., Free CoA-mediated regulation of intermediary and central metabolism: an hypothesis which accounts for the excretion of alphaketoglutarate during aerobic growth of Escherichia coli on acetate. Res Microbiol $2005,156,874-879$.

El-Mansi M., Cozzone A. J., Shiloach J., Eikmanns B. J., Control of carbon flux through enzymes of central and intermediary metabolism during growth of Escherichia coli on acetate. Curr Opin Microbiol 2006, 9, 173-179.

Elias J. E., Haas W., Faherty B. K. G., S. P., Comparative evaluation of mass spectrometry platforms used in large-scale proteomics investigations. Nat Methods 2005, 2, 667-675.

Ellmark P., Ingvarsson J., Carlsson A., Lundin S. B., et al., Identification of protein expression signatures associated with $H$. pylori infection and gastric adenocarcinoma using recombinant antibody microarrays. Mol Cell Proteomics 2006, 5, 1638-1646.

Euzéby J., List of new names and new combinations previously effectively, but not validly, published. Int J Syst Evol Microbiol 2006, 56, 1-6.

Fei H., Chaillou S., Hirel B., Polowick P., et al., Effects of the overexpression of a soybean cytosolic glutamine synthetase gene (GS15) linked to organspecific promoters on growth and nitrogen accumulation of pea plants supplied with ammonium. Plant Physiol Biochem 2006, 44, 543-550.

Fink A., Chaperone-mediated protein folding. Physiol Rev 1999, 79, 425-449. Finocchiaro G., Ito M., Ikeda Y., Tanaka K., Molecular cloning and nucleotide sequence of cDNAs encoding the alpha- subunit of human electron transfer flavoprotein. J Biol Chem 1988, 263, 15773-15780. 
Fisher K., Dilworth M. J., Kim C. H., Newton W. E., Azotobacter vinelandii nitrogenases with substitutions in the FeMo-cofactor environment of the MoFe protein: effects of acetylene or ethylene on interactions with $\mathrm{H}+\mathrm{HCN}$, and $\mathrm{CN}$. Biochemistry 2000, 39, 10855-10865.

Fisher K., Dilworth M. J., Newton W. E., Azotobacter vinelandii vanadium nitrogenase: formaldehyde is a product of catalyzed HCN reduction, and excess ammonia arises directly from catalyzed azide reduction. Biochemistry 2006, 45, 4190-4198.

Fitzgerald-Hughes D., Coleman D., O'Connell B., Differentially expressed proteins in derivatives of Candida albicans displaying a stable histatin 3-resistant phenotype. Antimicrob Agents Chemother 2007, 51, 2793-2800.

Fleischmann R. D., Adams M. D., White O., Clayton R. A., et al., Whole-genome random sequencing and assembly of Haemophilus influenzae Rd. Science 1995, 269, 496-512.

Foor F., Janssen K., Magasanik B., Regulation of synthesis of glutamine synthetase by adenylylated glutamine synthetase. Proc Nat Acad Sci USA 1975, $72,4844-4848$.

Fredrickson J. K., Balkwill D. L., Drake G. R., Romine M. F., et al., Aromaticdegrading Sphingomonas isolates from the deep subsurface. Appl Environ Microbiol 1995, 61, 1917-1922.

Fu H., Burris R. H., Ammonium inhibition of nitrogenase activity in Herbaspirillum seropedicae. J Bacteriol 1989, 171, 3168-3175.

Fu H. A., Hartmann A., Lowery R. G., Fitzmaurice W. P., et al., Posttranslational regulatory system for nitrogenase activity in Azospirillum spp. J Bacteriol 1989, 171, 4679-4685. 
Fujii K., Satomi M., Morita N., Motomura T., et al., Novosphingobium tardaugens sp. nov., an oestradiol-degrading bacterium isolated from activated sludge of a sewage treatment plant in Tokyo. Int J Syst Evol Microbiol 2003, 53, 47-52.

Fuxius S., Eravci M., Broedel O., Weist S., et al., Technical strategies to reduce the amount of "false significant" results in quantitative proteomics. Proteomics $2008,8,1780-1784$.

Gallon J. R., Cheng J., Dougherty L. J., Gallon V. A., et al., A novel covalent modification of nitrogenase in a cyanobacterium. FEBS Lett 2000, 468, 231-233.

Garret R. H., Grisham C. M., in: Biochemistry 2 Edn., Harcourt College Publishers, Fort Worth 1999, pp. 927-948.

Garrity G. M., Bell J. A., Lilburn T., in: Brenner, D. J., Krieg, N. R., Staley, J. T., Garrity, G. M., (Eds.), Bergey's Manual of Systematic Bacteriology, Vol. 2 (The Proteobacteria), part C (The Alpha-, Beta-, Delta-, and Epsilonproteobacteria) 2 Edn., Springer, New York 2005, p 1.

Georgiadis M., Komiya H., Chakrabarti P., Woo D., et al., Crystallographic structure of the nitrogenase iron protein from Azotobacter vinelandii. Science 1992, 257, 1653-1659.

Glaeser S., Kämpfer P., Busse H., Langer S., Glaeser J., Novosphingobium acidiphilum sp. nov., an acidophilic salt-sensitive bacterium isolated from the humic acid-rich Lake Grosse Fuchskuhle. Int J Syst Evol Microbiol 2009, 59, 323330.

Godoy F., Vancanneyt M., Martinez M., Steinbuchel A., et al., Sphingopyxis chilensis sp. nov., a chlorophenol-degrading bacterium accumulates polyhydroxyalkanoate, and transfer of Sphingomonas alaskensis to Sphingopyxis alaskensis comb. nov. Int J Syst Evol Microbiol 2003, 53, 473-477. 
Gordon J., Shah V., Brill W., Feedback inhibition of nitrogenase. J Bacteriol 1981, $148,884-888$.

Gottesman S., Proteases and their targets in Escherichia coli. Annu Rev Genet 1996, 30, 465-506.

Govezensky D., Greener T., Segal G., Zamir A., Involvement of GroEL in nif gene regulation and nitrogenase assembly. J Bacteriol 1991, 173, 6339-6346.

Gupta R. S., Mok A., Phylogenomics and signature proteins for the alpha Proteobacteria and its main groups. BMC Microbiol 2007, 7, 106.

Hahne H., Wolff S., Hecker M., Becher D., From complementarity to comprehensiveness - targeting the membrane proteome of growing Bacillus subtilis by divergent approaches. Proteomics 2008, 8, 4123-4136.

Hamana K., Miyagawa K., Matsuzaki S., Occurrence of sym-homospermidine as the major polyamine in nitrogen-fixing cyanobacteria. Biochem Biophys Res Commun 1983, 112, 606-613.

Hamano Y., Matsuura N., Kitamura M., Takagi H., A novel enzyme conferring streptothricin resistance alters the toxicity of streptothricin D from broadspectrum to bacteria-specific. J Biol Chem 2006, 281, 16842-16848.

Han M.-J., Lee S. Y., Proteome profiling and its use in metabolic and cellular engineering. Proteomics 2003, 3, 2317-2324.

Han M., Yoon S., Lee S., Proteome analysis of metabolically engineered Escherichia coli producing Poly(3-hydroxybutyrate). J Bacteriol 2001, 183, 301-308.

Han M. J., Lee S. Y., The Escherichia coli proteome: past, present, and future prospects. Microbiol Mol Biol Rev 2006, 70, 362-439. 
Haqqani A., Kelly J., Stanimirovic D., Quantitative protein profiling by mass spectrometry using label-free proteomics. Methods Mol Biol 2008, 439, 241-256.

Hardy R. W. F., Holsten R. D., Jackson E. K., Burns R. C., The Acetylene Ethylene Assay for N2 Fixation: Laboratory and Field Evaluation. Plant Physiol $1968,43,1185-1207$.

Hartmann A., Burris R. H., Regulation of nitrogenase activity by oxygen in Azospirillum brasilense and Azospirillum lipoferum. J Bacteriol 1987, 169, 944-948.

Hartmann A., Fu H., Burris R., Regulation of nitrogenase activity by ammonium chloride in Azospirillum spp. J Bacteriol 1986, 165, 864-870.

Hecker M., A proteomic view of cell physiology of Bacillus subtilis-bringing the genome sequence to life. Adv Biochem Eng Biotechnol 2003, 83, 57-92.

Hecker M., Antelmann H., Büttner K., Bernhardt J., Gel-based proteomics of Gram-positive bacteria: A powerful tool to address physiological questions. Proteomics 2008, 8, 4958-4975.

Hecker M., Volker U., Towards a comprehensive understanding of Bacillus subtilis cell physiology by physiological proteomics. Proteomics 2004, 4, 37273750.

Hennig L., WinGene/WinPep: User-Friendly software for the analysis of amino acid sequences. BioTechniques 1999, 26, 1170-1172.

Herendeen S. L., VanBogelen R. A., Neidhardt F. C., Levels of major proteins of Escherichia coli during growth at different temperatures. J Bacteriol 1979, 139, 185-194.

Hodges M., Enzyme redundancy and the importance of 2-oxoglutarate in plant ammonium assimilation. J Exp Bot 2002, 53, 905-916. 
Hong H., Patel D. R., Tamm L. K., van den Berg B., The Outer Membrane Protein OmpW Forms an Eight-stranded beta-Barrel with a Hydrophobic Channel. J Biol Chem 2006, 281, 7568-7577.

Hu Y., Uttamchandani M., Yao S. Q., Microarray: a versatile platform for highthroughput functional proteomics. Comb Chem High Throughput Screen 2006, 9, 203-212.

Huergo L., Souza E., Araujo M., Pedrosa F., et al., ADP-ribosylation of dinitrogenase reductase in Azospirillum brasilense is regulated by AmtBdependent membrane sequestration of DraG. Mol Microbiol 2006, 159, 326-337.

James S., Melnyk S., Pogribna M., Pogribny I., Caudill M., Elevation in Sadenosylhomocysteine and DNA hypomethylation: potential epigenetic mechanism for homocysteine-related pathology. J Nutr 2002, 132, 2361S-2366S.

Joerger R. D., Wolfinger E. D., Bishop P. E., The gene encoding dinitrogenase reductase 2 is required for expression of the second alternative nitrogenase from Azotobacter vinelandii. J Bacteriol 1991, 173, 4440-4446.

Johnson D., Dos Santos P., Dean D., NifU and NifS are required for the maturation of nitrogenase and cannot replace the function of isc-gene products in Azotobacter vinelandii. Biochem Soc Trans 2005, 33, 90-93.

Jossek R., Reichelt R., Steinbüchel A., In vitro biosynthesis of poly(3hydroxybutyric acid) by using purified poly(hydroxyalkanoic acid) synthase of Chromatium vinosum. Appl Microbiol Biotechnol 1998, 49, 3258-3266.

Jurat-Fuentes J. L., Adang M. J., A proteomic approach to study Cry1Ac binding proteins and their alterations in resistant Heliothis virescens larvae. J Invertebrate Pathol 2007, 95, 187-191. 
Kampfer P., Witzenberger R., Denner E. B., Busse H. J., Neef A.,

Novosphingobium hassiacum sp. nov., a new species isolated from an aerated sewage pond. Syst Appl Microbiol 2002, 25, 37-45.

Kaplan M., Novosphingobium aromaticivorans: A potential initiator of primary biliary cirrhosis. Amer J Gastroenterol 2004, 99, 2147-2149.

Kawahara K., Kuraishi H., Zähringer U., Chemical structure and function of glycosphingolipids of Sphingomonas spp and their distribution among members of the $\alpha-4$ subclass of Proteobacteria. J Ind Microbiol Biotechnol 1999, 23, 408-413.

Kawai F., Sphingomonads involved in the biodegradation of xenobiotic polymers. J Ind Microbiol Biotechnol 1999, 23, 400-407.

Keasling J. D., Chou H., Metabolic engineering delivers next-generation biofuels. Nat Biotechnol 2008, 26, 298-299.

Kelley S. T., Theisen U., Angenent L. T., St Amand A., Pace N. R., Molecular analysis of shower curtain biofilm microbes. Appl Environ Microbiol 2004, 70, 4187-4192.

Kent H. M., Baines M., Gormal C., Smith B. E., Buck M., Analysis of sitedirected mutations in the $\alpha$-and $\beta$-subunits of Klebsiella pneumoniae nitrogenase. Mol Microbiol 1990, 4, 1497-1504.

Kichise T., Fukui T., Yoshida Y., Doi Y., Biosynthesis of polyhydroxyalkanoates (PHA) by recombinant Ralstonia eutropha and effects of PHA synthase activity on in vivo PHA biosynthesis. Int J Biol Macromol 1999, 25, 69-77.

Kim D. Y., Kim H. C., Kim S. Y., Rhee Y. H., Molecular characterization of extracellular medium-chain-length poly(3-hydroxyalkanoate) depolymerase genes from Pseudomonas alcaligenes strains. J Microbiol 2005, 43, 285-294. 
Kim S., Burgess B., Evidence for the direct interaction of the nifW gene product with the MoFe protein. J Biol Chem 1996, 271, 9764-9770.

Klassen G., Souza E. M., Yates M. G., Rigo L. U., et al., Nitrogenase switch-off by ammonium ions in Azospirillum brasilense requires the GlnB nitrogen signaltransducing protein. Appl Environ Microbiol 2005, 71, 5637-5641.

Kleiner D., Kleinschmidt J., Selective inactivation of nitrogenase in Azotobacter vinelandii batch cultures. J Bacteriol 1976, 128, 117-122.

Klose J., Protein mapping by combined isoelectric focusing and electrophoresis of mouse tissues. A novel approach to testing for induced point mutations in mammals. Humangenetik 1975, 26, 231-243.

Klugkist J., Haaker H., Inhibition of nitrogenase activity by ammonium chloride in Azotobacter vinelandii. J Bacteriol 1984, 157, 148-151.

Kohler C., Wolff S., Albrecht D., Fuchs S., et al., Proteome analyses of Staphylococcus aureus in growing and non-growing cells: a physiological approach. Int J Med Microbiol 2005, 295, 547-565.

Kolibachuk D., Miller A., Dennis D., Cloning, molecular analysis, and expression of the polyhydroxyalkanoic acid synthase (phaC) gene from Chromobacterium violaceum. Appl Environ Microbiol 1999, 65, 3561-3565.

Kolkman A., Olsthoorn M. M., Heeremans C. E., Heck A. J., Slijper M., Comparative proteome analysis of Sacharomyces cerevisiae grown in chemostat cultures limited for glucose or ethanol. Mol Cell Proteomics 2005, 4, 1-11.

Kosako Y., Yabuuchi E., Naka T., Fujiwara N., Kobayashi K., Proposal of Sphingomonadaceae Fam. Nov., consisting of Sphingomonas Yabuuchi et al., 1990, Erythrobacter Shiba and Shimidu 1982, Erythromicrobium Yurkov et al., 1994, Porphyrobacter Fuerst et al., 1993, Zymomonas Kluyver and van Niel 1936, and 
Sandaracinobacter Yurkov et al., 1997, with the type genus Sphingomonas Yabuuchi et al., 1990. Microbiol Immunol 2000, 44, 563-575.

Koskinen R., Ali-Vehmas T., Kämpfer P., Laurikkala M., et al., Characterization of Sphingomonas isolates from Finnish and Swedish drinking water distribution systems. J Appl Microbiol 2000, 89, 687-696.

Kostyál E., Nurmiaho-Lassila E.-L., Puhakka J. A., Salkinoja-Salonen M., Nitrification, denitrification, and dechlorination in bleached kraft pulp mill wastewater. Appl Microbiol Biotechnol 1997, 47, 734-741.

Kuchta K., Chi L., Fuchs H., Potter M., Steinbüchel A., Studies on the Influence of Phasins on Accumulation and Degradation of PHB and Nanostructure of PHB Granules in Ralstonia eutropha H16. Biomacromolecules 2007, 8, 657-662.

Kuhla J., Oelze J., Dependence of nitrogenase switch-off upon oxygen stress on the nitrogenase activity in Azotobacter vinelandii. J Bacteriol 1988, 170, 5325-5329.

Kwon H.-R., Kim Y.-C., Nucleotide Sequence and Secondary Structure of 5S rRNA from Sphingobium chungbukense JJ77. J Microbiol 2007, 45, 79-82.

Laane C., Krone W., Konings W., Haaker H., Veeger C., Short-Term Effect of Ammonium Chloride on Nitrogen Fixation by Azotobacter vinelandii and by Bacteroids of Rhizobium leguminosarum. Eur J Biochem 1980, 103, 39-46.

Larsen M. R., Roepstorff P., Mass spectrometric identification of proteins and characterization of their post-translational modifications in proteome analysis. Fresenius' Journal of Analytical Chemistry 2000, 366, 677-690.

Lee I. Y., Kim M. K., Chang H. N., Park Y. H., Regulation of poly- $\beta$ hydroxybutyrate biosynthesis in nicotinamide nucleotide in Alcaligenes eutrophus. FEMS Microbiol Lett 1995, 131, 35. 
Lee S.-H., Pulakat L., Parker K. C., Gavini N., Genetic Analysis on the NifW by Utilizing the Yeast Two-Hybrid System Revealed that the NifW of Azotobacter vinelandii Interacts with the NifZ to Form Higher-Order Complexes. Biochem Biophys Res Commun 1998, 244, 498-504.

Lee S. Y., Bacterial Polyhydroxyalkanoates. Biotechnol Bioeng 1996, 49, 1-14.

Lemoigne M., Products of dehydration and of polymerization of $\beta$ hydroxybutyric acid. Bull Soc Chem Biol 1926, 8, 770-782.

Lemos J., Luzardo Y., Burne R., Physiologic effects of forced down-regulation of dnaK and groEL expression in Streptococcus mutans. J Bacteriol 2007, 189, 15821588.

Leys N. M., Ryngaert A., Bastiaens L., Verstraete W., et al., Occurrence and phylogenetic diversity of Sphingomonas strains in soils contaminated with polycyclic aromatic hydrocarbons. Appl Environ Microbiol 2004, 70, 1944-1955.

Li H. Azotobacter vinelandii nitrogenase: multiple substrate reduction sites and effects of $\mathrm{pH}$ on substrate reduction and CO inhibition. PhD Thesis, Virginia Polytechnic Institute and State University, Blacksburg 2002.

Liebergesell M., Sonomoto K., Madkour M., Mayer F., Steinbuchel A., Purification and characterization of the poly(hydroxyalkanoic acid) synthase from Chromatium vinosum and localization of the enzyme at the surface of poly(hydroxyalkanoic acid) granules. Eur J Biochem 1994, 226, 71-80.

Lillemoen J., Cameron C., Hoffman D., The stability and dynamics of ribosomal protein L9: investigations of a molecular strut by amide proton exchange and circular dichroism. J Mol Biol 1997, 268, 482-493.

Lin J., Huang S., Zhang Q., Outer membrane proteins: key players for bacterial adaptation in host niches. Microbes Infect 2002, 4, 325-331. 
Linkerhagner K., Oelze J., Cellular ATP levels and nitrogenase switchoff upon oxygen stress in chemostat cultures of Azotobacter vinelandii. J Bacteriol 1995, 177, $5289-5293$.

Linn T., Losick R., The program of protein synthesis during sporulation in Bacillus subtilis. Cell 1976, 8, 103-114.

Linsen L., Locherbach J., Berth M., Becher D., Bernhardt J., Visual Analysis of Gel-Free Proteome Data. IEEE Transactions on Visualization and Computer Graphics 2006, 12, 497-508.

Liu Z. P., Wang B. J., Liu Y. H., Liu S. J., Novosphingobium taihuense sp. nov., a novel aromatic-compound-degrading bacterium isolated from Taihu Lake, China. Int J Syst Evol Microbiol 2005, 55, 1229-1232.

Ludden P., Lehman L., Roberts G., Reversible ADP-ribosylation of dinitrogenase reductase in a nifD- mutant of Rhodospirillum rubrum. J Bacteriol $1989,171,5210-5211$.

Ludden P., Roberts G., Regulation of nitrogenase activity by reversible ADP ribosylation. Curr Top Cell Regul 1989, 30, $23-56$.

Ludden P. W. (2001) Nitrogenase Complex. In Zheng, Y., Tickle, C., Jansson, R., Kehrer-Sawatzki, H., Cooper, D. N., Melino, G., Delves, P., Battista, J., Levitan, I., Roberts, K., Bynum, W. F., Harper, D., eds, Encyclopedia of Life Sciences. John Wiley \& Sons Ltd.

Luli G., Strohl W., Comparison of growth, acetate production, and acetate inhibition of Escherichia coli strains in batch and fed-batch fermentations. Appl Environ Microbiol 1990, 56, 1004-1011.

Madison L., Huisman G., Metabolic engineering of poly(3-hydroxyalkanoates): from DNA to plastic. Microbiol Mol Biol Rev 1999, 63, 21-53. 
Mancinelli R. L., The nature of nitrogen: an overview. Life Support Biosph Sci 1996, 3, 17-24.

Mandon K., Michel-Reydellet N., Encarnacion S., Kaminski P. A., et al., Polybeta-hydroxybutyrate turnover in Azorhizobium caulinodans is required for growth and affects nifA expression. J Bacteriol 1998, 180, 5070-5076.

Marino D., Frendo P., Ladrera R., Zabalza A., et al., Nitrogen fixation control under drought stress. Localized or systemic? Plant Physiol 2007, 143, 1968-1974.

Marouga R., David S., Hawkins E., The development of the DIGE system: 2D fluorescence difference gel analysis technology. Anal Bioanal Chem 2005, 382, 669-678.

Martin D., Reinhold-Hurek B., Distinct Roles of PII-Like Signal Transmitter Proteins and $a m t \mathrm{~B}$ in Regulation of nif Gene Expression, Nitrogenase Activity, and Posttranslational Modification of NifH in Azoarcus sp. Strain BH72. J Bacteriol 2002, 184, 2251-2259.

Martinez-Argudo I., Little R., Shearer N., Johnson P., Dixon R., The NifL-NifA System: a Multidomain Transcriptional Regulatory Complex That Integrates Environmental Signals. J Bacteriol 2004, 186, 601-610.

Merali S., Vargas D., Franklin M., Clarkson Jr A., S-adenosylmethionine and Pneumocystis carinii. J Biol Chem 2000, 275, 14958-14963.

Mittendorf V., Bongcam V., Allenbach L., Coullerez G., et al., Polyhydroxyalkanoate synthesis in transgenic plants as a new tool to study carbon flow through beta-oxidation. Plant J 1999, 20, 45-55.

Moeck G. S., Coulton J. W., TonB-dependent iron acquisition: mechanisms of siderophore-mediated active transport. Mol Microbiol 1998, 28, 675-681. 
Moshiri F., Crouse B., Johnson M., Maier R., The "nitrogenase-protective" FeSII protein of Azotobacter vinelandii: overexpression, characterization, and crystallization. Biochemistry 1995, 34, 12973-12982.

Moskowitz G. J., Merrick J. M., Metabolism of poly-beta-hydroxybutyrate. II. Enzymatic synthesis of D-(-)-beta hydroxybutyryl coenzyme A by an enoyl hydrase from Rhodospirillum rubrum. Biochemistry 1969, 8, 2748-2755.

Muller S., Bley T., Babel W., Adaptive responses of Ralstonia eutropha to feast and famine conditions analysed by flow cytometry. J Biotechnol 1999, 75, 81-97.

Nakagawa H., Kirimura K., Nitta T., Kino K., et al., Recycle Use of Sphingomonas sp. CDH-7 Cells for Continuous Degradation of Carbazole in the Presence of MgCl. Curr Microbiol 2002, 44, 251-256.

Nakamura J., Straub K., Wu J., Lou L., The glutamine hydrolysis function of human GMP synthetase. Identification of an essential active site cysteine. J Biol Chem 1995, 270, 23450-23455.

Nandi B., Nandy R. K., Sarkar A., Ghose A. C., Structural features, properties and regulation of the outer-membrane protein $\mathrm{W}(\mathrm{OmpW})$ of Vibrio cholerae. Microbiology 2005, 151, 2975-2986.

Neef A., Witzenberger R., Kämpfer P., Detection of sphingomonads and in situ identification in activated sludge using $16 S$ rRNA-targeted oligonucleotide probes. J Ind Microbiol Biotechnol 1999, 23, 261-267.

Neumann L., Spinozzi F., Sinibaldi R., Rustichelli F., et al., Binding of the major phasin, PhaP1, from Ralstonia eutropha H16 to poly(3-hydroxybutyrate) granules. J Bacteriol 2008, 190, 2911-2919. 
Niederhoffer E., Naranjo C., Bradley K., Fee J., Control of Escherichia coli superoxide dismutase ( $\operatorname{sod} A$ and $\operatorname{sodB}$ ) genes by the ferric uptake regulation (fur) locus. J Bacteriol 1990, 172, 1930-1938.

Nikaido H., Microdermatology: cell surface in the interaction of microbes with the external world. J Bacteriol 1999, 181, 4-8.

Ninfa A. J., Atkinson M. R., PII signal transduction proteins. Trends Microbiol $2000,8,172-179$.

Noda I., Green P. R., Satkowski M. M., Schechtman L. A., Preparation and properties of a novel class of polyhydroxyalkanoate copolymers.

Biomacromolecules 2005, 6, 580-586.

Nordlund S., Ludden P., in: Klipp, W., Masepohl, B., Gallon, J., Newton, W., (Eds.), Genetics and Regulation of Nitrogen Fixation in Free-Living Bacteria, Kluwer Academic Publishers 2004, pp. 175-196.

O'Farrell P. H., High resolution two-dimensional electrophoresis of proteins. J Biol Chem 1975, 250, 4007-4021.

O'Neill H., Mayhew S. G., Butler G., Cloning and Analysis of the Genes for a Novel Electron-transferring Flavoprotein from Megasphaera elsdenii. EXPRESSION AND CHARACTERIZATION OF THE RECOMBINANT PROTEIN. J Biol Chem 1998, 273, 21015-21024.

Oeding V., Schlegel H. G., Beta-ketothiolase from Hydrogenomonas eutropha H16 and its significance in the regulation of poly-beta-hydroxybutyrate metabolism. Biochem J 1973, 134, 239-248.

Okamoto S., Lezhava A., Hosaka T., Okamoto-Hosoya Y., Ochi K., Enhanced expression of S-adenosylmethionine synthetase causes overproduction of actinorhodin in Streptomyces coelicolor A3(2). J Bacteriol 2003, 185, 601-609. 
Oke V., Long S. R., Bacteroid formation in the Rhizobium-legume symbiosis. Curr Opin Microbiol 1999, 2, 641-646.

Oshiman K.-i., Tsutsumi Y., Nishida T., Matsumura Y., Isolation and characterization of a novel bacterium, Sphingomonas bisphenolicum strain AO1, that degrades bisphenol A. Biodegradation 2007, 18, 247-255.

Page W. J., Manchak J., Rudy B., Formation of poly(hydroxybutyrate-cohydroxyvalerate) by Azotobacter vinelandii UWD. Appl Environ Microbiol 1992, 58, 2866-2873.

Pal R., Bhasin V. K., Lal R., Proposal to reclassify [Sphingomonas] xenophaga Stolz et al. 2000 and [Sphingomonas] taejonensis Lee et al. 2001 as Sphingobium xenophagum comb. nov. and Sphingopyxis taejonensis comb. nov., respectively. Int J Syst Evol Microbiol 2006, 56, 667-670.

Parsons J. F., Calabrese K., Eisenstein E., Ladner J. E., Structure and Mechanism of Pseudomonas aeruginosa PhzD, an Isochorismatase from the Phenazine Biosynthetic Pathway. Biochemistry 2003, 42, 5684-5693.

Peekhaus N., Conway T., What's for Dinner?: Entner-Doudoroff Metabolism in Escherichia coli. J Bacteriol 1998, 180, 3495-3502.

Peng X., Egashira T., Hanashiro K., Masai E., et al., Cloning of a Sphingomonas paucimobilis SYK-6 gene encoding a novel oxygenase that cleaves lignin-related biphenyl and characterization of the enzyme. Appl Environ Microbiol 1998, 64, 2520-2527.

Peters J. W., Fisher K., Dean D. R., Nitrogenase Structure and Function: A Biochemical-Genetic Perspective. Annu Rev Microbiol 1995, 49, 335-366. 
Peters J. W., Stowell M. H. B., Soltis S. M., Finnegan M. G., et al., Redoxdependent structural changes in the nitrogenase P-cluster. Biochemistry 1997, 36, 1181-1187.

Pettinari J. M., Chaneton L., Vazquez G., Steinbuchel A., Mendez B. S., Insertion sequence-like elements associated with putative polyhydroxybutyrate regulatory genes in Azotobacter sp. FA8. Plasmid 2003, 50, 36-44.

Pettinari M., Vázquez G., Silberschmidt D., Rehm B., et al., Poly(3hydroxybutyrate) synthesis genes in Azotobacter sp. strain FA8. Appl Environ Microbiol 2001, 67, 5331-5334.

Pham D., Burgess B., Nitrogenase reactivity: effects of $\mathrm{pH}$ on substrate reduction and CO inhibition. Biochemistry 1993, 14, 13725-13731.

Philmus B., Christiansen G., Yoshida W. Y., Hemscheidt T. K., Post-translational Modification in Microviridin Biosynthesis. ChemBioChem 2008, 9, 3066-3073.

Poirier Y., Erard N., MacDonald-Comber Petetot J., Synthesis of polyhydroxyalkanoate in the peroxisome of Pichia pastoris. FEMS Microbiol Lett 2002, 207, 97-102.

Poirier Y., Somerville C., Schechtman L. A., Satkowski M. M., Noda I., Synthesis of high-molecular-weight poly([R]-(-)-3-hydroxybutyrate) in transgenic Arabidopsis thaliana plant cells. Int J Biol Macromol 1995, 17, 7-12.

Poirier Y., Ventre G., Caldelari D., Increased flow of fatty acids toward betaoxidation in developing seeds of Arabidopsis deficient in diacylglycerol acyltransferase activity or synthesizing medium-chain-length fatty acids. Plant Physiol 1999, 121, 1359-1366.

Pope M. R., Murrell S. A., Ludden P. W., Covalent modification of the iron protein of nitrogenase from Rhodospirillum rubrum by adenosine 
diphosphoribosylation of a specific arginine residue. Proc Natl Acad Sci USA $1985,82,3173-3177$.

Post E., Kleiner D., Oelze J., Whole cell respiration and nitrogenase activities in Azotobacter vinelandii growing in oxygen controlled continuous culture. Arch Microbiol 1983, 134, 68-72.

Pötter M., Müller H., Reinecke F., Wieczorek R., et al., The complex structure of polyhydroxybutyrate (PHB) granules: four orthologous and paralogous phasins occur in Ralstonia eutropha. Microbiology 2004, 150, 2301-2311.

Pötter M., Muller H., Steinbuchel A., Influence of homologous phasins (PhaP) on PHA accumulation and regulation of their expression by the transcriptional repressor PhaR in Ralstonia eutropha H16. Microbiology 2005, 151, 825-833.

Pötter M., Steinbüchel A., Poly(3-hydroxybutyrate) granule-associated proteins: impacts on poly(3-hydroxybutyrate) synthesis and degradation.

Biomacromolecules 2005, 6, 552-560.

Povolo S., Tombolini R., Morea A., Anderson A., et al., Isolation and characterization of mutants of Rhizobium meliloti unable to synthesize poly- $\beta$ hydroxybutyrate. Can J Microbiol 1994, 40, 823-829.

Quillaguaman J., Hashim S., Bento F., Mattiasson B., Hatti-Kaul R., Poly(betahydroxybutyrate) production by a moderate halophile, Halomonas boliviensis LC1 using starch hydrolysate as substrate. J Appl Microbiol 2005, 99, 151-157.

Ramsay B. A., Ramsay J. A., Cooper D. G., Production of Poly-betaHydroxyalkanoic Acid by Pseudomonas cepacia. Appl Environ Microbiol 1989, 55, 584-589. 
Rao V., Darrow R., Keister D., Effect of oxygen tension on nitrogenase and on glutamine synthetases I and II in Rhizobium japonicum 61A76. Biochem Biophys Res Commun 1978, 81, 224-231.

Reeh S., Pedersen S., Neidhardt F. C., Transient rates of synthesis of five aminoacyl-transfer ribonucleic acid synthetases during a shift-up of Escherichia coli. J Bacteriol 1977, 129, 702-706.

Rees D. C., Akif Tezcan F., Haynes C. A., Walton M. Y., et al., Structural basis of biological nitrogen fixation. Philos Transact A Math Phys Eng Sci 2005, 363, 971 984; discussion 1035-1040.

Rehm B., Krüger N., Steinbüchel A., A new metabolic link between fatty acid de novo synthesis and polyhydroxyalkanoic acid synthesis. The PHAG gene from Pseudomonas putida KT2440 encodes a 3-hydroxyacyl-acyl carrier proteincoenzyme a transferase. J Biol Chem 1998, 273, 24044-24051.

Rehm B. H. A., Polyester synthases: natural catalysts for plastics. Biochem J 2003, $376,15-33$.

Reinders J., Lewandrowski U., Moebius J., Wagner Y., Sickmann A., Challenges in mass spectrometry-based proteomics. Proteomics 2004, 4, 3686-3703.

Reinecke F., Steinbüchel A., Ralstonia eutropha Strain H16 as Model Organism for PHA Metabolism and for Biotechnological Production of Technically Interesting Biopolymers. J Mol Microbiol Biotechnol 2009, 16, 91-108.

Reitzer L., Nitrogen assimilation and global regulation in Escherichia coli. Ann Rev Microbiol 2003, 57, 155-176.

Reusch R., Sparrow A., Gardiner J., Transport of poly-beta-hydroxybutyrate in human plasma. Biochim Biophys Acta 1992, 1123, 33-40. 
Ribbe M., Gadkari D., Meyer O., N2 fixation by Streptomyces thermoautotrophicus involves a molybdenum-dinitrogenase and a manganese-superoxide oxidoreductase that couple $\mathrm{N}_{2}$ reduction to the oxidation of superoxide produced from $\mathrm{O}_{2}$ by a molybdenum-CO dehydrogenase. J Biol Chem 1997, 272, 26627-26633.

Rich P. R., The molecular machinery of Keilin's respiratory chain. Biochem Soc Trans 2003, 31, 1095-1105.

Riis V., Mai W., Gas chromatographic determination poly- $\beta$-hydroxybutyric acid in microbial biomass after hydrochloric acid propanolysis. J Chromatogr $1988,445,285-289$.

Ritchie G. A., Senior P. J., Dawes E. A., The purification and characterization of acetoacetyl-coenzyme A reductase from Azotobacter beijerinckii. Biochem J 1971, $121,309-316$.

Roe M. R., Griffin T. J., Gel-free mass spectrometry-based high throughput proteomics: Tools for studying biological response of proteins and proteomes. Proteomics 2006, 6, 4678-4687.

Rosen R., Büttner K., Schmid R., Hecker M., Ron E. Z., Stress-induced proteins of Agrobacterium tumefaciens. FEMS Microbiol Ecol 2001, 35, 277-285.

Rosen R., Sacher A., Shechter N., Becher D., et al., Two-dimensional reference map of Agrobacterium tumefaciens proteins. Proteomics 2004, 4, 1061-1073.

Rudolf M., Kroneck P. M., The nitrogen cycle: its biology. Met Ions Biol Syst $2005,43,75-103$.

Sabra W., Zeng A. P., Lunsdorf H., Deckwer W. D., Effect of oxygen on formation and structure of Azotobacter vinelandii alginate and its role in protecting nitrogenase. Appl Environ Microbiol 2000, 66, 4037-4044. 
Sandhiya G. S., Sugitha T. C., Balachandar D., Kumar K., Endophytic colonization and in planta nitrogen fixation by a diazotrophic Serratia sp. in rice. Indian J Exp Biol 2005, 43, 802-807.

Sarma A., Emerich D., A comparative proteomic evaluation of culture grown vs nodule isolated Bradyrhizobium japonicum. Proteomics 2006, 6, 3008-3028.

Schauder S., Shokat K., Surette M. G., Bassler B. L., The LuxS family of bacterial autoinducers: biosynthesis of a novel quorum-sensing signal molecule. Mol Microbiol 2001, 41, 463-476.

Schelin J., Lindmark F., Clarke A., The clpP multigene family for the ATPdependent Clp protease in the cyanobacterium Synechococcus. Microbiology 2002, $148,2255-2265$.

Schilke B., Voisine C., Beinert H., Craig E., Evidence for a conserved system for iron metabolism in the mitochondria of Saccharomyces cerevisiae. Proc Natl Acad Sci USA 1999, 96, 10206-10211.

Scott J. D., Ludwig R. A., Azorhizobium caulinodans electron-transferring flavoprotein $\mathrm{N}$ electrochemically couiples pyruvate dehydrogenase complex activity to $\mathrm{N}_{2}$ fixation. Microbiology 2004, 150, 117-126.

Selao T. T., Nordlund S., Norén A., Comparative Proteomic Studies in Rhodospirillum rubrum Grown under Different Nitrogen Conditions. J Proteome Res 2008, 7, 3267-3275.

Senior P., Dawes E., The regulation of poly-beta-hydroxybutyrate metabolism in Azotobacter beijerinckii. Biochem J 1973, 134, 225-238.

Senior P. J., Beech G. A., Ritchie G. A., Dawes E. A., The role of oxygen limitation in the formation of poly- $\beta$-hydroxybutyrate during batch and continuous culture of Azotobacter beijerinckii. Biochem J 1972, 128, 1193-1201. 
Senior P. J., Dawes E. A., Poly- $\beta$-hydroxybutyrate biosynthesis and the regulation of glucose metabolism in Azotobacter beijerinckii. Biochem J 1971, 125, 55-66.

Serafim L. S., Lemos P. C., Oliveira R., Reis M. A., Optimization of polyhydroxybutyrate production by mixed cultures submitted to aerobic dynamic feeding conditions. Biotechnol Bioeng 2004, 87, 145-160.

Sharma L., Kumar Singh A., Panda B., Mallick N., Process optimization for poly-[beta]-hydroxybutyrate production in a nitrogen fixing cyanobacterium, Nostoc muscorum using response surface methodology. Bioresource Technology $2007,98,987-993$.

Sherman M., Goldberg A., Heat shock-induced phosphorylation of GroEL alters its binding and dissociation from unfolded proteins. J Biol Chem 1994, 269, 31479-31483.

Sherman M. Y., Goldberg A. L., Heat shock in Escherichia coli alters the proteinbinding properties of the chaperonin groEL by inducing its phosphorylation. Nature 1992, 357, 167-169.

Shi H., Nikawa J., Shimizu K., Effect of modifying metabolic network on poly-3hydroxybutyrate biosynthesis in recombinant Escherichia coli. J Biosci Bioeng $1999,87,666-677$.

Singh R., Mailloux R., Puiseux-Dao S., Appanna V., Oxidative stress evokes a metabolic adaptation that favors increased NADPH synthesis and decreased NADH production in Pseudomonas fluorescens. J Bacteriol 2007, 189, 6665-6675.

Slade A. H., Gapes D. J., Stuthridge T. R., Anderson S. M., et al., N-ViroTech-a novel process for the treatment of nutrient limited wastewaters. Water Sci Technol 2004, 50, 131-139. 
Sprent J., Sprent P. Nitrogen Fixing Organisms: Pure and Applied Aspects, 2nd Edn. Chapman Hall, London \& New York 1990

Sriram V., Du W., Gervay-Hague J., Brutkiewicz R. R., Cell wall glycosphingolipids of Sphingomonas paucimobilis are CD1d-specific ligands for NKT cells. Eur J Immunol 2005, 35, 1692-1701.

Staal M., Rabouille S., Stal L., On the role of oxygen for nitrogen fixation in the marine cyanobacterium Trichodesmium sp. Environ Microbiol 2007, 9, 727-736.

Steen H., Mann M., The ABC's (and XYZ's) of peptide sequencing. Nat Rev Mol Cell Biol 2004, 5, 699-711.

Steenhoudt O., Vanderleyden J., Azospirillum, a free-living nitrogen-fixing bacterium closely associated with grasses: genetic, biochemical and ecological aspects. FEMS Microbiol Rev 2000, 24, 487-506.

Steinbüchel A., Fuchtenbusch B., Bacterial and other biological systems for polyester production. Trends Biotechnol 1998, 16, 419-427.

Steinbüchel A., Hustede E., Liebergesell M., Pieper U., et al., Molecular basis for biosynthesis and accumulation of polyhydroxyalkanoic acids in bacteria. FEMS Microbiol Rev 1992, 9, 217-230.

Steinbüchel A., Schlegel H., Physiology and molecular genetics of poly(betahydroxy-alkanoic acid) synthesis in Alcaligenes eutrophus. Mol Microbiol 1991, 5, 535-542.

Storz G., Tartaglia L. A., Farr S. B., Ames B. N., Bacterial defenses against oxidative stress. Trends Genet 1990, 6, 363-368. 
Sudesh K., Taguchi K., Doi Y., Effect of increased PHA synthase activity on polyhydroxyalkanoates biosynthesis in Synechocystis sp. PCC6803. Int J Biol Macromol 2002, 30, 97-104.

Suzuki S., Hiraishi A., Novosphingobium naphthalenivorans sp. nov., a naphthalene-degrading bacterium isolated from polychlorinated-dioxincontaminated environments. J Gen Appl Microbiol 2007, 53, 221-228.

Taguchi S., Doi Y., Evolution of Polyhydroxyalkanoate (PHA) Production System by "Enzyme Evolution": Successful Case Studies of Directed Evolution. Macromolecular Bioscience 2004, 4, 145-156.

Taguchi S., Nakamura H., Hiraishi T., Yamato I., Doi Y., In vitro evolution of a polyhydroxybutyrate synthase by intragenic suppression-type mutagenesis. J Biochem 2002, 131, 801-806.

Takahashi N., Kaji H., Yanagida M., Hayano T., Isobe T., Proteomics: advanced technology for the analysis of cellular function. J Nutr 2003, 133, 2090S-2096S.

Takeuchi M., Hamana K., Hiraishi A., Proposal of the genus Sphingomonas sensu stricto and three new genera, Sphingobium, Novosphingobium and Sphingopyxis, on the basis of phylogenetic and chemotaxonomic analyses. Int J Syst Evol Microbiol 2001, 51, 1405-1417.

Takeuchi M., Sakane T., Yanagi M., Yamasato K., et al., Taxonomic study of bacteria isolated from plants: proposal of Sphingomonas rosa sp. nov., Sphingomonas pruni sp. nov., Sphingomonas saccharolytica sp. nov., and Sphingomonas mali sp. nov. Int J Syst Bacteriol 1995, 45, 334-341.

Takeuchi M., Sawada H., Oyaizu H., Yokota A., Phylogenetic Evidence for Sphingomonas and Rhizomonas as Nonphotosynthetic Members of the Alpha-4 Subclass of the Proteobacteria. Int J Syst Bacteriol 1994, 44, 308-314. 
Takusagawa F., Kamitori S., Markham G., Structure and Function of SAdenosylmethionine Synthetase: Crystal Structures of S-Adenosylmethionine Synthetase with ADP, BrADP, and PPi at $2.8 \AA$ A Resolution. Biochemistry 1996, $35,2586-2596$.

Tauro P., Kapoor K., Yadav K., in: An introduction to Microbiology, New Age International (P) Limited, New Delhi 1986, pp. 160-174.

Tessmer N., König S., Malkus U., Reichelt R., et al., Heat-shock protein HspA mimics the function of phasins sensu stricto in recombinant strains of Escherichia coli accumulating polythioesters or polyhydroxyalkanoates. Microbiology 2007, $153,366-374$.

Thiel M., Kaschabek S. R., Groning J., Mau M., Schlomann M., Two unusual chlorocatechol catabolic gene clusters in Sphingomonas sp. TFD44. Arch Microbiol $2005,183,80-94$.

Tholl D., Ober D., Martin W., Kellermann J., Hartmann T., Purification, molecular cloning and expression in Escherichia coli of homospermidine synthase from Rhodopseudomonas viridis. Eur J Biochem 1996, 240, 373-379.

Tiirola M. A., Busse H. J., Kampfer P., Mannisto M. K., Novosphingobium lentum sp. nov., a psychrotolerant bacterium from a polychlorophenol bioremediation process. Int J Syst Evol Microbiol 2005, 55, 583-588.

Tsagou V., Kefalogianni I., Sini K., Aggelis G., Metabolic activities in Azospirillum lipoferum grown in the presence of $\mathrm{NH}_{4}{ }^{+}$. Appl Microbiol Biotechnol 2003, 62, 574-578.

Tsai M., Saier M. J., Phylogenetic characterization of the ubiquitous electron transfer flavoprotein families ETF-a and ETF-b. Res Microbiol 1995, 146, 397-404. 
Tsuge T., Metabolic improvements and use of inexpensive carbon sources in microbial production of polyhydroxyalkanoates. Journal of Bioscience and Bioengineering 2002, 94, 579-584.

Tsuge T., Fukui T., Matsusaki H., Taguchi S., et al., Molecular cloning of two (R)-specific enoyl-CoA hydratase genes from Pseudomonas aeruginosa and their use for polyhydroxyalkanoate synthesis. FEMS Microbiol Lett 2000, 184, 193-198.

Turner M., Yang X., Yin D., Kuczera K., et al., Structure and function of Sadenosylhomocysteine hydrolase. Cell Biochem Biophys 2000, 33, 101-125.

Uchino K., Saito T., Thiolysis of poly(3-hydroxybutyrate) with polyhydroxyalkanoate synthase from Ralstonia eutropha. J Biochem (Tokyo) 2006, $139,615-621$.

Ureta A., Nordlund S., Evidence for Conformational Protection of Nitrogenase against Oxygen in Gluconacetobacter diazotrophicus by a Putative FeSII Protein. J Bacteriol 2002, 184, 5805-5809.

Uttamchandani M., Wang J., Yao S. Q., Protein and small molecule microarrays: powerful tools for high-throughput proteomics. Mol Biosyst 2006, 2, 58-68.

VanBogelen R., Schiller E., Thomas J., Neidhardt F., Diagnosis of cellular states of microbial organisms using proteomics. Electrophoresis 1999a, 20, 2149-2159.

VanBogelen R. A., Probing the molecular physiology of the microbial organism, Escherichia coli using proteomics. Adv Biochem Eng Biotechnol 2003, 83, 27-55.

VanBogelen R. A., Greis K. D., Blumenthal R. M., Tanic T. H., Matthews R. G., Mapping regulatory networks in microbial cells. Trends Microbiol 1999b, 7, 320328. 
Vandamme P., Coenye T., Taxonomy of the genus Cupriavidus: a tale of lost and found. Int J Syst Evol Microbiol 2004, 54, 2285-2289.

Vaneechouette M., Kampfer P., De Baere T., Falsen E., Verschraegen G., Wautersia gen. nov., a new genus accommodating the phylogenetic lineage including Ralstonia eutropha and related species, and proposal of Ralstonia [Pseudomonas] syzygii (Roberts et al. 1990) comb. nov. Int J Syst Evol Microbiol 2004, 54, 317-327.

Vazquez G., Pettinari M., Méndez B., Evidence of an association between poly(3-hydroxybutyrate) accumulation and phosphotransbutyrylase expression in Bacillus megaterium. Int Microbiol 2003, 6, 127-129.

Vlamis-Gardikas A., The multiple functions of the thiol-based electron flow pathways of Escherichia coli: Eternal concepts revisited. Biochim Biophys Acta Gen Subj 2008, 1780, 1170-1200.

Voigt B., Schweder T., Becher D., Ehrenreich A., et al., A proteomic view of cell physiology of Bacillus licheniformis. Proteomics 2004, 4, 1465-1490.

Voigt B., Schweder T., Sibbald M. J. J. B., Albrecht D., et al., The extracellular proteome of Bacillus licheniformis grown in different media and under different nutrient starvation conditions. Proteomics 2006, 6, 268-281.

Wang F., Lee S., Poly(3-Hydroxybutyrate) Production with High Productivity and High Polymer Content by a Fed-Batch Culture of Alcaligenes latus under Nitrogen Limitation. Appl Environ Microbiol 1997, 63, 3703-3706.

Wang M., Wu J. Q., Dennison J. B., Bridges A. S., et al., A gel-free MS-based quantitative proteomic approach accurately measures cytochrome P450 protein concentrations in human liver microsomes. Proteomics 2008, 8, 4186-4196. 
Webb C., Koutinas A. A., Wang R., in: Zhong, J.-J., (Ed.) Advances in Biochemical Engineering/Biotechnology, Vol. 87Springer-Verlag Berlin Heidelberg New York 2004, pp. 195-268.

Wendisch V. F., de Graaf A. A., Sahm H., Eikmanns B. J., Quantitative determination of metabolic fluxes during coutilization of two carbon sources: comparative analyses with Corynebacterium glutamicum during growth on acetate and/or glucose. J Bacteriol 2000, 182, 3088-3096.

White D. C., Sutton S. D., Ringelberg D. B., The genus Sphingomonas: physiology and ecology. Curr Opin Biotechnol 1996, 7, 301-306.

Wieczorek R., Pries A., Steinbuchel A., Mayer F., Analysis of a 24-kilodalton protein associated with the polyhydroxyalkanoic acid granules in Alcaligenes eutrophus. J Bacteriol 1995, 177, 2425-2435.

Wilmes P., Wexler M., Bond P. L., Metaproteomics Provides Functional Insight into Activated Sludge Wastewater Treatment. PLoS One 2008, 3, e1778.

Wolfe A. J., The acetate switch. Microbiol Mol Biol Rev 2005, 69, 12-50.

Xie C. H., Yokota A., Sphingomonas azotifigens sp. nov., a nitrogen-fixing bacterium isolated from the roots of Oryza sativa. Int J Syst Evol Microbiol 2006, $56,889-893$.

Yabuuchi E., Kosako Y., Fujiwara N., Naka T., et al., Emendation of the genus Sphingomonas Yabuuchi et al. 1990 and junior objective synonymy of the species of three genera, Sphingobium, Novosphingobium and Sphingopyxis, in conjunction with Blastomonas ursincola. Int J Syst Evol Microbiol 2002, 52, 1485-1496.

Yabuuchi E., Kosako Y., Yano I., Hotta H., Nishiuchi Y., Transfer of two Burkholderia and an Alcaligenes species to Ralstonia gen. nov: proposal of Ralstonia pickettii (Ralston, Palleroni and Doudoroff 1973) comb. nov., Ralstonia 
solanacearum (Smith 1896) comb. nov. and Ralstonia eutropha (Davis 1969) comb. nov. Microbiol Immunol 1995, 39, 897-904.

Yabuuchi E., Yano I., Oyaizu H., Hashimoto Y., et al., Proposals of Sphingomonas paucimobilis gen. nov. and comb. nov., Sphingomonas parapaucimobilis sp. nov., Sphingomonas yanoikuyae sp. nov., Sphingomonas adhaesiva sp. nov., Sphingomonas capsulata comb. nov., and two genospecies of the genus Sphingomonas. Microbiol Immunol 1990, 34, 99-119.

Yang D. C., Im W. T., Kim M. K., Ohta H., Lee S. T., Sphingomonas soli sp. nov., a beta-glucosidase-producing bacterium in the family Sphingomonadaceae in the alpha-4 subgroup of the Proteobacteria. Int J Syst Evol Microbiol 2006, 56, 703707.

Yu Z., Wu X., Li D., Yang S., et al., Enhancement of the production of SAM by overexpression of SAM synthetase in Pichia pastoris. Sheng Wu Hua Xue Yu Sheng Wu Wu Li Xue Bao (Shanghai) 2003, 35, 127-132.

Zakhia F., Jeder H., Willems A., Gillis M., et al., Diverse bacteria associated with root nodules of spontaneous legumes in Tunisia and first report for nifH-like gene within the genera Microbacterium and Starkeya. Microb Ecol 2006, 51, 375393.

Zhang J., The role of heterologous nifAc product in the regulation of nif expression in Agrobacterium tumefaciens. Chin J Biotechnol 1997, 13, 31-36.

Zhang J., Hao N., Chen G. Q., Effect of expressing polyhydroxybutyrate synthesis genes (phbCAB) in Streptococcus zooepidemicus on production of lactic acid and hyaluronic acid. Appl Microbiol Biotechnol 2006, 71, 222-227. 
Zhang Y., Burris R., Ludden P., Roberts G., Presence of a second mechanism for the posttranslational regulation of nitrogenase activity in Azospirillum brasilense in response to ammonium. J Bacteriol 1996, 178, 2948-2953.

Zhang Y., Burris R. H., Ludden P. W., Roberts G. P., Comparison studies of dinitrogenase reductase ADP-ribosyl transferase/dinitrogenase reductase activating glycohydrolase regulatory systems in Rhodospirillum rubrum and Azospirillum brasilense. J Bacteriol 1995, 177, 2354-2359.

Zhao J., Shimizu K., Metabolic flux analysis of Escherichia coli K12 grown on 13C-labeled acetate and glucose using GC-MS and powerful flux calculation method. J Biotechnol 2003, 101, 101-117.

Zhao Y., Bian S.-M., Zhou H.-N., Huang J.-F., Diversity of Nitrogenase Systems in Diazotrophs. J Integr Plant Biol 2006, 48, 745-755.

Zhou H. W., Guo C. L., Wong Y. S., Tam N. F., Genetic diversity of dioxygenase genes in polycyclic aromatic hydrocarbon-degrading bacteria isolated from mangrove sediments. FEMS Microbiol Lett 2006, 262, 148-157.

Zhu K., Zhao J., Lubman D. M., Miller F. R., Barder T. J., Protein pI Shifts due to Posttranslational Modifications in the Separation and Characterization of Proteins. Analytical Chemistry 2005, 77, 2745-2755.

Zhu X., Tang G., Granier F., Bouchez D., Galili G., A T-DNA insertion knockout of the bifunctional lysine-ketoglutarate reductase saccharopine dehydrogenase gene elevates lysine levels in Arabidopsis seeds. Plant Physiol 2001, 126, 1539 1545.

Zwietering M. H., Jongenburger I., Rombouts F. M., Riet K. v. t., Modeling of the Bacterial Growth Curve. Appl Environ Microbiol 1990, 56, 1875-1881. 
